\title{
REATIVIDADE DE LIGANTES NA QUIMICA DOS CIANOFERRATOS
}

NEYDE YUKIE MURAKAMI IHA

TESE DE DOUTORAMENTO

Prof. Dr. HENRIQUE EISI TOMA

ORIENTADOR 
Ao Mărio Eiji

pela compreensão, paciéncia e amor

Ao Marcel, meu "fofinho" 
Ao Prof. Dr. Henrique Eisi Toma

pela oportunidade concedida,

pelas proveitosas discussões, ajuda

cientifica e estimulo,

pela oxientaça segura e interesse com

que acompanhou este trabalho,

$e$ sobretudo, pela amizade oferecida

meu maior e sincero agradecimento 
AGRADECIMENTOS

Ao Märio Eiji pelo apoio e incentivo nos momentos mais di ficeis

Aos meus pais e irmãos pela ajuda e condigões fornecidas para que o presente trabalho pudesse ser realizado

Aos professores e funcionärios do Instituto de Quimica que contribuiram para a realizagão deste trabalho

Ao nosso grupo pela agradável convivêneia

Aós colegas do IQ-USP, principalmente aos do bloco-2 tér reo pelos momentos agradáveis e descontraidos

A Ruthinha e Maria Elisa pela amizade e pela ajuda espontânea que sempre prestaram

A Prof. Dra. Helena Li Chum por me despertar para a ciênci

A todos que de alguma forma contribuiram para esse trabalh

A Coordenagão do Aperfeigoamento de Pessoal de Nivel Superior (CAPES) e ao Conselho Nacional de Pesquisa (CNPq) pelas bolsas concedidas 


\section{LISTAS DE FÓRMULAS}

piridina carbonil-




imetilsulfóxido


As reações entre o ion pentacianoferrato(II) e os isōmeros de acetilpiridina $\left(\mathrm{py}(\mathrm{CO}) \mathrm{CH}_{3}\right)$ foram estudadas com o intuito de estabelecer o mecanismo da reação de ataque nucleofílico ao grupo nitrosilo coordenado. Estas rea ções de adição foram acompanhadas pela tēcnica "stopped flow" a $25,0^{\circ} \mathrm{C}$, em condiçōes de pseudo primeira ordem, em meio alcalino com força iônica $0,10 \mathrm{M}$ ajustada com LiCl0 4 . Durante o processo, constatou-se que a formação dos produtos é precedida pelo aparecimento de intermediārio azul com pequenos tempos de vida. A formação deste intermediārio envol ve o ataque da acetilpiridina na forma de carbānion, ao gru po nitrisilo coordenado, em competição com a adição do íon hidroxila. A lei da velocidade para o mecanismo proposto nesta etapa, tem a expressão abaixo para a'constante dé ve locidade observada

$$
\mathrm{k}_{\mathrm{obs} 1}=\mathrm{Kk}_{\mathrm{L}}\left|\mathrm{Py}(\mathrm{CO}) \mathrm{CH}_{3}\right|\left|\mathrm{OH}^{-}\right|+\mathrm{k}_{\mathrm{OH}}\left|\mathrm{OH}^{-}\right|+\mathrm{k}_{-\mathrm{L}}
$$

Os valores de $\mathrm{Kk}_{L}$ e $\mathbf{k}_{-L}$ são respectivamente $1,91 \pm 0,05 \times 10^{2} \mathrm{M}^{-2} \mathrm{~s}^{-1}$ e $0,90 \pm 0,02 \times 10^{-1} \mathrm{~s}^{-1}$ para ace tilpiridina com substituintes na posição para; $3,70 \pm 0,10 x$ $10 \mathrm{M}^{-2} \mathrm{~s}^{-1}$ e $0,86 \pm 0,02 \times 10^{-1} \mathrm{~s}^{-1}$ para o derivado na pos $\mathrm{i}$ ção meta e $1,42 \pm 0,04 \times 10 \mathrm{M}^{-2} \mathrm{~s}^{-1}$ e $00,46 \pm 0,01 \times 10^{-1} \mathrm{~s}^{-1}$ para o derivado em orto. $0 \mathrm{k}_{\mathrm{OH}}$ obtido nas condições exper $\mathbf{i}$ mentais $\overline{\mathrm{e}} 0,302 \mathrm{M}^{-1} \mathrm{~s}^{-1}$. 
O decaimento do intermediārio ocorre devido a dissociação da espécie coordenada pelo no cuja labilização pode ser provocada ou ocorrer em paralelo à isomerização do 1igante. Esta reação tambēm depende tanto da concentração do ligante como da concentração da hidroxila. A lei da velocida de resultante do mecanismo proposto, consistente com o com portamento cinētico, leva à expressão

$$
k_{\text {obs2 }}=\frac{k_{\mathrm{d}_{\mathrm{T}}}\left|\mathrm{Py}(\mathrm{CO}) \mathrm{CH}_{3}\right|\left|\mathrm{OH}^{-}\right|+\mathrm{kOH}_{\mathrm{OH}}\left|\mathrm{OH}^{-}\right|}{1+\mathrm{K}_{\mathrm{T}}\left|\mathrm{Py}(\mathrm{CO}) \mathrm{CH}_{3}\right|\left|\mathrm{OH}^{-}\right|}
$$

Os, valores de $k_{d}$ e $K_{T}$ determinados são respectivamente, $8,3 \times 10^{-2} \mathrm{~s}^{-1}$ e $2,1 \times 10^{3} \mathrm{M}^{-2}$ para derivados em para, $5,0 \times 10^{-2} \mathrm{~s}^{-1}$ e $3,90 \times 10^{2} \mathrm{M}^{-2}$ para o derivadó em meta e $3,2 \times 10^{-2} \mathrm{~s}^{-1}$ e $2,95 \times 10^{2} \mathrm{M}^{-2}$ para 0 derivado em orto.

A consistēncia do mecanismo proposto foi verifi cada atravēs das constantes obtidas em experiēncias independentes acompanhando o decaimento dos intermediārios sintetizados. o mecanismo foi ainda confirmado através dos estu dos independentes das etapas propostas no mecanismo $310 b a 1$.

Esta adição das acetilpiridinas ao grupo No coordenado foi aproveitada na obtenção de ligantes carbonil-oximas correspondentes. Estes ligantes py(CO)CHNOH bem como as acetilpiridinas foram utilizados para sintetizar série de complexos $\mathrm{Fe}(\mathrm{CN})_{5} \mathrm{~L}^{3-}$ a partir do ion aquopentacianoferrato 
(II $), \quad \mathrm{Fe}(\mathrm{CN})_{5} \mathrm{H}_{2} \mathrm{O}^{3-}$

A caracterização dos ligantes e complexos sinte tizados foi feita na região de infravermelho, visīvel e ul tra-violeta. Os espectros eletrónicos obtidos foram decompos tos usando-se as funções Gaussianas simples e dupla e a lognorma 1 .

Os complexos apresentam-se fortemente coloridos com bandas de absorção na região do visível e ultra-violeta prōximo, cujas transições podem ser classificadas em

a. Transições de Transferēncia de Carga Fe-L (CT)

b. Transições de Campo Ligante (d-d)

c. Transições Internas nos Ligantes ( $L-L)$

d. Transições de Transferência de Carga Fe-CN (CT)

Foram ainda verificados os efeitos de $\mathrm{pH}$ so bre as bandas de transferéncia de carga e as variações espec trais provenientes da oxidação do complexo.

Os estudos de espectroscopia envolvendo os complexos intermediārios sintetizados foram feitos na tentativa de obter informações estruturais e propriedades para se esta belecer correlação com parâmetros cinéticos determinados.

o comportamento eletroquímico dos complexos em estudo foi investigado através da voltametria cíclica. A par tir destes dados obteve-se os parāmetros termodināmicos bem como a correlação do $E^{0}$ com a frequēncia da transição de transferēncia, de carga $v_{\mathrm{TC}}(\mathrm{Fe}-\mathrm{L})$. 
OS complexos $\mathrm{Fe}(\mathrm{CN})_{5} \mathrm{py}(\mathrm{CO}) \mathrm{CHNOH}^{3-}$ apresentam comportamento fotoquímico tîpico, com deslocamento batocrômi co das bandas de transferēncia de carga no decorrer da irradiação com luz visível e ultra-violeta.

A fotosubstituição dos cianetos nos complexos $\mathrm{Fe}(\mathrm{CN})_{5} \mathrm{~L}^{3-}$ foi constatada pela primeira vez com o uso de $1 \underline{i}$ gantes que apresentam caracteristicas quelantes (como etile nodiamina e py(CO)CHNOH) e estabilizam os complexos tetra cianoferrato(II) correspondentes.

A irradiação quase monocromātica no complexo $\mathrm{Fe}(\mathrm{CN})_{5} \mathrm{en}^{3-}$ mostra um rendimento quāntico de $0,087 \pm 0,003$ para a saída do cianeto. A espécie formada fotoquimicamente foi isolada e a'sua identidade foi confirmada espectroscopicamente e tambēm, atravēs da reação de oxidação com formação do tetracianoferrato com di imina.

A anālise do pentaciano(etilenodiamina)ferrato (II) consumido e a quantidade do complexo tetracianoferirato correspondente formada mostra que a reação representada a seguir

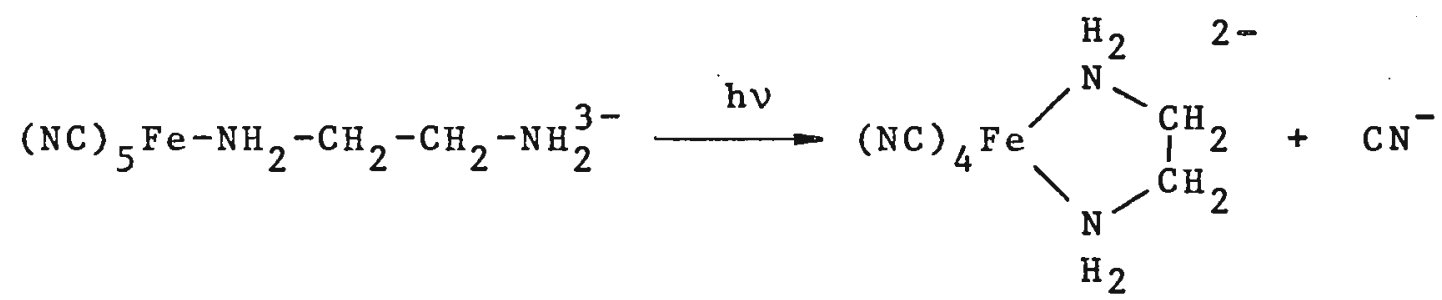

é o único processo fotoquímico efetivo que ocorre durante. o período de irradiação. 
I. INTRODUÇAO $\ldots \ldots \ldots \ldots \ldots \ldots \ldots \ldots \ldots \ldots \ldots \ldots \ldots \ldots \ldots \ldots$

II. NITROPRUSSIATO E A REATIVIDADE DO GRUPO NITROSILO COORDENADO $\ldots \ldots \ldots \ldots \ldots \ldots \ldots \ldots \ldots \ldots \ldots \ldots \ldots \ldots \ldots \ldots$

2.1. Estruturas e Propriedades Espectrais ..... 19

2.2. Eletroquímica e Fotoquímica ............. 22

2.3. Reação de Adição e Substituição ........... 29

III. ASPECTOS DE REAÇÕES FOTOQUIMICAS DOS COMPOSTOS

DE COORDENAÇAO ..................... 43

3.1. Introdução $\ldots \ldots \ldots \ldots \ldots \ldots \ldots \ldots \ldots \ldots \ldots$

3.2. Principios de Fotoquimica ............ 44

3.3. Fotosubstituição ................. 51

IV . PARte experimental e tratamento de dados $\ldots . .$.

4.1. Preparação e Purificação de Compostos .... 55

4.2. Aparelhagem e Técnicas Experimentais ..... 61

4.3. Tratamento de Dados ................. 78

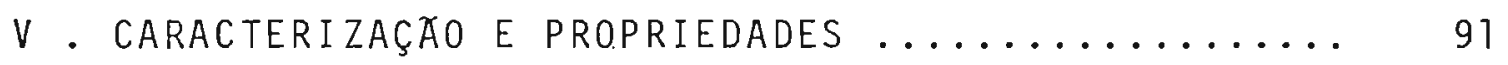

5.1. Espectros Eletrônicos ............... 91

5.2. Espectros de Absorção na Região do Infraverme1ho ...................... 142

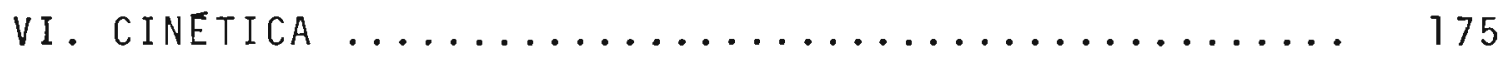

6.1. Cinética de Formação e Substituição do

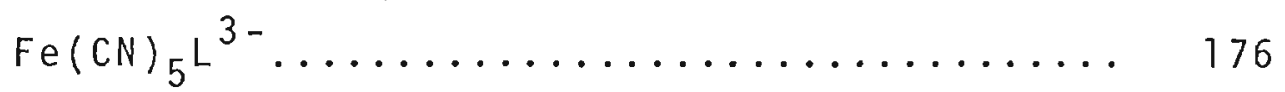

6.2. Reação de Adição das Acetilpiridinas ao

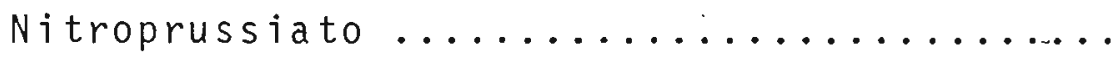


VII. VOLTAMETRIA CICLICA E DETERMINAÇĀO DE PARĀMETROS ELETROQUIMICOS E CONSTANTES DE ESTABILIDADE... 266

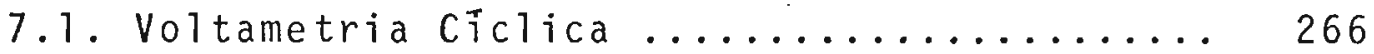

7.2. Determinação de Parāmetros Termodināmicos.. 290

VIII. REAÇOES FOTOINDUZIDAS $\ldots \ldots \ldots \ldots \ldots \ldots \ldots \ldots$

8.1. Sistema $\mathrm{Fe}(\mathrm{CN})_{5} \mathrm{py}(\mathrm{CO}) \mathrm{CHNOH}^{3-}$ - Fotosubstituição de $\mathrm{CN}^{-} \ldots \ldots \ldots \ldots \ldots \ldots \ldots \ldots$

8.2. Sistema $\mathrm{Fe}(\mathrm{CN})_{5} \mathrm{en}^{3-}$ - Fotosubstituição de $\mathrm{CN}^{-} \ldots \ldots \ldots \ldots \ldots \ldots \ldots \ldots \ldots \ldots \ldots$

8.3. Sistema $\mathrm{Fe}(\mathrm{CN})_{5} \mathrm{CO}^{3-}$ - Fotosubstituição

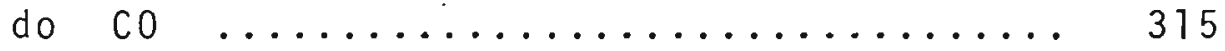

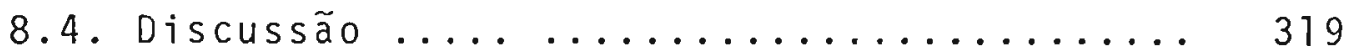

IX. PLANO DE PESQUisa E ALgUNS RESULtAdOS PARCIAIS. $\quad 325$

9.1. Catāi ise e Reação de Ligantes Coordenados. 325

9.2. Reações Fotoinduzidas .............. 328

9.3. Correlação entre as Propriedades Espectrais e Termodināmicas nos Compostos de Coordena-

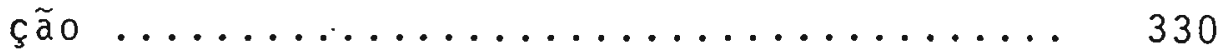

9.4. Resultados Parciais .............. 331

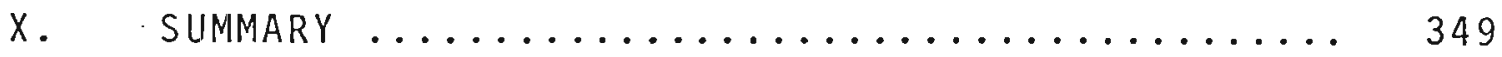

XI. APENDICE ............................ 354

11.1. Decomposição das Bandas de Absorção ..... 354

11.2. Derivação das Leis de Velocidade ....... 360

11.3. Resultados Experimentais Complementares.. 371

XII. REFERENCIAS BIBLIOGRAFICAS ............ 387 


\section{1- INTROOUÇÄO}

O processo de coordenação, embora possa ser descrito como uma simples interação eletrostática-covalente entre um ion metālico e os ligantes que o envolvem, traz co mo consequência um número ilimitado de modificaçōes no comportamento tanto do íon metálico como do ligante. Desde o tempo de Werner, a química de coordenação tem fixado suas a tenções principalmente nas variações das propriedades do ion metālico. As implicações destas podem ser observadas a través de mudança no comportamento (i) cinético; modificando velocidades e padrões de reações, (ii) espectroscópico; pelas perturbações nos niveis de energia em função do campo ligante e (iii) termodinämico; manifestando-se nos valores das constantes de estabilidade e potenciais'eletroquīmicos dos compostos formados. E certo porém que as modificações nas propriedades do ion metāiico tambēm são acompanhadas de variações drásticas nas propriedades do grupo coordenado,al terando a própria reatividade do ligante.

O ĩon metálico, sendo mais "mole" que o próton: é geralmente menos efetivo do que este na polarização do e: létron do substrato. Contudo a função do ion ou complexo me tālico não se restringe apenas à remoção de densidade ele trônica; ao contrārio dos prótons, eles podem aumentar a de! sidade eletrōnica nos ligantes. Um outro contraste provém dc fato do ion metālico estabelecer ligações segundo seu nūmerc de coordenação, incluindo a possibilidade de formar tanto :- 
gações $\sigma$ como $\pi$, dada a variedade de simetria de orbitais que possuem.

Do ponto de vista mecanístico, os íon metálicos podem causar os seguintes efeitos no ligante coordenado.

\section{Eletrônico}

Os elétrons são parcialmente deslocados pelo íon ou com plexo métálico, sendo transferidos completamente no caso de reações redox. Através da remoção ou doação da densidade ele trônica, os ion metālicos podem mascarar eletrófilos ou nu cleófilos pela perda do cátion $\left(H^{+}\right)$ou então novos eletrófilos pela perda de um ànion.

\section{Estërico}

0 ỉon metālico geralmente imporā uma condição estérica na reação do ligante, devido à configuração específica da sua esfera de coordenação.

\section{Equilíbrio}

A formação de um quelato metālico é favorecida pelo forte efeito entrōpico em soluções diluỉdas, aumentando assim, a fossibilidade de formar uma dada espécie reativa ou um com plexo ativado, com o metal interagindo com vārios pontos, si multaneamente.

Na realidade, a participação do ion metālico ou complexo na função de alterar a reatividade do ligante envol ve provavelmente uma combinação dos efeitos citados.Isso se torna evidente nas funções descritas a seguir; deixando-se de 
lado os aspectos relacionados com as reações de transferēncia de elétrons ou fotoestimuladas.

a. Catālise ācida de Lewis, pela ativação da ligação do subs trato quỉmico através da polarização da ligação via coordenação.

Na catālise àcida de Lewis, o ion metālico apa rece para diminuir a energia de ativação da reação, tanto pela ativação do estado fundamental como pela estabilização do estado excitado.

A hidrōlise do glicinato de etila na presença de $\mathrm{Cu}^{2+} \overline{\mathrm{e}} 1,3 \times 10^{5}$ vezes mais rāpida do que a do éster 1 ivre e $3,1 \times 10^{3}$ vezes mais rāpida do que hidrōlise do éster protonado (1). O efeito observado provém claramente da pola rização do grupo carbonila, com deslocamento de densidade $\underline{e}$ letrōnica, conforme esquematizado abaixo

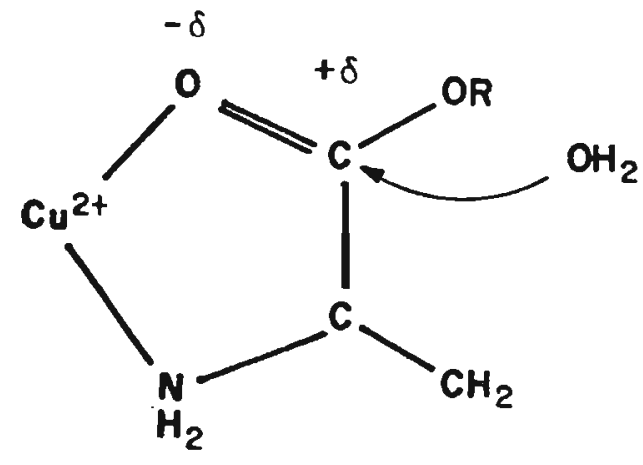

Essa polarização deixa o ātomo de carbono mais positivo e facilita a recepção dos elétrons do nucleófilo. b. Diminuição de densidade eletrōnica do substrato causando 
aumento da concentração de espécie nucleofỉlica, refletindo ainda uma perturbação do pKa pela coordenação do ion metāli co.

A coordenação de um ácido fraco a ions metālicos conduz a um aumento na nucleofilicidade efetiva da base conjugada correspondente. Em geral o fenômeno pode envolver vārias etapas, onde numa delas o ion metálico promove a dís sociação do ion hidrogênio do nucleófilo, conforme represen tado a seguir

$$
\begin{array}{cl}
M^{x+}+L H_{n} \rightleftharpoons\left[M L H_{n}\right]^{x+} & \begin{array}{l}
\text { etapa de } \\
\text { coordenação }
\end{array} \\
{\left[M L H_{n}\right]^{x+} \rightleftharpoons\left[M L H_{n-1}\right]^{(x-1)+}+H^{+}} & \begin{array}{l}
\text { etapa de } \\
\text { deprotonação }
\end{array} \\
{\left[M L H_{n-1}\right]^{(x-1)+}+R X \rightarrow\left[M-\stackrel{R}{L}-H_{n-1}\right]^{x+}+X^{-}} & \text {ataque } \\
\text { nucleofílico }
\end{array}
$$

A coordenação chega a afetar alēm de trēs unidades de pKa, dependendo da força com que o ion metālico car regado positivamente interage com os residuos ácidos do ligante coorderiado. Essa perturbação do pka, obviamente pode produzir um grande aumento da concentração efetiva das especies nucleofílicas.

c. Mascaramento dos nucleófilos pela diminuição da densidade eletrōnica do substrato.

A remoção da densidade eletrônica do substrato 
produz sensĩveis variações na reatividade do ligante. Por $\underline{e}$ xemplo, a formação da ligação o através do par de elétrons da amōnia, leva ao mascaramento da basicidade do ligante no complexo $\mathrm{Cu}\left(\mathrm{NH}_{3}\right)_{4}{ }^{2+}$.

d. Aumento da nucleofilicidade do substrato através do au mento da densidade eletrónica.

Os ions metālicos que formam fortes ligaçōes $\pi$ podem aumentar a densidade eletrónica do substrato coordena do atravēs da retrodoação.

0 complexo representado a seguir

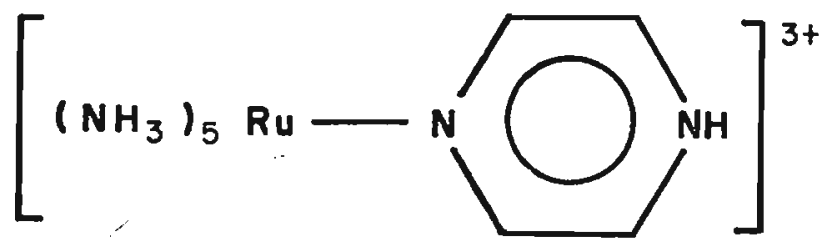

apresenta um pKa de 2,5 comparado a 0,5 do ligante livre(2). 0 Ru(II) forma forte ligação $\pi$ e atravēs da retrodoação au menta a basicidade do ligante.

e. Mascaramento do eletrófilo pelo aumento da densidade ele trōnica.

Atravēs da interação $\pi$, jā citada no îtem an terior, os grupos pentacianoferrato(II) (3) e pentaaminrutê nio(II) (4), aumentam a densidade eletrónica do ligante, es - tabilizando p-formilpiridina em relação à sua forma hidrata da. 

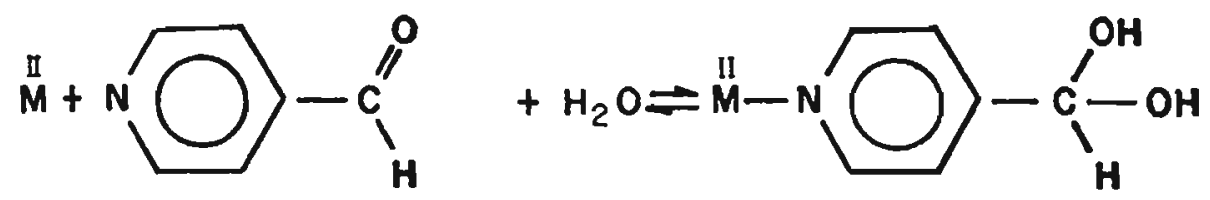

Os valores das constantes de ridratação a $37^{\circ} \mathrm{C}$ são 0,$84 ; 0,48$ e 0,20 , respectivamente para o ligante livre e nos complexos de ferro(II) e rutênio(II).

f. Facilitando o ataque nucleofílico no substrato pela neutralização da carga nos estados fundamentais e ou de transi ção.

Nos substratos negativos, a coordenação ao ĩon metálico positivo pode auxiliar o ataque de um nucleófilo aniōnico pela minimização da repulsão coulōmbica.

g. Efeito "Template" facilitando a reação pelo alinhamento preciso de reagentes atravēs da coordenação ao íon metālico.

0 metal atua como ponto de encontro("collecting point") para os reagentes, mantendo-os nos lugares adjacentes e em posições relativamente fixas. Esta imposição de con formação especîfica pela coordenação pode acelerar bastante a velocidade das reações em que as outras conformações difi cultariam ou impossibilitariam.

0 pré alinhamento dos reagentes através do ion metālico é ilustrado na reação representada da página a seguir. 


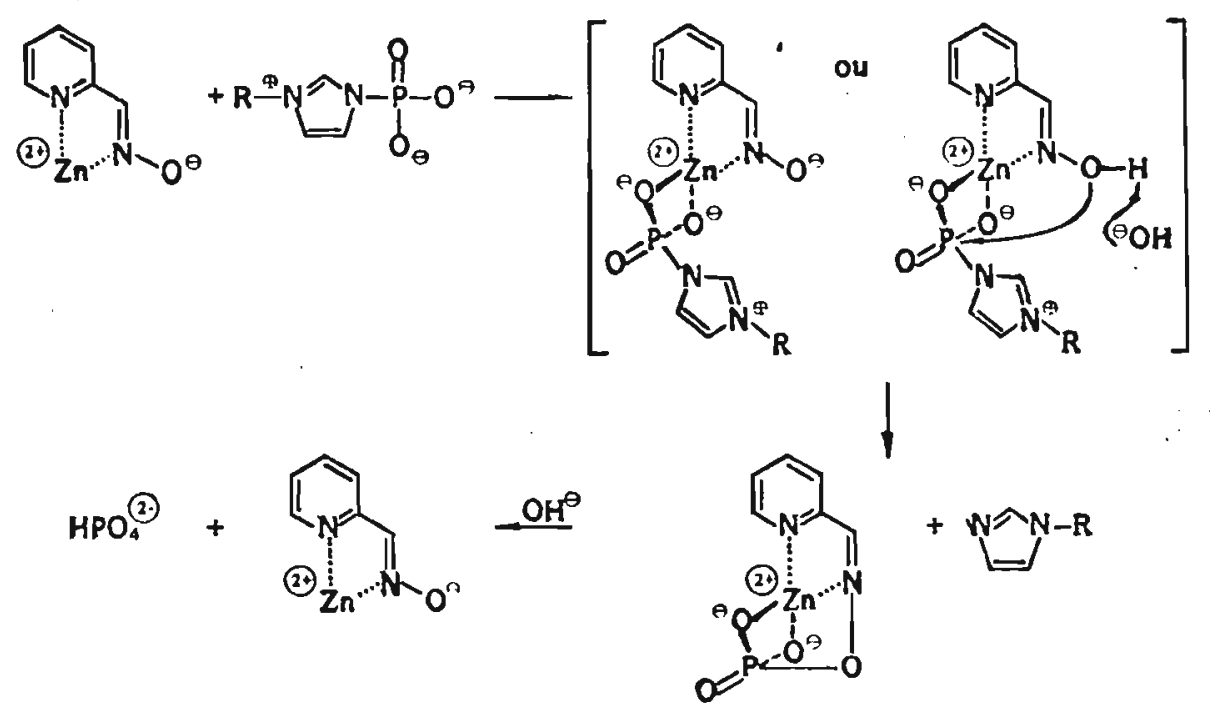

Na hidrōlise de fosforil-imidazol ou N-metilfo forilimidazol (5), além da ação do $Z n$ (II) como ponto de encontro dos reagentes, pode-se ver vārios dos efeitos mencio nados anteriormente.

Nesta reação o complexo carboxáldoximazincó(II atua como um catalisador efetivo e especifico. A coordena ção do carboxaldoxima ao ion zinco, perturba o pKa de 10,04 a 6,5 , embora mantenha uma nucleofilicidade comparável ac da forma hidroxi. Portanto, a coordenação proporciona um aumento da espécie nucleofílica e ainda, diminui a repulsão coulômbica entre o diāniọ fosforil e carboxaldoxima, aproxi mando os reagentes envolvidos.

0 efeito "template" é um dos mais importantes nas reações de metaloenzimas, formação de quelatos, condensação "template", reações de inserção organometālica e cicl oligomerização de alcenos e alcinos. Em geral este efeito $\bar{\epsilon}$ 
classificado em três categorias.

\section{i. Cinētico}

0 efeito "template" cinētico estā presente em reações onde o produto não poderia ser formado na ausēncia do ion metālico. Este atua coordenando-se aos reagentes, im pondo-lhes determinada estereoquímica para promover uma série de etapas controladas, como indicadas no exemplo a se guir $(6,7,8)$.

$$
\mathrm{NiCl}{ }_{2}+2 \mathrm{H}_{2} \mathrm{NCH}_{2} \mathrm{CH}_{2} \mathrm{SH} \frac{\mathrm{NaOH}}{\mathrm{Soluça \textrm {O }}}
$$


ii. Termodinâmico

$$
0 \text { efeito "template" termodināmico atua nas rea }
$$

ções onde o ĩon metálico influencia a posição de equitíbrio, deslocando-a no sentido de formação da espécie que se coordena fortemente.

A reação de formação do macrociclo descrito a seguir ocorre mesmo na ausēncia do ĩon metāico (9)

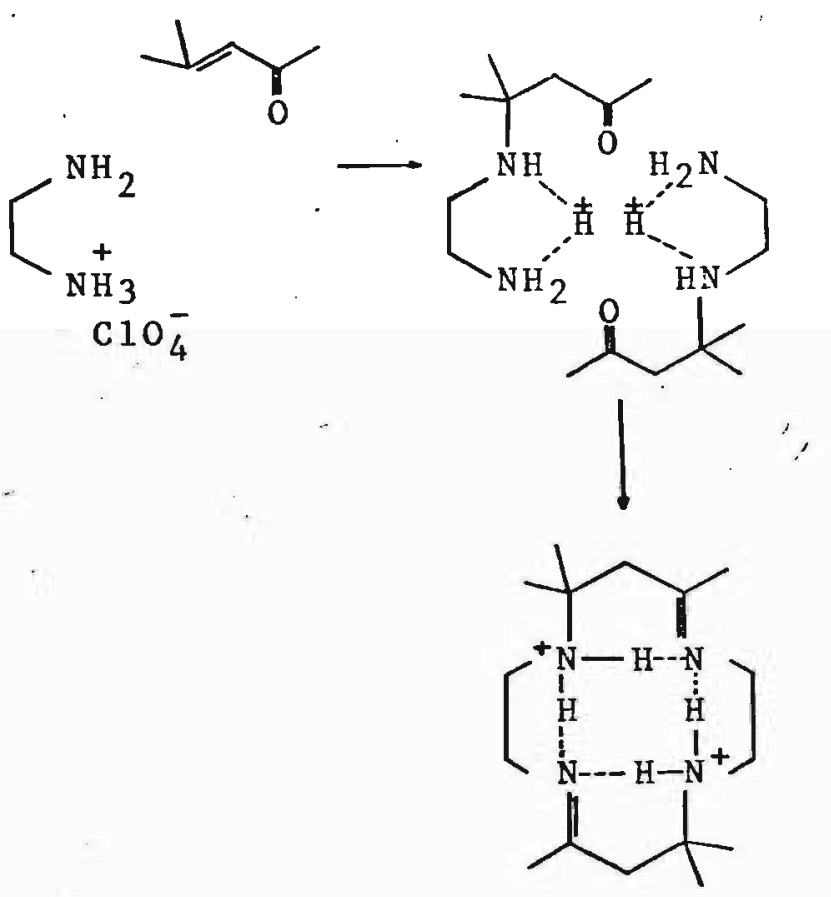

Porém, a presença do $N$ i(II) possibilita a remo ção do macrociclo do equilíbrio na forma do complexo (10), conforme representado na pāgina a seguir. 


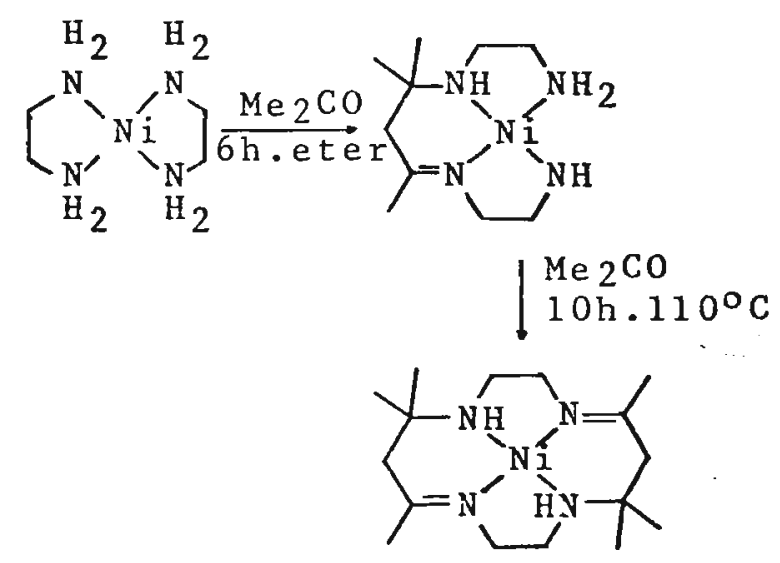

i i E. Equilibrio

E o efeito produzido pela combinação dos efeitos cinētico e termodināmico. Nesse caso, os reagentes reagem reversivelmente para dar um intermediário que forma um complexo estável com o metal, de tal forma que toda a rea ção se dá vià complexo metālico. E interessante verificar a seguir (8), que a presença do ion metālico leva à formação do complexo de base de Schiff, com alto rendimento, ao passo que na sua ausência o que se obtēm é uma mistura de tiazois, tiazolinas e mercaptais.<smiles>O=C1CCCCC1=O</smiles><smiles>NCCS</smiles>

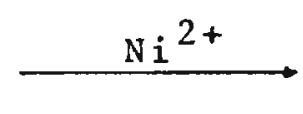<smiles></smiles>

h. Mascaramento de um grupo funcional 
A coordenação pode proteger grupos especĩficos e limitar o número de sítios em relação ao ligante livre.

Uma das aplicações mais ūteis ē na sīntese de derivados de amino ácidos como a conversão de citrolina em ornitina através da reação apresentada a seguir.
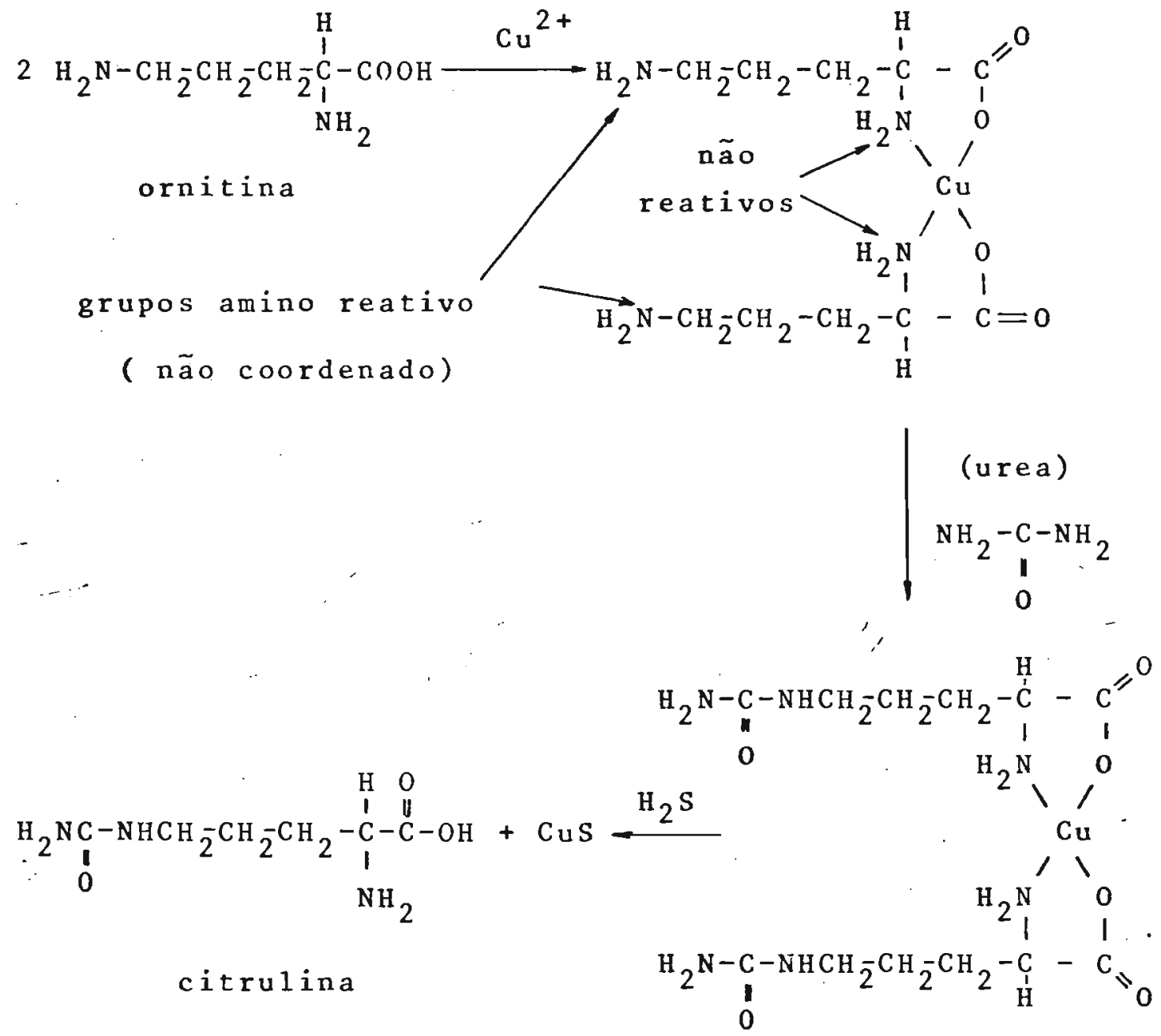

Atravēs da coordenação e formação do anel quelato, o metal remove um dos grupos amino reativo da ornitina e torna a reação específica para o grupo $\mathrm{NH}_{2}$ não coordenado (11). 
i. Estabilização do estado de transição atravēs da formação de quelato.

Em alguns casos, a estrutura do substrato no estado de transição é mais adequada para a formação de quela tos do que no seu estado inicial.

No mecanismo de hidratação de 2-ciano-1,10-fe nantrolina catalisada pelo níquel (12), a principal função do ĩon metālico é a de forçar a efetivação de uma reação a través de estabilização do intermediārio.
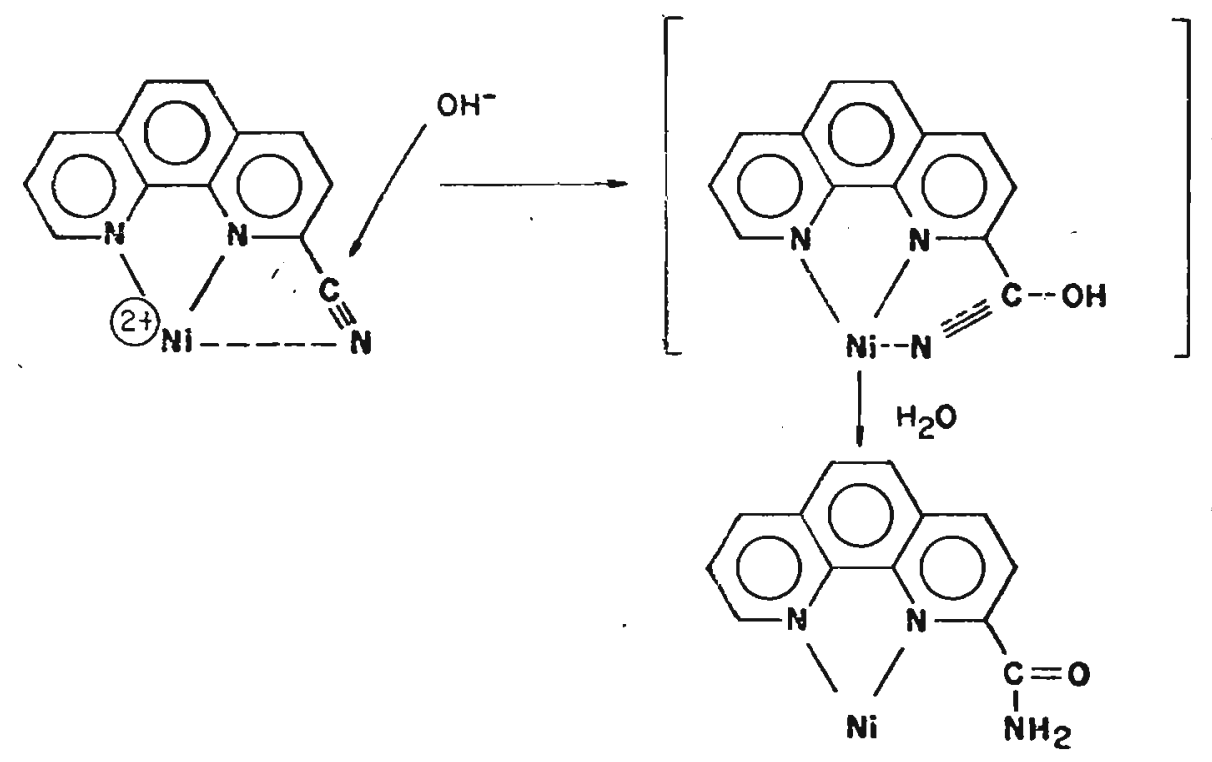

O Ni(II) proporciona um aumento na constante de velocidade por um fator de $10^{7}$ em relação ao ligante livre.

Muitos desses efeitos citados, ou outros, foram reconhecidos há muito tempo atrās, e datam desde o inīcio da química de coordenação. Embora numerosas observações sempre tenham feito parte da literatura, apenas em torno de 1960 , surgem estudos sistemáticos de reações de ligantes coordenados. Vários textos de revisão (13-19) foram publicados em 
torno de 1963; ano em que Karl Ziegler e Giulio Natta recebe ram o prêmio Nobel pelo estudo de polimerização esteroespecî fica de olefinas catalisada pela mistura de sais de haletos de metais de transição e alquil alumínio (20,21).

A química de ligantes coordenados é um campo de grande potencial e, com importantes implicações tecnológicas (22). As aplicaçōes tīpicas podem ser ilustradas pelo proces so de hidroformilação catalisada pelo complexo de carbonilocobalto(23), pelo processo Wacker (24) de oxidação de olefinas num complexo de palādio, pelo processo de carbonilação do metanol catalisada pelo complexo de ródio na produção de ácido acético (25-26), entre muitos outros.

Alēm das aplicações quĩmicas bāsicas, incluindo a preparação de novos complexos e sīnteses orgānicas usando catalisadores metālicos, a reação do ligante coordenado ainda apresenta grande interesse biolōgico $(27-32)$.

Uma das tendēncias atuais, compreendida pela bioinorgânica, preocupa-se com a elucidação dos processos biológicos vitais, como a fixação de nitrogēnio, a conversão de energia pelos seres vivos e a sua habilidade de empregar catalisadores para esse fim. Exemplos de tais catalisadores são as enzimas que controlam a sintese e a degradação de moléculas importantes biologicamente (33). O processo de hidrō lise ou hidratação dos substratos carbonila ou fosforila pelas enzimas $(28 a, 33 a, 34)$, bem como a sua compreensão através de sistemas modelos $(27 a, 29 a, 31 a, 35)$ ilustra aspectos importantissimos da reatividade do ligante coordenado. Estes aspectos tambēm podem ser visualizados atravēs do comporta - 
mento e reatividade (28b) do oxigēnio molecular coordenado em diferentes substratos (36).

A importāncia da reação de ligantes coordenados, promovida pela irradiação de 1 uz $(37,38)$, pode ser facilmente justificada se lembrarmos que existe um enorme interesse em conhecer o potencial energētico de reações provocadas pela luz e suas aplicações (39).

0 estudo de reações fotoinduzidas ē de grande im portância para desvendar e compreender como o sistema biológ co apresenta habilidade de capturar e utilizar energia lumino sa para promover processos fotossintēticos. As reações fotoserisīveis apresentam tambēm amplo interesse tecnológico: 0 conhecimento sobre a estabilidade de tintas e corantes com respeito à 1 uz e a fotodegradação de polímeros, como a polimerização fotoiniciada, sem dūvida ilustra a relevância desse campo.

Ao longo das duas ūltimas dēcadas, vārios ąrtigos de revisão (28a, 40-52) tem abordado diferentes aspectos das reações de ligantes, com visões e organizações distintas. Mesmo os livros textos bāsicos de química inorgânica $(53,54)$ apresentam e discutem a reatividade de ligantes coordenados mostrando a relevāncia do tema. 0 seu conhecimento à resenta grande importância pela aplicações em sîntese $(17,43,49,51$, $55,56)$, catāi ise e no conhecimento da reatividade de siste mas biolōgicos. 
0 presente trabalho teve como objetivo abordar vārios aspectos da reatividade de ligantes, dentro de uma 1 i nha voltada para as implicações de fatores estruturais e ele trônicos na sistemātica do comportamento quỉmico.

Vārias alteraçōes provenientes da coordenação d ligante foram analisadas atravēs de estudos cinéticos da rea ção de adição dos isōmeros de acetilpiridina ao nitroprussia to. Para elucidar o mecanismo da reação foram efetuados estu dos paralelos das etapas envolvidas no mecanismo global. 0 intermediário envolvido na reação foi obtido e caracterizado pelo espectro infravermelho e visivel.

A influēncia da coordenação sobre as propriedades espectrais e termodināmicas foi analisada determinando-s os valores de pKa e estudando-se as variações espectrais pro vēnientes da coordenação, da oxidação do metal e da mudança de meio.

Investigou-se ainda, os processos que ocorrem subsequentemente à interação com radiação visīvel e ultravio leta-próximo, verificando: (i) como a luz induz uma determi nada reação quîmica nos compostos de coordenação e (ii) o me canismo das reações envolvidas comparadas às reações te்rmi cas. Na tentativa de estabelecer o mecanismo da reação foto. química envolvida no processo de fechamento de anel nos com. plexos $\mathrm{Fe}(\mathrm{CN})_{5} \mathrm{Py}(\mathrm{CO}) \mathrm{CHNOH}^{3-}$ desenvolveu-se o estudo dos s. temas auxiliares e fez-se a anālise dos rendimentos quânti. cos correspondentes a cada etapa.

Tais estudos de reatividade dos compostos de 
coordenação foram associados com os aspectos relacionados com a estabilidade termodināmica, com o grau de resistēncia à mudança nos estados formais de oxidação cujos fatores dependem intrinsicamente de parāmetros estruturais. Estes aspectos fo ram analisados a partir dos parāmetros eletroquímicos obti dos pela técnica de voltametria cỉclica. A associação destes, com os dados obtidos nos estudos cinēticos, permitiu avaliar a influéncia do ligante na estabilização de determinados estados de oxidação.

Com estes estudos enveredou-se por um novo campo na química dos cianoferratos, cujos tabalhos jā haviam si do desenvolvidos pelo nosso grupo de pesquisa focalizando a pectos de correlações de estrutura, reatividade e intervalēn cia (229), mecanismo de transferēncia de elétrons $(230,231)$, bioinorgânica $(232,233)$ e efeitos de solvente (234).

A tese $\bar{e}$ redigida obedecendo ao seguinte esquema .

No capitulo II é feita uma discussão sobre o complexo pentaciano(nitrosil)ferrato(II) ou simplesmente, ni troprussiato e a reatividade do ligante NO coordenado, sob forma de revisão.

No capitulo II i descreve-se um resumo dos princīpios de fotoquímica inorgânica, por tratar-se de assunto ainda pouco explorado em nosso pais. As reações de fotosubstituição nos complexos $d^{6}$ campo forte são comentadas breve mente.

A parte experimental e o tratamento de dados são 
descritos no capítulo IV.

A apresentação e dicussão de dados são abordadas nos capītulos V, VI, VII e VIII. Inicialmente (Cap. V) é feita a caracterização e uma discussão das propriedades do sistema em estudo, sob o efeito da coordenação. A seguir(Cap VI) desenvolveu-se todo o tratamento cinētico e mecanistico da reação de adição. No capittulo VII são apresentadas as informações obtidas da voltametria cĩclica e a avaliação das constantes de estabilidade. Reações de fotosubstituição, incluindo mecanismos de fechamento de anel e uma discussão sobre o estado excitado reativo são abordados no capitulo VIII Uma visão do sistema e o plano de trabalho com alguns resultados parciais estão no capītulo IX para o prosseguimento de atividade de pesquisa. 


\section{II- NITROPRUSSIATO E A REATIVIDADE DO GRUPO NITROSILO COORDENADO}

Os nitrosilo-complexos de metais de transição são conhecidos há mais de um século e no decorrer deste perî. do surgiram vários textos gerais de revisão (57-66).

Entretanto, em comparação ao carbonilo-comple xos correspondentes, tem sido muito pouco investigado. A jus tificativa provavelmente está no fato da ligação M-NO ser muito forte, e dos complexos não apresentarem reações de des locamento do ligante que são tão importantes nos processos cataliticos promovidos pelo metalo-carbonilos. Uma das pou cas exceções, que ressalta no campo da reatividade dos nitro silo-complexos, é o ion nitroprussiato $\left(\mathrm{Fe}(\mathrm{CN})_{5} \mathrm{NO}^{2-}\right), \quad 0$ qual tem atraīdo interesse considerāvel durante vārios perīo dos na histōria da quĩmica(67).

A reação entre o ĩon nitroprussiato e $\mathrm{SH}^{-}$, $\mathrm{SO}_{3}{ }^{2-}$ e compostos orgānicos com grupos metila àcidos, dá origem a complexos intensamente coloridos e constitue a base para "spot-test" descrito pelo Feigl (68) há mais de quatro décadas.

Além de fins analiticos, o ion pentacianonitrosilferrato(II) apresenta grande importāncia pelas aplicações em sīntese $(62,72-74)$, a inda pouco explorada. Vários trabalhos tem surgido mostrando a função e a aplicação de nitro prussiato para fins biológicos $(75,76)$, como na terapia de cāncer (77) e controle de hipotensão (78). 
Um novo estimulo para investigar a reatividade do No vem crescendo com o desenvolvimento do controle. de poluição na tentativa de remoção ou pelo menos, na diminuição da concentração de No nos gases de exaustão expelidos pelos motores de combustão interna.

Um interesse adicional vem da possibilidade de produzir compostos organonitrogenados do óxido nitrico em rea ções associadas ou controladas pelos catalisadores de metais de transição.

\subsection{Estruturas e Propriedades Espectrais}

Um' comentārio breve sobre a ligação terminal en tre o NO e o metal é pertinente, no sentido de elucidar de terminados comportamentos cinéticos do mesmo ( 79 ).

Atravēs da coordenação, o no pode atuar como um doador de elétrons dando $\mathrm{NO}^{+}$(isoeletrônico ao Co) ou co mo um receptor de elétrons dando $\mathrm{NO}^{-}$( ou mesmo $\mathrm{N}_{2} \mathrm{O}_{2}{ }^{2-}$ ), ou ainda, uma mistura entre essas formas.

A estrutura linear (A) corresponde ao estado de oxidação $\mathrm{NO}^{+}$com hibridização $\mathrm{sp}^{2}$ do nitrogēnio onde - ligante comporta-se como doador de trēs elétrons. Para o óxido de nitrogēnio na forma $\mathrm{NO}^{-}$, a estrutura correspondente é angular (B), com o ligante atuando como doador de um elétron, possuindo um par de elétrons livre que o torna angu$1 \mathrm{ar}$. 


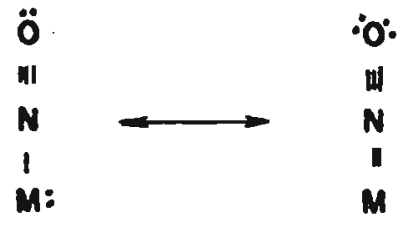

(A)

$\therefore$.

\section{I}

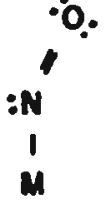

(B)

Na atribuição do estado de oxidação formal, foi ignorada a existência da ligação $\pi$ entre o metal e o ligan te. Desde que ela é vital para a coordenação linear de No, muitas vezes a designação $\mathrm{NO}^{+}$tem sido criticada como uma forma não representativa da distribuição de carga real. Como formalismo, pode-se encarar a coordenação do $\mathrm{NO}^{+}$como sendo anāloga a ligação metal carbonila, com acoplamento sinergístico de ligação o e $\pi^{\prime}$. Esta situação pode ser representada pela estrutura $c$.

$$
\begin{aligned}
& \substack{0 \\
\vdots \| N \\
1 \\
m} \\
& m \leqslant n \leqslant 2
\end{aligned}
$$

c

A disçussão de, se o no é ligado de uma manej ra linear ou angular, resume-se na verdade na extensão en que o par de elétrons em questão estā sendo forçado a resi dir no orbital atōmico do nitrogēnio (angular) ou se hā un orbital molecular de energia mais baixa à sua disposição. 
A força da retrodoação ē sensivelmente refletida nos parāmetros físicos do ligante como frequēncia de esti ramento e constante de força de $\mathrm{N}-0$, comprimento de ligação N-O e, tambēm nas variações do comportamento eletrofĩlico(59, $67)$.

Uma discussão mais pormenorizada da interação M-NO, avaliada por meio de medidas físicas, pode ser acompa nhada nas 1 iteraturas citadas ou nos textos de revisão. Es tas informações devem ser atualizadas com as publicações mais recentes sobre: redeterminação da estrutura $(80,81)$, efeito Mossbauer. (82), cālculo de orbitais moleculares (83), ressonāncia magnética nuclear (84) e novas atribuições de transições eletrōnicaś, (85).

Uma correlação bastante interessante entre estrutura e reatividade é feita pelo Bottomley e Grein (86), reinterpretando o estudo dos orbitais moleculares usando a aproximação INDO (87). A partir deste, é feita a atribuição dos dados espectrais e, as implicações no comportamento ciné tico e oxi-redutivo. A determinação de cargas formais nos àtomos individuais mostra que o àtomo de nitrogēnio do ion $\mathrm{Fe}(\mathrm{CN})_{5} \mathrm{NO}^{2-}$ apresenta a carga positiva mais elevada em rela ção a outros pentacianonitrosilo-complexos. Isto correlaciona-se com o fato de que tanto o ataque nucleofilico como a redução ocorrem no àtomo de nitrogénio do nitrosilo coordena do. 


\subsection{Eletroquĩmica e Fotoquĩmica}

Um relato simples sobre o comportamento eletroquỉmico, principalmente a redução e, reação fotoquímica do ligante No no nitroprussiato é feito com a finalidade de estabelecer alguma relação entre este e sua reatividade eletrofîica.

A redução eletroquỉmica de $\mathrm{Fe}(\mathrm{CN})_{5} \mathrm{NO}^{2-}$ tem si do realizada tanto em água como em outros solventes, com resultados controvertidos a cerca da natureza dos produtos da redução.

Os primeiros estudos eletroquimicos de $\mathrm{Fe}(\mathrm{CN})_{5}$. $\mathrm{NO}^{2-}$ foram realizados utilizando-se a técnica de polarografia com a obtenção de 3 ondas $(88,89)$. Estes estudos e or vāa rios-que vieram a seguir (90-93), tem demonstrado que exist no minimo dois produtos resultantes da reduçáo monoeletronica do Ton nitroprussiato. A identidade desses produtos, un de cor amarela marron e outro azul, tem levado a vārias formulações como: $\mathrm{Fe}(\mathrm{CN})_{5} \mathrm{NO}^{3-}, \mathrm{Fe}(\mathrm{CN})_{5} \mathrm{NOH}^{2-}, \mathrm{Fe}(\mathrm{CN})_{4} \mathrm{NO}^{2-}$, $\mathrm{Fe}(\mathrm{CN})_{5} \mathrm{NO}_{2}^{5-}, \mathrm{Fe}(\mathrm{CN})_{4}(\mathrm{NC}) \mathrm{NO}^{3-}$ e $\mathrm{Fe}_{2}(\mathrm{CN})_{10}^{6-}$.

A maioria das discussões tem se centrado nos dois primeiros, com afirmações conflitantes na atribuição pé ra as espécies azuis e marron, embora o processo de redução tenha sido estudado por uma variedade de técnicas de sintese (94-99) e de medidas físicas como EPR (100-112), espectro Mossbauer (113), cristalográfico (114) e termoanalítico(109: O estudo de Masek et al $(92,93)$ sobre a reduçãc 
eletroquỉmica com värias técnicas como polarografia, voltame tria cīclica e coulometria em solução aquosa mostrou dois processos de redução monoeletrōnica e reversīvel seguida de uma redução multieletrônica irreversível a $-0,9 \mathrm{~V}$. Is to 1e vou-os a proporem um esquema de possĩveis processos existentes na redução do ĩon nitroprussiato em solução aquosa repre sentada a seguir

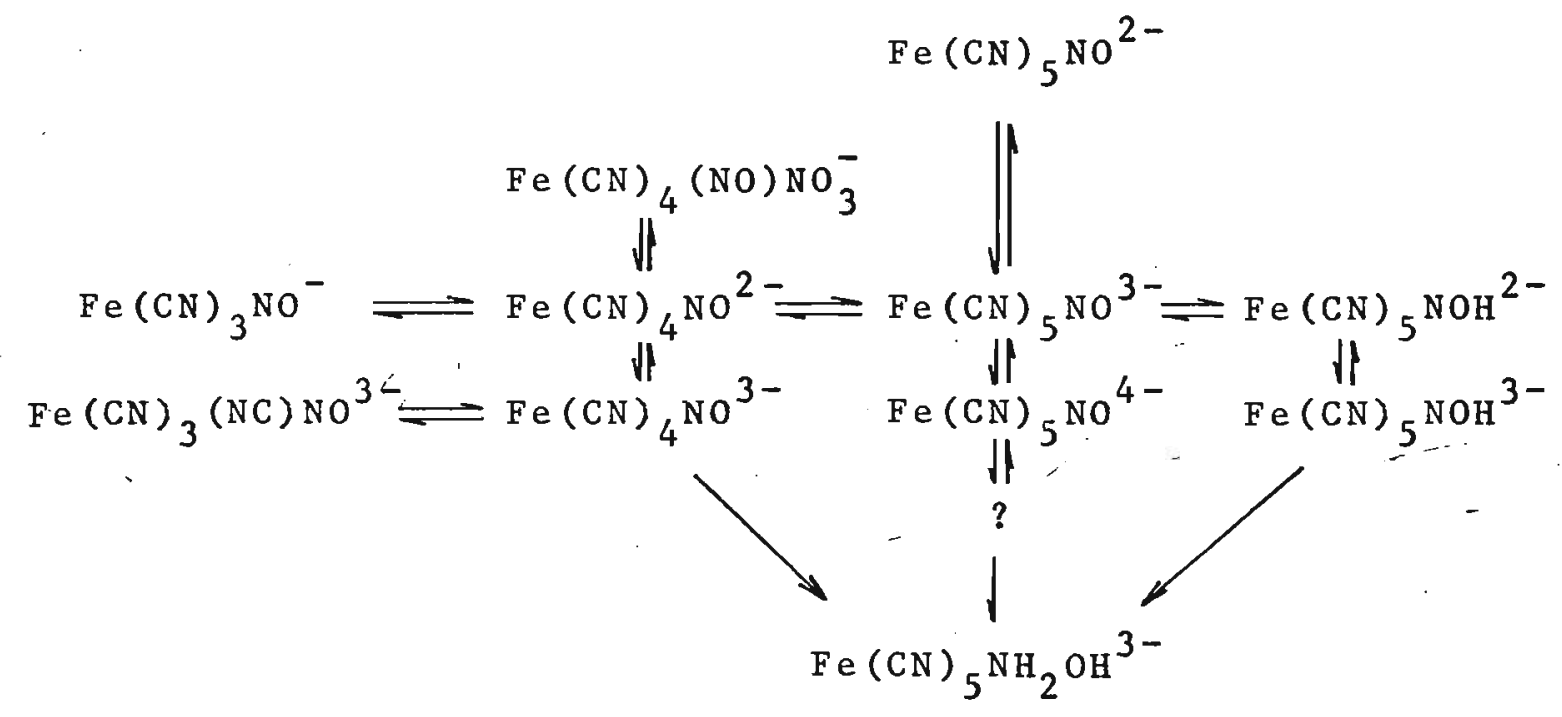

Já, em meio aprōtico, usando acetonitrila e diclorometano como solvente, Bowden et al (115) observaram uma perda rāpida do cianeto apōs o processo de redução, com a for mação do ānion azul $\mathrm{Fe}(\mathrm{CN})_{4} \mathrm{NO}^{2-}$. Este por sua vez apre senta uma oxidação reversîvel a velocidade de varredura rāpida levando-os a proporem o mecanismo representado no esquema da página a seguir. 


$$
\begin{aligned}
& \mathrm{Fe}(\mathrm{CN})_{5} \mathrm{NO}^{2-} \\
& -0,82 \mathrm{v} \\
& \mathrm{Fe}(\mathrm{CN})_{5} \mathrm{NO}^{3-} \\
& \downarrow^{k_{1}} \\
& \mathrm{Fe}(\mathrm{CN})_{4} \mathrm{NO}^{-} \underset{-0,66 \mathrm{~V}}{\rightleftharpoons} \mathrm{Fe}(\mathrm{CN})_{4} \mathrm{NO}^{2-} \underset{-1,23 \mathrm{~V}}{\rightleftharpoons} \mathrm{Fe}(\mathrm{CN}){ }_{4} \mathrm{NO}^{3-}
\end{aligned}
$$

Os estudos de redução monoeletrônica do ĩon per tacianonitrosilferrato(II) em solução aquosa, usando técnica de radiólise contínua e em pulso (116), levaram ao resultadc similar ao anterior, com formação do composto amarelo-marror $\mathrm{Fe}(\mathrm{CN})_{5} \mathrm{NO}^{3-}$, que apresenta um decaimento de primeira orden com respeito à perda de $\mathrm{CN}^{-}$, formando um composto azu1, ider tificado como $\mathrm{Fe}(\mathrm{CN})_{4} \mathrm{NO}^{2-}$. A concentração relativa das duas primeiras espécies depende acentuadamenté dó pH e da concentração do cianeto, sendo sensīvel à presença de oxigênio produzindo $\mathrm{Fe}(\mathrm{CN})_{5} \mathrm{NO}^{2-}, \mathrm{Fe}(\mathrm{CN})_{5} \mathrm{NO}(\mathrm{OH})^{2-}$ e espécie polimérica.

Estes fatos deixam claro que pelo menos a pri. meira etapa de redução é monoeletrōnica (116), com formação da espécie $\mathrm{Fe}(\mathrm{CN})_{5} \mathrm{NO}^{3-}$ que absorve a $\lambda_{\max } 345 \mathrm{~nm}$ e $440 \mathrm{nn}$ $\left(\varepsilon_{\max } 3,5 \times 10^{3}\right.$ e $5,5 \times 10^{2} \mathrm{M}^{-1} \mathrm{~cm}^{-1}$, respectivamente). Es se composto é instāvel e se dissocia rapidamente labilizande - cianeto, formando $\mathrm{Fe}(\mathrm{CN})_{4} \mathrm{NO}^{2-} \operatorname{com} \lambda_{\max }$ a $615 \mathrm{~nm}\left(\varepsilon_{\operatorname{ma}}\right.$ ) igual a $\left.3,8 \times 10^{2} \mathrm{M}^{-1} \mathrm{~cm}^{-1}\right)$. 
Sob a ação de 1uz, pentacianonitrosilferrato(II) apresenta vārias reações, muitas das quais ainda não bem de finidas.

Há mais de quatro décadas atrás observaram que a ação da luz solar no $\mathrm{Fe}(\mathrm{CN})_{5} \mathrm{NO}^{2-}$ dä origem ao azul de Berlin, HCN e NO (117). Baudisch (118) relatou que os pro dutos imediatos da fotodecomposição de $\mathrm{Fe}(\mathrm{CN})_{5} \mathrm{NO}^{2-}$ são apa rentemente $\mathrm{NO}$ e $(\mathrm{NC})_{5} \mathrm{FeH}_{2} \mathrm{O}^{2-}$. Jà o Griffith (119) observou a fotoredução do ion nitroprussiato em solução aquosa, dando origem a $\mathrm{Fe}(\mathrm{CN})_{5} \mathrm{NO}^{3-}$.

Mitra et al (120) observaram que a irradiação

com à luz não filtrada $(\lambda>300 \mathrm{~nm})$ do $\mathrm{Fe}(\mathrm{CN}){ }_{5} \mathrm{No}^{2-}$ em solu ção neutra, resúlta num decrēscimo de pH, que retorna ao seu valor original apōs a interrupção da irradiação. 0 fenōmeno observado foi atribuỉdo à reação fotoquỉmica primāria

$$
\mid \mathrm{Fe}^{\mathrm{II}}(\mathrm{CN})_{5} \mathrm{NO}^{+} \mathrm{I}^{2-} \stackrel{\mathrm{h} \nu}{\longrightarrow} \mathrm{Fe}^{\mathrm{II}}(\mathrm{CN})_{5}^{3-}+\mathrm{NO}^{+}
$$

seguida pela hidrōlise de $\mathrm{NO}^{+}$

$$
\mathrm{NO}^{+}+\mathrm{H}_{2} \mathrm{O} \longrightarrow 2 \mathrm{H}^{+}+\mathrm{NO}_{2}^{-}
$$

No entanto, a presença de $\mathrm{NO}_{2}{ }^{-}$não foi deteta da por Buxton et al (129) quando a fotōlise com $\lambda>300$ nm foi feita na ausēncia de ar. Na presença de ar detetouse tanto a presença de $\mathrm{NO}_{2}{ }^{-}$como de $\mathrm{NO}_{3}{ }^{-}$, o que levaram a formular: 


$$
\begin{aligned}
& \mathrm{Fe}^{\mathrm{II}}(\mathrm{CN})_{5} \mathrm{NO}^{+2-} \stackrel{\mathrm{hv}}{\longrightarrow} \mathrm{Fe}^{\mathrm{III}}(\mathrm{CN})_{5}^{2-}+\mathrm{NO}^{\circ} \\
& 2 \mathrm{NO}+\mathrm{O}_{2} \longrightarrow \mathrm{NO}_{2} \longrightarrow \mathrm{H}_{2}^{-}+\mathrm{NO}_{3}^{-}+2 \mathrm{H}^{+}
\end{aligned}
$$

Este fenōmeno jā tinha sido observado nas rea ções fotoinduzidas realizadas em dimetilformamida $(103,121$, 122), com obtenção de solução azul com as mesmas caracterîsticas espectrais da espécie reduzida eletroquimicamente.

Jezowska-Trzebiatowska et a 1 (123), estudando a fotōlise com luz monocromática, observaram ( $\lambda=329 \mathrm{~nm})$ a produção de $\mathrm{Fe}^{3+}$ como um produto da decomposição de nitroprussiato e, citaram a banda localizada nesse comprimento de onda, como fotoquimicamente ativa.

-Em 1972 Mitra et al (124) refizeram os seus es tudos ( $\lambda$ entre 340-430 nm) numa solução deaerada confirmando o mecanismo por eles formulado. Além dos dados ante riores, detetaram a presença de $\mathrm{NO}_{2}{ }^{-}$atravēs de spot-test e observaram o aumento na banda de absorção a $394 \mathrm{~nm}$ com c tempo de fotōlise. Essa banda por eles atribuĩda ao ior $\mathrm{Fe}^{\mathrm{II}}(\mathrm{CN})_{5} \mathrm{H}_{2} \mathrm{O}^{3-}$, pode corresponder à espēcie (NC) ${ }_{5} \mathrm{Fe}^{\mathrm{III}} \mathrm{H}_{2} \mathrm{O}^{2-}$ com $\lambda_{\max }$ a $395 \mathrm{~nm}(125,126)$.

Wolfe e Swinehart (127) fizeram um estudo mais completo, fotolisando a solução com comprimentos de onda maj ores do que $300 \mathrm{~nm}$ e, luz monocromática a 366 e $436 \mathrm{~nm}$, observando à variação da concentração de $\mathrm{H}^{+}, \mathrm{O}_{2} \in$ 
(NC) ${ }_{5} \mathrm{Fe}^{\mathrm{III}} \mathrm{H}_{2} \mathrm{O}^{2-}$ em função do tempo de fotōlise. 0 rendimento quântico da formação do pentacianoaquoferrato(III) mos trou uma dependēncia com o comprimento de onda utilizado. A $436 \mathrm{~nm}$ o rendimento foi, 0,18 mol.einstein $^{-1} \mathrm{e}, \mathrm{a} 366 \mathrm{~nm}$ foi 0,35 mol.einstein ${ }^{-1}$. 0 processo fotoquímico primārio em torno de $400 \mathrm{~nm}\left(\mathrm{~d}_{\mathrm{xz}}, \mathrm{d}_{\mathrm{yz}} \rightarrow \pi{ }^{*}(\mathrm{NO})\right)$, corresponde a fotooxida ção do nitroprussiato e, as variações observadas em concentração de $\mathrm{H}^{+}$e $\mathrm{O}_{2}$ correspondem a processos secundārios envolvendo reação de No.

Jā, a investigação de Jarzynowski et al (128) mostrou que a irradiação na região de $23,2 \mathrm{kK}$ (431 nm) è ina tiva dentro do limite de sensibilidade experimental, enquanto que a reação, fotoquímica na região de $30,6 \mathrm{kK}(326,8 \mathrm{~nm})$ è aquela representada pela equação

$$
\left|\mathrm{Fe}^{\mathrm{II}}(\mathrm{CN})_{5} \mathrm{NO}\right|^{2-}+\mathrm{H}_{2} \mathrm{O} \stackrel{\mathrm{hU}}{\longrightarrow} \mid \mathrm{Fe}^{\mathrm{II}}(\mathrm{CN})_{5} \mathrm{H}_{2} \mathrm{O}^{3-}+\mathrm{NO}^{+}
$$

e, a irradiação na região de $40,7 \mathrm{kK}(245,7 \mathrm{~nm})$ corresponde a um processo redox e troca de NO por. $\mathrm{H}_{2} \mathrm{O}$.

$$
\left|\mathrm{Fe}^{\mathrm{II}}(\mathrm{CN})_{5} \mathrm{NO}\right|^{2-}+\mathrm{H}_{2} \mathrm{O} \stackrel{\mathrm{h \nu}}{\longrightarrow}\left|\mathrm{Fe}^{\mathrm{III}}(\mathrm{CN})_{5} \mathrm{H}_{2} \mathrm{O}\right|^{2-}+\mathrm{NO}
$$

A explicação para o tal comportamento veio com a nova atribuição do espectro de pentacianonitrosilferratol II), recentemente publicado por Golebiewski e Wasielewska (85). Eles mostraram que a banda I $(23,2 \mathrm{kK})$, banda II $(30,6$ KK) e banda III $(32,8$ e 35,0 KK) são parcialmente $d$-d e parcialmente transição interna do ligante, enquanto que a 
banda IV a 40,7 kK corresponde à transição de transferên cia de carga.

Quando o ion nitroprussiato é irradiado na presença de solução aquosa de tiocianato (129-132), tiuréa (13ミ e anilina (134), se observa o desenvolvimento de coloração a zu 1 .

observando a formação de coloração azul quando

a solução alcalina de $\mathrm{Fe}(\mathrm{CN})_{5} \mathrm{NO}_{2}{ }^{4-}$ contendo $\mathrm{NCS}^{-}$é acidj ficada, Andrade e Swinehart (13) postularam um provāvel meca nismo, esquematizado a seguir.

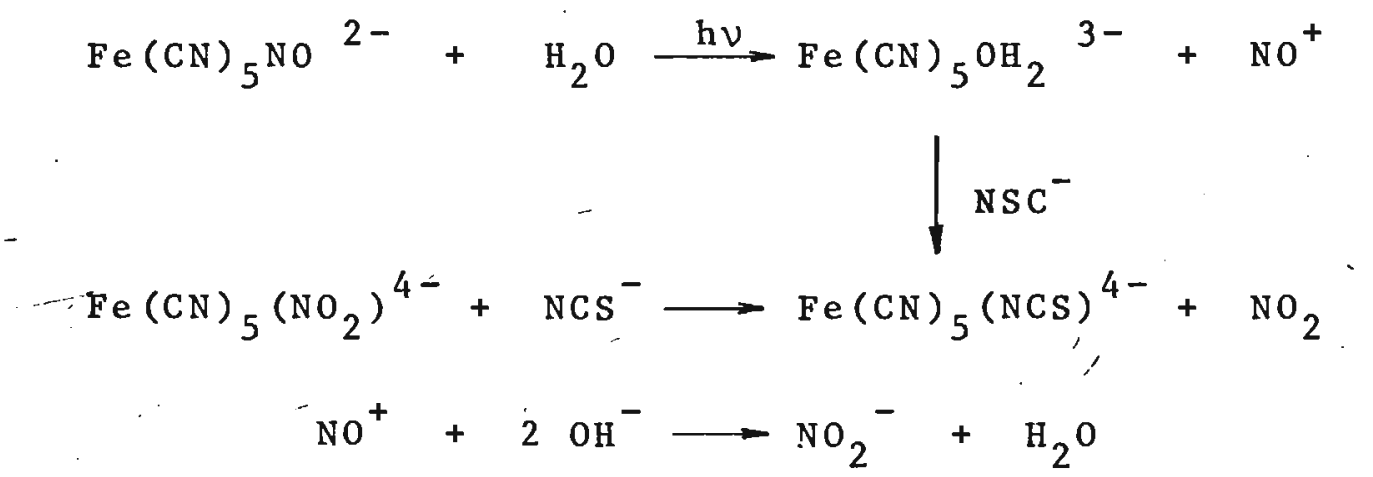

Já o West e Storie (135) verificaram a forma ção de complexo azul de $\mathrm{Fe}^{\mathrm{III}}(\mathrm{CN})_{5} \mathrm{SCN}^{3-}$ e óxido nîtrico, onde a etapa determinante envolve a formação de pentaciano. tiocianoferrato(II) que é então rapidamente oxidado por $\mathrm{NO}_{2}{ }^{-}$ ou ācido nitroso para o produto final. Estudo posterior de fotōlise de nitroprussiato contendo tiourēa(156), levaram $\bar{c}$ propor o mecanismo a seguir

$$
\mathrm{Fe}(\mathrm{CN}){ }_{5} \mathrm{NO}_{2} \mathrm{H}^{3-}+\mathrm{H}^{+} \stackrel{\mathrm{K}}{\rightleftharpoons} \mathrm{Fe}(\mathrm{CN})_{5} \mathrm{NO}^{2-}+\mathrm{H}_{2} \mathrm{O}
$$




$$
\mathrm{Fe}(\mathrm{CN}){ }_{5} \mathrm{NO}_{2} \mathrm{H}^{3-}+\text { tiouréa- } \mathrm{Fe}(\mathrm{CN}){ }_{5} \mathrm{tiuréa}^{3-}+\mathrm{HNO}_{2}
$$

seguido pela formação do complexo azul de Fe(III)-tiuréa via $\mathrm{Fe}(\mathrm{CN})_{5}$ tiouréa $+\mathrm{H}^{+}+\mathrm{HNO}_{2} \stackrel{\text { rápida }}{-} \mathrm{Fe}(\mathrm{CN})_{5}$ tiuréa $+\mathrm{NO}+\mathrm{H}_{2} \mathrm{O}$

\subsection{Reação de Adição e Substituição}

A reação de adição dos nucleōfilos ao No coor denado ao nitroprussiato é conheciada desde meados do século $X I X$.

Entre 1910 e 1930 Cambi et al (137-142) prepararam e caracterizaram uma grande variedade de compostos qúe resultam da reação entre base e (NC) ${ }_{5} \mathrm{FeNO}^{2-}$, dominando a in vestigação da quỉmica deste ion.

Embora o teste de cores usando ion nitroprussia to, como a reação de Gmelin para identificar $\mathrm{SH}^{-}$, o teste de Boedeker para sulfito, entre outros, seja conhecido a muitos anos, a quĩmica dessas reações tem sido estudada apenas mais recentemente.

A propriedade do grupo nitrosilo coordenado bem como o seu estado formal de oxidação pode ser avaliada obser vando alguns aspectos da sua reatividade.

0 grupo $\mathrm{NO}^{+}$livre apresenta os seguintes equi 1íbrios (59) 


$$
\mathrm{NO}^{+}+\mathrm{OH}^{-} \rightleftharpoons \mathrm{HNO}_{2}+\mathrm{OH}^{-} \rightleftharpoons \mathrm{NO}_{2}^{-}+\mathrm{H}_{2} \mathrm{O}
$$

e a constante de equilíbrio para a reação esquematizada aba: xo $\overline{\mathrm{e}} 2,3 \times 10^{31}(64)$.

$$
\mathrm{NO}^{+}+2 \mathrm{OH}^{-} \rightleftharpoons \mathrm{NO}_{2}^{-}+\mathrm{H}_{2} \mathrm{O}
$$

enquanto que no equilíbrio anālogo representado para 0 ĩon nitroprussiato o seu valor $\bar{e}$ de $1,5 \times 10^{6} \mathrm{M}^{-2}$ (143).

$$
(\mathrm{NC})_{5} \mathrm{FeNO}^{2-}+2 \mathrm{OH}^{-} \rightleftharpoons(\mathrm{NC})_{5} \mathrm{FeNO}_{2}^{4-}+\mathrm{H}_{2} \mathrm{O}
$$

Emboŕa os valores das constantes de equilíbrio mostrem que a eletrofilicidade do grupo nitrosilo coordenad seja bem menor do que na sua forma livre, pode-se percebe que no complexo o No age como doador de três elétrons, at: ando formalmente como $\mathrm{NO}^{+}$do que $\mathrm{NO}^{\circ}$ que não apresenta este tipo de equilíbrio àcido-base.

Deve-se observar ainda, que para produzir um. concentração apreciāvel de $\mathrm{NO}^{+}$necessita-se de concentra çōes extremamente elevadas de $\mathrm{H}^{+}$, enquanto que o ĩon nitro prussiato, $(\mathrm{NC})_{5} \mathrm{FeNO}^{2-}$; a tua como fonte de $\mathrm{NO}^{+}$a baixa ac. dez, proporcionando uma oportunidade única de explorar a qu. mica de $\mathrm{NO}^{+}$sob condições onde $\mathrm{H}^{+}$não estā competindo com este pelo sitio nucleofílico. 
As reações de adição dos nucleofilos ao penta cianonitrosilferrato(II) poden ser esquematizadas atravës da equação geral

$$
\text { (NC) }{ }_{5} \mathrm{FeNO}^{2-}+\mathrm{B}^{\mathrm{n}} \rightleftharpoons(\mathrm{NC})_{5} \mathrm{FeN}(\mathrm{B})^{\mathrm{n}-2}
$$

onde a base $B$ e normalmente 11 gada ao nitrogênio do grupo NN.

Muitas destas reações jă foram comentadas na re visāo de Swinehart (67) e consequentemente serāo abordadas brevemente na anālise a seguir,onde serā dada ênfase às pu blicações mais recentes ou algumas reações que estão mais di retamente relacionadas com a presente tese.

a. HIDROXIDO

o equilíbrio abaixo estudado por diversos autores $(89,141,143,144)$

$$
\text { (NC) }{ }_{5} \mathrm{FeNO}^{2-}+2 \mathrm{OH}^{-} \rightleftharpoons \text { (NC) }{ }_{5} \mathrm{FeNO}_{2}{ }^{4-}+\mathrm{H}_{2} \mathrm{O}
$$

teve uma investigaçăo mais completa realizada por Swinehart e Rock (143), com determinação de parāmetros cinēticos e termodinâmicos. A constante de equilíbrio obtida é $1,5 \times 10^{6}$ a $298 \mathrm{~K}$ e $\Delta H^{0}=-16,2 \mathrm{kcal} / \mathrm{mol}$ e $\Delta \mathrm{S}^{0}=-26,1 \mathrm{cal} / \mathrm{mol}$. grau. 
0 mecanismo proposto para a reação é representa

do a seguir

$$
\begin{aligned}
& \text { (NC) }{ }_{5} \mathrm{FeNO}^{2-}+\mathrm{OH}^{-} \frac{\mathrm{k}_{1}-(\mathrm{NC})_{5} \mathrm{FeNO}_{2} \mathrm{H}^{3-}}{(\mathrm{NC})_{5} \mathrm{FeNO}_{2} \mathrm{H}^{3-}+\mathrm{OH}^{-} \longrightarrow \text { (NC) }{ }_{5} \mathrm{FeNO}_{2}{ }^{4-}+\mathrm{H}_{2} \mathrm{O}}
\end{aligned}
$$

onde a primeira etapa é a determinante da reação $\left(k=0,55 M^{-1}\right.$. $\mathrm{s}^{-1}$ a $298 \mathrm{k}$ com $\Delta H^{\dagger}=12,6 \mathrm{kcal} / \mathrm{mol}$ e $\Delta S^{\ddagger}=-17,5 \mathrm{cal} \cdot \mathrm{mol}$ : $\operatorname{grau}^{-1}$ ).

0 produto da segunda etapa, $(\mathrm{NC})_{5} \mathrm{FeNO}_{2}{ }^{4-}$ apre senta o seguinte equilibrio

$$
\text { (NC) }{ }_{5} \mathrm{FeNO}_{2}{ }^{4-}+\mathrm{H}_{2} \mathrm{O} \underset{\mathrm{k}_{\mathrm{f}}}{\stackrel{\mathrm{k}_{\mathrm{d}}}{\rightleftharpoons}}(\mathrm{NC})_{5} \mathrm{FeH}_{2} \mathrm{O}^{3-}+\mathrm{NO}_{2}^{-}
$$

e os valores de $k_{d}=1,4 \times 10^{-4} \mathrm{M}^{-1} \mathrm{~s}^{-1}$ a $298 \mathrm{~K}\left(\Delta \mathrm{H}^{\ddagger}=\right.$ $21,6 \mathrm{kcal} / \mathrm{mol}$ e $\Delta \mathrm{S}^{\dagger}=3,6 \mathrm{cal}^{\circ} \mathrm{mol}^{-1} \mathrm{grau}^{-1}$ ) e $\mathrm{k}_{\mathrm{f}}=0,40 \mathrm{M}^{-1}$. $\mathrm{s}^{-1}$ a $298 \mathrm{~K}\left(\Delta H^{\ddagger}=9,3 \mathrm{kcal} / \mathrm{mol}\right.$ e $\Delta S^{\ddagger}=-28,8 \mathrm{cal} \cdot \mathrm{mol}^{-1}$ $\operatorname{grau}^{-1}$ ).

Estudos de infravermelho (145) e troca de $0^{18}$ (146) mostram que o grupo $\mathrm{NO}_{2}{ }^{-}$estä ligado como nitro $\mathrm{Fe}-\mathrm{NO}_{2}$ ) e não sob a forma nitrito (Fe-0NO).

\section{b. AMONNIA E ETILENODIAMINA}

A reação de adição de amônio ao Ton nitropruss 1 ato é a base do procedimento na preparação do $\mathrm{Na}_{3} \mathrm{Fe}(\mathrm{CN})_{5} \mathrm{NH}_{3}$ 
$(74,147)$, cujo aspecto mecanístico vem sendo estudado (148, 149).

A reação sugerida inicialmente $(147,148)$, repre sentada a seguir

$$
\mathrm{Fe}(\mathrm{CN})_{5} \mathrm{NO}^{2-}+\mathrm{OH}^{-}+\mathrm{NH}_{3} \longrightarrow \mathrm{Fe}(\mathrm{CN})_{5} \mathrm{NH}_{3}{ }^{3-}+\mathrm{N}_{2}+2 \mathrm{H}_{2} \mathrm{O}
$$

é provavelmente a estequiometria provāvel a alta concentra ção de $\mathrm{NH}_{3}$ e $\mathrm{OH}^{-}$. A concentração mais baixa de amõnía $(\mathrm{pH}=12,5)$, foi detetada a presença estequiométrica de $\mathrm{NO}_{2}^{-}$ (149) de acordo com a equaçāo abaixo

$$
\mathrm{Fe}(\mathrm{CN})_{5} \mathrm{NO}^{2-}+2 \mathrm{OH}^{-}+\mathrm{NH}_{3} \longrightarrow \mathrm{Fe}(\mathrm{CN})_{5} \mathrm{NH}_{3}{ }^{3-}+\mathrm{NO}_{2}{ }^{-}+\mathrm{H}_{2} \mathrm{O}
$$

e o mecanismo proposto envolve as seguintes etapas

$$
\begin{aligned}
& \mathrm{Fe}(\mathrm{CN})_{5} \mathrm{NO}^{2-}+\mathrm{OH}^{-} \stackrel{\mathrm{K}_{1}}{\rightleftharpoons} \mathrm{Fe}(\mathrm{CN})_{5} \mathrm{NO}_{2} \mathrm{H}^{3-} \\
& \mathrm{Fe}(\mathrm{CN})_{5} \mathrm{NO}_{2} \mathrm{H}^{3-}+\mathrm{OH}^{-} \stackrel{\text { râpida }}{\longrightarrow} \mathrm{Fe}(\mathrm{CN})_{5} \mathrm{NO}_{2}{ }^{4-}+\mathrm{H}_{2} \mathrm{O} \\
& \mathrm{Fe}(\mathrm{CN})_{5} \mathrm{NO}_{2}{ }^{4-}+\mathrm{H}_{2} \mathrm{O} \stackrel{\mathrm{K}_{2}}{=} \mathrm{Fe}(\mathrm{CN})_{5} \mathrm{H}_{2} \mathrm{O}^{3-}+\mathrm{NO}_{2}{ }^{-} \\
& \mathrm{Fe}(\mathrm{CN})_{5} \mathrm{H}_{2} \mathrm{O}^{3-}+\mathrm{NH}_{3} \stackrel{\text { râpida }}{\longrightarrow} \mathrm{Fe}(\mathrm{CN})_{5} \mathrm{NH}_{3}{ }^{3-}+\mathrm{H}_{2} \mathrm{O}
\end{aligned}
$$

No intervalo de $\mathrm{pH}$ de 11,4 a 12,5 o valor de $k_{1}$ estā entre 0,43 a $0,57 \mathrm{~m}^{-1} \mathrm{~s}^{-1}$ e o valor de $0,04 \mathrm{M}^{-1} \mathrm{~s}^{-1}$ obtido a pH 13 è atribuído pelos autores à provável mudan 
ça de mecanismo. Comportamento similar è sugerido à etilenodiamina (149) embora o desprendimento de gases e mudança no comportamento cinētico observados a $\mathrm{pH}$ maiores que 12,0 sejam atribuidos com poucos detalhes ao ataque direto da eti lenodiamina.

c. HIDROXILAMINA E AZOTETO

A reação do azoteto com o $\mathrm{Fe}(\mathrm{CN})_{5} \mathrm{NO}^{2-}(150) \bar{e}$ representado como

$$
\begin{aligned}
& \text { (NC) }{ }_{5} \mathrm{FeNO}^{\star 2-}+{ }^{*} \mathrm{NNN}^{-}+\mathrm{OH}^{-} \rightleftharpoons \text { (NC) }{ }_{5} \mathrm{Fe}^{\mathrm{II}_{\mathrm{H}_{2} \mathrm{O}^{3-}}+\mathrm{N}_{2}+{ }^{\star} \mathrm{NNO}^{\star}} \\
& 0 \text { mecanismo da adição de } \mathrm{N}_{3}{ }^{-} \text {ao Ton nitroprus }
\end{aligned}
$$

siato leva à formação de

$$
\text { (NC) } 5^{\mathrm{FeN}} \mathrm{N}_{3}
$$

$\left(k=0,2 \mathrm{M}^{-1} \mathrm{~s}^{-1}\right)$, seguida pela decomposiçāo dessa espécie para

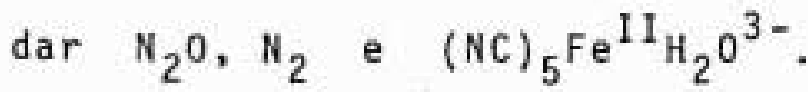

A reação entre $\mathrm{NH}_{2} \mathrm{OH}^{-}$e nitroprussiato ( 148 , 150) representada a seguir

$$
\text { (NC) }{ }_{5} \mathrm{FeNO}^{2-}+{ }^{\star} \mathrm{NH}_{2} \mathrm{O}^{*} \mathrm{H}+\mathrm{OH}^{-} \longrightarrow \text { (NC) }{ }_{5} \mathrm{Fe} \mathrm{II}_{\mathrm{H}_{2}} \mathrm{O}^{3-}+{ }^{\star} \mathrm{NNO}^{\star}+\mathrm{H}_{2} \mathrm{O}
$$


mostram que o oxigênio e o nitrogēnio central do $\mathrm{N}=0$ vem da hidroxilamina $(150)$.

A lei da velocidade sugere um pré-equilíbrio en tre as duas espécies formando um intermediário seguido pelo ataque de uma terceira espécie, sendo esta a etapa deterni nante da velocidade. Embora a cinética não defina a espécíe intermediăria, e o estudo da decomposição deste não tenha s $\underline{1}$ do examinado, a adição da hidroxilamina ao nitroprussiato pa rece estar bem estabelecida. A adiçāo direta do $\mathrm{NH}_{2} \mathrm{OH}$ ao gru po NO de (NC) ${ }_{5} \mathrm{FeNO}^{2-}$, leva a um aduto que é entāo atacado pelo $\mathrm{OH}^{-}$e perde o próton, resultando na formaçāo de

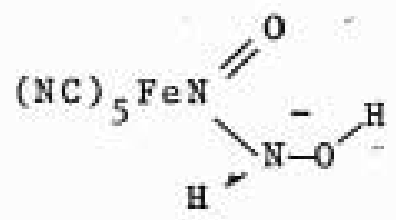

A constante de velocidade ē dada como $4,5 \times 10^{5} \mathrm{M}^{-2} \mathrm{~s}^{-1}$ a $25^{\circ} \mathrm{C}$. Em função deste valor, è pouco provävel o mecanismo proposto pelo Beck et al (148), envolvendo interação ini cial entre (NC) $\mathrm{FeNO}_{5}^{2-}$ e $\mathrm{OH}^{-}$formando $\mathrm{Fe}(\mathrm{CN})_{5} \mathrm{NO}_{2} \mathrm{H}^{3-}$ e posterior ataque da hidroxilamina. A reaçāo de adição de $\mathrm{OH}^{-}$ au nitroprussiato apresenta meia vida de 430 segundos (143) e seria etapa determinante comparada à meia vida da reação (NC) ${ }_{5} \mathrm{FeNO}^{2-}-\mathrm{NH}_{2} \mathrm{OH}-\mathrm{OH}^{-}$com pouco dëcimos de um segundo. 
A coloraçāo vermelho-violeta $(139,141)$ resultan te da reação entre (NC) ${ }_{5} \mathrm{FeNO}^{2-}$ com compostos contendo um grupo ionizăvel, conheciada como reação de Gmelin, tem sido usada como teste de cor extremamente sensivel tanto para sul fitos orgānicos como inorgânicos.

Obtenção $(151,152)$, eletrotitulação (152) e cinética (153) da reação tiol tem sido interpretada em termos de formaçāo da espécie A que em meío bāsíco, transforma-se em $B$

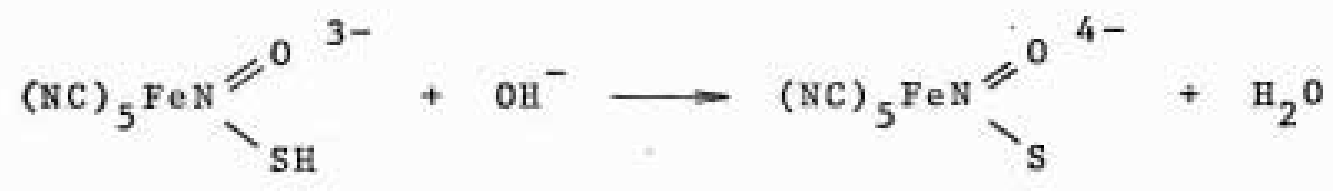

A

B

A velocidade de formação de $A, \vec{e}$ de primeira ordem tanto el relação à concentração de $\mathrm{HS}^{-}$como do Ton (NC) ${ }_{5} \mathrm{FeNO}^{2-}$ con $k=170 \mathrm{M}^{-1} \mathrm{~s}^{-1}$ a $\mu=1,0$ e $298 \mathrm{~K}$. 0 decaimento da coloração atribuĩda à formação da espécie da espécie $B \quad \bar{e} 1,3 \times 10^{-2} \mathrm{~s}^{-1}$ a $\mu=1,0$ e $298 \mathrm{~K}$; parecendo entretanto ser demasiadamente lenta para a reação que envolve simples transferência de prōton. Cabe aquí o comentá rio de que este podería ser interpretado também en termos da dissociação do intermediărio e formação da espécie (NC) ${ }_{5} \mathrm{FeNO}$ na reação paralela que deve estar ocorrendo entre o nitropru siato e $\mathrm{O} \mathrm{OH}^{-}$.

Baran e Muller (154) sugeriram que o nitrossulfito poderia ser reformulado como $\mathrm{Fe}_{2}(\mathrm{CN})_{10}\left(\mathrm{~N}_{2} \mathrm{O}_{2} \mathrm{~S}_{2}\right)^{3-}$ conten 
do possivelmente os grupos
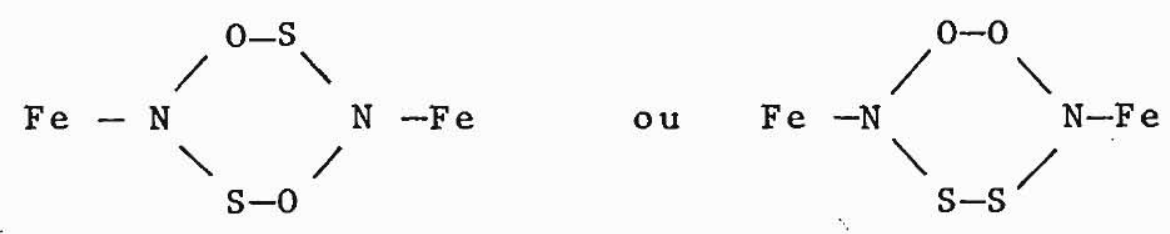

mas, na ausência de dados cristalogräficos torna-se altamen te especulativa.

Soluções alcalinas de mercaptanas reagem rapida mente com (NC) ${ }_{5} \mathrm{FeNO}^{2}$ - para dar solução vermelha (139). Esse tipo de reação tem sido usada desde longa data como um tes te para o amino ācido cisteina (155).

A ádição dos ãnions tiol ( $\mathrm{HS} \cdot \mathrm{CH}_{2} \cdot \mathrm{CH}_{2} \mathrm{OH}, \ldots$, HS. $\mathrm{CH}_{2} \cdot \mathrm{CO}_{2}{ }^{-}, \mathrm{HSPh}, \mathrm{HS} . \mathrm{SH}_{2} \mathrm{Ph}, \mathrm{HS}^{-}$e cisteína) ao ion $\mathrm{ni}_{-}-$ troprussiato estudada pela tēcnica "stopped-flow" (97) conduzem a uma dependência de primeira ordem na concentração de cada reagente.

$$
\text { (NC) }{ }_{5} \mathrm{Fe}-\mathrm{NO}^{2-}+\mathrm{RS}^{-} \rightleftharpoons(\mathrm{NC})_{5} \mathrm{Fe}-\mathrm{N}>_{\mathrm{SR}}^{0}
$$

Para a decomposição da espécie formada foram propostos dois mecanismos dos quais aquele representado a se guir foi mais satisfatōrio para explicar o comportamento experimental com $\beta$-mercaptoetanol; embora a anālise detalhada tenha sido prejudicada devido a interferência das reações pa ralelas. 


$$
\text { (NC) }{ }_{5} \mathrm{Fe}^{\mathrm{II}} \underbrace{0}_{\mathrm{SR}}{ }^{3-}+\mathrm{RS}^{-} \longrightarrow(\mathrm{NC})_{5} \mathrm{Fe}-\mathrm{N}=0^{4-}+\mathrm{RS} \cdot \mathrm{SR}
$$

A cinētica da reação de cisteĩna $\left(\mathrm{NH}_{2} \mathrm{CH}\left(\mathrm{CH}_{2} \mathrm{SH}\right) \mathrm{CO}_{2}\right.$ com nitroprussiato foi estudada mais recentemente (156) num intervalo de $\mathrm{pH}$ de 7,5 a 11 . Na presença de oxigênio é en contrada uma etapa catalitica da oxidação de cisteỉna a cistina. 0 decaimento da espēcie vermelha $\left(\mathrm{Fe}(\mathrm{CN}) 5 \mathrm{SR}^{3-}\right.$ ) a $\lambda=$ $522 \mathrm{~nm}$, foi estudada sob värias condiçōes e o mecanismo pró posto $\bar{e}$ apresentado da seguinte forma

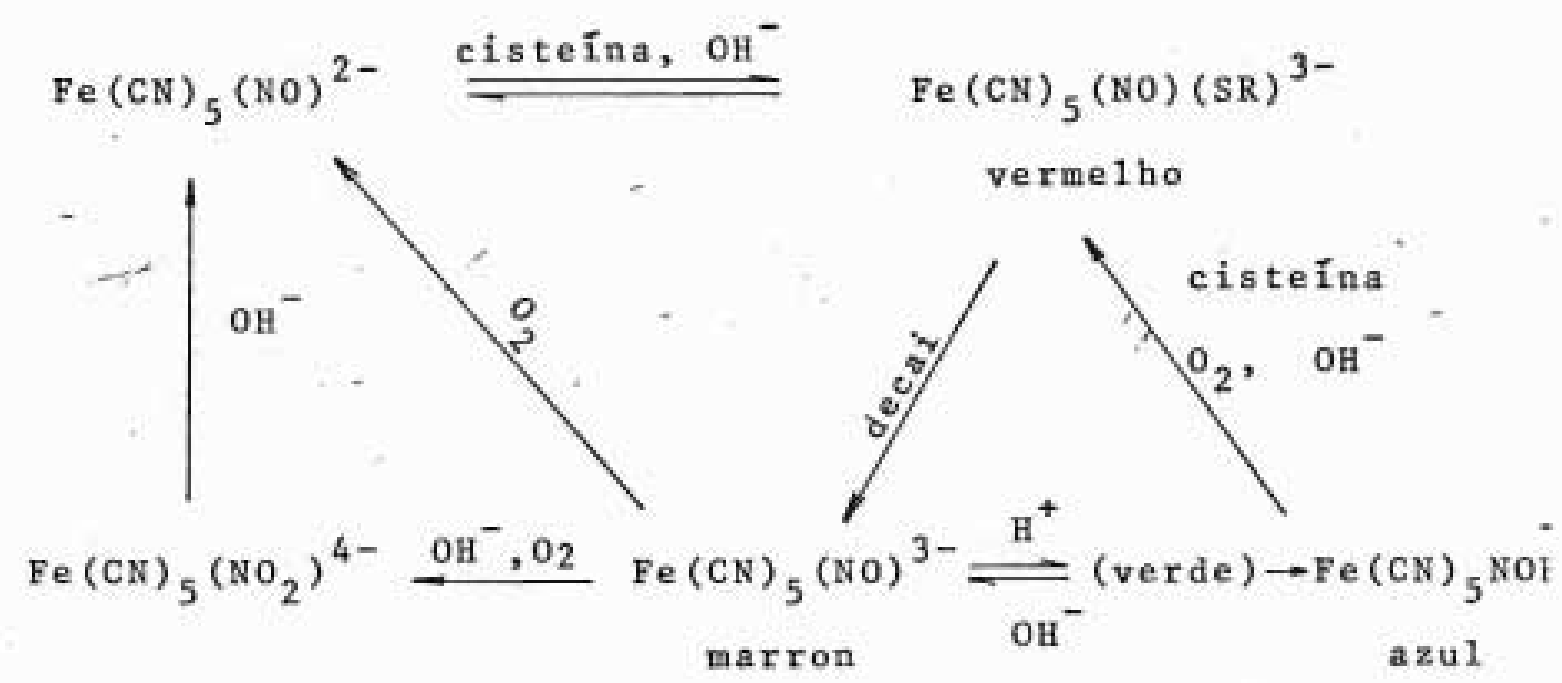

embora, a espēcie azul formada quando a soluçāo è acidulada, recentemente vem sendo atribuỉda à perda do cianeto formando $\mathrm{Fe}(\mathrm{CN})_{4} \mathrm{NO}^{2-}(116)$. Nesse caso tambēm as concentraçōes relativas das duas espécies dependem acentuadamente do $\mathrm{pH}$, da concentração do cianeto e sensĩveis à presença de $\mathrm{O}_{2}$.

A1ēm destes, mais estudos foram realizados (157 
-161), este ūitimo propondo mecanismo pouco convincente, embora não apresente constantes de velocidade e dados cinēti cos para que possa confirmā-10.

e. SULFITO

A mistura de sọluçōes de $\mathrm{SO}_{3}{ }^{2-}$ e $(\mathrm{NC})_{5} \mathrm{FeNO}^{2-}$ resulta numa solução de coloração vermelha, muito intensa., conhecida como reação de Boedeker (162). Essa coloração é in tensificada pela presença de eletrōlitos inertes mas, vai de caindo com o tempo, resultando-se por fim (NC) ${ }_{5} \mathrm{FeSO}_{3}{ }^{5-}$.

0 estudo destás reações tem sido realizado em vārios solventes, variando a concentração de eletrólitos i nertes e, com anālise estrutural do composto vermelho (163 17i). A formulação baseada na anālise infravermelha (167) è $\mathrm{Fe}(\mathrm{CN})_{5} \mathrm{~N}(=0) \mathrm{OSO}_{2}{ }^{4-}$, indicando que a ligação do $\mathrm{SO}_{3}{ }^{2-}$ a $\mathrm{NO}^{+}$ é feita atravēs do oxigênio.

f. CETONAS E COMPOSTOS CONTENDO HIDROGENIOS ACIDOS

Uma infinidade de cetonas e compostos relaciona dos reagem com o ĩon nitroprussiato (67) dando em geral composto vermelho que resulta na formação de (NC) ${ }_{5} \mathrm{FeH}_{2} \mathrm{O}^{3-}$ e oxima do composto orgānico correspondente. Contudo a cinētica de formação destes compostos tem sido estudada apenas em $n \mathfrak{i}$ vel elementar (172-176).

o esquema geral da reação è mencionado na pāgi- 


$$
\begin{gathered}
\mathrm{RCOCH}_{3}+\mathrm{OH}^{-} \stackrel{\mathrm{K}}{\rightleftharpoons} \mathrm{CH}_{2} \mathrm{COR}^{-}+\mathrm{H}_{2} \mathrm{O} \\
\mathrm{Fe}(\mathrm{CN})_{5} \mathrm{NO}^{2-}+\mathrm{CH}_{2} \mathrm{COR}^{-} \stackrel{\mathrm{K}}{\longrightarrow}(\mathrm{NC})_{5} \mathrm{Fe}-\mathrm{N}=\mathrm{CH}_{2} \mathrm{COR}=(\mathrm{NC})_{5}{ }^{\mathrm{Fe}-\mathrm{N}^{-}}{ }_{\mathrm{CHC}}
\end{gathered}
$$

e a velocidade de formação do composto colorido é dita como sendo de primeira ordem em relação à concentração dos reagen tes, indicativo de que a formação de carbânion a partir da cetona $\bar{e}$ a etapa determinante da velocidade. A constante de velocidade observada $\left(0,39 \mathrm{M}^{-2} \mathrm{~s}^{-1}\right)$ corresponderia na realida de ao produto da constante de equilibrio com constante de ve locidade da etapa determinante (kK).

A cinētica de decomposição da espécie colorida só foi estudada pelos Swinehart e Schmidt (174). Para a pro panona o decaimento do composto intermediärio é independente da concentração de hidrōxido e cetona.

$$
\text { (NC) }{ }_{5} \mathrm{Fe}\left(\mathrm{C}_{3} \mathrm{H}_{5} \mathrm{NO}_{2}\right)^{3-}+\mathrm{H}_{2} \mathrm{O} \stackrel{\mathrm{k}_{1}}{\longrightarrow}-(\mathrm{NC})_{5} \mathrm{FeB}_{2} \mathrm{O}^{3-}+\underset{\mathrm{H}}{\stackrel{\mathrm{n}}{\mathrm{H}}} \stackrel{\stackrel{\mathrm{H}}{\mathrm{C}}-\mathrm{NOH}}{\mathrm{C}-\mathrm{H}}
$$

com valor de $k_{1}=2,9 \times 10^{-4} \mathrm{M}^{-1} \mathrm{~s}^{-1}$ a $298 \mathrm{~K}$ e $\mu=1,0$

Entretanto, reação anăloga com butanona e 3-pen tanona apresenta dependência tanto em concentração de $\mathrm{OH}^{-}$co mo da cetona, com a lei de velocidade do tipo

$$
-\frac{d[\mathrm{C}]}{d t}=k_{2}[\mathrm{c}]\left[\mathrm{OH}^{-}\right]+k_{3}[\mathrm{c}]\left[\mathrm{OH}^{-}\right] \text {[cetona] }
$$


Ainda que não tenham postulado o mecanismo de formação nem de dissociação para essas reações, mostram que a reação de decaimento da espēcie colorida é distinta para a cetona usada.

g. OUTRAS REAÇÕES

Atuando como transportador de $\mathrm{NO}^{+}$, o ion nitro prussiato permite ainda uma infinidade de reação com tiuréas $(157,177-180), \operatorname{SCN}^{-}(30,181,182)$, aminoácidos $(73,183), \mathrm{S}^{2-}$ (184), $\mathrm{Se}^{2-}(177)$ e $\mathrm{Te}^{2-}(177)$, formando intermediārio colorido:

0 que se percebe é, que apesar das reações de ${ }^{-} \underline{a}$ dição ao nitrosilo coordenado sejam bem conhecidas e usadas, o mecanismo da reação ē pouco investigado. 0 conhecimento da reatividade do NO coordenado pode proporcionar vārias vanta gens como as relacionadas a seguir:

(i) A possibilidade de efetuar nitrosação orgânica a ba $x a$ acidez ou mesmo em condições neutras.

(ii) A possibilidade de obter um complexo contendo $\mathrm{NO}^{+}$ "super eletrōfilo" com densidade eletrōnica efetiva menor do que o próprio

(iii) A possibilidade de sintetizar "in loco" ligantes nitrogenados tais como, $\mathrm{N}_{2} \mathrm{O}$ ou ligantes multidentados. mais complexos, atravēs da reação ao nO coordenado 
e sua obtenção pela subsequente dissociação fácil do ligante produzido

(iv) A possibilidade de aplicação na conversão ambiental de $\mathrm{NO}$ e $\mathrm{CO}$ em $\mathrm{N}_{2} \mathrm{O}$ ou $\mathrm{N}_{2}$ e $\mathrm{CO}_{2}$, através do grupo nitrosilo coordenado. 


\section{III - ASPECTOS de REAÇŌES fOtOQUÍMICAS DOS COMPOSTOS DE COORDENAÇÄO}

\subsection{Introdução}

0 interesse pelo comportamento fotoquímico dos compostos de coordenação vem crescendo desde meados do sécu10 XX, principalmente no sentido de explorar as reações quĩ micas possiveis e, sua potencial aplicaçäo na conversão de energía, sintese, catālise, fotocromismo, fotografia e outro sistemas de imagens e materiais óticos em geral.

0 estudo das reações fotoinduzidas dos compos tos de coordenação proporciona ainda uma oportunidade de examinar o comportamento da série de compostos en que a maior variação se localiza na estrutura eletrōnica do átomo centra e a química do estado excitado.

A fotoexcitação dos compostos de coordenação po de causar vārios tipos de reação cuja natureza depende do átomo metálico e ligantes envolvidos, do comprimento de onda da irradiação e das condiçōes experimentais.

As reaçōes fotoquỉmicas podem ser classificadas conforme as alteraçōes produzidas, por exemplo, nos números formais de oxidação do metal e/ou ligante (reaçōes de fotooxidação), na composição da esfera de coordenação (reação de fotosubstituição e reaçōes relacionadas), no arranjo de coor denação do ligante ( reações de fotoisomerização) e ainda reações que envolvem ligante coordenado. 


\subsection{Principios de Fotoquímica}

Um comentārio suscinto sobre os princīpios de fotoquîmica é feito com a finalidade ūnica de introduzir o vocabulário e os conceitos mais comuns. Discussões detalhadas podem ser encontradas em livros textos gerais do campo ( 187 $-190)$.

A absorção de um fóton por uma espēcie A leva à formação de uma substância $A^{*}$ de vida curta, eletrônicamente excitada. A energia absorvida (i) pode ser dissipada quimicamente ( $i i$ ) ou fisicamente ( $i i i$, $i v$ ) de acordo com a $\underline{e}$ quação geral :

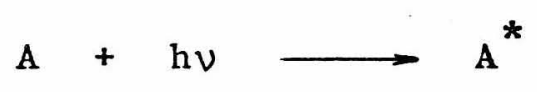

$A^{*} \rightarrow$ produto primário $\rightarrow$ produto final

$\mathrm{A}^{*} \rightarrow \mathrm{A}+\mathrm{h} v$

$\mathrm{A}^{*} \longrightarrow \mathrm{A}+\mathrm{calor}$

0 estado da espécie produzida na excitação de pende da energia do quantum de luz absorvida. 0 estado exc $\underline{i}$ tado pode dissipar sua energia de diferentes formas. Estados excitados de alta energia normalmente convertem-se rapidamen te para o estado excitado de energia mais baixa ( representa do pelo processo 1 da figura 3.1.$)$, do qual outros processos podem originar. A transição sem radiação entre os estados da mesma multiplicidade (por exemplo, processos 1,2 e 4 ) é 

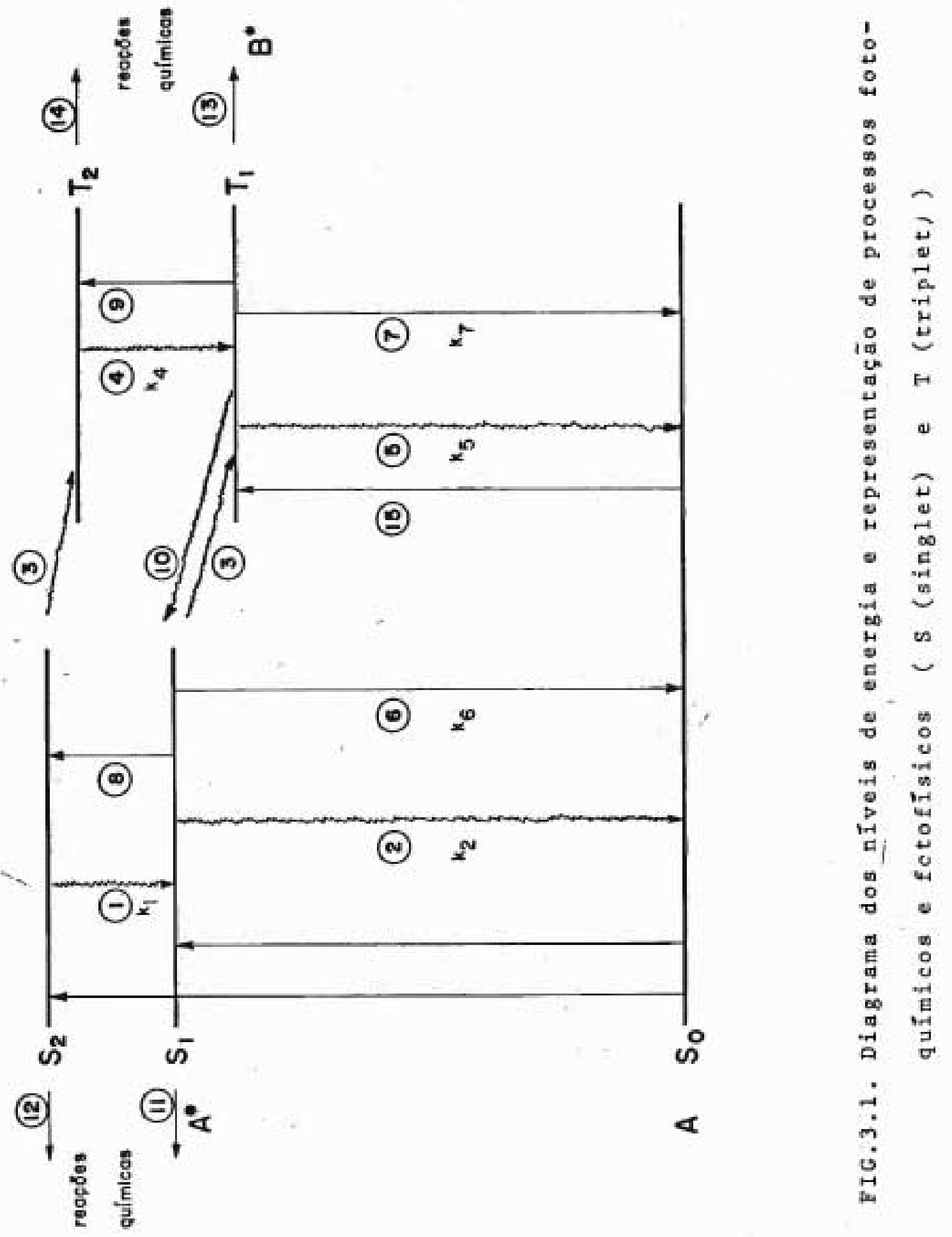
chamada de conversão interna (IC) e aquelas entre os estados de multiplicidades diferentes (processo 3 ) de cruzamento inter-sistema (ISC). 0 decaimento radioativo dos estados ex citados è chamado de fluorescência se ocorrer entre os estados da mesma multiplicidade (processo 6 ) e fosforescência se é envolvida uma variação na multiplicidade (processo 7 ). Emissão após repopulação ${ }^{*}$ térmica do $S_{1}$ a partir do $T_{1}$ ( processo 10 seguido pelo processo 6 ) è chamado de fluorescēncia com retardamento. As reações quỉmicas (processo 1114 ) podem surgir de algum estado excitado de energia alta, mas a maioria das fotoconversões originam do estado excitado de energia mais baixa $\left(S_{1}, T_{1}\right)$, uma vez que estes possuem meia vida maiorido que os estados de energia mais alta.

A primeira lei da fotoquímica diz que apenas - a radiação absorvida pode ser efetiva na produção de variações quîmicas. A segunda lei estabelece que a absorção de um fó ton produz uma molēcula excitada. Esta lei não se aplica na irradiação com intensidades muito altas, como as de lasers ou em flash fotōlise, onde poderia resultar na absorção de mais de um fóton por estado excitado produzido.

A energia do fóton absorvido pela molécula é da da por $\Delta E=h \nu$, onde $E \bar{e}$ a constante de Planck e $\nu$. é a frequência da radiação absorvida.

As moléculas excitadas são intāveis e dacaem atravēs de alguns processos de estabilização. Esta estabiliZar" no Zugar do verbo mais correto, povoar. 
zação pode ocorrer atravēs da reação quĩmica e ou processos de desativação física.

Cada processo que parte com a absorção de um fóton e termina com o desaparecimento da molécula ou sua desativação é chamado de processo primário. A eficiência de um processo primário fotoquímico ou fotofísico, representadc por $\mathbf{A}+\mathbf{h v} \rightarrow \mathbf{B}$, $\vec{e}$ dada pela medida do rendimento quấ tico $(\Phi)$, definido como :

$$
\Phi=\frac{\text { nọ de B formado por unidade de tempo e volume }}{\text { quanta de luz absorvidos pela espécie A, por uni- }}
$$

A determinação do rendimento quântico obviamen te necessita de medidas de duas grandezas :?

- variação na concentração de A

- número de fótons absorvido pelo A

Um sistema fotoquĩmico mais simples, que envolve uma reação unimolecular e uma desativação física unimole. cular, ambas originadas de um estado excitado diretamente al cançado pela irradiação, pode ser representado a seguir:
A $\stackrel{\text { hV }}{\longrightarrow} \mathrm{A}^{*}$
(ativação)
$\mathrm{A}^{*} \stackrel{\mathrm{k}_{1}}{\longrightarrow}$ B
(reação) 


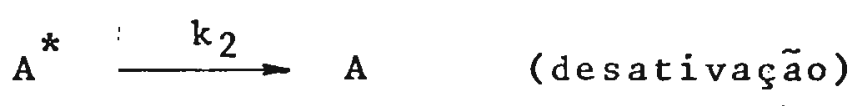

Assumindo que a concentração do estado excitado alcança rapi damente o valor estacionário, temos que

$$
\begin{aligned}
& \frac{d\left[A^{*}\right]}{d t}=I_{a}-k_{1}\left[A^{*}\right]-k_{2}\left[A^{*}\right]=0 \\
& I_{a}=\left(k_{1}+k_{2}\right)\left[A^{*}\right]
\end{aligned}
$$

pela definição o rendimento quāntico do processo é

$$
\Phi_{B}=\frac{d[B]}{d t}=\frac{k_{1}\left[A^{*}\right]}{I_{a}}
$$

substituindo I por expressão (1)

$$
\Phi_{B}=\frac{k_{1}}{k_{1}+k_{2}}
$$

0 que geralmente acontece é que o estado excita do $A^{*}$ diretamente atingido pela irradiação dá origem a $n$ processos primários e o rendimento quântico de um processo especīico $x$ é dado pela razão da constante de velocidade daquele processo pela soma das constantes de velocidade de todos os $n$ processos que desativam o estado excitado. 


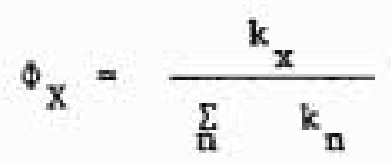

Para se saber a eficiência de uma reaçăo foto quỉmica deve-se determinar tanto a velocidade de formaçăo do produto ( $d p / d t$ ) ou do decaimento do reagente (-dA/dt) como a velocidade com que os fötons săo absorvidos pelo material irradiado $\left(\mathrm{I}_{\mathrm{a}}\right)$. Este ültimo, $\left(\mathrm{I}_{\mathrm{a}}\right)$, chamado de intensidade da radiação absorvida e geralmente expressa como o nümero de moles de fótons ( ou einsteins) absorvido por segundo.

Em termos quantitativos, Ia é relacionada com a intensidade da luz incidente $I_{0}$ atravēs da lei de Beer

$$
I_{a}=I_{0}\left(1-10^{-\varepsilon c l}\right)
$$

onde

c è a concentraçāo do substrato

E è a absortividade molar do substrato

$\ell$ é o comprimento do caminho ōtico

E importante notar que a altas absortividades, onde $I_{a}$ - $I_{0}$, a velocidade da reação fotoquímica é aproxima damente de ordem zero no substrato irradiado.

0 rendimento quântico pode frequentemente varia com o comprimento de onda da irradiação, bem como, em alguns casos, a prōpria reação fotoquỉmica, em funçăo da energia de excitação. 
A desativação reativa do estado excitado de com posto de coordenação pode ocorrer atravēs de vārias formas mencionadas, que podem ser agrupadas em :

i. fotoreação de substituição ou relacionadas à substị tuição

ii. fotoreação de oxi-redução

iii. fotoreação do ligante

E frequentemente observado que a reação do tipo i $\bar{e}$ induzida pela irradiação na banda d-d (campo ligante) e que a do tipo $i j, \bar{e}$ promovida pela excitação de transferência de carga, enquanto que o processo iji está associado com excitação envolvendo a transição eletrōnica entre orbitais localizados no ligante $\left(L_{-} L_{-}\right)$.

No entanto, a classificação da reação fotoquĩmica de acordo com o tipo de banda de absorção irradiada só é vāilida como uma primeira aproximação. As bandas de absorção de diferentes características podem superpor-se em algu ma extensão. A excitação de um tipo de transição pode eventualmente resultar numa população de um outro tipo de estado excitado atravēs de conversão interna ou processos de cru zamento inter-sistema. Ainda, o produto da reação pode diferir acentuadamente daquele gerado pelo processo fotoquímico primārio. 


\subsection{Fotosubstituição}

Uma discussão simples sobre alguns aspectos das reações de fotosubstituição nos complexos de configuração $n d^{6}$ - campo forte, é feita a seguir.

Detalhes das reações fotoquĩmicas dos compostos de coordenação podem ser encontrados em livros textos de Adamson (37), Balzani e Carassiti(191), Geoffroy e Wrighton (192) e no Photochemistry - Specialist Periodical Report (193) como nos artigos de revisão mais recentes (38, 194 199).

A reação de fotosubstituição do ligante pode se utilizada para sintetizar novos complexos metālicos que são inacessíveis ou difíceis de seren obtidos pela substituição tērmica ou, devidó à competição da reação térmica envolvendo outras partes dos complexos. Desempenha ainda, um importante papel na catālise fotoiniciada por metais de transição (200) podendo também atuar como uma forma de elucidar a estrutura química dos intermediários presentes em catálise homogênea.

As reações de fotosubstituição podem envolver variações significantes nos espectros ōticos, como resultado de : (i) substituição do ligante modificando substancialmente a interação média do campo ligante ou (ii) pela perda ou incorporação de um ligante envolvido na absorção de transferēncia de carga. Associado a isso, decorre uma grande potencialidade de efeitos de fotocromismo nos sistemas. 0 despren dimento de um ligante em particular, pode ainda trazer outra 
consequéncias físicas como variação de pH ou da carga total da espécie; as quais podem ser convenientemente utilizadas em sistemas fotosensiveis.

Um aspecto importante das reações fotoquỉmicas, incluindo a fotosubstituição, ē a de permitir testar teorias, e verificar sua aplicabilidade à quĩmica dos estados excitados, acessĩveis pela absorçāo de luz.

A maioria das publicações sobre a fotoquímica da substituição nos complexos $M L_{5} X,{ }^{6} d^{6}$ de campo forte, envolvem ion metálico de Co(III), Rh(III) e Ir (III). Para a maioria dos complexos, são determinados tanto o rendimento quãntico da substituição do ligante $X$ como do ligan te $-\mathrm{L}(38,195,197)$.

Considerando-so inicialmente o sistema. $\mathrm{C}_{4 \mathrm{~V}}$, $\mathrm{Cc}(\mathrm{CN})_{5} \mathrm{x}^{3-}$, a fotosubstituição geralmente envolve o ligante X (199-204), isto é, o ligante no eixo z é labilizado pe1 a população do orbital $d_{z} 2\left(a_{I}\right) \sigma_{z}^{*}$.

A fotosubstituição de cianetos (207) nos comple xos $\mathrm{Co}(\mathrm{CN})_{5} \mathrm{OH}^{3-}$ e $\mathrm{Co}(\mathrm{CN})_{5} \mathrm{OH}_{2}{ }^{2-}$ depende do comprimento de onda da irradiação e é maior à medida em que se aumenta a energia de excitação. Esse aumento na substituição de $\mathrm{CN}^{-}$foi

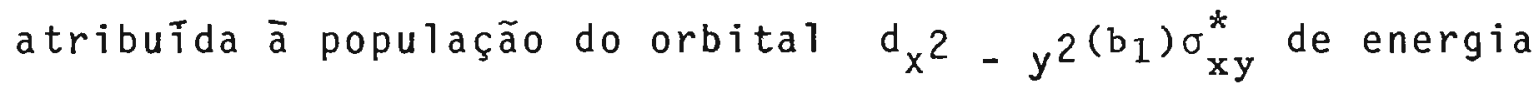
mais alta.

Comportamentos semelhantes são encontrados para os outros complexos $n d^{6}$ de spin baixo, do tipo $M L_{5} X$. Para a maioria dos sistemas, parece que os estados excitados 
mais reativos são aqueles contendo densidade eletrōnica em orbitais eg antiligante e que, quando essas espēcies exci tadas eletrōnicamente são relaxadas vibrônicamente, as distāncias internucleares e geometria molecular diferem significativamente em relação ao estado fundamental.

0 ion ferro(II) forma complexos de campo forte com os 1 igantes como cianeto, derivados de cianetos, carbonila ou, ligantes bidentados insaturados como 2,2 ' bipiridina e 1,10 fenantrolina.

Assim como nos complexos de Co(II), podem ser esperadas duas transições de campo ligante permitidas pelo spin, ${ }^{1}{ }_{A_{1 g}} \rightarrow{ }^{1} T_{1 g}$ e $\quad{ }^{1} A_{1 g} \rightarrow{ }^{1} T_{2 g}$, sendo esta $\bar{u} 1$ tima de energia mais alta. As bandas de absorção correspondentes ccorrem na região de ultravioleta próximo e frequentemente a parecem como ombros de uma absorção intensa de transférēn cia de carga ou absorções internas do liganté.

Excitação de campo ligante conduz em geral $\bar{a}$ fotoaquação, como no sistema mais investigado, $\mathrm{Fe}(\mathrm{CN})_{6}{ }^{4-} \cdot \mathrm{A}$ etapa primāria do processo de fotōilse $(191,208)$ pode ser re presentada como

$$
\mathrm{Fe}(\mathrm{CN})_{6}^{4-}+\mathrm{H}_{2} \mathrm{O} \stackrel{\mathrm{hv}}{\longrightarrow} \mathrm{Fe}(\mathrm{CN})_{5} \mathrm{H}_{2} \mathrm{O}^{3-}+\mathrm{CN}^{-}
$$

com um rendimento quāntico de 0,4 no intervalo de $\mathrm{pH}$ de 7,0 a 10 (209).

Apesar de ter sido publicado em 1961 que 0 complexo $\mathrm{Fe}(\mathrm{CN})_{5} \mathrm{CO}^{3-}$ é resistente à luz solar (210), jā 
era conhecida a muito tempo que a solução aquosa desse complexo libera monōxido de carbono (211). Em 1975 Vogler e Kunkely (212), refizeram os estudos e encontraram um rendimento quântico de 0,90 para o desprendimento de co na região de 300 a $370 \mathrm{~nm}$.

A irradiação a $365 \mathrm{~nm}$ de $\mathrm{Fe}(\mathrm{CN})_{5} \mathrm{AsO}_{3} \mathrm{H}_{3}{ }^{3-}$ na presença de nitrobenzeno (213), conduz à saî̀da do ligante $\mathrm{AsO}_{3} \mathrm{H}_{3}$ com o rendimento quāntico de 0,09 a $0,0^{0} \mathrm{C}$ e $\mathrm{pH}$ $=6,8$.

Figard e Petersen (214) observaram o comportamento fotoquimico do $\mathrm{Fe}(\mathrm{CN})_{5} \mathrm{~L} \quad(L=N$-heterociclico aromático) quando irradiado na região de trannferência de car ga. " 0 rendimento quāntico de substituição do liganie L en contra-se na faixa de 0,2 a 0,4 para os complexos com $\lambda_{\max }$ da banda de transferéncia de carga a comprimento de onda menor do que $480 \mathrm{~nm}$. Para os demais, esse rendimento cai pelo menos por um fator de dez.

Para explicar a dependēncia do rendimento quān tico em função da energia de transferēncia de carga é pro posto um diagrama de nível de energia, cuja discussão detalhada serā fejta em paralelo no capítulo VIII, juntamente com o diagrama proposto através dos nossos trabalhos. 


\section{IV-PARTE EXPERIMENTAL E TRATAMENTO DE DADOS}

4.1. Preparação e Purificação de Compostos

$\underline{\operatorname{LiC10}}_{4}$

o perclorato de $1 \bar{i}$ tio foi preparado pela neutr $\underline{\underline{c}}$ 1 ização do ácido perclórico com carbonato de lītio, conforme descrito na literatura (3). A padronização da solução foi fe ta com o auxilio de resina trocadora de ion (Baker CG 240): na forma $\mathrm{H}^{+}$, titulando-se potenciometricamente o àcido $1 \mathbf{i}$ berado com o hidrōxido de $1 \bar{i}$ tio.

\section{LIGANTES}

Carbóni1-0ximas ( py(CO)CHNOH)

As piridinacarboniloximas foram sintetizadas . $\epsilon$ purificadas conforme o procedimento ligeiramente modificado daquele descrito por Toma et al (72) : $5 \mathrm{ml}$ de acetilpiridina foram adicionadas rapidamente sob agitação, em $100 \mathrm{~m} 1 \mathrm{~d} \epsilon$ uma solução aquosa contendo $4 \mathrm{~g}$ de hidrōxido de sōdio (para - derivado em orto, o rendimento é aumentado usando-se um va 1 ume de $40 \mathrm{ml}$ ). A seguir foram adicionados $10 \mathrm{~g}$ de nitro prussiato de sódio, finamente dividido, observando-se a formação de uma solução escura. Apōs trēs minutos foram adicionados $5 \mathrm{ml}$ de ácidoacético glacial e $12 \mathrm{ml}$ de dimetilsul fóxido. Quando a solução praticamente descorada foi resfriada, observou-se a formação de um precipitado. cristalino, es- 
branquiçado que foi separado por filtração e lavado com āgua fria.

A recristalização foi feita por dissolução em volume suficiente de água $\left(\sim 80^{\circ} \mathrm{C}\right)$ seguida de resfriamento len to à temperatura ambiente e depois, em banho de gelo.

Os resultados de microanālise realizados no IQUSP mostram as seguintes composições

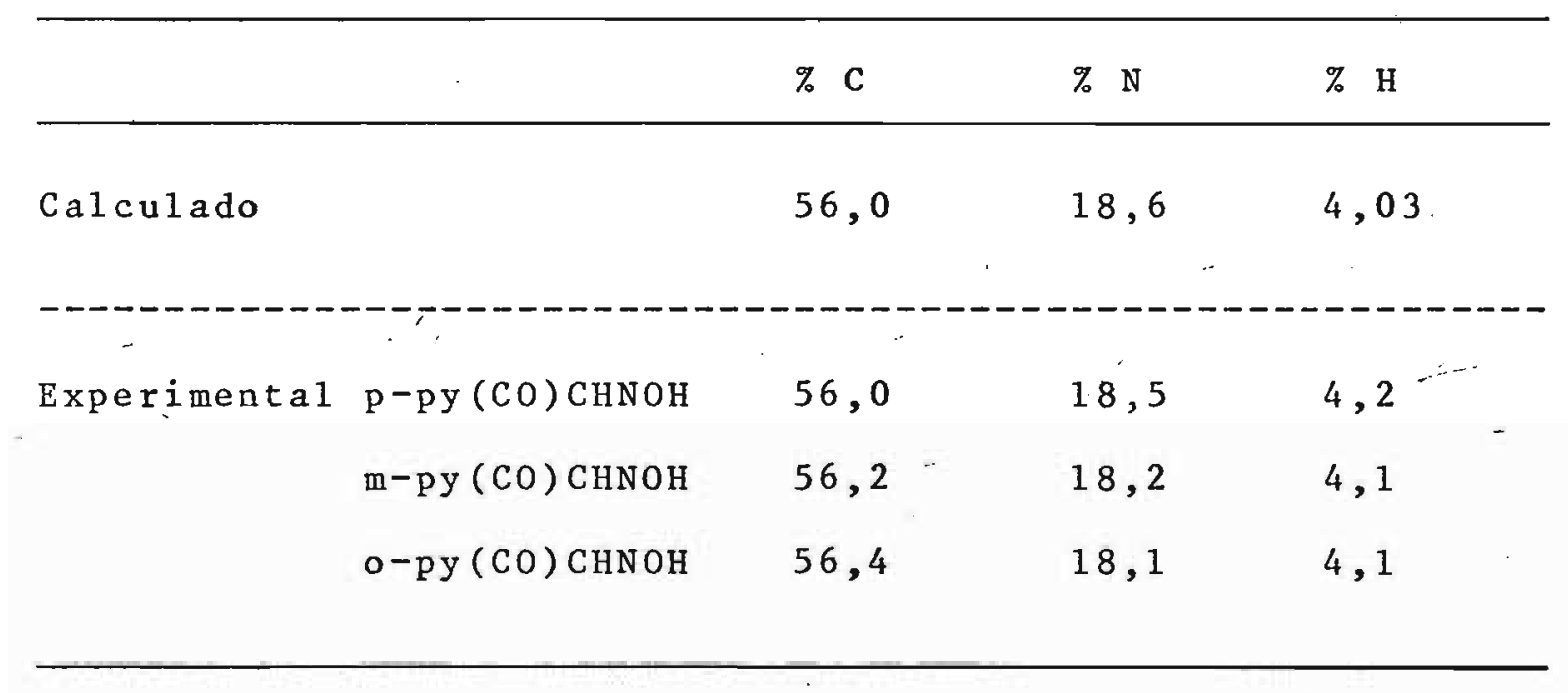

Os rendimentos finais, apōs duas recristaliza ções, baseadas na massa de nitroprussiato de sōdio, foram $55 \%, 75 \%$ e $33 \%$ para os derivados em orto, meta e para, respectivamente. A perda na recristalização é apreciavelmente al ta para o derivado com o substituinte em orto que é bastante solūvel.

Acetilpiridinas $\left(\mathrm{py}(\mathrm{CO}) \mathrm{CH}_{3}\right)$ 
ioch Light) foram purificadas por destilação sob pressão re Izida, após secagem com peneiras moleculares (Alfa Inorganic !ntron - $3 A$ ), recém ativadas. 0-acetilpiridina (Aldrich) i usado diretamente, sem qualquer purificação.

itros

Isonicotinato de sódio foi obtido pela neutraliição do ācido isonicotīnico (Aldrich) com hidrōxido de sódio.

1,10 fenantrolina (Aldrich), 4-formilpiridina $11 \mathrm{drich}$ ), isonicotinato de metila (Aldrich), isonicotinaami , (A1drich), pirazinaamida (A1drich), ácido nicotínico (A1-ich), imidazol (Aldrich) e etilenodiamina (Riedel), foram iadas diretamente, sem qualquer purificação.

\section{IMPLEXOS}

iinpentacianoferrato(II) de sódio $-\mathrm{Na}_{3} \mathrm{Fe}(\mathrm{CN})_{5} \mathrm{NH}_{3} \cdot 3 \mathrm{H}_{2} \mathrm{O}$

0 composto foi preparado a partir de pentacianotrosilferrato(II) de sōdio dihidratado, de acordo com a aiptação (3) do procedimento descrito por Brauer (74).

!ntacianoferrato(II) com Ligantes Insaturados - $\mathrm{Na}_{3} \mathrm{Fe}(\mathrm{CN})_{5} \mathrm{~L}$

Os complexos coordenados pelo nitrogēnio piridīco foram sintetizados a partir de $\mathrm{Na}_{3} \mathrm{Fe}(\mathrm{CN})_{5} \mathrm{NH}_{3} \cdot 3 \mathrm{H}_{2} \mathrm{O}$ e 0 i 1 Inte em questão e, precipitados pela adição constante de al101 etilico p.a., destilado e saturado com NaI, sob constan- 
te agitação.

As anālises elementares foram efetuadas por pro cedimento microanalítico (IQ-USP). O conteúdo total de ferro foi determinado por titulação potenciométrica com Ce(IV), em meio tamponado a $\mathrm{pH}_{4,4}$ (vide apēndice 11.3.1.).

$\mathrm{Na}_{3} \mathrm{Fe}(\mathrm{CN})_{5} \mathrm{~L} \cdot \mathrm{xH}_{2} \mathrm{O} \quad \% \mathrm{~N} \quad \% \mathrm{H} \quad \% \mathrm{Fe}$

$\mathrm{p}-\mathrm{py}(\mathrm{CO}) \mathrm{CHNOH} .3 \mathrm{H}_{2} \mathrm{O}$

ca 1 cu 1 ado

experimental

m-

ca 1 cu 1 ado

experimental

p-py $(\mathrm{CO}) \mathrm{CH}_{3} \cdot 4 \mathrm{H}_{2} \mathrm{O}$

calculado

experimental

$\mathrm{m}-\mathrm{py}(\mathrm{CO}) \mathrm{CH}_{3} \cdot 3 \mathrm{H}_{2} \mathrm{O}$

ca 1 cu 1 ado

experimental
21,36

2,36

12,17

19,94

3,95

12,22 
dos cianoferratos, e parece decorrer do próprio procedimento microanāitico, jā que apresentou-se bastante insatisfatōrio mesmo com padrões de pureza analitica, como o ferrocianeto de potāssio.

Os resultados mais afetados foram para o carbono, sendo sempre mais baixos que o esperado, e pouco reprodu tīveis, razão pela qual não se prestou maiores significâncias aos mesmos.

Sem excluir a possibilidade de contaminação, ou • tra fonte de erro estā na higroscopicidade dos compostos, que torna o nūmero de moléculas de $\mathrm{H}_{2} \mathrm{O}$ bastante incerto. Depender do do secante utilizado e do tempo de permanéncia no dessecador esse nümero nem sempre é reprodutivel. Os valores citados são portanto aproximados e não devem ser tomados como critério de pureza. Para os casos em que o teor analitico se torni crītico, prefiriu-se gerar os complexos em solução aquosa a partir do sal $\mathrm{Na}_{3} \mathrm{Fe}(\mathrm{CN})_{5} \mathrm{NH}_{3} \cdot 3 \mathrm{H}_{2} \mathrm{O}$, de alta pureza e fácil ma nipulação.

Intermediários coordenados pela oxima

os complexos $\mathrm{Fe}(\mathrm{CN})_{5} \mathrm{~L}^{3-}$, coordenados pela oxima ou NO, foram sintetizados a partir das acetilpiridinas e nitroprussiato, em proporções estequiomētricas, em solução eta nōlica alcalinizada. Sob constante agitação adicionou-se nitroprussiato de sōdio dissolvido em pequena quantidade de água, seguido pela adição de etanol p.a. até a precipitação. Este $\bar{e}$ filtrado rapidamente para evitar possîuel isomeriza - 
ção ou decomposição, e lavado com ā lcool.

Carbonilpentacianoferrato(II) - $\mathrm{Na}_{3} \mathrm{Fe}(\mathrm{CN})_{5} \mathrm{CO} .2 \mathrm{H}_{2} \mathrm{O}$

0 complexo $\mathrm{Na}_{3} \mathrm{Fe}(\mathrm{CN})_{5} \mathrm{CO}_{2} 2 \mathrm{H}_{2} \mathrm{O}$ foi sintetizado a partir do borbulhamento continuo do fluxo de monóxido de car bono (gerado da reação entre ácido förmico e sulfūrico) numa solução de $\mathrm{Na}_{3} \mathrm{Fe}(\mathrm{CN})_{5} \mathrm{NH}_{3} \cdot 3 \mathrm{H}_{2} \mathrm{O}$, conforme descrito por Toma et a 1 (215).

Tetracianoetilenodiaminaferrato(II) $-\mathrm{Na}_{4} \mathrm{Fe}(\mathrm{CN})_{4}$ en

Tetracianoetilenodiaminaferrato(II) foi prepara do a partir de peclorato de ferro (II) e etilenodiamina de a cordo com o procedimento similar utilizado por Goto et al(216)

Tris(oxalato)ferrato(III) de potássio $-\mathrm{K}_{3} \mathrm{Fe}\left(\mathrm{C}_{2} \mathrm{O}_{4}\right)_{3} \cdot 3 \mathrm{H}_{2} \mathrm{O}$

O ferrioxalato de potāssio, utilizado como actị nōmetro, foi preparado segundo o procedimento citado por Hatchard e Parker (217), misturando-se sob agitação e no escuro, três volumes de uma solução de oxalato de potássio 1,5M com um volume de uma solução de cloreto férrico 1,5 M. A recristalização foi feita dissolvendo-se o complexo em àgua quente. Os critais obtidos após o resfriamento lento, foram separados por filtração no escuro e, secos em dessecador com cloreto de cálcio.

A solução $0,006 M$ de actinōmetro foi preparada dissolvendo-se $0,2947 \mathrm{~g}$ do cristal em $\mathrm{H}_{2} \mathrm{SO}_{4} 0,1 \mathrm{~N}$ até comple 
tar o volume de $100 \mathrm{ml}$.

4.1A.Preparo de Soluções

As soluções foram preparadas por pesagem direta das massas adequadas das substâncias em volume adequado de $\underline{a}$ gua deionizada e deaerada.

4.2. Aparelhagem e Técnicas Experimentais

4.2.1. Espectros de Absorção na Região do Visível e Ultraviọ leta

As medidas de absorção na região do visível e ultra-violeta foram efetuadas en espectrofotônetros Cary mode $10-14$ e 17 .

Foram empregadas celas retangulares de quartzo de caminho ótico igual a $1,00 \mathrm{~cm}$ e celas cilindricas do me. mo material, com caminhos óticos de 0,100 e 5,00 cm.

As medidas espectrofotométricas utilizadas na determinação de pKa dos ligantes py(CO)CHNOH e dos com plexos correspondentes foram realizadas numa cela espectrofo tométrica de quartzo de $1,00 \mathrm{~cm}$ de caminho ótico, colada a um reservatōrio com capacidade de $15 \mathrm{~m} 1$, conforme representado na figura $A$ da página a seguir.

0s espectros dos complexos, sempre que necessários, foram obtidos na presença de excesso do ligante livre, para minimizar o efeito de dissociação. 


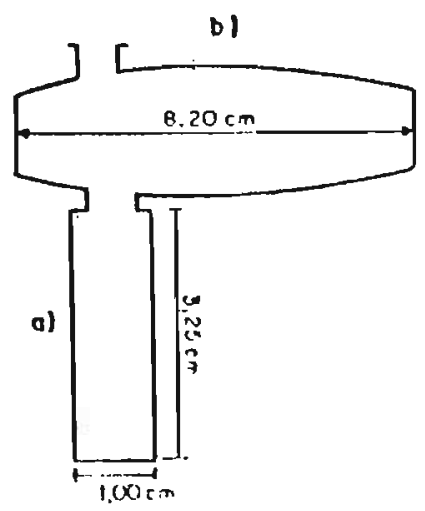

FIG.A. - Cela Espectrofotométrica Utilizada na Determinação de pKa

Aș'soluções dos complexos de pentacianoferrato (III) foram obtidas a partir das soluções correspondentes de pentacianoferrato(II), mediante a oxidação com excesso de Ce(IV), seguido da retenção dos íons de Ce(III) e Ce(IV) na resina catiónica (Baker CG 240) na forma $\mathrm{H}^{+}$.

A solução eluída foi recolhida no meio tamponado com àcido acētico e acetato de sōdio $(0,5 \mathrm{M} / 0,5 \mathrm{M})$ para evi tar a protonação do complexo.

A solução de $\mathrm{Fe}(\mathrm{CN})_{5} \mathrm{p}-\mathrm{py}(\mathrm{CO}) \mathrm{CH}_{3}{ }^{2-}$ apresentouse estāvel, sem evidências de decomposição no intervalo de tempo empregado para medidas experimentais ( pelo menos por trēs horas).

As soluções dos demais complexos da forma oxidada se decompõem muito mais rapidamente.

Os espectros registrados logo apōs a eluição fọ 
ram semelhantes àqueles obtidos pela oxidação com $\mathrm{H}_{2} \mathrm{O}_{2}$.

0 controle de temperatura foi feita por um circulador termostatizador Uniwersiny, modelo UTU, acoplado ao suporte da cela do espectrofotómetro.

4.2.2. Espectro de Absorção na Região do Infravermelho

Os espectros vibracionais foram obtidos com 0 espectrofotōmetro Perkin-Elmer, modelo 337 na região de 400 a $4000 \mathrm{~cm}^{-1}$.

As amostras foram preparadas na forma de pastilhas de brometo de potāssio e de emulsão em nujol e fluorolu be, colocada entre placas de brometo de potássio.

4.2.3. Espectros de Absorção da Amostra Sōlida na Região do Infravermelho Pröximo e Visivel

os espectros dos intermediārios coordenados pela oxima foram registrados em emulsão de fluorolube no espec trofotómetro Cary-17.

A emulsão foi colocada entre cela de quartzo e filme de retroprojetor $3 M$ previamente 1 impo com acetona. 0 espectro é registrado contra o branco preparado da mesma for ma tendo como amostra o $\mathrm{Na}_{3} \mathrm{Fe}(\mathrm{CN})_{5} \mathrm{CO} \cdot 2 \mathrm{H}_{2} \mathrm{O}$.

4.2.4. Espectro de Absorção no Visível - Técnica"Stopped-Flo $\dot{A}$ reação de $\mathrm{Fe}(\mathrm{CN})_{5} \mathrm{NO}^{2}-$ com acetilpiridinas el 
meio alcalino conduz ao aparecimento e desaparecimento de uma coloração azul distinta dos produtos finaiś. Esse processo não pode ser acompanhado atravēs de métodos convencionais. Para o registro do espectro de intermediārio na região do vi sīvel utilizou-se a técnica "stopped-flow", determinando-se as absorbāncias nos vārios instantes correspondentes às reações de formação e desaparècimento dos intermediários. o estudo das reações em vārios comprimentos de onda com a escala previamente calibrada, permitiu o traçado manual das curvas de absorção dos intermediārios, bem como dos produtos imedia tos das reações.

\subsubsection{Medidas Potenciométricas}

As medidas potenciométricas foram efetuadas num potenciómetro Expandomatic SS-2 ou Orion Research, modelo 801, usando-se um eletrodo combinado de platina e Ag/AgCl e solução saturada de $\mathrm{NaCl}$ e AgCl como solução eletrolîtica.

As titulações potenciométricas foram realizadas em meio tamponado com ācido acētico e acetato de sódio $(0,5 \mathrm{M} /$ $0,5 \mathrm{M})$. Nesta faixa de $\mathrm{pH}$ entre 4,30 a 4,60, os efeitos de protonação são praticamente desprezíveis.

Para medidas de $\mathrm{pH}$ utilizou-se um microeletrodo de vidro e Ag/AgCl combinados da Beckman. A solução de KCl original do eletrodo foi substituĩda por solução saturada de $\mathrm{NaCl}$ e AgCl (Orion) para evitar a formação de precipitado de $\mathrm{KClO}_{4}$.

A termostatização foi feita com o auxĩlio de um 
ciculador termostatizador Haake Instr. Inc., modelo FE, dentro de $0,1^{\circ} \mathrm{C}$.

4.2.6. Medidas Cinēticas

As medidas cinēticas de reações lentas e da dis sociação dos intermediārios foram acompanhadas no espectrofo tōmetro Cary-14. Para esse fim, utilizou-se um sistema de mi! tura construído por seringa calibrada, inserida num bloco de termostatização do suporte de cela. Para a termostatização di solução, empregou-se um circulador termostatizador de marca Uniwerslny, modelo UTU, acoplado ao suporte de cela do espec trofotōmetro.

As medidas cinéticas de reações rāpidas foram e! tudadas pela técnica "stopped-flow" (218-221), num apare 1 ho Durrum, modelo D- 110, acoplado a um osciloscōpio registrador Hewlett-Packard.

A figura 4.1. na pāgina a seguir, mostra o es quema do sistema "stopped-flow". As informações sobre a rea ção estudada foram obtidas espectrofotometricamente e observadas no osciloscópio na forma de gráficos que mostram a variação da voltagem com o tempo, sendo a voltagem proporciona à transmitância. As imagens foram fotografadas usando-se uma cãmara da Hewlett-Packard, modelo 198-A, que opera com fil mes polaróides, tipo 107.

As medidas foram feitas usando-se cela de mistu ra de caminho ótico igual a $2,00 \mathrm{~cm}$, na faixa de transmi - 

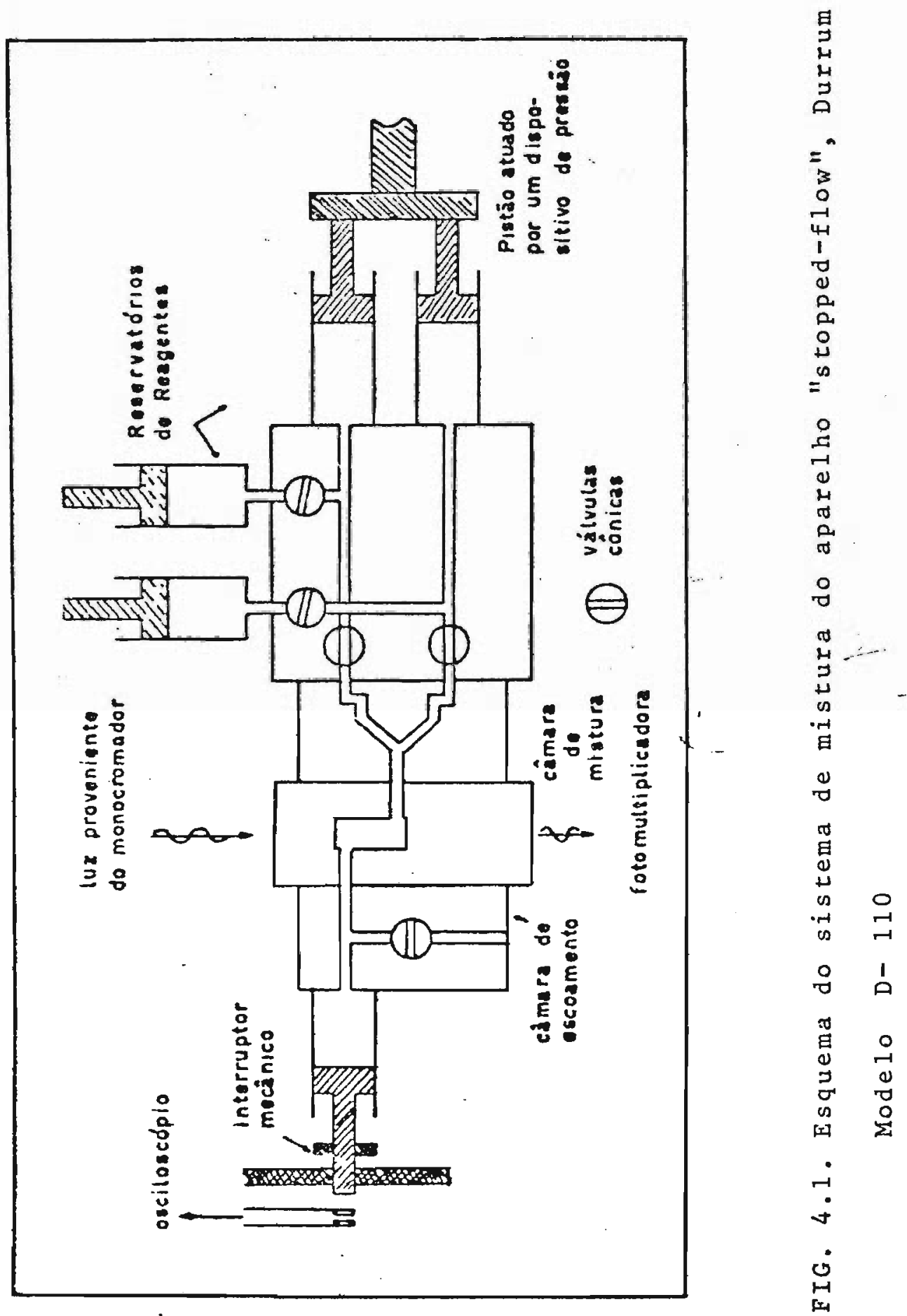
tāncia superior a $80 \%$, onde pode-se considerar linear a de pendência da absorbância com a transmitância.

o controle da temperatura foi feito com o auxí1 io de um termostato Magni Whirl, modelo Blue, equipado com compressor.

4.2.7. Medidas Eletroquímicas

Para medidas eletroquīmicas de voltametria cī clica, foi empregado o sistema modulado de PARC (Princeton Applied Research Corporation), composto de programador uni versal Modelo 175, potenciostato e galvanostato Modelo $173 \mathrm{~m}$. nido de conversor logarítmico de corrente Modelo 376, numa configuração mostrada no esquema abaixo, onde o potenciostato é conectado ao programador universal que opera como gerador de onda triangular.

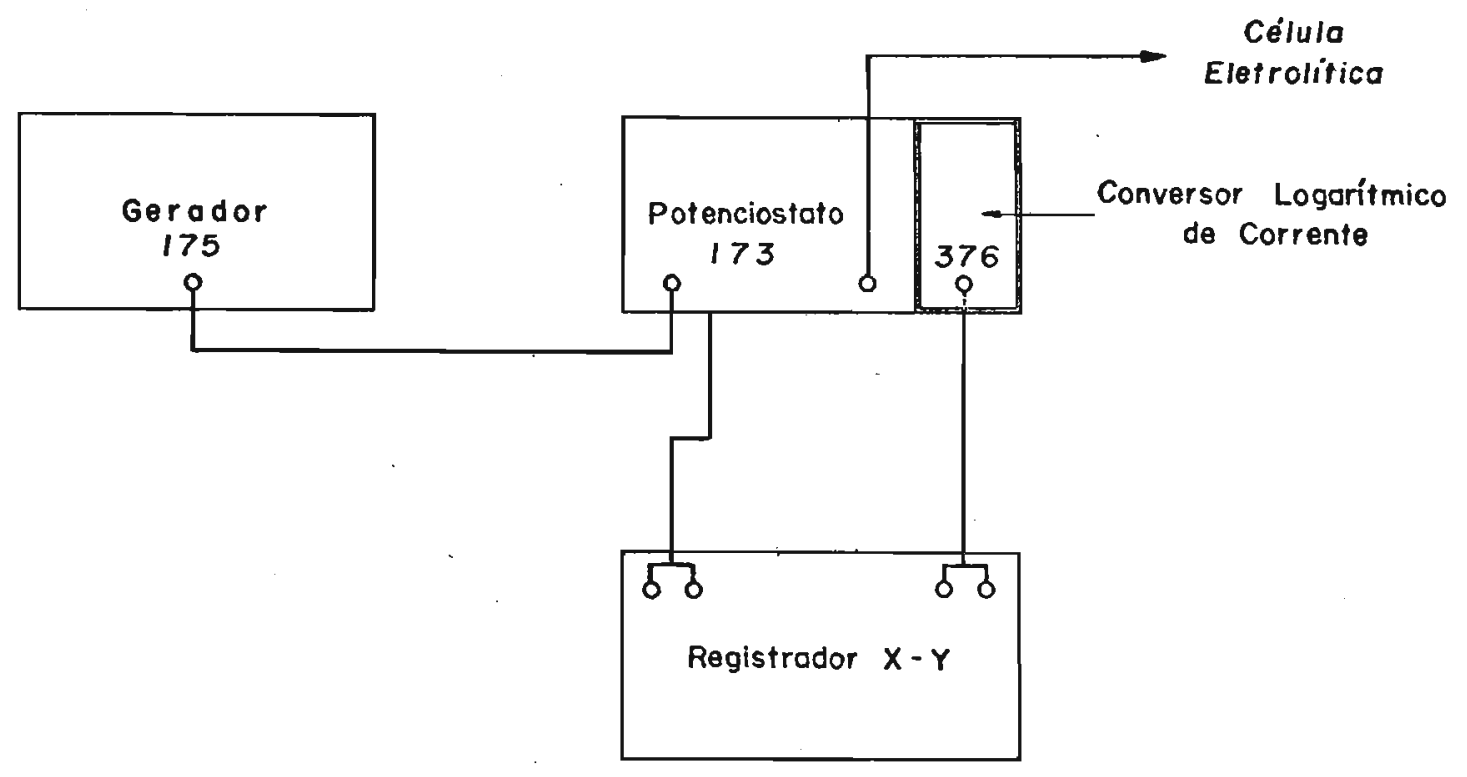


Com este sistema, aplica-se uma variação linear de potencial em função do tempo, entre os eletrodos de referência e trabalho. 0 dominio de potencial é de $\pm 5 \mathrm{~V}$ e as ve $10 \mathrm{cidades}$ de varredura de potencias de $1 \times 10^{-3}$ a $11 \times 10^{3} \mathrm{~V}$. $s^{-1}$. O potencial inicial e final pode ser selecionado dentro de $2 \mathrm{mV}$.

D aparelho possui um dispositivo para compensação de queda ôhmica que o torna ūtil no estudo de soluções pouco condutoras ou a velocidade de varredura räpida.

0 registrador $x-y$ de Houston Instrument RE0074 tipo 3 acompanha a variação da corrente com o potencial, com precisão de $\pm 0,2 \%$ de toda escala.

\section{Célulà Eletrolîtica}

Foi empregada uma célula eletrolîtica projetada tendo-se por objetivo a facilidade de montagem, desmontagem, 1 impeza, termostatização e versatilidade. o volume da solu ção necessária para o estudo pode ser controlado simplesmente, pelo uso adequado de recipientes com capacidade de $5 \mathrm{ml}$ atē $50 \mathrm{ml}$ de solução, introduzido no sistema de termostati zù̧̧̃o.

A figura 4.2. mostra o desenho esquemātico da célula eletrolítica imersa no banho termostātico. Ela é muni da de uma tampa de lucite com orifícios através dos quais pa dronizam as posições dos compartimentos do sistema de eletro dos e degasagem. 
69

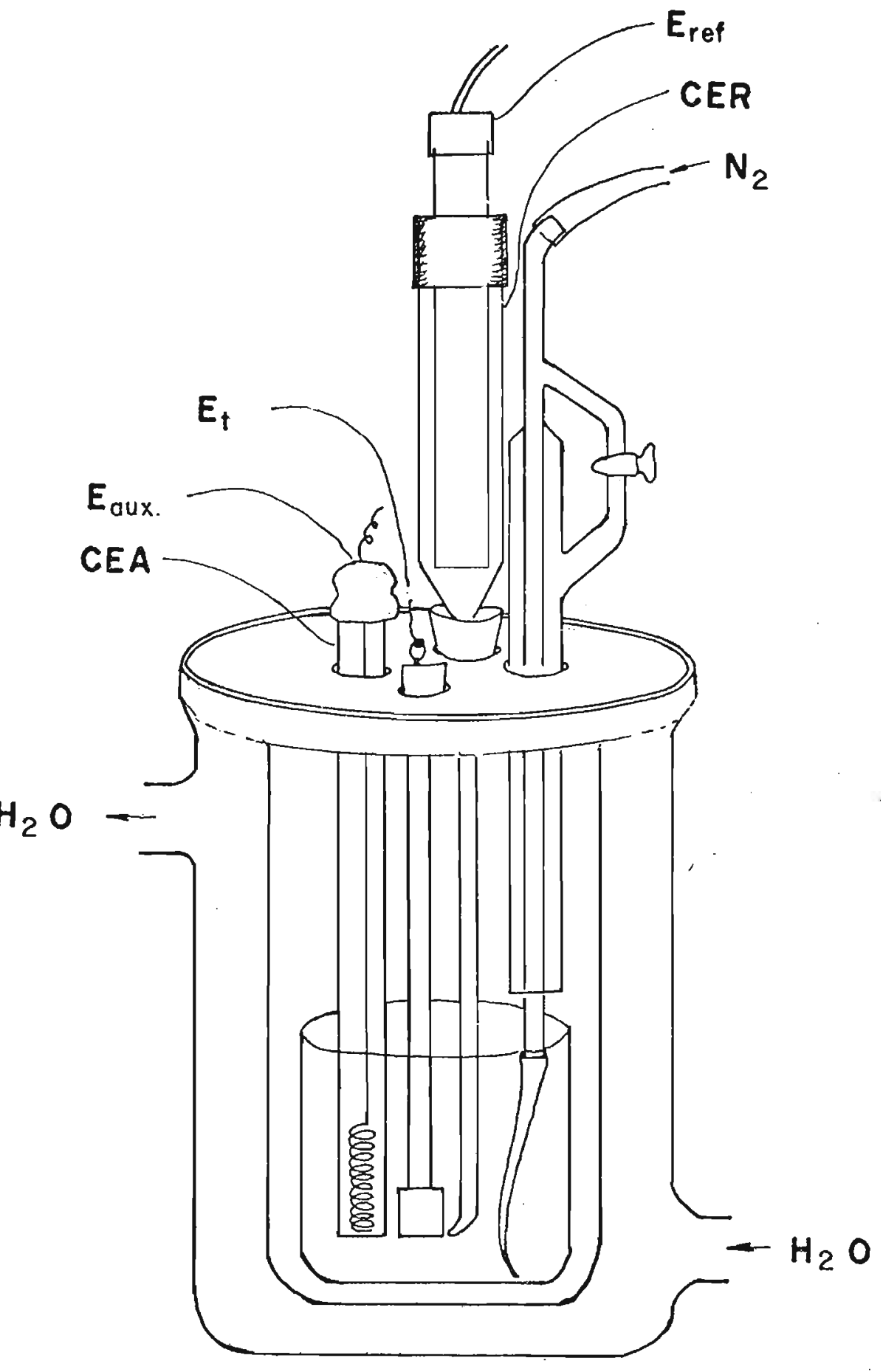

FIG. 4.2. CËLULA ELETROLITICA 
os componentes da célula são:

- Eletrodo de trabalho $\left(E_{t}\right)$

Eletrodo de placa de platina de $0,54 \pm 0,01 \mathrm{~cm}^{2}$ de ārea efetiva.

- Compartimento do eletrodo auxiliar (CEA)

Consiste de um tubo de vidro de pyrex de $9,5 \mathrm{~cm}$ de comprimento e $8 \mathrm{~mm}$ de diâmetro interno, tendo a extremida de inferior terminada em placa de vidro sinterizado de porosidade média e, contēm a solução de eletrōlito suporte.

- Eletrodo auxiliar ( $\left.E_{a u x}\right)$

Eletrodo de platina helicoidal imerso no CEA.

- Compartimento do eletrodo de referéncia (CER)

Constituĩdo de um tubo de vidro pyrex de $14 \mathrm{~mm}$ de diāmetro inicial cuja extremidade inferior termina em capilar de Luggin-Harber. A finalidade deste capilar é diminuir a queda ôhmica entre os eletrodos de trabalho e referência e no seu interior contēm apenas a solução de eletrōlito suporte. A distância entre a extremidade do capilar e o eletrodo de trabalho foi mantida em torno de $2 \mathrm{~mm}$ o que corresponde cerca do triplo do diâmetro interno do capilar. Esta condi ção satisfaz a recomendação de Piontelli (265) para que a per turbação do campo elétrico pelo capilar seja desprezível nas 
proximidades da superficie do eletrodo de trabalho.

- Elétrodo de referēncia ( $E_{\text {ref }}$ )

Eletrodo de $\mathrm{Ag} / \mathrm{AgCl}$ da Orion Research com solu ção interna de $\mathrm{KCl} l \mathrm{M}$ saturada de $\mathrm{AgCl}$.

- Tubo de borbulhamento de nitrogēnio ou argônio

Munida de uma torneira de saída dupla para borbulhamento da solução antes da eletrōlise e passagem do gás inerte sôbre a mesma durante a eletrōlise.

A célula é fixada no banho termostático mediante. as garras da tampa e base. Para a termostatização da solu ção empregou-se um circulador termostatizador Forma Temp. da Forma Scientific Inc..

\section{Obtenção dos Voltamogramas}

Inicialmente a solução do eletrōlito suporte é deaerada pelo menos por 15 minutos na célula já montada. 0 gās borbulhado, argōnio ou nitrogēnio da White Martins, tipo SS que se passa por uma solução de vanādio (II) (Fisher p. a.) $0,1 \mathrm{M}$ em meio $\mathrm{HCl}$ 3M. A solução redutora é mantida em contato permanente com zinco amalgamado, para a sua constante regeneração. Após essa etapa, o gās é lavado, passando-se atravēs de um frasco lavador contendo a solução $0,5 \mathrm{M}$ de $\mathrm{KCl}$ para eliminar possiveis resíduos da solução redutora e permi 
tir saturação do gās com respeito a vapor d'āgua. A linha em pregada neste tratamento é toda de vidro, sendo as conexões feitas com juntas esféricas de vidro, presas com clips metā1 ico.

Atingida a temperatura de $25,0 \pm 0,1^{\circ} \mathrm{C}$, inicia - se a eletrólise e o registro dos voltamogramas cíclicos com a solução em repouso e sob atmosfera inerte.

Apōs a observação dos voltamogramas cĩclicos dos brancos, quando necessārio, mergulha-se o eletrodo de platina em àgua rēgia e a seguir lava-se com àgua deionizada.

A solução do complexo em estudo é deaérada por 20 minutos na cêlula jä montada, tempo suficiente também para a termostatização, apōs o qual se inicia o registro. dos vol tamogramas.

A varredura de potencial inicia-se no sentido a nōdico, com velocidades que variam entre $0,200 \mathrm{a} 0,005 \mathrm{Vs}^{-1}$, dependendo do composto em estudo.

o potencial inicial é escolhido de maneira a for necer uma linha base para o pico anōdico, adequado à anālise do voltamograma cíclico.

Entre dois voltamogramas cíclicos sucessivos, borbulha-se a solução com o objetivo de destruir a camada de difusão e, aguarda-se cerca de 4 minutos para a solução entrar novamente em repouso.

0 dispositivo de correção de queda ôhmica é ac onado quando se faz necessārio. 


\section{3}

4.2.8. Medidas Fotoquîmicas

As radiações monocromáticas na região de 200 a $600 \mathrm{~nm}$ com as intensidades relativas, dicriminadas na tabela abaixo, são obtidas usando-se uma lāmpada de mercūrio estabilizada (St-75 da Hanau - 90 W) alimentada pela fonte da Hanau-002348.

Intensidades Relativas
$\lambda(\mathrm{nm})$
$\lambda(\mathrm{nm})$

\begin{tabular}{rrrr}
\hline 238 & 2 & 297 & 15 \\
240 & 2 & 302 & 25 \\
248 & 7 & $313,$, & 55 \\
254 & 30 & 334, \\
265 & 17 & 366 & 7 \\
270 & 2 & $405 / 408$ & 43 \\
280 & 6 & 435 & 67 \\
289 & 5,5 & 546 & 95 \\
\hline
\end{tabular}

A transmitância dos filtros de Coleman foi re gistrada no espectrofotómetro Cary-17 (FIG.4.3.) e utilizada para monocromatização ou quase monocromatização dos compri - 


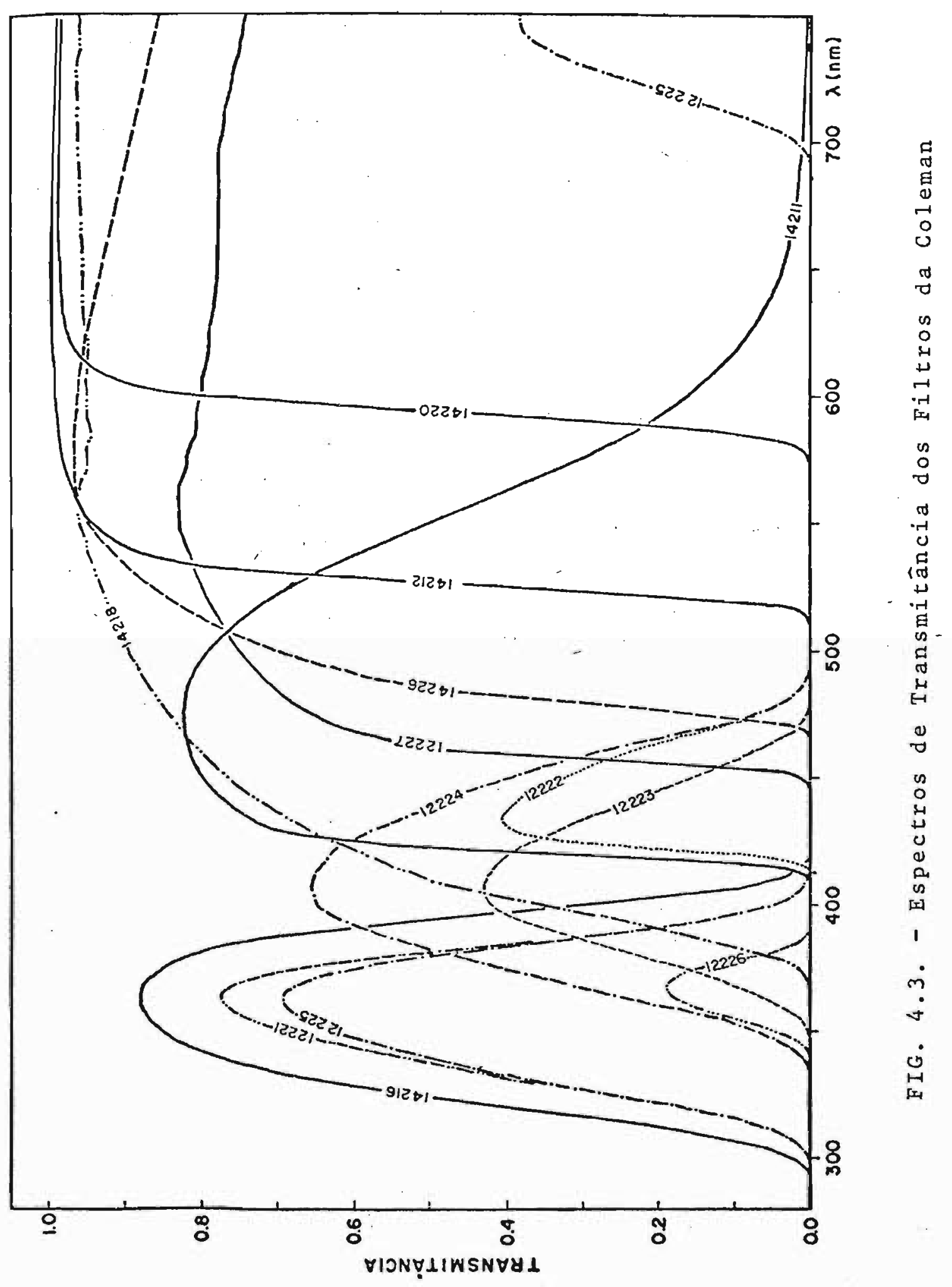


mentos de onda adequados. Utilizou-se o filtro 12.225 para selecionar a linha de $366 \mathrm{~nm}$ e o filtro 12.223 para o con junto de comprimento de onda predominantemente em 405/408 e $436 \mathrm{~nm}$.

\section{A fotōise foi realizada numa cela cilindrica} de quartzo de caminho ōtico de $5,00 \mathrm{~cm}$ para aumentar a fra ção de luz incidente absorvida. A solução foi mantida sob at mosfera de argōnio e homogeneizada atravēs de agitador magnē tico durante a irradiação. Para sistemas onde o número de es pécies fotoinduzidas foi determinado espectrofotometricamen te, a cela de fotólise é adaptada com tygon à cela espectrofotométrica do mesmo material com caminho ótico de $1,00 \mathrm{~cm}$, segundo da figura abaixo.

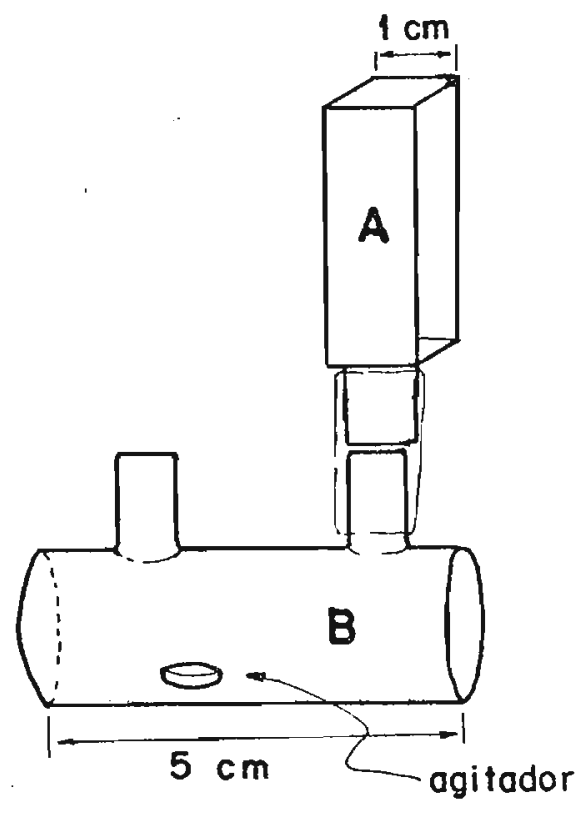

As variações espectroscōpicas da solução fotolị sada podem ser determinadas após cada período de irradiação, 
no espectrofotômetro cary - 14 .

o conjunto foi termostatizado pelos circulado res-termostatizadores acoplados aos suportes de cela, Haake Instr. Inc. Modelo FE na fotōlise e Uniwersiny Modelo UTU no registro dos espectros.

A figura 4.4. mostra a cela de fotólise utiliza da para acompanhar a reação fotoquímica pela tēcnica de voltametria ciclica.

A intensidade da lâmpada foi calibrada no in $\bar{i}-$ cio e no fim de cada experiência, pelo uso de solução 0,006M de actinōmetro de ferrioxalato de potássio $(217,222,223)$.

Cada determinação actinométrica foi feita apōs a lâmpada entrar no regime de operação eficiente e estável ; cerca de uma hora.

O gräfico de calibração para jons de ferro (II) foi construído usando-se a fenantrolina como reagente analítico (224).

Devido a sua extrema sensibilidade, o ferrioxalato de potássio foi o actinōmetro adequado para este sistema cuja intensidade luminosa não ē alta. Outras vantagens de se actinômetro são os fatos de apresentarem baixo coeficiente de temperatura e uma eficiência quāntica quase uniforme num amplo intervalo de comprimento de onda entre $250 \mathrm{~nm}$ a $580 \mathrm{~nm}(217,189$ e 222$)$. 


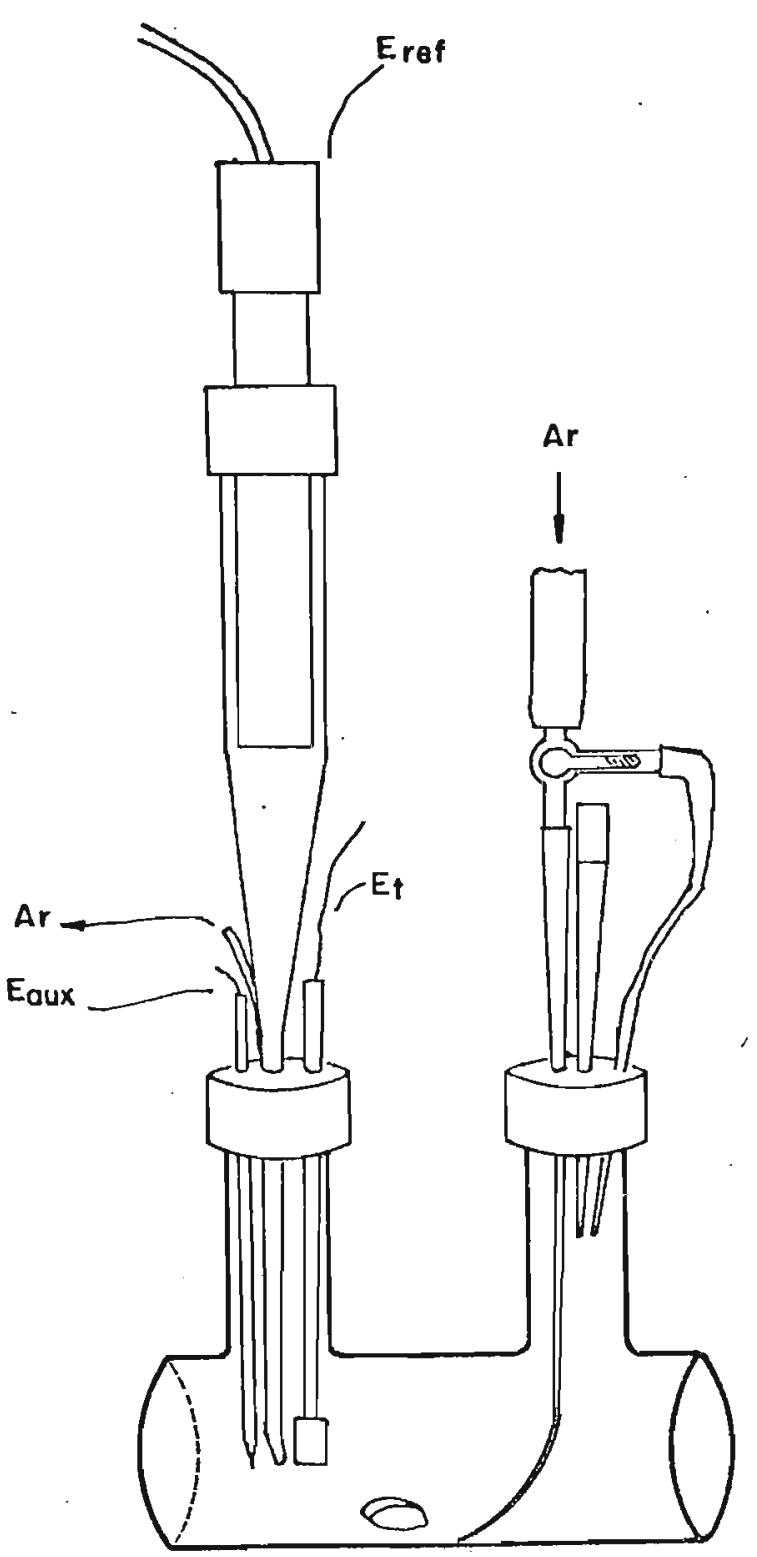

FIG. 4.4. Cela de Fotólise com Sistemas de Eletrodos e Degasagem 
4.3. Tratamento dos Dados

\subsubsection{Espectros Eletrōnicos}

As absorbāncias foram lidas diretamente fazendo-se a correção para o branco traçado nas mesmas condições experimentais usadas para a amostra.

As absortividades molares utilizadas para fins analiticos foram avaliadas pela lei de Beer atravēs da medida de absorbāncia a vārias concentrações.

0 māximo dos espectros é deteminado através do valor limite da média de comprimento de onda $\left(\left(\lambda_{1}+\lambda_{2}\right) / 2\right)$ onde a absorbāncia A é a mesma para $\lambda_{1}$ e $\lambda_{2}$ onde $A \rightarrow A_{0}(225)$.

A decomposição das bandas (vide Apēndice 11.1) é feita usando-se as funções Gaussiana simples, Gaussiana du pla e a log-normal.

\section{a. Gaussiana Simples e Dupla}

Os espectros foram reconstruídos mediante o uso da expressão abaixo para a Gaussiana simples

$$
\varepsilon=\varepsilon_{0} 2^{-}\left(\frac{\lambda-\lambda}{\delta}\right)
$$

onde $\quad \varepsilon_{0}=$ coeficiente de extinção no māximo de absorção $\lambda_{0}=$ comprimento de onda no māximo de absorção 


$$
\delta=\text { metade da largura de meia banda }
$$

A mesma expressão pode ser usada para Gaussiana dupla quando se substitui por $\delta(-)$ e $\delta(+)$ para $\nu<v_{0}$ e $\nu>v$, respectivamente.

b. Distribuição Log-Normal

A curva log-normal foi reconstruída através da equação

$\varepsilon(z)=y_{0} \exp -\left\{\frac{\ln 2}{(\ln \rho)^{2}}\left[\ln \left(\frac{z-z_{0}}{H} \frac{\rho^{2}-1}{\rho}+1\right)\right]^{2}\right\}$

$$
\text { para } \begin{aligned}
z>z_{0} & -\frac{H \rho}{\rho^{2}-1} \\
\text { onde } \quad \rho & =\frac{z_{2}-z_{0}}{z_{0}-z_{1}} \\
c & =(\ln \rho) \sqrt{21 n 2} \\
b & =H \rho /\left(\rho^{2}-1\right) \exp \left(c^{2}\right) \\
a & =z_{0}-H \rho /\left(\rho^{2}-1\right)
\end{aligned}
$$

A ārea da banda de absorção foi determianda atravēs da fōrmula

$$
A=\delta_{\text {banda }} \varepsilon(\tilde{\nu}) d \tilde{\nu}
$$


Quando a curva é suposta Gaussiana pode-se calcular a ārea atravēs da fórmula

$$
A=2,1289 \varepsilon_{0} \delta
$$

Ao considerar a assimetria para a curva Gaussia na deve-se usar a fórmula

$$
A=a_{s} \varepsilon_{0} H
$$

onde $H$ é a largura da meia banda e a Calculando -se a ārea da banda numericamente, a travēs da regra de Simpson com nümero de retângulos ( $n$ ) igual a 30 , chega-se, dèntro do erro experimental, ao mesmo resultado obtido através das fórmulas mencionadas, em par ícular com aquela representada pela expres.são (3).

Tanto a decomposição das bandas como o cálculo das āreas foram efetuados com o auxîlio de uma calculadora programāvel HP-97.

4.3.2. Determinação do pKa

A determinação dos valores de pKa foi feita atravēs da equação

$$
\mathrm{pH}=\mathrm{pKa}+\log \frac{\mathrm{A}^{-}}{\mathrm{HA}}
$$


onde $A^{-} \bar{e}$ a espēcie na forma não protonada e

HA na forma protonada

Esta expressão pode ser convertida em termos dt absorbāncia (3), em

$$
\mathrm{pH}=\mathrm{pKa}+\log \frac{A-A_{f}}{A_{0}-A}
$$

onde : $\quad A_{0}=$ absorbāncia da espécie não protonada

$A_{f}=$ absorbāncia da espécie protonada

$A=$ absorbāncia da mistura

Quando necessārio, o valor de $A_{0}$ foi estimads através de cálculos iterativos, partindo-se inicialmente de välor experimental e, aproximando-o sucessivamente, até que - grāfico de $\mathrm{pH}$ versus $\log \left((A-A f) /\left(A_{0}-A\right)\right)$, apresente ur coeficiente angular unitário, previsto teoricamente.

$$
0 \text { pH medido foi corrigido (226) atravēs da equi }
$$

ção abaixo

$$
\left|H^{+}\right|=\frac{10^{-p H} \text { medido }}{y^{H^{+}}}
$$

onde

$$
-\log y^{H^{+}}=\frac{0,5 Z_{i}^{2} I^{1 / 2}}{1+I^{1 / 2}}
$$

é vālida para a força iōnica até em torno de $8 . z_{i}$ são a: 
cargas dos ions compõem o meio e o I è a força iōnica da da por

$$
I=\frac{1}{2} \Sigma \mathrm{Ci} Z \mathrm{Zi}^{2}
$$

sendo $C i$ a concentração molar do ion $i$.

\subsubsection{Medidas Cinëticas}

As constantes de velocidade de pseudo primeira ordem foram avaliadas graficamente, determinando-se o coeficiente angular da função

$$
\ln \frac{A_{\infty}-A_{0}}{A_{\infty}-A_{t}}=k_{o b s} \cdot t
$$

onde : $\quad A_{0}=$ absorbāncia da solução no tempo zero

$A_{t}=$ absorbāncia da solução no tempo $t$

$A_{\infty}=$ absorbāncia da solução apōs o término da rea ção

$k_{\text {obs }}=$ constante de velocidade de pseudo primeira ordem

Os gräficos apresentam-se geralmente 1 ineares, pelo menos para um período superior a duas meia-vidas.

Nas reações onde se observam duas ou mais eta pas, a linearidade dos gräficos de $\ln \left(A_{\infty}-A_{t}\right)$ para cada tapa só é possível numa situação onde se minimiza a influência da outra. A origem do problema está portanto, na varia - 


\section{3}

ção èm $A_{\infty}$, devido à influēncia da reação seguinte. Em tais casos, ampliou-se a escala de tempo para obter os dados cinēticos pelo mētodo de Guggenheim (227).

Os valores de kobs tabelados representam a mé dia de duas a três determinações experimentais.

As entalpias e entropias de ativação foram calculadas de acordo com a teoria do estado de transição de Eyring (226), partindo-se da expressão

$$
k_{r}=\frac{k k T}{h} e^{-\Delta H^{\ddagger} / R T} e^{\Delta S \neq / R}
$$

onde: $k_{r}=$ constante de velocidade

$$
\begin{aligned}
K= & \text { coeficiente de tranmissão assumido como sendo } \\
& \text { unitārio } \\
& =\text { constante de Boltzman } \\
T \quad & \text { temperatura absoluta } \\
h \quad= & \text { constante de Planck } \\
R \quad= & \text { constante universal dos gases } \\
\Delta H^{\ddagger}= & \text { entalpia de ativação } \\
\Delta S^{\ddagger}= & \text { entropia de ativação }
\end{aligned}
$$

A determinação das constantes de velocidade bem como os parāmetros de ativação foram avaliados através de ca. culos de regressão linear, excluindo-se os eventuais pontos discrepantes dos gräficos, previamente traçados. 
4.3.4.1. Determinação dos Parāmetros Eletroquĩmicos

Para os voltamogramas cĩclicos correspondentes a processos monoeletrōnicos e reversiveis, que apresentam a linha base anōdica e catódica bem definida, obtēm-se os parâa metros assinalados na figura 4.5 .

a. Corrente de pico

$i_{p c}=$ corrente de pico catōdico

$i_{p a}=$ corrente de pico anódico

obtida mediante a distāncia tomada verticalmente, ao mă ximo da corrente ao prolongamento da linha base.

b. Potencial de pico

$E_{p a}=$ potencial de pico anōdico

$E_{p c}=$ potencial de pico catódico

Dado pela projeção vertical do māximo da corrente sobre o eixo dos potenciais.

c. Potencial de meio pico

$E_{p a / 2}=$ potencial de meio pico anödico

$E_{p c / 2}=$ potencial de meio pico catódico

Determina-se sobre a curva, o ponto que corresponde à metade da altura do pico da corrente mäxima. Projetando-se este ponto sobre o eixo dos potenciais obtém-se 0 $E_{p / 2}$

d.Potencial de meia onda $\left(E_{1 / 2}\right)$ 


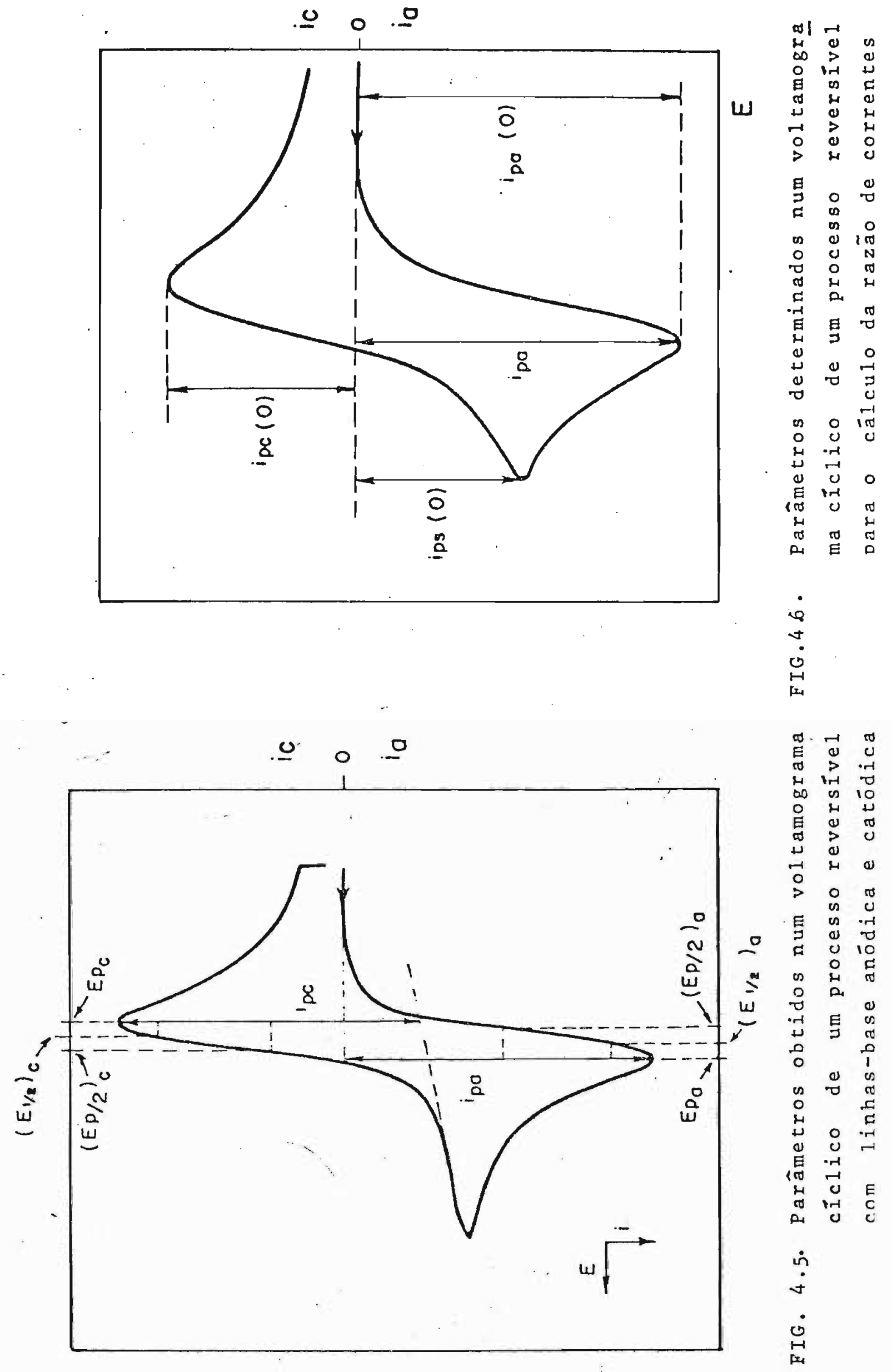


E o potencial à $85,17 \%$ do $i_{p}$ e nos sistemas reversi veis corresponde ao potencial de meia onda polarogräfico - $\Delta E_{p}$ - é a diferença entre os potenciais de pico anōdico e catódico.

Para os voltamogramas cĩclicos que não apresen1 inha base catódica bem definida, deve-se inverter o pocial adequadamente e aplicar o método de Nicholson (228) permite calcular a razão $i_{p c} /{ }^{i}$ pa mediante a equação

$$
\frac{i_{p c}}{i_{p a}}=\frac{i_{p c(0)}}{i_{p a(0)}}+\frac{0,485 i_{p s(0)}}{i_{p a(0)}}+0,086
$$

Os significados dos componentes da equação é in ado na figura 4.6 .

.4.2. Determinação da Area do Eletrodo de Trabalho

A ārea do eletrodo de platina utilizado foi de'minada através de voltametria cĩclica de uma solução aquo de $\mathrm{Fe}(\mathrm{CN})_{6}{ }^{4-}$ em KCl $0,5 \mathrm{M}$ a $25,0^{\circ} \mathrm{C}$.

A figura 4.7. traz o gräfico de $i_{p a}$ vs a concen ção de $\mathrm{Fe}(\mathrm{CN})_{6}{ }^{4-}$ a velocidade de varredura de potenciais 0,050 e $0,020 \mathrm{~V} \cdot \mathrm{s}^{-1}$. A àrea do eletrodo determinada a par - do seu coeficiente angular é de $0,54 \pm 0,01 \mathrm{~cm}^{2}$. 


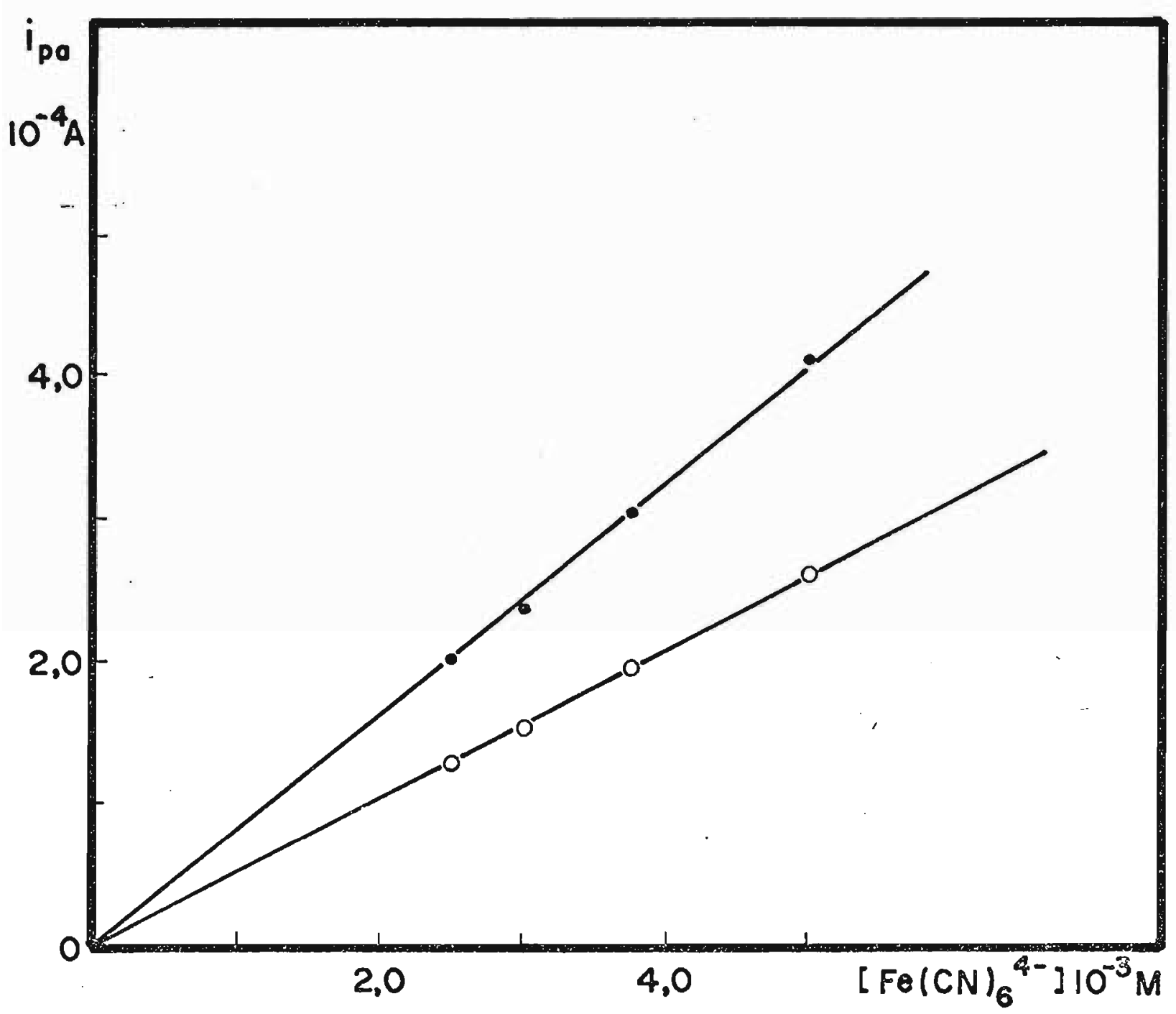

FIG. 4.7. Corrente de pico anódico em função. da concentração de $\quad \mathrm{Fe}(\mathrm{CN})_{6}^{4-}$ $\mathrm{t}=25,0^{\circ} \mathrm{C}$ $\mathrm{v}=0,050 \mathrm{~V} \cdot \mathrm{s}^{-1}(\ldots) \quad \mathrm{v}=0,020 \mathrm{~V} \cdot \mathrm{s}^{-1}(0 \circ 0)$ 
4.3.5. Tratamento dos Dados Fotoquímicos

4.3.5.1. Intensidade da 1 uz incidente ( ${ }_{0}{ }^{i}$ )

o sistema lâmpada - filtro foi calibrado para cada experiēncia através do actinōmetro ferrioxalato de po tāssio mediante a expressão abaixo, nas condições em que a fração da 1 uz incidente absorvida pela amostra seja praticamente igual a unidade.

$$
I_{0}^{i}=\frac{n_{a}}{\Phi_{a} t\left(1-10^{-\varepsilon_{0}[A] \ell}\right)}
$$

onde : $\varepsilon_{0}=$ coeficiente de extinção na frequência de ă sorção

$$
\begin{aligned}
& \text { [A] = concentração da amostra } \\
& \ell=\text { caminho ótico percorrido } \\
& I_{0}^{i}=\text { intensidade da } 1 u z \text { incidente } \\
& t=\text { tempo de irradiação } \\
& \Phi_{\mathrm{a}}=\text { rendimento quāntico do actinômetro a irradiado } \\
& n_{a}=\text { nümero de ĩons ou àtomos formados no processo } \\
& \text { durante o tempo } t \text { de irradiação } \\
& 1-10^{-\varepsilon_{0}}[A] \ell=\text { fração da } 1 \text { uz incidente absorvida pela amos- }
\end{aligned}
$$

0 nümero de ions de ferro(II) $\left(n_{a}\right)$ formado na solução de actinōmetro é determinado atravēs da fōrmula apre sentada na pāgina seguinte. 


$$
n_{F e}{ }^{2+}=\frac{6,023 \times 10^{20} v_{1} v_{3} \log \left(I_{0} / I\right)}{v_{2} \& \varepsilon}
$$

onde: $\quad v_{1}=$ volume da solução de actinōmetro irradiado(ml)

$$
\begin{aligned}
& V_{2}=\text { volume da alĩquota tomada para anālise (ml) } \\
& v_{3}=\text { volume final para o qual a alíquota } V_{2} \bar{e} \text { diluI } \\
& \log \left(I_{0} / I\right)=\text { medida da densidade ōtica da solução } \\
& \ell=\text { comprimento da cela espectrofotomētrica } \\
& \varepsilon=\text { valor experimental do } \varepsilon \text { do complexo de } \mathrm{Fe}^{2+} \\
& \text { determinado na calibração }
\end{aligned}
$$

4.3.5.2. Determinação de nümero de espēcies $\left(n_{x}\right)$ geradas fotoquímicamente

A determinação do número de espécies geradas fo toquímicamente foi feita de modo direto, acompanhando-se as variações espectroscōpicas ou eletroquímicas da amostra foto 1 isada, Nas situações em que esta determinação direta é difi cultada ou, mesmo para confirma-la, utilizou-se uma reação quĩmica auxiliar para então determinar o $n_{x}$ através de anālises espectroscópica e ou eletroquímica dos complexos forma dos ou remanescentes.

4.3.5.3. Cálculo de Rendimento Quāntico ( $\Phi)$

Sabendo-se o número de moléculas ou ions $\left(n_{x}\right)$ 
da espēcie que sofreu reação fotoquîmica, pode-se determinar o rendimento quāntico do produto $\left(\Phi_{x}\right)$ através de uma fórmu 1 a simplificada para o caso em que a fração da luz incidente absorvida pela amostra tende a unidade.

$$
\Phi_{x}=\frac{n_{x} t_{a} \Phi_{a}}{n_{a} t_{x}}
$$

onde $\Phi_{a}=$ rendimento quântico do actinōmetro a comprimento de onda e temperatura determinados

$t_{x}=$ tempo de irradiação da amostra

$t_{a}=$ tempo de irradiação da solução do actinōmetro 


\section{V- CARACTERIZAÇÃO E PROPRIEDADES}

\subsection{Espectros Eletrónicos}

5.1.1. Espectros Eletrōnicos dos Complexos $\mathrm{Fe}(\mathrm{CN})_{5} \mathrm{~L}^{3-}$ e dos Ligantes Livre

os complexos apresentam-se fortemente colori dos, com bandas de absorção na região do visĩvel e do ultrạ violeta próximo.

os espectros eletrônicos na região do visivel para os complexos de pentacianoferrato(II), assim como para os ligantes livres e os complexos na região do ultravioleta são ilustrados nas figuras 5.7. a 5.10. e 5.1. a 5.6., res pectivamente.

Basicamente as transições eletrōnicas observadas nos $\mathrm{Fe}(\mathrm{CN})_{5} \mathrm{~L}^{3-}$ podem ser classificadas em (229):

a. Transição de transferēncia de carga $F e \rightarrow L$ (TC)

b. Transição de campo ligante ( $d \rightarrow d$ )

c. Transições internas nos ligantes ( $L \rightarrow L$ )

d. Transições de transferência de carga $\mathrm{Fe} \rightarrow \mathrm{CN}$

Para a maioria dos complexos estudados, os espectros podem ser gerados com boa concordāncia por meio de uma função Gaussiana simples (235), assumindo-se o compri mento de onda como variável independente. 
Para fins de comparação também se fez a anālise dos espectros atravēs do emprego das funções Gaussianas duplas (236) e distribuição log-normal (237). A decomposi ção pode ser observada nos espectros das figuras 5.1. a 5.10.

Tomando a função log-normal como sendo a mais adequada (238) para descrever as distorções dos espectros, percebe-se que a Gaussiana dupla se aproxima muito desta fun ção. As diferenças encontradas de uma anālise para a outra são em geral pequenas e, semelhantes às observadas por Siano e Metzler (237). Pode-se dizer que, de uma maneira geral, a distribuição log-normal se ajusta muito bem aos dados, e melhor descreve a assimetria das bandas, como no caso do $\mathrm{Fe}(\mathrm{CN})_{5}\left(\mathrm{~m}-\mathrm{py}(\mathrm{CO}) \mathrm{CH}_{3}\right)^{3-}$.

Para os derivados com os substituintes em posi ção para, a decomposição dos espectros mostra a existência de uma banda de absorção de baixa intensidade, semelhante às observadas nos complexos de pentacianoferrato(II) com $\mathrm{NH}_{3}$, NO, dmso, $\mathrm{NO}_{2}{ }^{-}, \mathrm{SO}_{3}{ }^{2-}$ e $\mathrm{MPz}^{+}$(3) atribuîdas à transição $d-d$ (239), orbitalmente permitida.

Já, para os derivados em meta, essa banda deve estar totalmente encoberta pela banda de transferéncia de carga. $0 \mathrm{Fe}(\mathrm{CN})_{5} \mathrm{m-py}(\mathrm{CO}) \mathrm{CHNOH}^{3-}$ apresenta uma banda de ba xa intensidade ao redor de $495 \mathrm{~nm}$. Não se tem uma atribuição mais definida para essa banda que poderia corresponder a uma transição de transferência de carga para o orbital de si metria $a_{2}$ do ligante ou, uma transição envolvendo grupo cromóforo oxima. E pouco provāvel associar a uma outra tran 
93

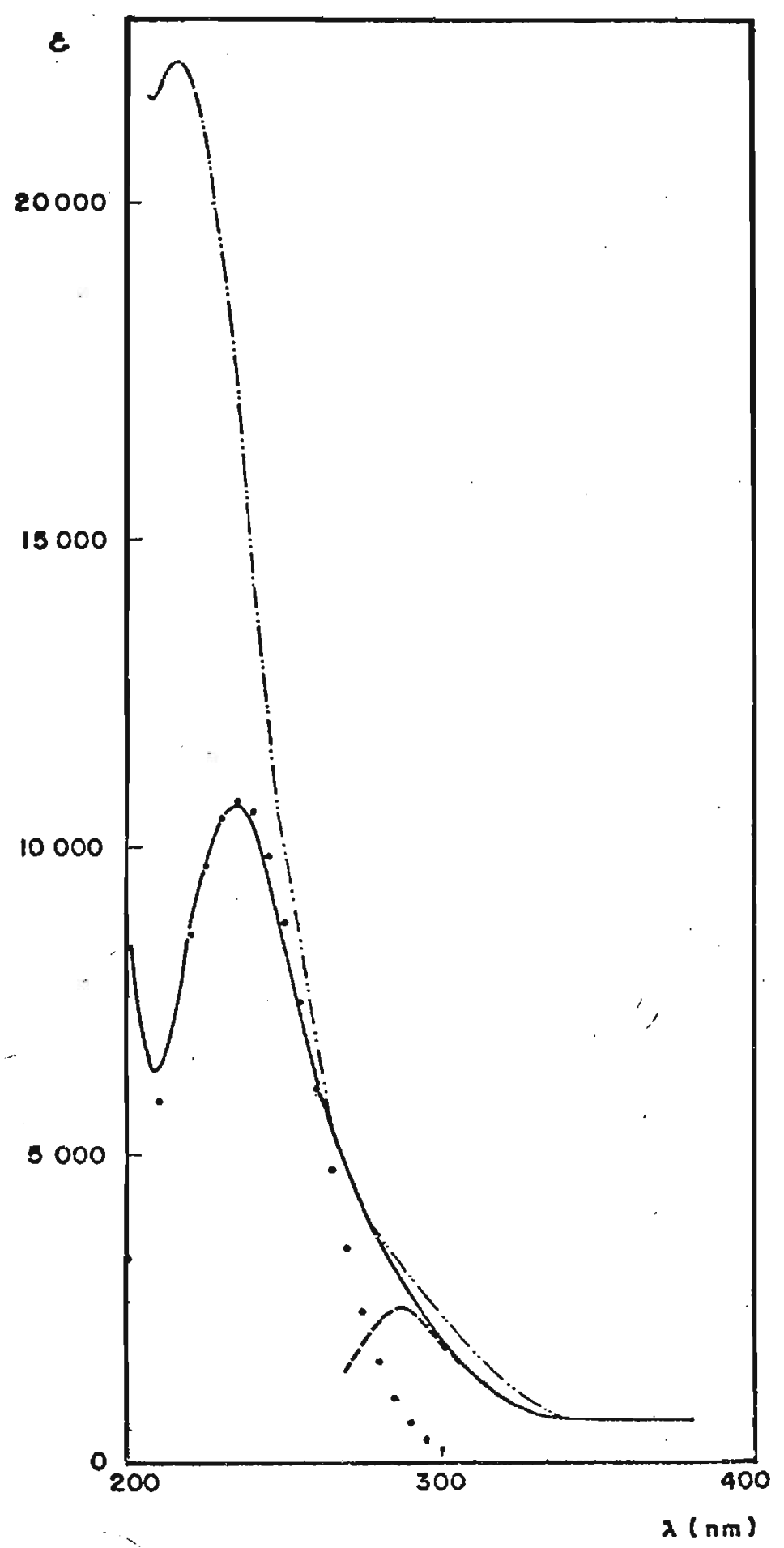

FIG. 5.1. Espectros eletrônicos na região. de ultra-violeta do complexo $\mathrm{Fe}(\mathrm{CN})_{5} \mathrm{p}-\mathrm{py}(\mathrm{CO}) \mathrm{CHNOH}^{3-}(-\cdots-\cdots)$ e do ligante p-py(CO)CHNOH (-), decomposição. Gaus siana $(\cdots) \quad t=25,0 \pm 0,1{ }^{\circ} \mathrm{C}$ 


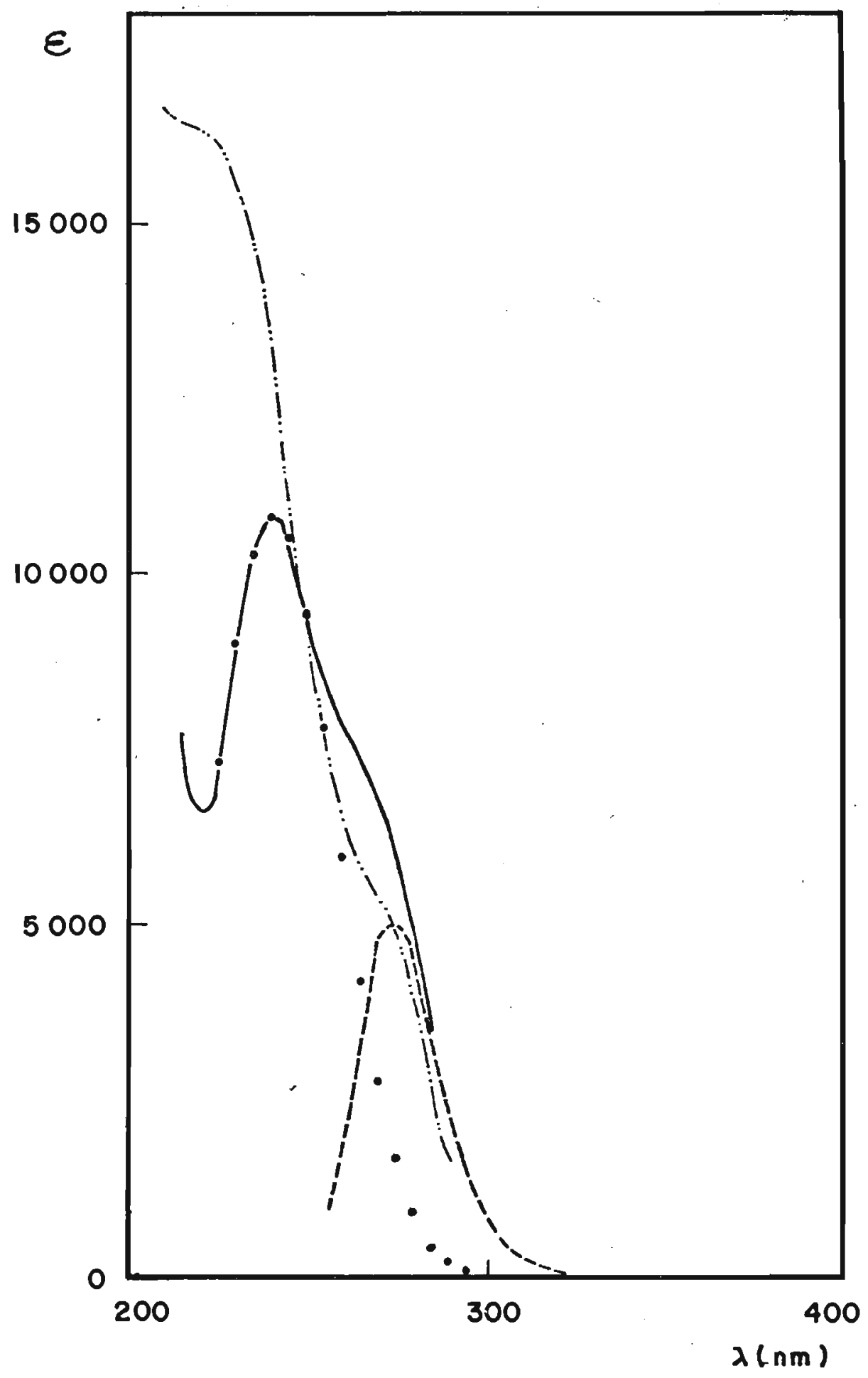

FIG. 5.2. Espectros eletrônicos na região de ultra-violeta

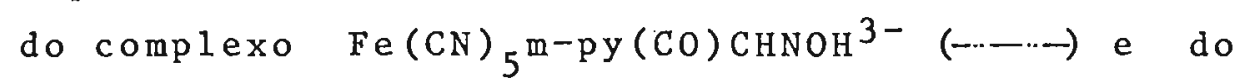
ligante m-py (CO)CHNOH (-), decomposição Gaus siana (..) $\quad t=25,0 \pm 0,1^{\circ} \mathrm{C}$ 
95

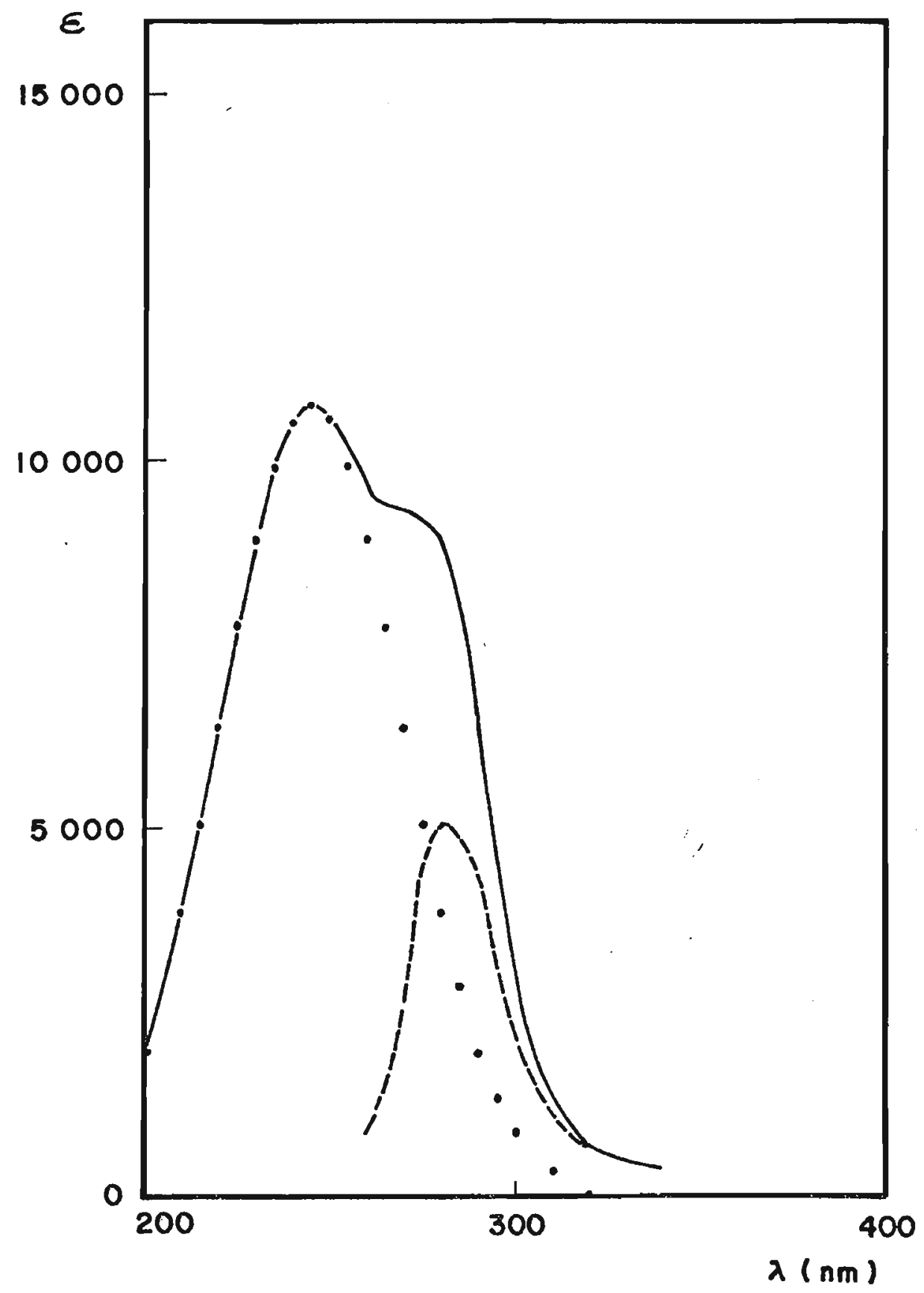

FIG. 5.3. Espectro Eletrônico na região de ultravioleta para o ligante o-py(CO)CHNOH ( - ) experimental (...) Gaussiana simples
$t=25,0 \pm 0,1^{\circ} \mathrm{C}$
$\mu=0,10 \mathrm{M}\left(\mathrm{LiClO}_{4}\right)$ 


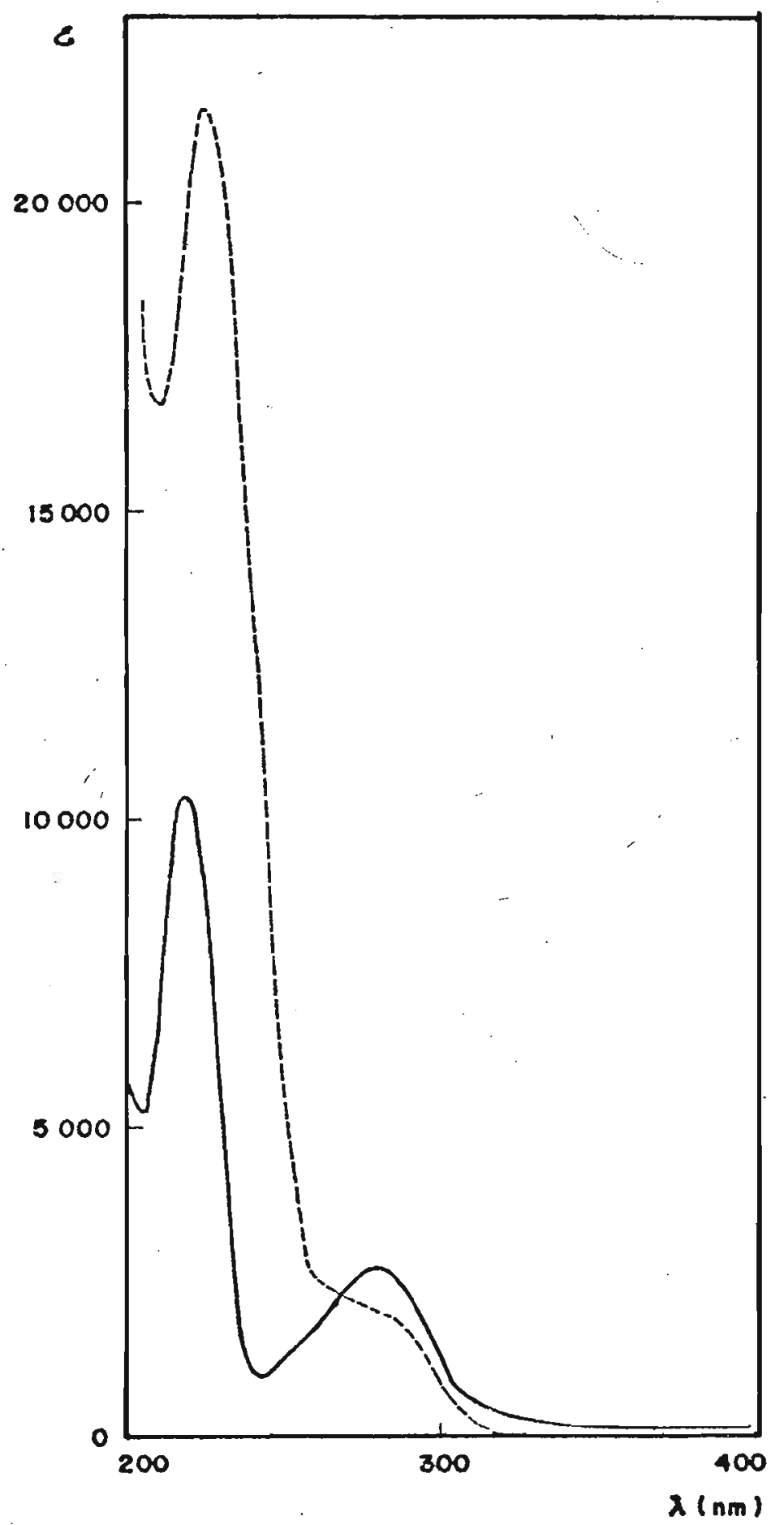

FIG. 5.4. Espectros Eletrônicos na região do ultravioleta para o complexo $\mathrm{Fe}(\mathrm{CN})_{5} \mathrm{p}^{-\mathrm{py}(\mathrm{CO}) \mathrm{CH}_{3}{ }^{3-}(---)}$ e o ligante $\mathrm{p}$-py(CO) $\mathrm{CH}_{3}$ (
$t=25.0 \pm 0.1^{\circ} \mathrm{C}$ $\mu=0.10(\operatorname{LiC} 10$, 


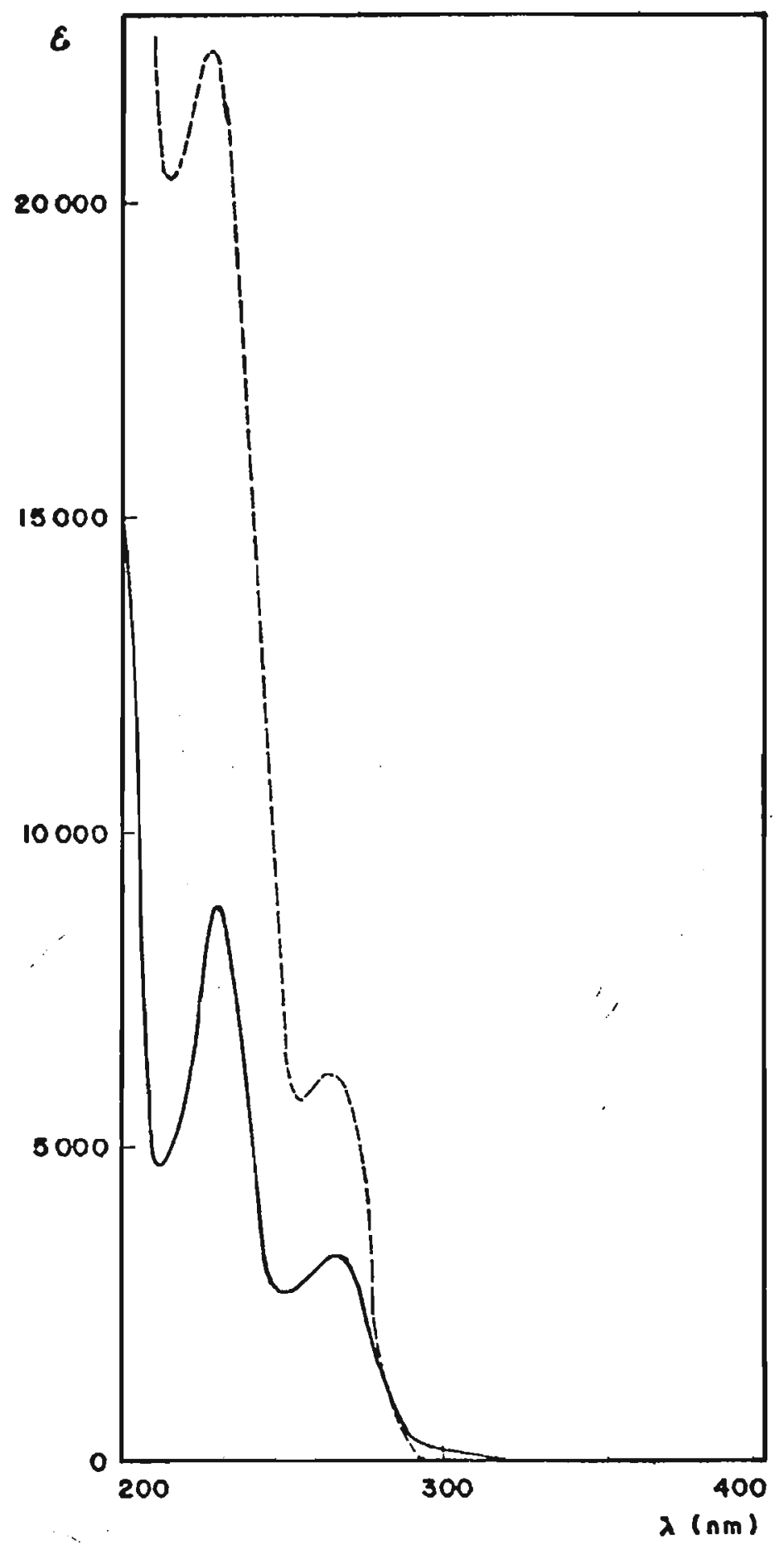

FIG. 5.5. Espectros eletrônicos na região de ultravioleta para o complexo $\mathrm{Fe}(\mathrm{CN})_{5} \mathrm{~m}-\mathrm{py}(\mathrm{CO}) \mathrm{CH}_{3}^{3-}(---)$ e o 1 igante m-py $(\mathrm{CO}) \mathrm{CH}_{3} \quad(-)$ temperatura $=25,0 \pm 0,1{ }^{\circ} \mathrm{C} \quad \mu=0,10\left(\mathrm{LiClO}_{4}\right)$ 


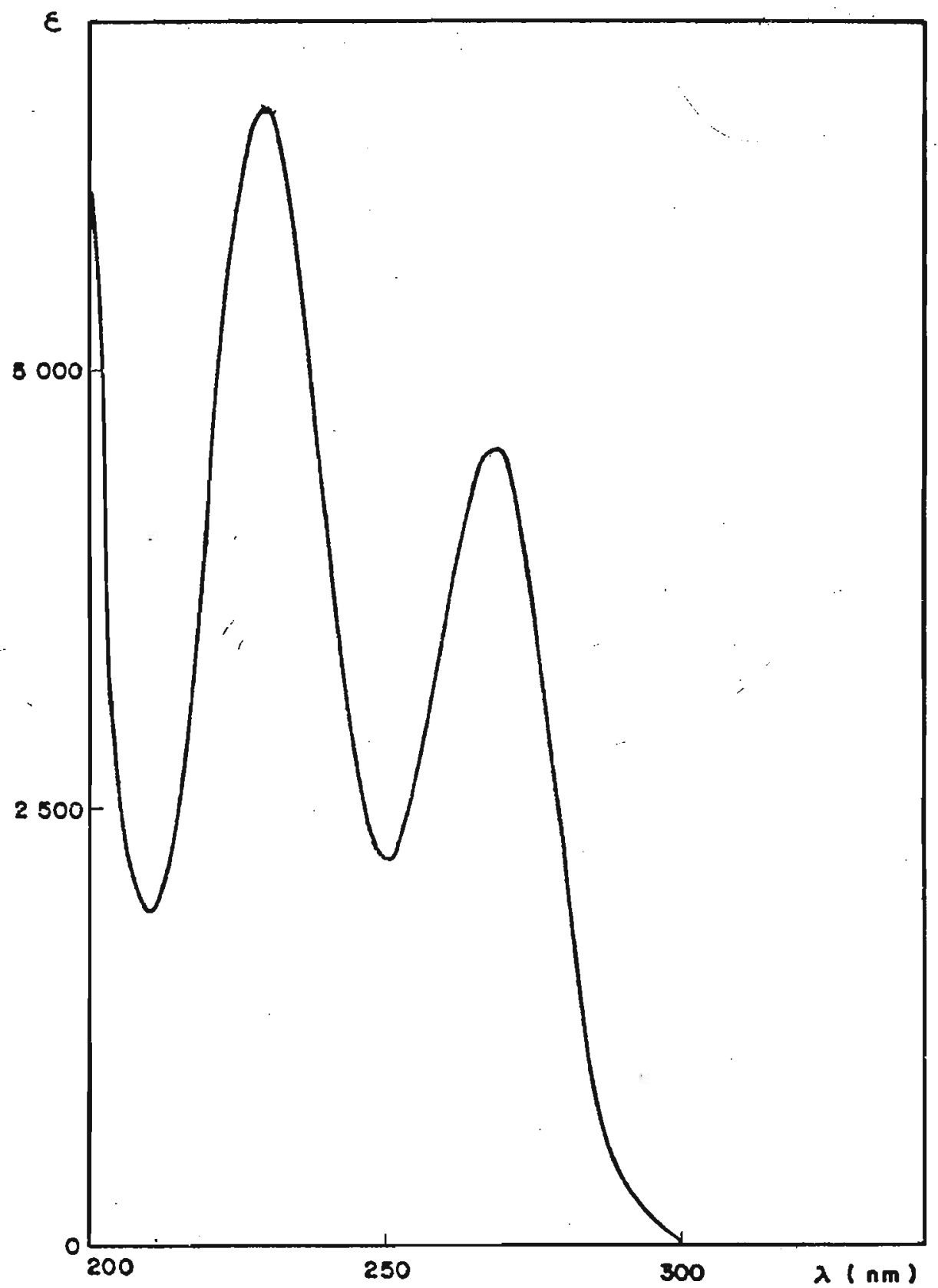

FIG. 5.6. Espectro eletrônico do ligante p-py (Co) $\mathrm{CH}_{3}$

$$
t=25,0 \pm 0,1^{\circ} \mathrm{C} \quad \mu=0,10\left(\mathrm{LiClO}_{4}\right)
$$


sição d-d resultante do abaixamento de simetria, uma vez que não se observa em todos os derivados meta-substituídos. Pode-se pensar tambēm, na presença de traços de impureza do $\underline{i}$ sōmero para.

As bandas na faixa de ultra-violeta, observadas na figuras $5.1,5.2,5.4$ e 5.5 para $\mathrm{Fe}(\mathrm{CN})_{5} \mathrm{~L}^{3-}$, embora su perpostas com as bandas vizinhas, são bastante semelhantes às apresentadas pelos ligantes 1 ivres. Comportamentos seme1hantes foram observados para os demais complexos de pentacianoferrato(II) com ligantes $N$-heterocíclicos (3).

Estes complexos com ligantes $\mathrm{N}$-heterocíclicos insaturados apresentam como caracteristica marcante, bandas na região do visível com coeficiente de extinção da ordem de $10^{3} \mathrm{M}^{-1} \mathrm{~cm}^{-1}$. Alêm da intensidade da transição ser bastante $\underline{\mathrm{e}}$ levada, a energia envolvida é sensỉvel à natureza do substituinte empregado. Esta banda que não ocorréno ligante livre ou no ion metálico isoladamente, é caracterîstica da banda de transferéncia de carga do metal para o ligante $(M \rightarrow L)$.

Levando em consideração a simetria do complexo com a inclusão do ligante $N$-heterocĩclico, a transformação dos orbitais deve ocorrer de acordo com as representações do grupo de ponto $C_{2 V}$ (FIG. 5.11).

As atribuições feitas podem ser acompanhadas através do diagrama simplificado de orbitais moleculares representado na figura 5.12 . 


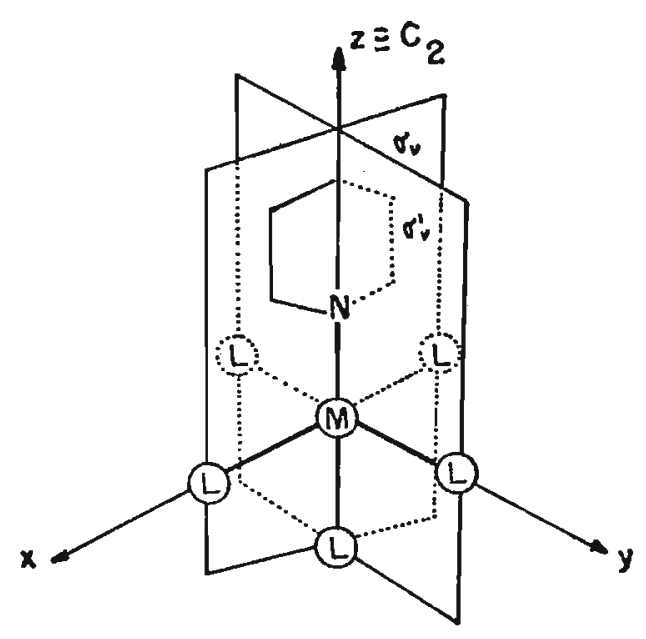

FIG. 5.11 - Eixos e Planos de Simetria do Complexo Pentacia noferrato(II) com ligantes $N$-heterocíclico.. no grupo de ponto $\mathrm{C}_{2 \mathrm{~V}}$

5.1.1.1. Transições Internas do Ligante $(L-L)$

As transições internas nos ligantes heterocĩ clicos nitrogenados (240-242) são aquelas que envolvem o par de elétrons livres do nitrogēnio para o orbital pi antili gante $\left(\pi^{\star}\right)$ de energia mais baixa $\left(n \rightarrow \pi^{\star}\right)$, e a transi ção do orbital ligante preenchido de energia mais alta para orbital pi antiligante $\left(\pi \rightarrow \pi^{\star}\right)$.

As transições do tipo $n \rightarrow \pi^{*}$ são de baixa intensidade (241), com $\varepsilon$ da ordem de $10^{2} \mathrm{M}^{-1} \mathrm{~cm}^{-1}$, e frequen temente aparecem encobertas.

Assim, trataremos mais das bandas de transição 
$\pi \rightarrow \pi^{*}$. Esta transição ocorre para a piridina (243) a $40 \mathrm{kK}$ $(\lambda=251 \mathrm{~nm}) \operatorname{com} \varepsilon=3600 \mathrm{M}^{-1} \mathrm{~cm}^{-1}$.

o grupo cromōforo cetona apresenta bandas inten sas $\pi \rightarrow \pi^{*}$ em torno de $166 \mathrm{~nm}(\nu=60 \mathrm{kK})$. Estas mesmas bandas, quando conjugadas com nūcleos aromáticos, como por exemplo a acetofenona, desloca-se para $245,5 \mathrm{~nm}(\nu=41 \mathrm{kK})$ $(242)$

observando-se os dados relacionados na tabela 5.1., pode-se fazer as seguintes atribuições. A banda corres pondente à energia mais baixa com $\varepsilon \sim 3000 \mathrm{M}^{-1} \mathrm{~cm}^{-1}$ deve cor responder à transferéncia de carga interna do anel piridín co.

A banda intensa de energia mais alta deve ser a transferéncia de carga $\pi \rightarrow \pi^{*}$;243) envolvendo o cromóforo carbonila.

o deslocamento destas bandas para energia mais baixas, em relação aos observados em cromóforos isolados, pode ser atribuido ao efeito de conjugação (242). Geralmente quando isto acontece, a banda de intensidade alta se des loca de 14 a $45 \mathrm{~nm}$, para comprimento de onda maiores em relação ao sistema aromātico simples não conjugado (244).

Isto se verifica com maior intensidade nas aldoximas, onde a banda de energia mais alta é deslocada para comprimento de onda maior. Provavelmente, o fato se deve ao efeito de conjugação estendida, envolvendo o cromōforo oxima.

Estes dados estão de acordo, quando se analisa 


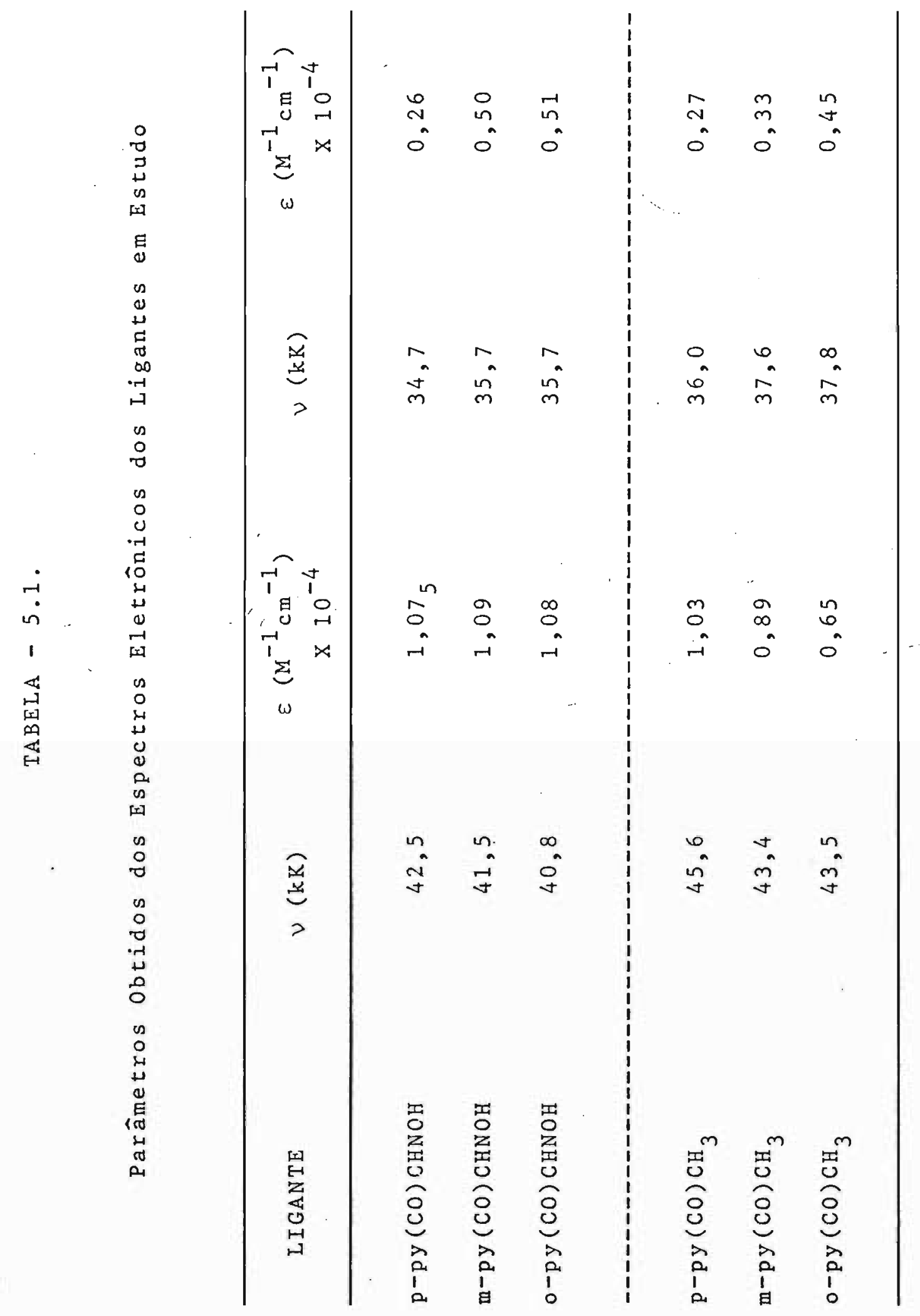


- espectro destas aldoximas deprotonadas, onde as bandas se deslocam para região de 300 nm (FIG.5.18).

0 deslocamento acentuado pode ser compreendido, se levarmos em consideração que a aldoxima deprotonada é um sistema altamente conjugado, onde os elétrons $\pi$ se distribuem em vārios centros ( $\mathrm{py}, \mathrm{CO}, \mathrm{NO}^{-}$).

A adição de um ou mais cromōforos em conjuga ção desloca a posição da absorção do sistema para comprimen tos de onda maiores. o coeficiente de extinção aumenta gradativamente, dependendo do nūmero de grupos cromōforos adicionais presentes. 0 sistema de elétrons $\pi$ estendido resul ta numa maior deslocalização dos mesmos. Consequentemente a energia necessāria para a transição $\pi \rightarrow \pi^{\star}$ é menor e a probabilidade de ocorrencia destas transições é maior.

5.1.1.2. Transições de Transferência de Carǵa

As atribuições feitas aos espectros de penta cianoferrato(II) com os ligantes em estudo estão relacionadas na tabela 5.2 .

As absorções intensas observadas abaixo de 220 nm, originam-se de transições de transferência de carga $\mathrm{d}_{\pi(\mathrm{Fe})} \rightarrow \mathrm{p}_{\pi *(\mathrm{CN})}$. Estas bandas, geralmente aparecem superpos tas com as absorções internas dos ligantes (3), no caso, en volvendo as transições internas do grupo cromōforo carbonila

A transição a $265 \mathrm{~nm}$ que aparece como ombro é atribuída à transição $\pi_{L} \rightarrow \pi_{L}^{*}$ ( piridina), também observa- 
104

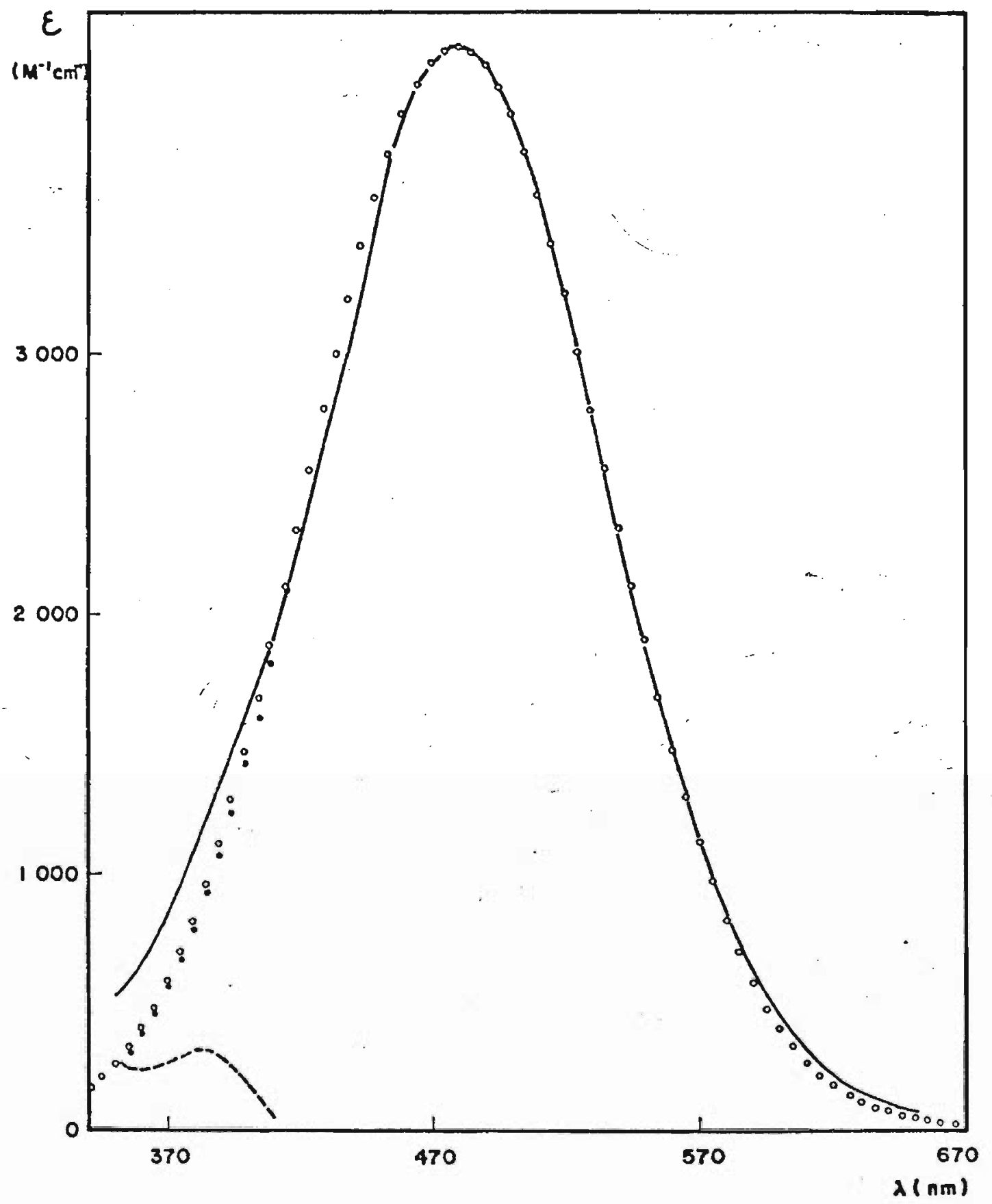

FIG. 5.7. Espectro eletrônico de absorção no visível para o complexo $\mathrm{Fe}(\mathrm{CN})_{5} \mathrm{p}-\mathrm{py}(\mathrm{CO}) \mathrm{CHNOH}^{3-}$ decomposição : log normal (०००) Gaussiana sim ples (.•) , Gaussiana dupla (………) $t=25,0 \pm 0,1{ }^{\circ} \mathrm{C} \quad \mu=0,10\left(\mathrm{LiC} 10_{4}\right)$ 


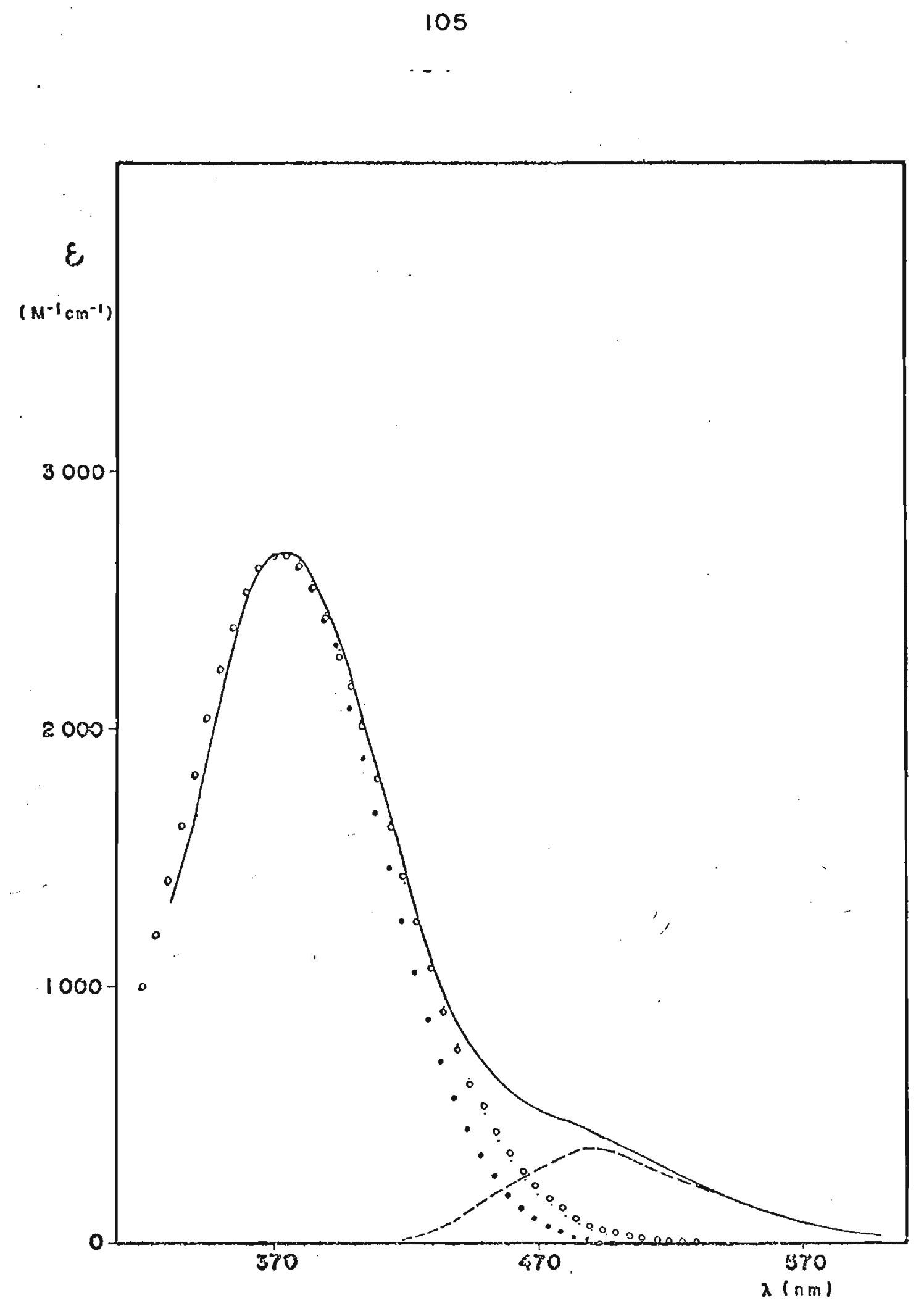

FIG. 5.8. Espectro eletrônico de absorção. no visível para o complexo $\quad \mathrm{Fe}(\mathrm{CN}) 5^{\mathrm{m}-\mathrm{py}(\mathrm{CO}) \mathrm{CHNOH}^{3-}}$ decomposição: $\log$ normal ( $\circ \circ)$, Gaussiana sim ples $(\ldots)$, Gausiana dupla (...)

$\mathrm{t}=25,0 \pm 0,1^{\circ} \mathrm{C} \quad \mu=0,10\left(\mathrm{LiClO}{ }_{4}\right)$ 
106

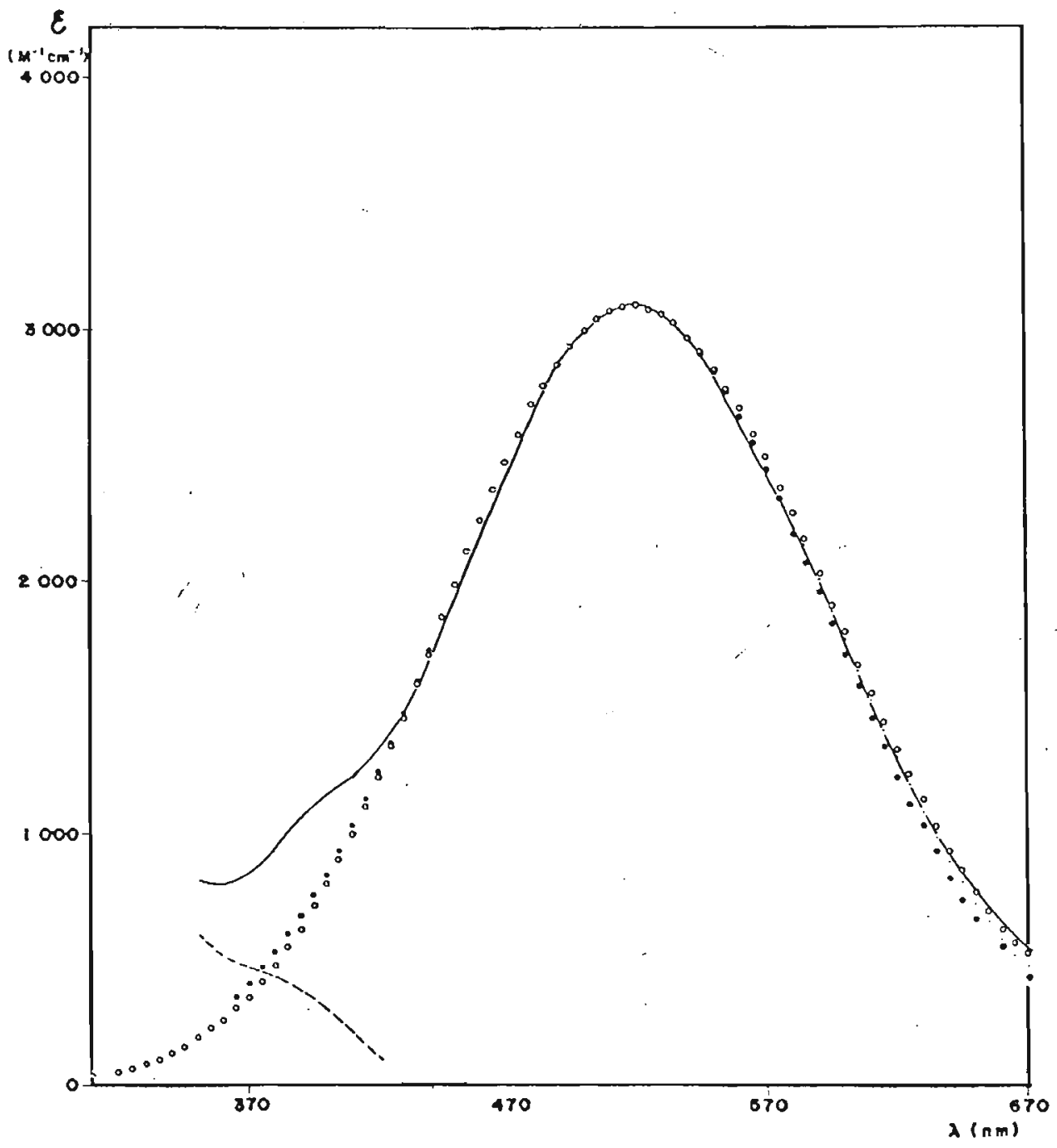

FIG. 5.9. Espectro eletrônico de absorção no visível para o complexo $\mathrm{Fe}(\mathrm{CN})_{5} \mathrm{p}-\mathrm{py}(\mathrm{CO}) \mathrm{CH}_{3}{ }^{3-}$ decomposição: $10 \mathrm{~g}$ normal (), Gaussiana sim ples ( ), Gaussiana dupla ( ) $t=25,0^{\circ} \mathrm{C} \quad \mu=0,10\left(\mathrm{LiClO} \mathrm{O}_{4}\right)$ 


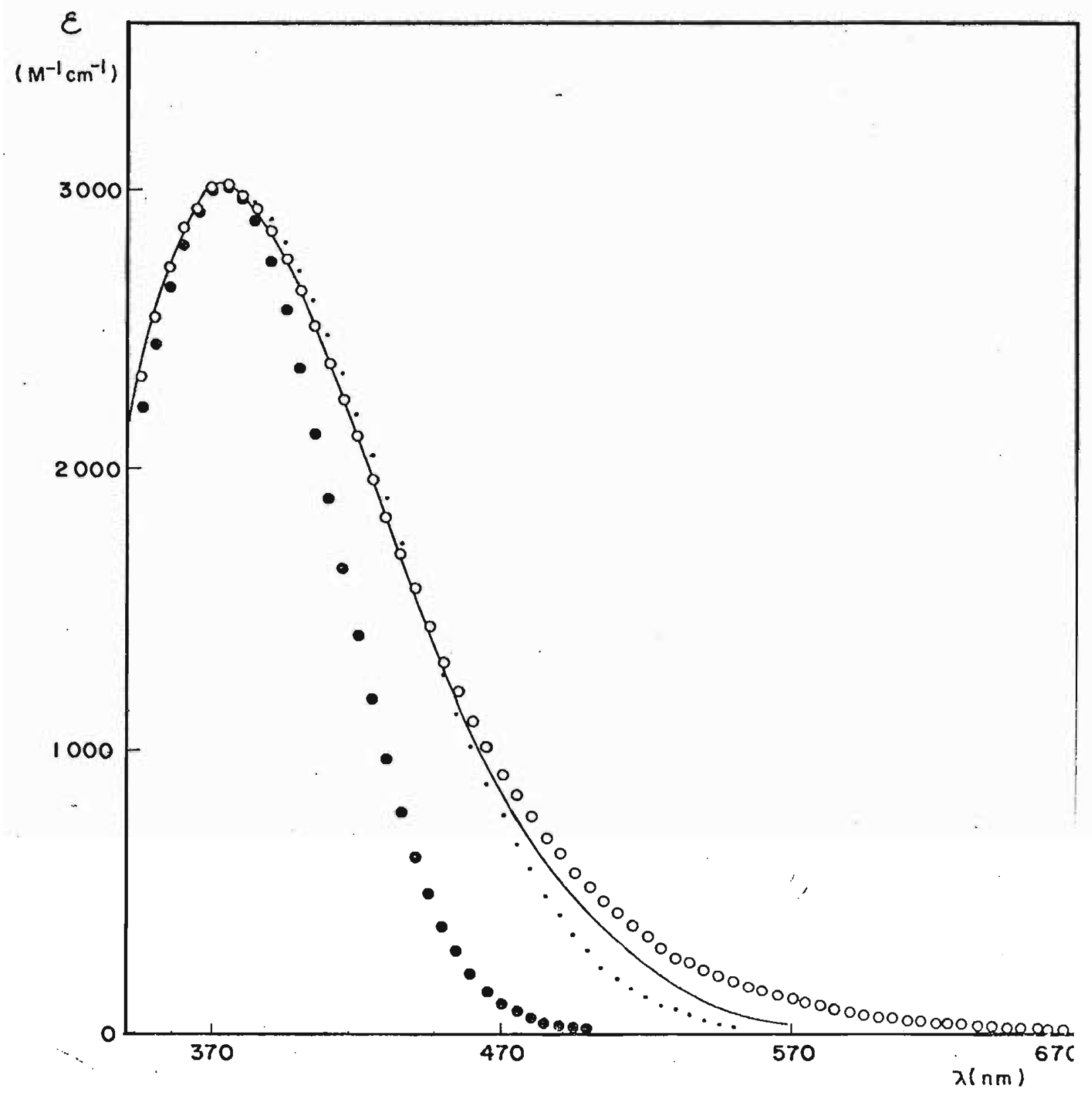

FIG. 5.10. Espectro eletrônico de absorção no visível para

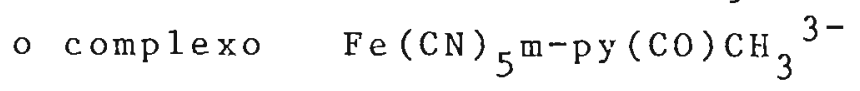
decomposição $\quad \log$ normal (0.0) Gaussiana simples (...)

Gausiana dupla (..)
$t=25,0 \pm 0,1{ }^{\circ} \mathrm{C}$
$\mu=0,10\left(\mathrm{LiC} 10_{4}\right)$ 


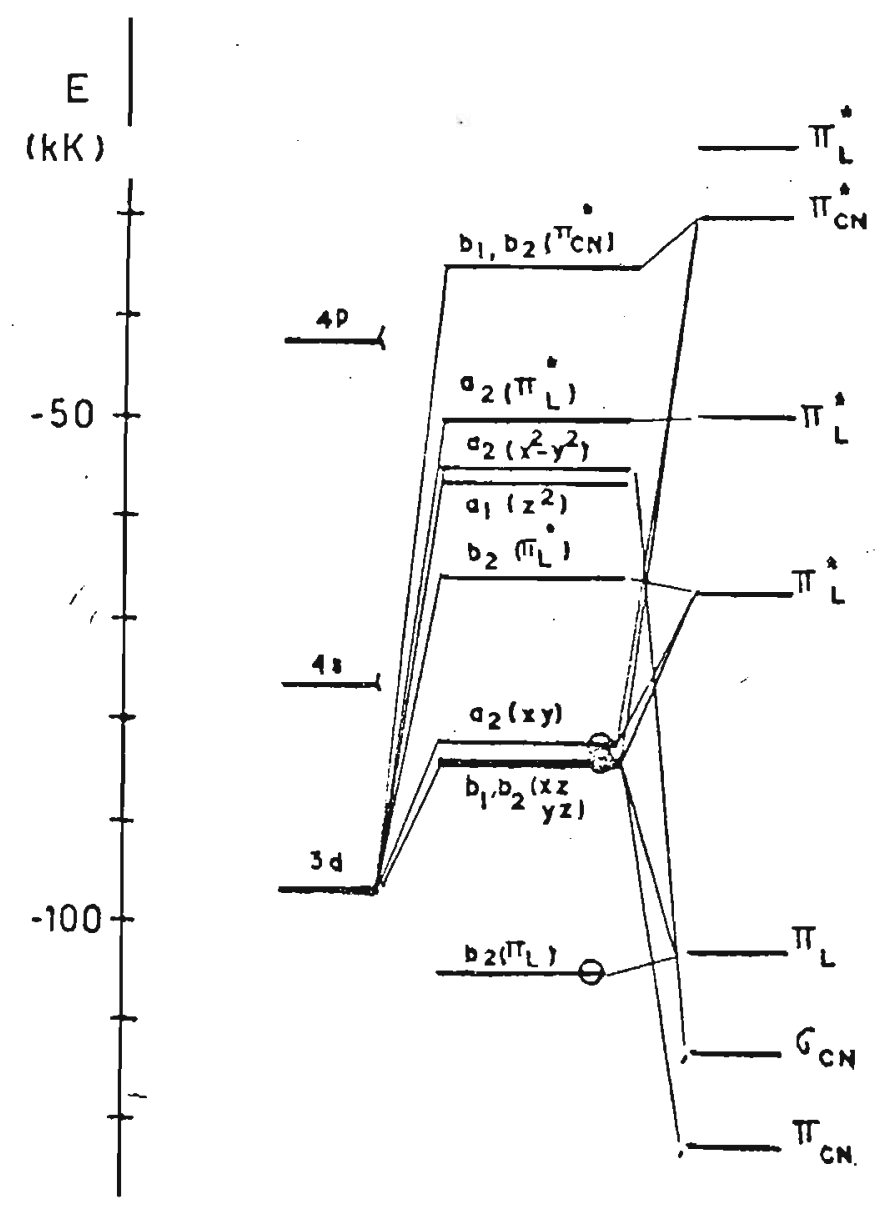

FIG. 5.12. Diagrama simplificado de orbitais moleculares para os complexos de pentacianoferrato(II). com ligantes aromáticos $\mathrm{N}$-heterociclico, cuja simetria pode ser considerada $C_{2 V}$ 


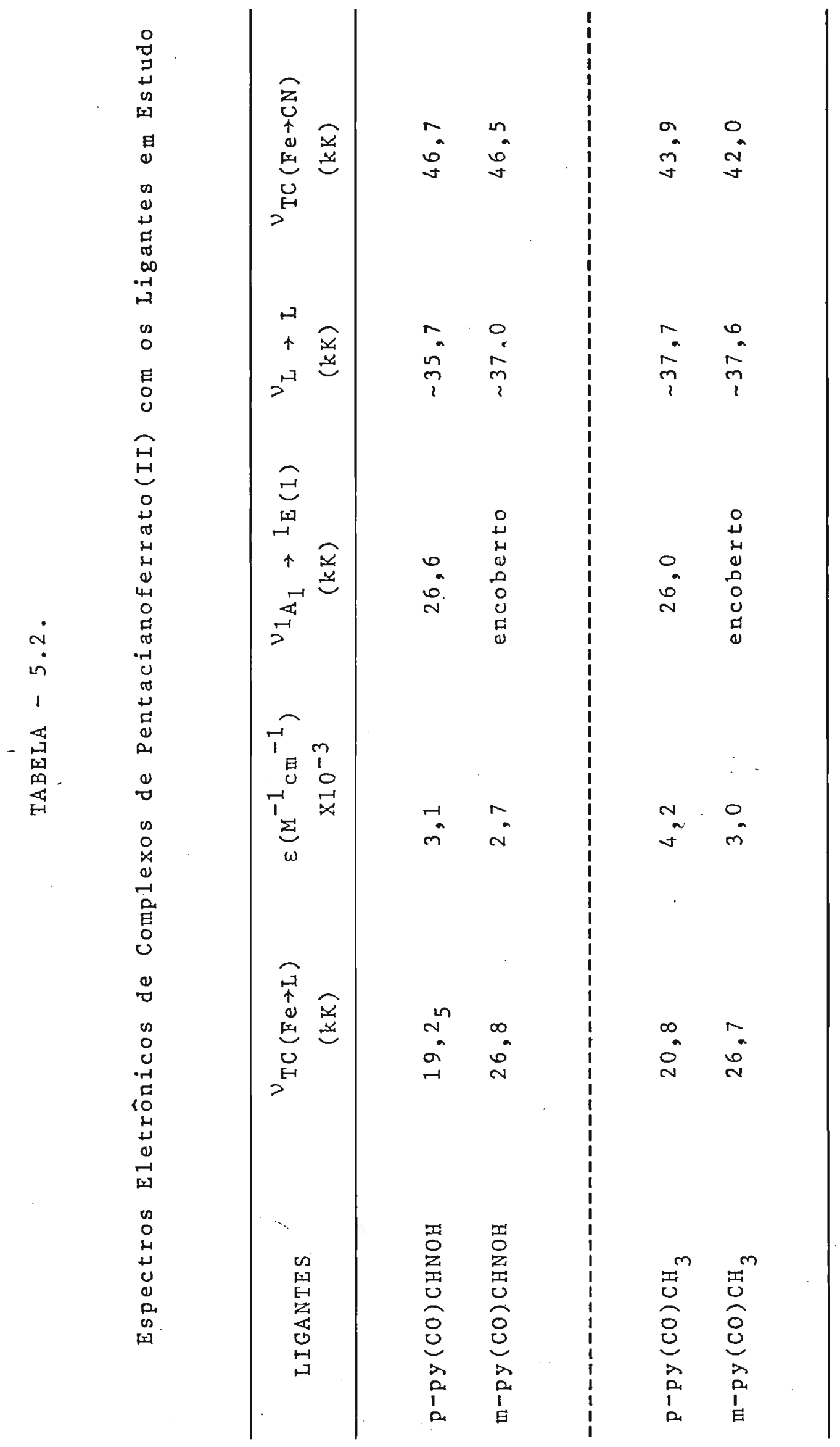


da no ligante 1 ivre:

A transição intensa, no visīvel, corresponde. à transferēncia de carga $\mathrm{Fe} \rightarrow \mathrm{L}\left(\mathrm{b}_{2}(\mathrm{yz}) \rightarrow \mathrm{b}_{2}\left(\pi_{\mathrm{L}}^{*}\right)\right)$.

No grupo $C_{2 V}$, todas as transições, com exceção das $a_{2} \rightarrow a_{1}$ e $b_{2} \rightarrow b_{1}$, são permitidas. As transições dos vārios orbitais ocupados do metal para o orbital de sime tria $a_{2}$ do 1 igante parecem ser pouco prováveis, devido ao plano nodal que este orbital apresenta na posição para. Este fato tornaria as transições pouco sensiveis à natureza do substituinte nesta posição, ao contrārio do que se observa. Isso faz com que apenas duas transições ainda se apresentem possiveis: $a_{2(x y)} \rightarrow b_{2\left(\pi_{L}^{*}\right)}$ e $b_{2(y z)}+b_{2\left(\pi_{L}^{*}\right)}$ (FIG. 5 . 12).

De acordo com as considerações introduzidas. por Day e Sanders (245), a intensidade da transição de trans ferência de carga depende diretamente do grau de recobrimen to orbital. Para que a integral de recobrimento seja diferen te de zero, os orbitais devem pertencer à mesma simetria, no grupo de ponto considerado. Uma vez que a transição $b_{2(y z)} \rightarrow$ $\mathrm{b}_{2\left(\pi_{L}^{*}\right)}$ não sofre nenhuma restrição e é a mais favorecida em termos de recobrimento orbital, as bandas de transferéncia de carga nos complexos de pentacianoferrato(II) são atribuI das a esta transição. As energias das bandas de transferência de carga na série dos complexos com ligantes aromäticos nitrogenados são bastante sensĩveis aos efeitos de substi tuintes no ligante, conforme pode ser observado na tabela 5. 3. 


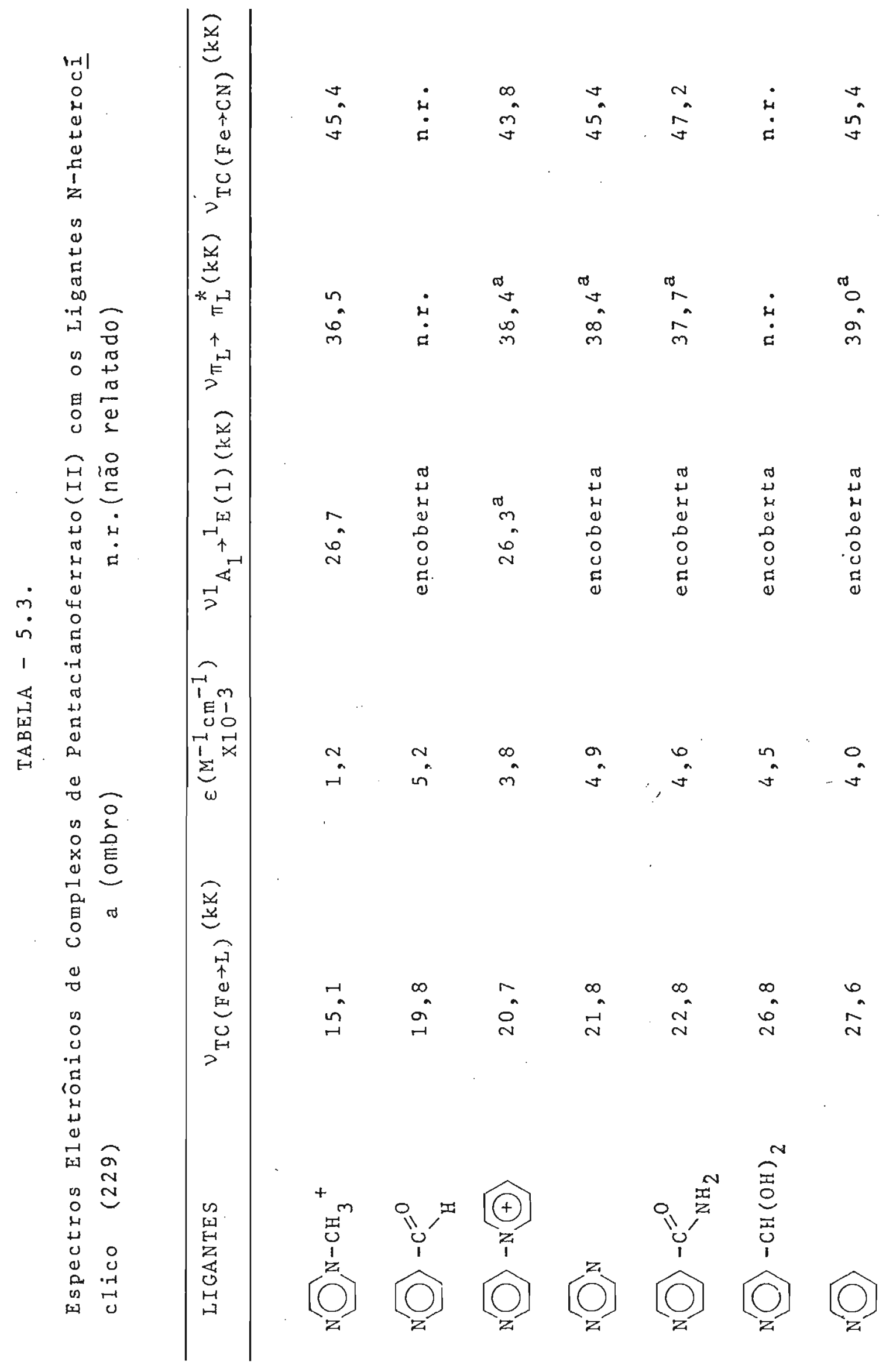


As transições de transferēncia de carga dão in formações sobre os processos de transferéncia intra molecular, que são admitidas ocorrendo em duas partes mais ou menos separadas do sistema atômico destrito ( $-B$ - B). Pode -se descrever para este processo:

$$
(A-B) \stackrel{h \nu}{\longrightarrow}\left(A^{-}-B^{+}\right)
$$

no qual o elétron é transferido de um orbital b doador, su postamente localizado predominantemente na parte doadora da molécula, a um orbital a receptor, localizado na parte re ceptora da molécula. Este processo pode ser qualificado de um processo redox intramolecular. Distingue-se do processo redox por não haver variação no nümero total de elétrons do sistema ( $A-B)$ e as distâncias interatōmicas durante 0 processo se mantēm constantes e iguais às da unidade (A - B).

A energia do processo ( 1 ) pode ser expressa $(246,247)$ como:

$$
h_{\nu}=P I-A E+C(a, b) \pm K(a, b)-\Delta H^{\prime} c
$$

Onde PI representa o potencial de ionização do orbital (inclui as variações de energia devido ao acoplamento spinórbita); $A E$ é a afinidade eletrōnica do receptor $A$; $C(a, b)$ é o termo coulōmbico de interação entre o orbital b e o ele tron no orbital a ; $K(a, b)$ e a integral de troca correspon dente, com sinal + ou - dependendo da orientação do spin eletrōnico no orbital a com relação ao elétron realmente 
presente em $\underline{b}$. Os termos $c(a, b)$ e $K(a, b)$ indicam que não houve mudança no nümero total de elētrons no sistema durante a transição espectral. O termo $\Delta H^{\prime}{ }_{c}$ representa a diferença das energias de formação das formas oxidada e reduzida.

Considerando-se que a separação dos orbitais a

e $\underline{b}$ é apreciável (3) e consequentemente os termos $C(a, b)$

e $K(a, b)$ são desprezíveis, podemos exprimir a energia de transferéncia de carga atravēs da expressão proposta por Murre11 (243):

$$
E_{C T}=P I-A E+C
$$

Assim, as variações nas energias de transferēn cia de carga dependem em primeiro lugar das posições relati vas dos níveis ocupados do metal e vazios do ligante.

Considerando o ion $\mathrm{Fe}(\mathrm{CN})_{5}^{3-}$ como doador no complexo $\mathrm{Fe}(\mathrm{CN})_{5} \mathrm{~L}^{3-}$, tanto as variações do termo coulômbico como o potencial de ionização podem ser considerados praticamente constantes numa sērie, uma vez que os ligantes (receptores) são muito semelnantes.

Dessa forma, as variações nas energias de trans ferência de carga refletern em primeiro plano, as tendéncias nas afinidades eletrōnicas dos ligantes aromäticos nitrogenados. A medida que a afinidade eletrōnica do ligante cresce, nota-se uma diminuição nas energias de transferēncia de carga, indicativo de uma maior aproximação entre os orbitais doador e receptor. 
As intensidades das bandas de transferéncia de carga nos complexos de pentacianoferrato(II) fóram avaliadas em termos da força do oscilador ( $f$ ) (248), conforme a tabela abaixo.

VALORES DAS FORÇAS DO OSCILADOR PARA OS COMPLEXOS Fe (CN ${ }_{5} \mathrm{~L}^{3-}$

\begin{tabular}{|c|c|c|c|}
\hline Ligante & $v_{\text {max }}(k K)$ & $\mathrm{f}$ & \\
\hline $\mathrm{p}-\mathrm{py}(\mathrm{CO}) \mathrm{CHNOH}$ & 19,25 & 0,101 & \\
\hline m-Py (CO)CHNOH & 26,8 & 0,086 & \\
\hline. &. & & \\
\hline $\mathrm{p}-\mathrm{py}(\mathrm{CO}) \mathrm{CH}_{3}$ & 20,8 & 0,110 & \\
\hline $\mathrm{m}-\mathrm{Py}(\mathrm{CO}) \mathrm{CH}_{3}$ & 26,7 & 0,094 & ${ }^{-}$ \\
\hline
\end{tabular}

os valores das forças do oscilador, relacionados na tabela, foram obtidos utilizando-se a ārea calculada supondo a curva Gaussiana. As āreas da banda calculada atra vês da integração numërica como a obtida pela curva gaussia na assimétrica são concordantes, dentro das aproxiniações feitas. O valor escolhido encontra-se entre os limites supe rior e inferior, obtidos pelos métodos citados.

0 momento dipolo (M) da molècula é definida co mo a distancia entre os centros de gravidade das cargas positivas e negativas, multiplicada pela magnitude destas car 
gas.

A localização do nūcleo, dentro da aproximação, pode ser fixada, entretanto, os elëtrons não podem ser localizados, e são descritos pela função probabilidade. o centro de gravidade dos elētrons é consequentemente uma média da função probabilidade.

A distāncia média entre os centros de gravidade das cargas negativa e positiva ē avaliada pela média da dis tãncia $r$ do centro de gravidade da carga positiva ao elētrons.

De acordo com a mecānica quāntica, esta mēdia $\bar{e}$ dada pelo integral

$$
\int \Psi_{i} \sum \text { er } \Psi_{i} d \tau=\int \Psi_{i} M \Psi_{i} d \tau
$$

onde a somatōria estende-se sobre todos os élétrons.

$$
\text { - Deste forma o momento dipolar da transição (M) }
$$

entre o estado fundamental e o estado excitado pode ser expresso

$$
M_{01}=\text { e } \underset{i}{i}<0\left|e_{1}\right| 1>
$$

onde $|0\rangle$ e $|1\rangle$ são as funções de onda para os dois es-. tados de tal maneira que

$$
\Psi_{0}=|0\rangle \quad \text { e }{ }^{\cdots} \quad \Psi_{1}=|I\rangle
$$


onde $\Psi_{0}=$ função de onda do estado fundamental (carāter metāi ico)

e $\quad \Psi_{1}=$ função de onda do estado excitado(carāter do $1 \underline{i}$ gante)

Supondo o caso simples de interação entre dois orbitais, fica simplificado o problema da abordagem teórica do sistema, onde apenas o orbital ocupado de maior energia do doador $\left(\psi_{0}\right)$ e o orbital desocupado de menor energia do receptor $\left(\psi_{1}\right)$, precisam ser considerados.

A integral de ressonância entre $\psi_{0}$ e $\quad \psi_{1} \bar{e}$

$$
\mathrm{H}_{01}=\left\langle\psi_{0}\left|\operatorname{er}{ }_{1}\right| \psi_{1}\right\rangle=\beta_{01}
$$

A integral de ressonância $\beta$ promove a mistura de dois orbitais $\psi_{0}$ e $\psi_{\text {T }}$ produzindo.

$$
\begin{aligned}
& \Psi_{0}=\left(1-\alpha_{0}{ }^{2}\right)^{1 / 2} \psi_{0}+\alpha_{0} \psi_{1} \\
& \Psi_{0}=\alpha_{1} \psi_{0}-\left(1-\alpha_{1}{ }^{2}\right)^{1 / 2} \psi_{1}
\end{aligned}
$$

Assumindo que $\Psi_{0}$ e $\Psi_{1}$ são ortogonais entre si e que a integral de recobrimento $\left(\mathrm{s}_{01}\right) \bar{e}$ desprezīvel, temos que $\alpha_{0}=\alpha_{1}=\alpha$ e

$$
{ }_{01}^{M}=e \alpha\left(r_{0}-r_{1}\right)
$$

o grau de mistura pode ser avaliado atravēs da 
teoria de perturbação (249) pela expressão

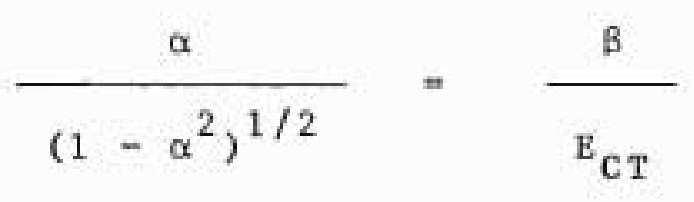

A força do oscilador (f) da transição é dada

por

$$
f=4,32 \times 10^{-9} \int \in(\bar{v}) d \bar{v}=1,085 \times 10^{-5} \vee D^{2}
$$

onde $\varepsilon$ é coeficiente de extinção molar, $v$ è a frequência da transição em nümero de ondas e $D$ é a força do dipolo ell Angstrons, definido pelo

$$
D=\frac{|M|}{e}
$$

Para os complexos de pentacianoferrato(II) as funções de ondas correspondentes para o estado fundamental e para o estado excitado, podem ser escritas da seguinte for ma

$$
\begin{aligned}
& \psi_{0}=\sqrt{1-\alpha_{0}{ }^{2}} \psi_{\mathrm{Fe}}+\alpha_{0} \Psi_{\mathrm{L}} \\
& \psi_{1}=\alpha_{1} \psi_{\mathrm{Fe}}-\sqrt{1-\alpha_{1}^{2}} \psi_{\mathrm{L}}
\end{aligned}
$$

onde $\quad \alpha_{0}=\alpha_{1}=\alpha$ para a aproximação $\quad \mathrm{S}_{\mathrm{EeL}}=0$ A avaliação do grau de mistura dos orbitais dọ 


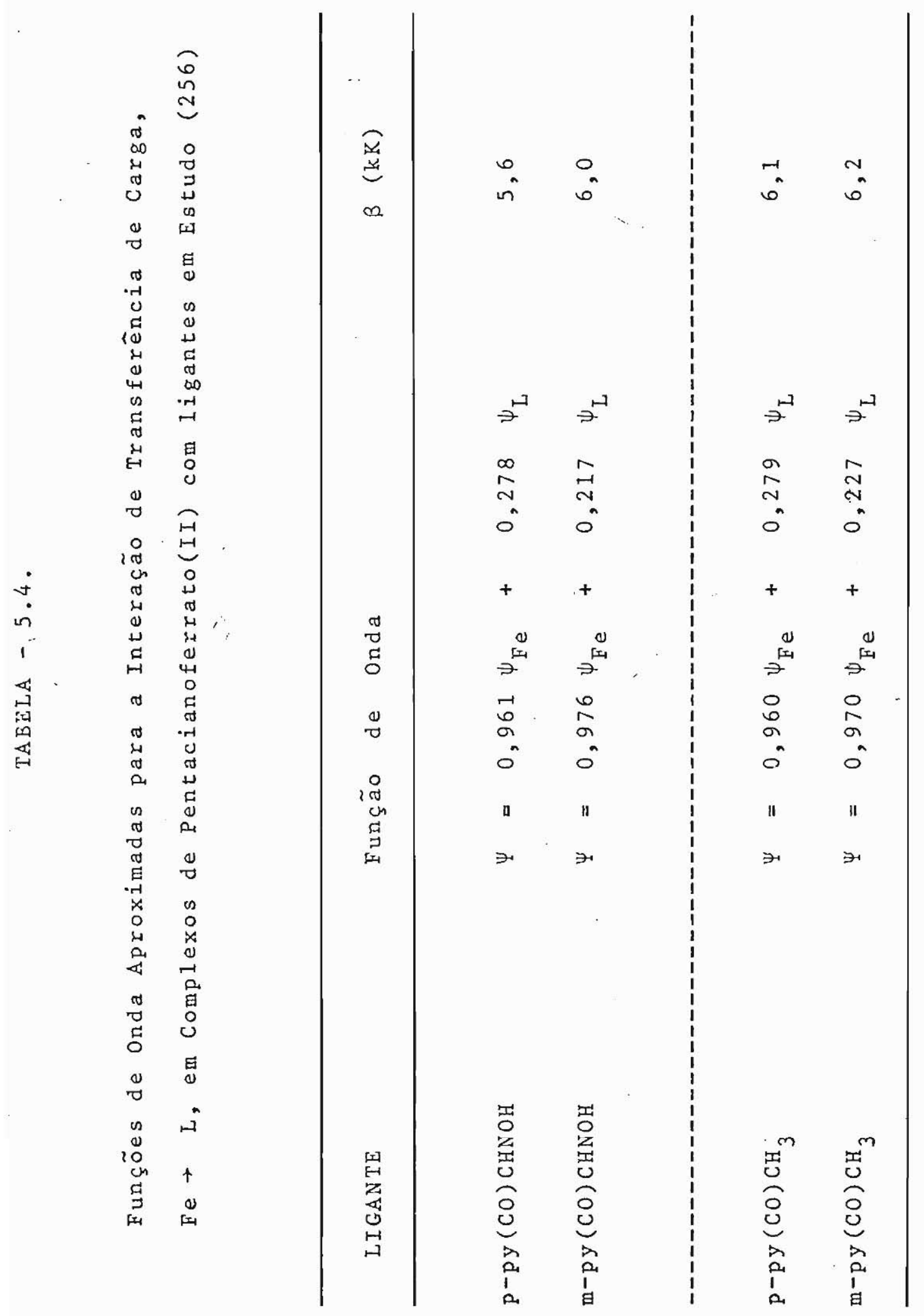


dores e receptores, pode ser feita com base em medidas de in tensidade das transições de transferēncia de carga em termos da força do oscilador.

Utilizando-se as expressões (3), ( $\mathrm{M}_{\mathrm{Fe}-\mathrm{L}}={ }^{\mathrm{e}} \mathrm{rr}_{\mathrm{Fe}-\mathrm{L}}$ (5) e (6) e tomando como $2,5 \mathrm{~A}$ a separação entre os centro doadores e receptores, pode-se chegar à função de onda re presentativa da interação de transferēncia de carga.

$\mathrm{Na}$ tabela 5.4. estão relacionadas estas funções e a integral de ressonāncia estimada atravēs da expressão(4)

Estes dados confirmam a existēncia da intera ção de transferência de carga bastante significativa, compa rāveis ou até maiores às encontradas nos demais complexos de pentacianoferrato(II) com ligantes $N$-heterocíclicos (229) principalmente com ligante pirazina.

5.1.1.3. Transições $d-d$

Para fins de comparação, as transições d-d são mais üteis, por serem observadas praticamente em toda a série de complexos de pentacianoferrato(II) (229).

A anālise dessa transição é facilitada com o uso da teoria do campo ligante. 0 desdobramento dos orbitais d dependerá da simetria e da força do campo criado pelos $1 \underline{j}$ gantes ao redor do ion metálico central.

Num campo octaēdrico, os orbitais d do ion me tālico desdobram-se em $e_{g}$ e $t_{2 g}$. Estes desdobram-se em $a_{1} e b_{1} e, b_{2} e$ e, respectivamente, num campo de simetria 
$\mathrm{C}_{4 \mathrm{~V}}$

A figura $5.13 \mathrm{~A}$ traz o esquema de desdobramento para os complexos de pentacianoferrato(II) onde os ligantes são de campo mais fraco do que o cianeto. Para cada desdo bramento estão representadas as expressões de energia dos or bitais (322). Na figura $5.13 \mathrm{~B}$ tem-se o desdobramento dos ter mos espectroscōpicos associados às diferentes configurações para um ion $d^{6}$.

As equações abaixo representam as energias de transição d-d permitidas por spin, das quais apenas a tran sição ${ }^{1} \mathrm{~A}_{1} \rightarrow{ }^{1}{ }_{\mathrm{E}(1)}$ é permitida pela simetria.

$$
\begin{aligned}
& \mathrm{E}\left({ }^{1} \mathrm{~A}_{1}^{\prime} \rightarrow{ }^{1} \mathrm{E}(1)\right)=10 \mathrm{Dq}-(35 / 4) \mathrm{Dt}-\mathrm{C} \\
& \mathrm{E}_{\left({ }^{1} \mathrm{~A}_{1} \rightarrow{ }^{1} \mathrm{~A}_{2}\right)}=10 \mathrm{Dq}-\mathrm{C} \\
& \mathrm{E}\left({ }^{1} \mathrm{~A}_{1} \rightarrow{ }^{1} \mathrm{~B}_{2}\right)=10 \mathrm{Dq}-4 \mathrm{Ds}-5 \mathrm{Dt}+16 \mathrm{~B}-\mathrm{C} \\
& \mathrm{E}\left({ }^{1} \mathrm{~A}_{1} \rightarrow{ }^{1} \mathrm{E}(2)\right)=10 \mathrm{Dq}+2 \mathrm{Ds}-25 / 4 \mathrm{Dt}+16 \mathrm{~B}-\mathrm{C}
\end{aligned}
$$

Os termos B e c são parâmetros de Racah e representam a repulsão intereletrōnica.

Um aspecto bastante importante destas transi ções d-d è que sua energia é função do parāmetro de dis torção tetragonal $\mathrm{D}_{\mathrm{t}}$, definido por Wenthworth e Piper (250) como

$$
\mathrm{D}_{\mathrm{t}}=\frac{2}{7}\left(\mathrm{Dq}^{\mathrm{xy}}-\mathrm{Dq}^{\mathrm{z+}}\right)
$$



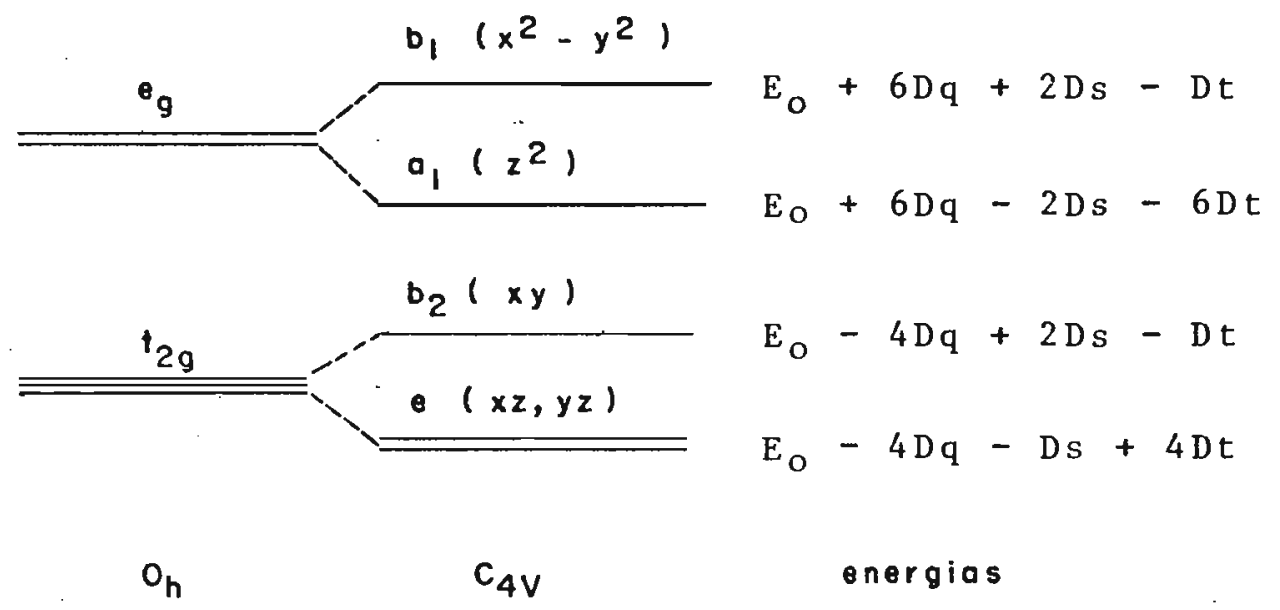

A - Desdobramento dos orbitais d num campo de simetria $o_{h}$ e $\mathrm{C}_{4 \mathrm{~V}} \mathrm{com}$ as energias correspondentes
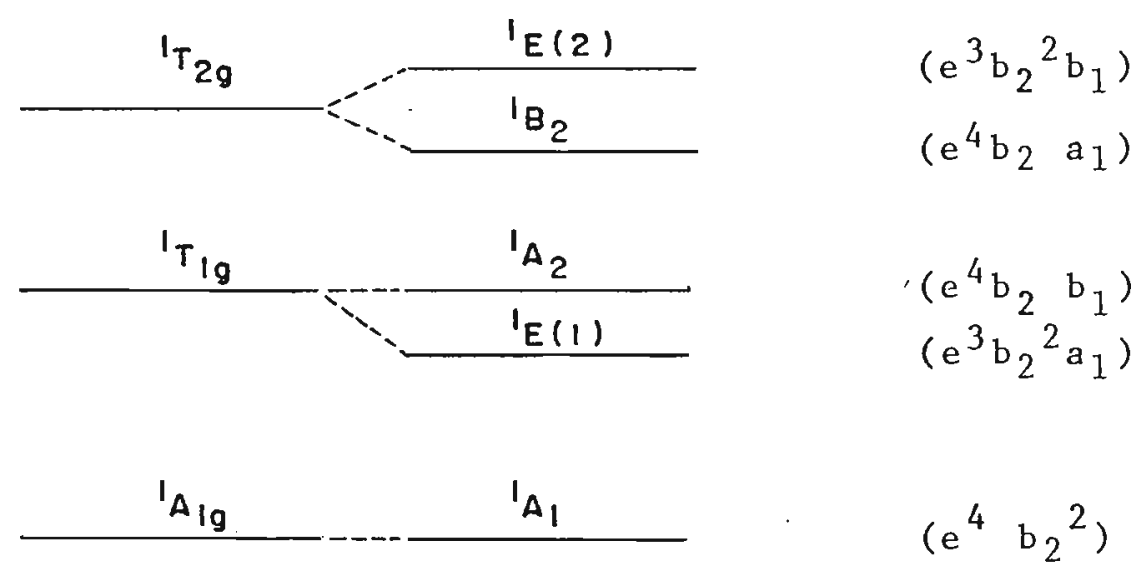

$\mathrm{O}_{\mathrm{h}} \quad \mathrm{C}_{4 \mathrm{~V}}$ configuração

B - Desdobramento dos termos espectroscópicos, para uma si metria $\mathrm{C}_{4 \mathrm{~V}}$ e as configurações correspondentes

FIG. 5.13. - Diagramas de desdobramento dos orbitais e dos termos espectroscópicos numa simetria $\mathrm{C}_{4 \mathrm{~V}}$ com alongamento axia1. 
Dq $^{x y}$ está associado aos cianetos, e Dq ${ }^{z+}$, associado ao $1 \underline{i}$ gante $\mathrm{L}$, no complexo $\mathrm{Fe}(\mathrm{CN})_{5} \mathrm{~L}^{\mathrm{n}-}$.

Se nos complexos de pentacianoferrato(II) os valores de 10Dq - C para os cianetos permanecessem idēnti cos ao do hexacianoferrato(II), possibilitaria uma avalia ção imediata do parāmetro Dt.

Apesar do termo c ser sensîvel à força do cam po (250), o parāmetro 10 Dq deve ser afetado pelas varia ções na distribuição de carga, que se propaga através das $1 \underline{i}$ gações no complexo.

Os cālculos de Dt efetuados desta maneira re sultam em valores pouco realîsticos, embora as variações re lativas de Dt e $\mathrm{Dq}^{\mathrm{z}}$ apresentarem-se bastante razoāveis.

A energia de transição ${ }^{1} \mathrm{~A}_{1} \rightarrow{ }^{1} E(1)$ está relácionada com Dt, e esta por sua vez é função de Dq e re flete diretamente a força do campo ligante. Portanto as ener gias das bandas $d-d$ nos cianoferratos refletem diretamente os valores relativos de Dq, associados aos ligantes L.

Desta maneira, baseando-se nos dados espectrais da tabela 5.2, 5.3 e daqueles relacionados por Toma (229), pode-se propor a seguinte série espectroquimica para os 1 igantes L, nos complexos de pentacianoferrato(II).

$\mathrm{NO}^{+}>\mathrm{CO}>\mathrm{CN}^{-}>$sulfoxido $>$sulfito-P $(\mathrm{Ph})_{3}>\mathrm{As}(\mathrm{Ph})_{3}>\mathrm{MPz}^{+}$ $\sim \mathrm{Sb}(\mathrm{Ph})_{3} \sim \mathrm{NO}^{\mathrm{N}} \mathrm{C}_{\mathrm{C}=\mathrm{N}-\mathrm{OH}}^{\mathrm{O}}>\widehat{\mathrm{NO}}_{\mathrm{C}^{\prime \prime} \mathrm{CH}_{3}}^{\mathrm{O}}>\mathrm{NON}_{\mathrm{N}}>\mathrm{N}-\mathrm{R} \sim \mathrm{N}_{\mathrm{N}}^{\mathrm{N}}$ 
$>\mathrm{NH}_{2} \mathrm{R}-\mathrm{NH}_{3}>\mathrm{H}_{2} \mathrm{O}$

A variação de Dq numa sērie é interpretada na teoria dos orbitais moleculares em termos das intensidades das interações $\sigma$ e $\pi$ entre o ion metālico e os ligantes coordenados. Interação o entre o àtomo doador do ligante e o ion metālico central conduzem a uma desestabilização dos orbitais de simetria eg, provocando um aumento no valor de $10 \mathrm{Dq}$.

Por outro lado, interações $\pi$, com transferēn cia de elëtrons do metal para o ligante, estabilizam os orbitais de simetria $t_{2 g}$, pela remoção de densidade eletróni ca do metal, contribuindo tambēm para o aumento de 10Dq.

Estes efeitos podem ser observados na figura a seguir
Ligação
$\sigma$
Ligação o e $\pi$
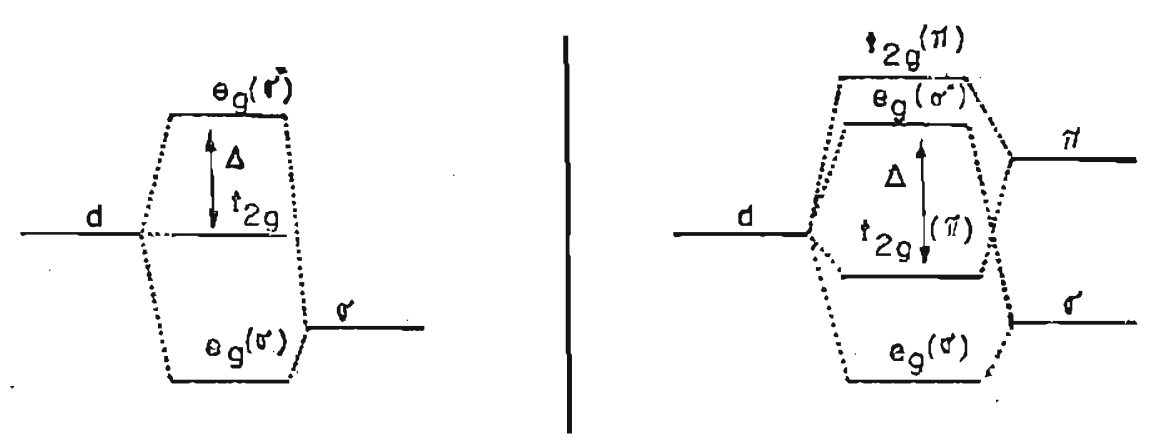

Influência das interações $\sigma$ e $\pi$ nos valores de $10 \mathrm{Dq}$ 
As variações observadas nos Dq, para os derivados com os substituintes na posição para, justificam-se atravēs das participações de interação $\pi$, com transferēn cia de carga no sentido metal $\rightarrow$ ligante.

E interessante notar que entre os 1 igantes em estudo o p-py(CO)CHNOH é o que apresenta maior interação "back-donation", equiparando-se quase ao ligante carregado, $\mathrm{N}$-metilpirazinio $\left(\mathrm{MPz}^{+}\right)$.

5.1.2. Espectro Eletrōnico dos Complexo de Pentacianoferrato (III) $-\mathrm{Fe}(\mathrm{CN})_{5} \mathrm{~L}^{2-}$

A oxidação dos complexos de pentacianoferrato (II) $\operatorname{com} L=$ acetilpiridina e carbonil-oximas derivadas, produz alterações drásticas nos espectros eletrōnicos apresentando bandas características na região do visível e ultra violeta prōximo (FIG. $5.14-5.17$ ).

Os complexos de pentacianoferrato(III) de configuração $d^{5}$ apresentam uma lacuna nos níveis ocupados do metal. Desta maneira tornam-se possíveis as transições de transferência de carga de baixa energia, provenientes dos $n \underline{1}$ veis ocupados do ligante pira o metal ( $L \rightarrow M)$.

Comparando-se os dados da tabela 5.6. com os espectros de complexos anālogos (229), pode-se fazer as seguin tes atribuições.

A banda ao redor de $415 \mathrm{~nm}$ è atribuīda (251) à transição de transferēncia de carga proveniente do orbital $\pi$, 


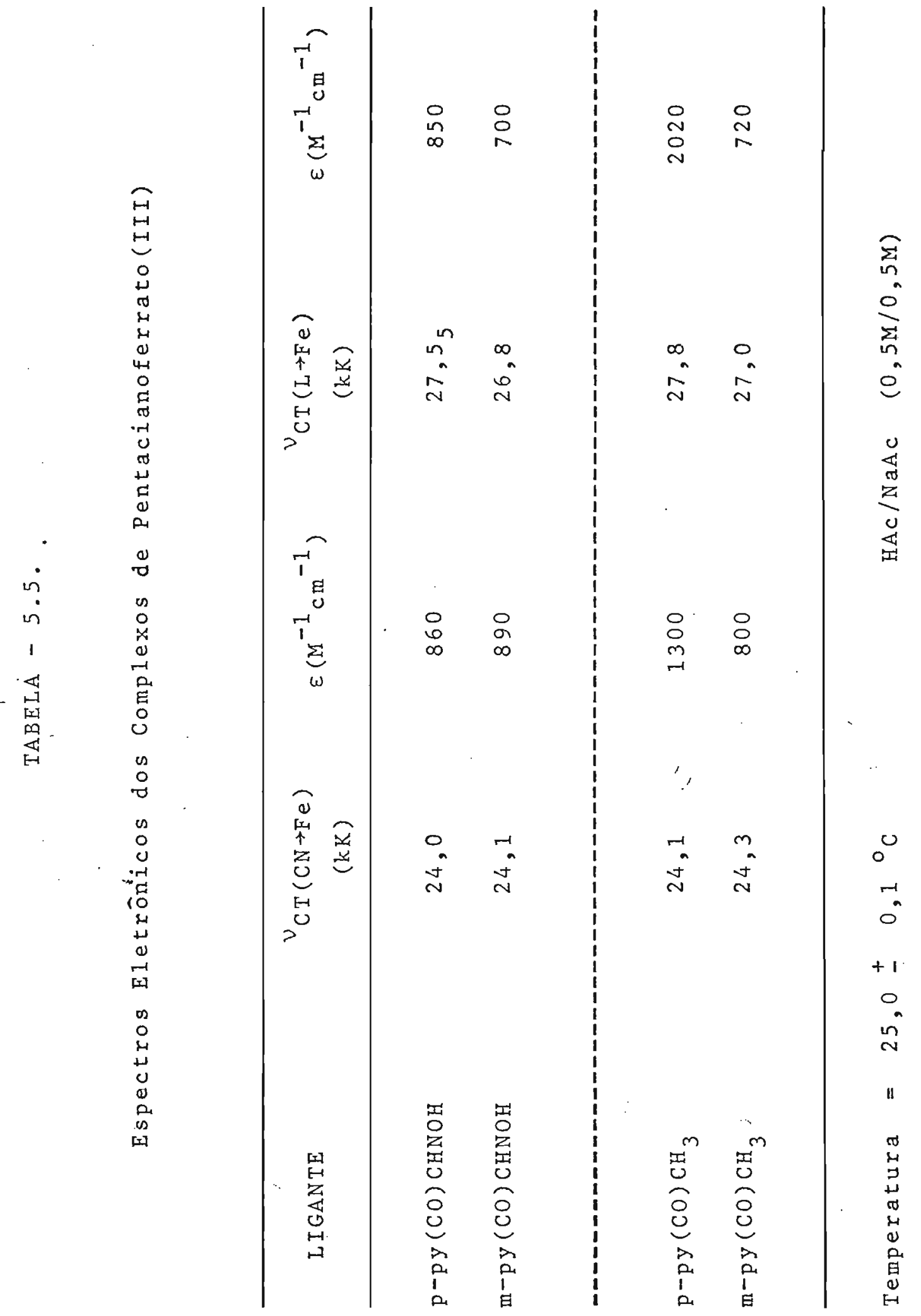


126

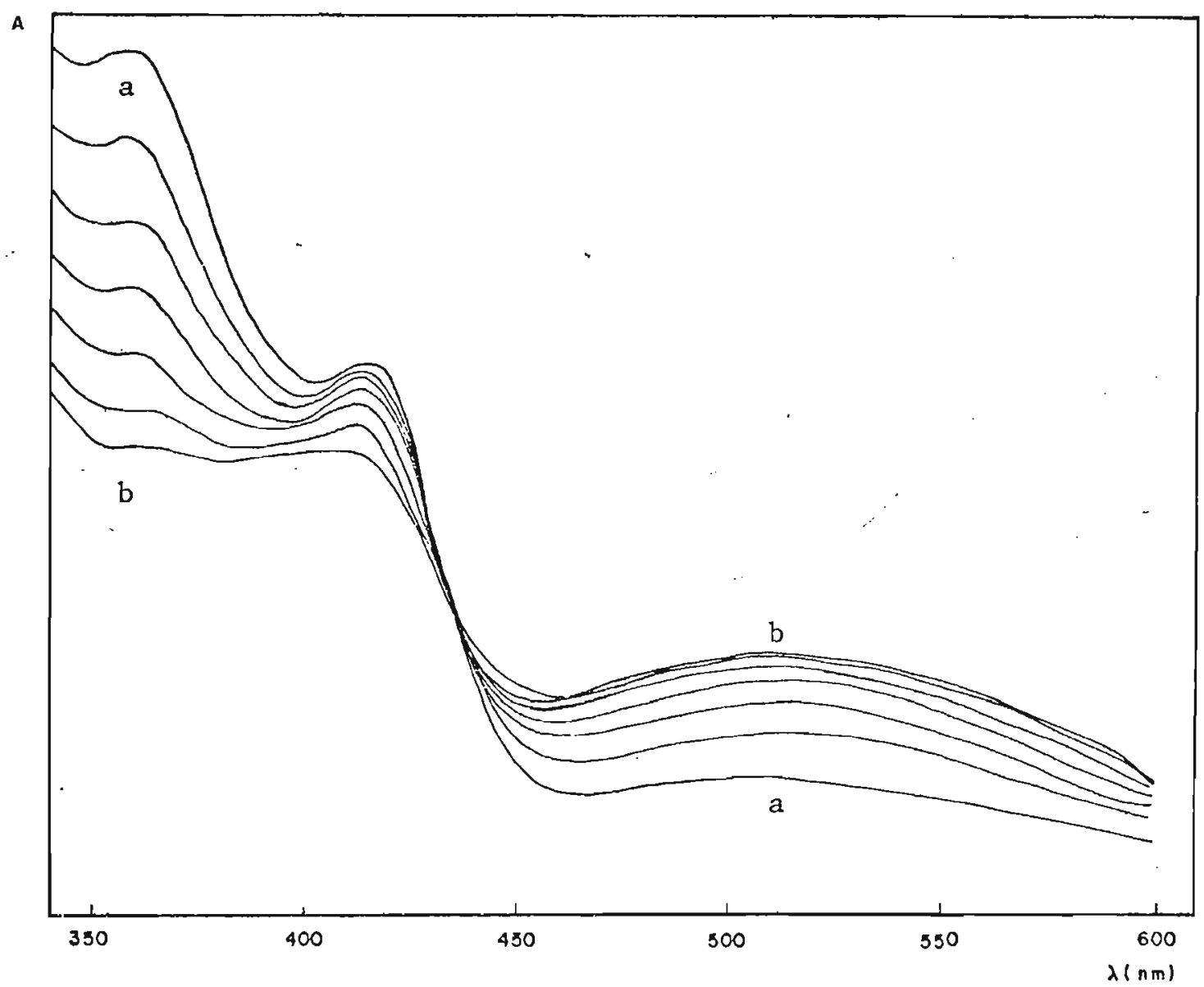

FIG. 5.14 - Dacaimento do espectro eletrônico de complexo $\left|\mathrm{Fe}(\mathrm{CN})_{5} \mathrm{P}-\mathrm{Py}(\mathrm{CO}) \mathrm{CHNOH}^{2-}\right|=7,68 \times 10^{-4} \mathrm{M}$ com - tempo $|\mathrm{p}-\mathrm{py}(\mathrm{CO}) \mathrm{CHNOH}|=3,84 \times 10^{-3} \mathrm{M}$

$t=25,0 \pm 0,1^{\circ} \mathrm{C} \quad \mathrm{NaAc} / \mathrm{HAC}(0,5 \mathrm{M} / 0,5 \mathrm{M})$

a. inicial b. final 


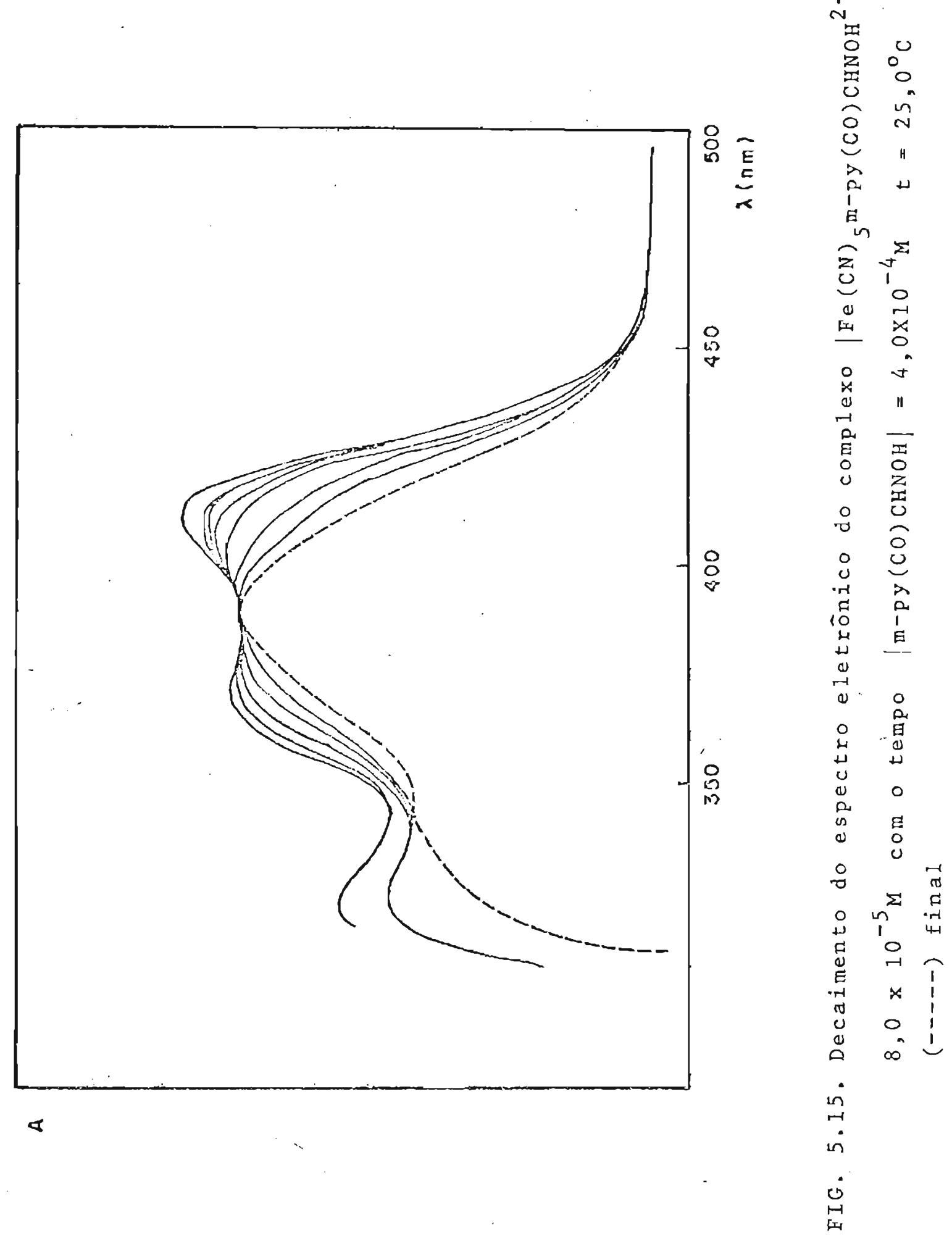

品

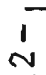




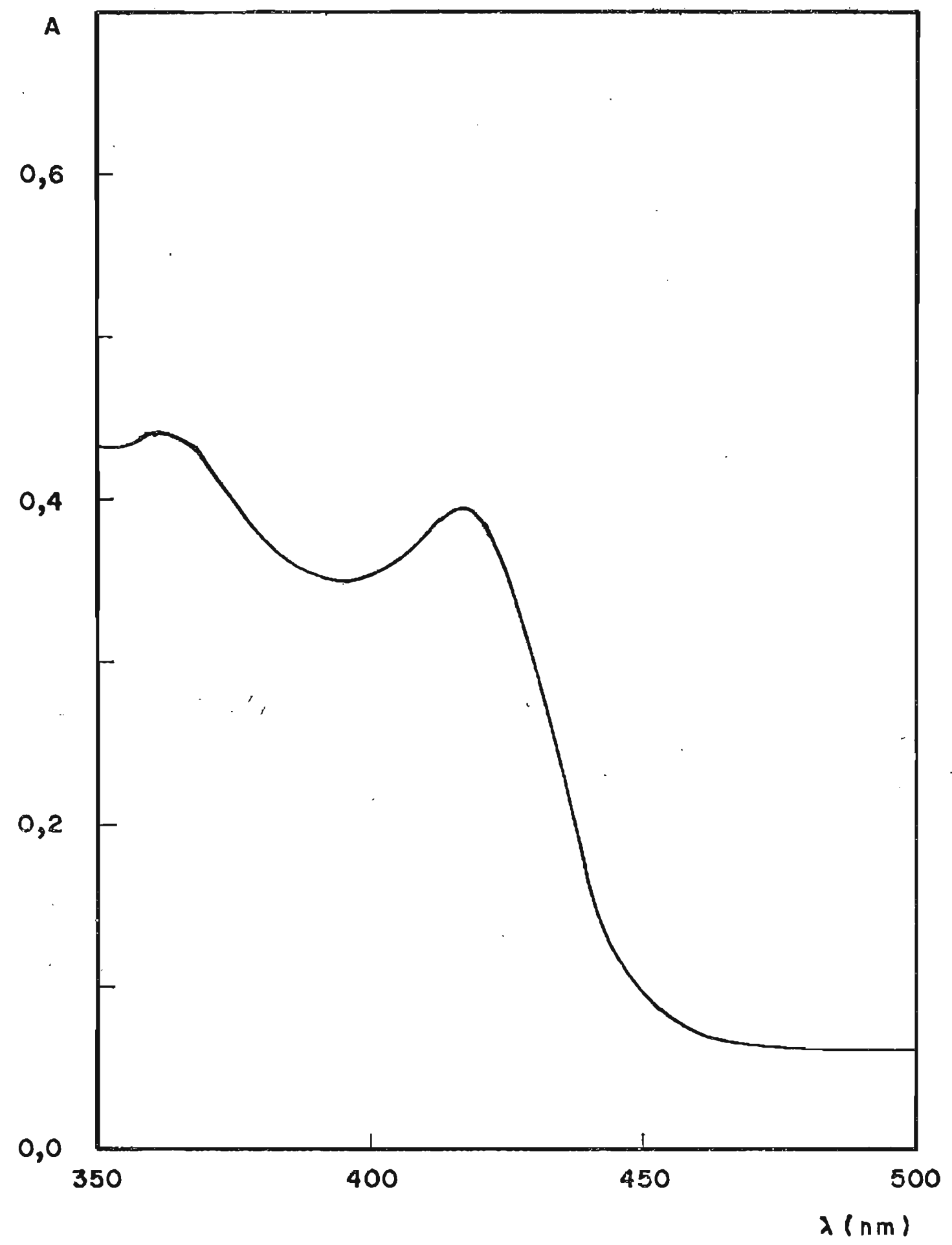

FIG. 5.16. Espectro eletrônico do complexo $\left|\mathrm{Fe}(\mathrm{CN}){ }_{5} \mathrm{p}^{-\mathrm{pyCOCH}}{ }_{3}^{2-}\right|$

$$
\begin{aligned}
& 4,0 \times 10^{-4} \mathrm{M} \\
& \left|\mathrm{p}-\mathrm{py}(\mathrm{CO}) \mathrm{CH}_{3}\right|=4,0 \times 10^{-3} \mathrm{M} \\
& \mathrm{t}=25,0 \pm 0,1^{\circ} \mathrm{C} \quad \mathrm{HAC} / \mathrm{NaAC}=0,5 \mathrm{M} / 0,5 \mathrm{M}
\end{aligned}
$$




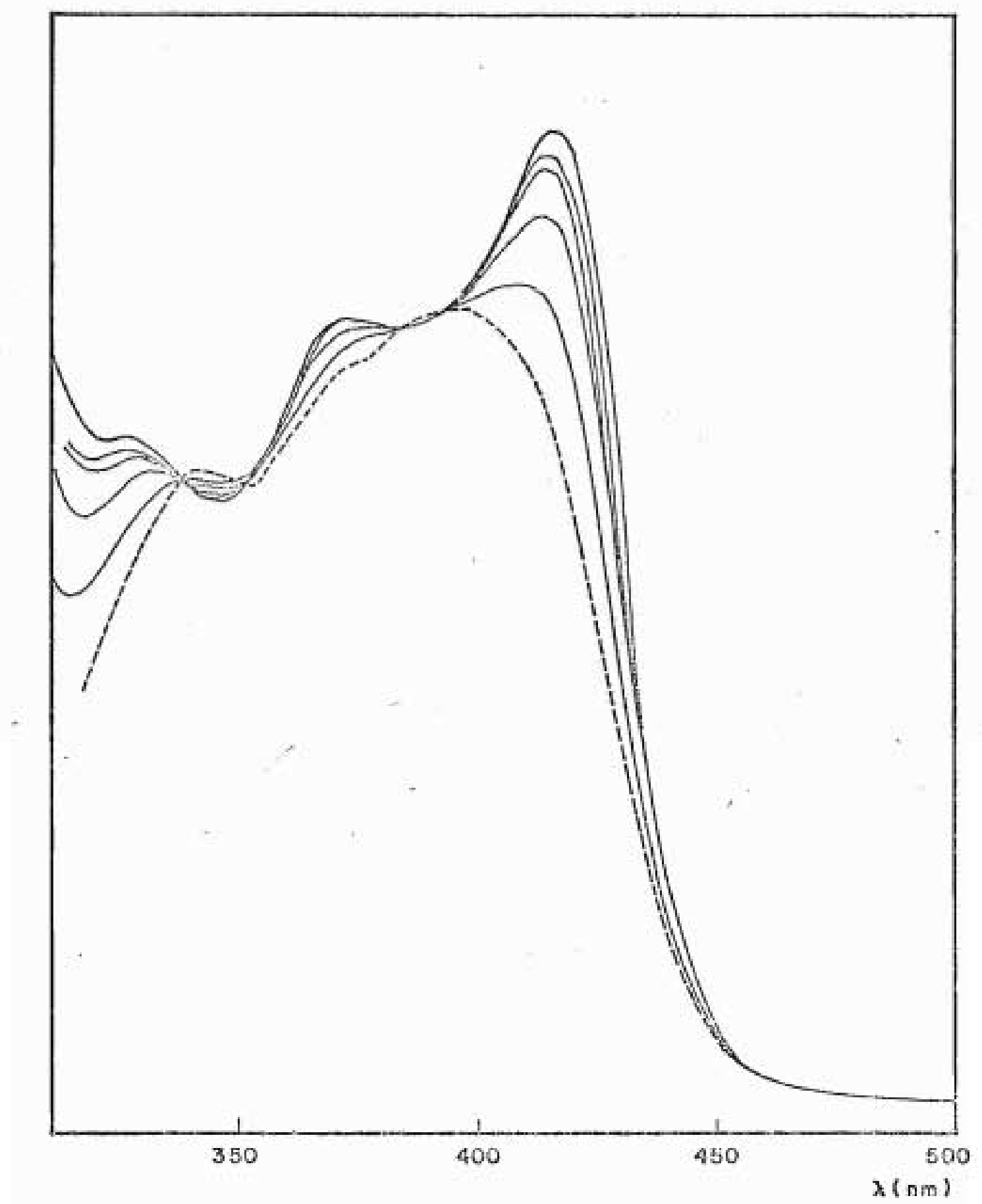

FIG. 5.17. Decaimento do espectro eletrônico do complexo

$$
\begin{aligned}
& \left|\mathrm{Fe}(\mathrm{CN})_{5} \mathrm{m-py}(\mathrm{CO}) \mathrm{CH}_{3}{ }^{2-}\right|=8,0 \times 10^{-4} \mathrm{M} \\
& \left|\mathrm{m}-\mathrm{py}(\mathrm{CO}) \mathrm{CH}_{3}\right|=8,0 \times 10^{-3} \mathrm{M} \\
& \mathrm{t}=25,0 \pm 0,1^{\circ} \mathrm{C} \quad \mathrm{HAC} / \mathrm{NaAC}=0,5 \mathrm{M} / 0,5 \mathrm{M} \\
& (---) \text { final }
\end{aligned}
$$


ocupado, dos cianetos para o subnivel 3d parcialmente pre enchido do metal $\left(P_{\pi(C N)} \rightarrow d_{\pi(F e)}\right)$. A pequena dependência das energias em relaçāo à natureza do ligante L $\vec{e}$ consistente com a atribuição, uma vez que não envolve diretamente os orbitais desses ligantes.

A transição ao redor de $360-370 \mathrm{~nm}$ tem sido atribuída como sendo transição de transferência de carga $\sigma(L)+d_{\pi(F e)}$, pelo fato de tambëm ocorrer em complexos com 1 igantes saturados $(251,252)$.

5.1.3. Efeito de $p H$ nos Espectros Eletrônicos - Determinaçäo de $p K a$

5.1.3.1. Determinaçāo de $p K a$ dos ligantes py $(\mathrm{CO}) \mathrm{CHNOH}$

Os espectros na regiāo do ultra-violeta das car bonil-oximas de acetilpiridinas variam bastante com o $p H$ quando este é superior a 4,80. 0 aumento do $\mathrm{pH}$ conduz a um aparecimento de banda na região de $300 \mathrm{~nm}$, correspondente à espēcie deprotonada. As variações nos espectros dos diversos isômeros de py(CO)CHNOH com o pH estäo ilustradas nas figuras 5.18 a 5.20 .

Nos espectros mostrados nas figuras citadas, po dem ser observados a existēncia do ponto isosbéstico consistente com o equilíbrio representado na pägina a seguir. 

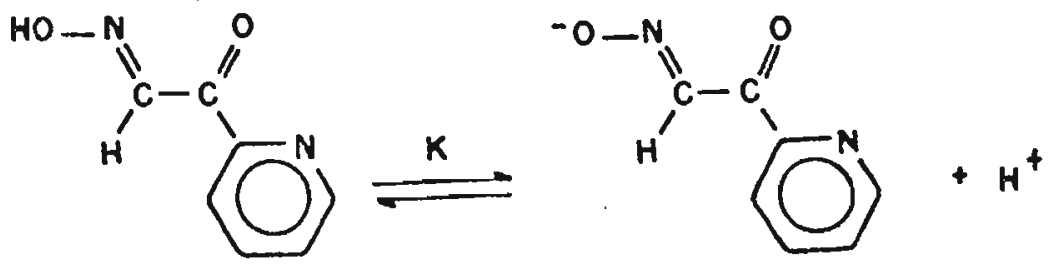

A determinação do valor de pKa foi feita espec trofotometricamente, usando-se a banda que aparece prōxima a $300 \mathrm{~nm}$ com a deprotonação.

A solução de partida é $4,0 \times 10^{-5} \mathrm{M}$ de 1 igante e $1,00 \times 10^{-3} \mathrm{M}$ de $\mathrm{NaH}_{2} \mathrm{PO}_{4}$ tendo a força iônica $0,10 \mathrm{M}$ ajustada com LiClO 4 . A adição de $\mathrm{NaOH}$ alcaliniza o meio, forman do o par $\mathrm{NaH}_{2} \mathrm{PO}_{4} / \mathrm{Na}_{2} \mathrm{HPO}_{4}$ para tamponar a solução, evitando desta maneira a influéncia de outras substāncias tais co mo $\quad \mathrm{ClO}_{2}$.

Do gräfico de $\log \left[H^{+}\right]$versus, $\log \left(\left(A_{0}-A\right) /\right.$ $\left.\left(A-A_{f}\right)\right)$, mostrado na figura 5.21 ., obtém-se os valores de pKa de 7,$46 ; 7,60$ e 7,74 para os derivados em para, meta e orto, respectivamente.

5.1.3.2. Determinação de pKa para $\mathrm{Fe}(\mathrm{CN})_{5} \mathrm{p}-\mathrm{py}(\mathrm{CO}) \mathrm{CHNOH}^{3-}$

(CO) $\mathrm{CHNOH}^{3-}$ apresenta um deslocamento hipsocrōmico $(\lambda$ menor) com o aumento de pH (FIG. 5.22).

A tendência observada estā de acordo com o fato da energia de transferéncia de carga metal-1igante variar aproximadamente segundo a equação de Murrell 


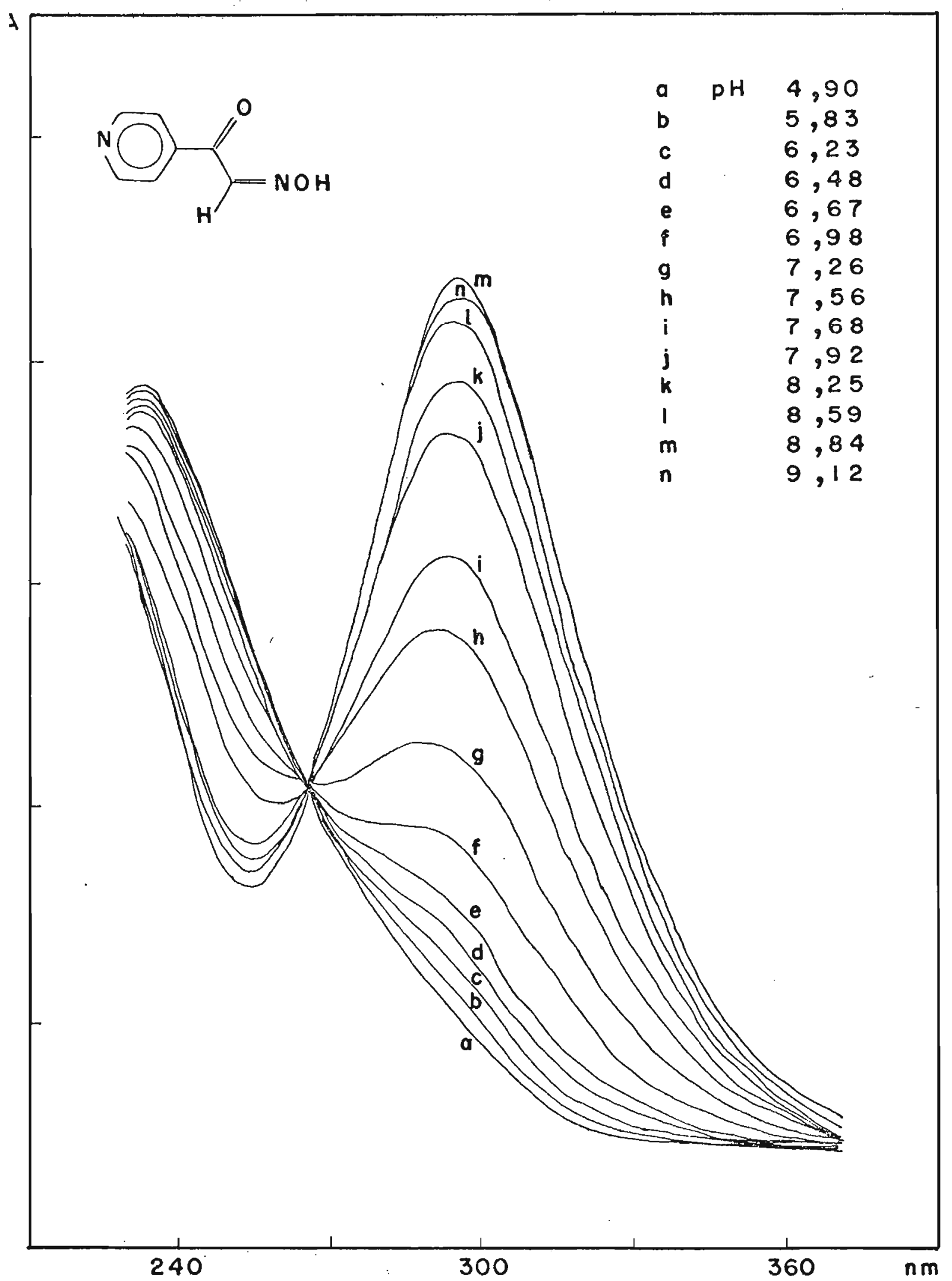

FIG. 5.18. Influência do pH no espectro do p-py(CO)CHNOH

$$
t=25,0^{\circ} \mathrm{C} \quad \mu=0,10\left(\mathrm{LiClO}{ }_{4}\right)
$$




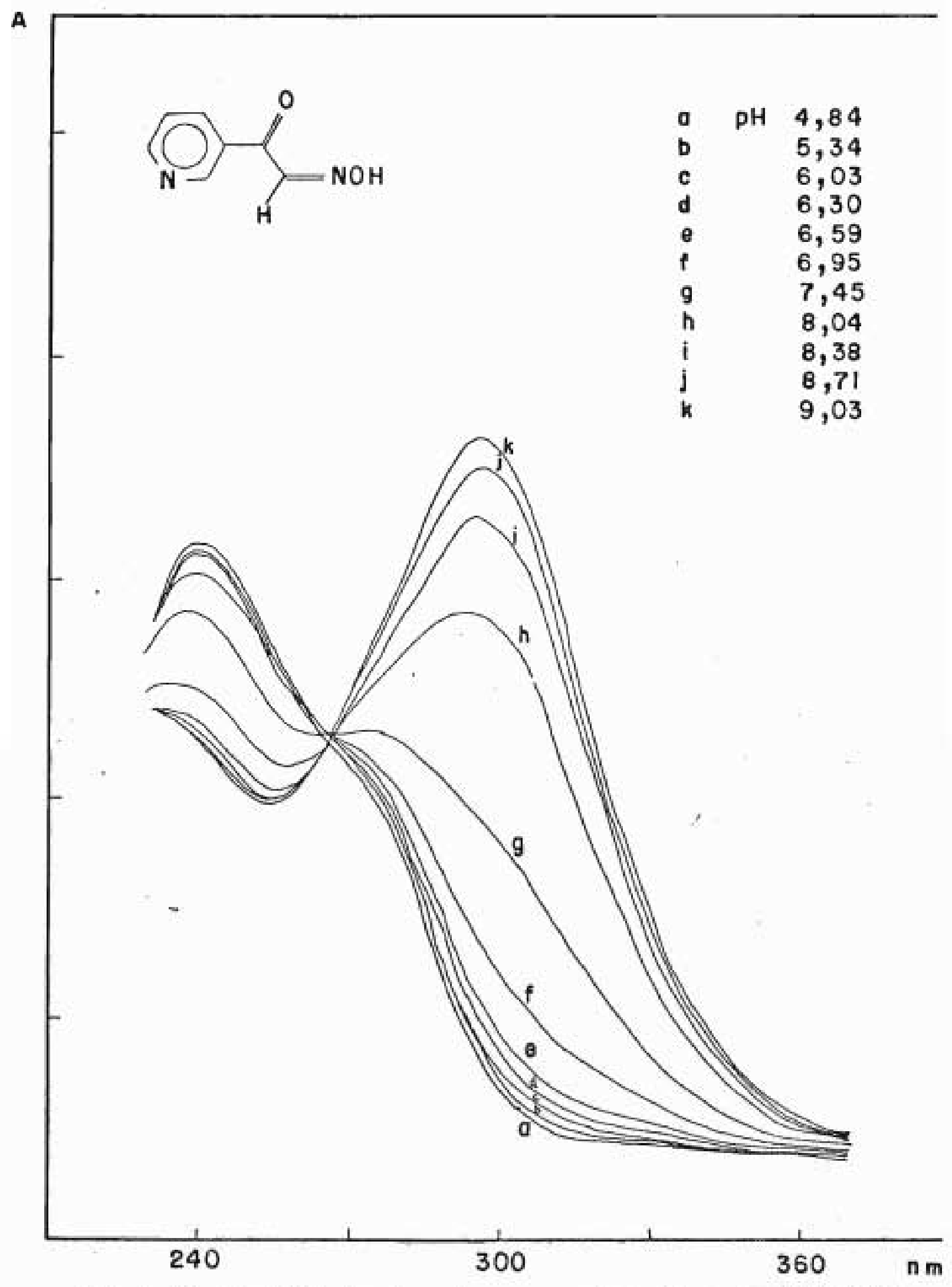

FIG.5.19. Influência do $p H$ no espectro do m-py (CO)cHNOH

$$
t=25,0 \pm 0,1^{\circ} \mathrm{C} \quad \mu=0,10\left(\mathrm{LiClO}_{4}\right)
$$




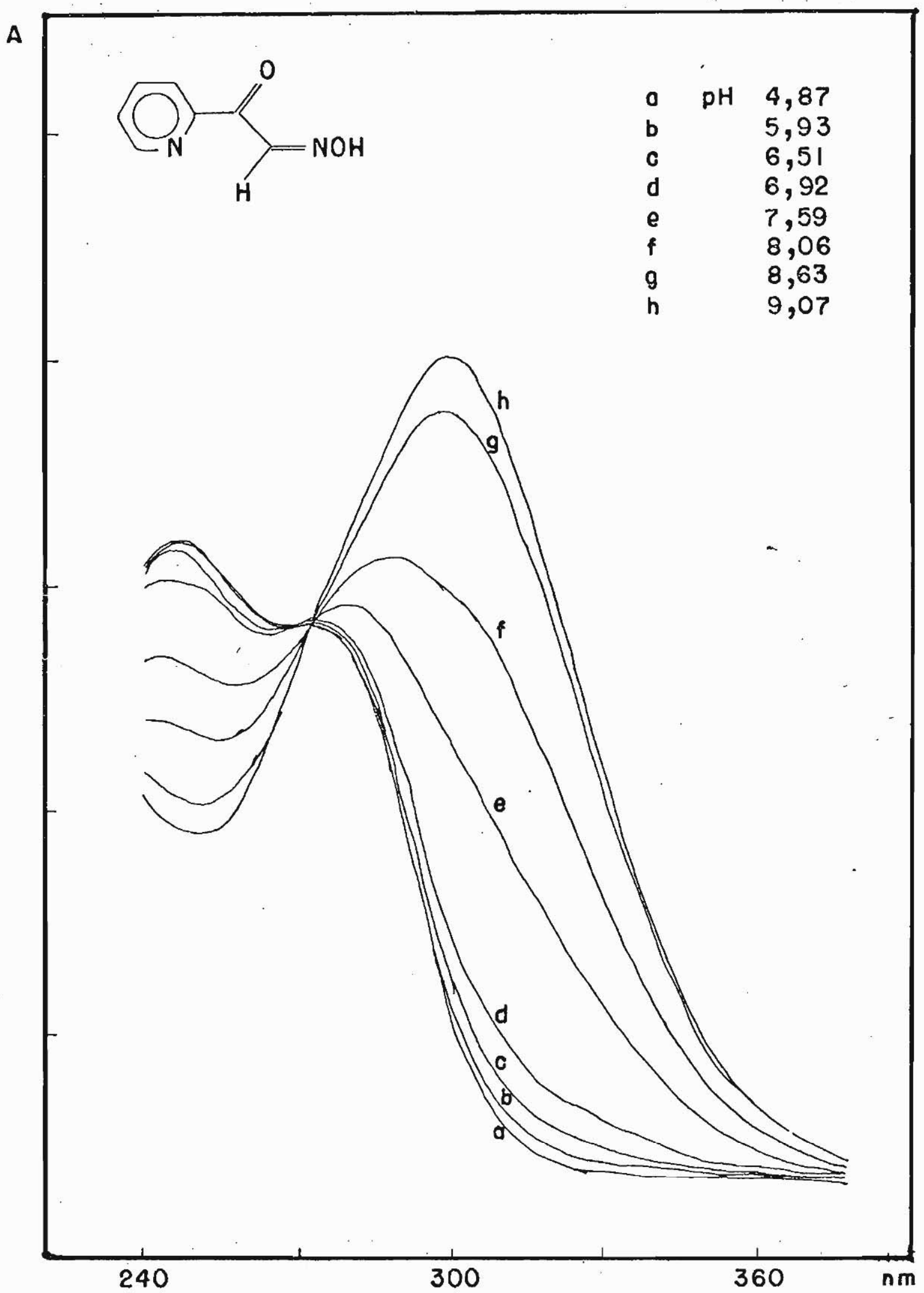

FIG. 5.20. Influência do $\mathrm{pH}$ no espectro do o-py(CO) CHNOH $t=25,0 \pm 0,1^{\circ} \mathrm{C} \quad \mu=0,10\left(\mathrm{LiCl}_{4}\right)$ 


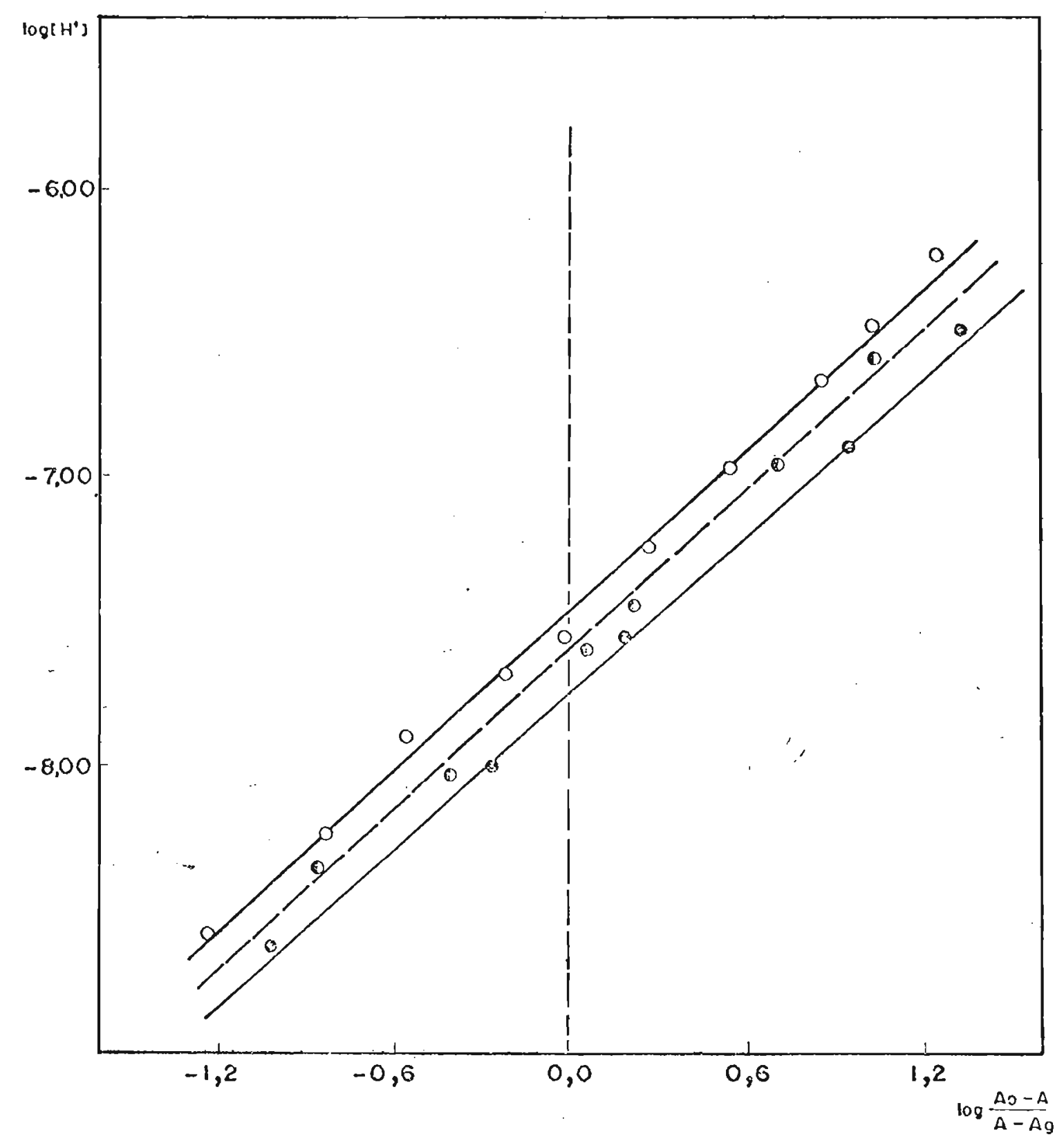

FIG. 5.21. Gráfico de $\log \left[\mathrm{H}^{+}\right]$vs $\log \left(\mathrm{A}_{\mathrm{o}}-\mathrm{A}\right) /\left(\mathrm{A}_{\mathrm{A}} \mathrm{A}_{\mathrm{f}}\right)$ para - p-py $(\mathrm{CO}) \mathrm{CHNOH}$

- m-py $(\mathrm{CO}) \mathrm{CHNOH}$

- o-py $(\mathrm{CO}) \mathrm{CHNOH}$ 


$$
{ }_{\mathrm{CT}}=\mathrm{PI}_{\mathrm{Fe}}-\mathrm{AE}_{\mathrm{L}}+\mathrm{C}
$$

Isto justifica o deslocamento hipsocrômico da banda de transferēncia de carga nos casos em que o ligante apresenta menor afinidade eletrōnica, como a oxima deprotonada .

No espectro ilustrado pode-se observar a existência do ponto isosbēstico, consistente com o equilïbrio

$$
\mathrm{Fe}(\mathrm{CN})_{5} \mathrm{~L}^{3-}(\mathrm{aq}) \rightleftharpoons \mathrm{Fe}(\mathrm{CN})_{5} \mathrm{~L}^{3-}(\mathrm{aq})+\cdots \mathrm{H}^{+}(\mathrm{aq})
$$

A determinação do valor de pKa foi feita espec trofotometricamente, partindo-se de uma solução $2,5 \times 10^{-4} \mathrm{M}$ do complexo com excesso de $6,0 \times 10^{-4} M$ de ligante livre para evitar a dissociação. A força iónica foi ajustada a 0,10

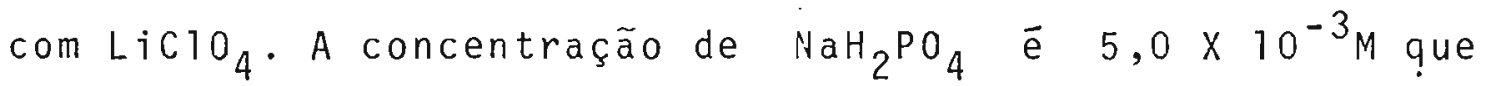
com a adição de $\mathrm{NaOH}$ alcaliniza o meio formando o par $\mathrm{Na}_{2} \mathrm{HPO}_{4} / \mathrm{NaH}_{2} \mathrm{PO}_{4}$ para tamponar a solução.

o valor de pKa determinado a partir do gräfico de $\log \left[H^{+}\right]$versus $\log \left(\left(A_{0}-A\right) /\left(A-A_{f}\right)\right)$ mostrado na figura 5.23 è de 7,83 .

Este valor, maior do que do ligante livre, indica a diminuição da acidez do ligante coordenado, devido à interação "back-donation", com transferēncia de densidade $\underline{\text { e }}$ letrônica do Fe(II) para o ligante heterociclico (236).

Para o estudo dos efeitos causados pelo abaixa 


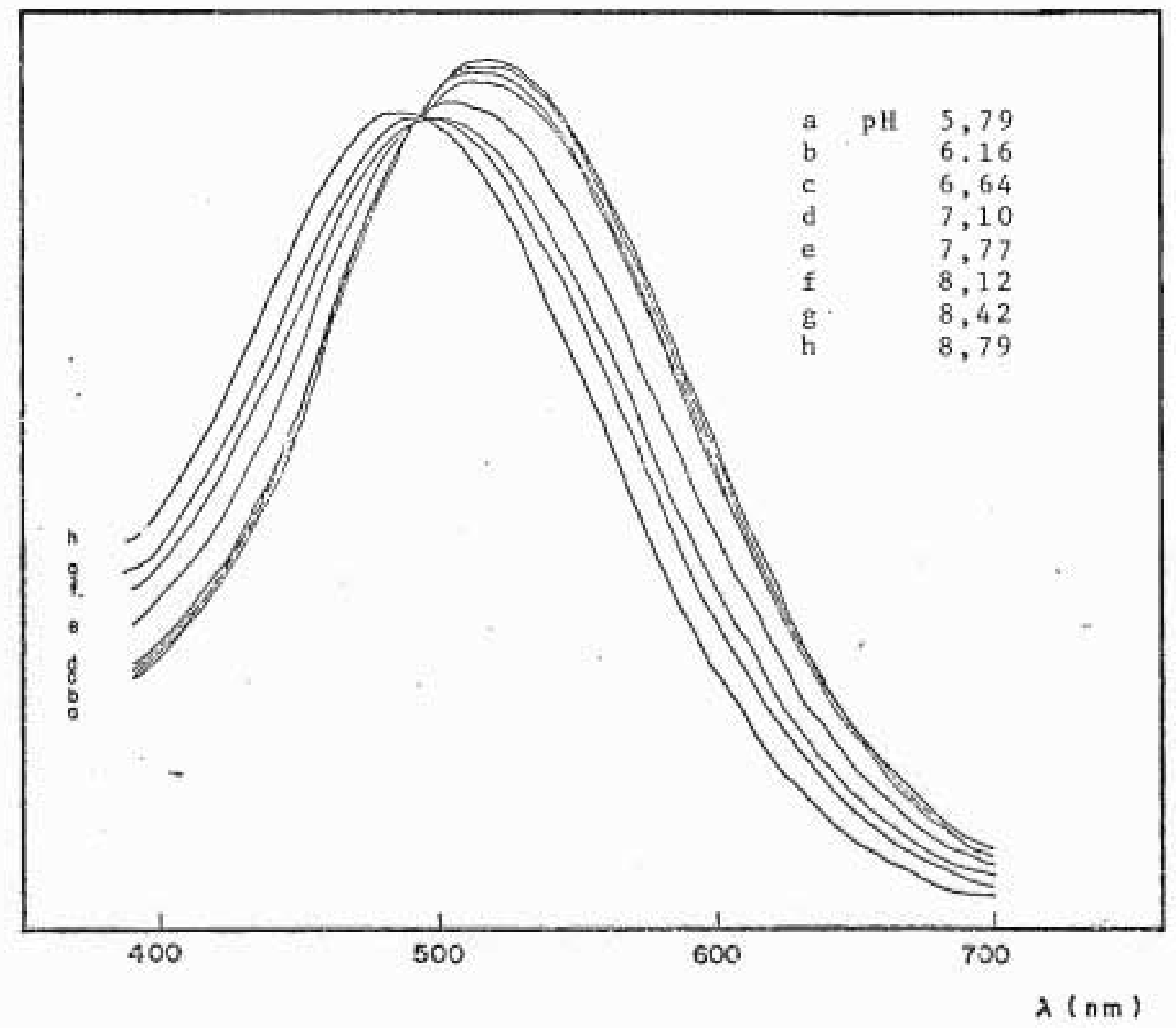

FIG. 5.22. Variaçäo no espectro eletrônico do complexo $\mathrm{Fe}(\mathrm{CN})_{5} \mathrm{p}-\mathrm{py}(\mathrm{CO}) \mathrm{CHNOH}^{3-} \mathrm{com}$ o aumento de $\mathrm{pH}$ $\mathrm{t}=25,0 \pm 0,0^{\circ} \mathrm{C} \quad \mu=0,10\left(\mathrm{LiClO}_{4}\right)$ 


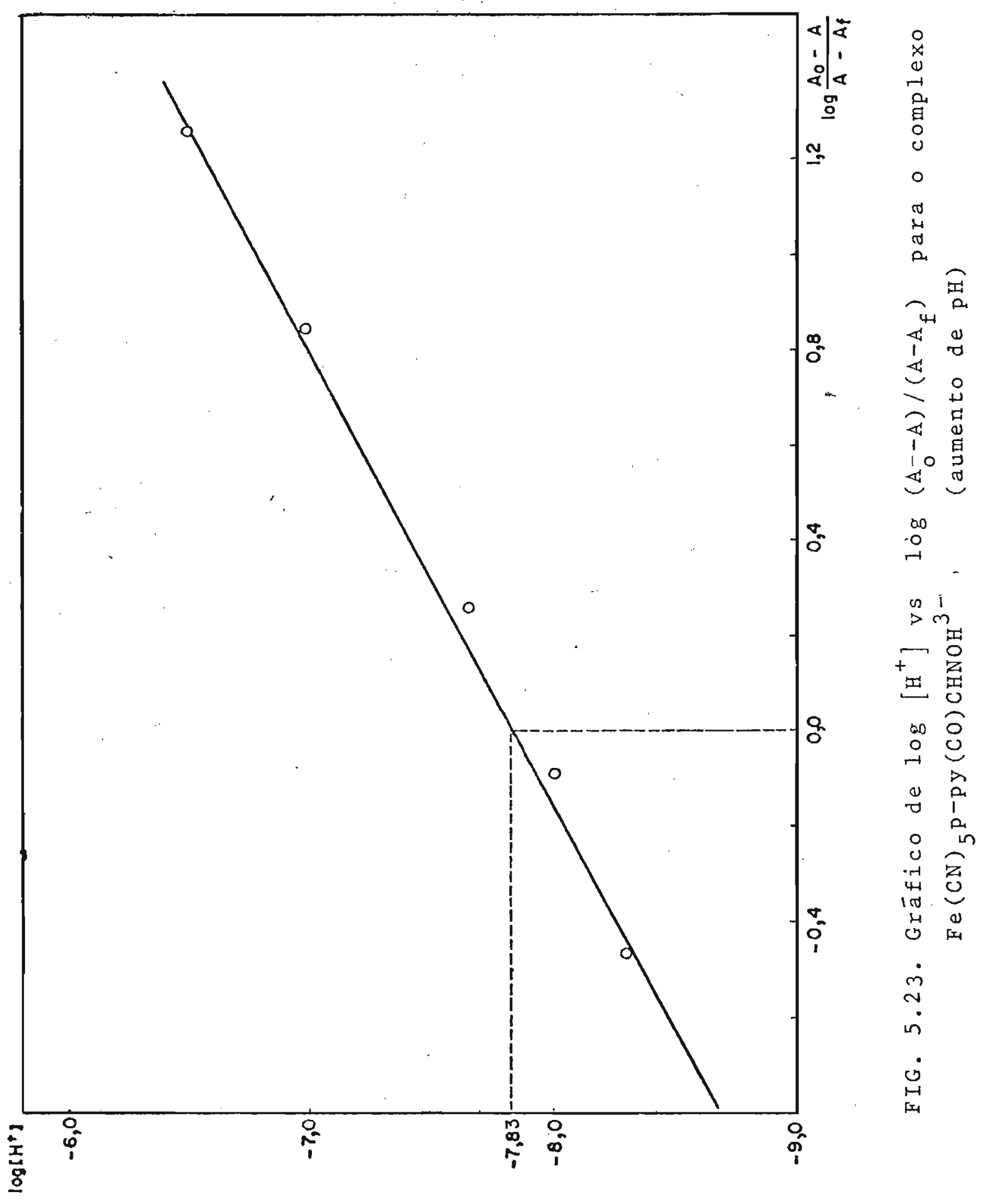


mento de $\mathrm{pH}$, deve-se partir de una solução de Liclo 4 previa mente acidulada e termostatizada, na qual se adiciona solução concentrada de complexo para evitar o efeito de decompo sição.

Aumentando-se a acidez, o espectro do complexo $\mathrm{Fe}(\mathrm{CN})_{5} \mathrm{p}-\mathrm{py}(\mathrm{CO}) \mathrm{CHNOH}^{3-}$ apresenta um deslocamento hipsocrómico na banda de transferēncia de carga, acompanhada pela perda de intensidade (FIG. 5.24).

Comportamentos semelhantes tem sido observados nos demais complexos de pentacianoferrato(II) com ligantes $\mathrm{N}$-heterocíclicos (3) e em complexos do tipo $\mathrm{Fe}(\mathrm{CN})_{2} \mathrm{~L}_{2}$ para $L=$ bipy e phen (253).

o equilíbrio envolvido pode ser representado

por

$$
\mathrm{HNC}-\mathrm{Fe}(\mathrm{CN})_{4} \mathrm{~L}^{2-} \rightleftharpoons \mathrm{Fe}(\mathrm{CN})_{5}^{\prime} \mathrm{L}^{3-}+\mathrm{H}^{+}
$$

- pKa determinado a partir do uso da equação (5) (îtem 4.3.2.), atravēs do procedimento jā citado è igual a 1,88 ( aqui o valor ajustado pelo mētodo iterativo $\bar{e} \circ A_{0}$ ) (FIG. 5.25.).

Deve-se notar que este valor é o mais baixo en contrado, junto com a pirazina (3), para os pentacianoferra tos com ligantes $\mathrm{N}$-heterociclico neutros.

A presença de um ligante como p-py(CO)CHNOH que tende a remover a densidade eletrōnica do metal dificulta a protonação do cianeto resultando num decréscimo da basicida 


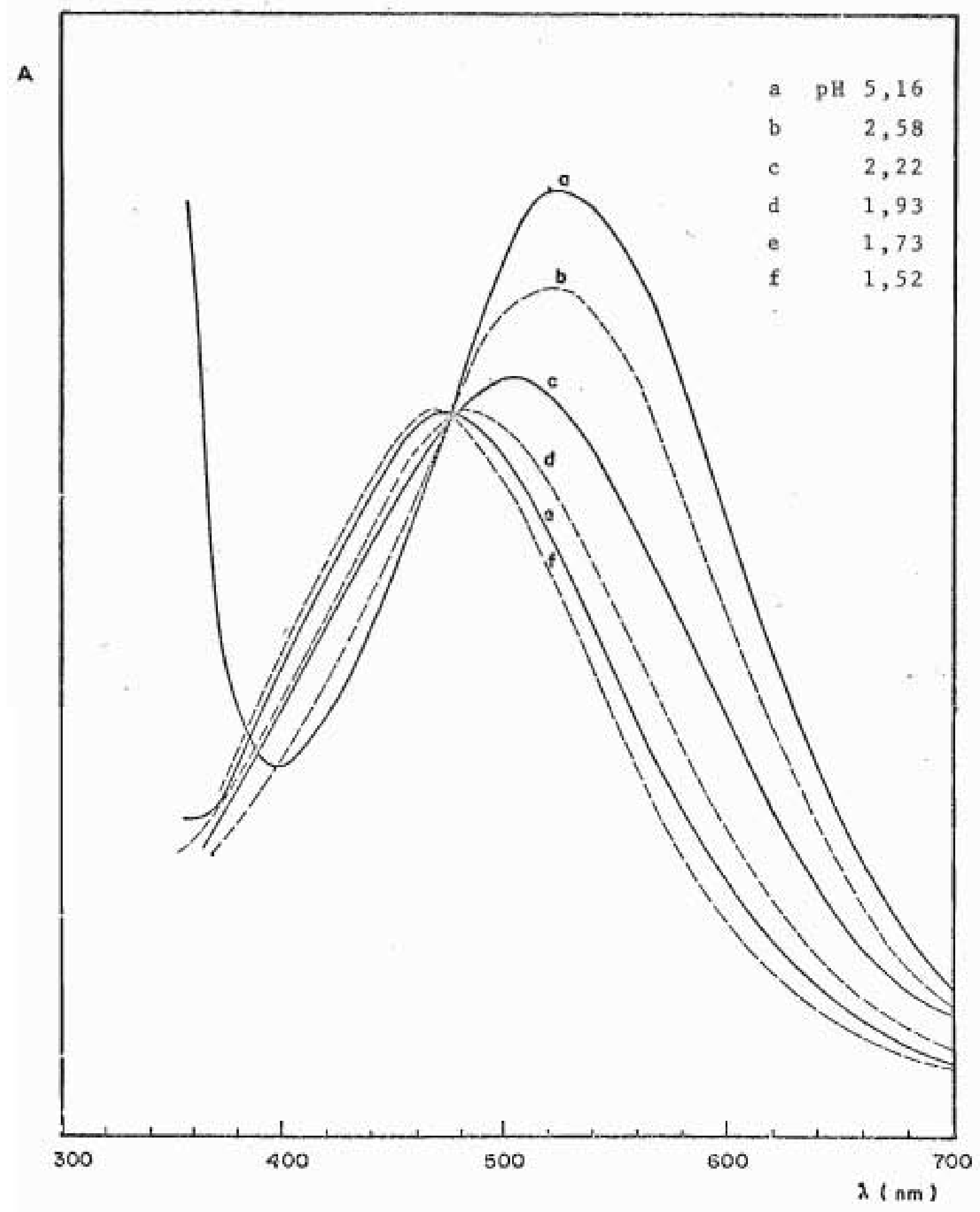

PIG. 5.24. Variaçäo do espectro eletrônico do complexo $\mathrm{Fe}(\mathrm{CN})_{5} \mathrm{p}-\mathrm{py}(\mathrm{CO}) \mathrm{CHNOH}^{3-}$ com a diminuição de $\mathrm{pH}$ $t=25,0 \pm 0,1^{\circ} \mathrm{C} \quad \mu=0,10\left(\mathrm{LiClO}{ }_{4}\right)$ 
141

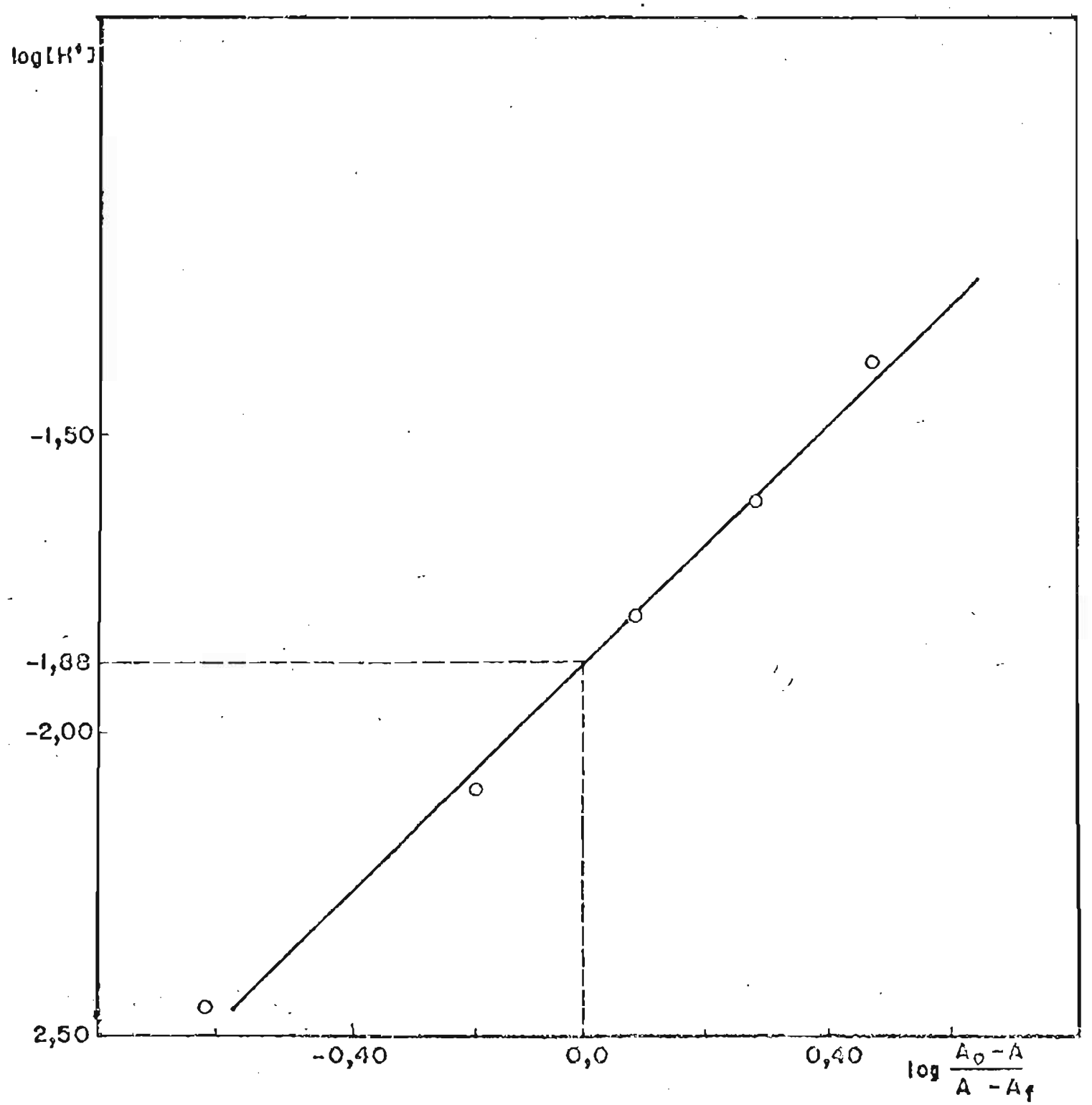

FIG. 5.25. Gráfico de $\log \left[\mathrm{HI}^{+}\right]$vs $\log \left(\mathrm{A}_{\mathrm{O}}-\mathrm{A}\right) /\left(\mathrm{A}-\mathrm{A}_{\mathrm{f}}\right) \mathrm{pa}-$ ra $\mathrm{Fe}(\mathrm{CN})_{5} \mathrm{P}-\mathrm{py}(\mathrm{CO}) \mathrm{CHNOH}^{3-}$ (abaixamento d $\epsilon$ $\mathrm{pH}$; 
de do complexo. Os valores de pKa decrescem com a diminui çāo de energia da banda de transferência de carga, uma vez que a basicidade do cianeto deve-se ao deslocamento da densidade eletrōnica do metal para o ligante heterocíclico.

\subsection{Espectros de Absorção na Regiäo do Infravermelho}

Os espectros de absorção no infravermelho do pentacianoferrato(II) com ligantes $\mathrm{N}$-heterocỉclicos apresen tam interesse pelas transiçōes vibracionais associadas aos grupos Metal - CN e Metal - N-heterocíclico.

Os espectros vibracionais dos ligantes $\mathrm{N}$-heterocíclicos e suá variação apōs a coordenação podem ser ob servadas nas figuras 5.26 a 5.32 .

De uma maneira geral, a coordenaçāo pode afetar - espectro vibracional atravēs de mudanças na simetria e nas densidades eletrōnicas e pela combinação dos modos normais de vibração.

5.2.1. Espectro de Absorçăo no Infravermelho para os Ligantes Livres

Os espectros dos 1 igantes 1 ivres estão reuni dos nas figuras 5.26 . e 5.27 . A atribuição tentativa dos es pectros foi feita por comparaçāo com os dados da literatura para os compostos semelhantes $(266-270)$ e consta na tabela 5.6 . e 5.7 . 
5.2.1.1. Acetilpiridinas $\left(\mathrm{py}(\mathrm{CO}) \mathrm{CH}_{3}\right)$

Na região de $3500 \sim 3125 \mathrm{~cm}^{-1}$ observam-se para todos os ligantes, fortes absorções indicativas da presença de àgua.

Para as piridinas substituĩdas esperam-se duas bandas de absorção entre 3095 a $3060 \mathrm{~cm}^{-1}$ e 3055 e $3010 \mathrm{~cm}^{-1}$ (271), referentes ao modo normal de estiramento $\mathrm{C}-\mathrm{H}$ do anel aromático. Estas duas bandas para as acetilpiridinas apa recem entre 3075 a $3020 \mathrm{~cm}^{-1}$.

Na região abaixo de $3000 \mathrm{~cm}^{-1}$ encontram-se as vibrações de estiramento C-H alifático (266).

A banda intensa com frequēncias de absorção prō xima a $1690 \mathrm{~cm}^{-1}$ corresponde ao estiramento $\mathrm{C}=0$, situandose dentro do intervalo de frequências esperado para as cetonas conjugadas $\left(1700 \sim 1670 \mathrm{~cm}^{-1}\right)(272,273)$.

As absorções em torno de $1650 \mathrm{~cm}^{-1}$ correspondem à deformação da āgua.

Anēis aromāticos e heteroaromáticos caracterizam-se por apresentarem bandas entre 1620-1420 $\mathrm{cm}^{-1}$. A vibra ção na região de $1600 \mathrm{~cm}^{-1}$ ("quadrant stretching") tem dois componentes: um dublet na região de $1620 \sim 1585 \mathrm{~cm}^{-1}$ e outro entre $1590-1565 \mathrm{~cm}^{-1}$ cujas intensidades são relativamente al tas para os anēis monosubstituĩdos pelos grupos aceptores de elétrons (274). A região de $1500 \mathrm{~cm}^{-1}$ corresponde a "semicircle stretching" e apresenta normalmente dois componen - 


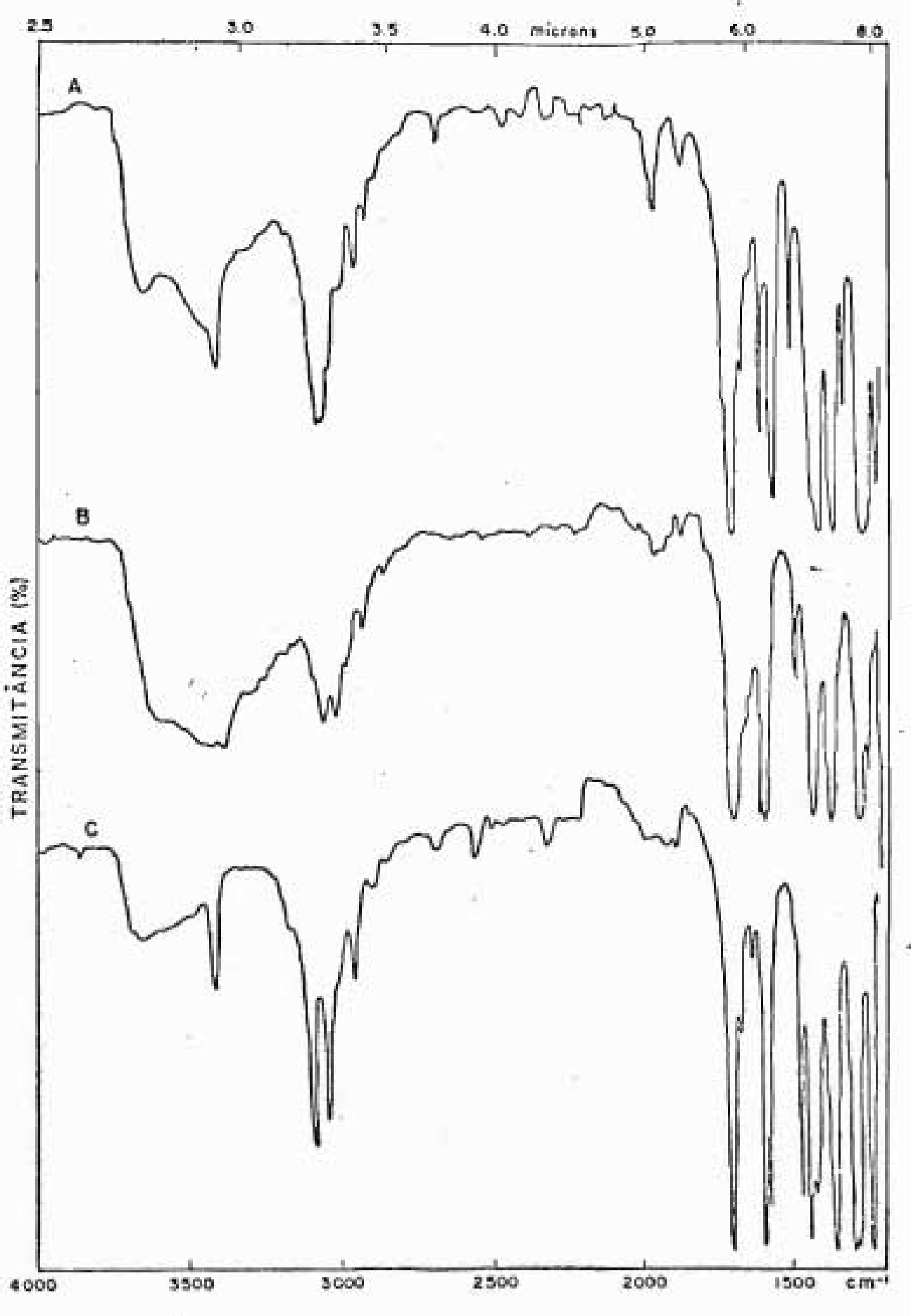

FIG5.26.A Espectro na Regiäo de Infravermelho de 4000 a $1300 \mathrm{~cm}^{-1}$ de A. p-py $(\mathrm{CO}) \mathrm{CH}_{3}$, B. m-py $(\mathrm{CO}) \mathrm{CH}_{3}$ c. o-py $(\mathrm{CO}) \mathrm{CH}_{3}$ 


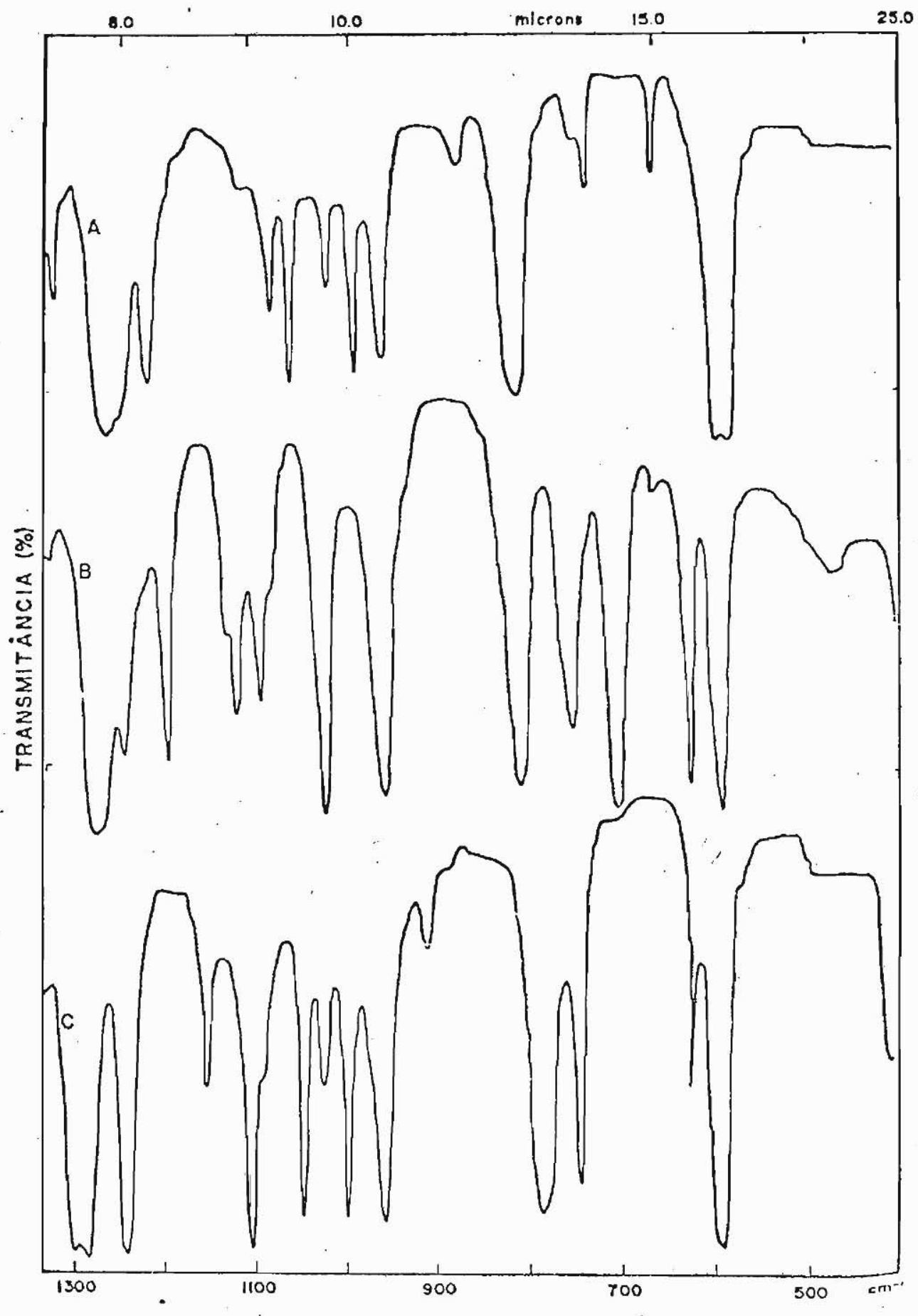

FIG.5 26.B. Espectro na Região de Infravermelho de 1300 a $400 \mathrm{~cm}^{-1}$ de A. p-py(CO) $\mathrm{CH}_{3}$, B. m-py $(\mathrm{CO}) \mathrm{CH}_{3}$ C. $\mathrm{p}-\mathrm{py}(\mathrm{CO}) \mathrm{CH}_{3}$ 


\section{6}

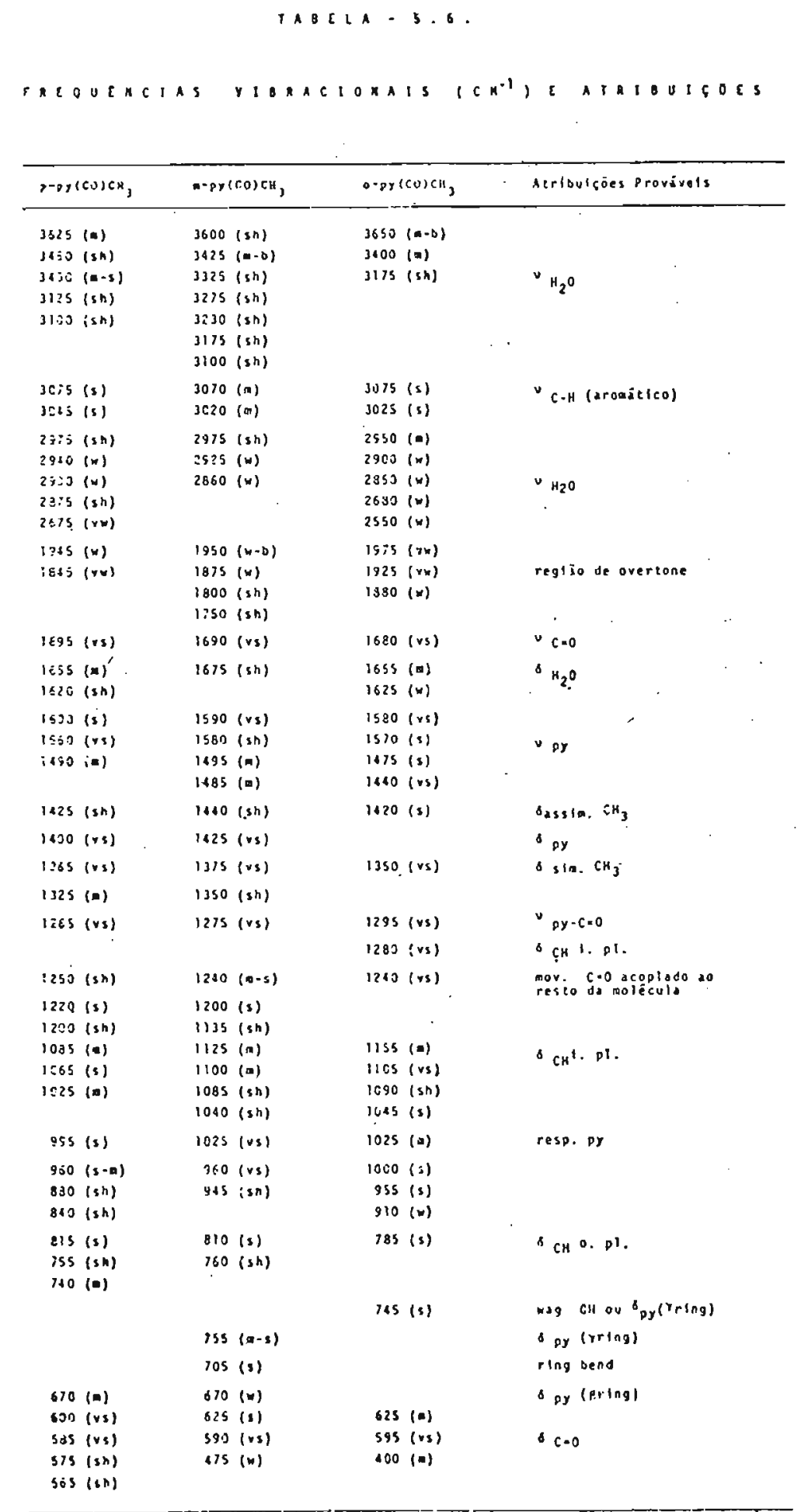

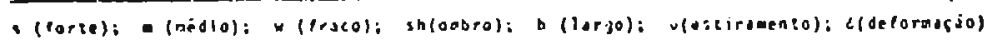


tes dos quais um está geralmente acima de $1470 \mathrm{~cm}^{-1}$ e outro na região de $1465 \sim 1430 \mathrm{~cm}^{-1}$.

Na tabela a seguir relacionam-se as bandas caracteristicas para os compostos de piridina nessa região.

Frequências de Estiramento do Anel Piridínico(274)

\begin{tabular}{lccccc}
\hline Substituintes & $\mathrm{A}_{1}$ & $\mathrm{~B}_{1}$ & $\mathrm{~A}_{1}$ & $\mathrm{~B}_{1}$ \\
para & $1603 \pm 5$ & $1561 \pm 8$ & $1520 \rightarrow 1480$ & $1415 \pm 4$ \\
meta & $1595 \pm 5$ & $1577 \pm 5$ & $1485 \rightarrow 1465$ & $1421 \pm 4$
\end{tabular}

0 simbolo $1615 \rightarrow 1585 \mathrm{~cm}^{-1}$ indica que substituintes doadores de elétrons causam absorção prōxima a $1615 \mathrm{~cm}^{-1}$ enquanto substituintes aceptores de elétrons causam absorção pröxima a $1585 \mathrm{~cm}^{-1}$.

As frequéncias de estiramento do anel piridinico para as acetilpiridinas encontram-se dentro destas regiõe mencionadas cujas bandas se encontram tabeladas na página a seguir. 


\begin{tabular}{lrrrr}
\hline Substância & $\mathrm{A}_{1}$ & $\mathrm{~B}_{1}$ & $\mathrm{~A}_{1}$ & $\mathrm{~B}_{1}$ \\
\hline p-py (CO) $\mathrm{CH}_{3}$ & 1600 & 1565 & 1490 & 1400 \\
m-py (CO) $\mathrm{CH}_{3}$ & 1590 & 1580 & 1495 & 1425 \\
o-py(CO) $\mathrm{CH}_{3}$ & 1580 & 1570 & 1485 & 1440 \\
\hline
\end{tabular}

As duas primeiras bandas são mais intensas que as $\bar{u} 1$ timas de acordo com o que se observa comumente (267). Na região de $1300-1000 \mathrm{~cm}^{-1}$ aparecem as bandas devido às vibrações de deformação dos ātomos de hidrogênio no plano do anel aromätico ( $\left.\delta_{\mathrm{CH}} \mathrm{i} \cdot \mathrm{p} 1.\right)$ - quatro primeiras co lunas - e modo de respiro do anel - ültima coluna - relacionadas na tabela abaixo. os valores entre parēnteses são os mencionados nas referēricias 268, 275, 276 e 277 .

\begin{tabular}{|c|c|c|c|c|c|}
\hline Substância & $\delta$ & $\mathrm{CH} \quad \mathrm{i} \cdot \mathrm{p} 1$. & & & resp. py \\
\hline$p-p y(C O) \mathrm{CH}_{3}$ & $\begin{array}{c}1220 \\
(1232 \rightarrow 1208)\end{array}$ & 1085 & 1065 & 1025 & 995 \\
\hline $\mathrm{m}-\mathrm{py}(\mathrm{CO}) \mathrm{CH}_{3}$ & $\begin{array}{c}1200 \\
(1202 \rightarrow 1182)\end{array}$ & $\begin{array}{c}1125 \\
1135(\mathrm{sh}) \\
(1124 \pm 5)\end{array}$ & 1100 & 1040 & 1025 \\
\hline o-py $(\mathrm{CO}) \mathrm{CH}_{3}$ & $\begin{array}{c}1280 \\
(1279 \pm 14)\end{array}$ & $\begin{array}{l}1155 \\
(1147 \pm 3)\end{array}$ & $\begin{array}{l}1105 \\
1095(\mathrm{sh})\end{array}$ & 1045 & 1000 \\
\hline
\end{tabular}


Forte absorção na região de $700 \mathrm{~cm}^{-1}$ corresponde à deformação do anel ("out of plane ring bending by sextants") e ocorre normalmente entre 710 e $670 \mathrm{~cm}^{-1}$. Há uma interação com as vibraçōes de deformação dos àtomos de hidrogénio para fora do plano do anel aromático ( $\delta_{\mathrm{CH}^{\mathrm{O}}} \mathrm{pl}$ ) devido ao acoplamento com os hidrogénios adjacentes e acopla mento ainda mais fraco com os hidrogēnios separados pelos grupos substituintes.

As vibraçōes de deformação do grupo $\mathrm{C}-\mathrm{CH}_{3}$, ocor rem na faixa de 1500-1850 $\mathrm{cm}^{-1}$ geralmente como duas baindas. A primeira no intervalo de $1500-1400 \mathrm{~cm}^{-1}$ correspondente à deformação assimétrica de $\mathrm{CH}_{3}$. A segunda, mais intensa é devido à deformação simētrica. Esta ocorre no intervalo de 1370 a $1550 \mathrm{~cm}^{-1}$ quando o grupo $\mathrm{CH}_{3}$ aparece pröximo à carbonila (278).

As cetonas aromāticas apresentám uma banda " na região de $1300-1230 \mathrm{~cm}^{-1}$ devido ao estiramento feni1-carbo nila ( $\left.\nu_{p y-c=0}\right)(266)$. Nas acetilpiridinas atribuem-se às bandas de 1260,1275 e $1295 \mathrm{~cm}^{-1}$ para os derivados em para, meta e orto, respectivamente.

A presença do grupo carbonila na molécula frequentemente dä origem ao aparecimento de uma banda de inten sidade mëdia na região de 1350 a $1200 \mathrm{~cm}^{-1}(267,279)$, prove niente de algum movimento do grupo carbonila acoplado com o resto da molécula.

No grupo $\mathrm{COCH}_{3}$ aparecem três bandas associadas com o modo de vibração de deformação do grupo $c=0$ prō 
ximo às frequências de 600,500 e $400 \mathrm{~cm}^{-1}$ (267).

\subsubsection{Carboni1 - Oximas ( $\mathrm{py}(\mathrm{CO}) \mathrm{CHNOH)}$}

As bandas na região de $3300 \sim 3150 \mathrm{~cm}^{-1}$, geral mente alargadas, correspondem ao estiramento $0-H$ de oxi mas ( $v_{\mathrm{OH}}$ - oxima). Estas tornam-se mais alargadas e mais intensas com a formação de pontes de hidrogênio, deslocando - se para frequências menores. Um acoplamento muito intenso, podendo chegar a $2500 \mathrm{~cm}^{-1}$ (267), indica a presença de forte ponte de hidrogēnio com estabilização atravēs de ressonãn cia.

\section{O-py(CO)CHNOH apresenta pico alargado e bem} definido na região de $3350 \mathrm{~cm}^{-1}$ indicando a existênciá de grupos $\mathrm{OH}$ livres ou fracamente associados.

Nos derivados em meta e para observam-se as bandas de estiramento $\mathrm{OH}$ bastante alargadas e deslocadas ao longo do intervalo de $2800-2400 \mathrm{~cm}^{-1}$, indicativo de uma forte associação.

As estruturas dos dois isômeros geométricos pos siveis para as oximas são representadas a seguir.

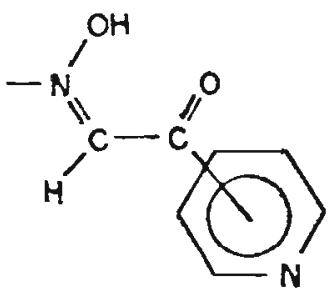

(a)

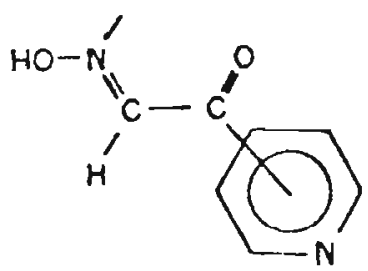

(b)

Dy(CO) HCNOH 


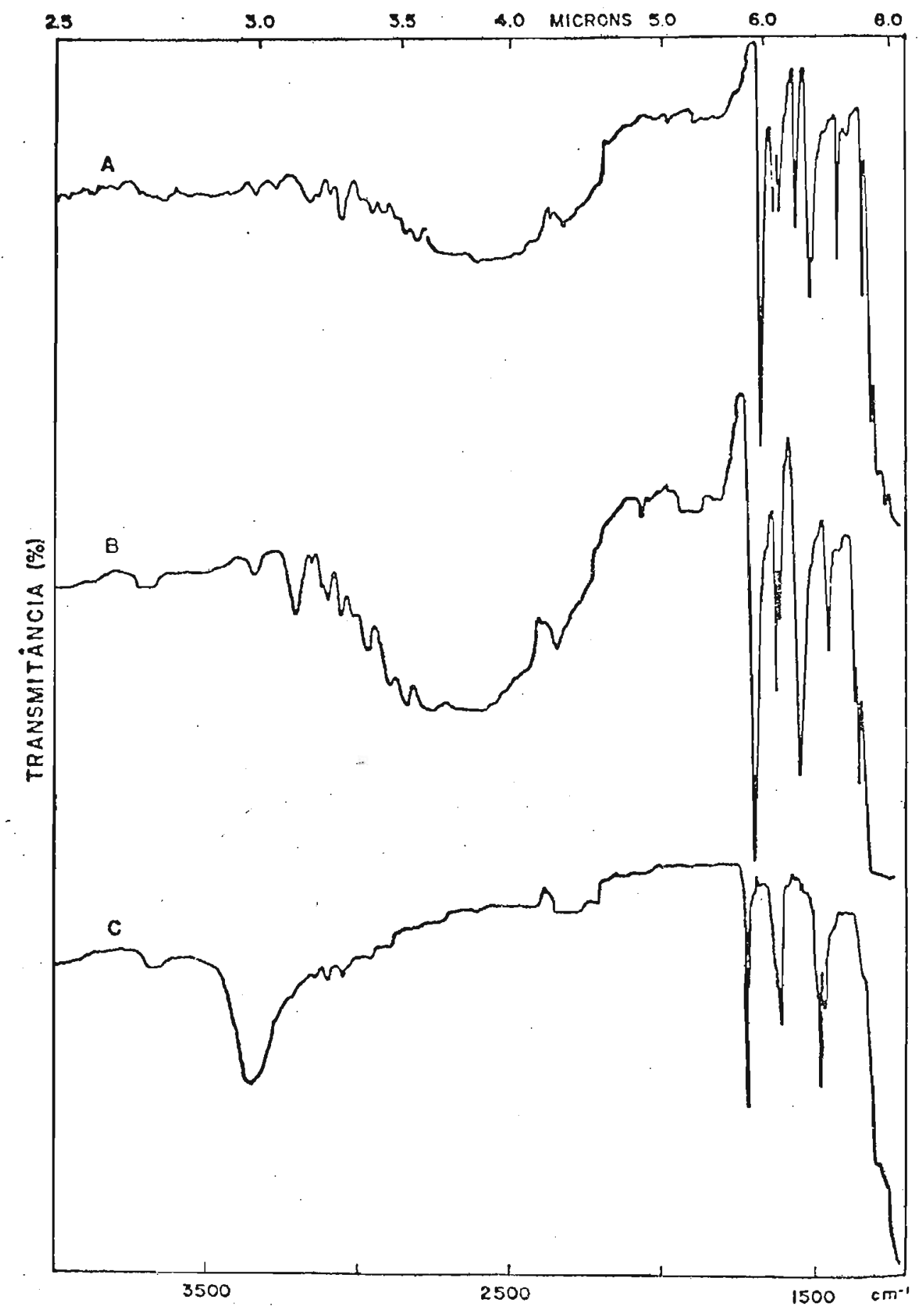

FIG. 5.27.A. Espectro na Região do Infravermelho de 4000 a $1300 \mathrm{~cm}^{-1}$ de A. p-py $(\mathrm{CO}) \mathrm{CHNOH}$
B. m-py $(\mathrm{CO}) \mathrm{CHNOH}$
C. o-py $(\mathrm{CO}) \mathrm{CHNOH}$ 


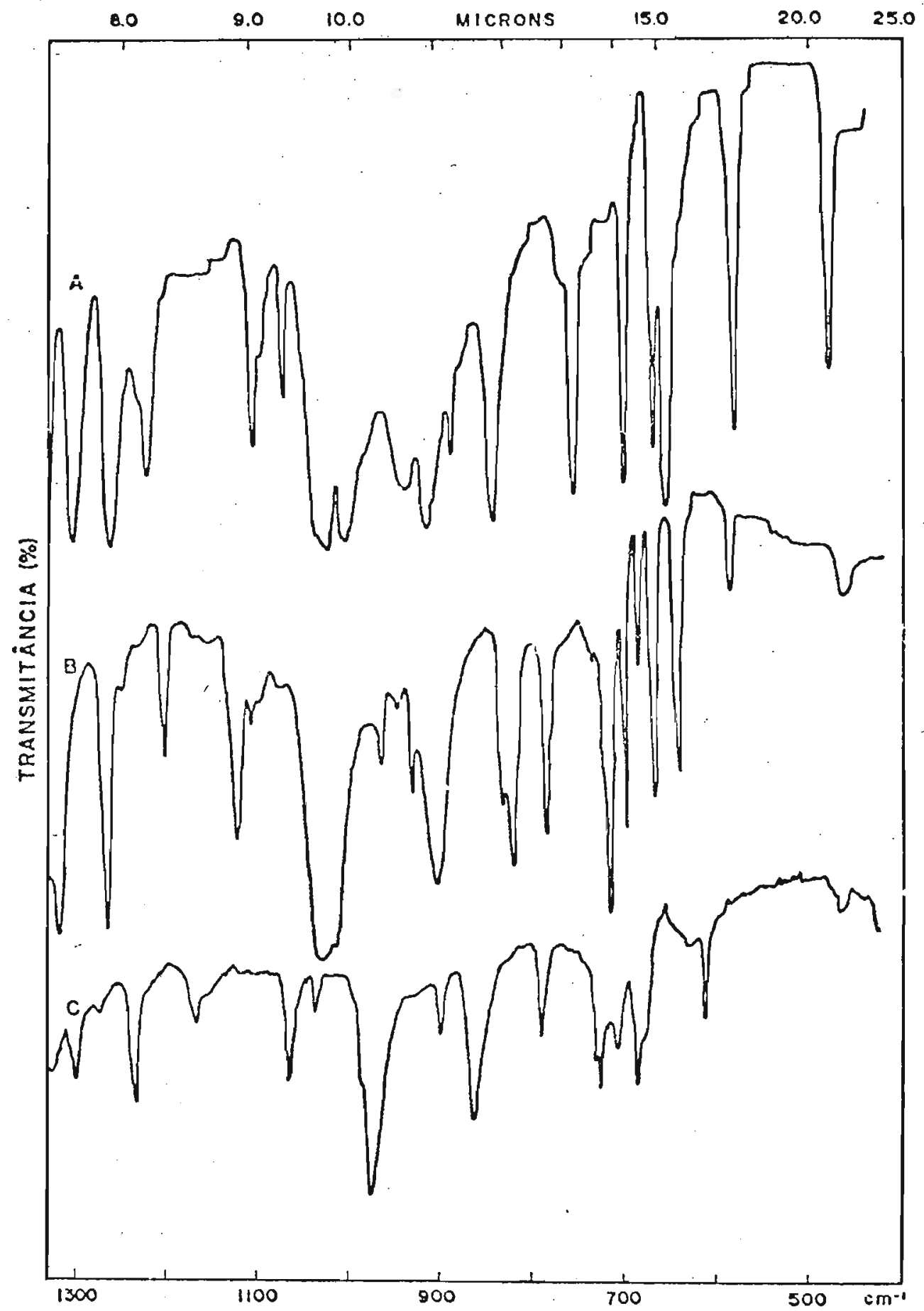

FIG. 5.27B. Espectro na Região do Infravermenlho de 1300 a $400 \mathrm{~cm}^{-1}$ de A. p-py (CO) CHNOH , B.m-py (CO) CHNOH c. o-py $(\mathrm{CO}) \mathrm{CHNOH}$ 


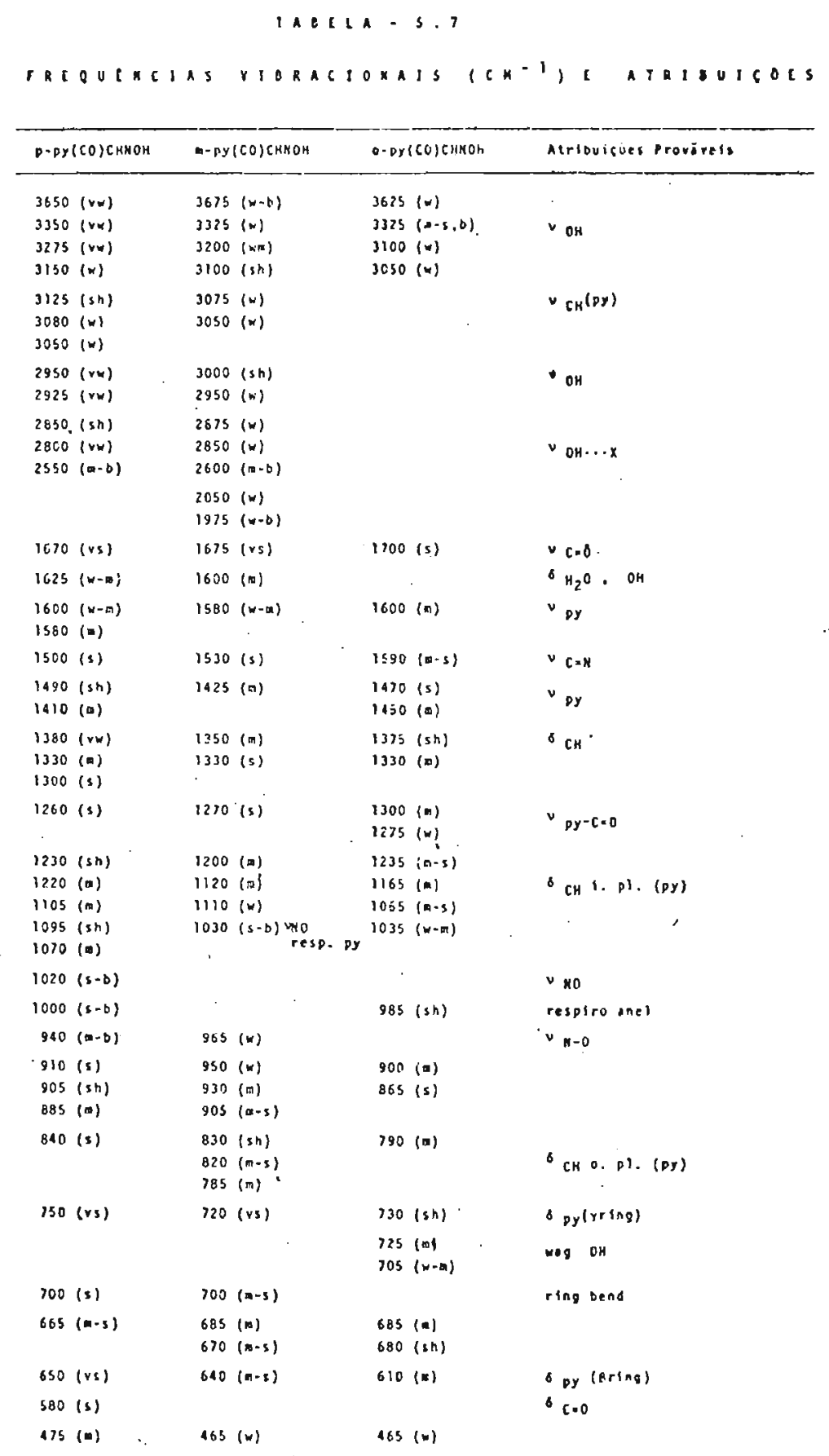

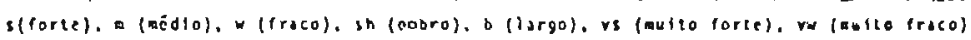
- (eslirsaenco, s(deformasjo) 
A estrutura do tipo A levaria à formação de uma interação entre $0-H \cdots O=C$ alëm de proporcionar nitro-

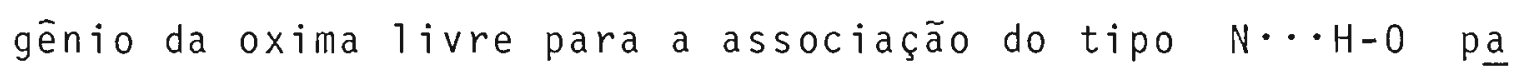
ra todos os isōmeros de acetilpiridina, independentemente.

Quando se tem cetonas conjugadas que apresen tam pontes de hidrogēnio $(0-H \cdots O=C)$, de tal maneira que a ressonāncia põe uma carga negativa no oxigênio da carbon la e lima carga positiva no átomo que faz a ligação com o próton, ocorre uma variação adicional na frequência de estiramento $C=0$. Devido à ponte de hidrogēnio, a ressonāncia é aumentada resultando num enfraquecimento da ligação $c=0$, abaixando mais ainda a frequēncia de estiramento $C=0$. Para as carbonil-oximas da acetilpiridina, estas vibrações aparecem nas frequências entre $1670 \mathrm{~cm}^{-1}$ até $1700 \mathrm{~cm}^{-1}$ que correspondem às de cetonas conjugadas sem pontes de hidro gènio.

Através destes dados, observa-se que a associa ção $C=0 \cdots H$ deve ser muito pequena. Isto sugere que a interação existente nos derivados em meta e para deve ser do tipo $\quad \mathrm{O}_{N} \cdot \mathrm{H}_{-0}$ que depende da presença do nitrogênio do anel piridínico estericamente livre. No derivado orto, devido aos efeitos estéricos dos grupos de vizinhança, não se tem a possibilidade desse tipo de associação.

Para os derivados com os substituintes do anel piridinico em posição para e meta, as bandas a 1500 e 1520 $\mathrm{cm}^{-1}$, respectivamente, são atribuĩdas ao estiramento $\mathrm{C}=\mathrm{N}$ ( cỉclica). Esta frequēncia è consideravelmente menor em rela 
ção a $1650 \sim 1620 \mathrm{~cm}^{-1}$ onde em geral ela é observada. Este abaixamento confirma a forte interação do nitrogēnio piridinico com o hidrogēnio da oxima. Nestes compostos, podese sugerir a existēncia das estruturas do tipo (I) onde 0 prōton da oxima é particularmente ionizado.

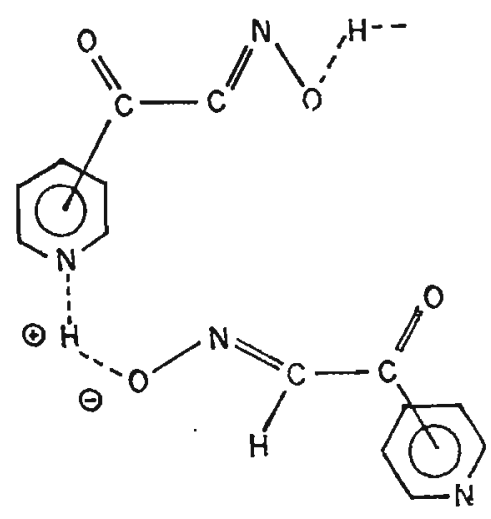

I

Esse efeito é verificado no espectro do sal de potássio de 2-piridinaldoxima (esquema II) e nos complexos que contēm o grupo $-\mathrm{C}=\mathrm{N}^{-} \mathrm{O}^{-}$(379). Nestes compostos observa - se que a atribuição do estiramento $C=N$ se faz numa região de frequência de absorção muito baixa para o referido grupo $\left(1519-1505 \mathrm{~cm}^{-1}\right)$.
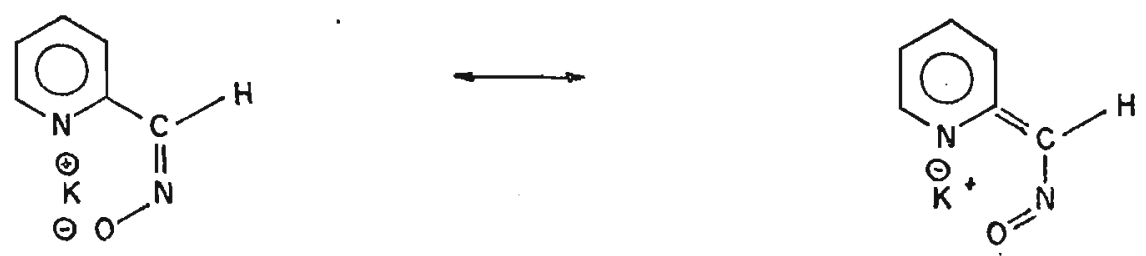
No o-py(CO)CHNOH atribui-se a banda a $1590 \mathrm{~cm}^{-1}$ à frequência de estiramento $\mathrm{C}=\mathrm{N}$.

Na frequência de absorção do estiramento N-0 hả uma variação inversa. A medida que o prōton da oxima tor na-se mais iōnico, hä provavelmente maior contribuição da es trutura $-N=0$; consequentemente a vibração $-C=N$ des loca-se a frequēncias menores, e a vibração $N$ - 0 , para fre quências maiores. Assim, nos derivados em meta e para, atri buição da banda para $v N-0$ foi feita considerando o pico em torno de $1030 \mathrm{~cm}^{-1}$. Esta é alargada,provavelmente devido ao envolvimento em processos de associação atravēs de ponte de hidrogēnio. Deve existir ainda a contribuição das vibrações correspondentes'́ao $\delta_{\mathrm{CH}^{i}}$ pl. do anel piridinico e respiro do anel que ocorre nessa região. 0 seu valor confirma a $e=$ xistēncia da estrutura do tipo $-\mathrm{C}=\mathrm{N}-\mathrm{O}^{-}$e $\mathrm{H}-\mathrm{O}-\mathrm{N}=\mathrm{C}$ ( com a oxima podendo ter ou não ponte de hidrogēnio) e encon tra-se entre $985 \mathrm{~cm}^{-1}$ atribuido a 2 -piridinaldoxima com 0 pröton parcilmente ionizado e $1075 \mathrm{~cm}^{-1}$ atribuído ao sal deste ligante (279). NO O-py(CO)CHNOH, a banda de estiramen to N-O corresponde a absorção intensa a $975 \mathrm{~cm}^{-1}$ cujo va lor indica uma associação bem menos intensa do próton da oxima.

A atribuição para as vibrações correspondentes ao anel piridínico fez-se baseando-se na tabela anteriormen te mencionada, e consta na tabela relacionada na pägina a seguir. 


\begin{tabular}{ccccc}
\hline Substância & $\mathrm{A}_{1}$ & $\mathrm{~B}_{1}$ & $\mathrm{~A}_{1}$ & $\mathrm{~B}_{1}$ \\
\hline p-py (CO) CHNOH & 1605 & 1550 & 1490 & 1410 \\
m-py (CO) CHNOH & - & 1580 & - & 1425 \\
o-py (CO) CHNOH & 1605 & - & 1470 & 1450 \\
\hline
\end{tabular}

Na região de $1300-1000 \mathrm{~cm}^{-1}$ temos $\delta_{\mathrm{CH}^{i}} \mathrm{pl}$. do anel e respiro do anel cuja atribuição também se baseou na tabela anteriormente transcrita.

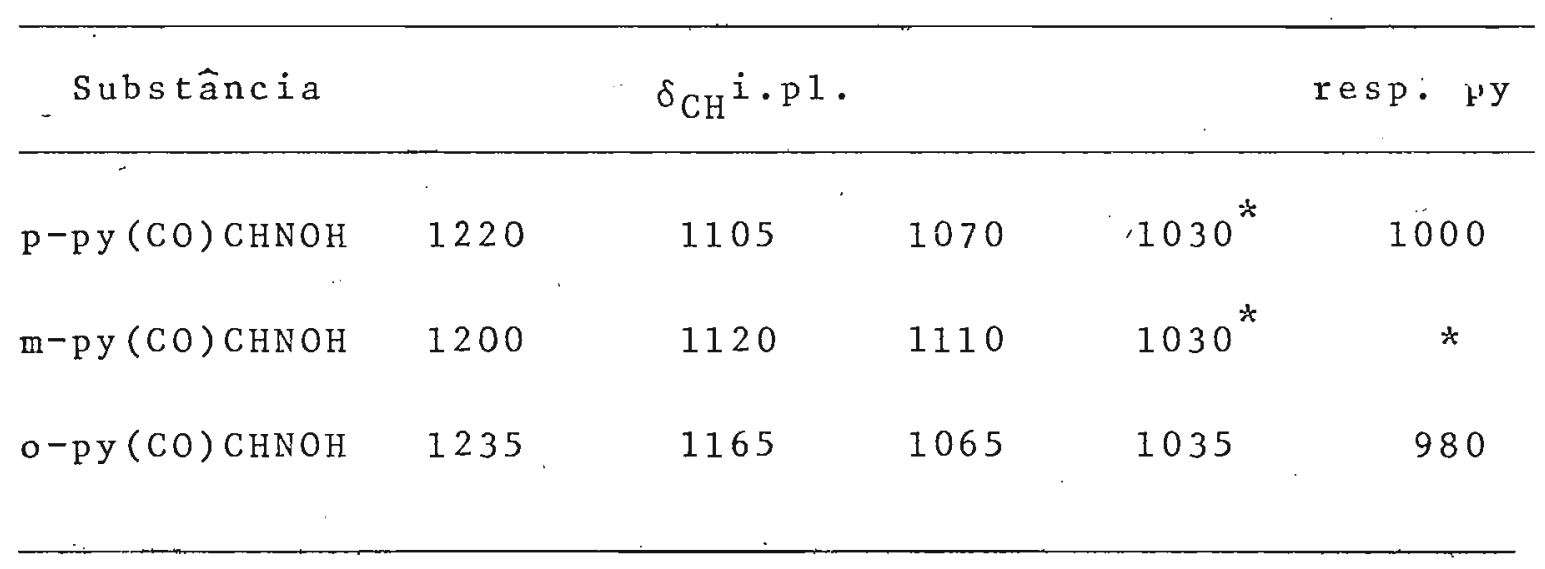

As demais atribuições fez-se por comparação com os dados da literatura para as piridinas substituĩdas con forme esquema utilizado para as acetilpiridinas e constam na tabela 5.7 .

* As bandas devem aparecer superpostas à da v $v_{N-O}$ 
5.2.2. Espectros de Absorção no Infravermelho para os comple xos

Os espectros de absorção no infravermelho dos complexos de pentacianoferrato(II) com ligantes $\mathrm{N}$-heteroci clico e dos intermediārios correspondentes estão reunidos nas figuras 5.28 a 5.32 .

A atribuição das diversas bandas foi feita por comparação com os dados para os ligantes livres e complexos anälogos (229) (TAB. 5.8. a 5.12.).

Na região de 3550 a $3000 \mathrm{~cm}^{-1}$ observam-se em todos os complexos, forte absorção indicativa da presença de àgua. Nessa mesma região, aparecem superpostas as absorções referentes aos modos normais de estiramento $\mathrm{C}-\mathrm{H}$.

As bandas intensas na região de 2100 a $2000 \mathrm{~cm}^{-1}$ são características do estiramento $C \equiv N$ em complexos de pen tacianoferrato(II).

De acordo com a teoria de grupo, os modos normais de vibração de estiramento $C \equiv N$ para um complexo $M_{i}(C N)_{5} L$ de simetria $C_{4 V}$ transformam-se de acordo com as re presentações $2 A_{1}$ (ativas no Raman e no I.V.), B $B_{1}$ (ativa no Raman) e E (ativa no Raman e Infravermelho).

Espera-se portanto a ocorrēncia de duas absorções ativas no infravermelho de simetria $A_{1}$ e outra, dupla mente degenerada, de simetria E.

As frequências vibracionais dos cianetos equa- 

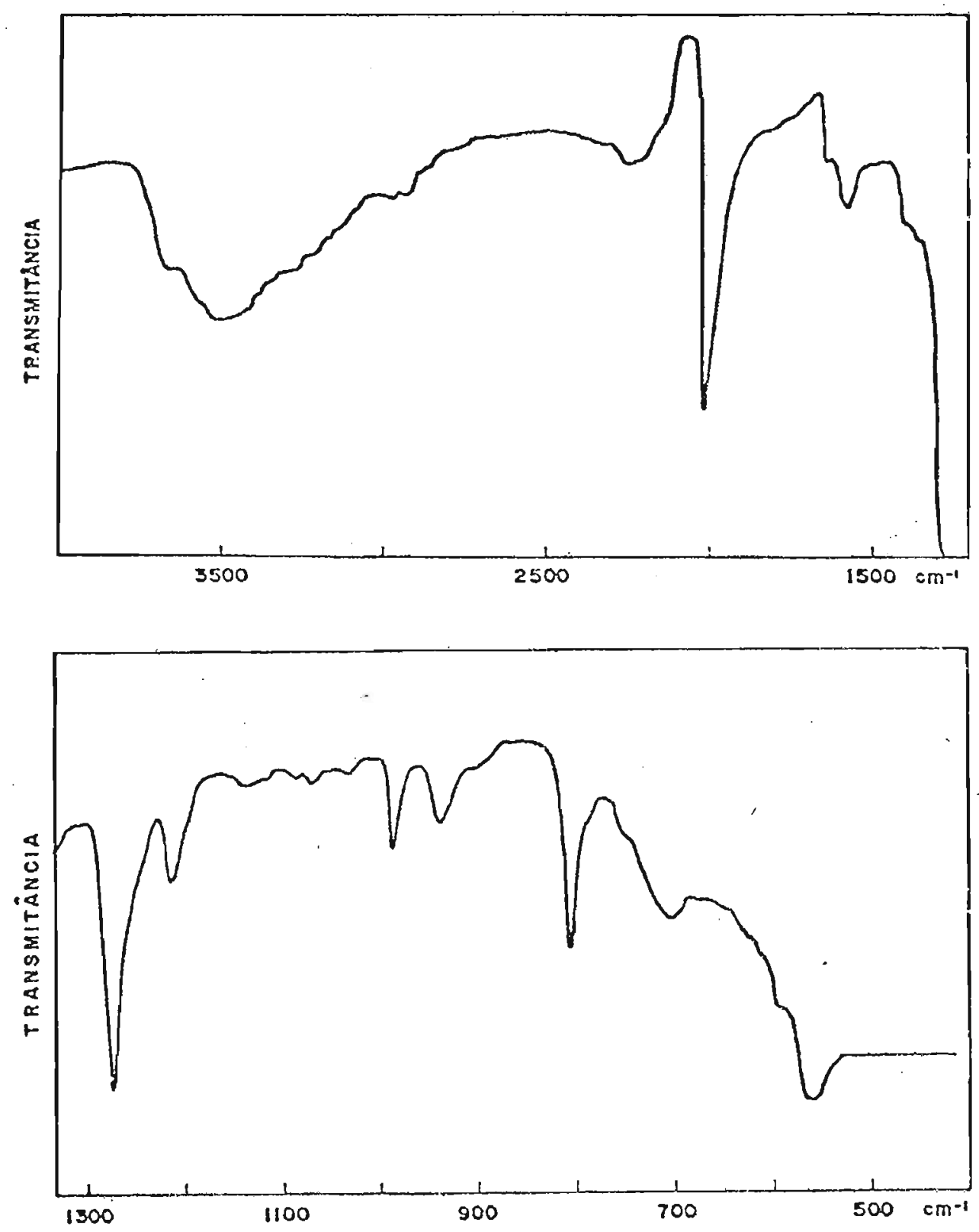

FIG. 5.28. Espectro na Região do Infravermelho do complexo $\mathrm{Fe}(\mathrm{CN})_{5} \mathrm{p}-\mathrm{py}(\mathrm{CO}) \mathrm{CH}_{3}$ 


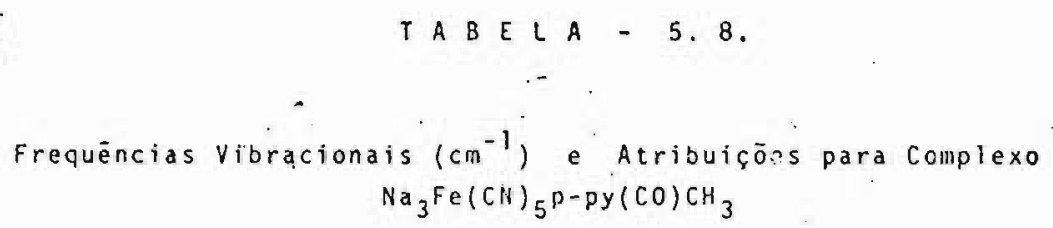

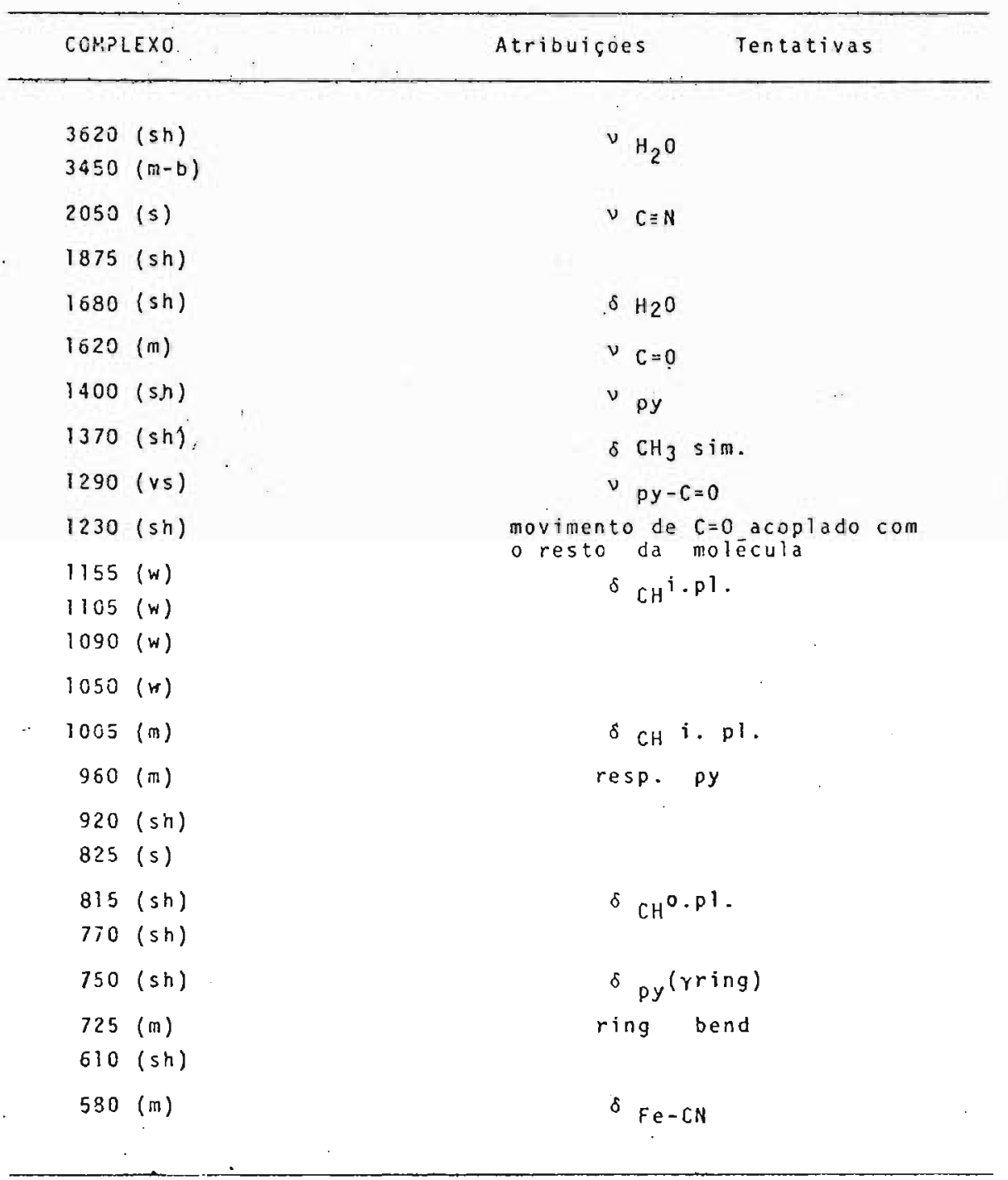

vs (muito forte), s (forte), $m$ (médio), w (fraco), sh (ombro) $v(e s t i r a m e n t o), \delta($ deformação) 


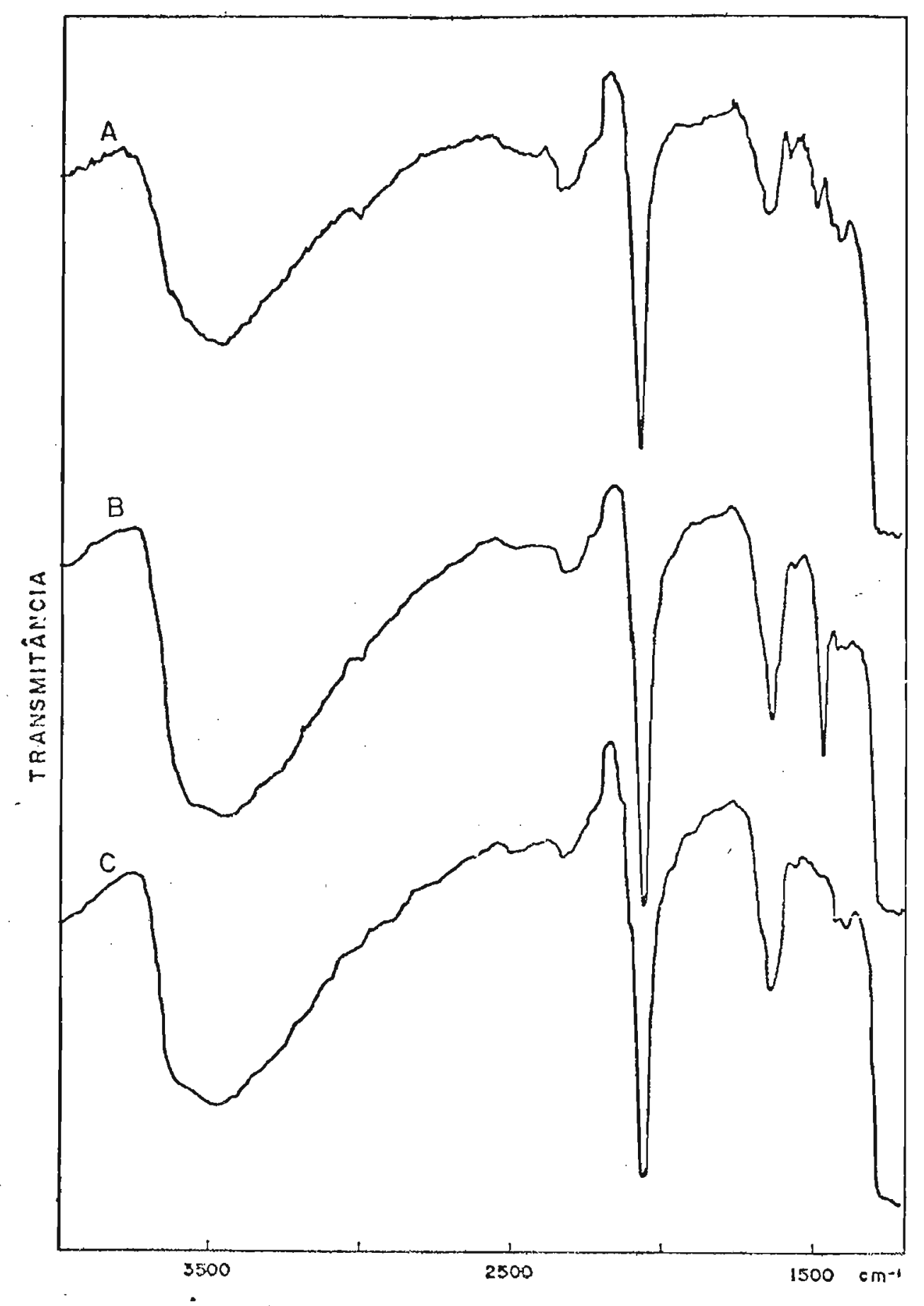

FIG. 5.29A. Espectro na Região do Infravermelho de 4000 a $1300 \mathrm{~cm}^{-1}$ dos complexos A. Fe (CN) ${ }_{5} \mathrm{p}-\mathrm{py}(\mathrm{CO}) \mathrm{CHNO}$ B. Intermediārio básico C. Intermediārio ācido 


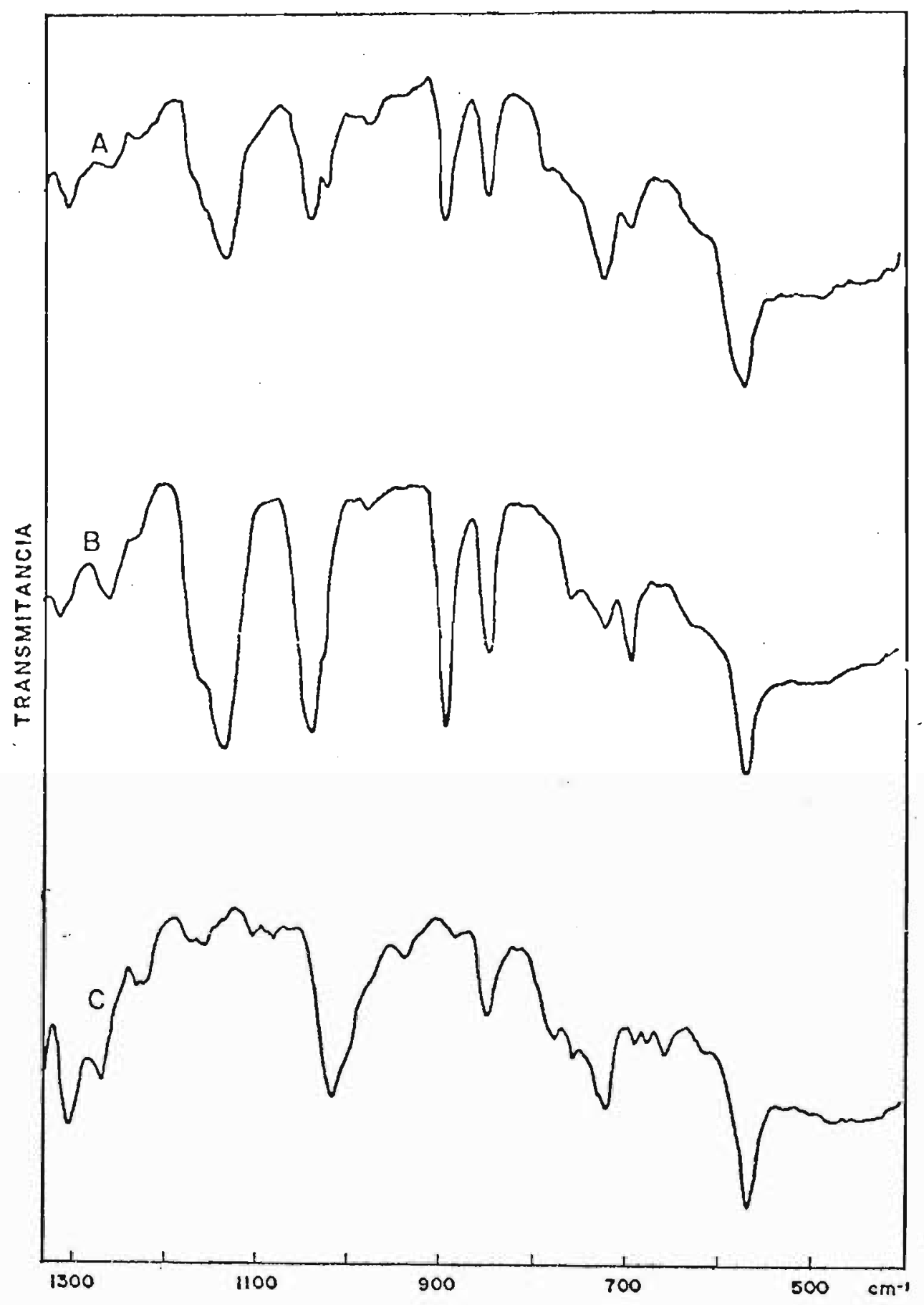

FIG. 5.29B. Espectro na Região do Infravermelho de 1300 a $400 \mathrm{~cm}^{-1}$ dos complexos A. Fe $(\mathrm{CN})_{5} \mathrm{p}-\mathrm{py}(\mathrm{CO}) \mathrm{CHNOH}$
B. Intermediārio bāsico
C. Intermediārio ácido 


\section{3}

T A B E LA - 5. 9.

Frequēncias Vibracionais $\left(\mathrm{cm}^{-1}\right)$ e Alribuiçào para complexus $\mathrm{Na}_{3}(\mathrm{CN})_{5} \mathrm{Fep}-\mathrm{py}(\mathrm{CO}) \mathrm{CH}$ YOH

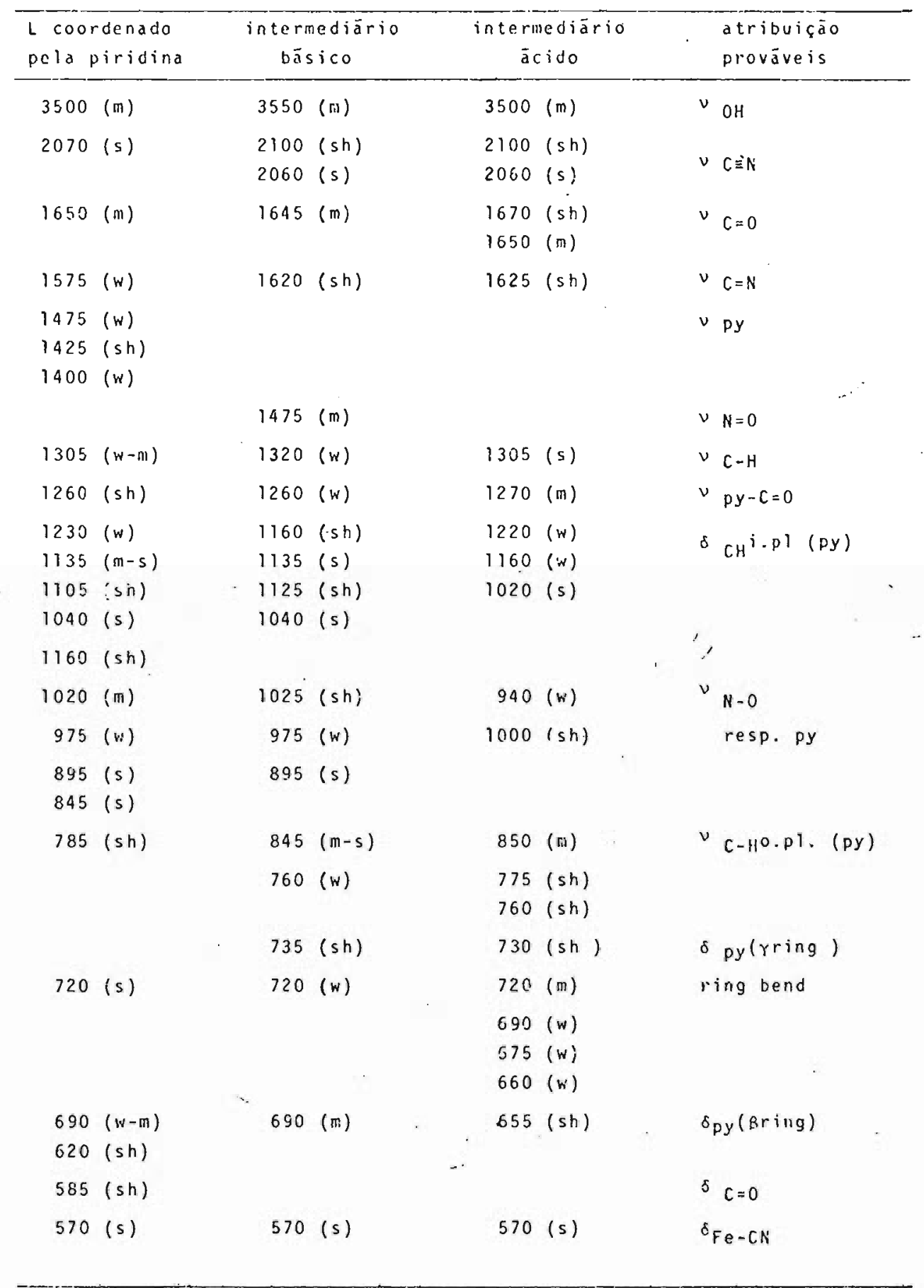

s (forte), m(mêdio), w(fraco), sh(cmbro), yestiramenta), d(deformação). 

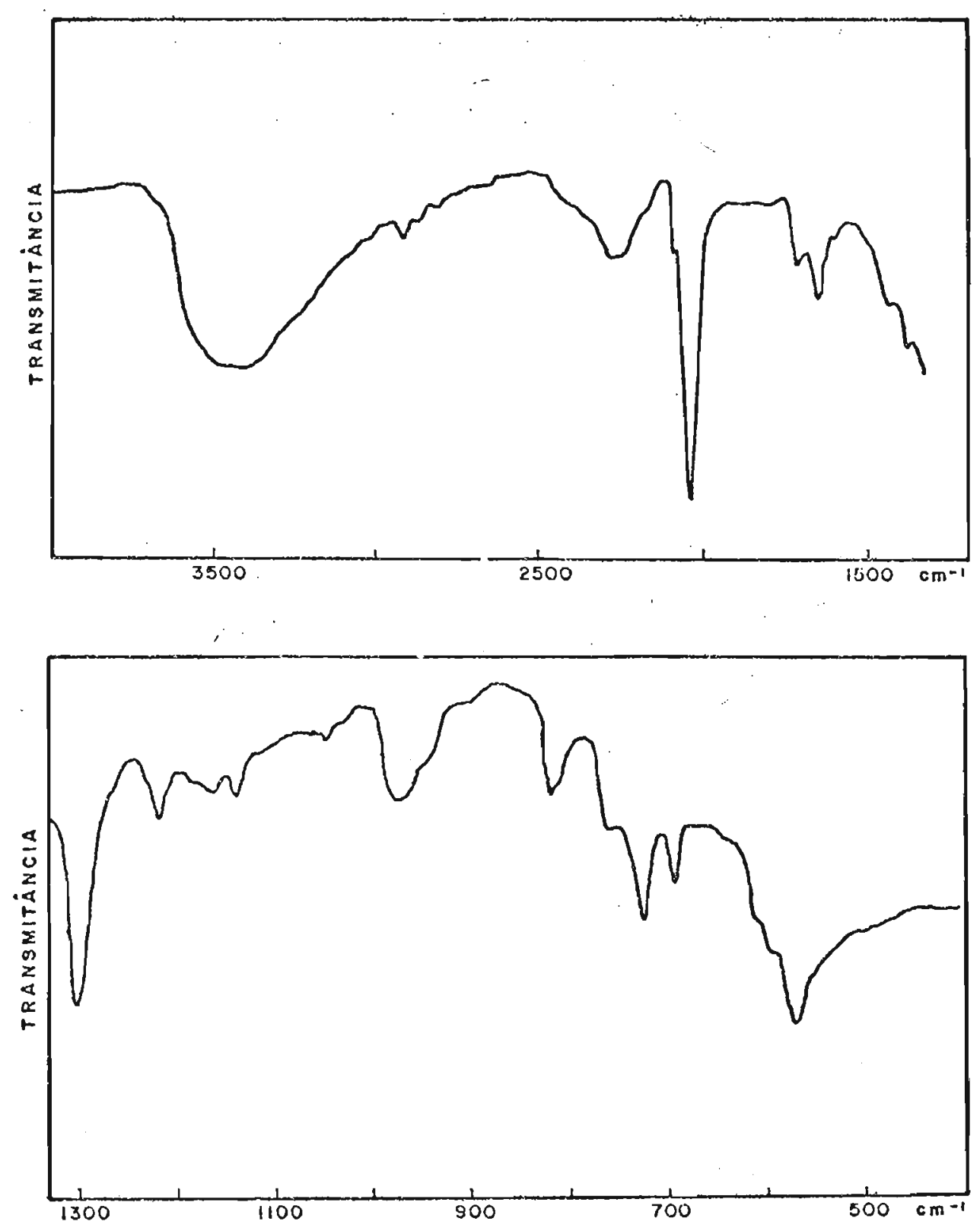

FIG. 5.30. Espectro na Região do Infravermelho do Complexo $\mathrm{Na}_{3} \mathrm{Fe}(\mathrm{CN}){ }_{5} \mathrm{~m}-\mathrm{py}(\mathrm{CO}) \mathrm{CH}_{3} \cdot 4 \mathrm{H}_{2} \mathrm{O}$ 
TABELA-5, 10.

Frequencias vitracionais $\left(\mathrm{Cm}^{-1}\right)$ e Atrituiçoes para Complexo $\cdot \mathrm{Na}_{3} \mathrm{Fe}(\mathrm{CN})_{5} \mathrm{~m} \cdot \mathrm{Py}(\mathrm{CO}) \mathrm{CH}_{3}$

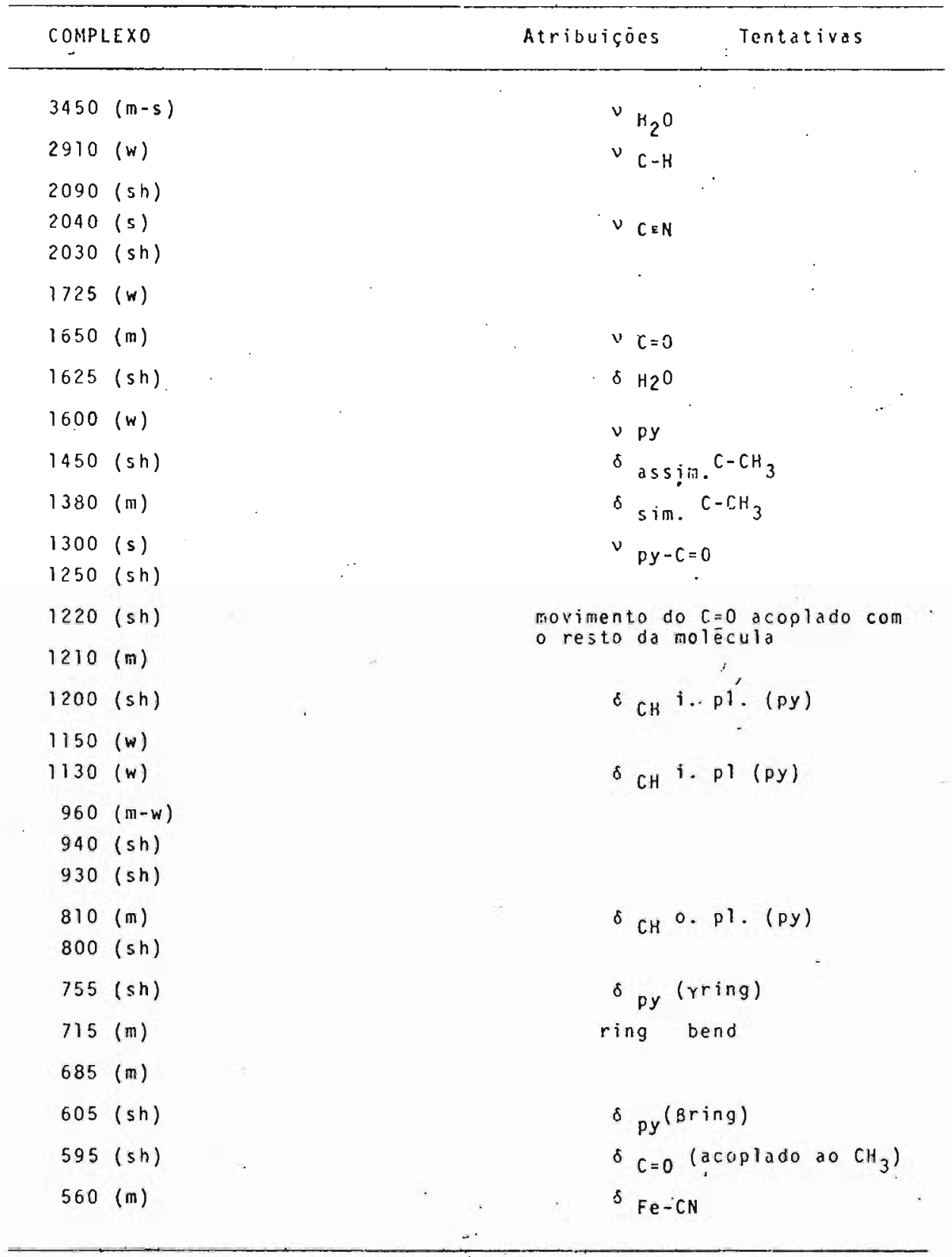

$s$ (forte), m (médio), w(fraco), sh (ombro), v(estiramento), o(deformação) 


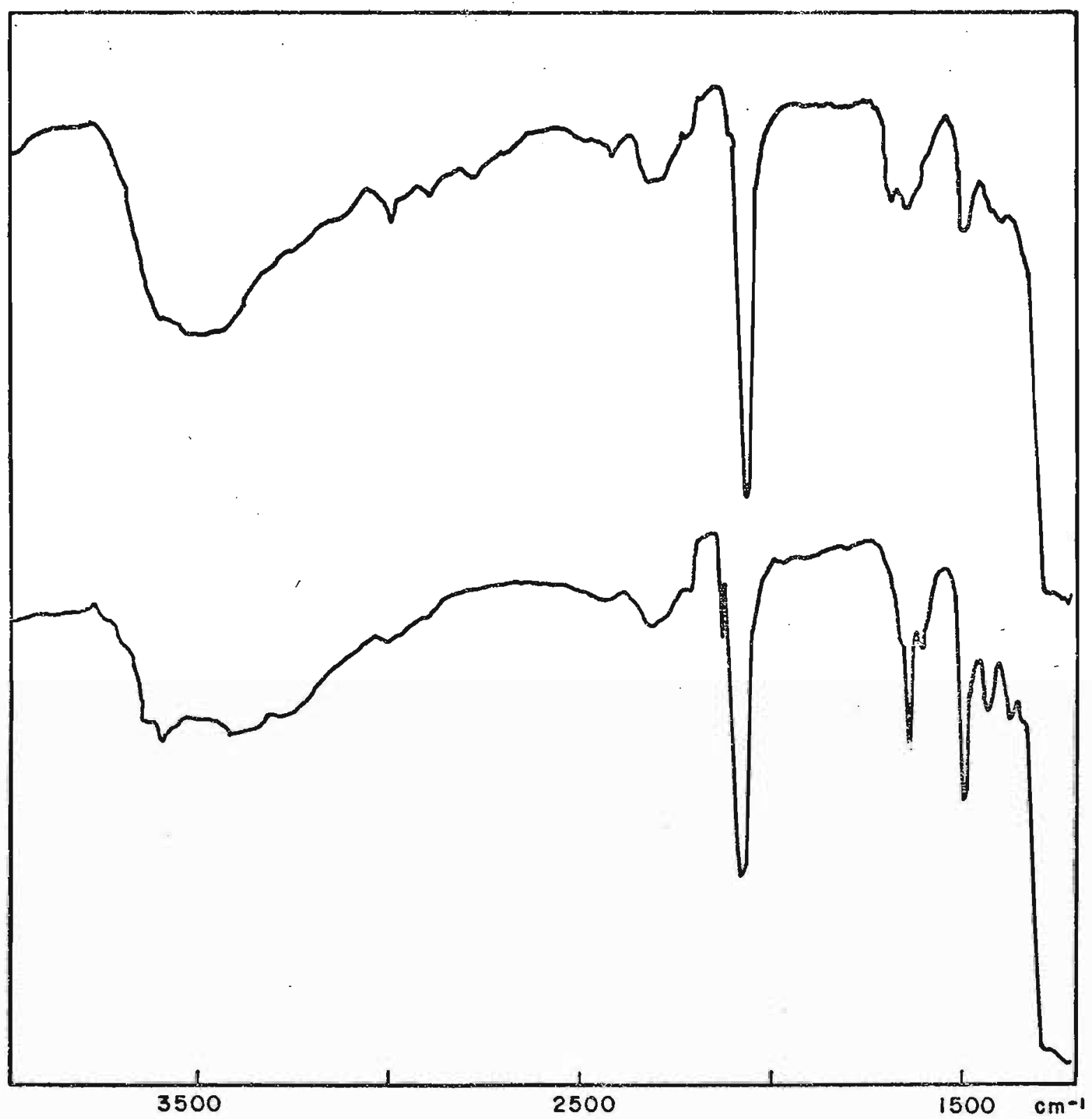

FIG. 5.31.A. Espectro na Região do Infravermelho de 4000 a $1300 \mathrm{~cm}^{-1}$ dos complexos

A. $\mathrm{Na}_{3} \mathrm{Fe}(\mathrm{CN}){ }_{5} \mathrm{~m}-\mathrm{py}(\mathrm{CO}) \mathrm{CHNOH} \cdot 3 \mathrm{H}_{2} \mathrm{O}$

B. Intermediārio bāsico 


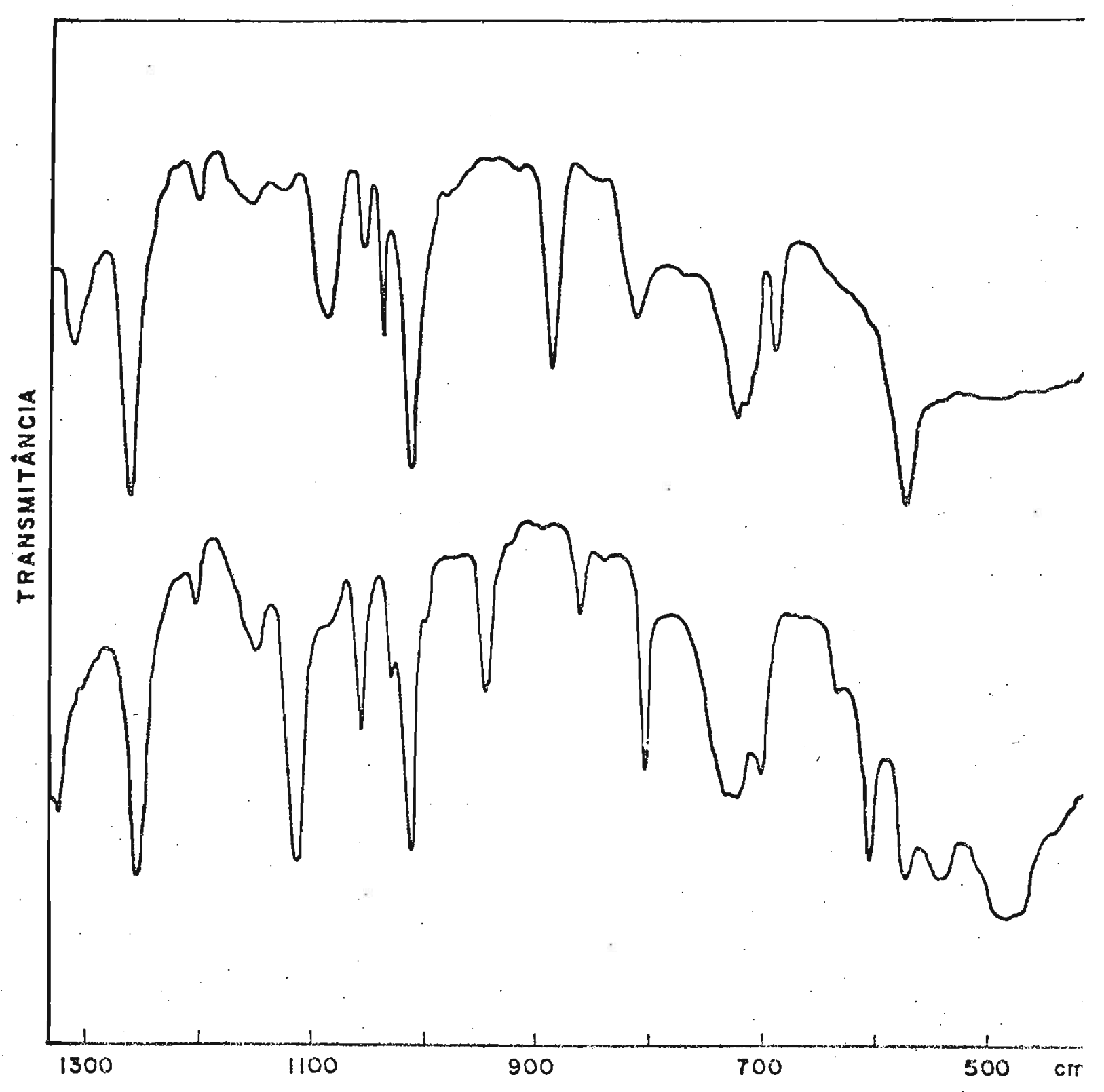

FIG.5.31.B. Espectro na Região do Infravermelho de 1300 a
a $400 \mathrm{~cm}^{-1}$ dos complexos
A. $\mathrm{Na}_{3} \mathrm{Fe}(\mathrm{CN})_{5} \mathrm{~m}-\mathrm{py}(\mathrm{CO}) \mathrm{CHNOH} \cdot 3 \mathrm{H}_{2} \mathrm{O}$
b. Intermediārio bāsico 
I A B E LA - 5. 11

Frequencias Vibracionais $\left(\mathrm{cm}^{-1}\right)$ e Alribuicoes para Complexos

$\mathrm{Na}_{3}(\mathrm{CN})_{5} \mathrm{FEH}-\mathrm{Py}(\mathrm{CO}) \mathrm{CHNOH}$

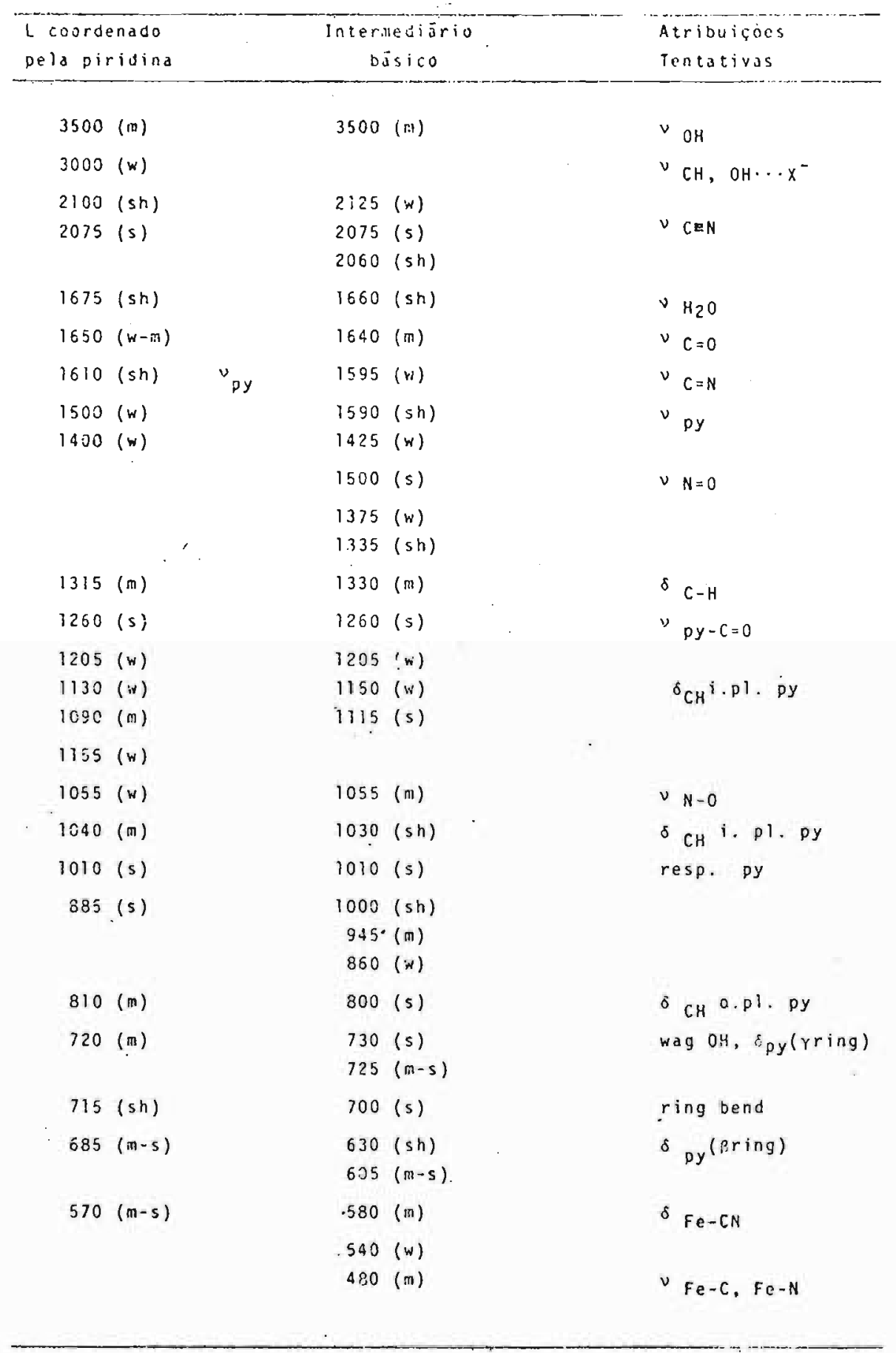

$s(f \circ r t e), m(m e ̈ d i a), m(f r a c o), s h(0 a b r o), v(e s t i r a m e n t o), s(d e f o r m a c a j o)$ 
toriais, do tipo $A_{1}$ e $E$ são provavelmente muito prōxima: Na maioria dos casos, essas transições ocorrem superpostas, dando origem a uma banda larga e assimëtrica. A presença de um pico fino, de intensidade fraca ou média, sempre em frequências mais altas, foi sugerida uma atribuição do tipo $A_{1}$ envolvendo o cianeto axial, por analogia com atribuição fẹ ta ao nitroprussiato.

Comparando-se as frequëncias de estiramento $C N$ em $\mathrm{Na}_{3} \mathrm{Fe}(\mathrm{CN})_{5} \mathrm{Py}(\mathrm{CO}) \mathrm{CH}_{3}$ e $\mathrm{Na}_{3} \mathrm{Fe}(\mathrm{CN})_{5} \mathrm{Py}(\mathrm{CO}) \mathrm{CHNOH}$ pode-se n! tar claramente a dependéncia da natureza do ligante $L$ no: complexos.

0 aumento da capacidade $\pi$ receptora do ligan te carbonil-oxima resulta no deslocamento da frequēncia de estiramento $C N$ para valores mais altos, implicando num au. mento da força dessa ligação. Essa variação da frequéncia de estiramento CN pode ser explicada em termos das estruturas de ressonāncia abaixo:

$$
\begin{array}{cc}
L \rightarrow F e=C=\ddot{N}: & L=F e \leftarrow C \equiv N: \\
(A) & (B)
\end{array}
$$

os ligantes que a tuam como doadores o favorecei a estrutura $A$, uma vez que não conseguem competir com os cianetos em termos de interação de retrodoação com o ion me tālico. Os ligantes $\pi$ receptores atuam de maneira oposta, favorecendo a estrutura $B$ com a diminuição da retrodoação para os cianetos. A retrodoação para os cianetos aumenta a 
população dos nîveis antiligantes dos cianetos, diminuindo a ordem de ligação, e portanto, a frequéncia de éstiramento $C N$. As absorções que ocorrem ao redor de $570 \mathrm{~cm}^{-1}$ nos complexos de pentacianoferrato(II) são atribuídas à deformação Fe-CN por analogia com a atribuição feita para o ion hexacianoferrato por Griffithe Turner (280).

As bandas de estiramento $\mathrm{Fe}-\mathrm{C}$ ou $\mathrm{Fe}-\mathrm{N} \quad(-400$ a $450 \mathrm{~cm}^{-1}$ ) poderiam ser de grande utilidade para fins de correlação mas, a sua localização em frequências mais afastạ das do infravermelho bem como a sua baixa intensidade fazem com que sejam frequentemente encobertas ou então poüco definidas.

0 complexo intermediārio $\mathrm{Fe}(\mathrm{CN})_{5} \mathrm{Py}(\mathrm{CO}) \mathrm{CHNOH}^{3-} /$ $\mathrm{Fe}(\mathrm{CN})_{5} \mathrm{py}(\mathrm{CO}) \mathrm{CH}_{2} \mathrm{NO}^{3-}$ ou $\mathrm{Fe}(\mathrm{CN})_{5} \mathrm{py}(\mathrm{CO}) \mathrm{CHNO}^{4-}$, coordenado. pelo nitrogēnio da oxima, apresenta. uma banda nova ao redor de $1500 \mathrm{~cm}^{-1}$ atribuída a frequéncia de estiramento $\mathrm{N}=0$ ou a frequéricia de estiramento $C=N$. Deslocamento deste tipo pa ra ${ }^{v} \mathrm{C}=\mathrm{N}$ pode ser observado para os complexos com o prōton oxima não removido (279).

A sintese do intermediārio deve envolver a etapa esquematizada na reação a seguir.

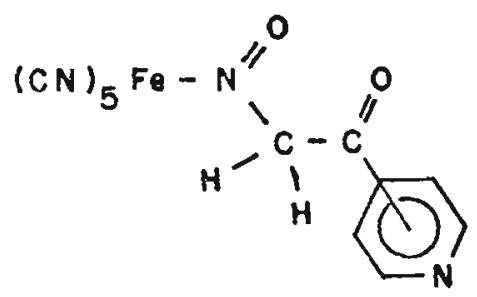

c

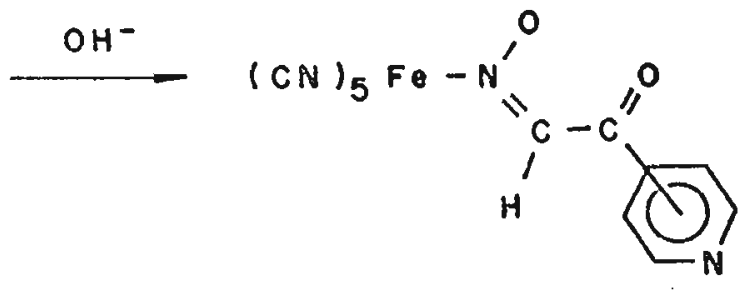

D 
171
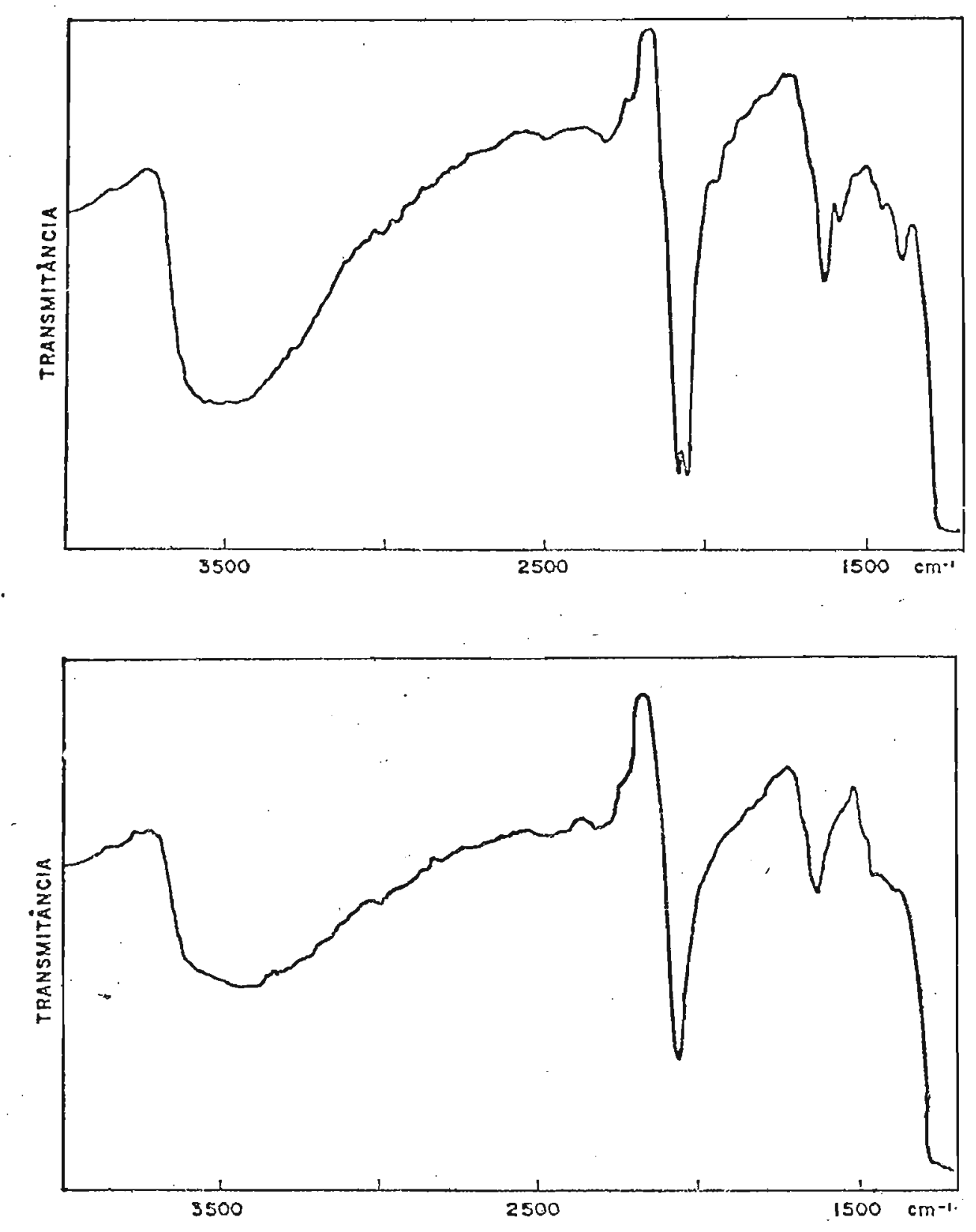

FIG.5.32.A. Espectro na Região do Infravermelho de 4000 a $1300 \mathrm{~cm}^{-1}$ dos complexos intermediários de $\mathrm{Fe}(\mathrm{CN})_{5}$ o-py(CO)CHNOH A. Forma ácida

B. Forma bāsica (?) 

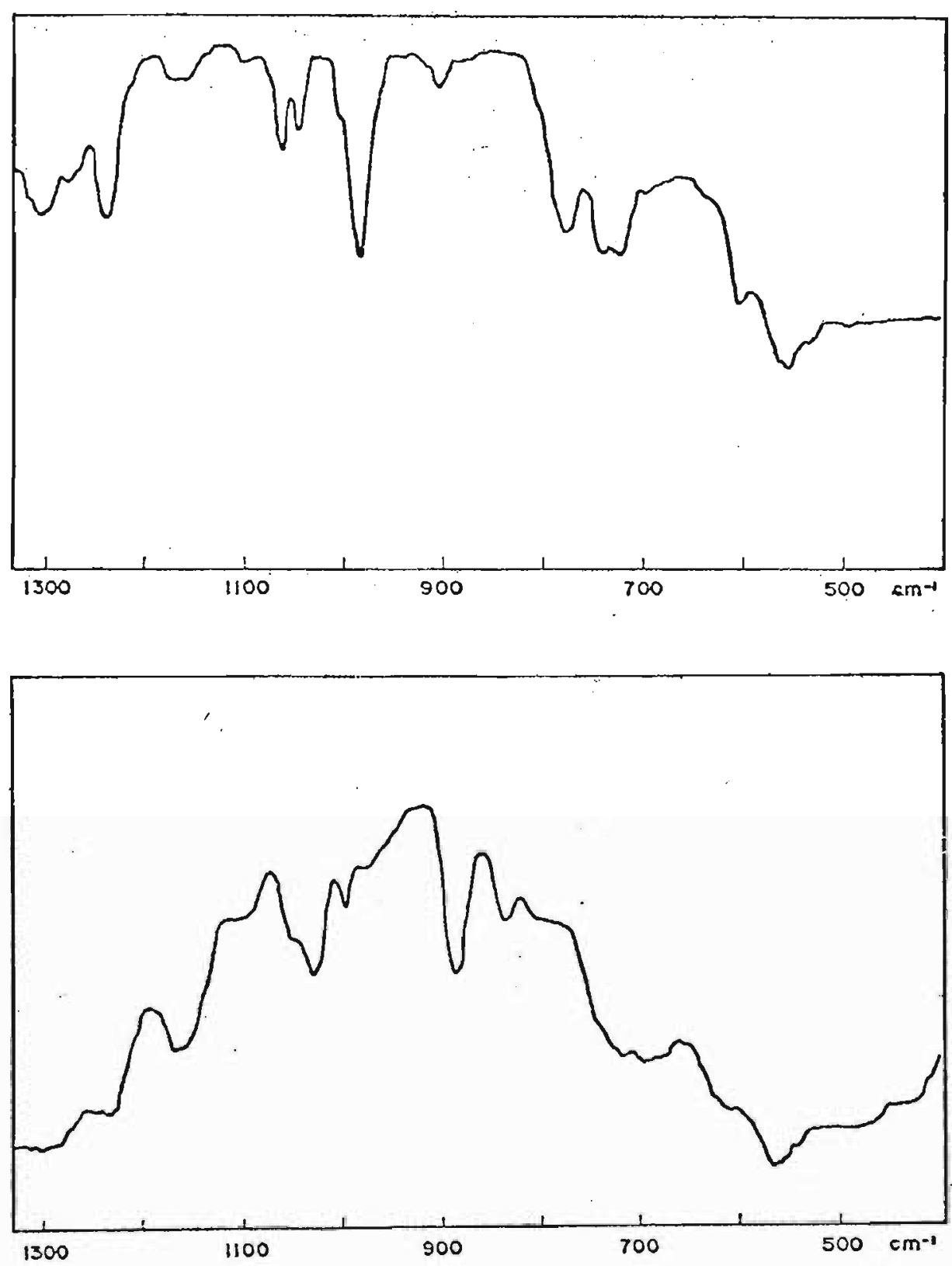

FIG.5.32.B. Espectro na Região do Infravermelho de 1300 a $400 \mathrm{~cm}^{-1}$ dos complexos intermediários de $\mathrm{Fe}(\mathrm{CN})_{5}{ }^{\circ-p y}(\mathrm{CO}) \mathrm{CHNOH}$ A. Forma äcida B. Forma básica 
T A BELA- 5. 12.

Frequencias Vibracionais $\left(\mathrm{cm}^{-1}\right)$ e Atribuiçōes para comolexos

$\mathrm{Na}_{3}(\mathrm{NC})_{5} \mathrm{Fe} . \mathrm{O}-\mathrm{Py}(\mathrm{CO}) \mathrm{CHNOH}$

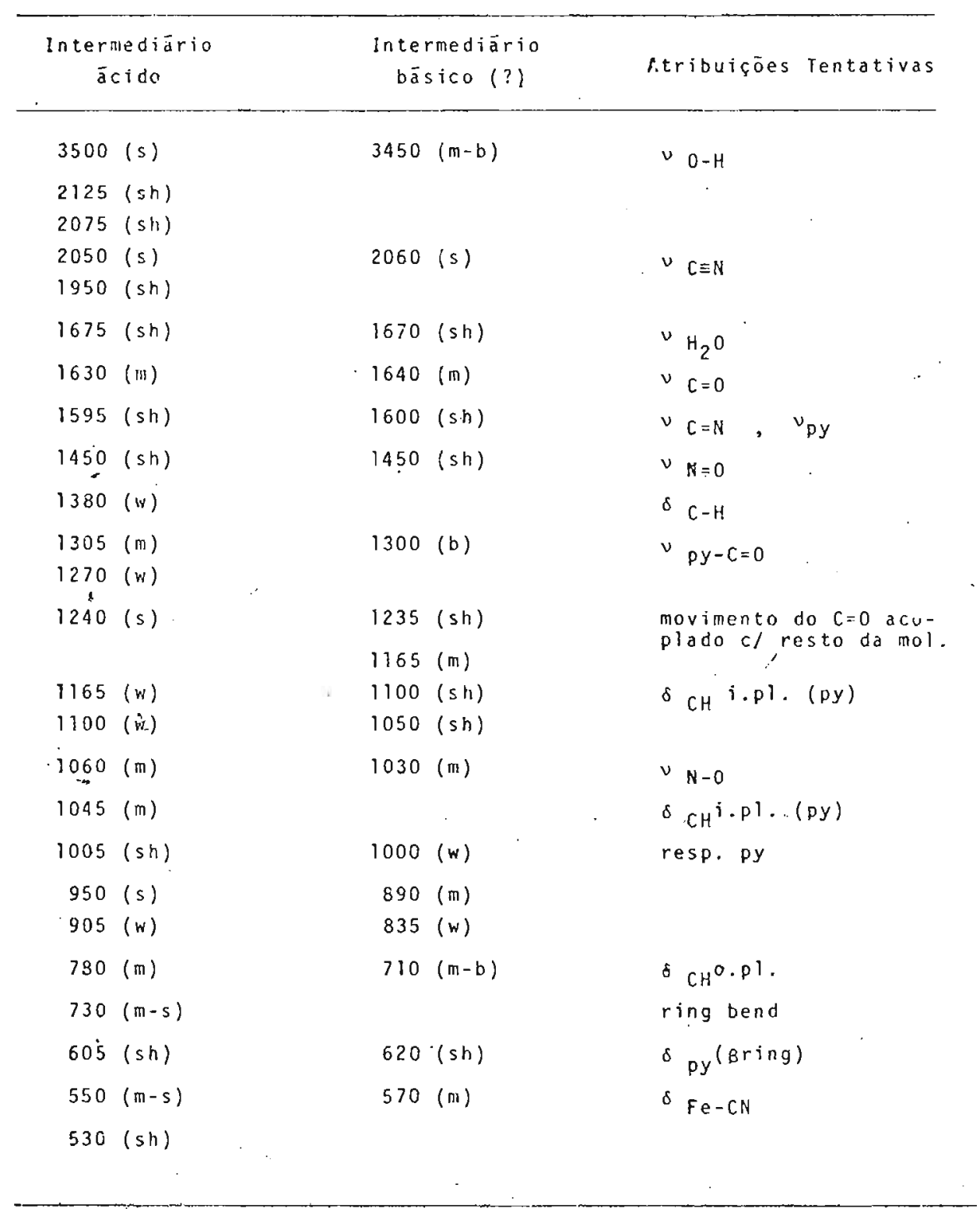

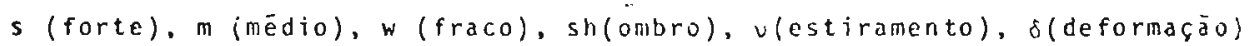


De tal forma que, tanto as formas $C$ como a $D$, bem como o produto final coordenado pela piridína podem estar presentes. A anāitise dos mesmos se torna bastante com plexa devido a esta provāvel mistura de espécies, principal mente para os derivados com os substituintes na posição para. 


\section{VI-CINÉTICA}

A quĩmica dos metalo-carbonilos fornece inūmeros exemplos do aproveitamento da reatividade de ligantes em processos de sintese (56). Fischer et al (254) obtive ram uma extensa variedade de intermediário carbeno-metāli cos de grande interesse, atravēs da reação de adição ao gru po carbonila. Apesar das reações de adição em nitrosilo-com plexos serem bastante conhecidas, raramente tem sido usadas em métodos preparativos.

0 interesse pelo isolamento, bem como pela pre paração de novas oximas, tem crescido enormemente nos ūitimos arics em virtude de suas aplicações analiticas e na química de coordenação (255).

Particularmente interessados ná sîntese de com. plexos contendo o grupo carbonil-oxima na molécula (72), o nosso estudo iniciou-se com a obtenção das aldoximas da ace tilpiridina, segundo o esquema simplificado

$$
\begin{gathered}
(\mathrm{NC})_{5} \mathrm{FeNO}^{2-}+\mathrm{CH}_{3}(\mathrm{CO}) \mathrm{py} \stackrel{\mathrm{OH}^{-}}{\rightarrow} \text { produto } \mathrm{X} \text { (intensamente } \\
\mathrm{Fe}(\mathrm{CN})_{5} \mathrm{dmsO}^{3-}+\mathrm{dmsO}(\mathrm{CO}) \mathrm{CHNOH}
\end{gathered}
$$


0 interesse pela natureza do produto $x$ inten samente colorido e, pela compreensão do mecanismo de adição das cetonas ao grupo nitrosilo coordenado, até o momento pou co investigado, motivou-nos o estudo da reação entre o ion nitroprussiato e os vārios isömeros da acetilpiridina.

0 estudo preliminar destas reações de adição mostrou que o mecanismo global é bem complexo, envolvendo vā rias etapas. Para a sua elaboração e compreensão, bem como para a obtenção de constantes de velocidades seriam necessā rios vários estudos cinéticos paralelos. Uma das etapas que certamente estaria presente nas condições de estudo cinētico da reação de adição, é aquela correspondente ao ataque das acetilpiridinas em excesso ao produto inicialmente formado.

A cinētica de formação e substituição dos complexos $\mathrm{Fe}(\mathrm{CN})_{5} \mathrm{~L}^{3-}$ onde $\mathrm{L}$ são os isōmeros das acetilpiridinas e carboni1-oximas correspondentes obtidas da reação de adição, foi estudada com o intuito de verificar e compreender a sua participação e influência no mecanismo da reação de a dição. Ao mesmo tempo, vem a complementar as informações ci llëticas do sistema pentacianoferrato(II)-Ligante (2.29, 257 252).

6.1. Cinētica de Formação e Substituição do Fe(CN) $5 L^{3-}$

6.1.1. Cinētica de Formaçäo de $\mathrm{Fe}(\mathrm{CN})_{5} \mathrm{~L}^{3-}$

A cinētica de formação das espēcies $\mathrm{Fe}(\mathrm{CN})_{5} \mathrm{~L}^{3-}$, 
a partir do ion aquopentacianoferrato(II), foi realizada em condições de pseudo primeira ordem, LiClo ${ }_{4} 0,10 M$ e à tem peratura de $25,0^{\circ} \mathrm{C}(263)$.

Em todos os casos, foram observados processos tîpicos de primeira ordem com respeito à formação dos produ tos $\mathrm{Fe}(\mathrm{CN})_{5} \mathrm{~L}^{3-}$, detectados em $515 \mathrm{~nm}$ (para $\mathrm{L}=\mathrm{p}-\mathrm{py}(\mathrm{CO}) \mathrm{CH}-$ $\mathrm{NOH}$ e $\left.\mathrm{p}-\mathrm{py}(\mathrm{CO}) \mathrm{CH}_{3}\right), 612 \mathrm{~nm}(\mathrm{o}-\mathrm{py}(\mathrm{CO}) \mathrm{CHNOH}), 365 \mathrm{~nm}(\mathrm{~m}-$ py $(\mathrm{CO}) \mathrm{CHNOH})$ e $385 \mathrm{~nm}\left(\mathrm{~m}\right.$-py $\left.(\mathrm{CO}) \mathrm{CH}_{3}\right)$ no aparelho "stopped - flow".

Na tabela 6.1. encontram-se os valores de kobs em função da concentração dos 1 igantes e nas figuras de 6.1 a 6.3. estão o gräfico de $k_{o b s}$ em função da concentração do ligante. Estes, com exceção do derivado em orto, que será discutido posteriormente, são retas que passam pela origem e, permitem obter a velocidade especîfica de formäção da es pëcie $\mathrm{Fe}(\mathrm{CN})_{5} \mathrm{~L}^{3-}\left(\mathrm{k}_{1}\right)$ a partir do coeficiente angular. A de pendēncia da constante de velocidade de formação com a temperatura "pode ser avaliada a partir dos dados tabelados ( TAB. 6.2.) e mostrados graficamente nas figuras 6.4. a 6.6. os parāmetros de ativação obtidos, juntamente com as veloci dades especîficas de formação dos compostos de pentacianofe rato(II) com ligantes mencionados, estão reunidos na Tab. A da pāgina a seguir.

Dos parāmetros tabelados pode-se observar se guintes aspectos:

- as velocidades específicas de formação e os parāmetros de ativação são praticamente constantes. 
TABELA - 6.1 .

Constante de Velocidade para a Reação de Formação. do Fe (CN ${ }_{5} \mathrm{~L}^{3-}$

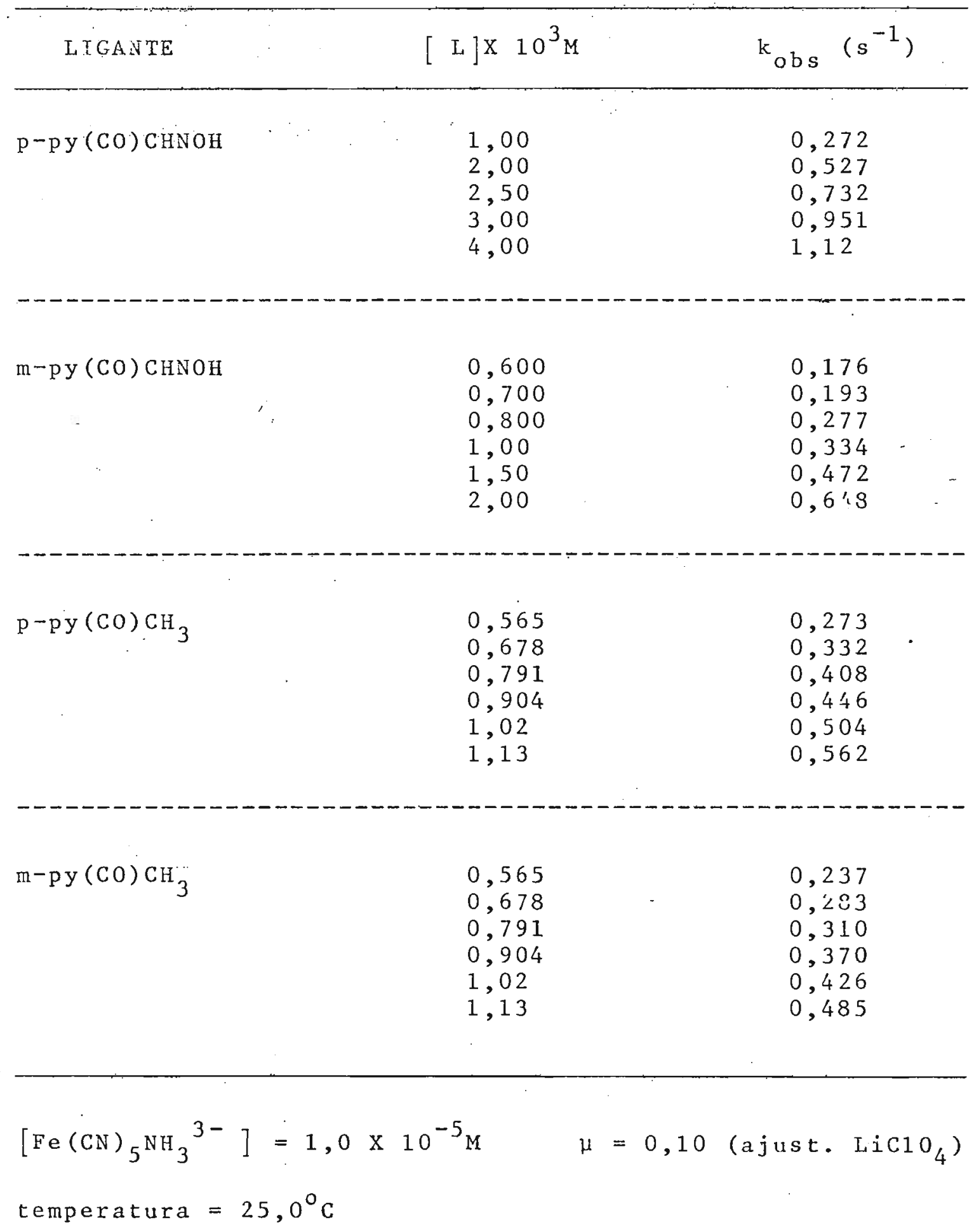




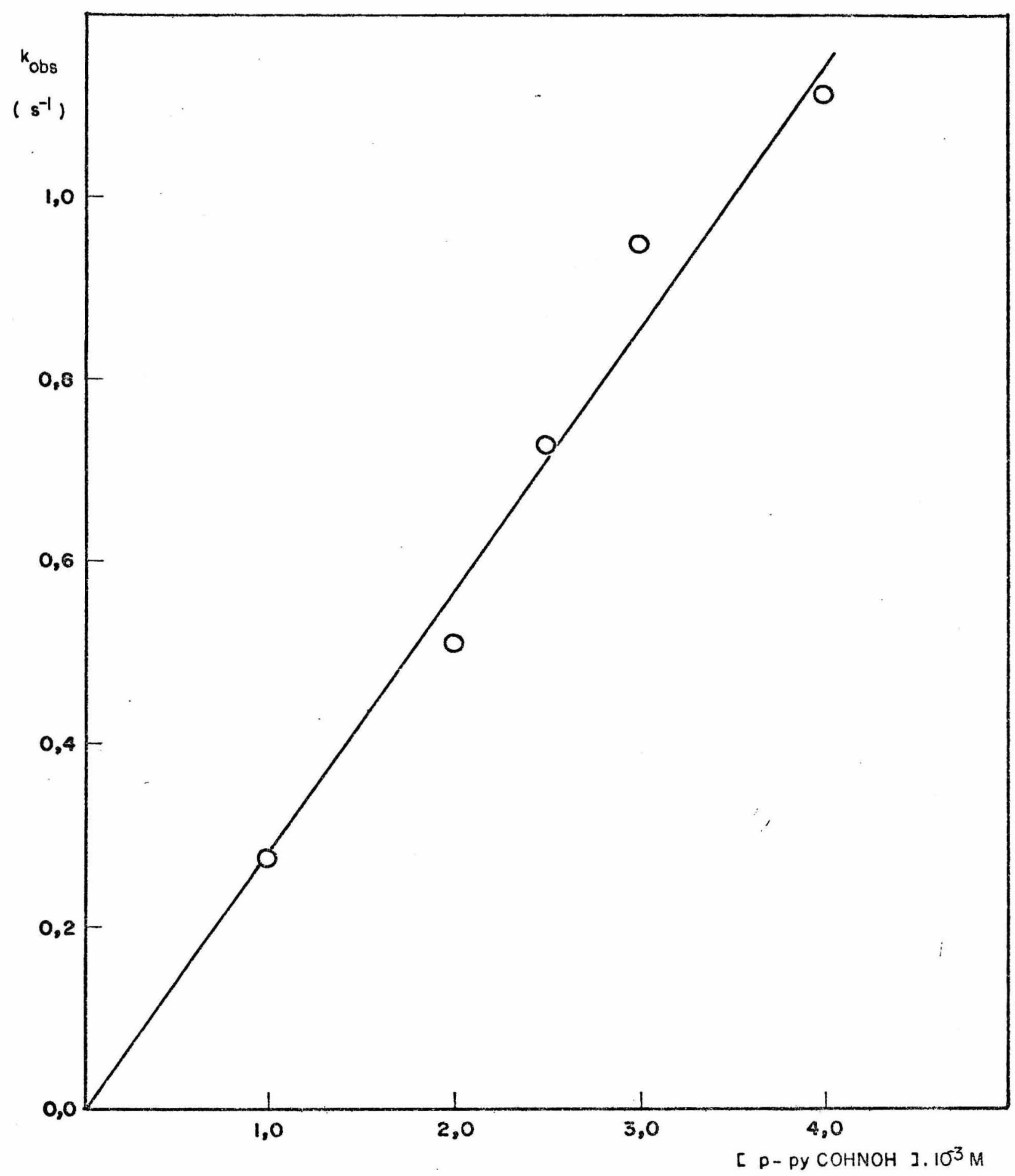

FIG. 6.1. Constantes de velocidade de formação do complexo $\mathrm{Fe}(\mathrm{CN})_{5} \mathrm{p}-\mathrm{py}(\mathrm{CO}) \mathrm{CHNOH}^{3-}$ em função da concentração de $\quad$-py $(\mathrm{CO}) \mathrm{CHNOH} \quad \mu=0,100\left(\mathrm{LiClO}_{4}\right) \quad \mathrm{t}=25,0^{\circ} \mathrm{C}$ 


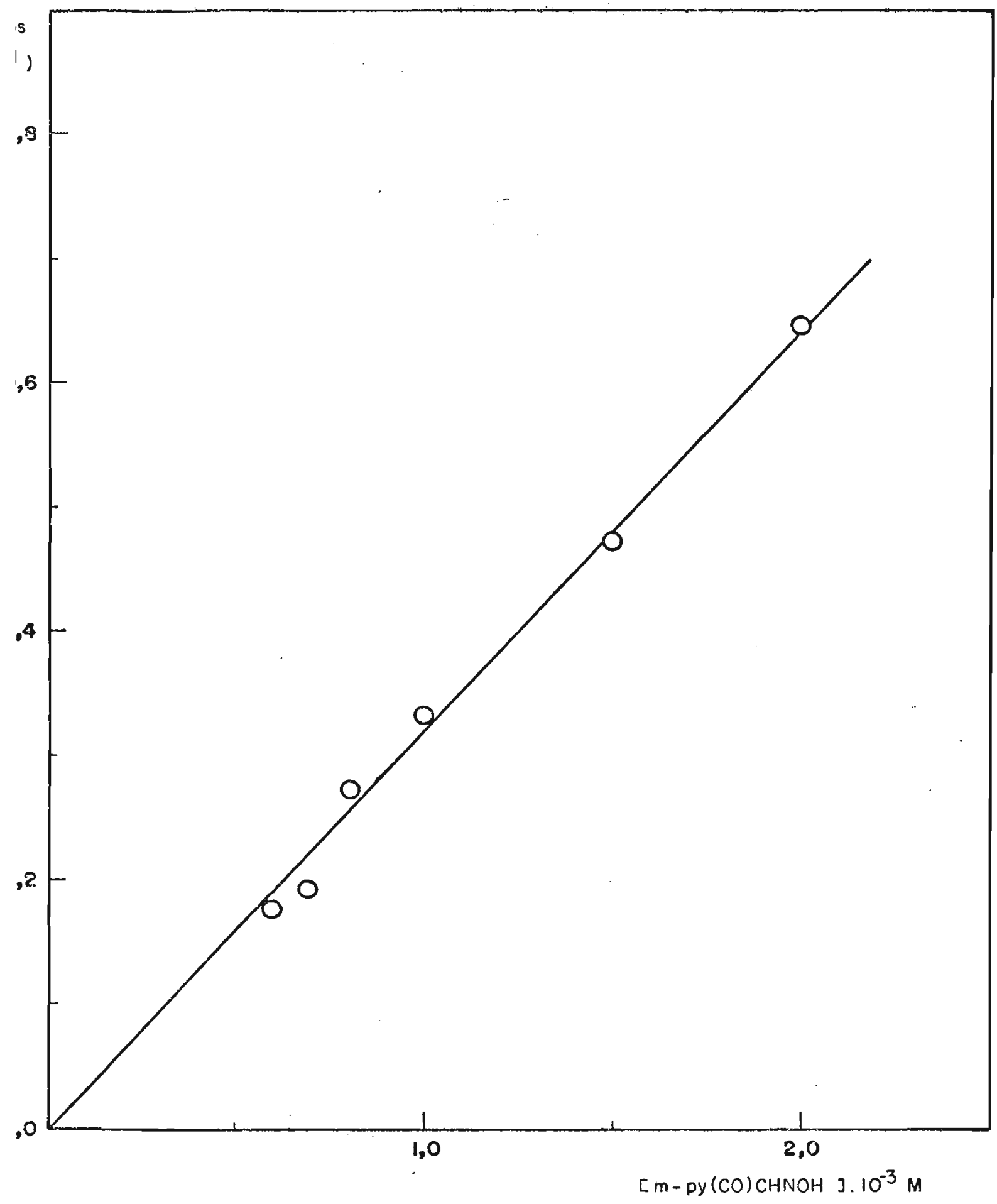

FIG. 6,2, Constante de velocidade de formação do complexo $\mathrm{Fe}(\mathrm{CN}){ }_{5} \mathrm{~m}-\mathrm{py}(\mathrm{CO}) \mathrm{CHNOH}^{3-}$ em função da concentração do ligante $\mu=0,100\left(\mathrm{LiClO}_{4}\right) \quad t=25,0^{\circ} \mathrm{C}$ 
181

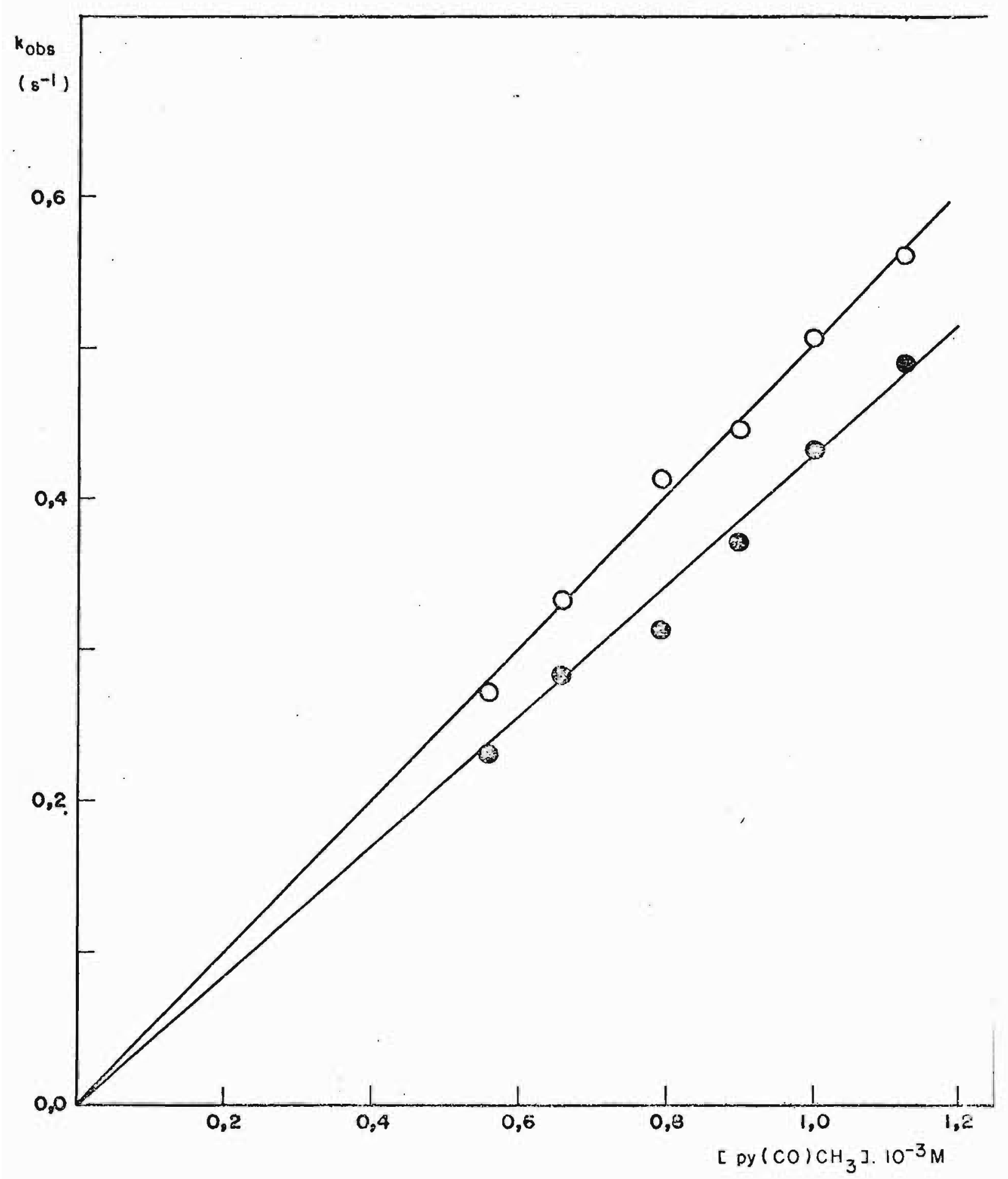

FIG. 6.3. Constantes de velocidade de formação do Fe (CN) $5^{\mathrm{L}^{3-}}$ em função da concentração do 1 igante
$\mathrm{O} L=\mathrm{p}-\mathrm{py}(\mathrm{CO}) \mathrm{CH}_{3}$
$\mu=0,100\left(\mathrm{LiClO}_{4}\right)$
- $\mathrm{L}=\mathrm{m}-\mathrm{py}(\mathrm{CO}) \mathrm{CH}_{3}$
$t=25,0 \pm 0,1{ }^{\circ} \mathrm{C}$ 


\section{TABELA - 6.2 .}

Dependência de Temperatura na Constante de Velocidade da Rea ̧̧ão de Formą̧ão do Complexo Fe(CN) ${ }_{5} \mathrm{~L}^{3-}$

\begin{tabular}{|c|c|c|}
\hline LIGANTE & temperatura $\left({ }^{\circ} \mathrm{C}\right)$ & $k_{o b s}\left(s^{-1}\right)$ \\
\hline $\begin{array}{l}\text { p-py }(\mathrm{CO}) \mathrm{CHNOH} \\
2,50 \times 10^{-3}\end{array}$ & $\begin{array}{l}32,5 \\
28,5 \\
24,0 \\
20,0 \\
16,0 \\
14,0 \\
13,0\end{array}$ & $\begin{array}{l}1,64 \\
1,14 \\
0,792 \\
0,560 \\
0,393 \\
0,333 \\
0,288\end{array}$ \\
\hline $\begin{array}{l}\text { m-py }(\mathrm{CO}) \mathrm{CHNOH} \\
8,00 \times 10^{-4}\end{array}$ & $\begin{array}{l}33,1 \\
28,0 \\
24,0 \\
20,0 \\
18,0 \\
14,8\end{array}$ & $\begin{array}{l}0,525 \\
0,389 \\
0,257 \\
0,172 \\
0,144 \\
0,103\end{array}$ \\
\hline $\begin{array}{l}\mathrm{p}-\mathrm{py}(\mathrm{CO}) \mathrm{CH}_{3} \\
9,04 \times 10^{-4}\end{array}$ & $\begin{array}{l}33,0 \\
32,8 \\
29,0 \\
24,0 \\
20,0 \\
16,0 \\
15,0\end{array}$ & $\begin{array}{l}0,990 \\
0,922 \\
0,693 \\
0,426 \\
0,298 \\
0,182 \\
0,179\end{array}$ \\
\hline $\begin{array}{l}m-\operatorname{py}(\mathrm{CO}) \mathrm{CH}_{3} \\
9,04 \times 10^{-4}\end{array}$ & $\begin{array}{l}33,0 \\
28,0 \\
24,0 \\
20,0 \\
16,0 \\
15,0\end{array}$ & $\begin{array}{l}0,896 \\
0,629 \\
0,428 \\
0,313 \\
0,193 \\
0,185\end{array}$ \\
\hline
\end{tabular}

$\left[\mathrm{Fe}(\mathrm{CN}) 5^{\left.\mathrm{NH}_{3}{ }^{3-}\right]=1,0 \times 10^{-5} \mathrm{M} \quad \mu=0,10(\text { ajus.LiC1O }}{ }_{4}\right)$ 


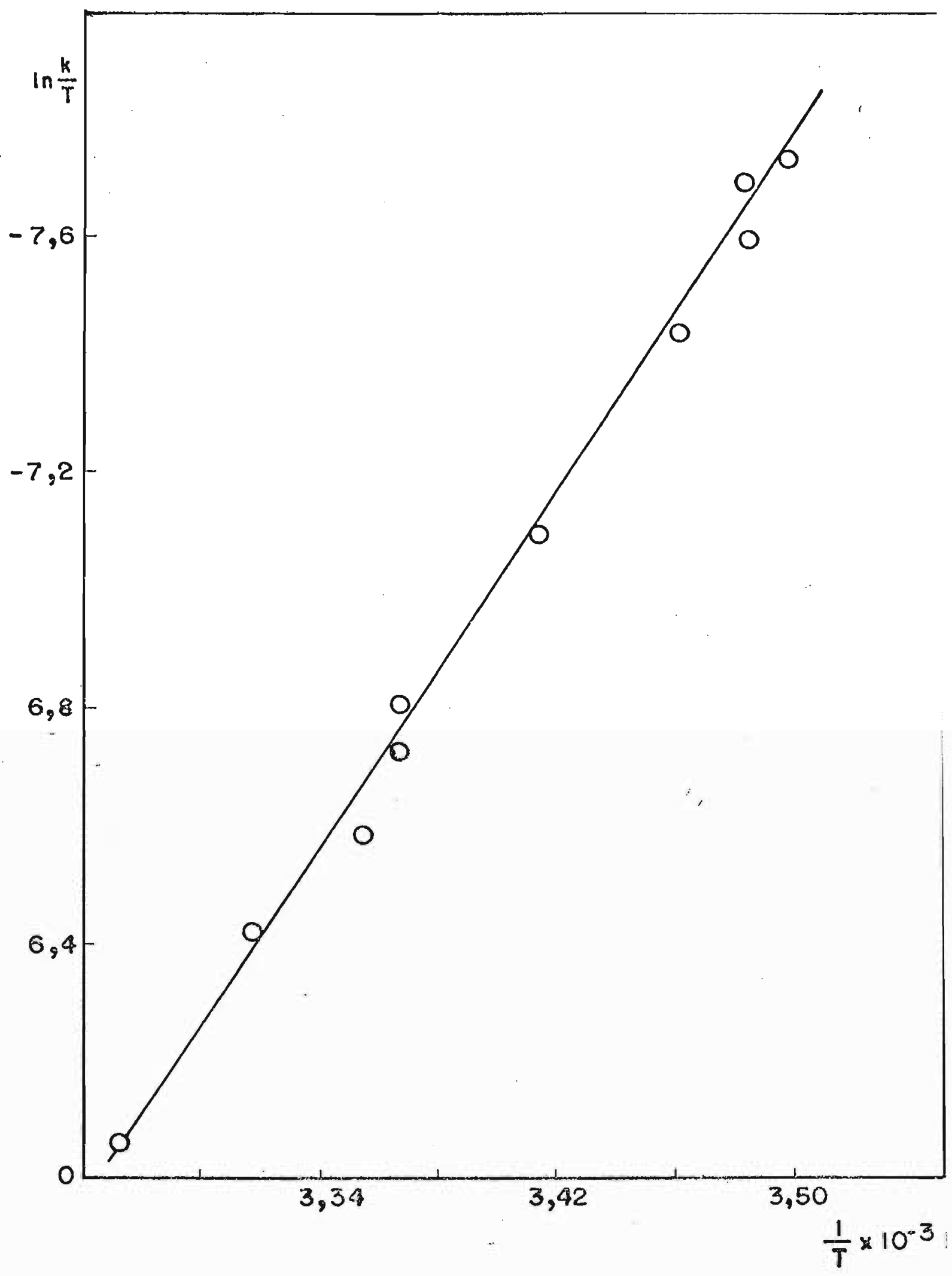

FIG. 6.4. Dependência de temperatura na constante de velocidade de formação do $\mathrm{Fe}(\mathrm{CN})_{5} \mathrm{p}-\mathrm{py}(\mathrm{CO}) \mathrm{CHNOH}^{3-}$ $\mu=0,100\left(\mathrm{LiClO}_{4}\right) \quad[\mathrm{p}-\mathrm{py}(\mathrm{CO}) \mathrm{CHNOH}]=2,50 \times 10^{-3} \mathrm{M}$ 


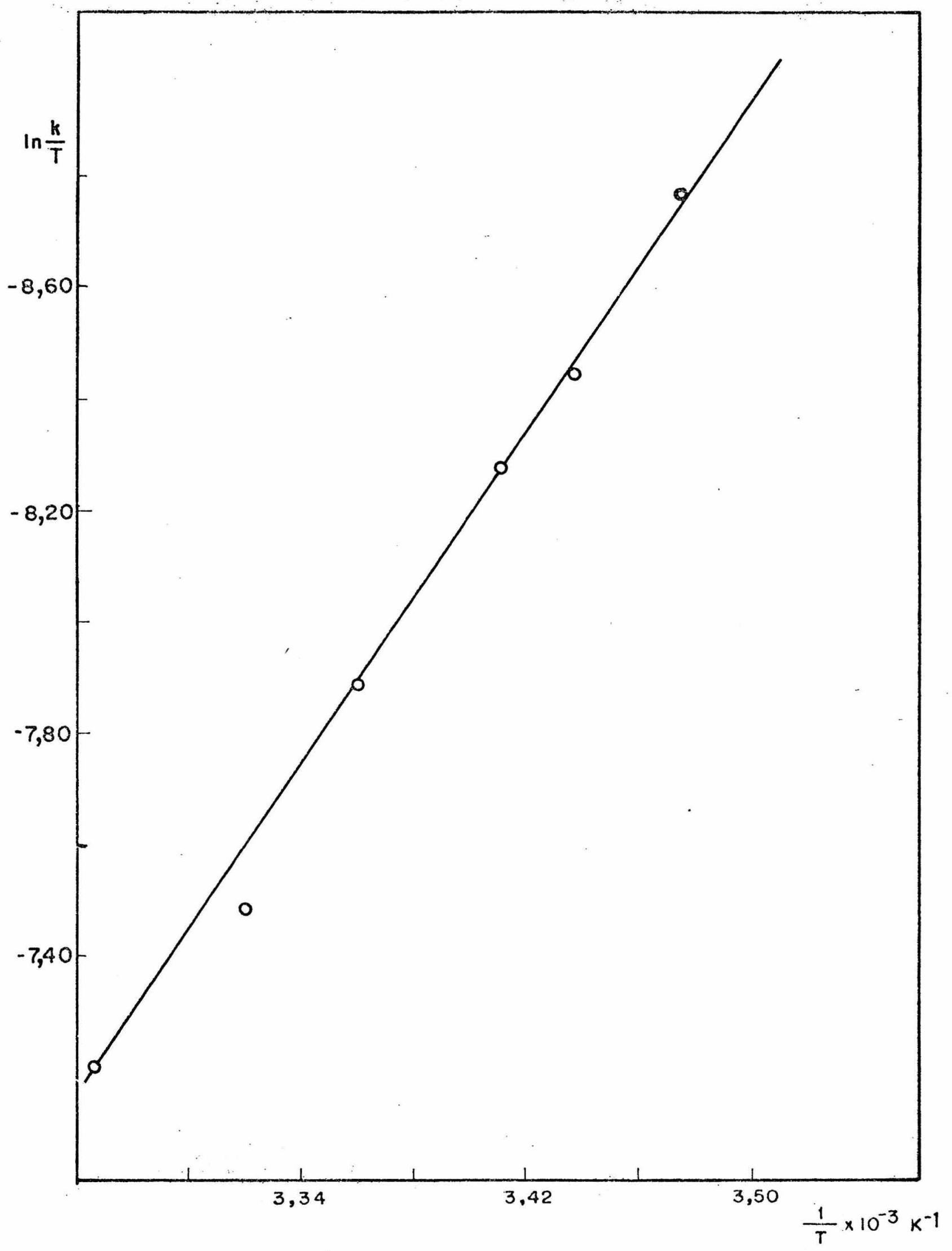

FIG. 6.5. Dependência de temperatura na constante de velocidade de formação do $\mathrm{Fe}(\mathrm{CN})_{5} \mathrm{~m} \mathrm{py}(\mathrm{CO}) \mathrm{CHNOH}^{3-}$ $\mu=0,100\left(\mathrm{LiClO}_{4}\right) \quad[\mathrm{m}-\mathrm{py}(\mathrm{CO}) \mathrm{CHNOH}]=8,00 \times 10^{-4} \mathrm{M}$ 


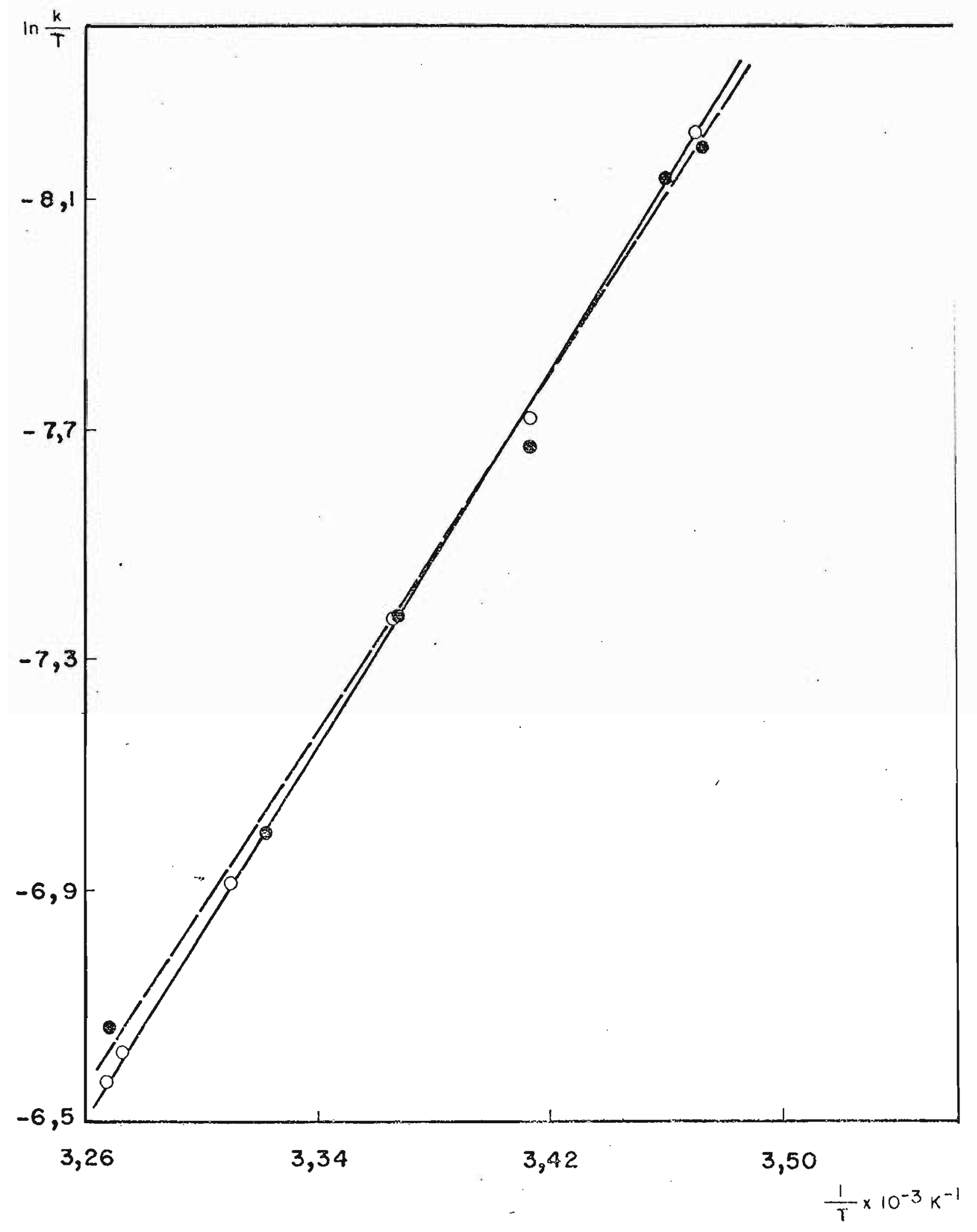

FIG. 6.6. Dependência de temperatura na constante de velocidade de formação do $\left.\mathrm{Fe}(\mathrm{CN})_{5} \mathrm{py} \mathrm{CO}\right) \mathrm{CH}_{3}{ }^{3-}$ $[\mathrm{L}]=9,04 \times 10^{-4} \mathrm{M} \quad \mathrm{O}\left(\mathrm{p}-\mathrm{py}(\mathrm{CO}) \mathrm{CH}_{3}\right) \cdot(\mathrm{m}-\mathrm{py}(\mathrm{CO}) \mathrm{c}$ 
TAB. A - Parâmetros cinéticos da reação correspondente a

$$
\mathrm{Fe}(\mathrm{CN}){ }_{5} \mathrm{H}_{2} \mathrm{O}^{3-}+\mathrm{L} \rightarrow \mathrm{Fe}(\mathrm{CN})_{5} \mathrm{~L}^{3-}+\mathrm{H}_{2} \mathrm{O}
$$

\begin{tabular}{|c|c|c|c|c|}
\hline LIGANTE & $\mathrm{M}^{-1} \mathrm{~s}^{-1}$ & $\begin{array}{c}\Delta \mathrm{H}^{\dagger} \\
\mathrm{kca} 1 / \operatorname{mol} 1\end{array}$ & $\begin{array}{c}\Delta \mathrm{S}^{\ddagger} \\
\mathrm{cal} / \mathrm{mol} \cdot \mathrm{grau}\end{array}$ & $\begin{array}{l}\Delta \mathrm{G} \neq \\
\mathrm{kcal} / \mathrm{mol}\end{array}$ \\
\hline $\mathrm{p}-\mathrm{py}(\mathrm{CO}) \mathrm{CHNOH}$ & 285 & 14,4 & 1,3 & 14,0 \\
\hline $\mathrm{m}-\mathrm{py}(\mathrm{CO}) \mathrm{CHNOH}$ & 323 & 14,9 & 3,1 & 14,0 \\
\hline $\mathrm{p}-\mathrm{py}(\mathrm{CO}) \mathrm{CH}_{3}$ & 498 & 16,1 & 8,1 & 13,7 \\
\hline$m-p y(C O) \mathrm{CH}_{3}$ & 423 & 15,2 & 19,1 & 13,8 \\
\hline
\end{tabular}

- as entropias de ativação são sempre positivas

Todos esses fatores são indicativos para um me canismo dissociativo, onde a saída do ligante coordenado constitui a etapa determinante da velocidade.

0 processo pode ser esquematizado como

$$
\begin{aligned}
& \mathrm{Fe}(\mathrm{CN})_{5} \mathrm{H}_{2} \mathrm{O}^{3-}(\mathrm{aq}) \stackrel{\mathrm{k}_{-a}}{\frac{\mathrm{k}_{\mathrm{a}}}{\mathrm{Fe}}(\mathrm{CN})_{5}{ }^{3-}(\mathrm{aq})}+\mathrm{H}_{2} \mathrm{O} \\
& \mathrm{Fe}(\mathrm{CN})_{5}^{3-}(\mathrm{aq})+\mathrm{L}(\mathrm{aq}) \stackrel{\mathrm{k}_{1}}{\longrightarrow} \mathrm{Fe}(\mathrm{CN})_{5} \mathrm{~L}^{3-}(\mathrm{aq})
\end{aligned}
$$

Assumindo hipōtese de estado estacionário para o intermediā rio, temos a relação descrita na pägina a seguir 


$$
\frac{d\left[\mathrm{Fe}(\mathrm{CN}) 5^{\left.\mathrm{L}^{3-}\right]}\right.}{d t}=k_{o b s}\left[\mathrm{Fe}(\mathrm{CN})_{5} \mathrm{H}_{2} \mathrm{O}^{3-}\right]
$$

onde

$$
k_{\text {obs }}=\frac{k_{1} k_{-a}[\mathrm{~L}]}{k_{a}+k_{1}[L]} \quad \text { (vide apēndice) }
$$

Considerando que o $\mathrm{k}_{\mathrm{a}}$ engloba a concentração de āgua que $\bar{e} 55,5 \mathrm{M}$, a contribuição do termo $\mathrm{k}_{1}[\mathrm{~L}]$ deve ser muito pequena e, pode-se a princĩpio despreza-10. Neste caso. a lei da velocidade reduz-se simplesmente a

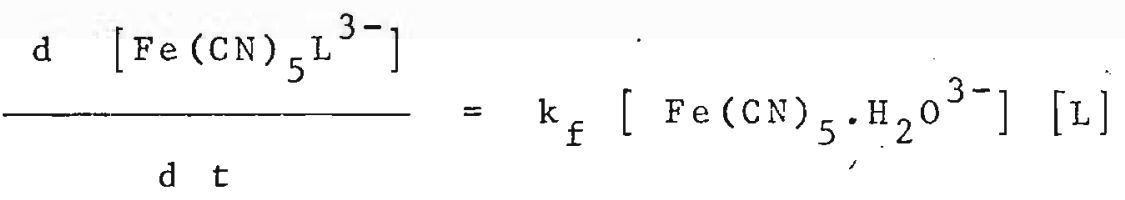

onde

$$
k_{f}=\frac{k_{-a} k_{1}}{k_{a}}
$$

Uma vez que a relação $k_{a} / k_{-a}$ é a mesma para todos os complexos, as variações relativas em $k_{f}$ são de terminadas essencialmente pelas variações em $\mathrm{k}_{1}$. Para as mc léculas neutras, a entrada na primeira esfera de coordenaçã expressão por $k_{1}$, deve ocorrer a velocidades próximas da ve locidade de difusão e ter valores comparáveis para moléculas 
semelhantes, como se verifica nos dados relacionados na tabela A.

6.1.2. Cinética de Substituição no $\mathrm{Fe}(\mathrm{CN})_{5} \mathrm{~L}^{3-}$

os complexos $\mathrm{Fe}(\mathrm{CN})_{5} \mathrm{~L}^{3-}$ com 1 igantes heterocïclico foram sintetizados e estudou-se a cinētica de substituição com dmso, atravēs de técnicas convencionais, uma vez que estas reações são mais lentas que as do aquopenta cianoferrato(II).

As medidas foram acompanhadas a $515 \mathrm{~nm}$ (para os derivados em para), $370 \mathrm{~nm}$ (para os derivados em meta) e $615 \mathrm{~nm}$ (para os derivados em orto) à força iōnica 0,10 em condições de pseudo primeira ordem com relação a ambos os ligantes envolvidos na reação.

0 processo pode ser esquematizado por

$$
\mathrm{Fe}(\mathrm{CN})_{5} \mathrm{~L}^{3-}+\mathrm{dmsO} \rightleftharpoons \mathrm{Fe}(\mathrm{CN})_{5} \mathrm{dmso}^{3-}+\mathrm{L}
$$

A dependência das constantes de velocidade com a concentração do dmso (dimetilsulfóxido) está tabelada ( TAB. 6.3.A e B) para os diferentes complexos e ilustradas nas figuras 6.7 e 6.8 para os complexos com os ligantes nitrogenados, substituĩdos em para e meta.

Para todos os complexos estudados pode ser cons tatada a existência de um patamar a altas concentrações de dmso. 
TABELA - 6.3.A.

Constantes de Velocidade para a Reação de Substituição no $\mathrm{Fe}(\mathrm{CN})_{5}$-py $(\mathrm{CO}) \mathrm{CHNOH}^{3-}$ com dimetilsulfóxido (dmso)

\begin{tabular}{|c|c|c|}
\hline LIGANTE & $\mathrm{dmso}] \times 10^{2} \mathrm{M}$ & $k_{o b s} 10^{4}\left(s^{-1}\right)$ \\
\hline \multirow[t]{6}{*}{ p-py (CO) CHNOH } & 0,250 & 4,17 \\
\hline & 0,500 & 4,97 \\
\hline & 1,00 & 5,58 \\
\hline & 5,00 & $6,1.8$ \\
\hline & 7,00 & 6,03 \\
\hline & 9,86 & 6,32 \\
\hline & & \\
\hline-1 & $-----\cdots-----1$ & -------------1 \\
\hline \multirow[t]{2}{*}{$\mathrm{m}-\mathrm{py}(\mathrm{CO}) \mathrm{CHNOH}$} & 0,125 & 6,49 \\
\hline & 0,250 & 7,87 \\
\hline \multirow[t]{4}{*}{$\cdots$} & 0,500 & 8,94 \\
\hline & 1,00 & 9,60 \\
\hline & 5,00 & 10,25 \\
\hline & 7,00 & 10,2 \\
\hline
\end{tabular}

$$
\begin{aligned}
& {\left[\mathrm{Fe}(\mathrm{CN})_{5} \cdot \mathrm{py}(\mathrm{CO}) \mathrm{CHNOH}^{3-}\right]=1,50 \times 10^{-4} \mathrm{M}} \\
& {[\mathrm{p}-\mathrm{py}(\mathrm{CO}) \mathrm{CHNOH}]=1,25 \times 10^{-3} \mathrm{M}} \\
& {[\mathrm{m}-\mathrm{py}(\mathrm{CO}) \mathrm{CHNOH}]=1,20 \times 10^{-3} \mathrm{M}} \\
& \mu=0,10 \text { ajustada com LiC10 } \\
& \text { temperatura }=25,0^{\circ} \mathrm{C}
\end{aligned}
$$


TABELA - 6.3.B.

Constantes de Velocidade para a Reação de Substituição no

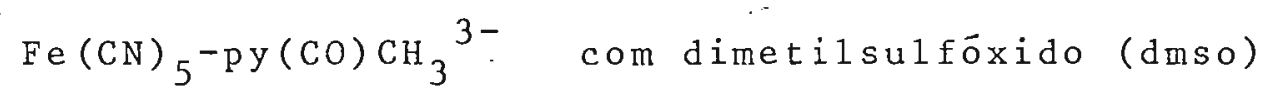

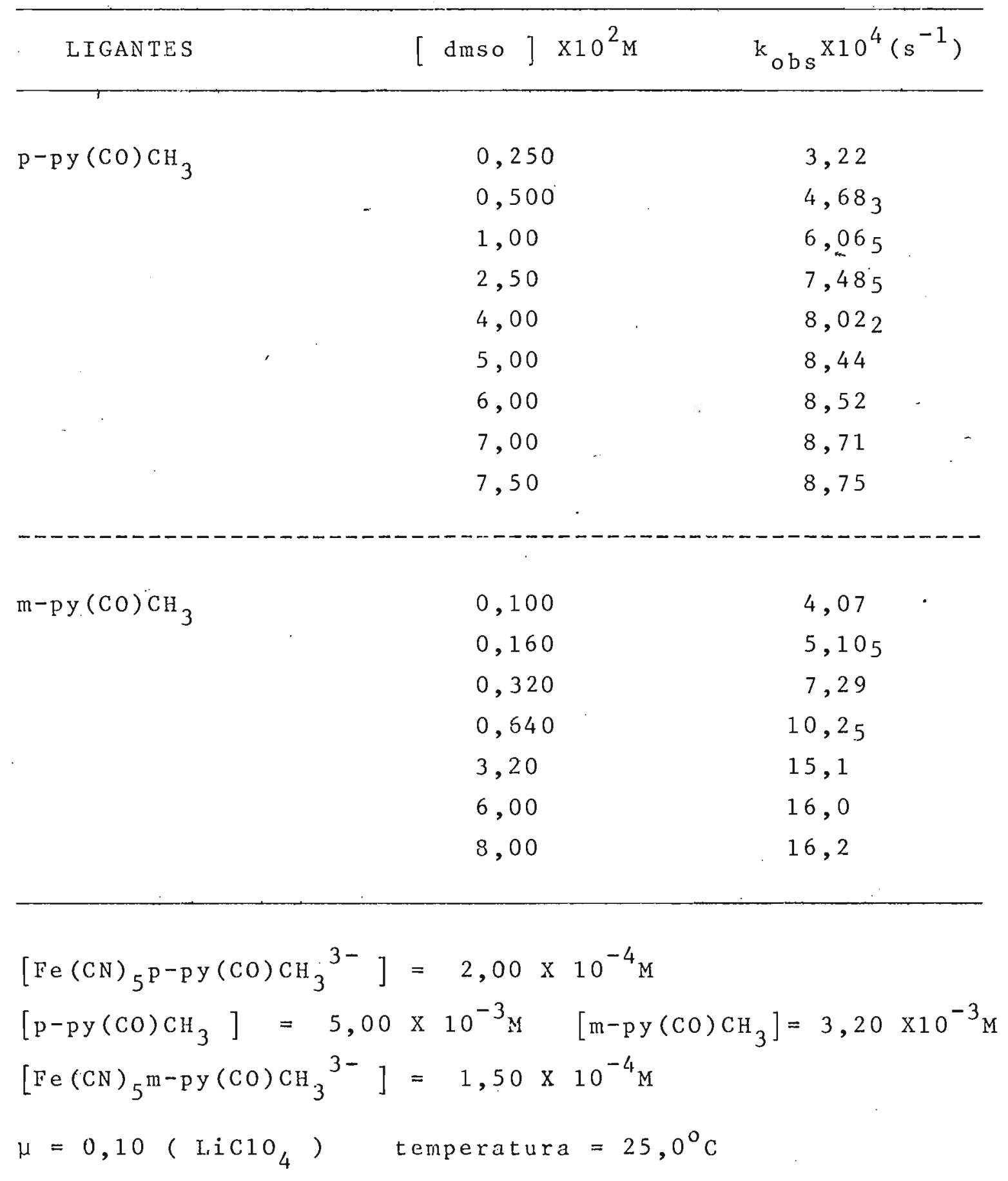


A existência de um ponto de saturação nas con. tantes de velocidade com respeito à concentração do reage. te atacante $\bar{e}$ indicativo de um mecanismo dissociativo 1 imi te.

$$
\text { Tomando-se como base o mecanismo abaixo }
$$

$$
\begin{aligned}
& \mathrm{Fe}(\mathrm{CN})_{5} \mathrm{~L}^{3-}(\mathrm{aq}) \frac{\mathrm{k}-1}{\mathrm{k}_{1}} \mathrm{Fe}(\mathrm{CN})_{5}{ }^{3-}(\mathrm{aq})+\mathrm{L}(\mathrm{aq}) \\
& \mathrm{Fe}(\mathrm{CN})_{5}{ }^{3-}(\mathrm{aq})+\mathrm{H}_{2} \mathrm{O} \rightleftharpoons \mathrm{K}=\mathrm{Fe}(\mathrm{CN}){ }_{5} \mathrm{H}_{2} \mathrm{O}^{3-}(\mathrm{aq}) \\
& \mathrm{Fe}(\mathrm{CN})_{5}{ }^{3-}(\mathrm{aq})+\mathrm{dmso}(\mathrm{aq}) \frac{\mathrm{k}_{2}}{\mathrm{k}_{-2}}=\mathrm{Fe}(\mathrm{CN})_{5} \mathrm{dmso}^{3-}(\mathrm{aq})
\end{aligned}
$$

e assumindo hipōtese do estado estacionārio para o interme diārio $\mathrm{Fe}(\mathrm{CN})_{5}{ }^{3-}(\mathrm{aq})$, a lei da velocidade que se obtém dada por:

$\underline{\mathrm{d}\left[\mathrm{Fe}(\mathrm{CN}) 5_{5 \mathrm{dms}^{3-}}\right]}=\mathrm{k}_{\mathrm{obs}}\left[\mathrm{Fe}(\mathrm{CN})_{5} \mathrm{dmsO}^{3-}\right]-\left[\mathrm{Fe}(\mathrm{CN})_{5} \mathrm{dmso}^{3-}\right.$ d $t$

onde

$$
k_{\text {obs }}=\frac{k_{-1} k_{2}[\mathrm{dmso}]+\mathrm{k}_{1} \mathrm{k}_{-2}[\mathrm{~L}]}{\mathrm{k}_{2}[\mathrm{dmso}]+\mathrm{k}_{1}[\mathrm{~L}]}
$$

(vide apêndice

$$
11.2 \text {. ) }
$$

Para este mecanismo observa-se dois aspectos importantes: 
1. Para uma concentração do ligante L pequena, à medida que se aumenta a concentração do ligante atacante, dmso, os termos $k_{-1} k_{2}$ [dmso] e $k_{2}$ [dmso] tendem a pre dominar no numerador e no denominador, respectivamente, da constante de velocidade. Isto faz com que a constante de velocidade caminhe para um comportamento de saturação onde a velocidade independe da concentração de dmso.

Quando a concentração do dmso é muito maior que a concentração do ligante, a constante de velocidade reduz-se simplesmente a $k_{-1}$ que e o valor obtido no ponto de saturação. Em outras palavras

$$
[\mathrm{dmso}] \gg[\mathrm{L}] \rightarrow \mathrm{k}_{\mathrm{obs}}=\mathrm{k}_{-1}
$$

A constante de velocidade no ponto de catura. ção representa, portanto a constante de saída do ligante L coordenado ao grupo pentacianoferrato(II).

2. Quando a concentração do dmso caminha para o valor nu1o, a constante de velocidade experimental reduz-se simplesmente a $k_{-2}$ que $\bar{e}$ a constante de velocidade de sa $\underline{1}$ da do ligante dmso coordenado ao grupo pentacianoferra to(II). Assim $k_{-2}$ é portanto a constante de velocidade para a ruptura da ligação Fe-dmso. Ou seja

$$
[\mathrm{dmso}] \ll[\mathrm{L}] \quad \rightarrow \quad \mathrm{k}_{\mathrm{obs}}=\mathrm{k}_{-2}
$$

Uma vez que o quociente $k_{a} / k_{-a} \bar{e}$ mesmo para to dos os complexos estudados, pode-se introduzir a constan 


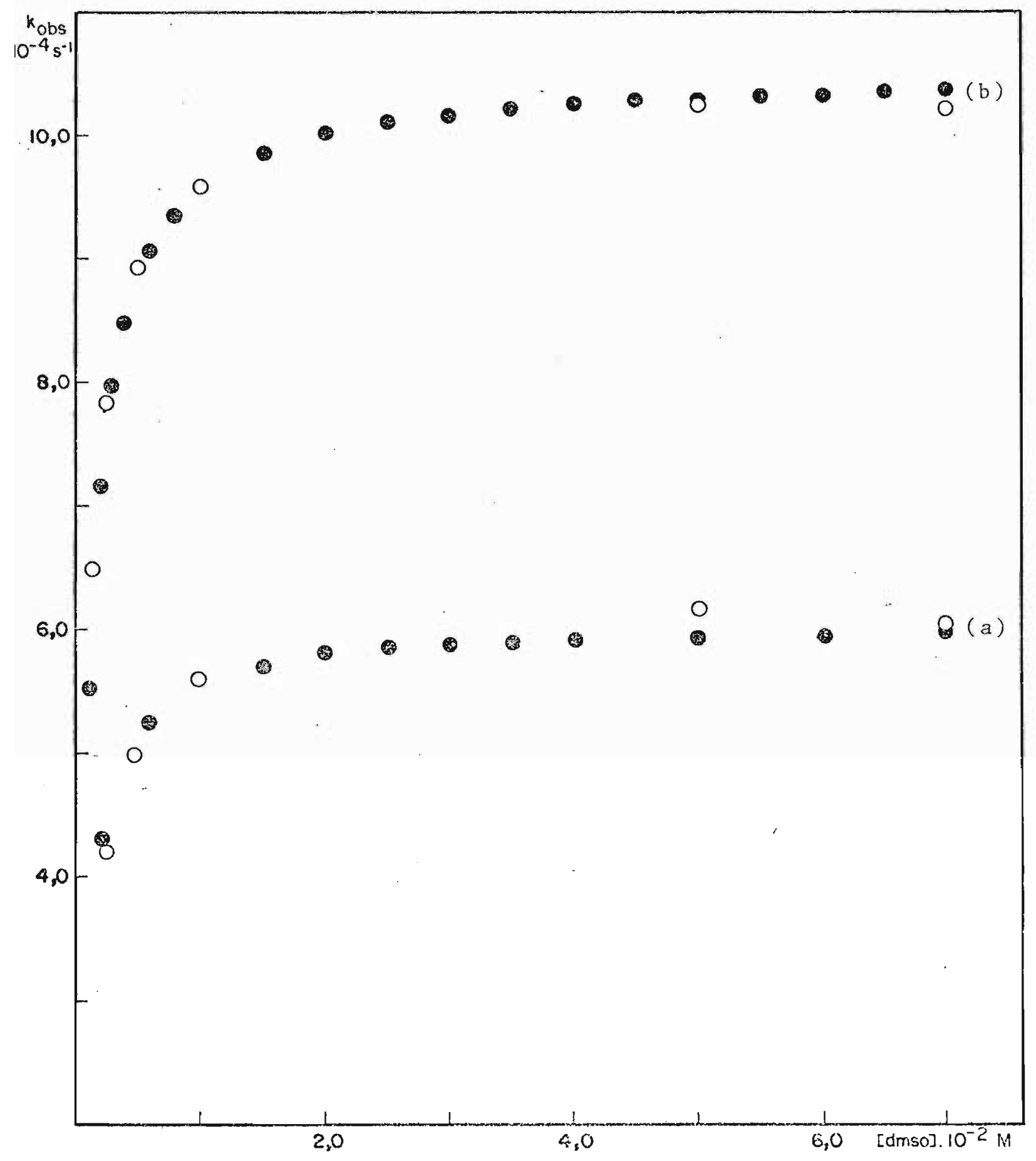

$3-$

FIG. 6.7. Comportamento de saturação para $\mathrm{Fe}(\mathrm{CH}){ }_{5} \mathrm{py}(\mathrm{CO}) \mathrm{CHNOH}$ $1,50 \times 10^{-4} M$ em função da concentração de dmso

a. p-py(CO)CHNCH b. m-py(CO)CHNOH $\left(-1,2 \times 10^{-3} \mathrm{M}\right)$

- pontos calculados o pontos experimentais

$\mu=0,100\left(\mathrm{LiC} 10_{4}\right) \quad t=25,0 \pm 0,1^{\circ} \mathrm{C}$ 


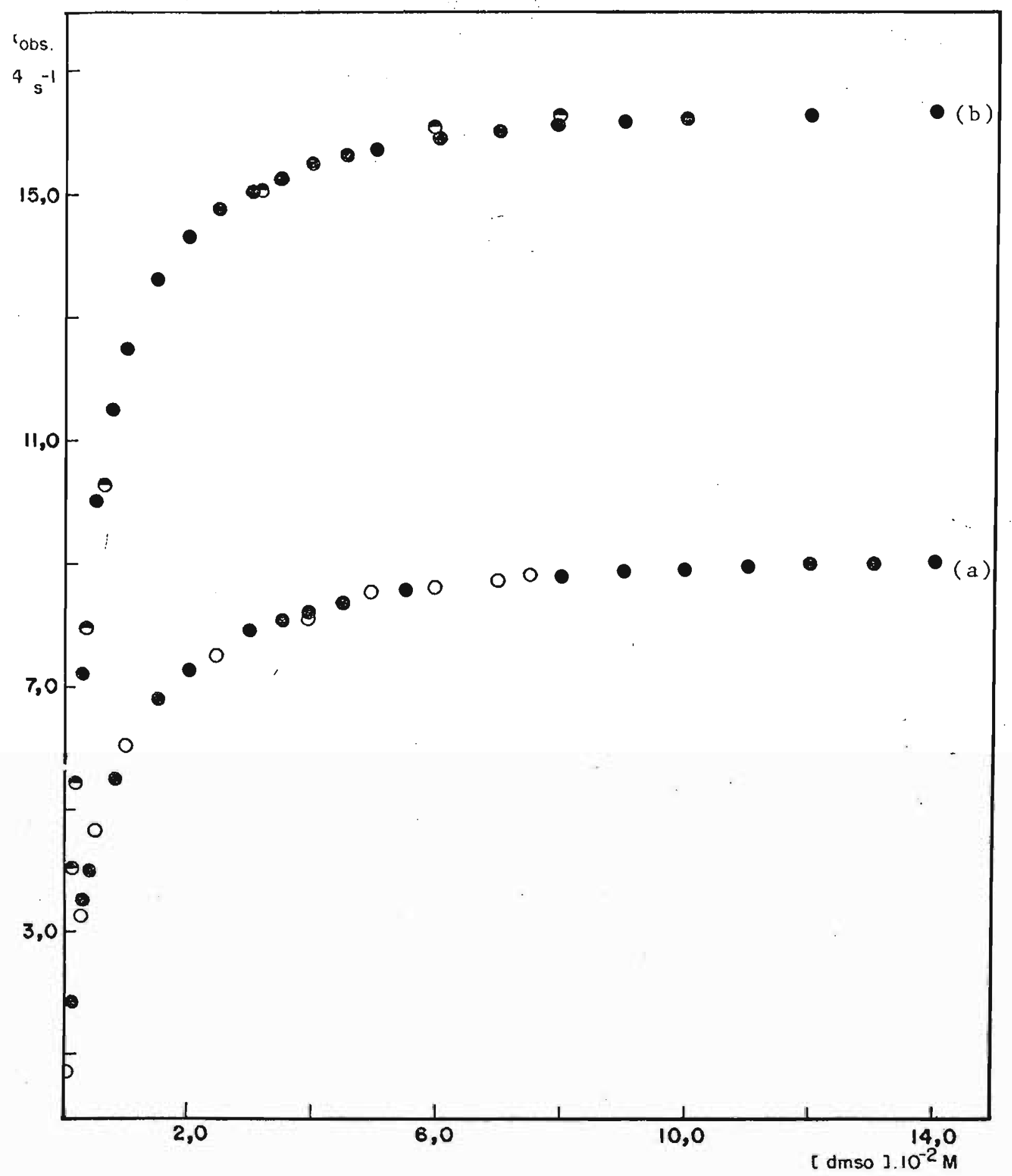

FIG. 6.8. Comportamento de saturação para $\mathrm{Fe}(\mathrm{CN}){ }_{5} \mathrm{py}(\mathrm{CO}) \mathrm{CH}_{3}^{3-}$ em função da concentração de dmso
a. $\mathrm{p}-\mathrm{py}(\mathrm{CO}) \mathrm{CH}_{3}$
- pontos calculados
b. m-py $(\mathrm{CO}) \mathrm{CH}_{3}$
$H=0,100\left(\mathrm{LiClO}_{4}\right)$
o pontos experimentais
$t=25,0 \pm 0,1^{\circ} \mathrm{C}$ 
te de velocidade de formação $k_{f}$ na equação (2).

$$
k_{o b s}=\frac{k_{-1} k_{f 2}[d m s o]+k_{f 1} k_{-2}[L]}{k_{f 1}[L]+k_{f 2}[d m s o]}
$$

Os valores de $k_{f 1}$ e $k_{-1}$ jā são conhecidos e obtidos na cinética de formação e dissociação, respectiva mente. As curvas de saturação podem ser geradas usando-se a expressão acima, substituindo-se os valores jā determinados para $k_{f 2}\left(370 \mathrm{~s}^{-1} \mathrm{M}^{-1}\right)$ e $k_{-2}\left(7,5 \times 10^{-5} \mathrm{~s}^{-1}\right)$ para o 1igan te dimetilsulföxido (264), a $\mathrm{LiClO}_{4}$ 0,10M. Os pontos calculados são indicados na figura (FIG. 6.7. e 6.8.) por pon tos cheios.

0 fato de se conseguir gerar curva concordante com os pontos experimentais, partindo-se das constantes determinadas independentemente, mostra a consistência do meca nismo.

Com o intuito de mostrar que o mecanismo pro posto independe da natureza do ligante atacante, estudou-se a cinētica de substituição no complexo $\mathrm{Fe}(\mathrm{CN})_{5} \mathrm{p}-\mathrm{py}(\mathrm{CO}) \mathrm{CH}_{3}{ }^{3-}$ utilizando m-py(CO) $\mathrm{CH}_{3}$ no lugar do dimetilsulfóxido. Notese que o comprexo $\mathrm{Fe}(\mathrm{CN})_{5} \mathrm{~m}-\mathrm{py}(\mathrm{CO}) \mathrm{CH}_{3}{ }^{3-}{ }^{3} \bar{a}$ foi bastante inves tigado neste trabaiho, e suas propriedades cinéticas e es pectroscópicas são particutarmente adequados a essa finatidade.

A figura 6.9. mostra que a substituição do dmsc por m-py(CO) $\mathrm{CH}_{3}$ conduz exatamente ao mesmo resultado, o que 


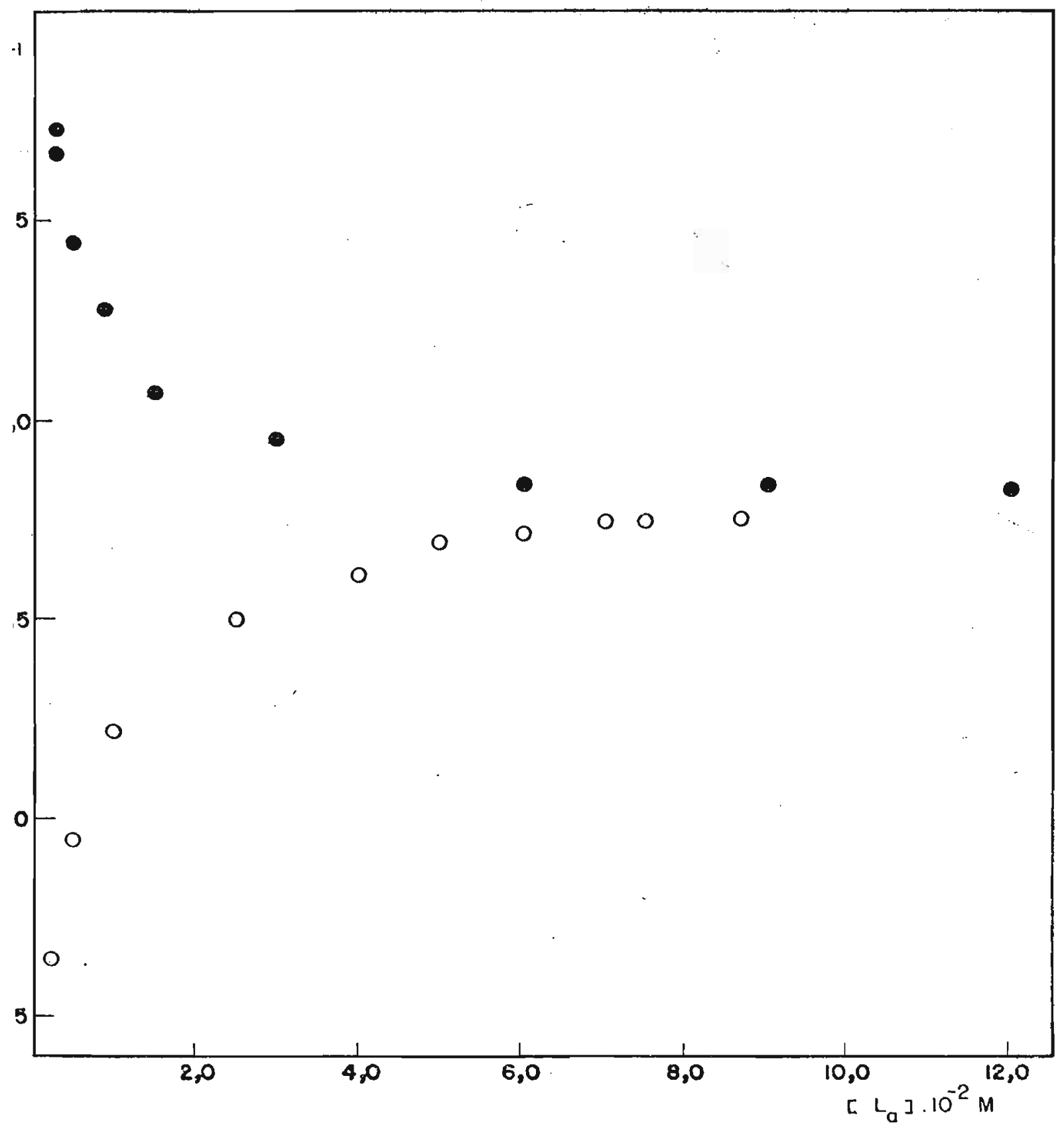

FIG. 6.9. Comportamento de saturação para $\mathrm{Fe}(\mathrm{CN}){ }_{5} \mathrm{p}$-py $(\mathrm{CO}) \mathrm{CH}_{3}^{3-}$ - m-py $(\mathrm{CO}) \mathrm{CH}_{3}$ como ligante atacante odmso como ligante atacante $\mu=0,100\left(\mathrm{LiClO}_{4}\right) \quad t=25,0 \pm 0,1^{\circ} \mathrm{C}$ 
indica que o comportamento de saturação é uma propriedade exclusiva do complexo de partida e não uma particularidade do ligante de ataque. A constante de velocidade no ponto de saturação tambëm permaneceu constante e igual ao obtido com dmso, dentro do erro experimental, o que evidencia que nes te ponto o processo está relacionado apenas com o ligante

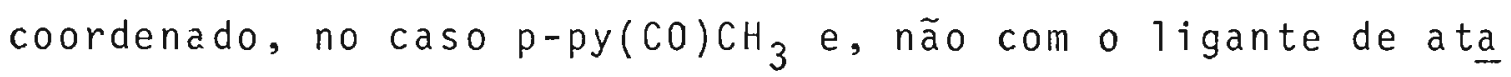
que.

A caracteristica da curva obtida quando se uti liza m-py(CO) $\mathrm{CH}_{3}$ como ligante atacante, pode ser entendida observando-se a equação (2). Neste caso deve-se substituir [ dmso ] pela $\left[\mathrm{m}-\mathrm{py}(\mathrm{CO}) \mathrm{CH}_{3}\right]$ e, $\mathrm{k}_{2}$ e $\mathrm{k}_{-2}$ rela ciona-se agora com a etapa

$$
\mathrm{Fe}(\mathrm{CN})_{5}^{3-}(\mathrm{aq})+\mathrm{m}-\mathrm{py}(\mathrm{CO}) \mathrm{CH}_{3} \frac{\mathrm{k}_{2}}{\mathrm{k}-2} \mathrm{Fe}(\mathrm{CN})_{5} \mathrm{~m}-\mathrm{py}(\mathrm{CO}) \mathrm{CH}_{3}{ }^{3-}
$$

e são respectivamente $423 \mathrm{M}^{-1} \mathrm{~s}^{-1}\left(\mathrm{k}_{\mathrm{f} 2}\right)$ e $16,8 \times 10^{-4} \mathrm{~s}^{-1}$.

$$
\text { Pela anālise, jā efetuada, sabe-se que a altas }
$$
concentrações do ligante atacante a constante de velocidade observada é aquela correspondente à saîda do ligante L co ordenado ao grupo pentacianoferrato e, deve ser independente do ligante de ataque. No entanto, quando a concentração do ligante atacante tende a zero, a constante de velocidade experimental reduz-se simplesmente a $k_{-2}$ que no caso corresponde à constante de velocidade da saida do ligante mpy $(\mathrm{CO}) \mathrm{CH}_{3}$ coordenado ao grupo pentacianoferrato(II). Uma vez que o valor de $k_{-2}$ para m-py(CO) $\mathrm{CH}_{3}$ é maior do que $0 k_{-1}$, 
correspondnete a p-py(CO) $\mathrm{CH}_{3}$, tem-se uma curva inversa $\bar{a}$ ob tida com o dmso e, a constante de velocidade observada di minui com o aumento da concentração do ligante atacante e, tendendo ao valor de $k_{-1}$.

Estes dados vem a confirmar, mais uma vez, a validade da expressão (2) e o mecanismo de substituição, evi denciando que a constante obtida no ponto de saturação rela ciona-se apenas com a ruptura da ligação Fe - L coordenado. Ao mesmo tempo este procedimento conduz a um valor mais real de $k_{-1}$ que deve estar entre os valores obtidos nas determinações cinēticas.

Os estudos sobre a dependēncia de temperatura foram efetuados' na região de saturação e os valores tabelados (TAB.6.4.A e 6.4.B.). A partir dos gräficos de $1 \mathrm{n}(\mathrm{k} / \mathrm{T})$ versus $1 / \mathrm{T}$ apresentados nas figuras 6.10 e 6.11 , determinaram-se os parāmetros termodināmicos.

Na tabela B da pägina a seguir, tem-se as cons tantes de velocidade de saida do ligante coordenado, $k_{-1}$, juntamente com os parāmetros de ativação.

Mais uma vez, para todos os casos estudados, a substituição dos 1 igantes coordenados se processa com uma variação positiva na entropia de ativação, caracteristica de um mecanismo dissociativo limite. 
TABELA - 6.4.A.

Dependência de Temperatura na Constante de Velocidade da Re: ção de Dissociação do Complexo $\mathrm{Fe}(\mathrm{CN}){ }_{5} \mathrm{py}(\mathrm{CO}) \mathrm{CHNOH}^{3-}$

\begin{tabular}{|c|c|c|}
\hline LIGANTE & temperatura $\left({ }^{\circ} \mathrm{C}\right)$ & $\mathrm{k}_{\mathrm{obs}} \mathrm{X} 10^{3}\left(\mathrm{~s}^{-1}\right.$ \\
\hline \multirow[t]{5}{*}{$\mathrm{p}-\mathrm{py}(\mathrm{CO}) \mathrm{CHNOH}$} & 16,0 & 0,143 \\
\hline & 20,0 & 0,272 \\
\hline & 25,0 & 0,618 \\
\hline & 28,9 & 1,006 \\
\hline & 33,4 & 1,97 \\
\hline \multicolumn{3}{|c|}{ 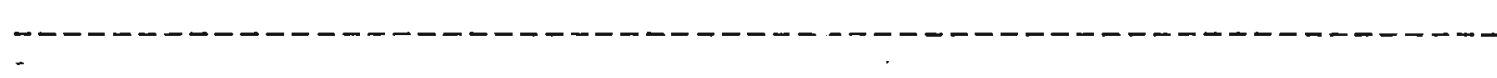 } \\
\hline \multirow[t]{5}{*}{$\mathrm{m}-\mathrm{P} \dot{\mathrm{y}}(\mathrm{CO}) \mathrm{CHNOH}$} & 16,1 & 0,250 \\
\hline & 21,0 & 0,555 \\
\hline & 25,0 & 1,02 \\
\hline & 28,3 & 1,59 \\
\hline & 33,5 & 3,25 \\
\hline
\end{tabular}

$$
\begin{aligned}
& {\left[\mathrm{Fe}(\mathrm{CN}){ }_{5} \mathrm{py}(\mathrm{CO}) \mathrm{CHNOH}\right]=1,50 \times 10^{-4} \mathrm{M}} \\
& {[\mathrm{p}-\mathrm{py}(\mathrm{CO}) \mathrm{CHNOH}]=4,00 \times 10^{-3} \mathrm{M}} \\
& {[\mathrm{m}-\mathrm{py}(\mathrm{CO}) \mathrm{CHNOH}]=1,20 \times 10^{-3} \mathrm{M}} \\
& {[\mathrm{dmso}]=5,68 \times 10^{-2} \mathrm{M} \text { para derivado em para }} \\
& 5,00 \times 10^{-2} \mathrm{M} \text { para derivado em meta } \\
& \mu=0,10 \text { ajustada com LiC10 }
\end{aligned}
$$


TABELA - 6.4.B.

Dependência de Temperatura na Constante de Velocidade da Reação de Dissociação dos Complexos Fe(CN) ${ }_{5} \mathrm{py}(\mathrm{CO}) \mathrm{CH}_{3}{ }^{3-}$

$\begin{array}{lll}\mathrm{p}-\mathrm{py}(\mathrm{CO}) \mathrm{CH}_{3} & 15,9 & 0,198 \\ & 19,98 & 0,372 \\ & 25,0 & 0,860 \\ 28,0 & 1,37 \\ 33,0 & 2,835\end{array}$

$\mathrm{m}-\mathrm{py}(\mathrm{CO}) \mathrm{CH}_{3}$

15,9

0,406

19,9

0,767

25,0

1,61

27,9

2,61

32,9

$4,98_{5}$

$\left[\mathrm{Fe}(\mathrm{CN})_{5} \mathrm{py}(\mathrm{CO}) \mathrm{CH}_{3}\right]=1,50 \times 10^{-4} \mathrm{M}$

$\left[\mathrm{p}-\mathrm{py}(\mathrm{CO}) \mathrm{CH}_{3}\right]=4,00 \times 10^{-3} \mathrm{M} \quad\left[\mathrm{m}-\mathrm{py}(\mathrm{CO}) \mathrm{CH}_{3}\right]=3,20 \times 10^{-3} \mathrm{M}$

[dmso $]=5,00 \times 10^{-2} \mathrm{M}$ para derivado em para $9,68 \times 10^{-2} \mathrm{M}$ para derivado em meta

$\mu=0,10$ ajustada com LiC10 4 


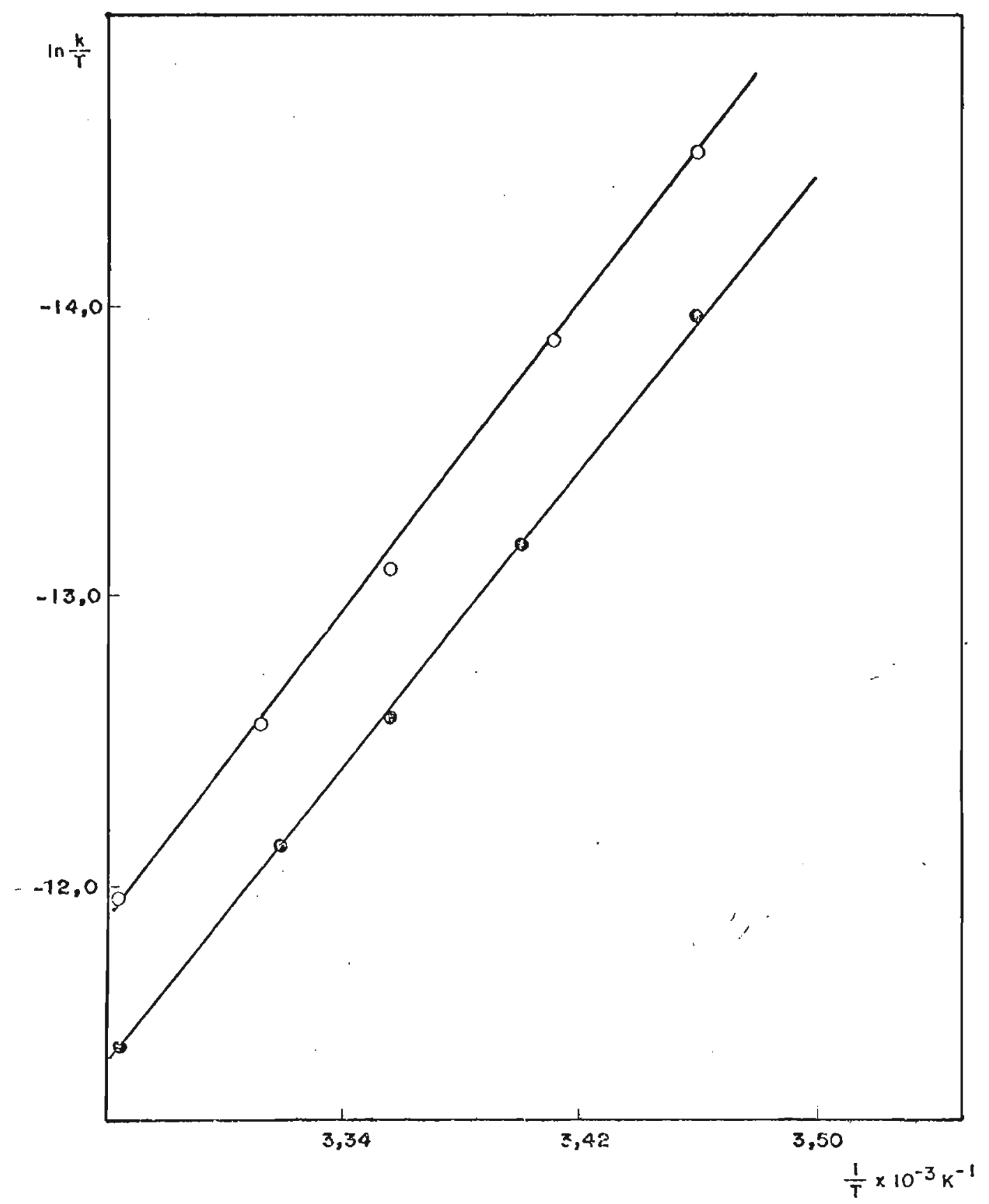

FIG. 6.10. Dependência de temperatura na constante de velocidade de substituição no $\mathrm{Fe}(\mathrm{CN}){ }_{5} \mathrm{py}(\mathrm{CO}) \mathrm{CHNOH}^{3-} \operatorname{com} \mathrm{c}$ ligante dmso no ponto de saturação $\left[\mathrm{Fe}(\mathrm{CN})_{5} \mathrm{py}(\mathrm{CO}) \mathrm{CHNOH}^{3--}\right]=1,50 \times 10^{-4} \mathrm{M} \quad \mu=0,100$ - p-py $(\mathrm{CO}) \mathrm{CHNOH}$ - $\mathrm{m}-\mathrm{py}(\mathrm{CO}) \mathrm{CHNOH}$ $\left[\right.$ dmso] $\begin{array}{lll}9,68 \times 10^{-2} \mathrm{M} & \text { (para derivado em para) } \\ 5,00 \times 10^{-2} \mathrm{M} & \text { (para derivado em meta) }\end{array}$ 


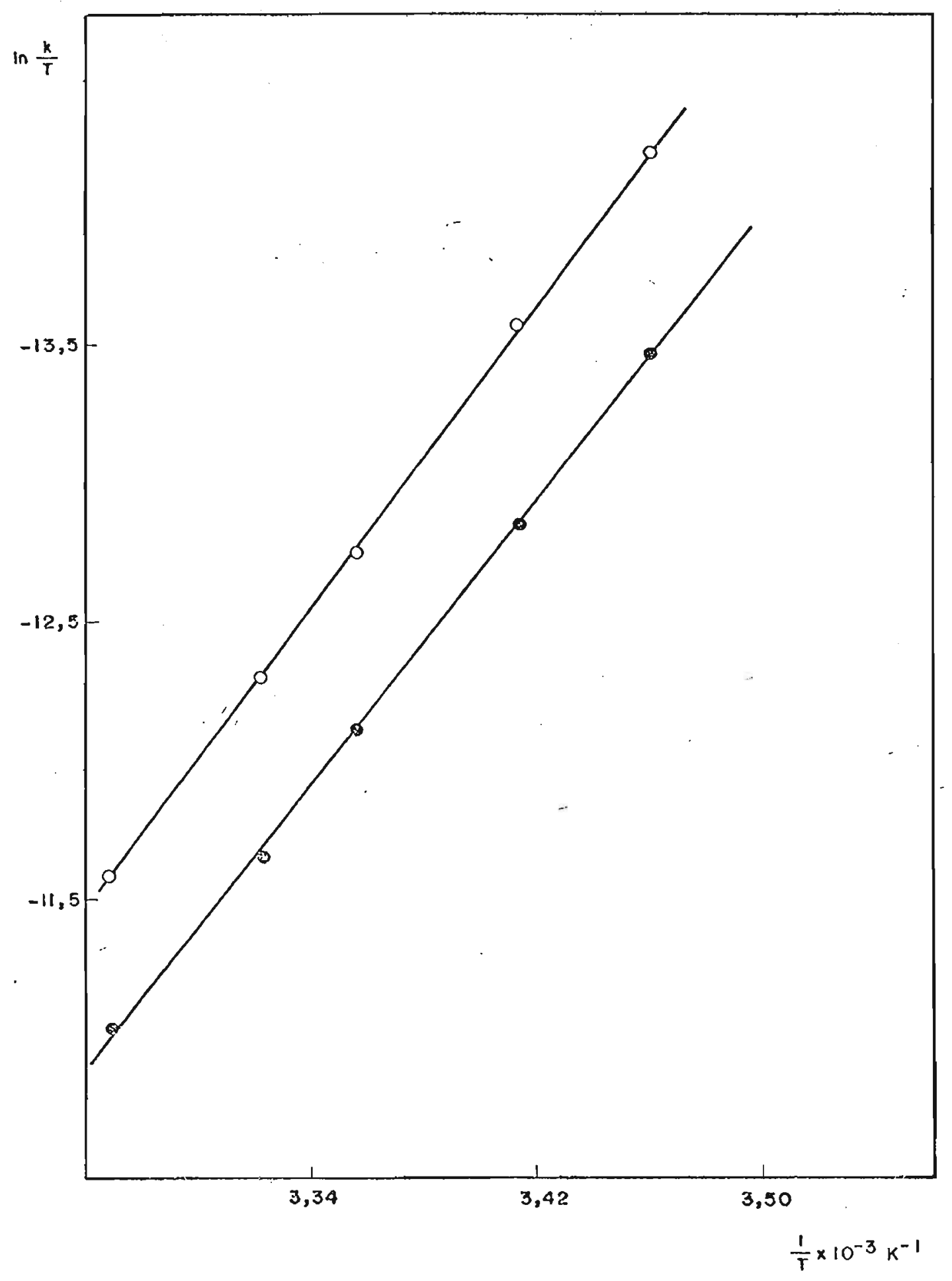

FIG.6.11. Dependência de temperatura na constante de velocidade de substituição no $\mathrm{Fe}(\mathrm{CN})_{5} \mathrm{py}(\mathrm{CO}) \mathrm{CH}_{3}^{3-}$ $1,5 \times 10^{-4} \mathrm{M}$ com 1 igante dmso no ponto de saturação - $\left[\mathrm{p}-\mathrm{py}(\mathrm{CO}) \mathrm{CH}_{3}\right]=4,00 \times 10^{-3} \mathrm{M}$ dmso $=5,00 \times 10^{-2} \mathrm{M}$ - $\left[\mathrm{m}-\mathrm{py}(\mathrm{CO}) \mathrm{CH}_{3}\right]=3,20 \times 10^{-3} \mathrm{M}$ dmso $=9,68 \times 10^{-2} \mathrm{M}$ $\mu=0,100 \quad\left(\mathrm{LiCl}_{4}\right)$ 


\section{3}

TAB. B - Parâmetros Cinéticos da Reação Correspondente a

$$
\mathrm{Fe}(\mathrm{CN})_{5} \mathrm{~L}^{3-} \stackrel{\mathrm{k}-1}{\longrightarrow} \mathrm{Fe}(\mathrm{CN})_{5}{ }^{3-}+\mathrm{L}
$$

\begin{tabular}{|c|c|c|c|c|}
\hline LIGANTE & $10^{4} \mathrm{~s}^{\mathrm{k}}=1$ & $\begin{array}{c}\Delta \mathrm{H}^{\neq} \\
\mathrm{kca} 1 / \mathrm{mol}\end{array}$ & $\begin{array}{c}\Delta \mathrm{S}^{\dagger} \\
\mathrm{cal} / \mathrm{mol} \cdot \mathrm{grau}\end{array}$ & $\begin{array}{l}\Delta \mathrm{G}^{\neq} \\
\mathrm{kcal} / \mathrm{mol}\end{array}$ \\
\hline $\mathrm{p}-\mathrm{py}(\mathrm{CO}) \mathrm{CHNOH}$ & 6,01 & 25,9 & 13 & $21,7_{5}$ \\
\hline m-py $(\mathrm{CO}) \mathrm{CHNOH}$ & 10,4 & 25,3 & 13 & 21,4 \\
\hline $\mathrm{p}-\mathrm{py}(\mathrm{CO}) \mathrm{CH}_{3}$ & 9,50 & 26,9 & 18 & 21,5 \\
\hline $\mathrm{m}-\mathrm{py}(\mathrm{CO}) \mathrm{CH}_{3}$ & 16,8 & 25,4 & 14 & 21,2 \\
\hline
\end{tabular}

6.1.3. Cinētica de Formação e Substituição no $\mathrm{Fe}(\mathrm{CN})_{5} \cdot 0-$ py $(\mathrm{CO}) \mathrm{CHNOH}$

O ligante orto-acetilpiridina não reage com 0 īon aquopentacianoferrato(II), uma vez que a posição reativa (nitrogênio da piridina) está impedida estericamente.

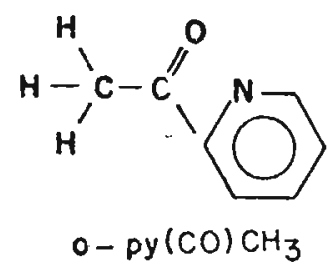


Assim, os comportamentos observados para os $1 \underline{i}$ gantes em para e meta não podem ser generalizados para os derivados em orto.

Na tabela 6.5. constam os valores de kobs pa ra diversas concentrações do ligante o-py(CO)CHNOH. O gräfico de kobs versus a concentração do ligante (FIG. 6.12) e uma reta que não passa pela origem. Este comportamento é tî pico de uma reação reversível

$\mathrm{Fe}(\mathrm{CN}){ }_{5} \mathrm{H}_{2} \mathrm{O}^{3-}+\mathrm{o}-\mathrm{py}(\mathrm{CO}) \mathrm{CHNOH} \rightleftharpoons \frac{\mathrm{k}^{\prime}}{\mathrm{k}_{\mathrm{d}}} \mathrm{Fe}(\mathrm{CN})_{5} \mathrm{~N}(\mathrm{OH}) \mathrm{CH}(\mathrm{CO}) \mathrm{py}^{3-}$
$+\mathrm{H}_{2} \mathrm{O}$

cuja expressão ṕara kobs è do tipo

$\mathrm{k}_{\mathrm{obs}}=\mathrm{k}^{\prime}[\mathrm{o}-\mathrm{py}(\mathrm{CO}) \mathrm{CHNOH}]+\mathrm{k}_{\mathrm{d}}$

(vide apêndice 11.2)

Os valores das constantes de velocidade de for mação (kobs $)$ com a temperatura, relacionados na tabela 6 . 5., envolvem a contribuição do termo $k_{d}$ e $k^{\prime}$ conforme a equação (3) acima.

os valores de kobs de dissociação com dife rentes concentrações do dmso e sua dependēncia com a temperatura, estão na tabela 6.6. Do gräfico de $\ln \left(k_{o b s} / T\right.$ ) versus $1 / T$ (FIG.6.13) determina-se os parāmetros de ativação da reação de substituição. Deste gräfico, pode-se tambēm obter a contribuição do termo $k_{d}$ a uma dada temperatura. 
TABELA - 6.5 .

Constantes de Velocidade para a Reação de Formação do Complexo $\mathrm{Fe}(\mathrm{CN}) 5^{\mathrm{O}-\mathrm{py}(\mathrm{CO}) \mathrm{CHNOH}^{3-}}$

Temperatura $\left({ }^{\circ} \mathrm{C}\right) \quad[\mathrm{o}-\mathrm{py}(\mathrm{CO}) \mathrm{CHNOH}] \quad \times 10^{3} \mathrm{M} \quad \mathrm{k}_{\mathrm{obs}} 10^{2}\left(\mathrm{~s}^{-1}\right)$

$\begin{array}{cc}25,0,00 & 1,63 \\ 4,00 & 1,99 \\ 5,00 & 2,40 \\ 6,00 & 2,79 \\ 7,00 & 3,02\end{array}$

$\begin{array}{ll}33,0 & 5,00 \\ 28,2 & 3,47 \\ 25,0 & 3,14 \\ 24,0 & 2,53 \\ 20,0 & 2,30 \\ 18,0 & 1,73 \\ 16,5 & 1,60\end{array}$

$\left[\mathrm{Fe}(\mathrm{CN})_{5} \mathrm{NH}_{3}^{3-}\right]=1,0 \mathrm{X} 10^{-5} \mathrm{M}$

$\mu=0,10$ ajustada com Li $\mathrm{ClO}_{4}$ 


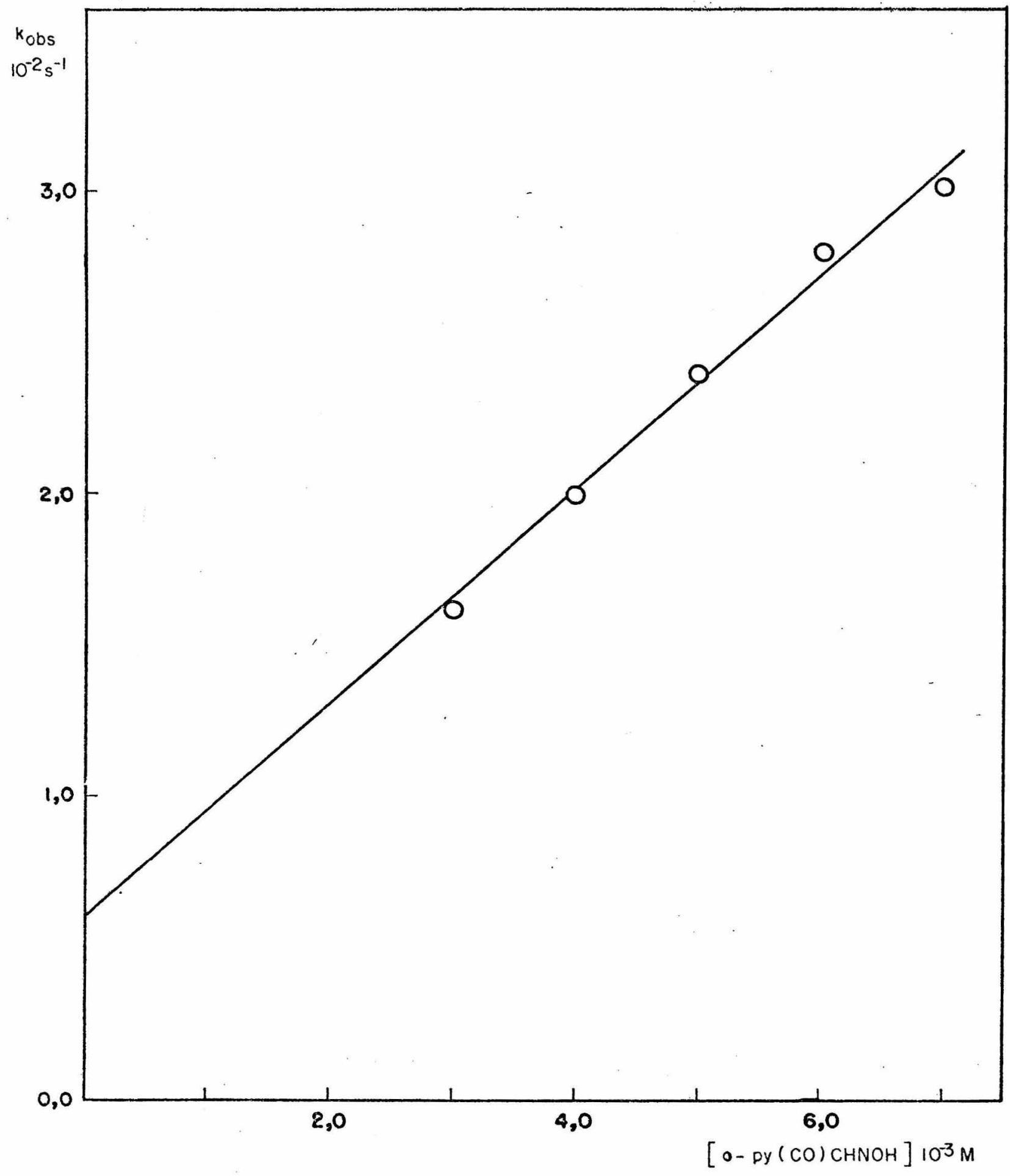

FIG. 6.12. Constante de velocidade de formação do complexo $\mathrm{Fe}(\mathrm{CN})_{5} \mathrm{o-py}(\mathrm{CO}) \mathrm{CHNOH}^{3-}$ em função da concentração do Iigante $\quad t=25,0 \pm 0,1^{\circ} \mathrm{C}$ $\mu=0,100\left(\mathrm{LiClO}_{4}\right)$ 
TABELA - 6.6 .

Constantes de Velocidade para a Reação de Dissociaçã do Complexo $\mathrm{Fe}(\mathrm{CN}) 5^{\mathrm{O}-\mathrm{py}(\mathrm{CO}) \mathrm{CHNOH}^{3-}}$

$$
\text { Temperatura }\left({ }^{\circ} \mathrm{C}\right) \quad[\mathrm{dmso}] \times 10^{2} \mathrm{M} \quad \mathrm{k}_{\text {obs }} \times 10^{2}\left(\mathrm{~s}^{-1}\right)
$$

25,0

0,250

0,71

0,500

0,71

1,00

0,69

5,00

0,71
16,1
0,500
0,28
20,1
0,44
25,0
0,71
28,0
1,0
32,0
1,4

$$
\begin{aligned}
& {\left[\mathrm{Fe}(\mathrm{CN})_{5} \text { o-py }(\mathrm{CO}) \mathrm{CHNOH}^{3-}\right]=2,00 \times 10^{-4} \mathrm{M}} \\
& {[\text { o-py }(\mathrm{CO}) \mathrm{CHNOH}]=4,00 \times 10^{-3} \mathrm{M}} \\
& \mu=0,10 \text { ajustada com LiC10 }
\end{aligned}
$$




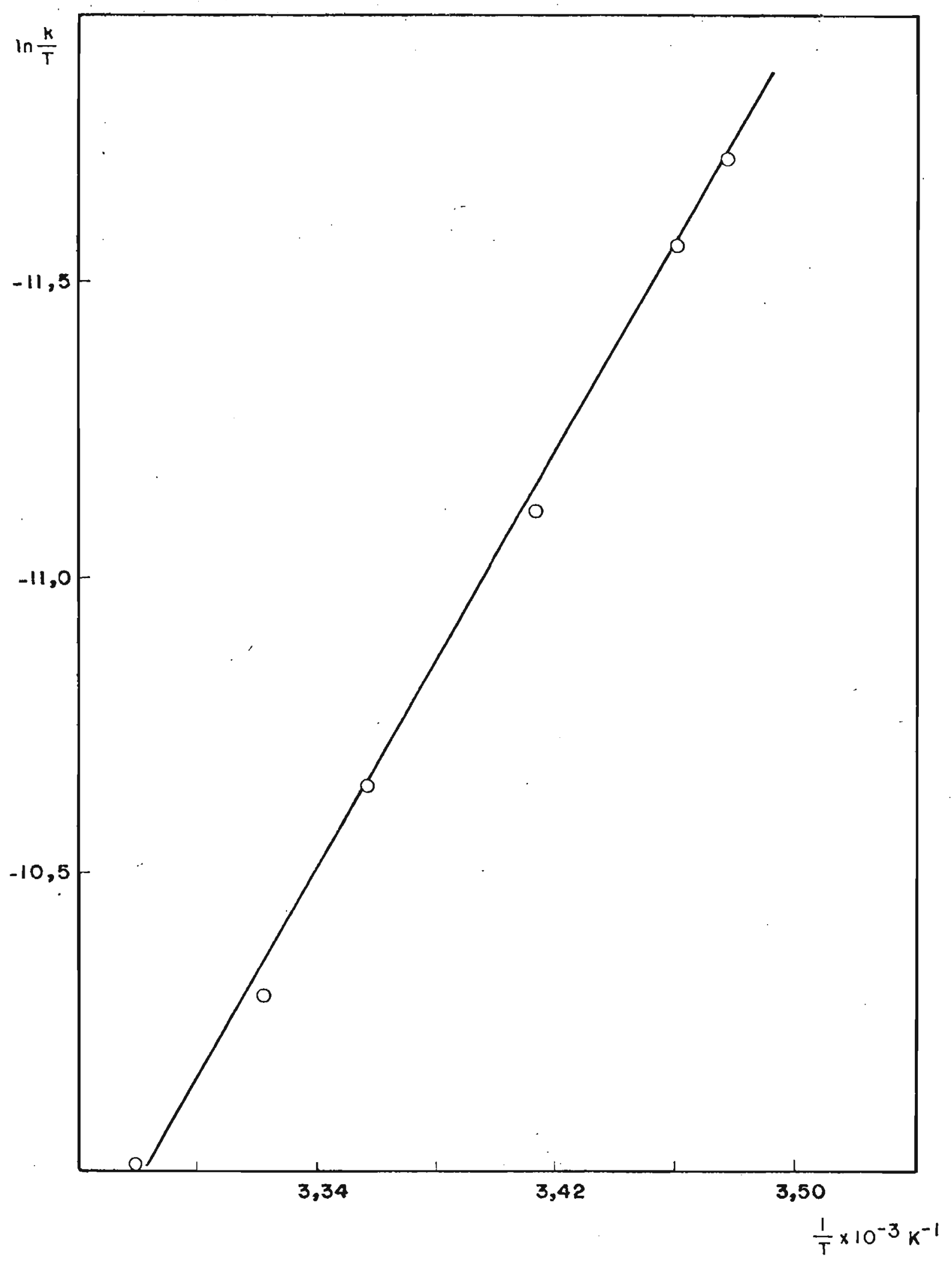

FIG. 6.13. Dependência da temperatura na constante de veloci dade de substituição no $\left.\mathrm{Fe}(\mathrm{CN}) 5^{\circ-p y C O}\right) \mathrm{CHNOH}^{3-}$ 2, $00 \times 10^{-4} \mathrm{M}$ com o ligante dmso, no ponto de satura ção $\left([\mathrm{dmso}]=5,00 \times 10^{-3} \mathrm{M}\right) \mu=0,100\left(\mathrm{LiClO}_{4}\right)$ 
Substituindo-se os valores de $k_{d}$, assim determinados, nas constantes de velocidade de formação dos complexos $\mathrm{Fe}(\mathrm{CN})_{5}$. o-py $(\mathrm{CO}) \mathrm{CHNOH}^{3-}(\mathrm{TAB} \cdot 6.5$.$) , pode-se obter a contribuição do$ termo $k^{\prime}$ [o-py(CO)CHNOH ] à dada temperatura, conforme relacionado na tabela abaixo.

TAB. C. - Dependência de Temperatura no Termo $k^{\prime}[$ o-py(CO)CH NOH ] da Constante de formação do Complexo

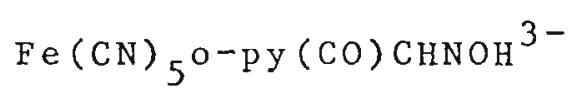

\begin{tabular}{cc}
$\begin{array}{c}\text { Temperatura } \\
\left({ }^{\mathrm{o}} \mathrm{C}\right)\end{array}$ & $\begin{array}{c}\text { o-py }(\mathrm{CO}) \mathrm{CHNOH}] \\
\times 10^{2}\left(\mathrm{~s}^{-\mathrm{I}}\right)\end{array}$ \\
\hline 33,0 & 2,81 \\
28,2 & 2,19 \\
25,0 & 1,82 \\
24,0 & 1,71 \\
20,0 & 1,34 \\
18,0 & 1,18 \\
16,0 & 1,04 \\
\hline
\end{tabular}

A partir destes dados constrōi-se o gräfico de $\ln \left(k^{\prime} / T\right)$ versus $1 / T$ (FIG.6.14) para a reação de formação da espécie $\mathrm{Fe}(\mathrm{CN})_{5} \mathrm{~L}-\mathrm{O}-\mathrm{py}(\mathrm{CO}) \mathrm{CHNOH}^{3-}$

* Os valores de kobs e $k^{\prime} d$ a diferentes temperaturas são obtidos da equacão da reta correspondente 


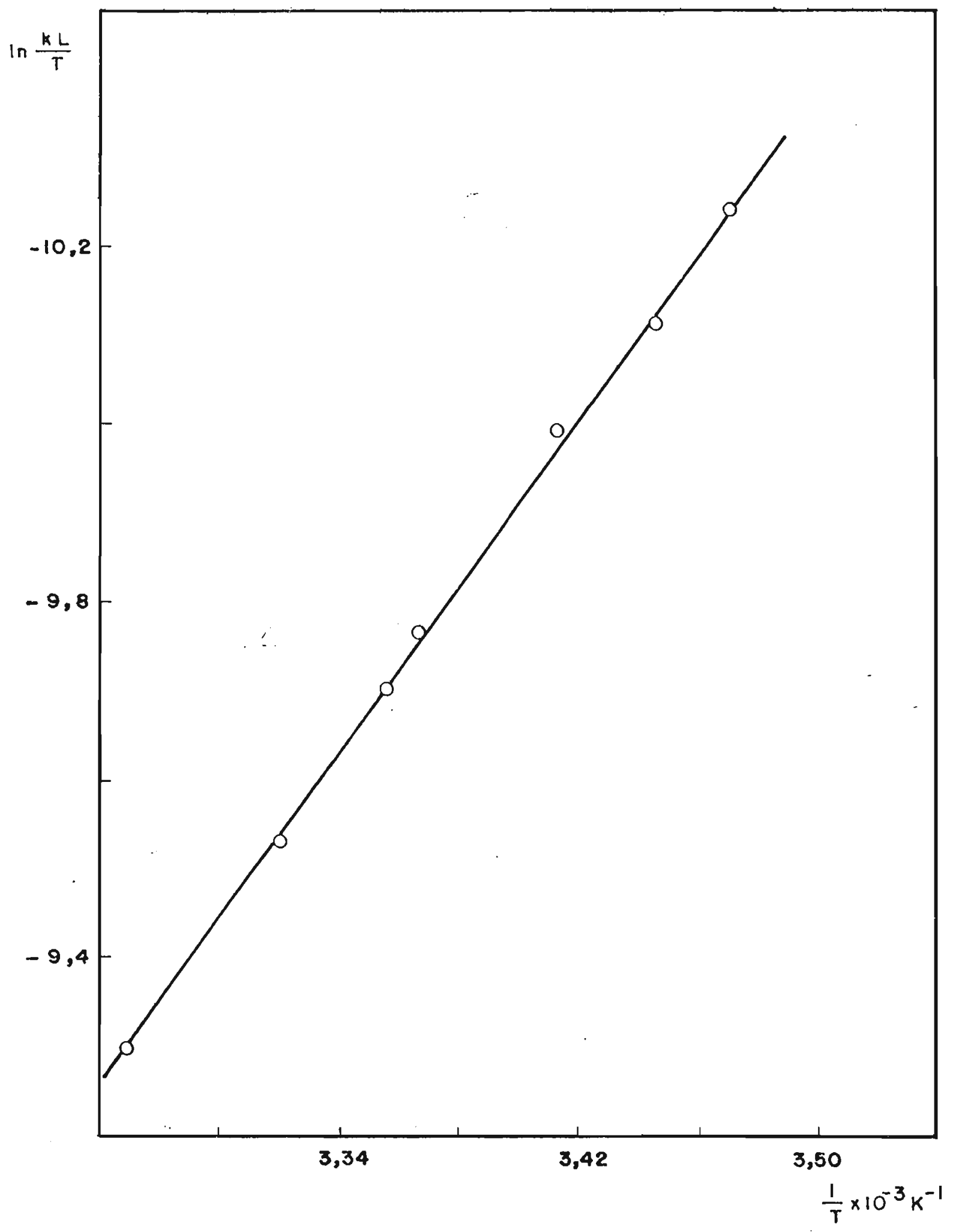

FIG.6.14. Dependência de temperatura na constante de velocidade de formação do $\mathrm{Fe}(\mathrm{CN}) 5^{\circ-p y C O) C H N O H}{ }^{3-} 1,00 \mathrm{X}$ $10^{-5} \mathrm{M} \quad[\mathrm{o}-\mathrm{py}(\mathrm{CO}) \mathrm{CHNOH}]=5,00 \times 10^{-3} \mathrm{M}$

$\left.\mu=0,100(\operatorname{LiClO})_{4}\right)$ 
os parâmetros cinéticos e termodinâmicos da rea ção de formação e substituição estão na tabela abaixo

$$
\mathrm{Fe}(\mathrm{CN}) 5^{\mathrm{o}-\mathrm{py}(\mathrm{CO}) \mathrm{CHNOH}^{3-}}
$$

Formação

$$
\begin{aligned}
& \mathrm{k} \quad \Delta \mathrm{H}^{\ddagger} \quad \Delta \mathrm{S}^{\ddagger} \quad \Delta \mathrm{G}^{\ddagger} \\
& \mathrm{M}^{-1} \mathrm{~s}^{-1} \mathrm{kcal} / \mathrm{mol} \mathrm{ca} 1 / \mathrm{mol} \cdot \mathrm{grau} \quad \mathrm{kcal} / \mathrm{mol} \\
& \begin{array}{llll}
3,51 & 9,75 & -23 & 16,6
\end{array}
\end{aligned}
$$

Dissociação
$s^{-1}$
$\Delta \mathrm{H}^{\neq}$
$\Delta \mathrm{s}^{\ddagger}$
$\Delta G^{\neq}$
$\mathrm{kca} 1 / \mathrm{mol}$
cal/mol.grau
$\mathrm{kca} 1 / \mathrm{mol}$

$$
7,-1 \times 10^{-3}
$$

17,3

$-10$

20,3

o valor da constante de formação é cerca de 100 vezes menor que para as demais oximas, o que poderia ser explicado pela existência de pré-equilíbrios $\left(k^{\prime}=k_{B} K\right)$, do tipo

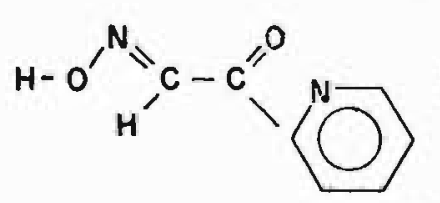

(A)

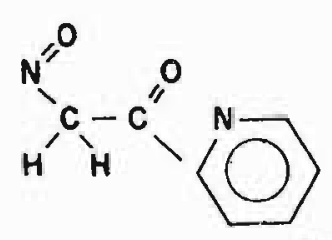

(B)

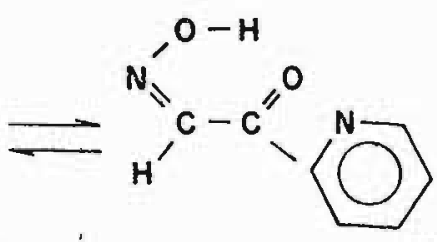

(C) 
Devido ao impedimento estërico do nitrogēnio do anel piridínico, a coordenação de carbonil-oxima derivado do ortoacetilpiridina $\overline{\mathrm{e}}$ bem menos favorecida em relação à forma tautomérica B, onde o nitrogênio (NO) torna-se disponível pela livre rotação, ou então à forma $c$.

Sem distinguir entre as duas ūitimas formas co ordenantes, pode-se sugerir o seguinte mecanismo:

$$
\begin{aligned}
& A \stackrel{{ }^{\prime K}}{=} \quad \text { B } \\
& \mathrm{Fe}(\mathrm{CN})_{5} \mathrm{H}_{2} \mathrm{O}^{3-} \frac{\mathrm{k}-\mathrm{H}_{2} \mathrm{O}}{\mathrm{k}_{\mathrm{H}_{2} \mathrm{O}}} \mathrm{Fe}(\mathrm{CN})_{5}{ }^{3-}+\mathrm{H}_{2} \mathrm{O}
\end{aligned}
$$

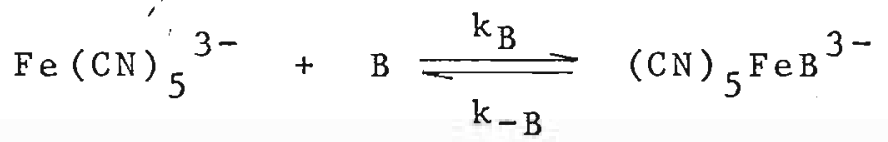

Assumindo a hipótese do estado esta.cionārio pa ra o intermediārio $\mathrm{Fe}(\mathrm{CN})_{5}{ }^{3-}$ e que o ligante esteja predominantemente na forma A, a lei da velocidade resulta numa equação, cujo $k_{o b s} \bar{e}$ dado por

$$
k_{\text {obs }}=k^{\prime}[\text { o-py }(\mathrm{CO}) \mathrm{CHNOH}]+k_{-B}
$$

onde $\quad k^{\prime}=k_{f B} k^{\prime} \quad($ vide apēndice 11.2 )

$$
0 \text { valor de } k_{-B} \text { igual a } 7,1 \times 10^{-3} s^{-1} \text {, obtido }
$$

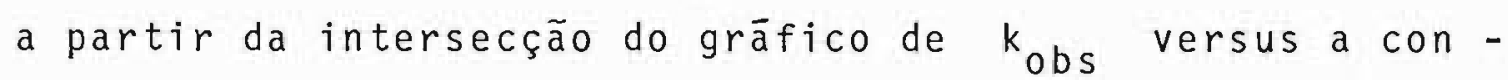
centração de o-py(CO)CHNOH (FIG. 6.9.) è concordante, den- 
tro do erro experimental, com $6,0 \times 10^{-3} \mathrm{~s}^{-1}$, obtido da ci nētica de substituição com dmso.

Nos derivados em meta e para, a coordenação ocorre pelo nitrogēnio da piridina que oferece geometria mais adequada. A contribuição da coordenação pelo nitrogēnio da oxima, para kobs deve ser desprezível por razões estēri cas ou dos equilibrios envolvidos que a diminui aproximadamente por um fator de $10^{-2}$.

\subsection{Reação de Adição das Acetilpiridinas ao Nitroprussiato}

Durante a sintese das carboni1-oximas, constatou-se que a formação dos produtos é precedida pelo aparec mento de intermediārio azul, com pequenos tempos de vida. A adição rāpida de etanol, logo apōs a formação do intermediā rio azul conduz a um precipitado da mesma cor, que foi in vestigado sob o ponto de vista cinético e espectroscōpico. os espectros infravermelho dos intermediārios, jä apresenta dos no capittulo anterior, demonstraram a presença de deriva dos carbonil piridínicos coordenados ao ferro. Os espectros eletrōnicos dos sōlidos tambēm foram registrados, utilizando-se a técnica de suspensão em fluorolube, na busca de evi déncias que possibilitassem a formulação da composição dos mesmos. Esses espectros podem ser observados nas figuras 6 . 15 a 6.17 .

o produto mais provāvel envolvido nas etapas 


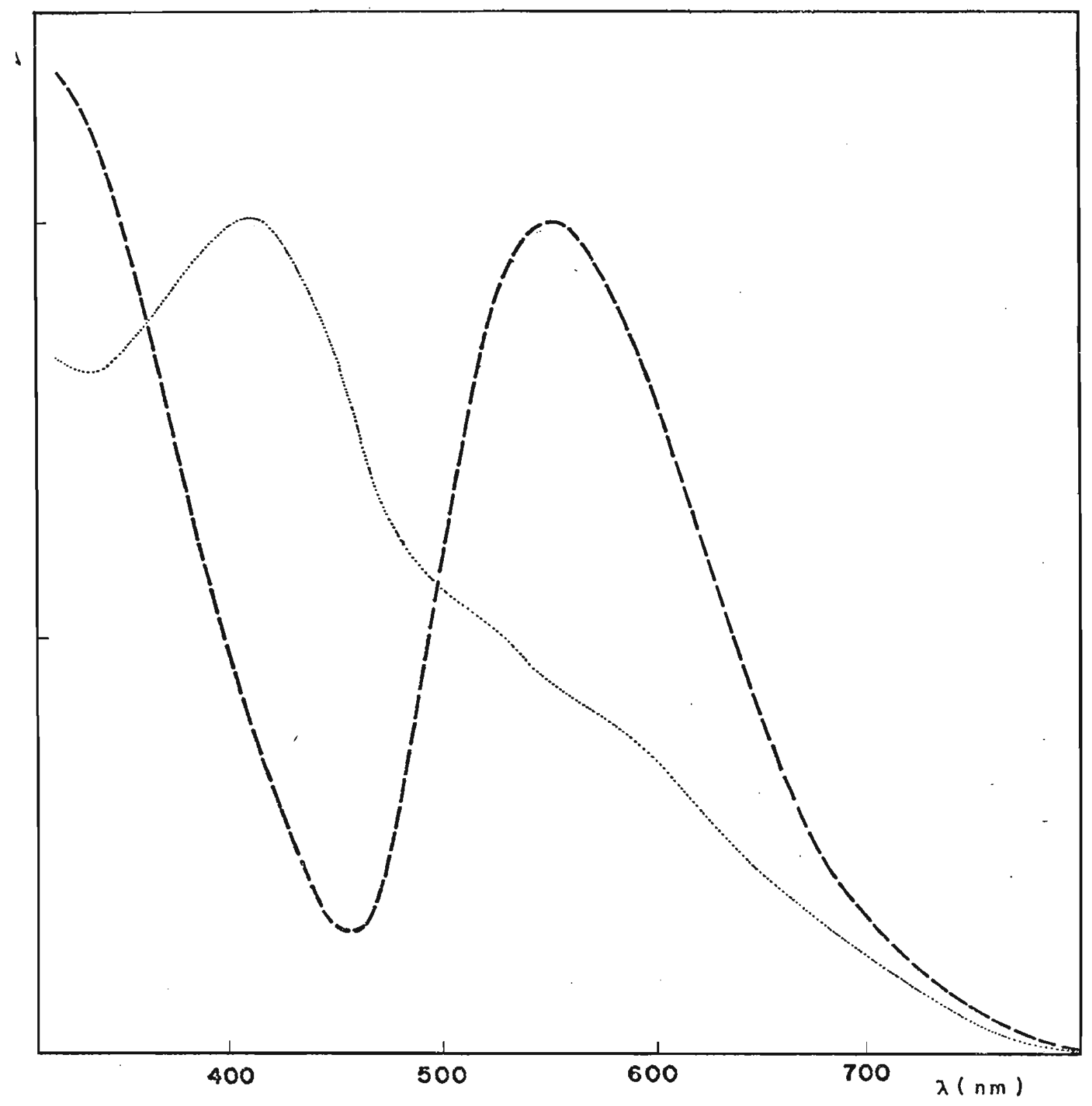

FIG. 6.16. Espectro eletrônico do $\mathrm{Na}_{3} \mathrm{Fe}(\mathrm{CN})_{5} \mathrm{~m}-\mathrm{py}(\mathrm{CO}) \mathrm{CH}_{2} \mathrm{NO}^{3-} /$ $\mathrm{Na}_{3} \mathrm{Fe}(\mathrm{CN})_{5} \mathrm{~m}-\mathrm{py}(\mathrm{CO}) \mathrm{CHNO}^{4-}(-\ldots-\ldots)$ e do $\mathrm{Na}_{3} \mathrm{Fe}(\mathrm{CN})_{5} \mathrm{~m}-\mathrm{py}(\mathrm{CO}) \mathrm{CHNOH}^{3-}$ coordenado pela piridi na $(\cdots \cdots \cdots)$ em emulsão com fluorolube 


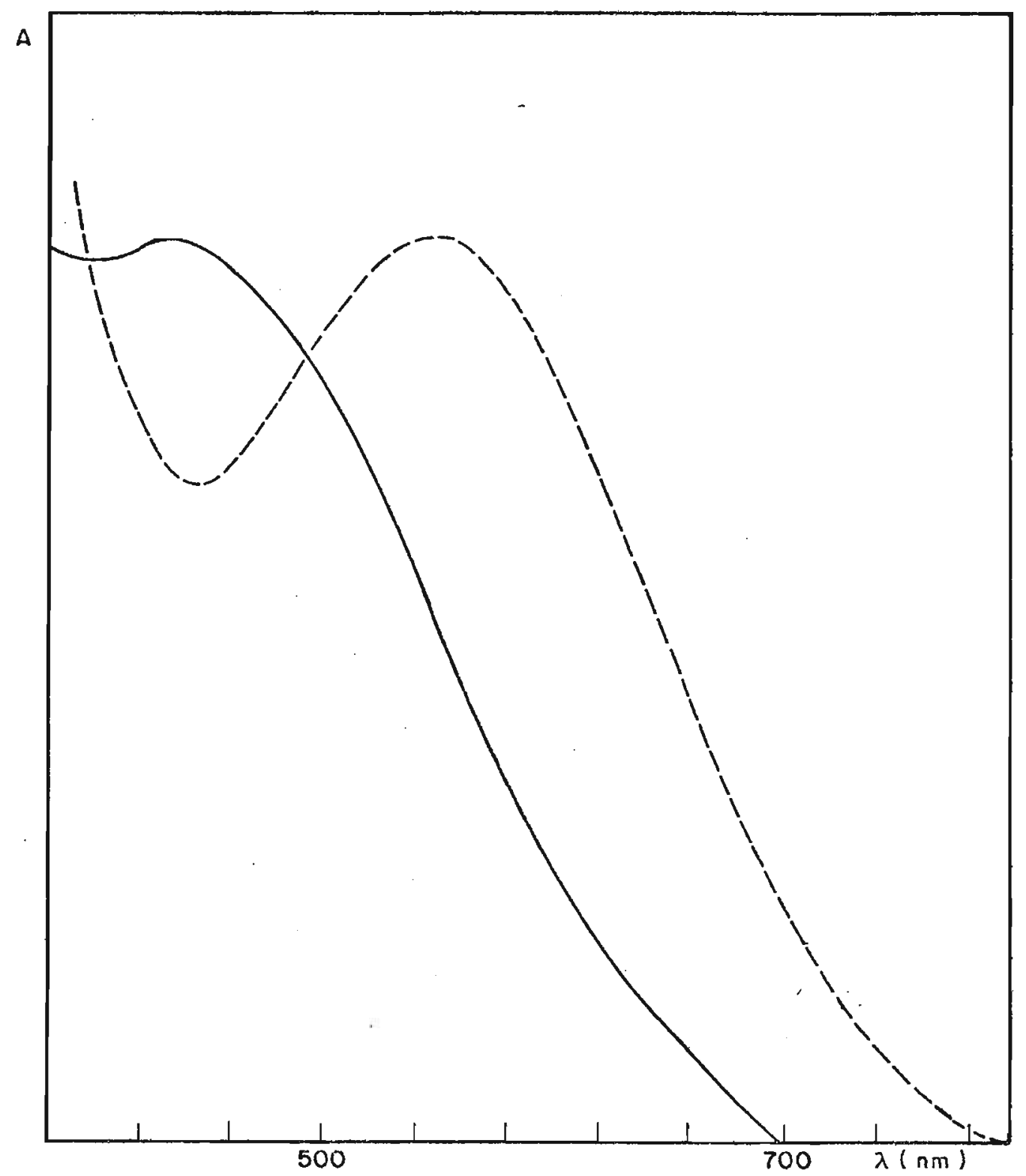

FIG.6.15. Espectro eletrônico do $\mathrm{Na}_{3} \mathrm{Fe}(\mathrm{CN})_{5} \mathrm{P}-\mathrm{py}(\mathrm{CO}) \mathrm{CH}_{2} \mathrm{NO}^{3}$ $\mathrm{Na}_{3} \mathrm{Fe}(\mathrm{CN})_{5} \mathrm{p}-\mathrm{py}(\mathrm{CO}) \mathrm{CHNO}^{4-}$ em emulsão com fluorolu ( - - - - ) e do $\mathrm{Na}_{3} \mathrm{Fe}(\mathrm{CN})_{5} \mathrm{p}-\mathrm{py}(\mathrm{CO}) \mathrm{CHNOH}^{3-}$ coord nado pela piridina, nas mesmas condiçöes 


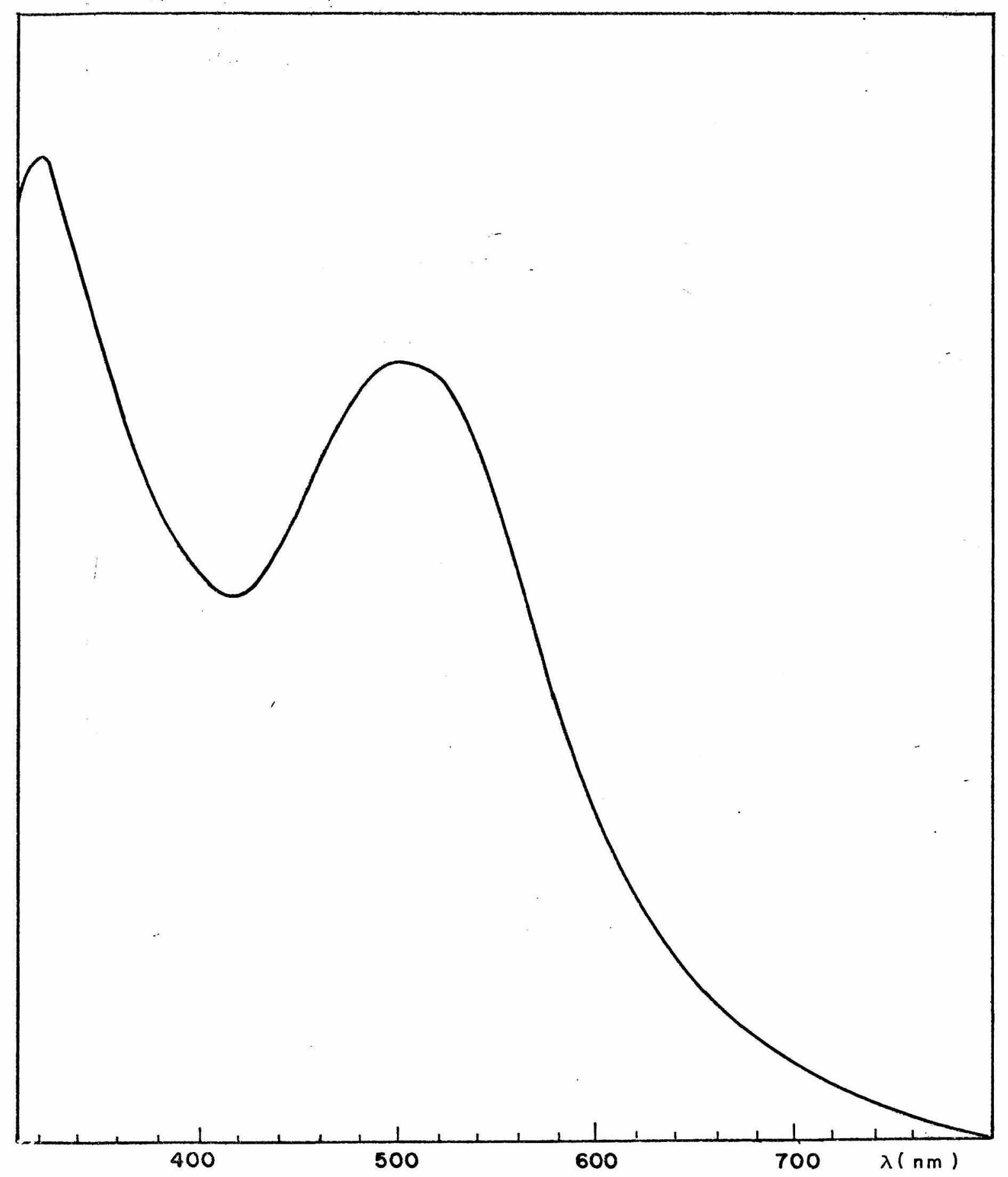

FIG.6.17. Espectro eletrônico do intermediärio (CN) ${ }_{5}$ Fe-o-py. ( CO ) $\mathrm{CH}_{2} \mathrm{NO}^{3-} /(\mathrm{CN})_{5} \mathrm{Fe} \cdot \mathrm{o}-\mathrm{py}(\mathrm{CO}) \mathrm{CHNOH}^{3-}$ em emulsão com fluorolube 
primárias de adição ao nitroprussiato seria do tipo

$\mathrm{Fe}(\mathrm{CN})_{5} \mathrm{NO}^{2-}+\mathrm{CH}_{2}(\mathrm{CO}) \mathrm{Py}^{-} \longrightarrow(\mathrm{CN})_{5} \mathrm{Fe}-\mathrm{N}_{\mathrm{CH}_{2}}(\mathrm{CO}) \mathrm{py}$

contudo seu isolamento como sōlido é dificultado pela labilidade em solução, fato este ainda complicado pelo equilî brio

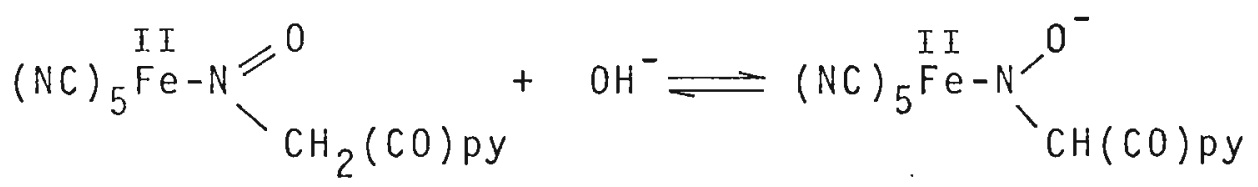

Este equilíbrio deve tornar-se importante em $\mathrm{pH}$ elevado, como nas condições de sīntese $\left(\left[\mathrm{OH}^{-}\right]=1 \mathrm{M}\right)$, onde a espécie oximato pode ser predominante. Evidéncias dis so são observadas pela adição de àcido acético à mistura, 10 go apōs a formação do intermediārio azulado. o que se nota nesse caso é a intensificação da tonalidade azul, o que poderia envolver a protonação da forma oximato, formando oxima correspondente.

Devido às complicações envolvidas no isolamento dos intermediārios, foram obtidos os espectros eletrōnicos dos mesmos em solução, pela técnica "stopped-flow". Esses espectros estão ilustrados nas figuras 6.18 a 6.20 .e de modo geral são semelhantes aos espectros das espécies isola das como sōlidos, conforme pode ser visto na tabela da pägina a seguir. 


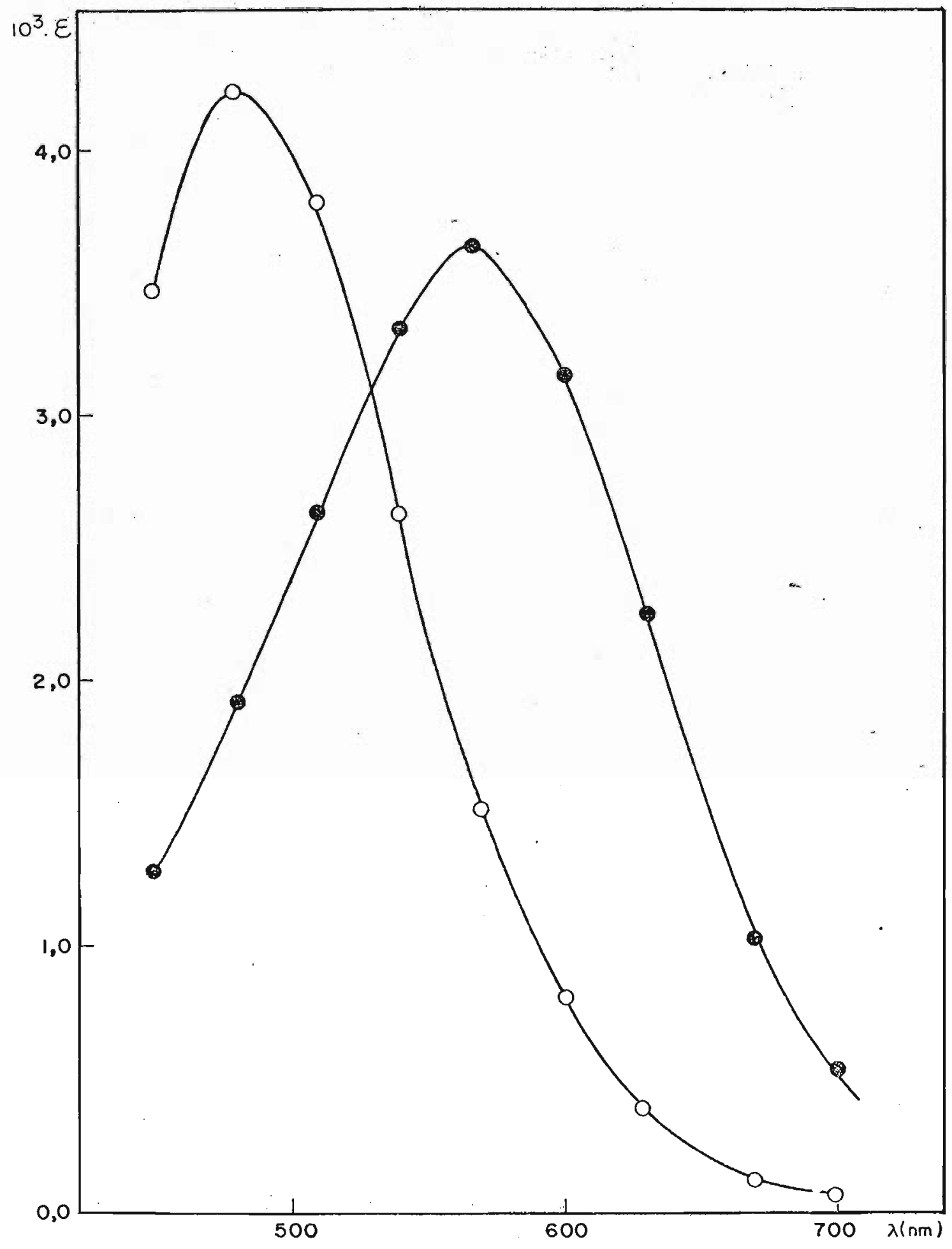

[G.6.18. Espectro eletrônico do intermediário ( • • ) e do produto ( py (CO) $\mathrm{CH}_{3}{ }^{3-}$, respectivamente, obtido pela Eccnica "stopped-flow" 


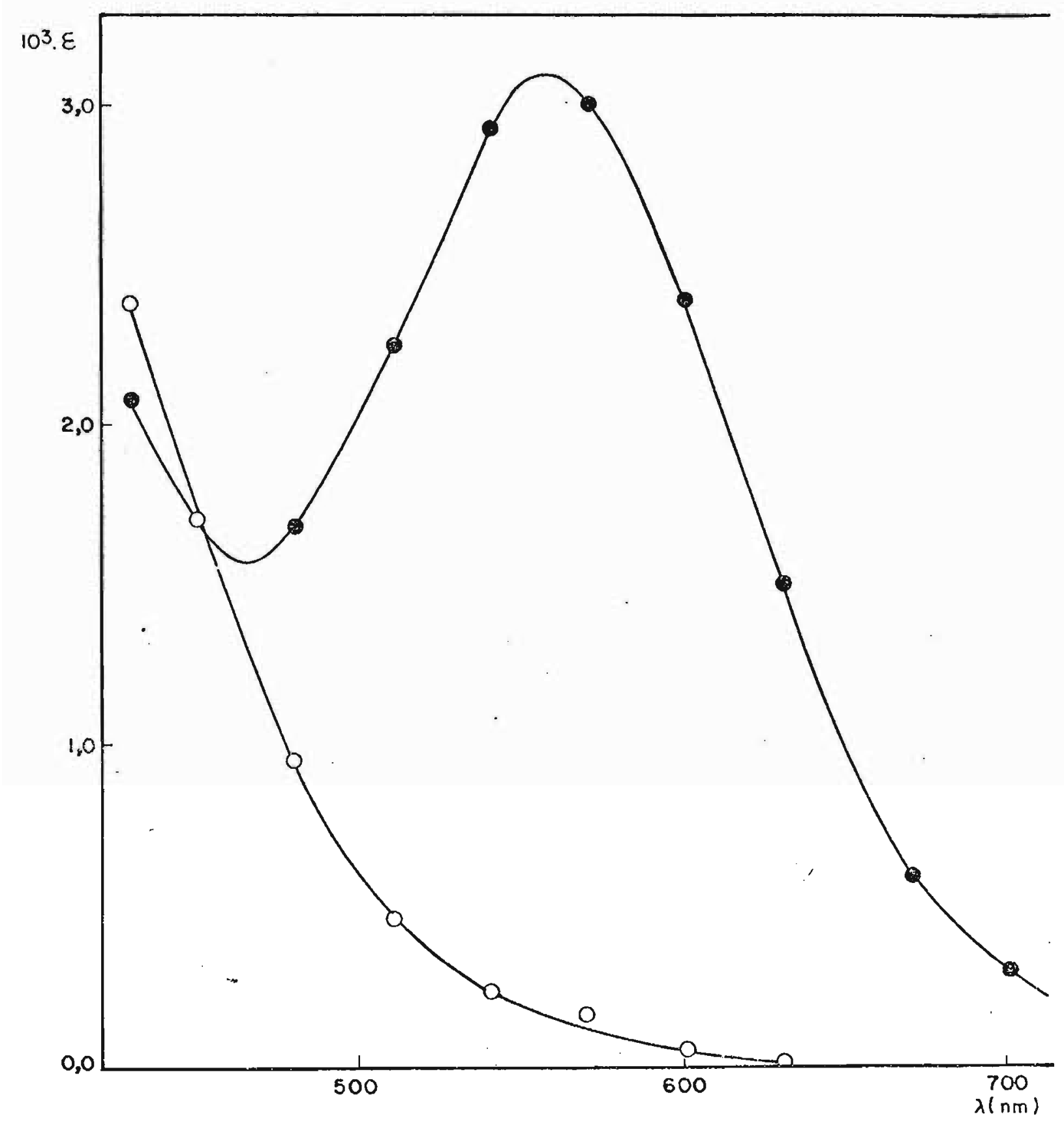

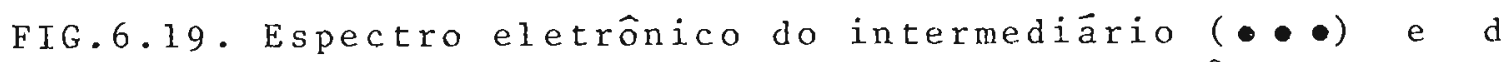

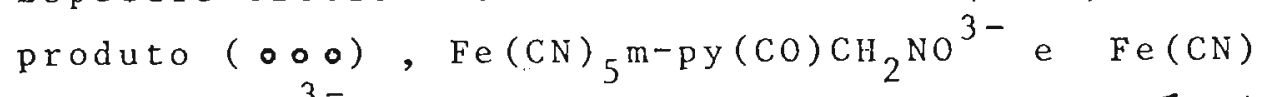
m-py $(\mathrm{CO}) \mathrm{CH}_{3}{ }^{3-}$, respectivamente, obtido pela técni ca "stopped-flow" 


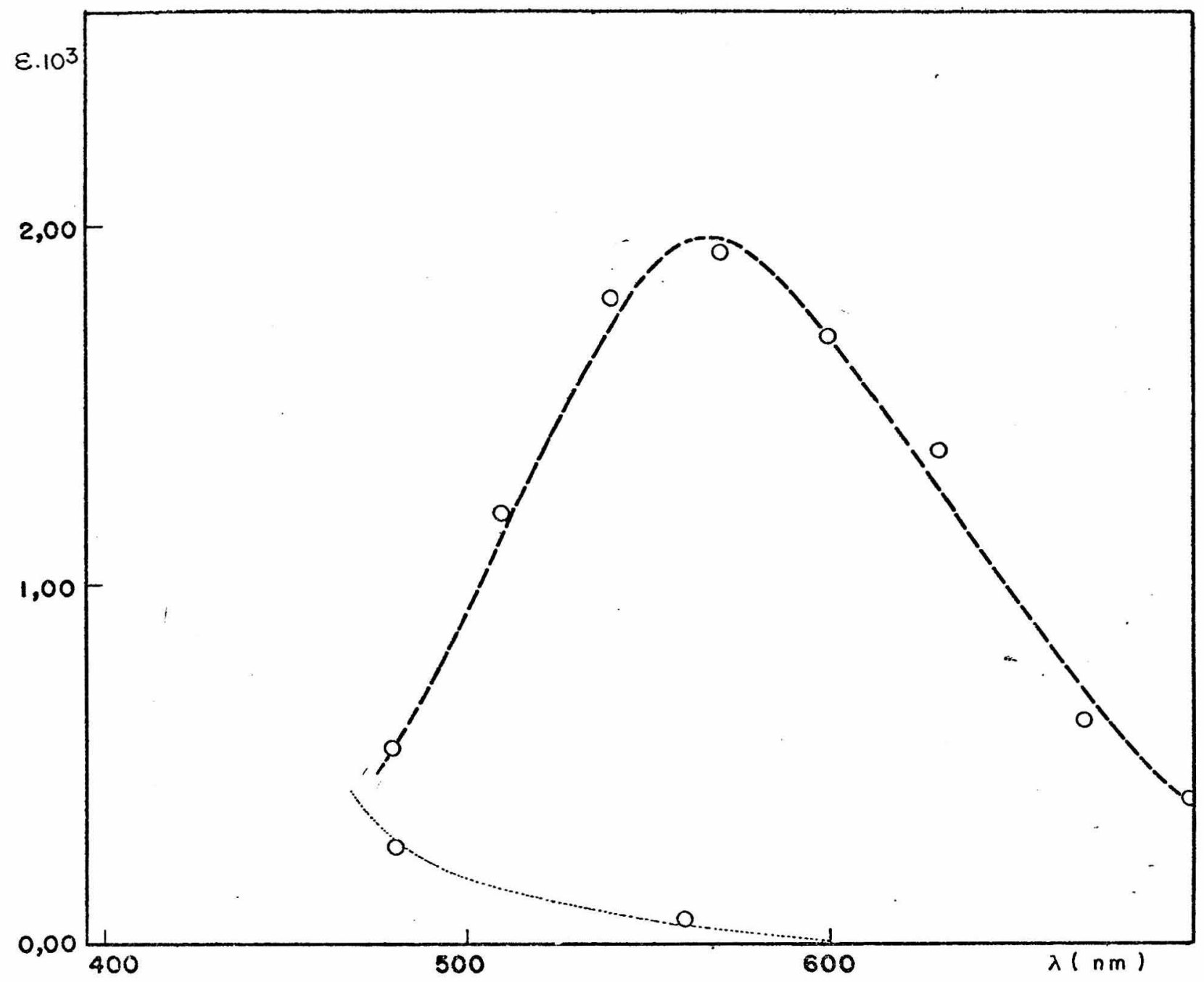

FIG. 6.20. Espectro eletrônico do intermediário $\mathrm{Fe}(\mathrm{CN}){ }_{5} \mathrm{o-py}(\mathrm{CO}) \mathrm{CH}_{2} \mathrm{NO}^{3-}$ e do produto, obtido pela técnica "stopped-flow" $\mu=0,100$ ajustada com LiC10 4 
Transições de Transferência de Carga para os Intermediário:

\begin{tabular}{ccc}
\hline LIGANTE & $\begin{array}{c}\lambda \text { max } \\
(\text { stopped-flow })\end{array}$ & $\begin{array}{l}\lambda \max \\
(\text { emulsão })\end{array}$ \\
\hline p-py (CO)CHNOH & 564 & 550 \\
m-py(CO)CHNOH & 558 & 550 \\
o-py (CO) CHNOH & 566 & $620^{*}$ \\
\hline
\end{tabular}

A produção da oxima livre deve estar associad. à etapa de decomposição do intermediārio, que poderia se visualizada como

$$
(\mathrm{CN})_{5} \mathrm{Fe}(\mathrm{NO}) \mathrm{CH}_{2}(\mathrm{CO}) \mathrm{py}^{3-} \longrightarrow \mathrm{Fe}(\mathrm{CN})_{5}{ }^{3}(\mathrm{aq})+\mathrm{py}(\mathrm{CO}) \mathrm{CH}_{2}
$$

Com a dissociação do complexo, a conversão do ligante à fo. ma de oxima, é facilitada visto que o grupo $N=0$ torna -s mais exposto ao ataque nucleofilico. (Note-se que através da retrodoação, os íons de ferro(II) deveriam diminuir con sideravelmente a probabilidade desse tipo de reação no com plexo).

$$
{ }^{\mathrm{N}}=\mathrm{CH}_{2}(\mathrm{CO})_{\mathrm{Py}}+\mathrm{OH}^{-} \rightleftharpoons \mathrm{N}^{-} \mathrm{O}_{\mathrm{CH}(\mathrm{CO}) \mathrm{Py}}^{-}+\mathrm{H}_{2} \mathrm{O}
$$


6.2.1. Comportamento Cinētico

As curvas cinéticas de formação e decaimento $\underline{0}$ btidos no aparelho "stopped-flow" estão ilustradas na figura 6.21. para os trēs isōmeros de acetilpiridina.

A escolha do comprimento de onda onde se deter minaram os parāmetros cinéticos foi baseada nos espectros 0 btidos pelo "stopped-flow" (FIG. 6.15 a 6.17) e fixadas em $560 \mathrm{~nm}$ para os derivados em orto e meta.

Na reação com p-acetilpiridina, a escolha desse comprimento de onda para as medidas cinēticas é maîs crîtica. O produto final da reação absorve também nessa região, coin māximo em $480 \mathrm{~nm}$. Determinadas condições de medida, in terferem nas investigações referentes às duas primeiras etạ pas, correspondentes à formação do intermediārio e o seu posterior desaparecimento. Isso porque, nas reações em que se observam duas ou mais etapas, a linearidade dos gráfịcos de $\ln \left(A_{\infty}-A_{t}\right)$ versus tempo para cada etapa só é possível numa situação onde se minimiza a interferência da outra. A origem do problema estaria portanto na determinação do $A_{\infty}$ devido à influēncia da reação seguinte.

A reação de adição de p-acetilpiridina ao ĩon nitroprussiato foi estudada a $680 \mathrm{~nm}$ após um estudo prelimi nar verificando o comportamento cinético a vārios comprimen to de onda, num intervalo de 580 a $700 \mathrm{~nm}$. 

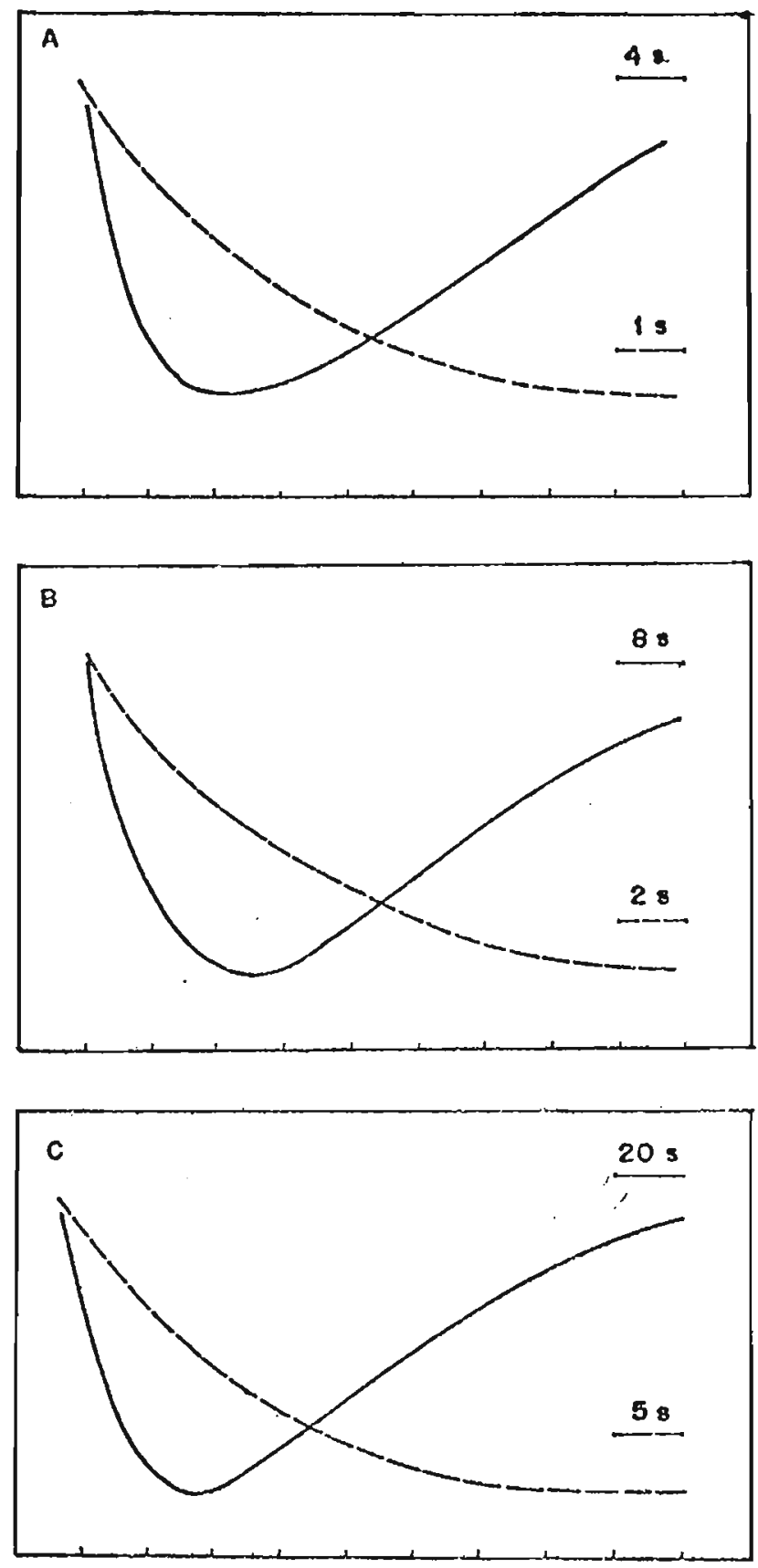

FIG.6.21. Curvas cinéticas de formação e decaimento do inte mediário na reação do ion nitroprussiato $4,00 \times 10^{-5}$ com diversos isômeros de acetilpiridina na presen ça de $\operatorname{LiOH}(0,04 \mathrm{M})$ a $25,0^{\circ} \mathrm{C} \quad \mu=0,100\left(\mathrm{LiClO}_{4}\right)$ $L=A \cdot p-p y(C O) \mathrm{CH}_{3}, B \cdot m-p y(C O) \mathrm{CH}_{3}, \mathrm{C} . \mathrm{o}-\mathrm{py}(\mathrm{CO}) \mathrm{C}$ 
A formação do composto azul é acompanhada no "stopped-flow", sob condições de pseudo primeira ordem à força iônica constante $(\mu=0,10 \mathrm{LiCl0} 4 / \mathrm{LiOH}) \bar{a} 25,0^{\circ} \mathrm{C}$.

A dependēncia de-k obs com a formação da hidroxila e do ligante está relacionada na tabela 6.7 e ilustrada nas figuras 6.22 e 6.23 para a reação com p-acetilpiridi na. A reação de adição com os derivados em orto e meta é mais Tenta mas, o mesmo tipo de dependência pode ser encontrado nas tabelas 6.8 e 6.9 e nas figuras 6.24 A e B. As retas não passam pela origem,indicando a existência de um termo que independe da concentração tanto do ligañ̂te como da hidroxila. Isto sugere a existēncia de uma etapa de retorno, onde a espécie (NC) ${ }_{5} \mathrm{Fe}(\mathrm{NO}) \mathrm{CH}_{2}(\mathrm{CO}) \mathrm{py}^{3-}$ estā em equilībrio com a forma dissociada. A formação do intermediārio azul en volve ataque das acetilpiridinas, na forma de carbānion, ao grupo nitrosilo coordenado, em competição com a adição do ion hidroxila, conforme o mecanismo apresentado

(1) $\mathrm{py}(\mathrm{CO}) \mathrm{CH}_{3}(\mathrm{aq})+\mathrm{OH}^{-}(\mathrm{aq}) \stackrel{\mathrm{K}}{\rightleftharpoons} \mathrm{py}(\mathrm{CO}) \mathrm{CH}_{2}{ }^{-}$(aq) $+\mathrm{H}_{2} \mathrm{O}$

(2) (NC) ${ }_{5} \mathrm{FeNO}^{2-}(\mathrm{aq})+\mathrm{OH}^{-} \stackrel{\mathrm{OHH}}{\longrightarrow}(\mathrm{NC})_{5} \mathrm{FeNO}_{2} \mathrm{H}^{3-}(\mathrm{aq})$

(2a) (NC) ${ }_{5} \mathrm{FeNO}_{2} \mathrm{H}^{3-}(\mathrm{aq})+\mathrm{OH}^{-}(\mathrm{aq}) \stackrel{\mathrm{ra} \mathrm{pida}}{\longrightarrow}(\mathrm{NC})_{5} \mathrm{FeNO}_{2}^{4-}$ (aq ) $+\mathrm{H}_{2} \mathrm{O}$

(3) (NC) ${ }_{5} \mathrm{FeNO}^{2-}(\mathrm{aq})+\mathrm{py}(\mathrm{CO}) \mathrm{CH}_{2}^{-}(\mathrm{aq}) \underset{\mathrm{k}_{-\mathrm{L}}}{\stackrel{\mathrm{k} \mathrm{L}}{\rightleftharpoons}}(\mathrm{NC})_{5} \mathrm{Fe}(\mathrm{NO}) \mathrm{CH}_{2}(\mathrm{CO}) \mathrm{py}$ 
TABELA - 6.7.

Constantes de Velocidade para a Reação de Formação do Inte. mediärio azul ( $\left.\mathrm{k}_{\mathrm{Obsl}}\right)$ a $25,0^{\circ} \mathrm{C}$ para $\mathrm{p}-\mathrm{py}(\mathrm{CO}) \mathrm{CH}_{3}$

$\left[\mathrm{p}-\mathrm{py}(\mathrm{CO}) \mathrm{CH}_{3}\right] \times 10^{2} \mathrm{M}\left[\mathrm{OH}^{-}\right] \times 10^{2} \mathrm{M} \quad \mathrm{kobsI}\left(\mathrm{s}^{-1}\right)$

$\begin{array}{cl}1,00 & 0,151 \\ 2,00 & 0,221 \\ 3,00 & 0,290 \\ 4,00 & 0,3665 \\ 5,00 & 0,450 \\ 6,00 & 0,545 \\ 7,00 & 0,595\end{array}$

$$
\begin{aligned}
& {\left[(\mathrm{NC}){ }_{5} \mathrm{FeNO}^{2-}\right]=6,0 \times 10^{-5} \mathrm{M}} \\
& \mu=0,10 \text { ajustada com LiC10 } \\
& \lambda=680 \mathrm{~nm}
\end{aligned}
$$

0,$199 ; 0,210$

0,$220 ; 0,235$

0,221

0,$261 ; 0,271$

0,$306 ; 0,314$ 


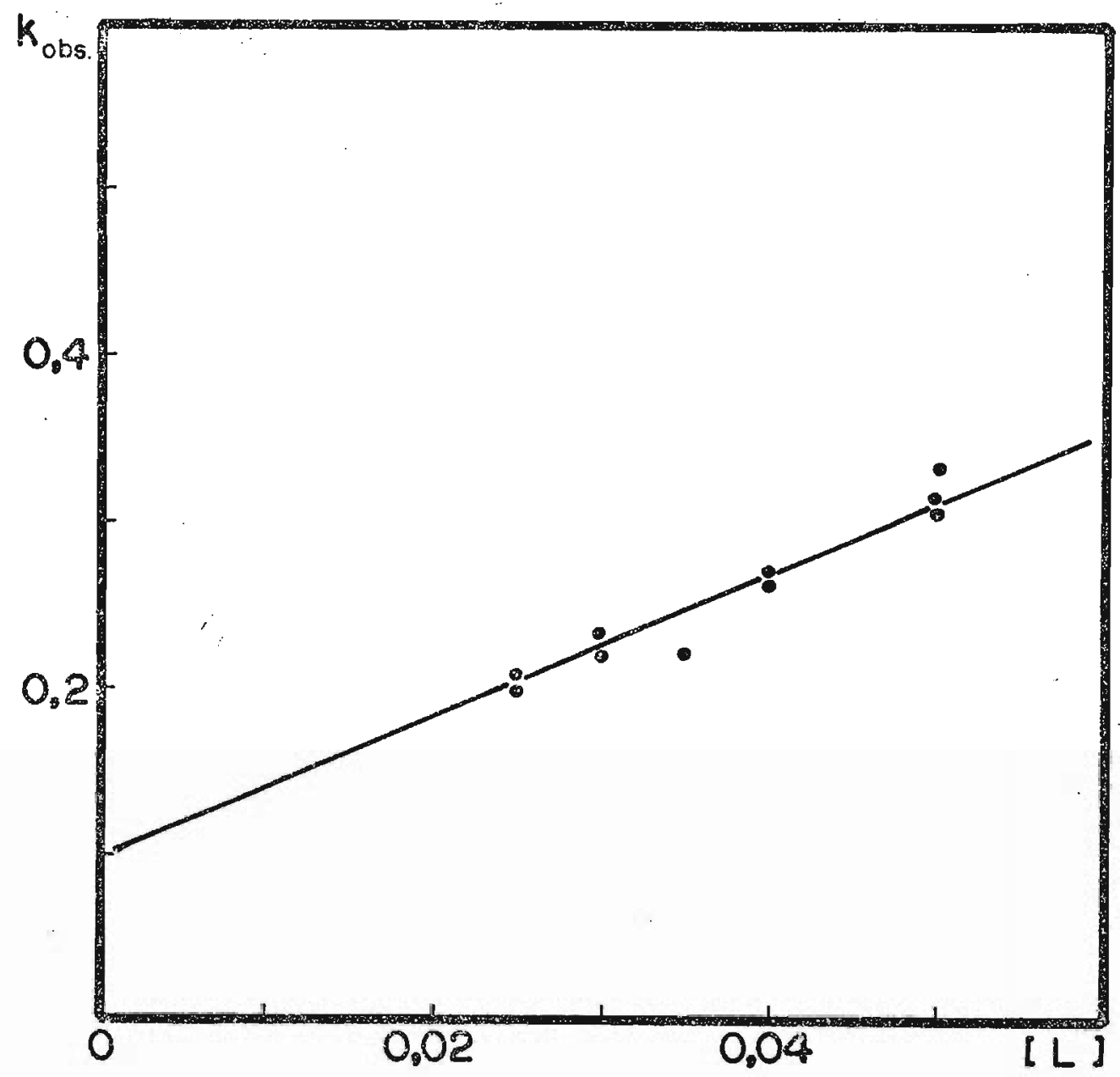

:G.6.23. Constantes de velocidade de formação do intermediá rio coordenado pelo No em função da concentração de $\mathrm{p}$-py(CO) $\mathrm{CH}_{3} \quad\left[\mathrm{OH}^{-}\right]=2,00 \times 10^{-2} \mathrm{M}$ $\mu=0,100\left(\mathrm{LiClO}_{4}\right) \quad t=25,0 \pm 0,1{ }^{\circ} \mathrm{C}$ 


$$
\sum
$$


TABELA - 6.8 .

onstantes de Velocidade para a Reação de Formação do Inter ediārio azul ( $\left.k_{o b s l}\right)$ em função da concentração de $\mathrm{OH}^{-}$

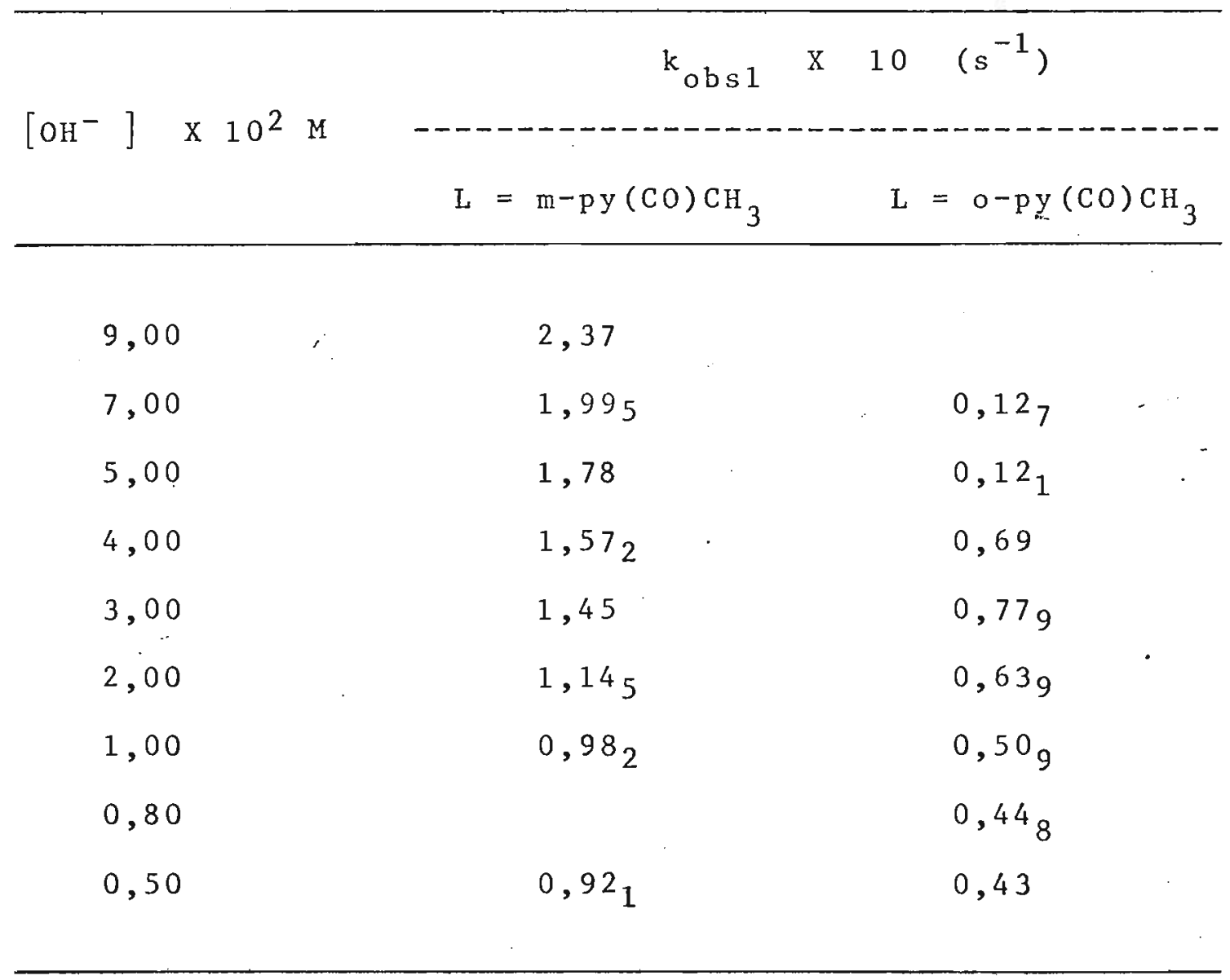

$\mathrm{L}]=3,53 \times 10^{-2} \mathrm{M}$

$\left.(\mathrm{NC}){ }_{5} \mathrm{FeNO}^{2-}\right]=4,0 \times 10^{-5} \mathrm{M}$

$=0,10$ ajustada com LiC10 4

$=560 \mathrm{~nm}$

emperatura $=25,0{ }^{\circ} \mathrm{C}$ 
TABELA - 6.9 .

Constantes de Velocidade para a Reação de Formação do Intex mediärio azul ( $\left.k_{o b s 1}\right)$ em Função da Concentração do Ligante

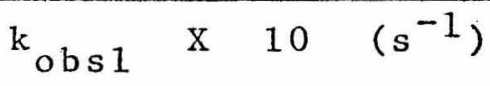

$[\mathrm{L}] \mathrm{X} \quad 10^{2} \mathrm{M}$

$$
\mathrm{L}=\mathrm{m}-\mathrm{py}(\mathrm{CO}) \mathrm{CH}_{3} \quad \mathrm{~L}=\mathrm{o}-\mathrm{py}(\mathrm{CO}) \mathrm{CH}_{3}
$$

$\begin{array}{ccc}4,50 & 1,25 & 0,64 \\ 0,65 \\ 4,00 & 1,21 & 0,67 \\ & 1,145 & 0,64 \\ 3,53 & 0,62 \\ 3,00 & 1,12 & 0,65 \\ 2,50 & 1,05 & 0,64 \\ 2,00 & & 0,63 \\ & 1,03 & 0,60\end{array}$

$[\mathrm{LiOH}]=2,00 \times 10^{-2} \mathrm{M}$

$\left[\mathrm{Fe}(\mathrm{CN})_{5} \mathrm{NO}^{2-}\right]=4,0 \times 10^{-5} \mathrm{M}$

$\mu=0,10 \mathrm{M}$ ajustada $\operatorname{com~LiClO} 4 \quad \lambda=560 \mathrm{~nm}$

temperatura $=25,0^{\circ} \mathrm{C}$ 


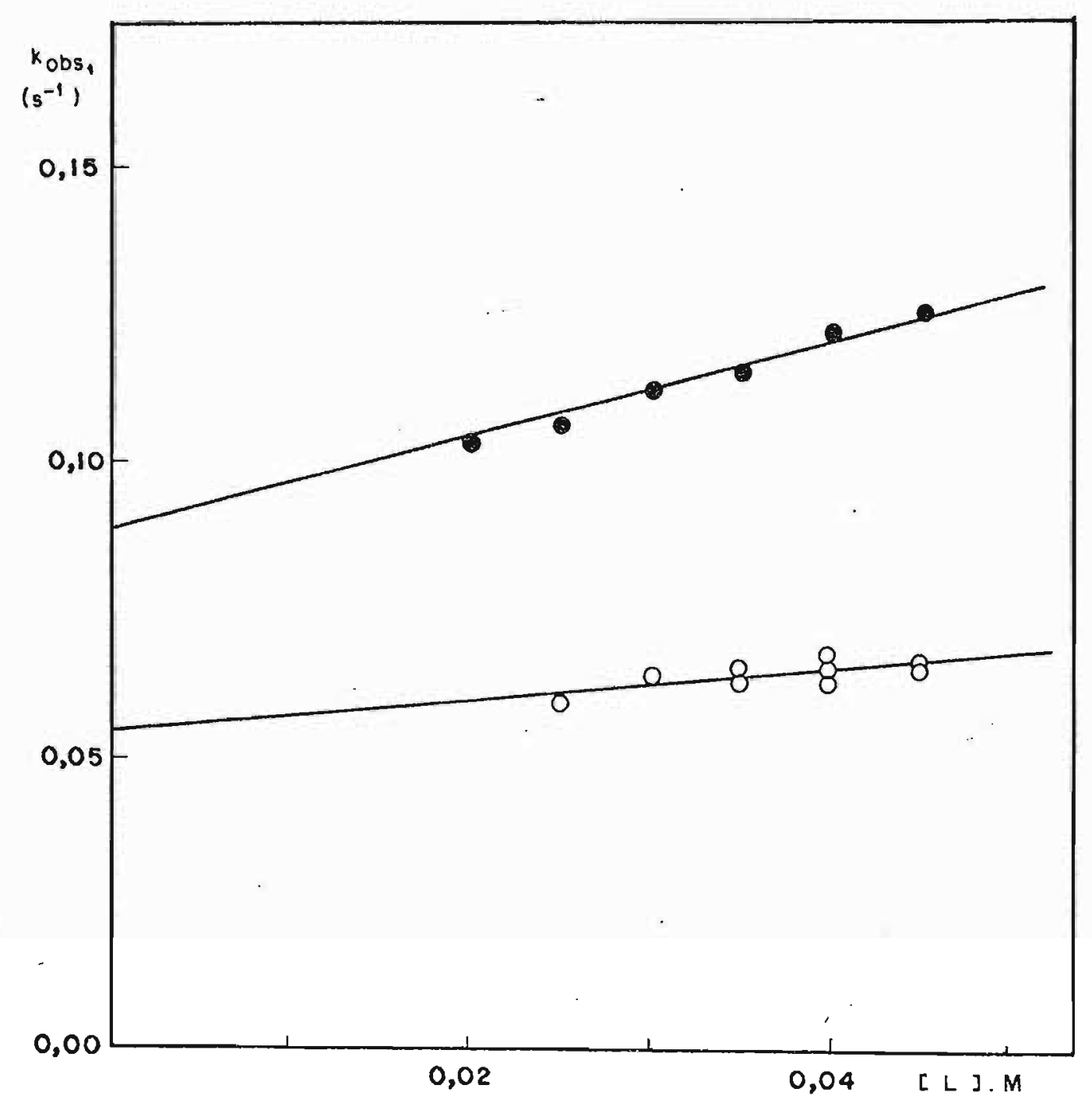

FIG.6.24.B. Constantes de velocidade de formação do intermediärio azul em funçäo da concentração de L

- $\mathrm{L}=\mathrm{m}-\mathrm{py}(\mathrm{CO}) \mathrm{CH}_{3}\left[\mathrm{OH}^{-}\right]=2,00 \times 10^{-2} \mathrm{M}$ - $\mathrm{L}=$ o-py $(\mathrm{CO}) \mathrm{CH}_{3}$

$\mu=0,100\left(\mathrm{LiClO}_{4}\right) \quad t=25,0 \pm 0,1^{\circ} \mathrm{C}$ 
Sendo a etapa (2a) uma reação rāpida, ācido-bă e, a etapa 2 é a determinante da reação entre o nitroprusiato e a hidroxila. A lei de velocidade para o mecanismo roposto tem a seguinte expressão para a constante de veloidade observada $\left(\mathrm{k}_{\mathrm{obs}}\right)$ :

$$
\mathrm{k}_{\mathrm{obs} 1}=\mathrm{k} \mathrm{k}_{\mathrm{L}}\left[\mathrm{py}(\mathrm{CO}) \mathrm{CH}_{3}\right]\left[\mathrm{OH}^{-}\right]+\mathrm{k}_{\mathrm{OH}}\left[\mathrm{OH}^{-}\right]+\mathrm{k}_{-\mathrm{L}}(4)
$$

( vide apêndice 11.2)

0s valores de $k_{-L}$ e $\mathrm{K}_{\mathrm{L}}$ determinados a artir dos gráficos das figuras 6.22 e 6.24 estão relaciona os na tabela a, seguir.

alores de $\mathrm{Kk}_{\mathrm{L}}$ e $\mathrm{k}_{-\mathrm{L}}$ obtidos dos gräficos de:

- kobs 1 vs $\left[\mathrm{OH}^{-}\right]$b. kobs 1 vs [L ]

LIGANTE $k_{-L}\left(s^{-1}\right) \quad k_{L}\left(s^{-1} M^{-2}\right)$

a

b

a

$\mathrm{b}$

$\begin{array}{lllll}\text {-py }(\mathrm{CO}) \mathrm{CH}_{3} & 0,088 & 0,092 & 191 & 211 \\ - \text { py }(\mathrm{CO}) \mathrm{CH}_{3} & 0,088 & 0,085 & 36,8 & 38,0 \\ \text {-py }(\mathrm{CO}) \mathrm{CH}_{3} & 0,045 & 0,047 & 14,6 & 13,7\end{array}$

Pode-se verificar que os valores determinados as experiēncias independentes são concordantes dentro do 
erro experimental e mostram a consisténcia do mecanismo.

$$
\text { A constante de velocidade da etapa (2), } \mathrm{k}_{\mathrm{OH}} \text {, }
$$

determinada através da expressão (4) em ambas as experiências é aproximadamente $0,30 \mathrm{~s}^{-1} \mathrm{M}^{-1}$. Este valor é comparāvel ao encontrado na 1 iteratura, realizada à força iōnica $1 \mathrm{M}$ em $\mathrm{NaCl}$ (143).

A fim de comparar o valor de $k_{\mathrm{OH}}$ calculado in diretamente atravēs da expressão (4), o estudo cinētico do sistema pentaciano(nitrosil)ferrato(II) - hidrōxido, onde as etapas (2) e (2a) da equação global são representadas de uma maneira simples como

$(\mathrm{NC})_{5} \mathrm{FeNO}^{2-}(\mathrm{aq})+2 \mathrm{OH}^{-} \stackrel{\mathrm{k}_{\mathrm{OH}}}{\longrightarrow}(\mathrm{NC})_{5} \mathrm{FeNO}_{2}^{-4}(\mathrm{aq})+\mathrm{H}_{2} \mathrm{O}$ foi feito nas condições experimentais da reação de adição. Uma vez que o produto da reação $(N C)_{5} \mathrm{FeNO}_{2}{ }^{4-}$ decai segundo o equilïbrio ( 143 )

$$
\begin{gathered}
(\mathrm{NC})_{5} \mathrm{FeNO}_{2}{ }^{4-}(\mathrm{aq})+\mathrm{H}_{2} \mathrm{O}^{\mathrm{K}_{\mathrm{H}_{2} \mathrm{O}}}(\mathrm{NC})_{5} \mathrm{FeOH}_{2}{ }^{3-}(\mathrm{aq})+\mathrm{NO}_{2}^{-} \text {(aq) } \\
\mathrm{K}_{\mathrm{H}_{2} \mathrm{O}}=1,4 \times 10^{-4} \mathrm{M}^{-1} \mathrm{~s}^{-1} \text { a } 25^{\circ} \mathrm{C} \text { e a } \mu=1,00 \quad(\mathrm{NaCl})
\end{gathered}
$$

a reação de interesse foi investigada na presença de excesso de ion nitrito.

0 valor de $\mathrm{k}_{\mathrm{OH}}\left(0,302 \mathrm{M}^{-1} \mathrm{~s}^{-1}\right)$ determinado a partir do grāfico de kobs em função da concentração de LiOH (FIG. 6.25, TAB.6.10) é concordante com o obtido an 
TABELA - 6.10 .

Constantes de Velocidade Para Reaçäo de Adiçäo de fon Hidro xila ao Ion Nitroprussiato em Funçāo da Concentraçäo de oH ${ }^{-}$

$$
\left[\mathrm{OH}^{-}\right] \times 10^{2} \mathrm{M} \quad \mathrm{k}_{\mathrm{obs}} \times 10^{2}\left(\mathrm{~s}^{-1}\right)
$$

1,00

0,51

0,45

2,90

0,75

0,70

3,00

0,96

1,04

4,00

1,29

1,32

5,00

1,59

1,62

7,00

2,11

$$
\begin{aligned}
& {\left[\mathrm{Fe}(\mathrm{CN})_{5} \mathrm{NO}^{2-}\right]=6,71 \times 10^{-5} \mathrm{M}} \\
& {\left[\mathrm{NO}_{2}-\right]=1,00 \times 10^{-3} \mathrm{M}} \\
& \lambda=400 \mathrm{~nm} \\
& \mu=0,10 \text { ajustada com LiC10 } \\
& \mu \\
& \text { temperatura }=25,0^{\circ} \mathrm{C}
\end{aligned}
$$




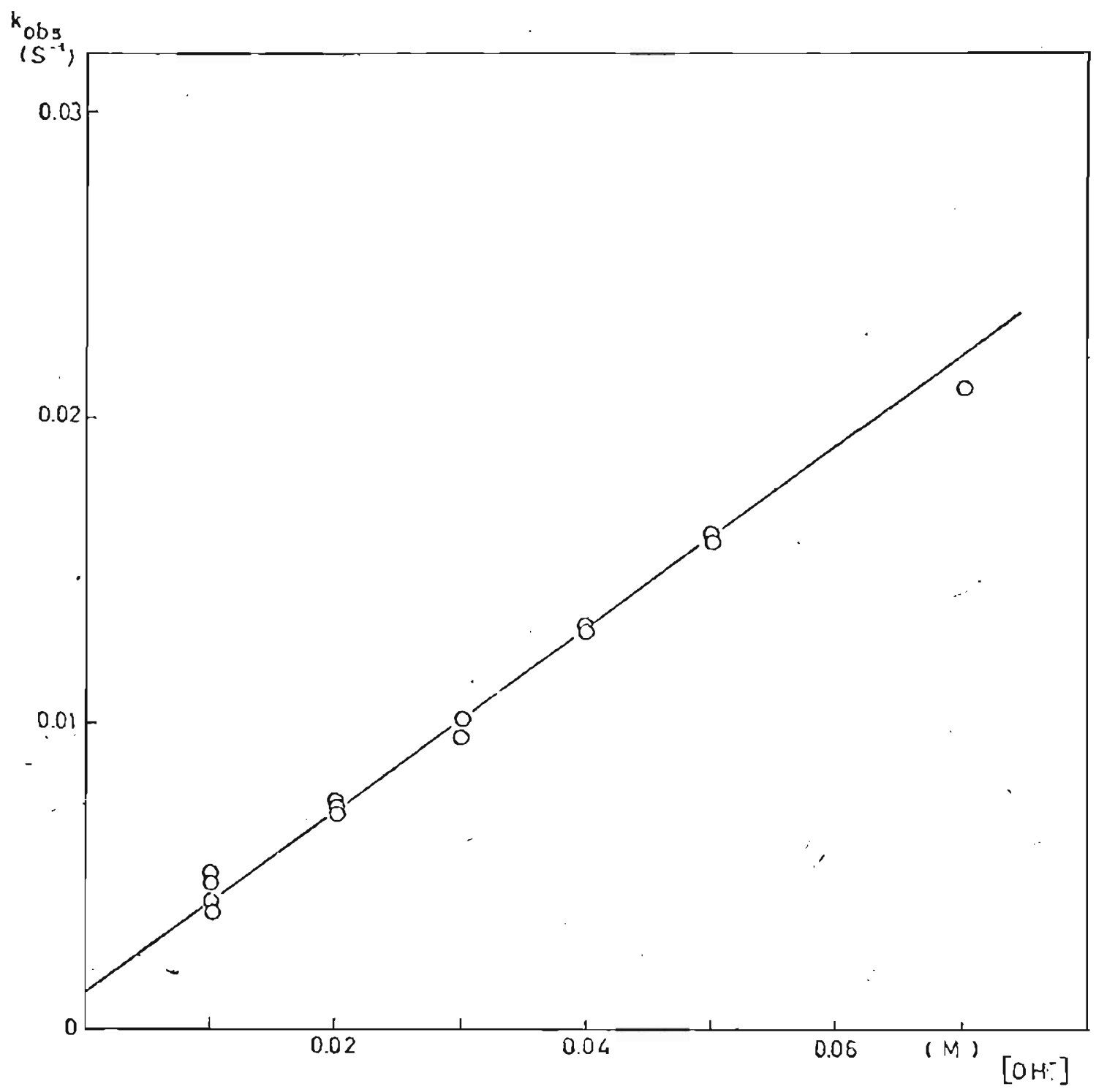

FIG.6.25. Constantes de velocidade da reação de adição de İon hidroxila ao nitroprussiato em função da con

$$
\begin{aligned}
& \text { tração de } \mathrm{OH}^{-} \quad \cdots\left[\mathrm{NO}_{2}^{-}\right]=1,00 \times 10^{-3} \mathrm{M} \\
& {\left[\mathrm{Fe}(\mathrm{CN})_{5} \mathrm{NO}^{2-}\right]=6,71 \times 10^{-5} \mathrm{M} \quad \lambda=400 \mathrm{~nm}} \\
& \mu=0,100\left(\mathrm{LiC1O}{ }_{4}\right) \\
& \mathrm{t}=25,0 \pm 0,1{ }^{\circ} \mathrm{C}
\end{aligned}
$$


teriormente, o que mais uma vez indica a validade do mecanis mo proposto

\subsubsection{Reaçāo de Decaimento do Intermediärio}

A reação mais Tenta que se observa no "stopped -flow" corresponde à dissociaçäo do intermediărio coordenado peio $N=0$, com formaçäo do aquopentacianoferrato(II).

$$
\begin{aligned}
& (\mathrm{NC}){ }_{5} \mathrm{FeNOCH}_{2}(\mathrm{CO}) \mathrm{py}^{3-}(\mathrm{aq}) \rightleftharpoons \mathrm{Fe}(\mathrm{CN})_{5}^{3-}(\mathrm{aq})+\mathrm{py}(\mathrm{CO}) \mathrm{CH}_{2} \mathrm{NO}^{-} \\
& (\mathrm{NC})_{5} \mathrm{Fe}(\mathrm{aq})^{3-}+\mathrm{H}_{2} \mathrm{O} \rightleftharpoons \mathrm{Fe}(\mathrm{CN})_{5} \mathrm{H}_{2} \mathrm{O}^{3-}
\end{aligned}
$$

Nas condiçōes experimentais deste estudo, o pro duto final predominante nas reaçōes entre os derivados con os substituintes em meta e para, $\vec{e}$ aquele coordenado pela pI ridina do $\mathrm{py}(\mathrm{CO}) \mathrm{CH}_{3}$, is to $\vec{e}, \mathrm{Fe}(\mathrm{CN})_{5} \mathrm{py}(\mathrm{CO}) \mathrm{CH}_{3}{ }^{3-}$, visto que a acetilpiridina encontra-se em grande excesso. As reaçöes de formaçäo e dissociaçāo desses produtos jâ foram descrí tas no inicio

$$
\text { (NC) }{ }_{5} \mathrm{Fe} \cdot \mathrm{H}_{2} \mathrm{O}^{3-}+\mathrm{py}(\mathrm{CO}) \mathrm{CH}_{3} \underset{\mathrm{k}_{-1}}{\stackrel{\mathrm{k}_{1}}{=}} \mathrm{Fe}(\mathrm{CN})_{5} \mathrm{Py}(\mathrm{CO}) \mathrm{CH}_{3}^{3-}(\mathrm{aq})
$$

Estas etapas posteriores à dissociaçāo do inter mediärio são rápidas e a velocidade do processo ê determina da peio decaimento do intermediärio azul que depende tanto da concentração do 1igante como da concentraçăo da hidroxila. Esta dependēncia pode ser observada nas tabelas 6.11 a 6.13 . 
Para a formação dos produtos finais é proposto o mecanismo a seguir, consistente com o comportamento cine-tico.

(1) $(\mathrm{CN})_{5} \mathrm{FeNO}^{2-}+\mathrm{Py}(\mathrm{CO}) \mathrm{CH}_{3}+\mathrm{OH}^{-} \stackrel{\mathrm{K}_{\mathrm{T}}}{\rightleftharpoons}(\mathrm{NC})_{5} \mathrm{Fe}(\mathrm{NO}) \mathrm{CH}_{2}(\mathrm{CO}) \mathrm{py}^{3-}$

$$
+\mathrm{H}_{2} \mathrm{O}
$$

(2) (NC) $)_{5} \mathrm{FeNO}^{2-}+\mathrm{OH}^{-} \stackrel{\mathrm{k}_{\mathrm{OH}}}{\longrightarrow}(\mathrm{NC})_{5} \mathrm{FeNO}_{2} \mathrm{H}^{3-} \underset{\mathrm{rapida}}{\stackrel{\mathrm{OH}^{-}}{\longrightarrow}}\left(\mathrm{NC}_{5} \mathrm{FeNO}_{2}{ }^{4-}\right.$

(3) $(\mathrm{NC}){ }_{5} \mathrm{Fe}(\mathrm{NO}) \mathrm{CH}_{2}(\mathrm{CO}) \mathrm{py}^{3-} \stackrel{\mathrm{k} d}{\longrightarrow}(\mathrm{NC})_{5} \mathrm{Fe}^{3-}+\mathrm{py}(\mathrm{CO}) \mathrm{CH}_{2} \mathrm{NO}^{3-}$

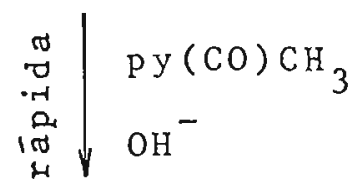

$$
\begin{aligned}
& \text { (NC) }{ }_{5} \mathrm{Fepy}(\mathrm{CO}) \mathrm{CH}_{3}{ }^{3-}+\mathrm{py}(\mathrm{CO}) \mathrm{CHNO}^{-}
\end{aligned}
$$

A lei de velociade nesse caso è

$$
\mathrm{k}_{\mathrm{obs}_{2}=\frac{\mathrm{k}_{\mathrm{d}} \mathrm{K}_{\mathrm{T}}\left[\mathrm{py}(\mathrm{CO}) \mathrm{CH}_{3}\right]\left[\mathrm{OH}^{-}\right]+\mathrm{k}_{\mathrm{OH}}\left[\mathrm{OH}^{-}\right]}{1+\mathrm{K}_{\mathrm{T}}\left[\mathrm{Py}(\mathrm{CO}) \mathrm{CH}_{3}\right]\left[\mathrm{OH}^{-}\right]}}^{(\text {vide apêndice 11.2.) }}
$$

Invertendo-se a expressão (5) pode-se chegar à (5a) que a presenta uma relação linear de $1 / k_{0 b s 2}$ com o inverso da concentração de $\mathrm{OH}^{-}$. 


\section{8}

TABELA - 6.11

Constantes de Velocidade para- a Reação de Decaimento do Intermediārio Azul $\left(\mathrm{k}_{0 \mathrm{bs} 2}\right)$ a $25,0^{\circ} \mathrm{C}$ para $\mathrm{p}-\mathrm{py}(\mathrm{CO}) \mathrm{CH}_{3}$ $\left[\mathrm{p}-\mathrm{py}(\mathrm{CO}) \mathrm{CH}_{3}\right] \times 10^{2} \mathrm{M} \quad\left[\mathrm{OH}^{-}\right] \times 10^{2} \mathrm{M} \quad \mathrm{k}_{\mathrm{obs} 2} 10^{2}\left(\mathrm{~s}^{-1}\right)$

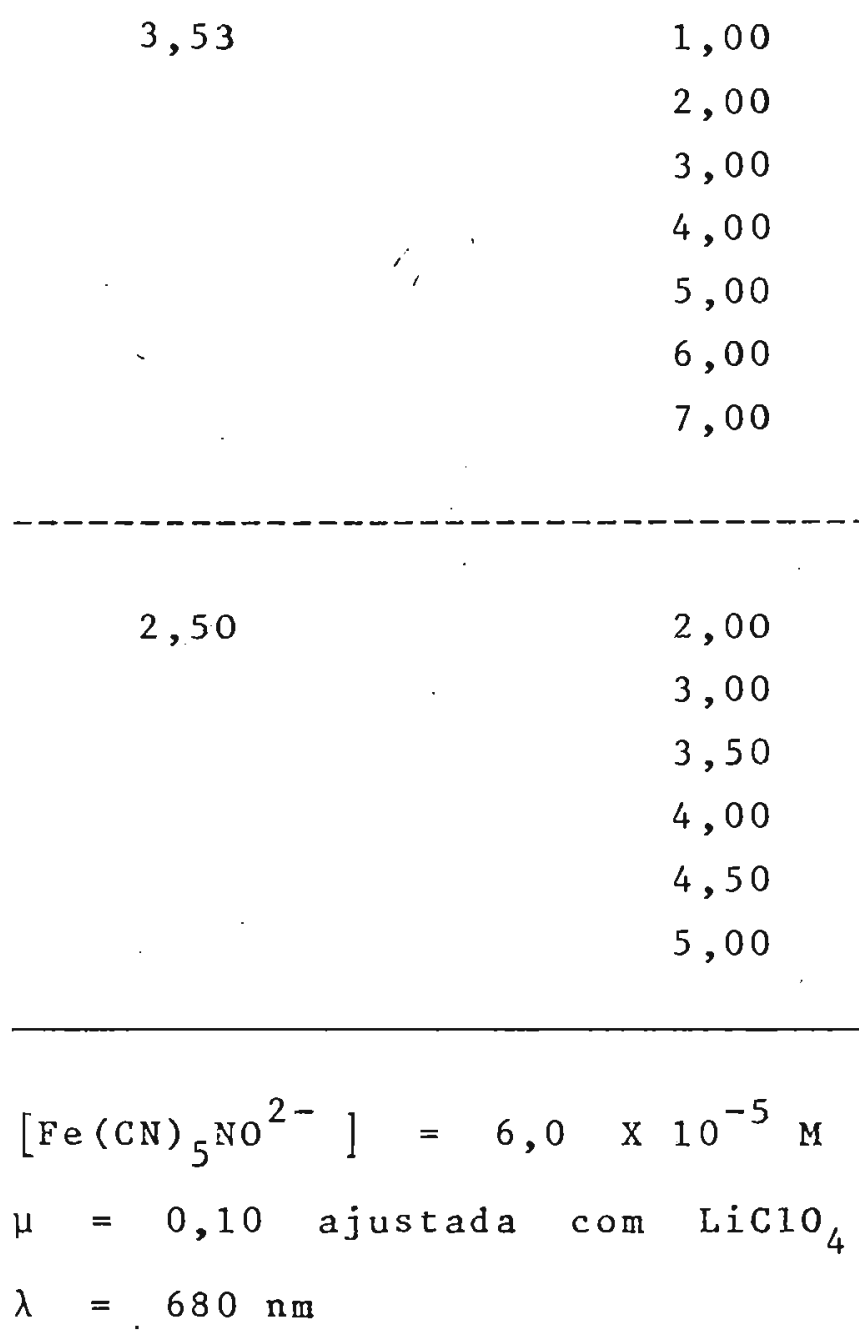

3,$22 ; 3,30$

5,$00 ; 5 \%, 22$

5,$95 ; 6,14$

6,$15 ; 6,80$

6,$62 ; 7,46$

7,$05 ; 7,44$

7,$10 ; 7,29$ 
Constantes de Velocidade Para a Reação de Decaimento do Intermediärio Azul (kobs2) em Função da Concentração de $\mathrm{OH}^{-}$

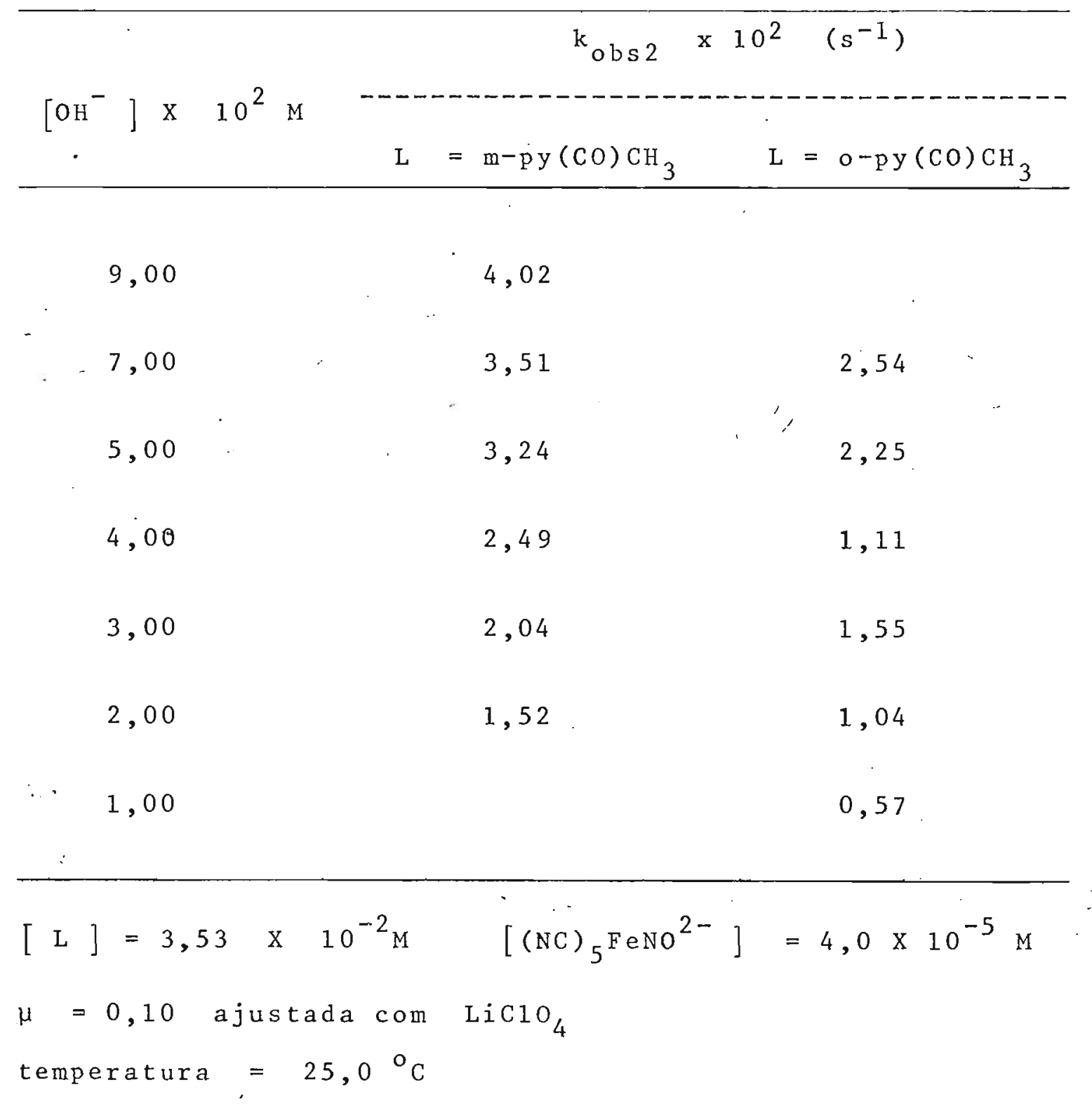


TABELA -6.13 .

Constantes de Velocidade Para a Reação de Decaimento do Intermediärio Azul (kobs 2 ) em Função da Concentração do Ligan te $\left(\mathrm{py}(\mathrm{CO}) \mathrm{CH}_{3}\right)$.

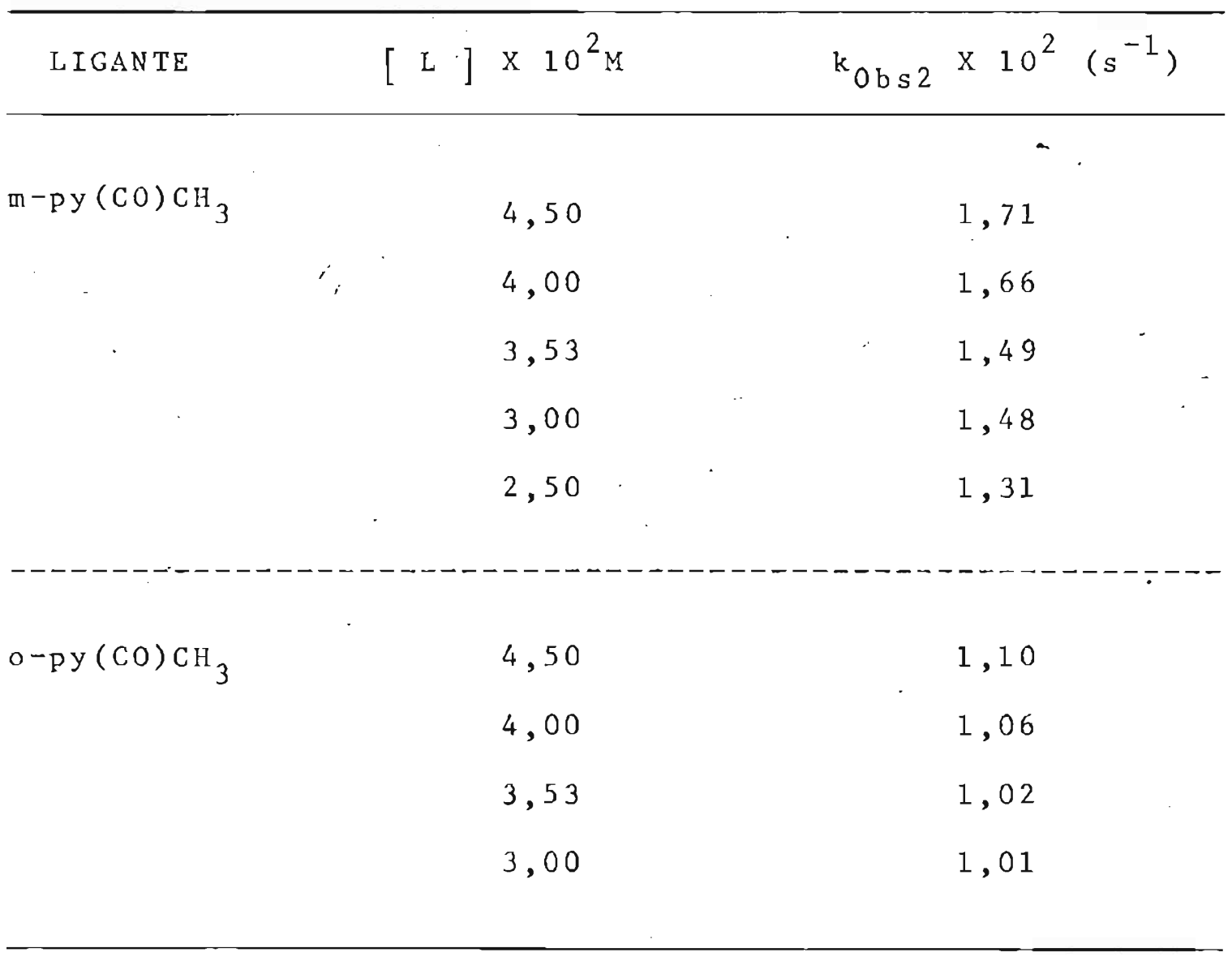

$[\mathrm{LiOH}]=2,00 \times 10^{-2} \mathrm{M}$

$\left[\mathrm{Fe}(\mathrm{CN})_{5} \mathrm{NO}^{2-}\right]=4,0 \times 10^{-5} \cdot \mathrm{M}$

$\mu=0,10$ ajustada com LiClo 4

temperatura $=25,0^{\circ} \mathrm{C}$ 


$$
\begin{gathered}
\frac{1}{k_{\mathrm{obs} 2}}=\frac{1}{\mathrm{k}_{\mathrm{d}} \mathrm{K}_{\mathrm{T}}\left[\mathrm{py}(\mathrm{CO}) \mathrm{CH}_{3}\right]+\mathrm{k}_{\mathrm{OH}}} \frac{1}{\left[\mathrm{OH}^{-}\right]} \\
\frac{\mathrm{k}_{\mathrm{T}}[\mathrm{L}]}{\mathrm{k}_{\mathrm{d}} \mathrm{K}_{\mathrm{T}}[\mathrm{L}]+\mathrm{k}_{\mathrm{OH}}}
\end{gathered}
$$

0s valores de kobs2 em função da concentração de $\mathrm{OH}^{-}$estão nas tabelas 6.11 e 6.12. A partir do grāfi co de $1 / k_{\text {obs } 2}$ versus $1 /\left[\mathrm{OH}^{-}\right]$das figuras 6.26 e 6.27 , os valores de $k_{d}$ e $k_{T}$ podem ser determinados e estão re lacionados na tabela a seguir.

Valores de $k_{d}$ e $K_{T}$ determinados a partir da expressão(5a)

\begin{tabular}{ccc}
\hline LIGANTE & $\mathrm{k}_{\mathrm{d}}\left(\mathrm{s}^{-1}\right)$ & $\mathrm{K}_{\mathrm{T}} \times 10^{2}$ \\
\hline $\mathrm{p}-\mathrm{py}(\mathrm{CO}) \mathrm{CH}_{3}$ & 0,083 & 21,0 \\
m-py(CO) $\mathrm{CH}_{3}$ & 0,050 & 3,90 \\
o-py(CO) $\mathrm{CH}_{3}$ & 0,032 & 2,95
\end{tabular}

Substituindo-se éssses valores na equação (5) de $k_{\text {obs2 }}$, temos os pontos calculados (pontos brancos) das figuras 6.28 e 6.29 que mostram o comportamento de kobs2 em função da concentração de LioH. 


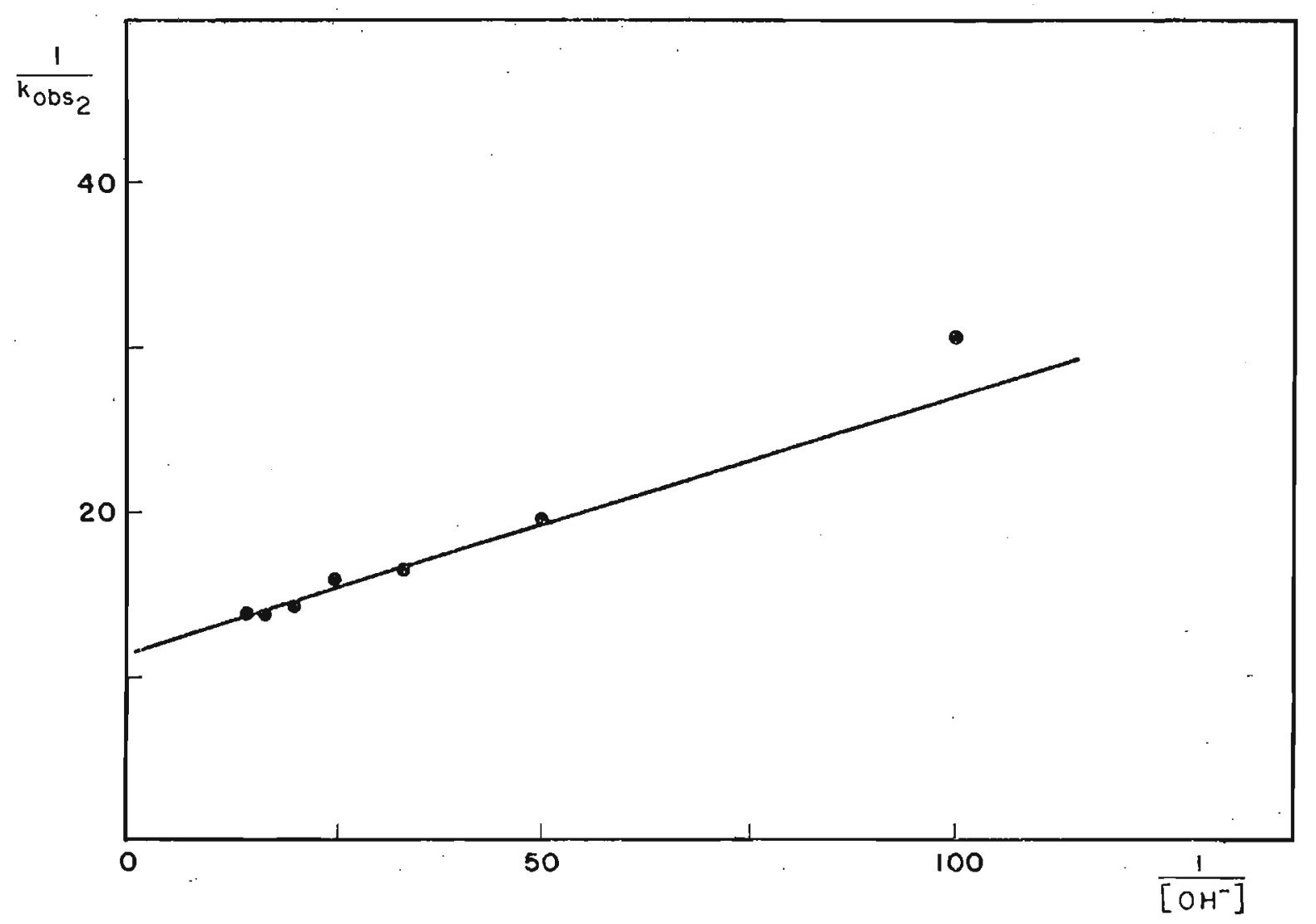

FIG.6.26. Inverso das constantes de velocidade da reação de decaimento do intermediärio azul em função do in verso da concentração de $\mathrm{OH}^{-}$ $\left[\mathrm{p}-\mathrm{py}(\mathrm{CO}) \mathrm{CH}_{3}\right]=3,53 \times 10^{-2} \mathrm{M}$ $\mu=0,100\left(\operatorname{LiC} 10_{4}\right) \quad t=25,0 \pm 0,1{ }^{\circ} \mathrm{C}$ 


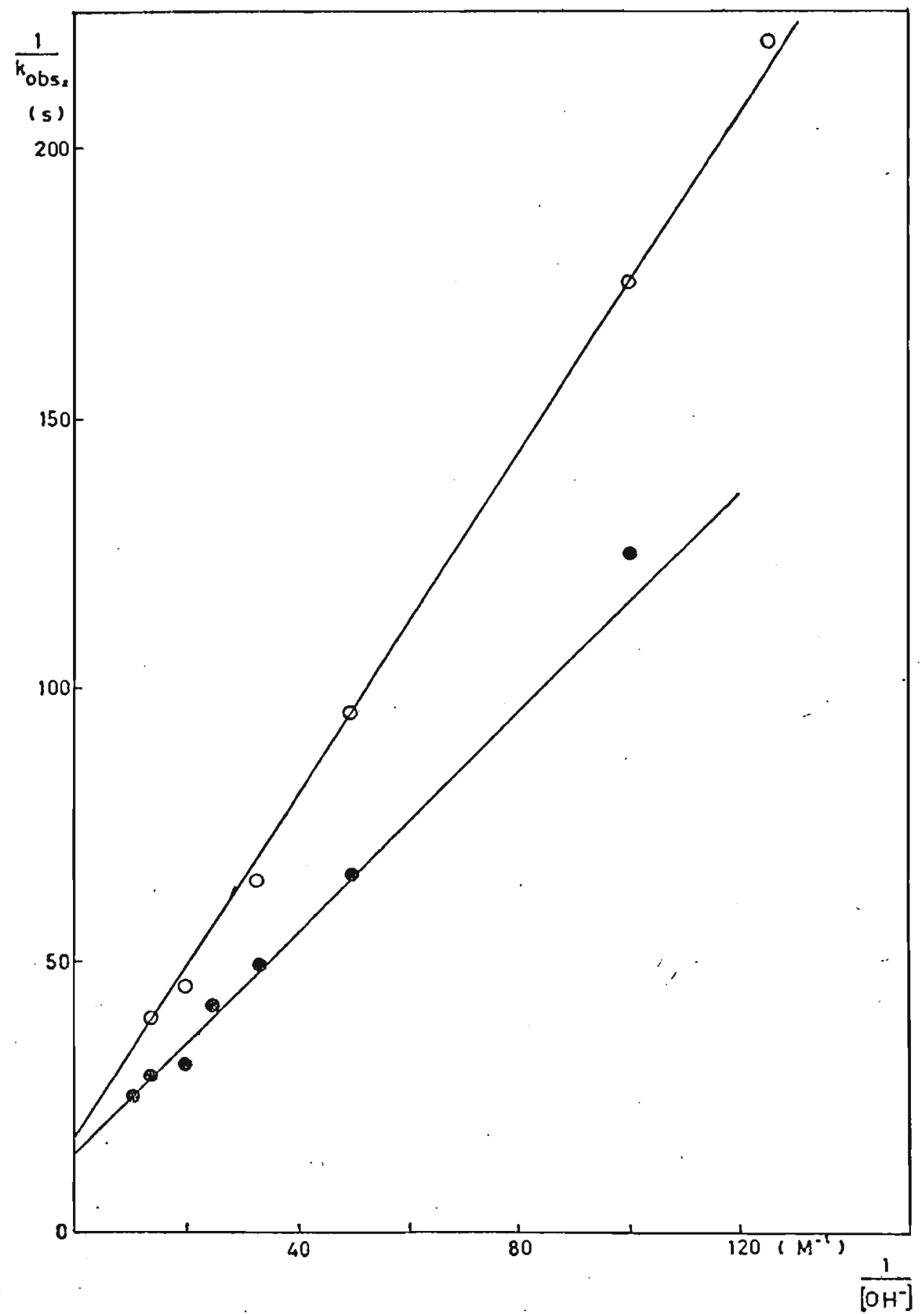

FIG.6.27. Constantes de velocidade da reação de decaimento do intermediário azul em função do inverso da concentração de $\mathrm{OH}^{-} \ldots[\mathrm{L}]=3,53 \times 10^{-2} \mathrm{M}$
- o-py $(\mathrm{CO}) \mathrm{CH}_{3}$
- $\mathrm{m}-\mathrm{py}(\mathrm{CO}) \mathrm{CH}_{3}$
$\mu=0,100\left(\mathrm{LiCl} 0_{4}\right)$
$t=25,0 \pm 0,1^{\circ} \mathrm{C}$ 


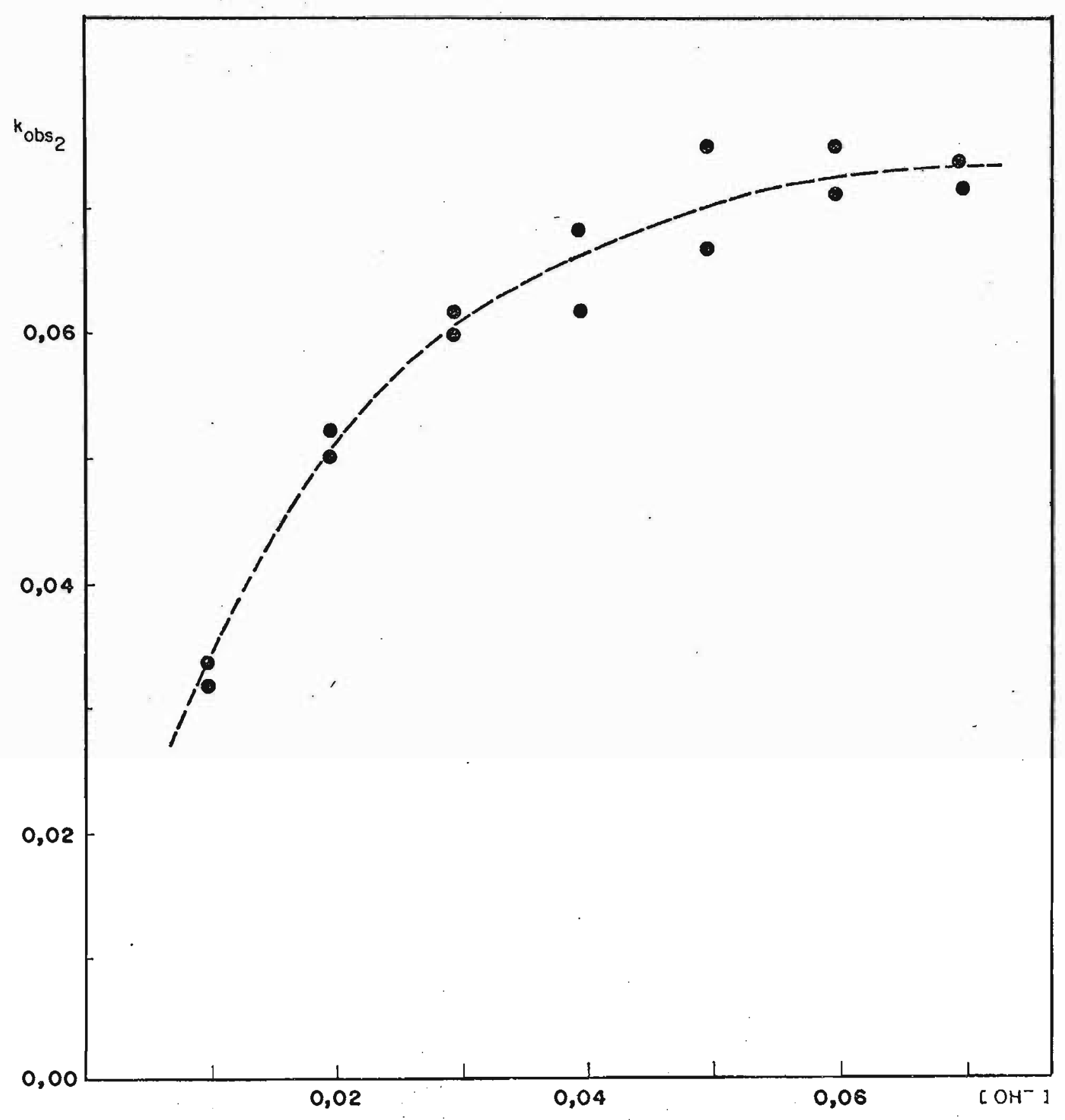

FIG.6.28. Constantes de velocidade da reação de decaimento do intermediário coordenado pelo no em função da concentração do íon hidroxila $\left[\mathrm{p}-\mathrm{py}(\mathrm{CO}) \mathrm{CH}_{3}\right]=$ $3,53 \times 10^{-2} \mathrm{M} \quad \mu=0,100(\mathrm{LiC10})_{4} \quad t=25,0^{\circ} \mathrm{C}$ 


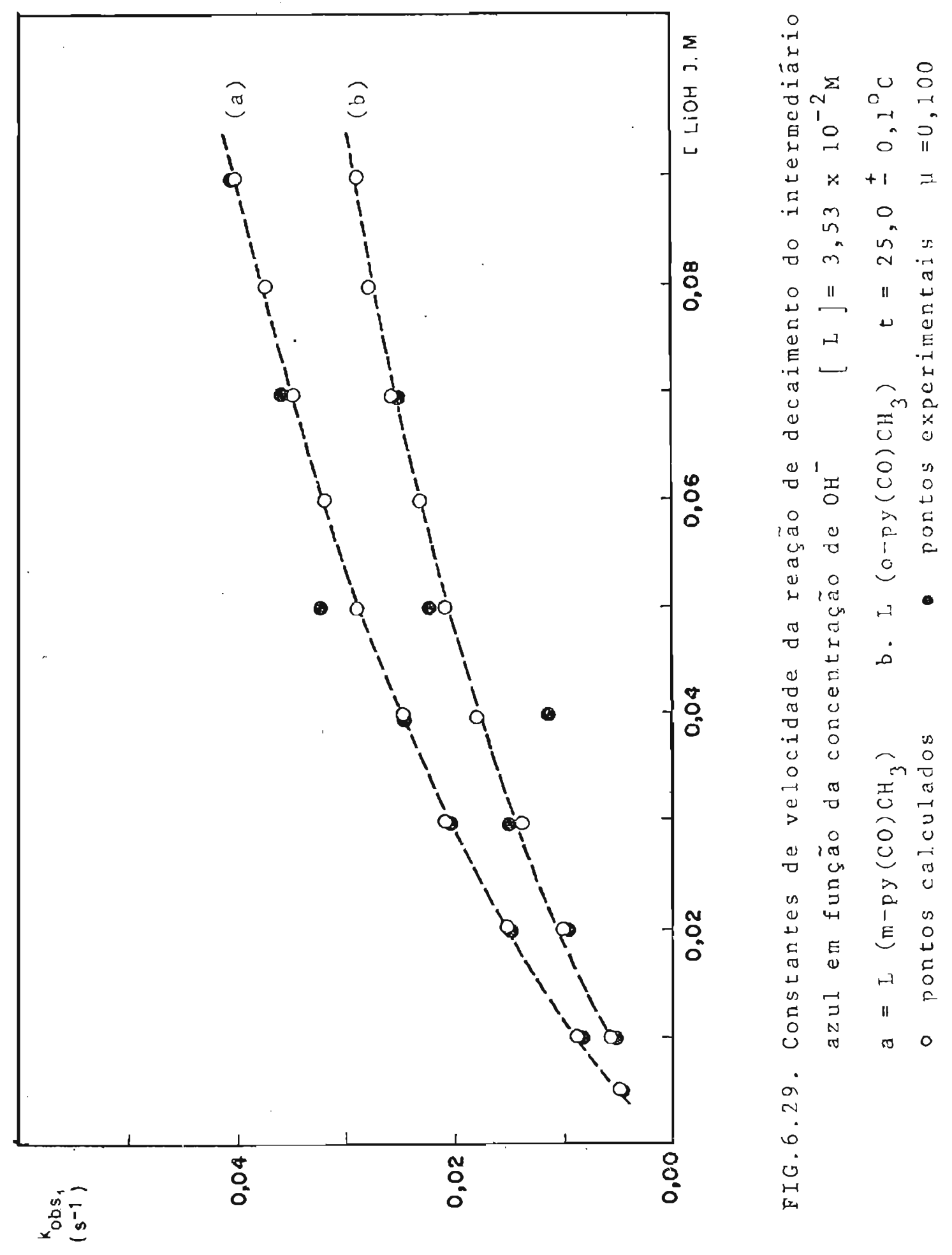


A variação de kobs2 em função da concentração do ligante (TAB. 6.11 e 6.13) estā ilustrada nas figuras 6 . 30 e 6.31. Para verificar a validade da expressão da lei de velocidade, substituem-se os valores de $k_{d}$, $k_{T}$ e $k_{0 H}$ deter minados jă independentemente na cinētica de formação e decom posição do intermediārio e analisa-se a dependencia do kobs2 com a concentração do ligante. Esta variação é representada pelos pontos cheios nos gráficos. A concordāncia observada é boa, mostrando que a expressão da lei de velocidade resultan te do mecanismo proposto é aplicāvel nas condições de estudo. Nestas condições, as etapas envolvidas na formação dos produtos podem ser representadas da seguinte forma

(1) $\mathrm{py}(\mathrm{CO}) \mathrm{CH}_{3}(\mathrm{aq})+\mathrm{OH}^{-}(\mathrm{aq}) \stackrel{\mathrm{K}}{\rightleftharpoons} \mathrm{py}(\mathrm{CO}) \mathrm{CH}_{2}^{-}(\mathrm{aq})+\mathrm{H}_{2} \mathrm{O}^{-}$.

(2) $(\mathrm{NC}){ }_{5} \mathrm{FeNO}^{2-}(\mathrm{aq})+\mathrm{OH}^{-}(\mathrm{aq}) \stackrel{\mathrm{k} \mathrm{OH}}{\longrightarrow}(\mathrm{NC})_{5} \mathrm{FeNO}_{2} \mathrm{H}^{3-}(\mathrm{aq})$

$(2 \mathrm{a})(\mathrm{NC})_{5} \mathrm{FeNO}_{2} \mathrm{H}^{3-}(\mathrm{aq})+\mathrm{OH}^{-}(\mathrm{aq}) \stackrel{\text { räpida }}{\longrightarrow}(\mathrm{NC})_{5} \mathrm{FeNO}_{2}^{4-}(\mathrm{aq})+\mathrm{H}_{2} \mathrm{O}$

(3) (NC) ${ }_{5} \mathrm{FeNO}^{2-}(\mathrm{aq})+\mathrm{py}(\mathrm{CO}) \mathrm{CH}_{2}^{-}(\mathrm{aq}) \underset{\mathrm{k}_{-\mathrm{L}}}{\stackrel{\mathrm{k}_{\mathrm{L}}}{\rightleftharpoons}}(\mathrm{NC})_{5} \mathrm{Fe}(\mathrm{NO}) \mathrm{CH}_{2}(\mathrm{CO}) \mathrm{py}^{3--}$

(4) $(\mathrm{NC}){ }_{5} \mathrm{Fe}(\mathrm{NO}) \mathrm{CH}_{2}(\mathrm{CO}) \mathrm{py}^{3-}(\mathrm{aq}) \stackrel{\mathrm{k}_{\mathrm{d}}}{\longrightarrow} \mathrm{Fe}(\mathrm{CN}) 5_{5}^{3-}(\mathrm{aq})+\mu \mathrm{y}(\mathrm{CO}) \mathrm{CH}_{2} \mathrm{NO}$

(5) $\mathrm{py}(\mathrm{CO}) \mathrm{CH}_{2} \mathrm{NO}(\mathrm{aq})+\mathrm{OH}^{-}(\mathrm{aq}) \stackrel{\text { rápida }}{\longrightarrow} \mathrm{py}(\mathrm{CO}) \mathrm{CHNO}^{-}+\mathrm{H}_{2} \mathrm{O}$

(6) $\mathrm{Fe}(\mathrm{CN}){ }_{5}^{3-}(\mathrm{aq})+\mathrm{H}_{2} \mathrm{O} \stackrel{\mathrm{R}_{\mathrm{a}}}{=} \mathrm{Fe}(\mathrm{CN}){ }_{5} \mathrm{H}_{2} \mathrm{O}^{3-}(\mathrm{aq})$

(7) $\mathrm{Fe}(\mathrm{CN})_{5}{ }^{3-}(\mathrm{aq})+\mathrm{py}(\mathrm{CO}) \mathrm{CH}_{3} \stackrel{\mathrm{ra} \mathrm{pida}}{\longrightarrow} \mathrm{Fe}(\mathrm{CN})_{5} \mathrm{py}(\mathrm{CO}) \mathrm{CH}_{3}{ }^{3}(\mathrm{aq})$ 


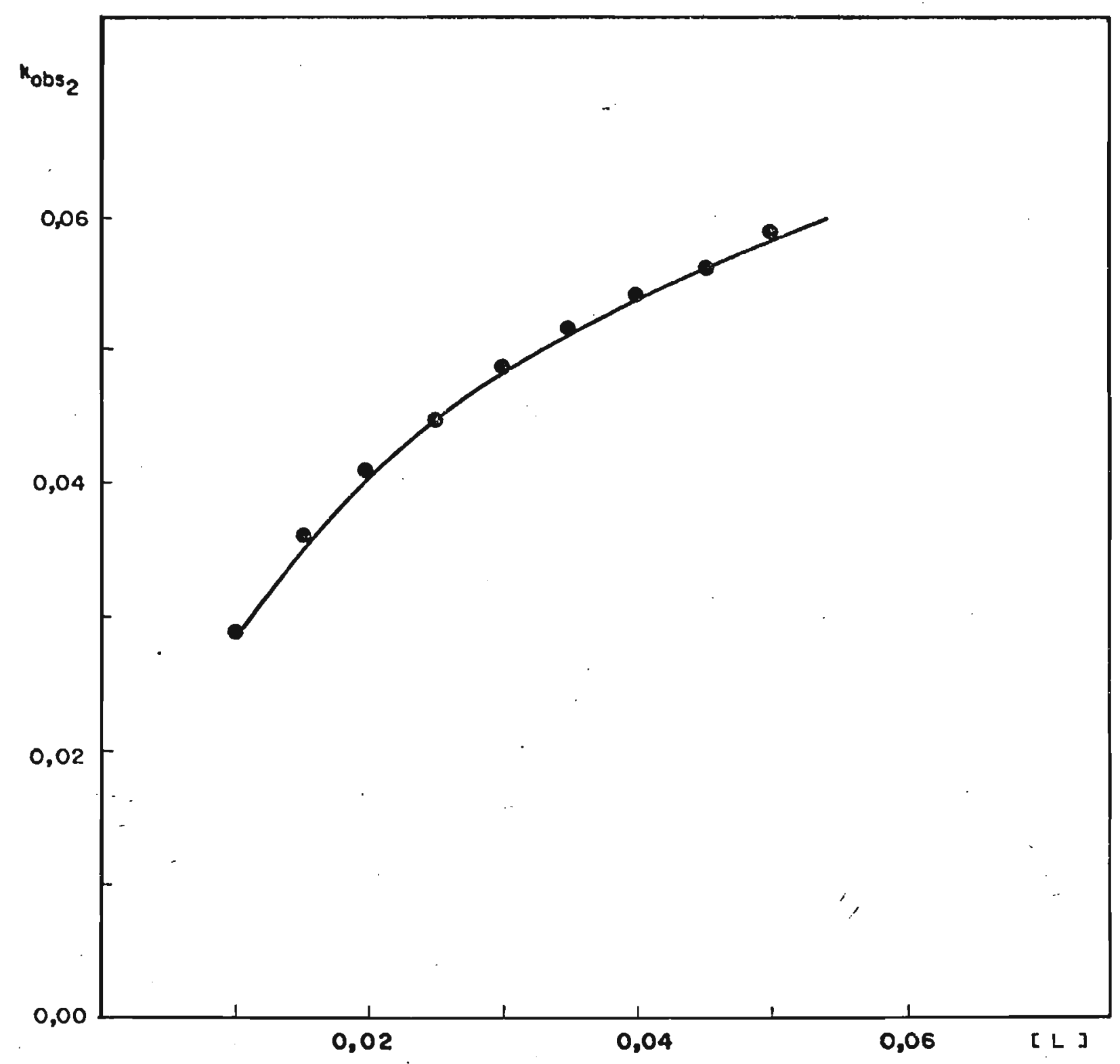

FIG.6.30. Constantes de velocidade para a reação de decaimento do intermediário azul em função da concentração do $\mathrm{p}-\mathrm{py}(\mathrm{CO}) \mathrm{CH}_{3} \quad[\mathrm{LiOH}]=0,02 \mathrm{M}$ $\mu=0,100\left(\mathrm{LiClO}_{4}\right) \quad t=25,0 \pm 0,1^{\circ} \mathrm{C}$ 


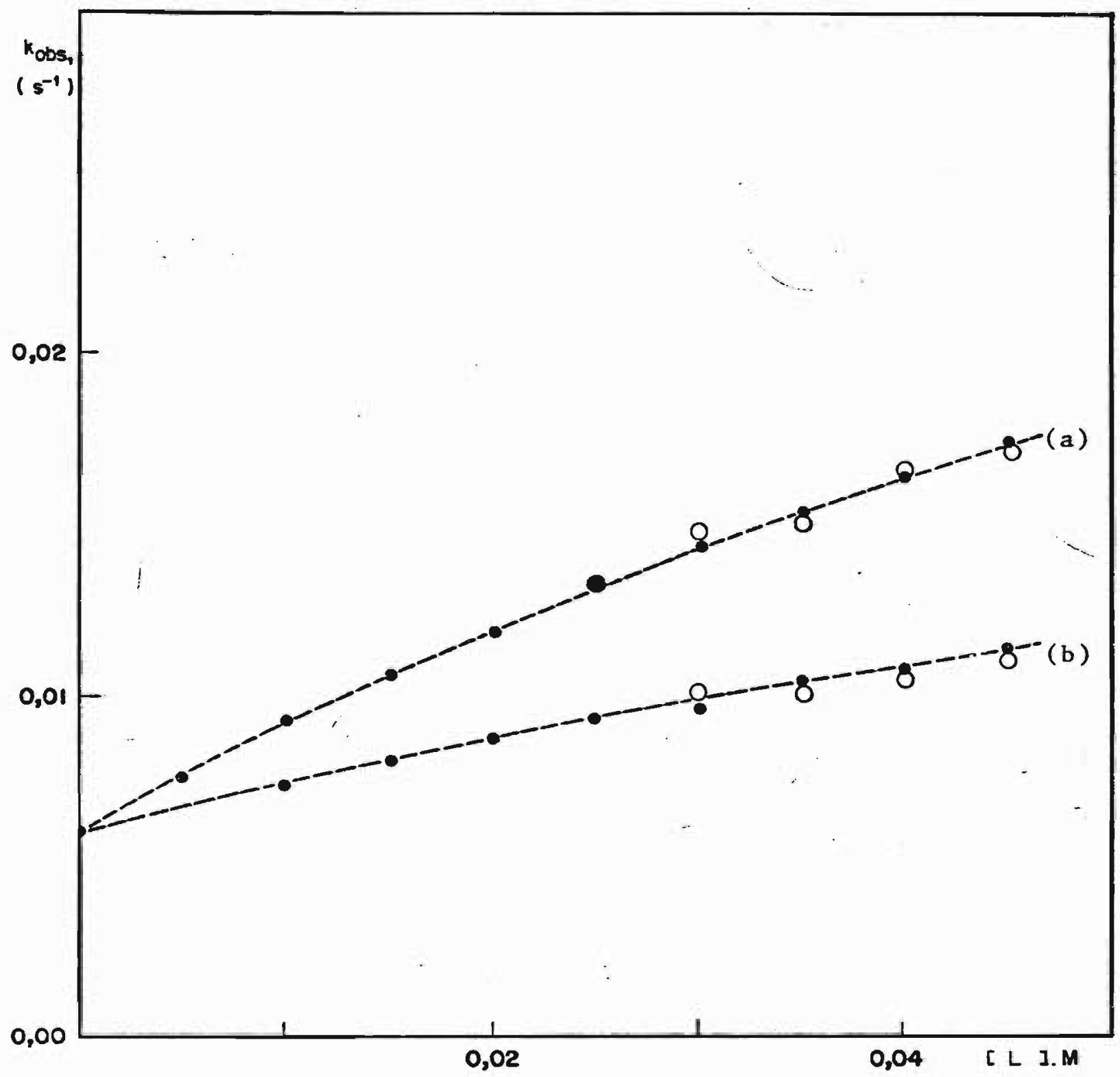

FIG. 6.31. Constantes de velocidade para a reação de decaimento do intermediário coordenado pelo no em função da concentração do ligante $\left[\mathrm{OH}^{-}\right]=0,02 \mathrm{M}$ - pontos calculados o pontos experimentais a. m-py $(\mathrm{CO}) \mathrm{CH}_{3}$ b. o-py $(\mathrm{CO}) \mathrm{CH}_{3} \quad \mu=0,100$. 
Sendo que a ūitima etapa sō aparece para $L$ igual a paracetilpiridina e metacetilpiridina.

Analisando-se estas etapas envolvidas no mecanismo global pode-se chegar à seguinte relação

$$
K_{T}=\frac{k_{L} \mathbf{R}}{k_{-L}}
$$

Os valores de $k_{L} K$ e $k_{-L}$ foram determinados na reação de formação do intermediārio coordenado pelo $(N=0)$. e relacionados na página 242 . Estes podem ser substituî dos na expressão (6) como uma outra forma de obter os valo res de $K_{T}$ e constam na tabela abaixo (A) juntos com aqueles obtidos no estudo cinético de decaimento do intermediário. (B) calculados atravēs da expressão (5a).

$$
\mathrm{K}_{\mathrm{T}}\left(10^{-2} \mathrm{M}^{-2}\right)
$$

LIGANTE

A

\begin{tabular}{|c|c|c|}
\hline$p-p y(\mathrm{CO}) \mathrm{CH}_{3}$ & 21,7 & 21,0 \\
\hline $\mathrm{m}-\mathrm{py}(\mathrm{CO}) \mathrm{CH}_{3}$ & 4,18 & 3,90 \\
\hline $0-p y(\mathrm{CO}) \mathrm{CH}_{3}$ & 2,94 & 2,95 \\
\hline
\end{tabular}

B

Estes dados, obtidos das constantes de velocidade colhidas de experiencias independentes, acompanhadas de incertezas correspondentes, apresentam uma boa concordāncia 
e mais uma vez indica a consistência do mecanismo proposto.

Com os intermediārios sintetizados fez-se um es tudo cinētico independente, acompanhando o seu decaimento no espectrofotōmetro Cary-14, nas mesmas condições experimentais utilizadas para o estudo das reações de adição das ace tilpiridinas a ón nitroprussiato, porém sem o ligante ace tilpiridina.

Nestas condições, de acordo com o mecanismo pos tulado, o desaparecimento do intermediārio azul poderia ocor rer de duas formas representadas a seguir

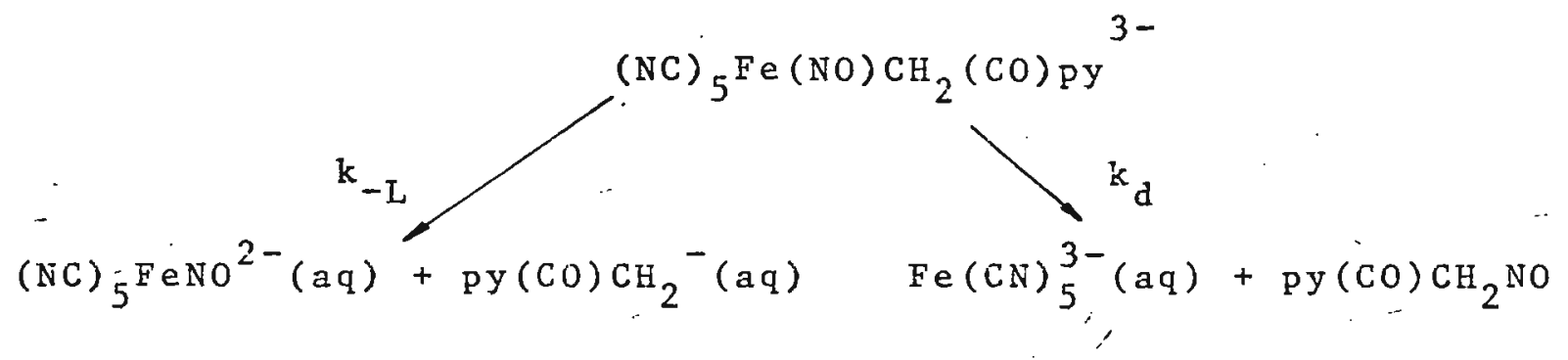

e correspondentes às etapas (3) e (4) do processo global.

Visto que as curvas cinēticas são praticamente de 1a. ordem, conclui-se que as constantes de velocidade en volvidas neste processo são da mesma grandeza, devendo si tuar-se dentro dos limites superior e inferior determinados por $k_{d}$ e $k_{-L}$. De fato, isto está consistente com as constan tes de velocidade observadas $\left(k_{\text {obs }}\right)$, cujos valores estão en tre 0,052 a $0,065 \mathrm{~s}^{-1}$ para $L=\mathrm{m}-\mathrm{py}(\mathrm{CO}) \mathrm{CH}_{2} \mathrm{NO}$ e $0,030 \mathrm{~s}^{-1}$ para $L=-0-p y(C O) \mathrm{CH}_{2} \mathrm{NO}$.

Para o $\mathrm{Fe}(\mathrm{CN})_{5} \mathrm{~m}-\mathrm{Py}(\mathrm{CO}) \mathrm{CH}_{2} \mathrm{NO}^{3-}$ em que as condições de trabaiho se encontram no limite do aparelho e, devi- 
do ao tempo gasto na homogeneização da mistura, as determinações cinéticas cairam no intervalo citado. Para o deriva do substituīdo em para, cujo decaimento é mais rāpido, não foi possivel fazer determinações cinéticas por este método. Tomando como base os valores de pK determina dos para acetona (307) e acetofenona (308), o valor da cons tante de equilibrio abaixo deve ser da ordem de $10^{-4}$.

$$
\mathrm{CH}_{3}-\stackrel{\mathrm{O}}{\mathrm{C}}-\mathrm{Py}+\mathrm{OH}^{-} \stackrel{\mathrm{K}}{=} \mathrm{CH}_{2}^{-}-\stackrel{\stackrel{0}{\|}}{\mathrm{C}}-\mathrm{Py}+\mathrm{H}_{2} \mathrm{O}
$$

Uma vez que os valores de $k_{L} K$ são determinados (TAB.p. 242), estima-se os valores de $k_{L}$ como $1,0 \times 10^{6} \mathrm{~s}^{-1} \mathrm{M}^{-1} ; 3,9 \times 10^{5} \mathrm{~s}^{-1} \mathrm{M}^{-1}$ e $1,4 \times 10^{5} \mathrm{~s}^{-1} \mathrm{M}^{-1}$ para os derivados em para, meta e orto, respectivamente. Tais va lores são da mesma ordem de grandeza encontrado na acetona $(174)$

os estudos independentes das etapas (2), (3) e (4), (6) e (7) auxiliaram bastante na elucidação do mecanis mo global, servindo como uma forma de teste para a validade deste, alëm de permitir a obtenção das constantes de veloci dade parciais, envolvidas em cada etapa (297). 


\section{VII - VDLTAMETRIA CICLICA E DETERMINACÃO DE PARÂMETROS ELETROQUIMICOS E CONSTANTES DE ESTABILIDADE}

\subsection{Yoltametria ciclica}

A voltametria cīclica é um dos métodos mais adequados para estudar detalhadamente a natureza, ou etapas de uma reação eletroquímica. Esses estudos permitem firmar base para controle da reação, bem como uma perspectiva de investigạção dos intermediários reativos.

Uma discussão detalhada do método, sob diferen tes aspectos, jā foi abordada nas dissertações de Moura(281), Benedetti(282), Rock(283) e Murakami(284); teses de Bulhoẽs (285) e Benedetti(286), como nos textos de Adams (287), Brown e Large (288) e Galus (289).

Para os complexos em estudo, cujas formas oridadas são pouco estāveis na solução, o uso de técnica rápida como a voltametria cíclica é a mais adequada na determina ção de $E^{0^{\prime}}$.

As figuras de 7.1. a 7.2. apresentam os voltamogramas cỉclicos dos complexos, com varredura inicial no sentido anódico e em diferentes velocidades de varredura de potenciais, a $25,0^{\circ} \mathrm{C}$ e em $0,5 \mathrm{M}$ de $\mathrm{KC} 1$.

Destes voltamogramas podem-se obter, as corren tes de pico anōdico $\left(i_{p a}\right)$ e catódico $\left(i_{p c}\right)$, bem como os potenciais de pĩco ánódico $\left(E_{p a}\right)$ e catōdico $\left(E_{p c}\right)$ e de meia - 


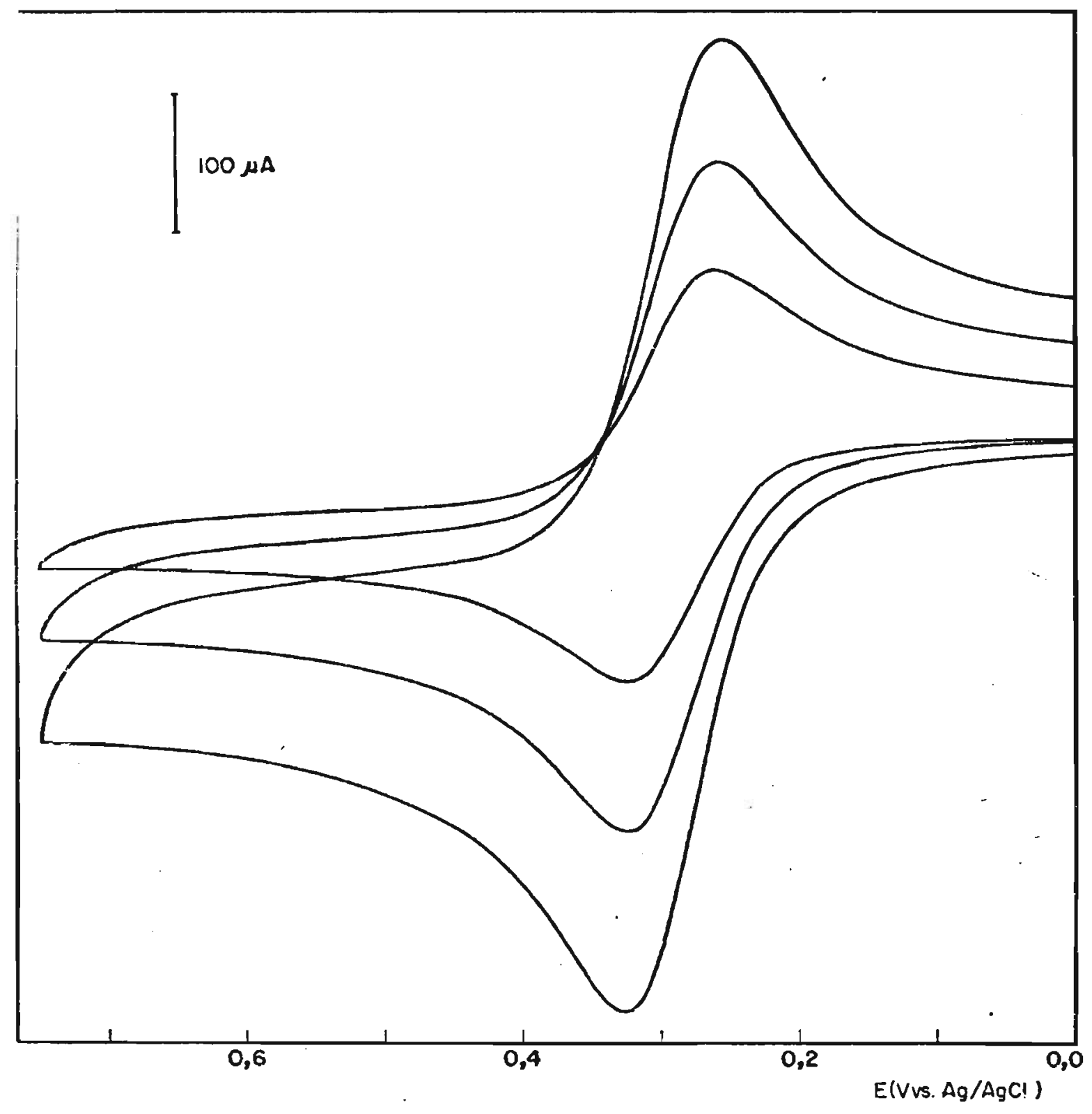

FIG.7.1A.Voltamogramas cíclicos de solução $4,00 \times 10^{-3} \mathrm{M}$ de $\mathrm{Fe}(\mathrm{CN}){ }_{5} \mathrm{p}-\mathrm{py}(\mathrm{CO}) \mathrm{CH}_{3}{ }^{3-}$ em $\mathrm{KCl} 0,50 \mathrm{M}$ a $25,0{ }^{\circ} \mathrm{C}$ $[\mathrm{L}]=4,50 \times 10^{-2} \mathrm{M} \quad \mathrm{v}=0,100 ; 0,050$ e $0,020 \mathrm{~V} \cdot \mathrm{s}^{-1}$ 
264

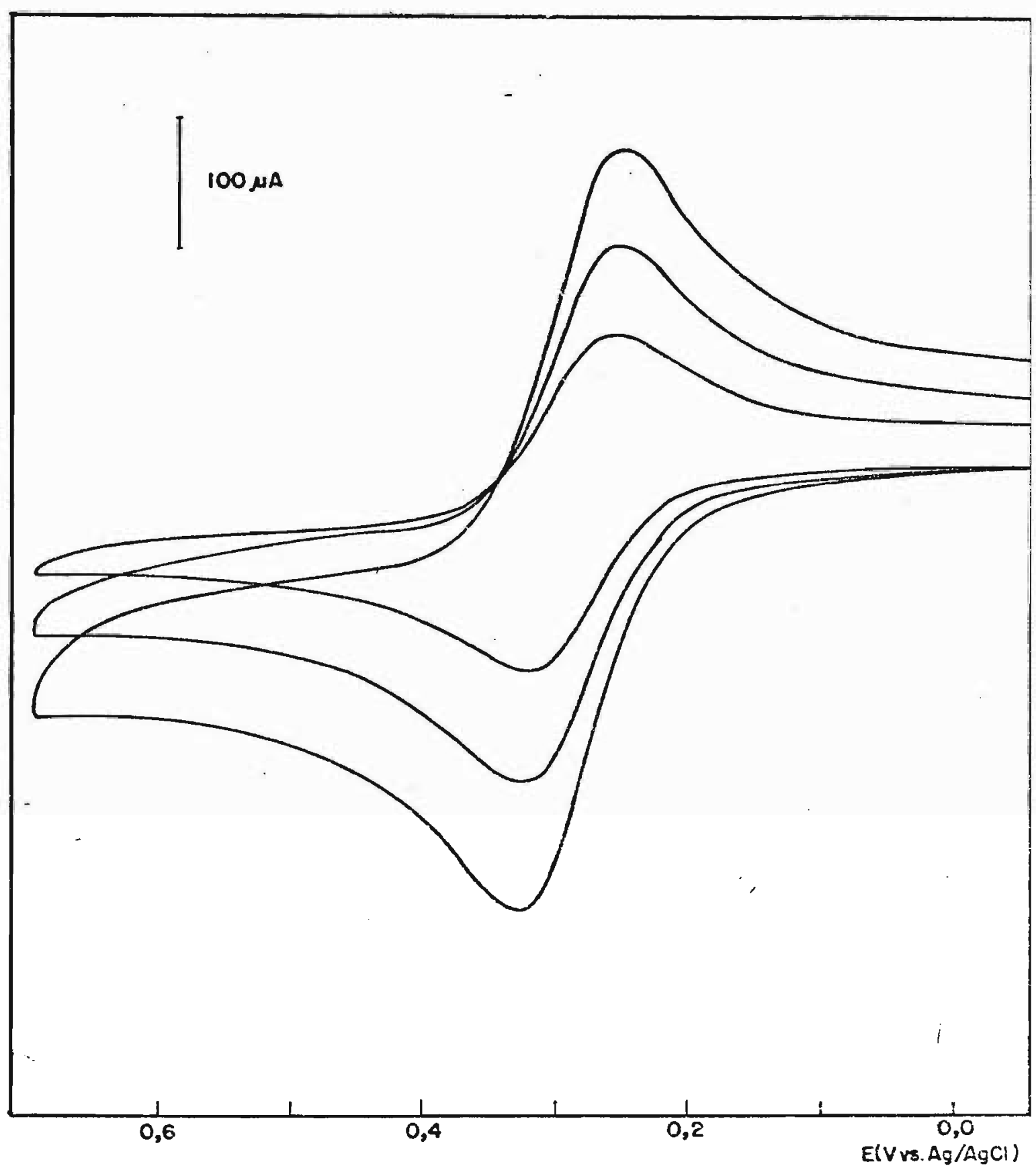

FIG.7.1B.Voltamogramas cíclicos de soluçäo $4,00 \times 10^{-3} \mathrm{M}$ de $\mathrm{Fe}(\mathrm{CN})_{5} \mathrm{m-py}(\mathrm{CO}) \mathrm{CH}_{3}{ }^{3-}$ em $\mathrm{KCl} \quad 0,50 \mathrm{M}$ a $25,0^{\circ} \mathrm{C}$ $[\mathrm{L}]=4,49 \times 10^{-2} \mathrm{M} \quad \mathrm{v}=0,100 ; 0,050 \mathrm{e} 0,020 \mathrm{V.s}{ }^{-1}$ 
265

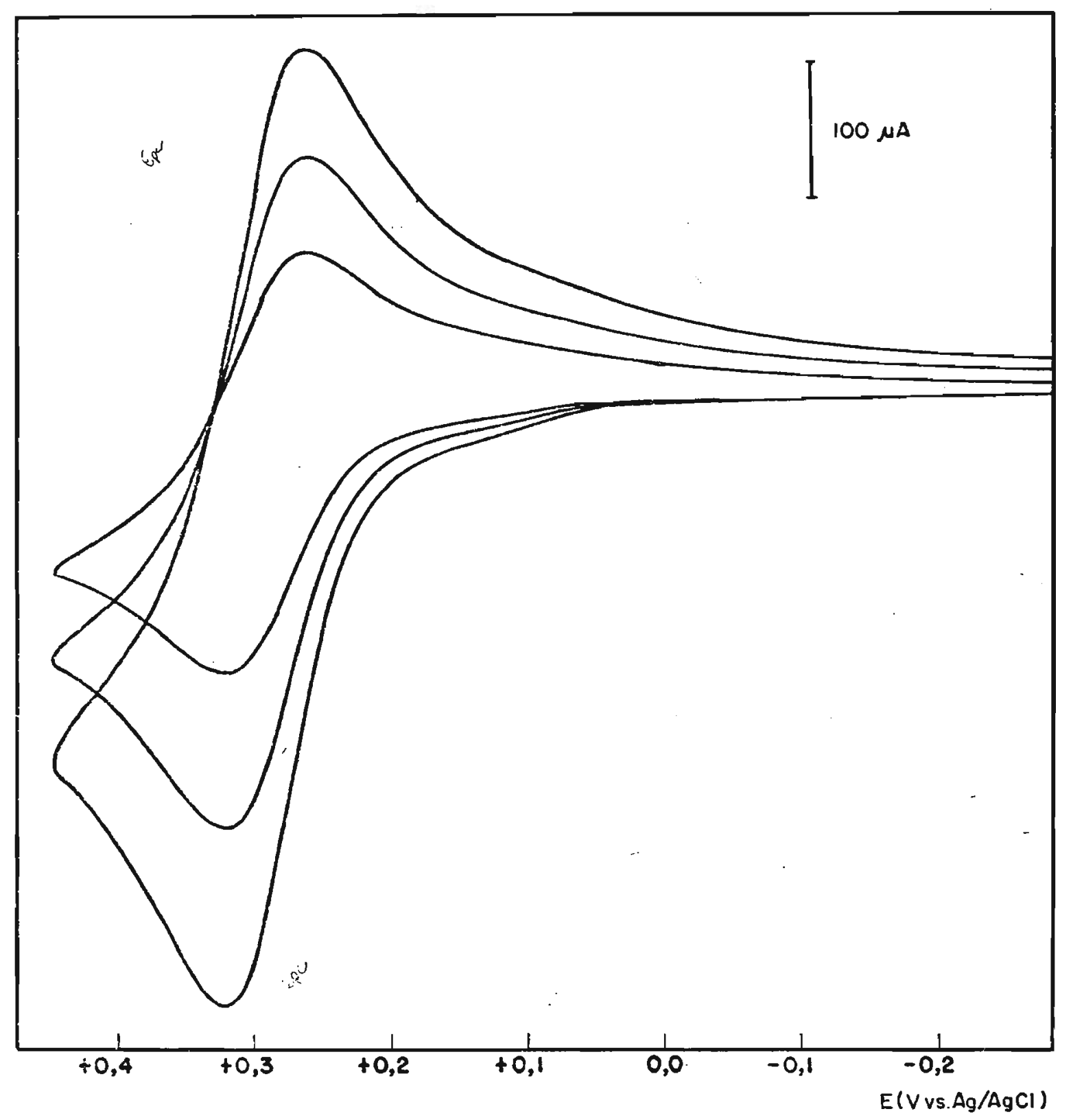

FIG.7.2A.voltamogramas cíclicos de solução $4,00 \times 10^{-3} \mathrm{M}$ de $\mathrm{Fe}(\mathrm{CN}){ }_{5} \mathrm{p}-\mathrm{py}(\mathrm{CO}) \mathrm{CHNOH}^{3-}$ em $\mathrm{KCl} 0,50 \mathrm{M}$ a $25,0^{\circ} \mathrm{C}$ $[\mathrm{L}]=1,20 \times 10^{-3} 11 \mathrm{v}=0,100 ; 0,050 \mathrm{e} 0,020 \mathrm{v} \cdot \mathrm{s}^{-1}$ 


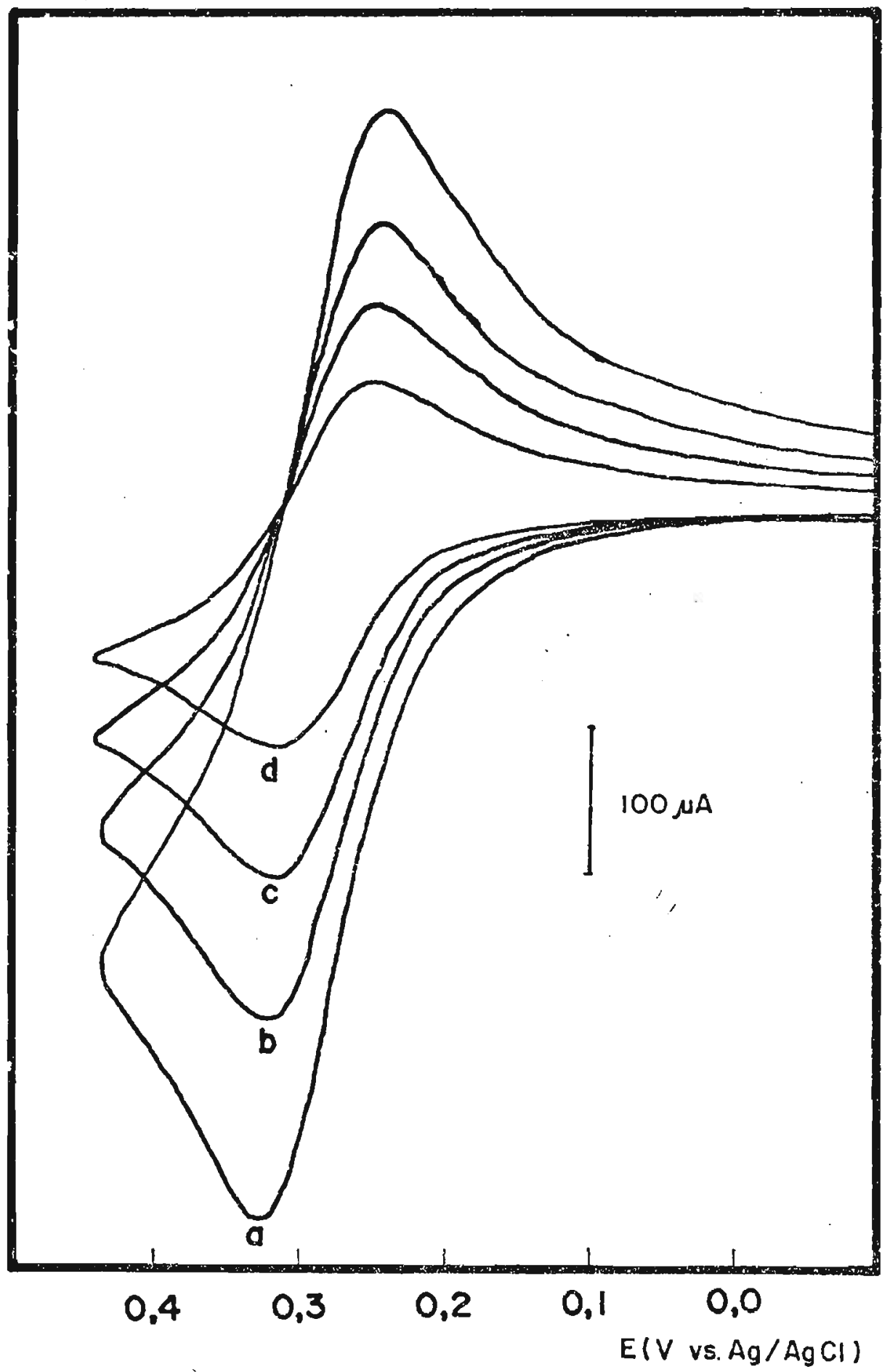

FIG.7.2B.Voltamogramas cíclicos de solução $4,06 \times 10^{-3} \mathrm{M}$ de

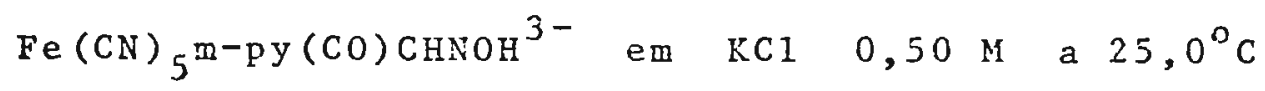
$\mathrm{v}=\mathrm{a} .0,200 ; \mathrm{b} .0,100 ; \mathrm{c} .0,050 ; \mathrm{d} .0,020{\mathrm{v} . \mathrm{s}^{-1}}^{-1}$ 
onda $\left(E_{1 / 2}\right)$, valores estes que compöem as tabelas 7.1. e 7 . 2., para diferentes velocidade de varredura de potenciais.

Por inspeção destas tabelas, verifica-se que os valores de potenciais de pico são independentes da velocidade de varredura de potenciais, dentro do erro experimen tal. Este fato consitui um primeiro critério de reversibili dade (290) dos processos de eletrodo investigados. Outros critērios de reversibilidade $(288,290)$, podem ser aplicados para a determinação do mecanismo do processo de eletrodo e constatados nas tabelas 7.3. e 7.4.

A razão das correntes de pico anōdico e cató dico é igual à unidade dentro do erro experimental, indepen dentemente da velocidade de varredura de potenciais.

A diferença entre os potenciais de picc anōdicoe catōdico deve ser igual a $59 / \mathrm{n} m \mathrm{mV}$ a $25,0^{\circ} \mathrm{C}$. Os valores obtidos experimentalmente são geralmente um pouco ma ores, principalmente a velocidade de varredura de potenciais mais rápidas. Estas condições, provocam a queda ohmica (iR) atravēs da célula que se traduz numa maior separação dos picos anōdico e catōdico, aumentando os valores de $\Delta E_{p}$. Consequentemente os valores de $E_{1 / 2}$ anōdico são deslocados para valores mais positivos e $E_{1 / 2}$ catódico para valores mais negativos. Nesses casos a diferença entre $E_{p}$ e $E_{1 / 2}$ exprime melhor a reversibilidade, uma vez que . em. tais casos tem-se a relação (290)

$$
\begin{aligned}
E_{p}=E_{1 / 2} \pm(0,0285 / \mathrm{n}) \cdot v & \begin{array}{l}
(+ \text { seg. anōdico }) \\
(- \text { seg. catōdico })
\end{array}
\end{aligned}
$$




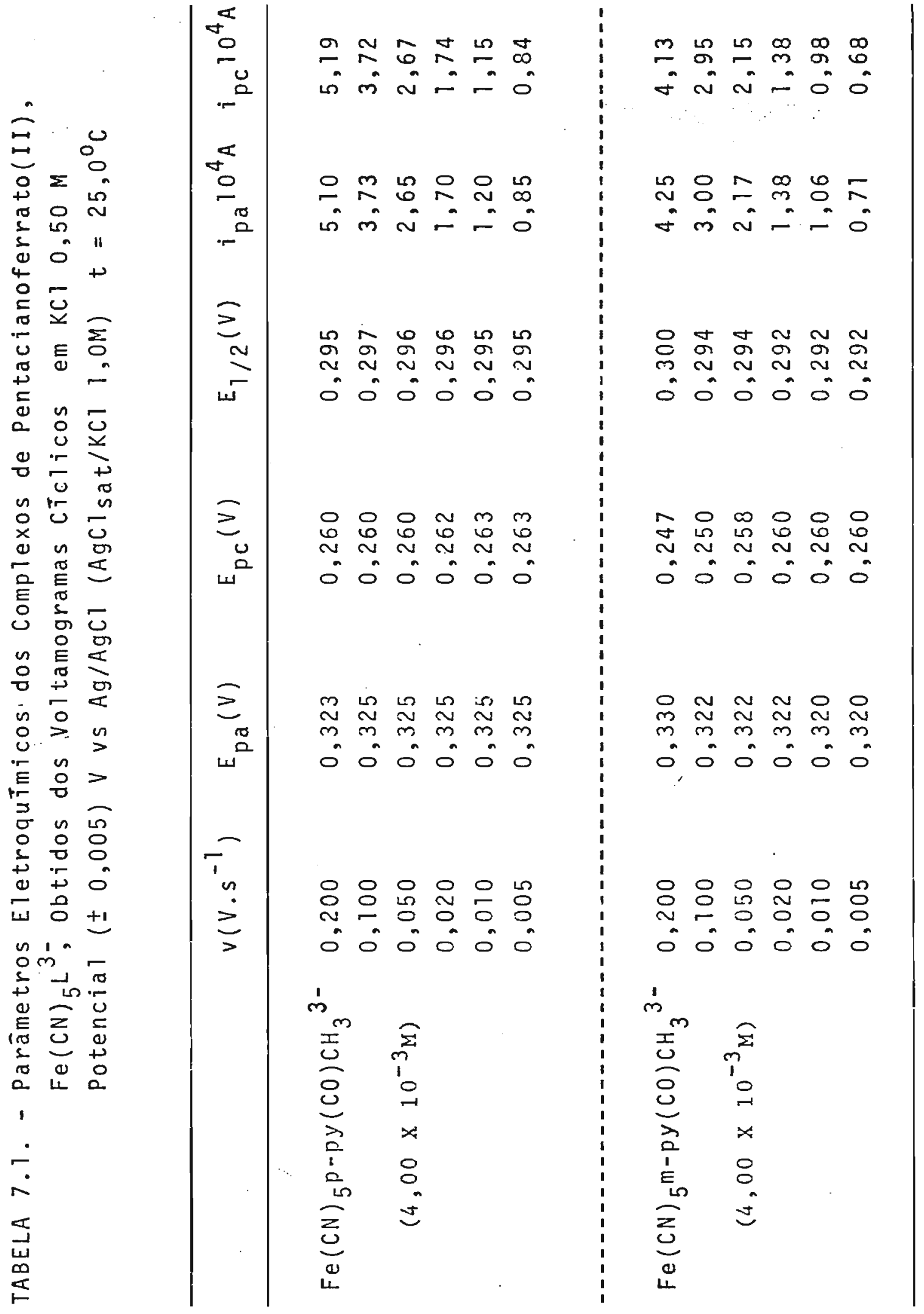




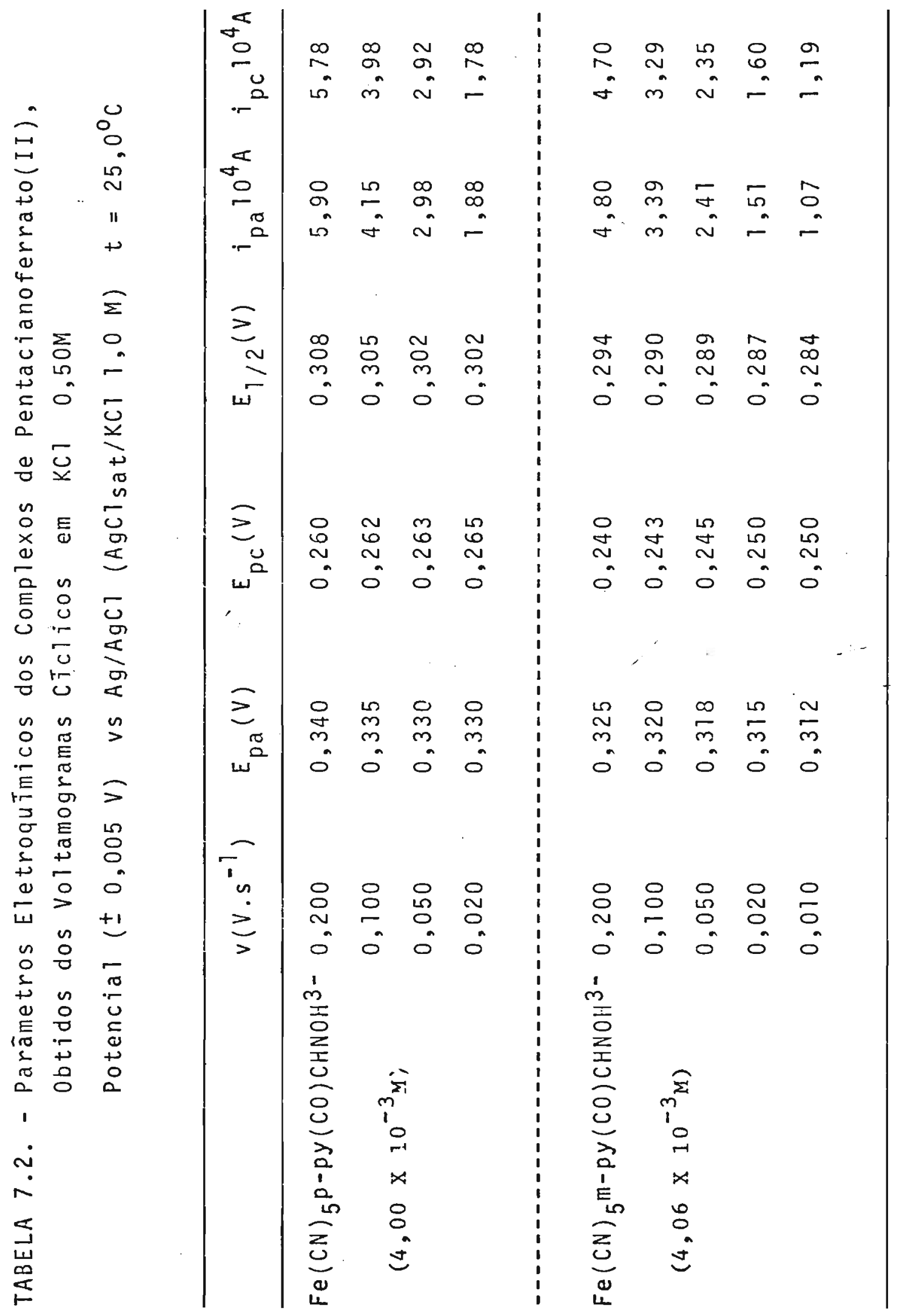




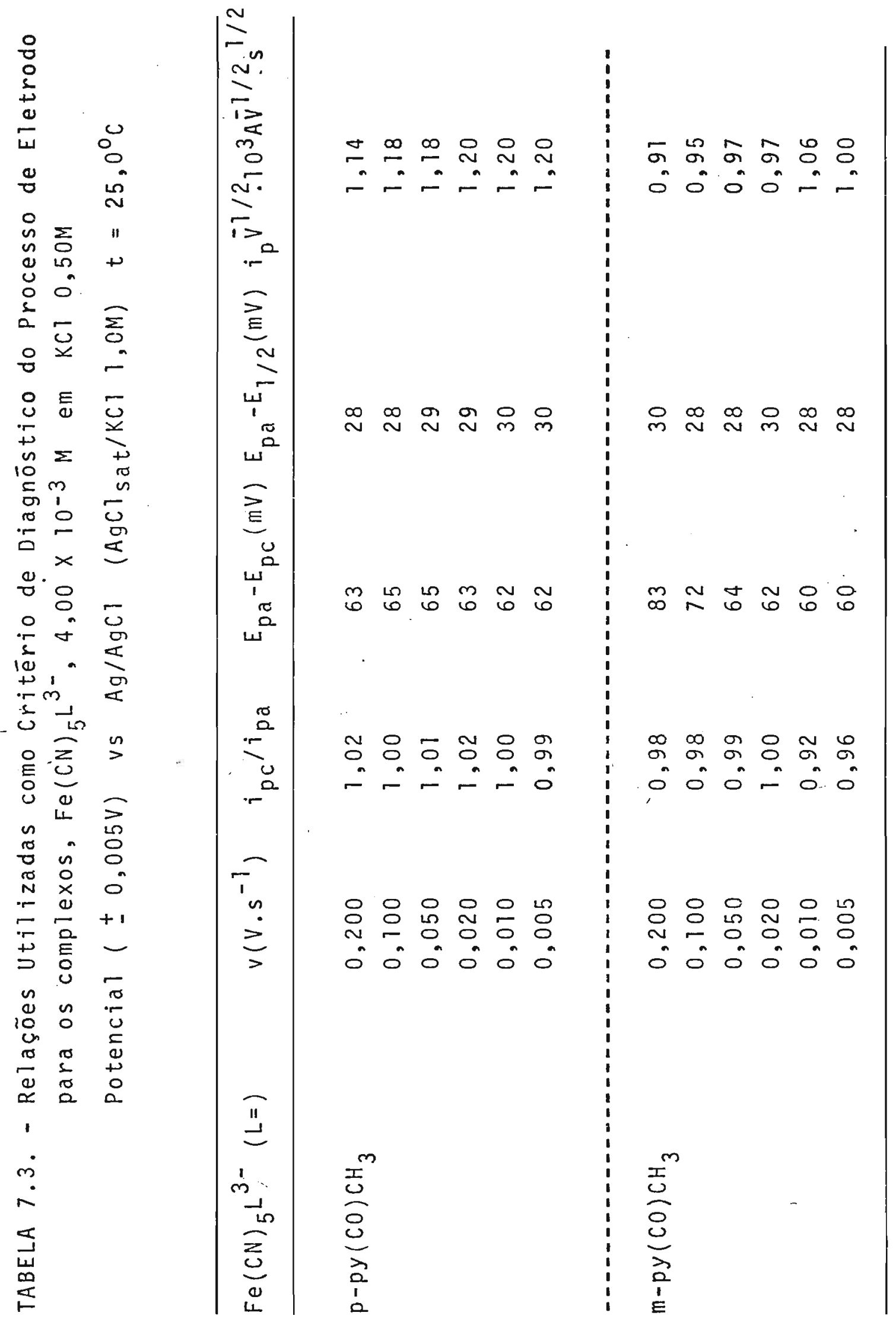




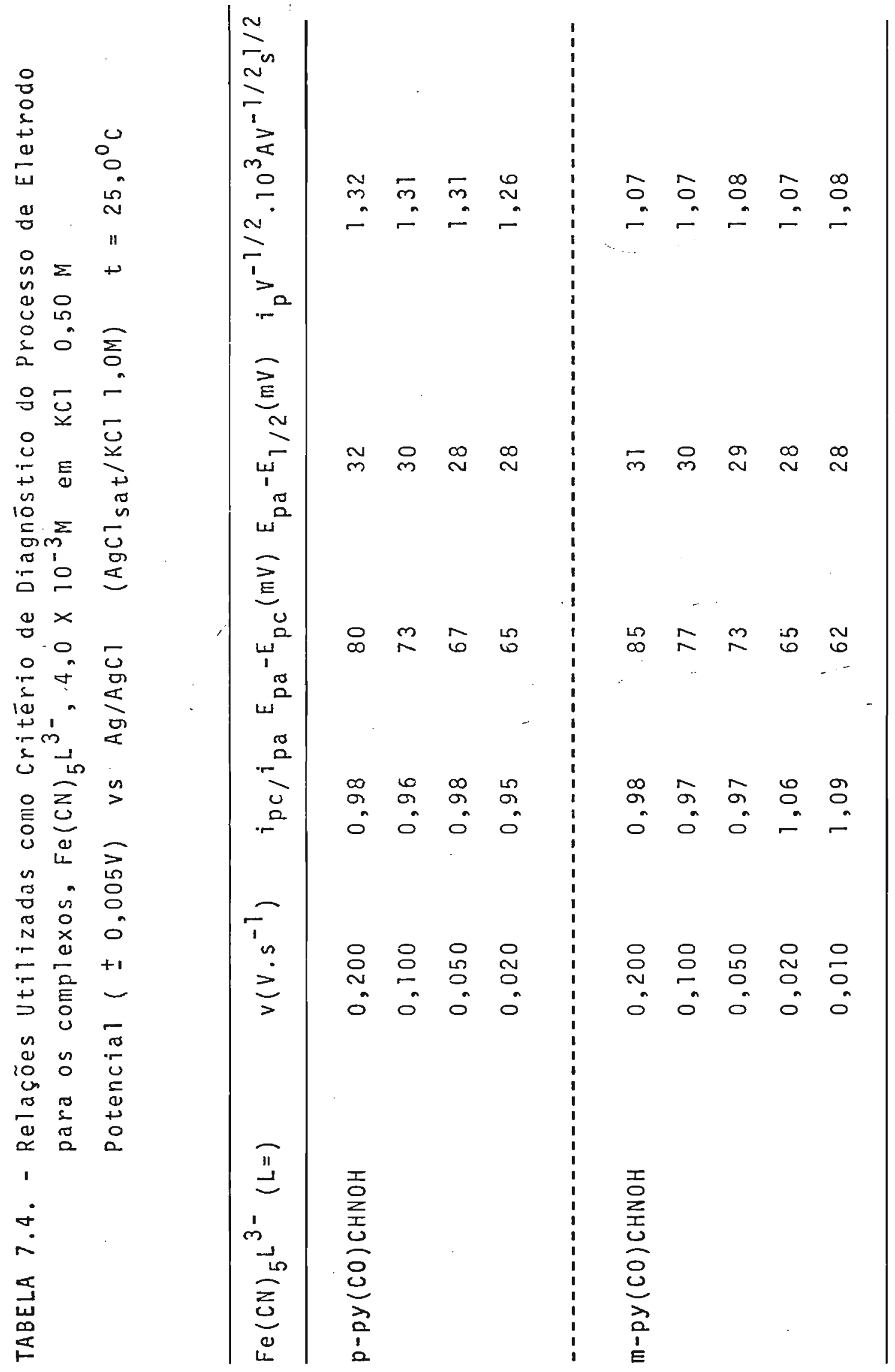


No entanto, a relação com o potencial de meio pico é um crí tério mais utilizado para sistemas com picos alargados.

$$
E_{p / 2}=E_{1 / 2} \pm \frac{28,0}{n} m V \begin{aligned}
& (+ \text { seg. catōdico) } \\
& \text { (- seg. anódico) }
\end{aligned}
$$

0 produto $i_{p} \times v^{7 / 2} \bar{e}$ constante dentro do erro experimental e independente do valor de velocidade de var redura dos potenciais. Esta independência observada na figu ra 7.3. certamente indica que o processo é controlado por difusão .

Uma outra maneira de avaliar a reversibilidade do processo de eletrodo para os sistemas em investigação, é a comparação destes resultados com os dados provenientes de composto cujo comportamento é bem conhecido como reversivel e monoeletrōnico, nas mesmas condições experimentais. Um es tudo neste sentido com o ferrocianeto mostrou-nos que o sís tema apresenta todas as condições de reversibilidade a velo cidades de varredura de potenciais até $0,050 \mathrm{~V} . \mathrm{s}^{-1}$. A veloci dades maiores, os valores de $\Delta E_{p}$ ou $E_{p}-E_{1 / 2}$ maiores, con mo ligeiras diferenças nas demais condições de reversibilidade podem ser atribuîdas à resistência da célula e podese fazer o uso de compensação da queda ohmica, mas sem ul trapassar à faixa de $0,0018(0,18 \%)$.

A equação de Randles-Sevcik para a corrente de pico na voltametria ciclica para processos de eletrodos reversiveis é

$$
i_{p}=602 \cdot n^{3 / 2} \cdot A \cdot C \cdot D^{1 / 2} \cdot v^{1 / 2} \cdot 0,4463
$$




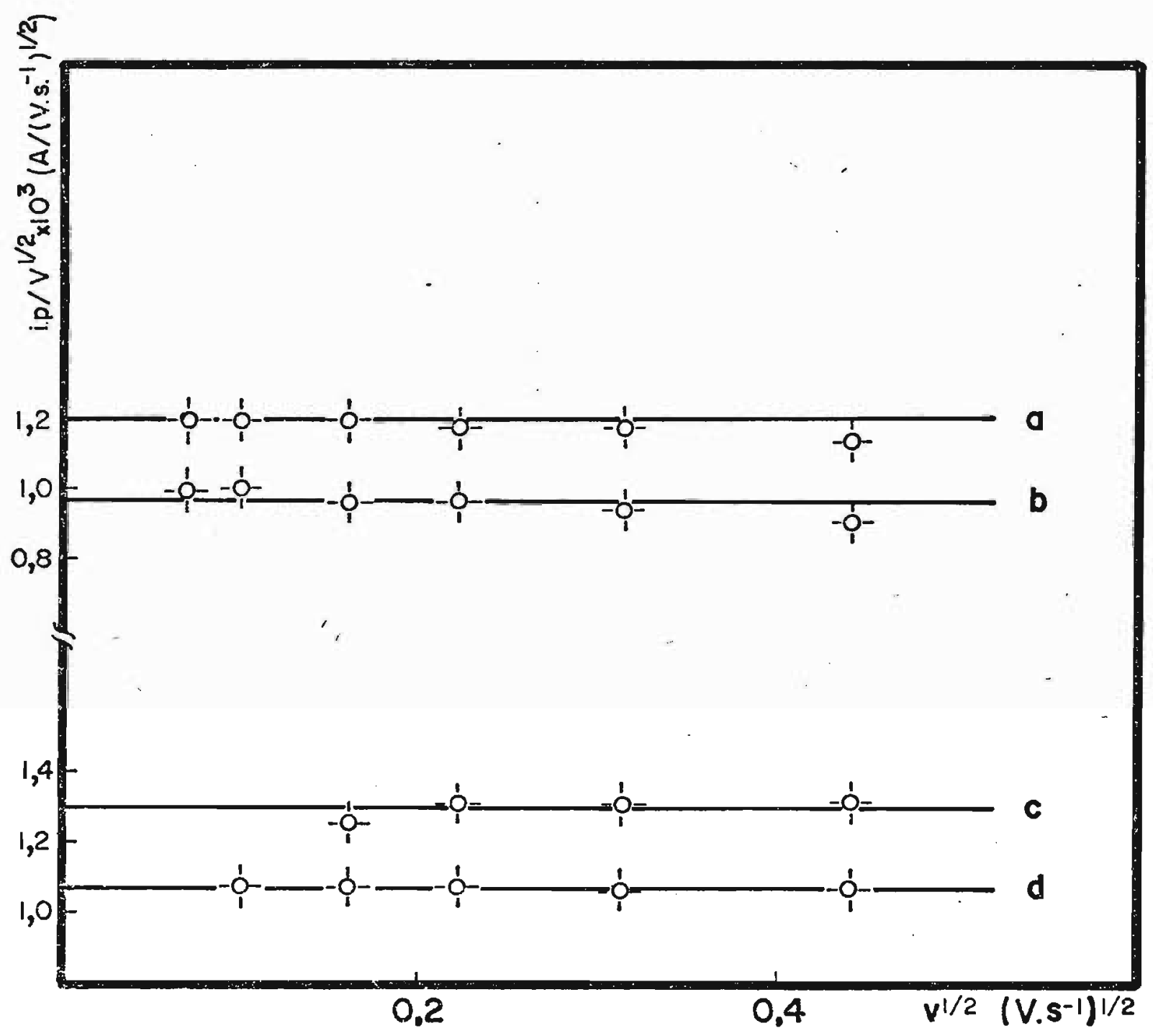

Fis.7.3. Variação do $i_{p} / v^{1 / 2}$ em função da velocidade de vaI redura de potenciais para $\mathrm{Fe}(\mathrm{CN})_{5} \mathrm{~L}^{3-}$, onde $\mathrm{L}$ igual a
a. $\mathrm{p}-\mathrm{py}(\mathrm{CO}) \mathrm{CH}_{3}$
b. $\mathrm{m}-\mathrm{py}(\mathrm{CO}) \mathrm{CH}_{3}$
c. p-py $(\mathrm{CO}) \mathrm{CHNOH}$
d. m-py $(\mathrm{CO}) \mathrm{CHNOH}$ 
Por esta equação, verifica-se que a corrence de pico é diretamente proporcional à concentração, a uma ve 10cidade de varredura de potenciais constante. A figura 7.4. mostra os dados experimentais de corrente de pico anōdico em função da concentração a uma velocidade de varredura de potenciais constante. A relação encontrada é linear e, a par tir do coeficiente angular determinou-se os coeficientes ale difusão relacionados ria tabela abaixo

Coeficientes de difusão dos complexos de $\operatorname{Fe}(\mathrm{CN}){ }_{5} \mathrm{~L}^{3-}$ calcu lados a partir do gráfico de $i_{p a}$ vs $\mathrm{Fe}(\mathrm{CN})_{5} \mathrm{~L}^{3-}$
$\mathrm{Fe}(\mathrm{CN}){ }_{5} \mathrm{~L}^{3-}$
$\mathrm{D}\left(10^{5} \mathrm{~cm}^{2} \mathrm{~s}^{-1}\right)$

\begin{tabular}{|c|c|}
\hline $\mathrm{Fe}(\mathrm{CN}){ }_{5} \mathrm{p}-\mathrm{py}(\mathrm{CO}) \mathrm{CH}_{3}{ }^{3-}$ & 0,48 \\
\hline 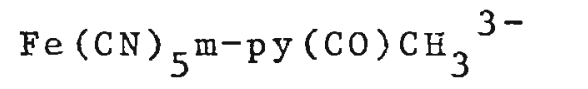 & 0,36 \\
\hline $\mathrm{Fe}(\mathrm{CN})_{5} \mathrm{p}-\mathrm{py}(\mathrm{CO}) \mathrm{CHNOH}^{3-}$ & 0,51 \\
\hline $\mathrm{Fe}(\mathrm{CN}) 5^{\mathrm{m}-\mathrm{py}(\mathrm{CO}) \mathrm{CHNOH}^{3-}}$ & 0,37 \\
\hline
\end{tabular}

$$
\mathrm{KCl}=0,5 \mathrm{M} \quad t=25,0^{\circ} \mathrm{C}
$$

Os valores de coeficientes de difusão estão na faixa encontrados para a maioria dos complexos de pentacianoferrato(II) (291) e menores do que $\mathrm{Fe}(\mathrm{CN})_{6}^{4-}$, o que os tornam razoāveis, mostrando que o sistema è realmente con trolado apenas por difusão (284).

A semelhança do comportamento dos complexos, 


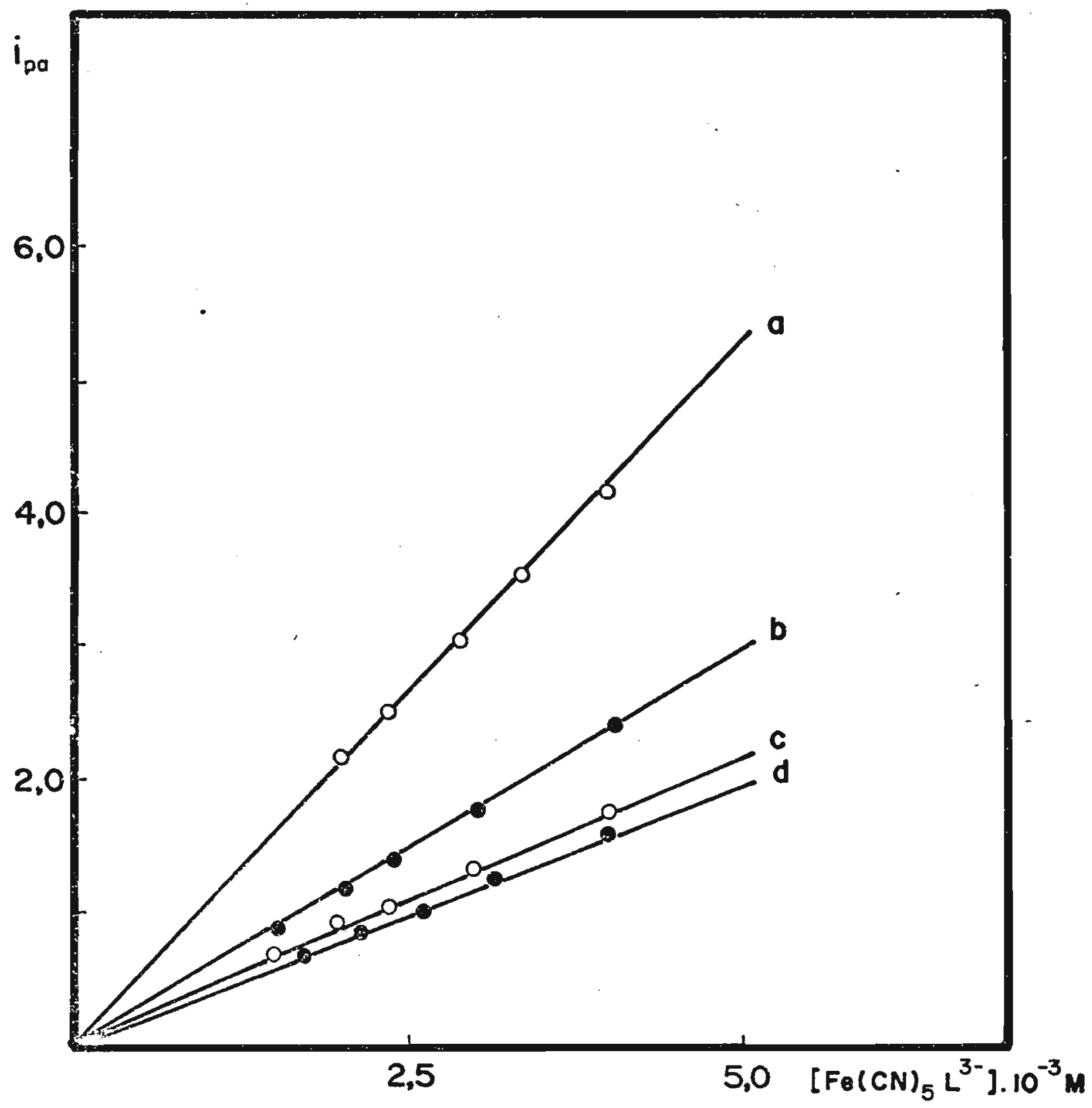

FIG.7.4. Corrente de pico anódico em função da concentração do $\mathrm{Fe}(\mathrm{CN})_{5} \mathrm{~L}^{3-}$ onde $\mathrm{L}=\mathrm{a} \cdot \mathrm{p}-\mathrm{py}(\mathrm{CO}) \mathrm{CHNOH}(\mathrm{v}=0,100 \mathrm{~V}$. $\left.\mathrm{s}^{-1}\right), \mathrm{b} \cdot \mathrm{m}-\mathrm{py}(\mathrm{CO}) \mathrm{CHNOH}\left(\mathrm{v}=0,050 \mathrm{~V} \cdot \mathrm{s}^{-1}\right), \mathrm{c} \cdot \mathrm{p}-\mathrm{py}(\mathrm{CO}) \mathrm{CH}_{3}$ $\left(v=0,020 \mathrm{v} \cdot \mathrm{s}^{-1}\right)$ e d. m-py $(\mathrm{CO}) \mathrm{CH}_{3}\left(\mathrm{v}=0,020 \mathrm{v} \cdot \mathrm{s}^{-1}\right)$ 
bem como a observāncia dos demais critérios de reversibilidade indicam que os processos de eletrodo podem ser melhor descritos como monoeletrónicos e reversíveis. Admitindo -se este mecanismo, é possivel obter o voltamograma cīclico cal culado (290), uma vez que os coeficientes de difusão são da ordem de grandeza correta, e compara-1o ao obtido experimen talmente.

A concordāncia entre a curva calculada e a experimental (FIG. 7.5.) caracteriza bem o processo de eletro do, descrito como reversivel, monoeletrōnico, controlado por difusão, correspondente à oxidação do íon metāiico central segundo a equação:

$$
\mathrm{Fe}(\mathrm{CN})_{5} \mathrm{~L}^{3-} \longrightarrow \mathrm{Fe}(\mathrm{CN})_{5} \mathrm{~L}^{2-}+e
$$

A figura 7.6. traz c voltamograma cíclico do complexo $\mathrm{Fe}(\mathrm{CN})_{5} \mathrm{p}-\mathrm{py}(\mathrm{CO}) \mathrm{CH}_{3}{ }^{3-}$ a diferentes temperaturas.

Os parāmetros eletroquímicos obtidos estão re lacionados na tabela 7.5. e, no gräfico 7.7. estão os dados para avaliar a reversibilidade do processo.

A temperatura afeta $0 E^{0}$ bem como $\Delta G^{0}$ atravēs da relação

$$
\Delta \mathrm{G}=-\mathrm{n} F \mathrm{E}^{\circ}=\Delta \mathrm{H}-\mathrm{T} \Delta \mathrm{S}
$$

A substituição da equação de Gibbs-Helmholtz (1a) na rela 


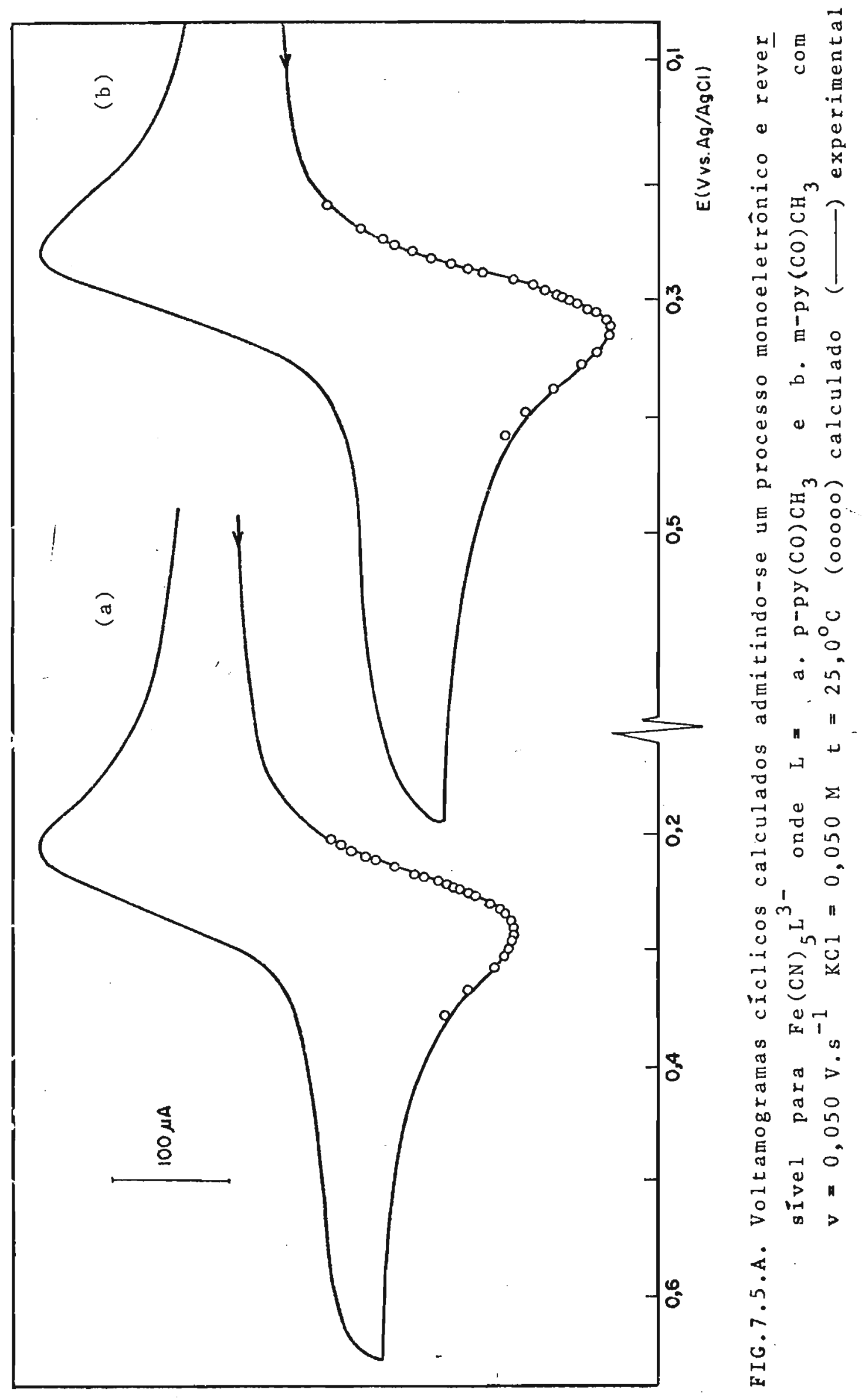


278

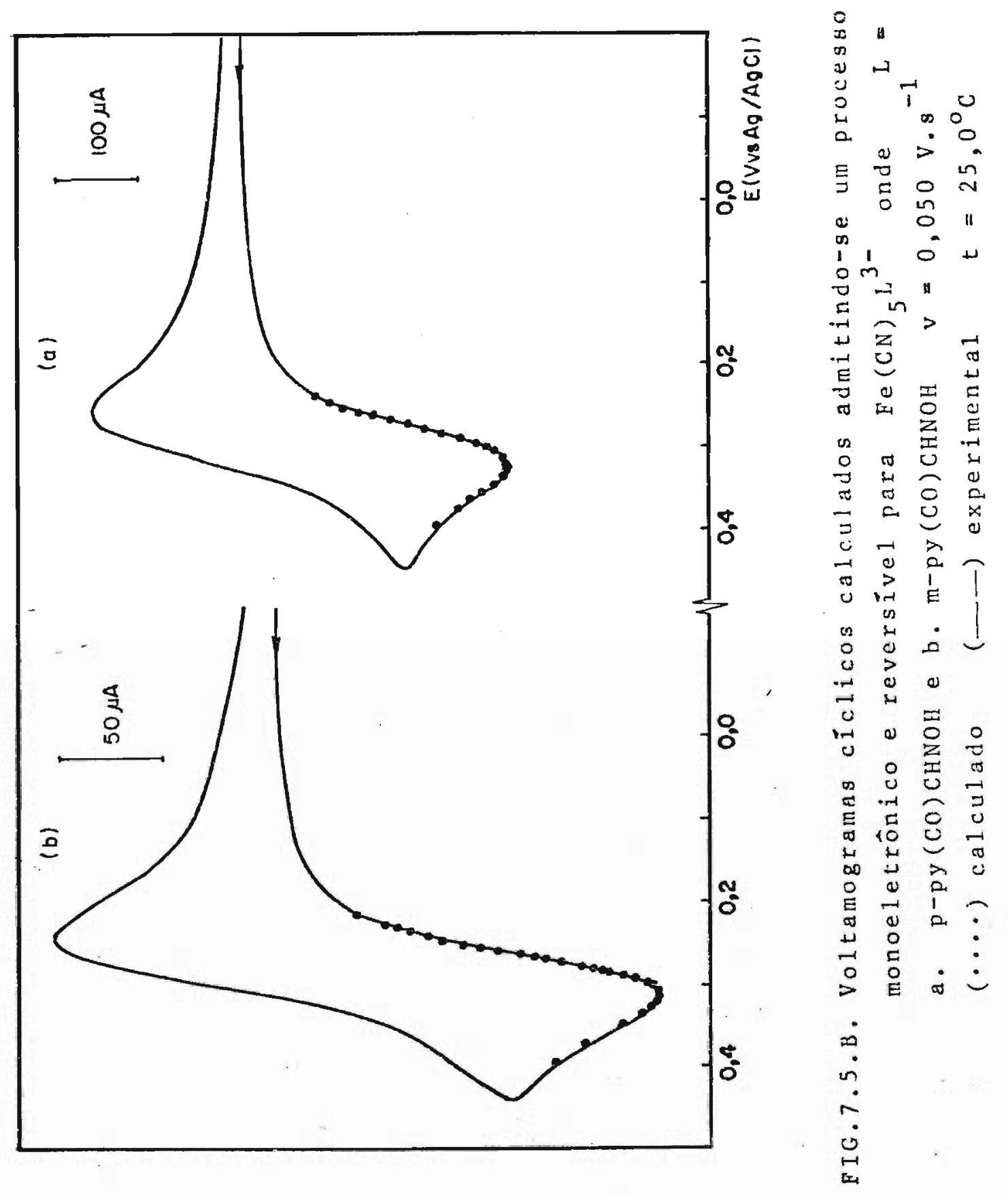




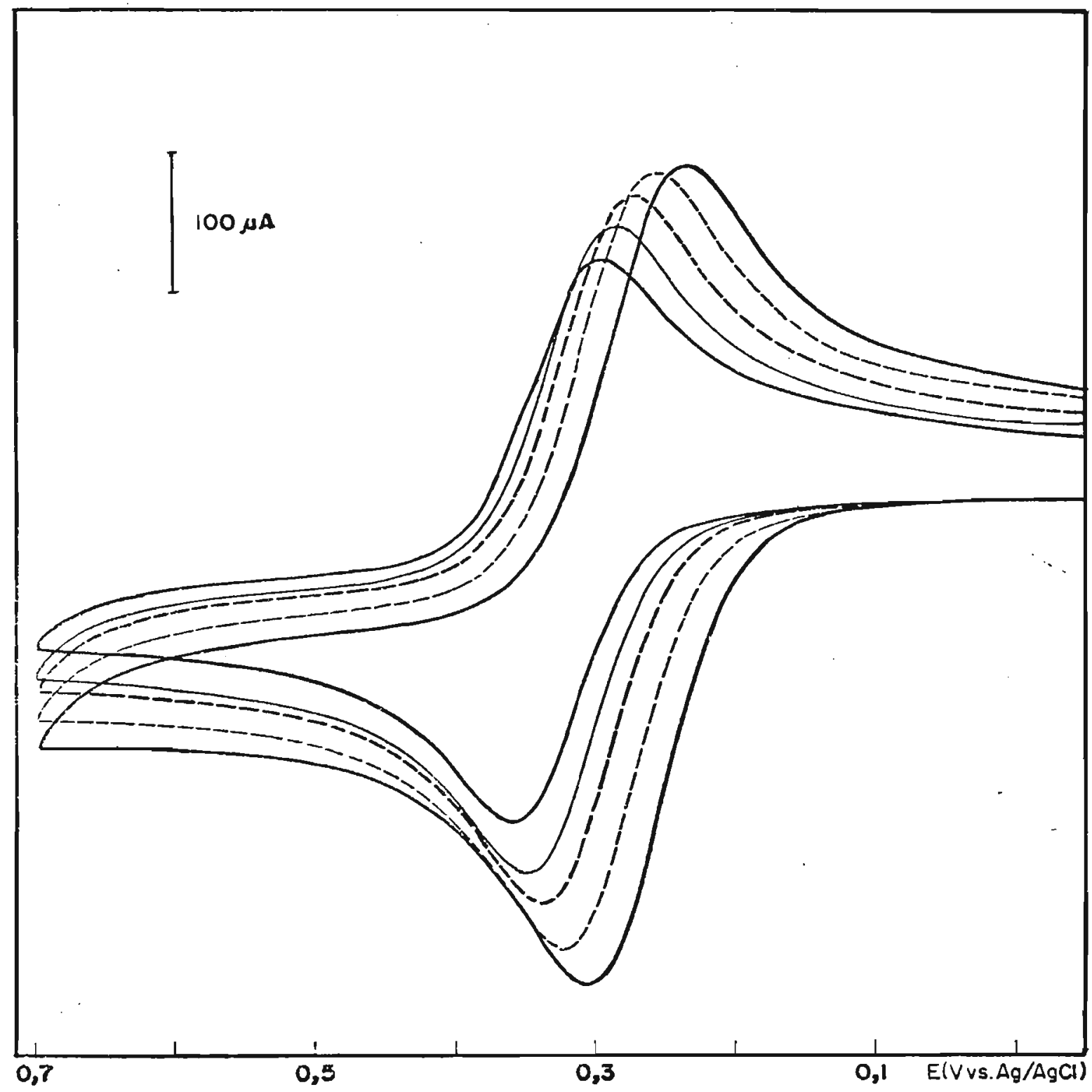

FIG.7.6. Voltamogramas cíclicos do complexo Fe(CN) ${ }_{5}$ p-py(Co). $\mathrm{CH}_{3}{ }^{3-} 3,99 \times 10^{-3} \mathrm{M}$ a diferentes temperaturas em $\mathrm{KCl} 0,50 \mathrm{M} \quad \mathrm{v}=0,050 \mathrm{~V} \cdot \mathrm{s}^{-1}$ 
TABELA - 7.5 .

Parâmetros eletroquímicos do complexo pentaciano(p-acetilpiridina)ferrato(II) obtidos dos voltamogramas cíclicos. a diferentes velocidade de varredura de potenciais e tempera tura em KCI $0,50 M$.

$\left[\mathrm{Fe}(\mathrm{CN})_{5} \mathrm{P}-\mathrm{py}(\mathrm{CO}) \mathrm{CH}_{3}{ }^{3-}\right]=3,99 \times 10^{-3} \mathrm{M}$ $\left[\mathrm{p}-\mathrm{py}(\mathrm{CO}) \mathrm{CH}_{3}\right]=4,70 \times 10^{-2} \mathrm{M}$

Potencial $=\mathrm{E}( \pm 0,005) \mathrm{V}$ vs $\mathrm{Ag} / \mathrm{AgCl}(\mathrm{AgCl} \mathrm{sat} / \mathrm{KCl} 1 \mathrm{M})$ 


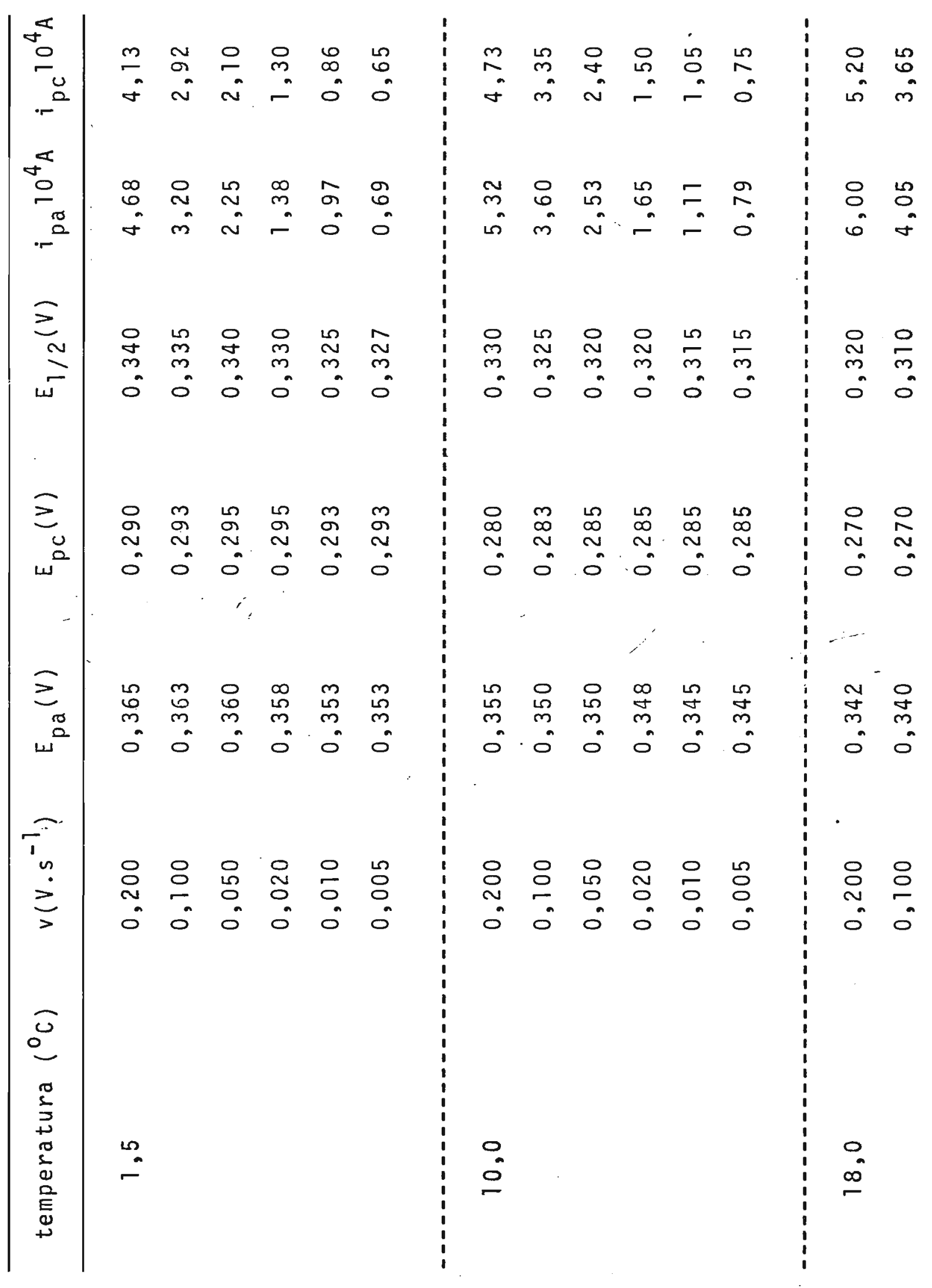




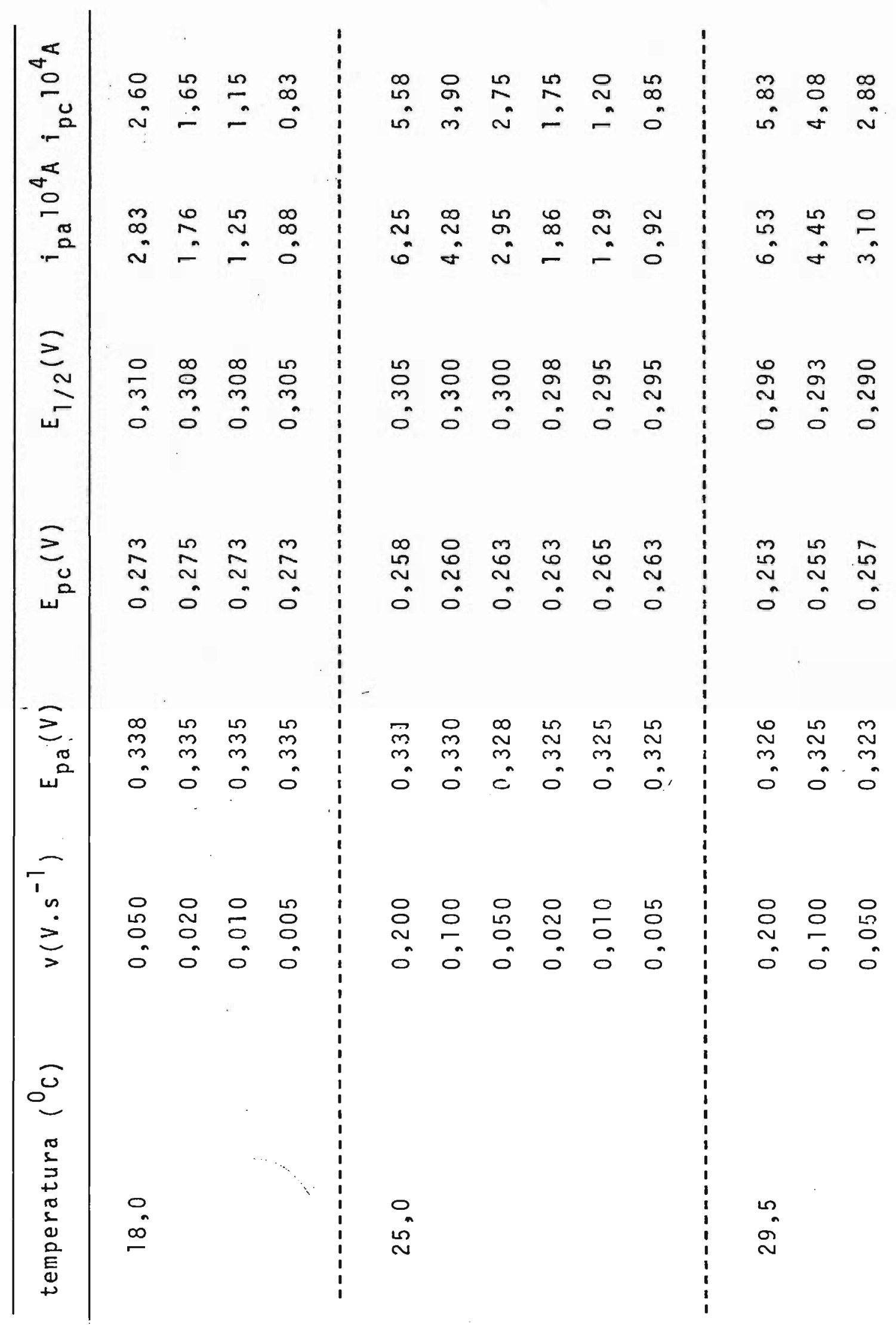




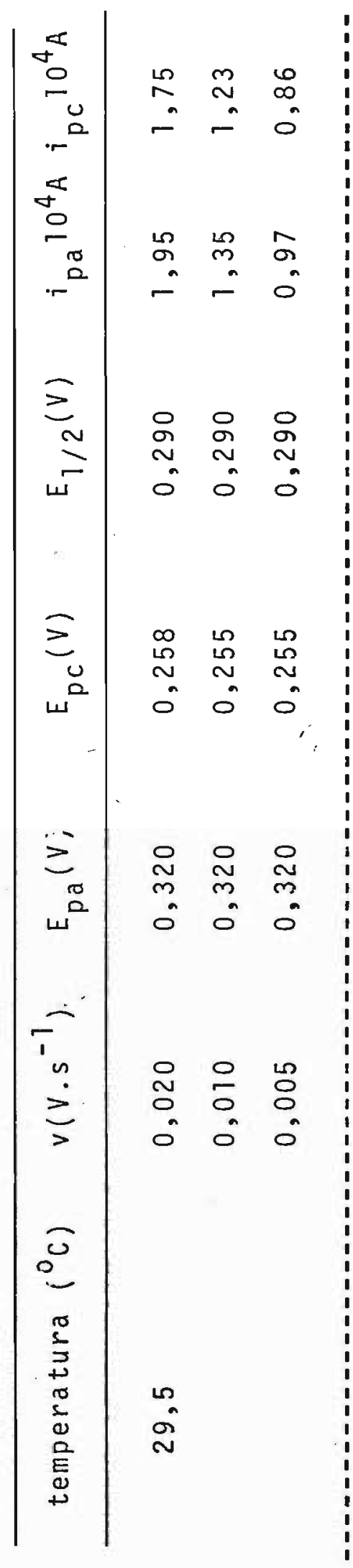

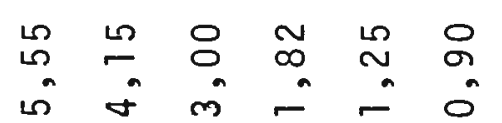

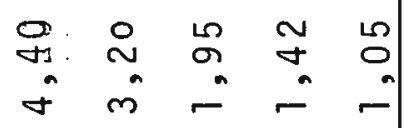

$\begin{array}{llllll}0 & 0 & \infty & 0 & \sigma & 0 \\ 0 & 0 & - & 0 & m & 0 \\ 0 & 0 & m & \cdots & - & -\end{array}$

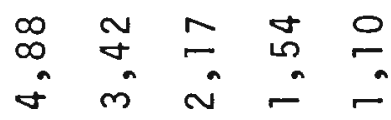

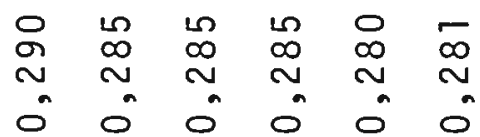

$\begin{array}{lllll}n & n & m & m & 0 \\ N & N & N & N & N \\ 0 & 0 & 0 & 0 & 0\end{array}$

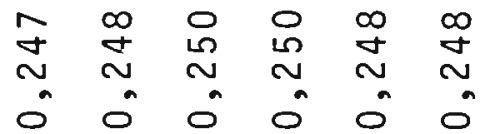

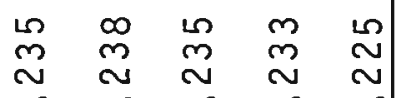

$\begin{array}{lllll}0 & 0 & 0 & 0 & 0 \\ 0 & 0 & 0 & 0\end{array}$

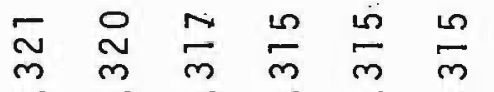

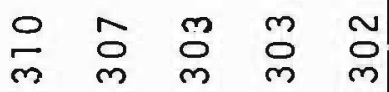

ڤ

० 000000

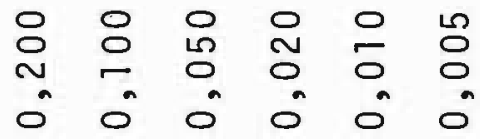

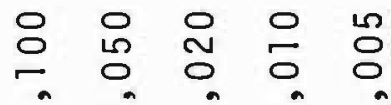

م 000000

ma

i 


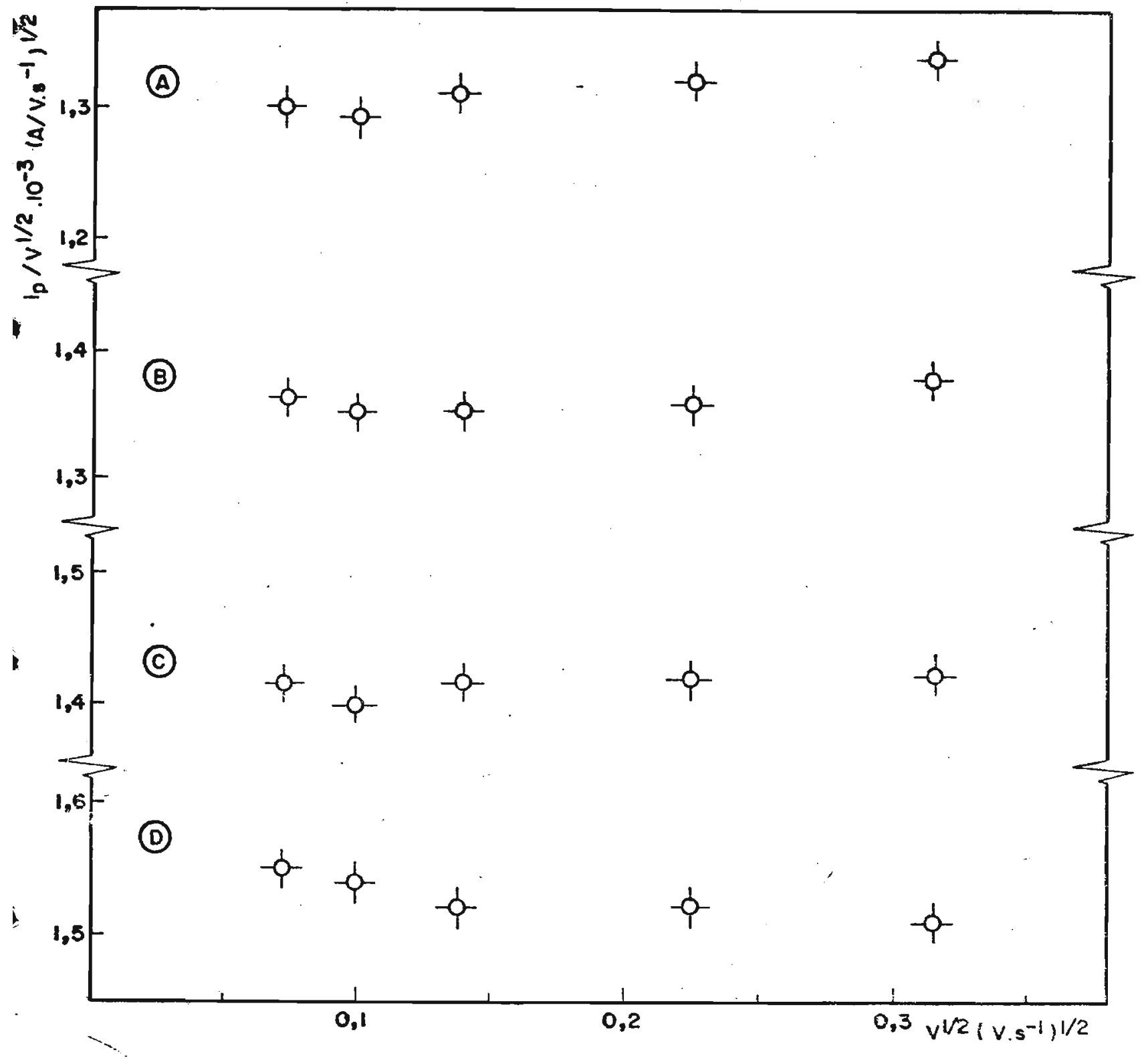

\footnotetext{
FIG.7.7.A. Variação do $i_{p} / v^{1 / 2}$ em função da velocidade de varredura de potenciais para $\mathrm{Fe}(\mathrm{CN})_{5}$ p-py(CO) $\mathrm{CH}_{3}^{3-}$
a diferentes temperaturas
a. $25,0^{\circ} \mathrm{C}$
b. $29,0^{\circ} \mathrm{C}$
c. $33,5^{\circ} \mathrm{C}$
d. $42,0^{\circ} \mathrm{C}$ 


\section{5}

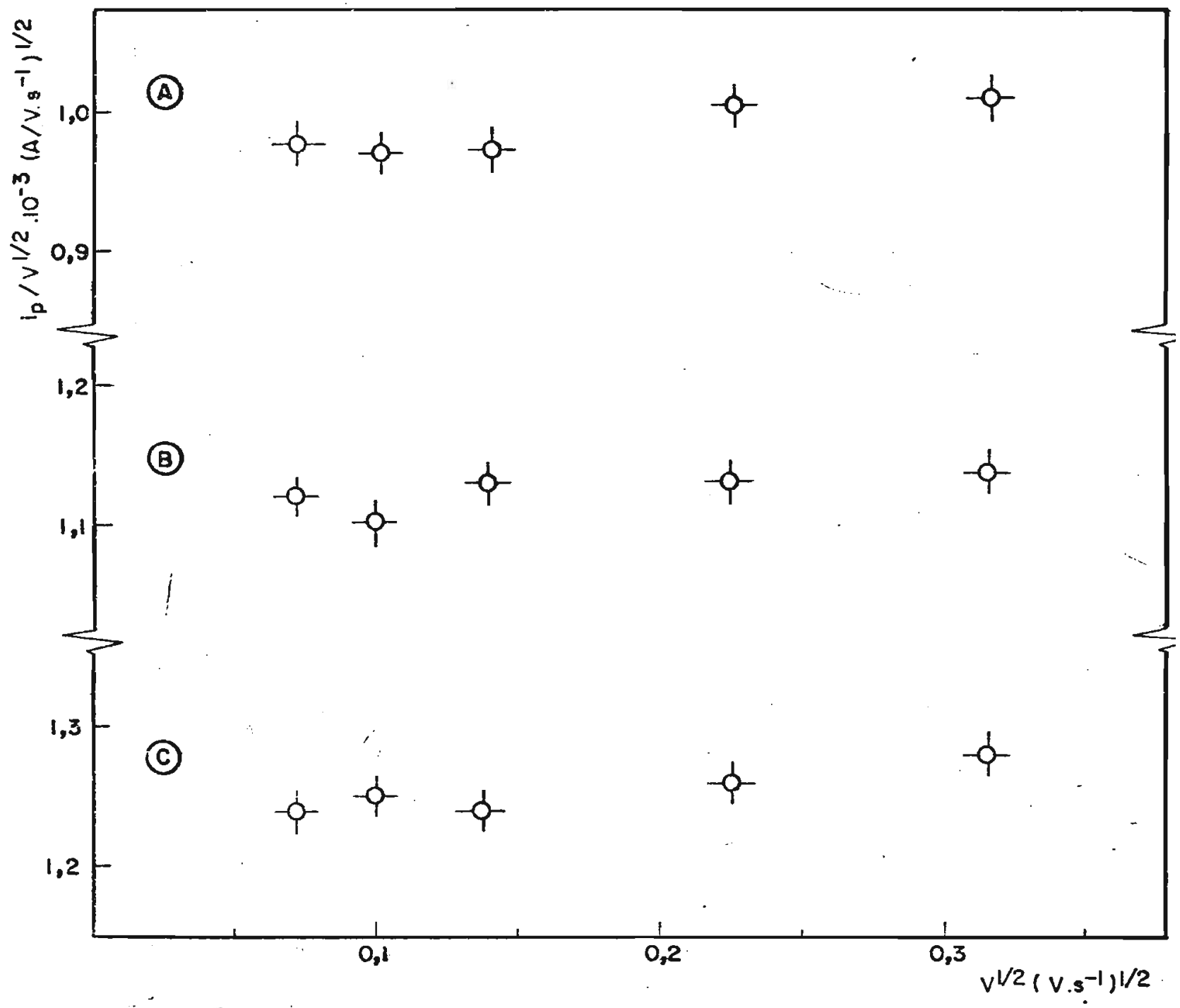

FIG.7.7.B. Variação do $i_{p} / v^{1 / 2}$ em função da velocidade de varredura de potenciais para $\mathrm{Fe}(\mathrm{CN}){ }_{5} \mathrm{p}-\mathrm{py}(\mathrm{CO}) \mathrm{CH}_{3}^{3-}$
a diferentes temperaturas
a. $1,5^{\circ} \mathrm{C}$
b. $10,0^{\circ} \mathrm{C}$
c. $18^{\circ} \mathrm{C}$ 


$$
\left(\frac{\partial \Delta G}{\partial T}\right)_{P}=-\Delta S=\frac{\Delta G-\Delta H}{T}
$$

ção (1), possibilita calcular $\Delta H$ e $\Delta S$ de uma reação pelo coeficiente de temperatura da força eletromotriz reversível.

$$
\Delta S=\left(-\frac{\partial \Delta G}{\partial T}\right)_{P}=\left(n F \frac{\partial E}{\partial T}\right)_{p}
$$

$$
\mathrm{e} \Delta \mathrm{H}=-\mathrm{nFE}+\mathrm{nF} \mathrm{T}\left(\frac{\partial \mathrm{E}}{\partial \mathrm{T}}\right)_{\mathrm{p}}
$$

Do grāfico de $E^{0}$ em função dá temperaturáa ab soluta, determina-se os valores de $\Delta S$ e $\Delta H$ que são 32 cal. $\mathrm{mol}^{-1} \mathrm{~K}^{-1}$ e $21,6_{5} \mathrm{kcal}^{\mathrm{mol}}{ }^{-1}$, respectivamente (FIG.7.8.A).

A influência da temperatura na corrente de pico pode ser avaliada a partir da equação de Randles-Sevcik, para processos de eletrodo reversiveis

$$
i_{p}=602 \mathrm{n}^{3 / 2} \mathrm{AC} \mathrm{v}^{1 / 2} 0,4463 \mathrm{D}^{1 / 2}
$$

que pode ser escrita como

$$
\frac{i_{p}}{268,7 n^{3 / 2} A \subset v^{1 / 2}}=D^{1 / 2}
$$




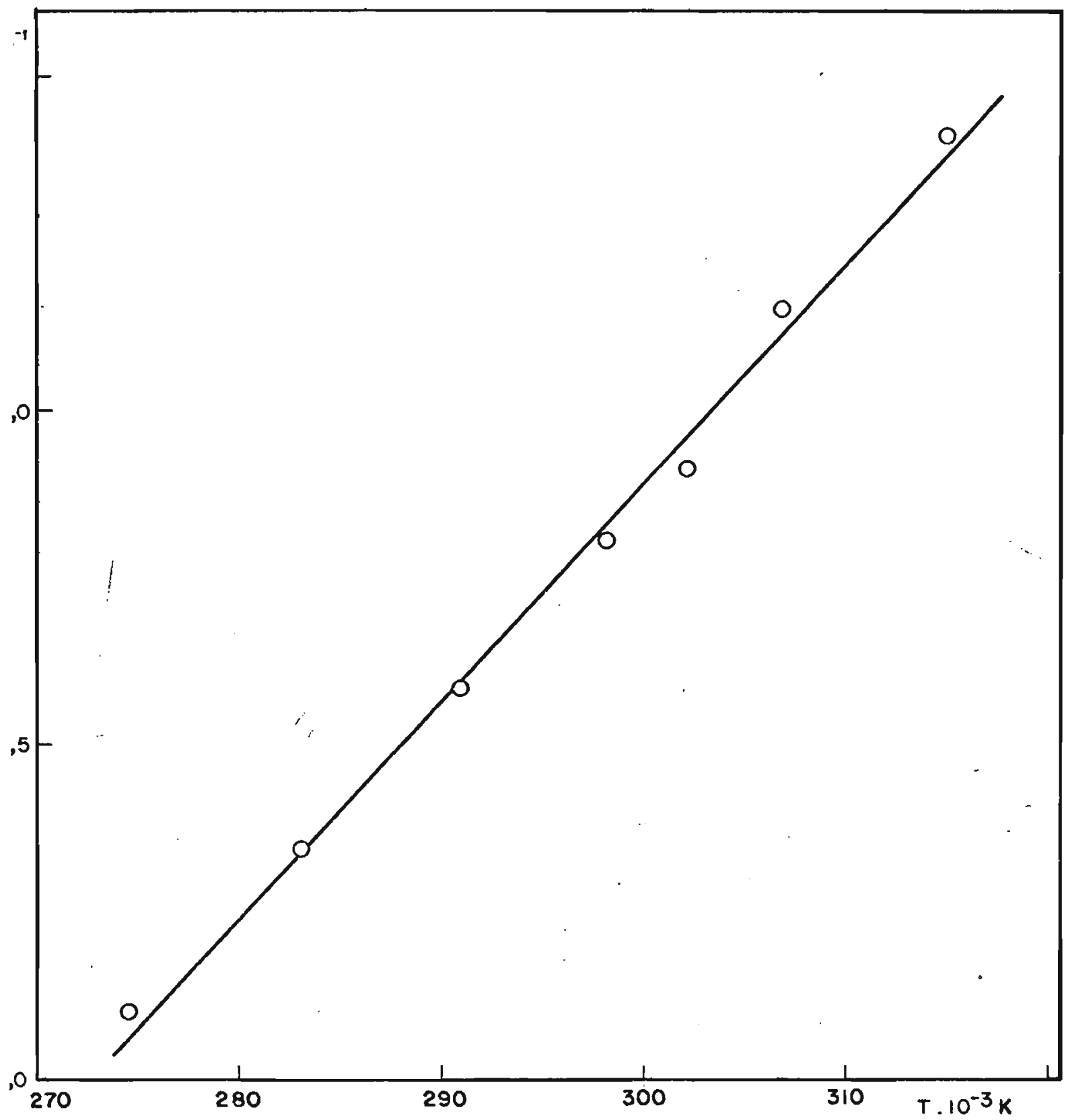

FIG.7.8.A. Gráfico de $\Delta G$ em função da temperatura absoluta $\Delta S=32 \mathrm{cal} \cdot \mathrm{mol}^{-1} \cdot \mathrm{K}^{-1}$

$\Delta \mathrm{H}=21,6_{5} \mathrm{kcal} \cdot \mathrm{mol}^{-1}$ 


\section{8}

ou

$$
\ln \frac{i_{p}}{268,7 \mathrm{n}^{3 / 2} A C v^{1 / 2}}=\frac{1}{2} \ln \mathrm{D}
$$

O coeficiente de difusão (D) segue a depen déncia de temperatura do tipo Boltzman

$$
D=D_{i} e^{-E_{a} / R T}
$$

onde

$$
\begin{aligned}
& \mathrm{D}_{i}=\text { fator de frequēncia para difusão } \\
& \mathrm{E}_{\mathrm{a}}=\text { energia de ativação difusional }
\end{aligned}
$$

Substituindo a equação (4) em (3) tem-se à forma final

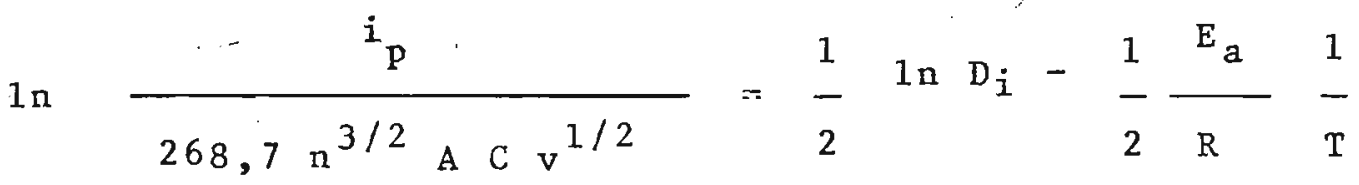

A partir do gräfico de $\ln \left(i_{p} / n^{3 / 2} A C v^{1 / 2}\right)$ ou do tipo representado na figura 7.8 B, pode-se obter a ener gia de ativação difusional para os processos reversíveis.

0 baixo valor de energia de ativação $\left(\mathrm{E}_{\mathrm{a}} \sim 3,1\right.$ kcal/mol.K), mostra mais uma vez que a etapa de oxidação é controlada por difusão. 


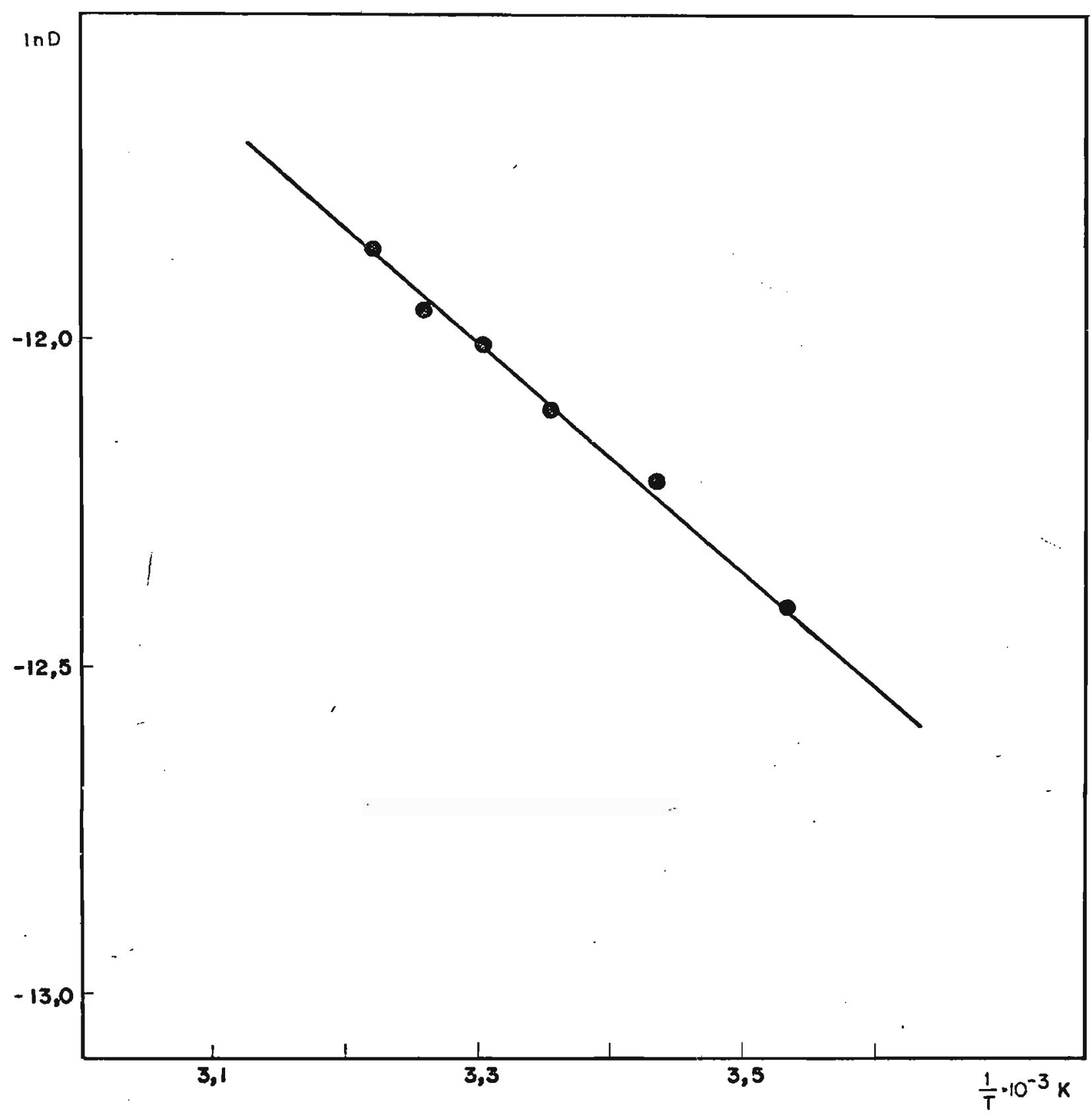

FIG.7.8.B. Gráfico de $\ln D$ em função do inverso de temperatura para determinação do coeficiente de ativação $(3,1 \mathrm{kcal} / \mathrm{mol} . \mathrm{K})$ $\mathrm{Fe}(\mathrm{CN})_{5} \mathrm{p}-\mathrm{py}(\mathrm{CO}) \mathrm{CH}_{3}^{3-}$ em $\mathrm{KCl} \quad 0,50 \mathrm{M}$ 
7.2. Determinação de Parāmetros Termodinâmicos

As constantes de equilíbrio $K$, da reação abaixo para os complexos de pentacianoferrato(II) podem ser obtidas das medidas cinéticas para as reações de formação e dissociação ( vide CAP. VI).

$$
\mathrm{Fe}(\mathrm{CN})_{5} \mathrm{H}_{2} \mathrm{O}^{3-}(\mathrm{aq})+\mathrm{L}(\mathrm{aq}) \frac{\mathrm{k}_{\mathrm{L}}}{\mathrm{k}_{-\mathrm{L}}} \mathrm{Fe}(\mathrm{CN})_{5} \mathrm{~L}^{3-}(\mathrm{aq})+\mathrm{E}_{2} \mathrm{O}
$$

onde

$$
\mathrm{R}=\frac{\mathrm{k}_{\mathrm{L}}}{\mathrm{k}-\mathrm{L}}
$$

Os parāmetros termodināmicos, $\Delta H$ e $\Delta S$ podem ser calculados das diferenças dis parâmetros de ativação das respectivas reações.

$$
\Delta \mathrm{H}=\Delta \mathrm{H}_{\mathrm{L}}^{\ddagger}-\Delta \mathrm{H}_{-\mathrm{L}}^{\ddagger}
$$

e

$$
\Delta s=\Delta s_{L}^{\ddagger}-\Delta s_{-L}^{\ddagger}
$$

Os valores relacionados na tabela 7.6. foram $\underline{0}$ btidos através dessas relações para os complexos estudados. As variações de entalpia observadas são pequenas, assim co mo as da constante de estabilidade. As variaçōes de entropia negativa sugerem que a entrada do ligante $\bar{e}$ acompanhada por um aumento de solvatação. 


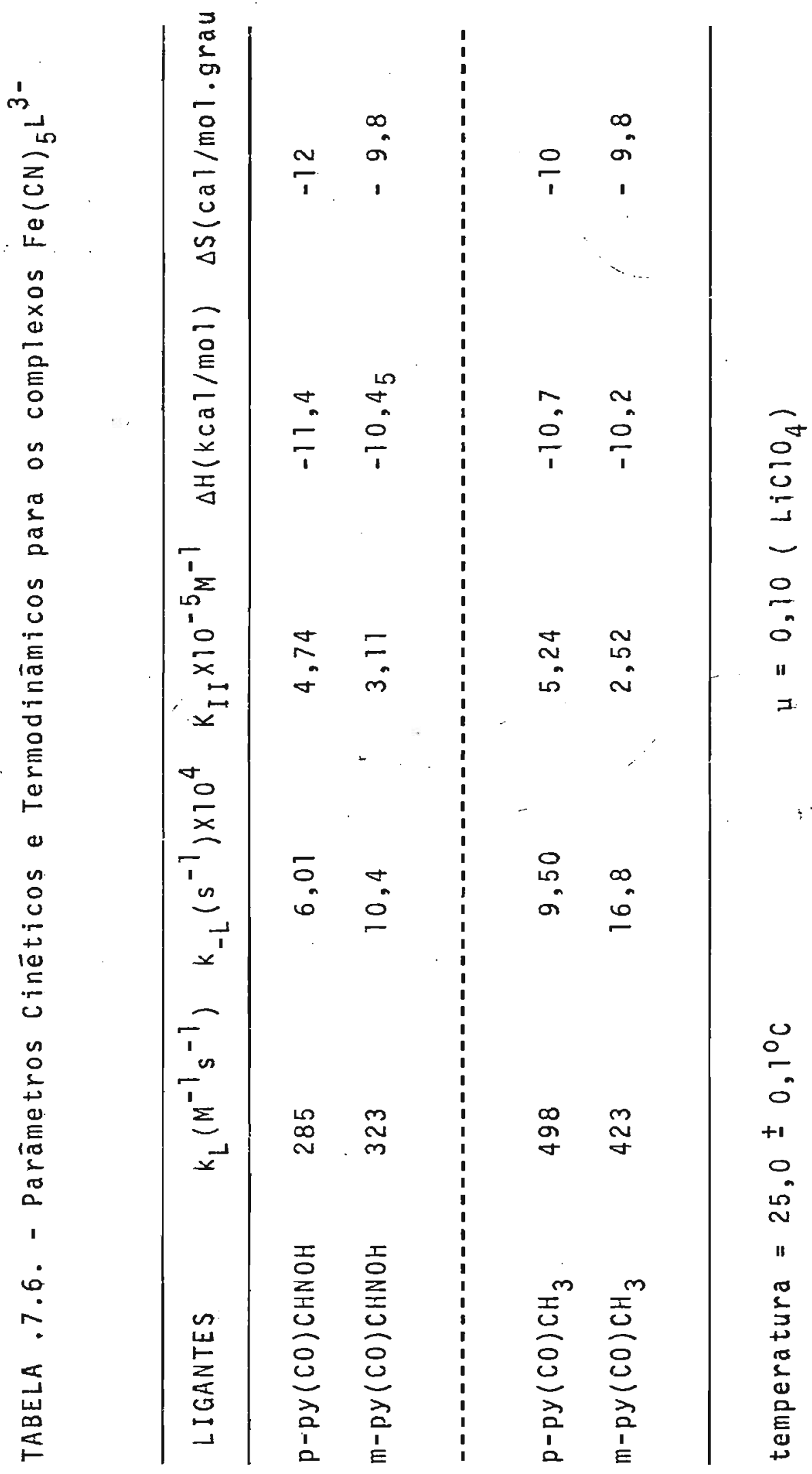


Muitos complexos de pentacianoferrato(II) são oxidados reversivelmente na solução aquosa, formando os com plexos correspondentes no estado de oxidação (III) (3).

os potenciais de meia onda $E_{T / 2}$ nos sistemas reversíveis, relacionam-se com os $E^{O^{\prime}}$, através da equação

$$
E_{1 / 2}=E^{0}-\frac{0,0592}{n} \log \left(\frac{D_{o x}}{D_{\text {red }}}\right)^{1 / 2}
$$

onde $D_{\text {red }} e D_{o x}$, referem-se aos coeficientes de difusão das espécies reduzidas e oxidadas, respectivamente.

De acordo com a equação, os potenciajs de meia onda podem ser igualados aos potenciais formais quando os coeficientes de difusão da forma oxidada e reduzida são iguais.

Esta aproximação pode ser esteńdida aos comple xos em estudo onde Schleintz e Von Loewis (291) tem mostra do que para os cianoferratos os coeficientes de difusão da forma reduzida é comparāvel ao da forma oxidada, sendo este 1 igeiramente maior.

os valores de $E^{0^{\prime}}$ obtidos da voltametria cícli ca estão na tabela 7.7 .

Os potenciais formais acompanham a diminuição da energia de transferéncia de carga, como pode ser observa da na figura 7.9. A voltametria cíclica dos compostos $\mathrm{Fe}(\mathrm{CN})_{5} \mathrm{~L}^{3-}$ onde $\mathrm{L}=\mathrm{p}-\mathrm{py}(\mathrm{CO}) \mathrm{H}, \mathrm{p}-\mathrm{py}(\mathrm{CO}) \mathrm{NH}_{2}$ e $\mathrm{p}-\mathrm{py}(\mathrm{CO}) \mathrm{OCH}_{3}$, está descrita no apēndice. 


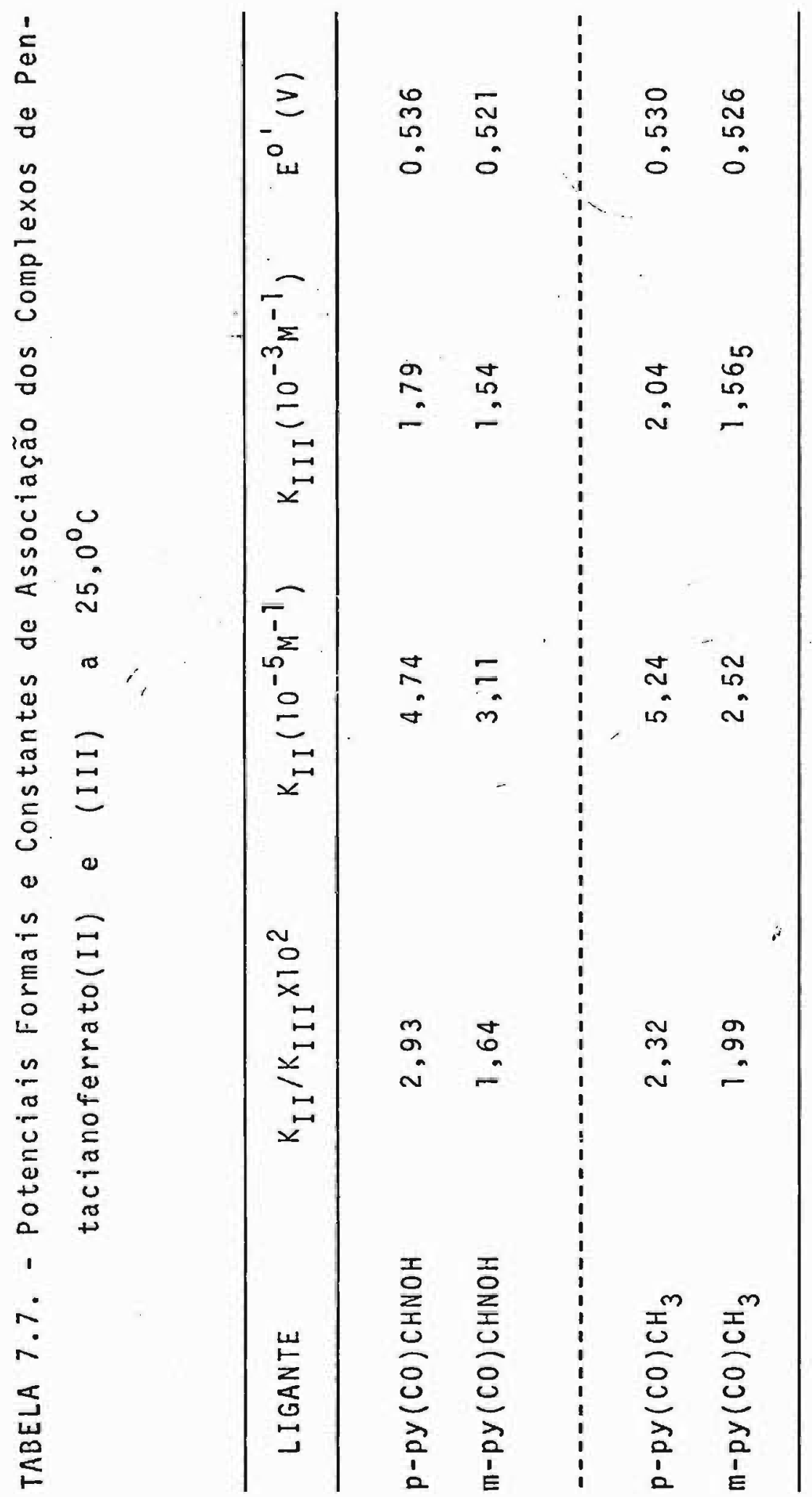




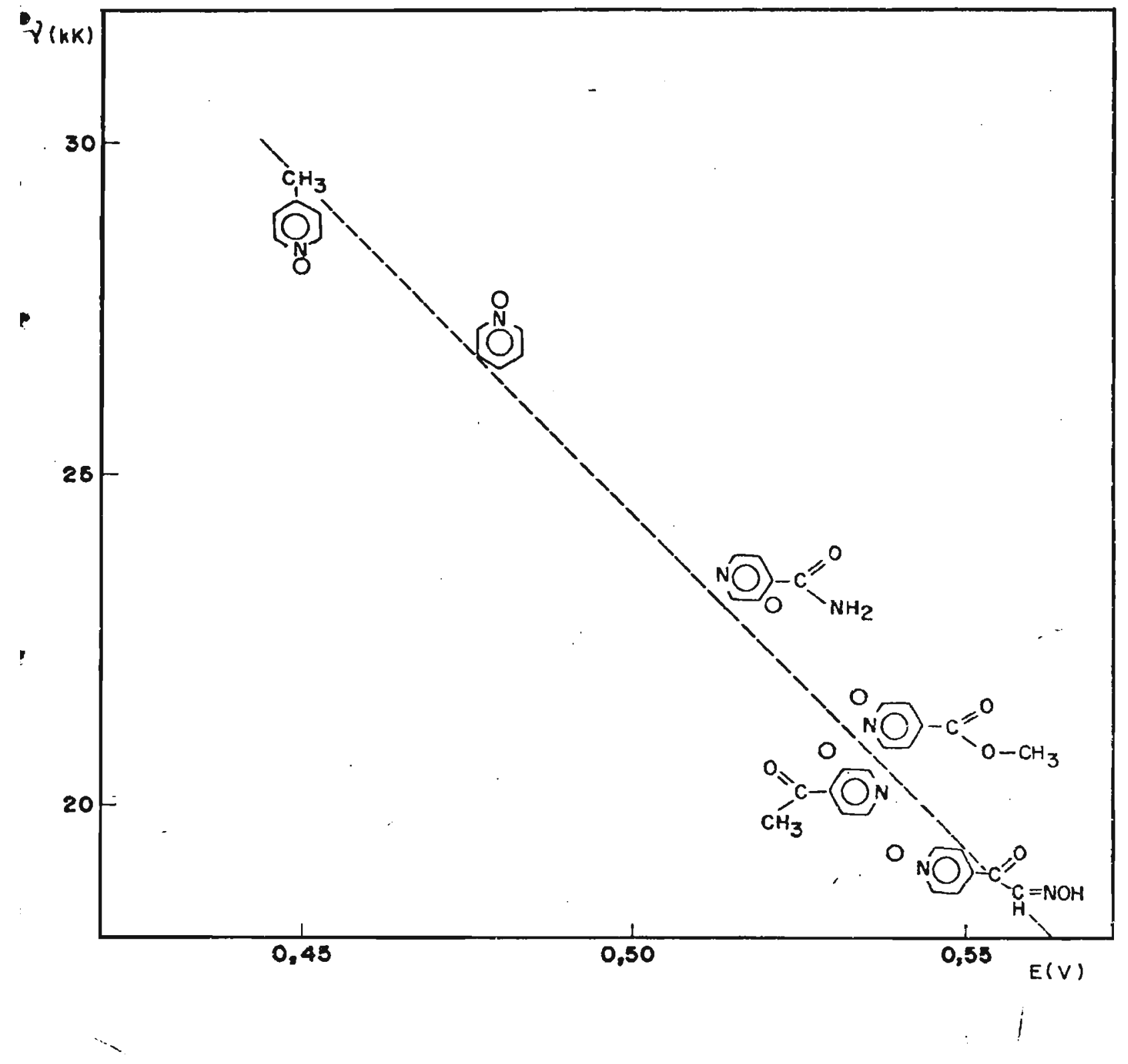

FIG.7.9. Correlação entre os potenciais formais Fe(CN) ${ }_{5} \mathrm{~L}^{2-13-}$ ( $L$ = Iigantes $N$-heterocíclicos) com a frequên cia de transferência de carga $\mathrm{Fe} \rightarrow \mathrm{L}\left(\mathrm{b}_{2}(\mathrm{yz}) \rightarrow\right.$ $\mathrm{b}_{\left.2\left(\pi_{\mathrm{L}}^{*}\right) \quad\right)}$ 
Neste gráfico observa-se uma boa correlação en tre $\mathrm{E}^{\mathrm{O}^{\prime}} \mathrm{Fe}(\mathrm{CN})_{5} \mathrm{~L}^{2-} / \mathrm{Fe}(\mathrm{CN})_{5} \mathrm{~L}^{3-}$ com a energia de transferéncia de carga $\left(\nu_{C T}\right)$.

A expressão para o potencial padrão em função da natureza do orbital onde se vai localizar a mudança no nūmero de elétrons (292) é dada por:

$\Delta G^{0}=-F E^{0}=-E_{J}+C(J, J)-\zeta(J)-\Delta \Delta H_{C}-\Delta \Delta H_{S}-T \Delta S^{\circ}+c t e$

$E_{J} \bar{e}$ a energia do orbial redox $J$

$C(J, J) \bar{e}$ a integral de Coulomb

$\zeta(J)$ é a energia de acoplamento spin-órbita

$\Delta \Delta \mathrm{H}_{c}$ é a diferença das energias das formas oxi dada e reduzida

$\Delta \Delta \mathrm{H}_{\mathrm{S}}$ é a diferença das energias de solvatação que acompanham a transição ox-red.

Comparando-se esta expressão com a equação

mencionada no capíturo $\mathrm{V}$,

$$
h \nu=P I_{b}-E_{a}+C(a, b) \pm K(a, b)-\Delta H_{c}^{\prime}
$$

sabe-se que a correlação entre a energia de transição com $E^{O^{\prime}}$ só é possivel (292) para os sistemas que obedeçam os se guintes requisitos:

(i) as distāncias interatōmicas nas formas oxi dada e reduzida não devem ser muito diferentes, de modo que 
$\Delta \Delta H_{c}$ e $\Delta H_{c}^{\prime}$ sejam tão parecicas quanto possível;

(ii) os termos $c(a, b)$ e $K(a, b)$ são despreziveis ou pode-se esperar que sejam razoavelmente constante dentro da sērie estudada;

(iii) a parte doadora (ou receptora) da molécu la não deve mudar muito apreciavelmente através da série de compostos comparados, de modo que o valor de $\mathrm{PI}_{\mathrm{b}}$ ( ou $\mathrm{AE}_{\mathbf{a}}$ seja praticamente constante na sërie estudada;

(iv) o valor de $\Delta \Delta H_{s}$ é constante na série comparada;

(v) o valor de $\Delta \mathrm{S}^{\circ}$ é constante na sērie comparada.

A expressão empīira para a entropia da partícuita- complexa $\bar{E}$

$$
\mathrm{S}^{\mathrm{O}}=\frac{3}{2} \mathrm{R} \ln \mathrm{M}+37-\frac{99}{\mathrm{r}_{\mathrm{O}}} \mathrm{E}
$$

onde $M$ representa o peso molecular, $r_{0}$ a distāncia de equilībrio metal-ligante, f é um fator que depende do arran jo estereoquimico do complexo e $z$ representa a carga. do complexo. Sendo a composição e a estrutura da forma ox igual à da forma Red, a variação de entropia $\Delta \mathrm{s}^{\circ}$ ( com $n=1$, tem a forma

$$
S^{0}=99 f \frac{\left(r_{0}\right)_{R e d}-\left(r_{0}\right)_{0 x}}{\left(r_{0}\right)_{\text {Red }} \cdot\left(r_{0}\right)_{0 x}} \cdot z_{r}+\frac{1}{\left(r_{0}\right)_{0 x}}
$$


Portanto o valor de $\Delta S^{\circ}$ será constante para uma série de complexos ( item (v)) com o mesmo valor de $z,\left(r_{0}\right)$ Red e $\left(r_{0}\right)_{0 x}$ e com o mesmo arranjo estereoquímico. Em geral, con dições (iv) e (v) necessitam de uma diferença constante na carga total entre as espécies oxidada e reduzida e uma distribuição de cargas semelhantes em ambas as espécies, a travēs da série estudada.

Para uma correlação realmente significativa, 0 orbital redox deve ser especificado e participar de modo es peciai na transição espectral, is to é, deve ser um orbital a ou b das formas oxidada ou reduzida.

Se as condições (i) a (v) forem obedecidas poder-se-ia esperár uma correspondencia biunivoca entre a variação de $E^{c}$ e a de hu. Isto é difícil de se encontrar, e geralmente se chega somente a uma relação linear entre ambos os valores. A correlação linear é geralmente observada para sēries limitadas de complexos, geralmente formada por 3 a 5 compostos $(293-295)$.

Através das informações da figura 7.9. e tabelas 7.6. e 7.7., pode-se dizer que os compiexos mencionados basicamente seguem as condições citadas. Os complexos com os ligantes $\mathrm{N}$-heterocīclicu carregados são excluĩdos da cor relação feita, pois de imediato não satisfazem o item (v).

As variações nos potenciais podem ser interpre tadas através do seguinte ciclo: 


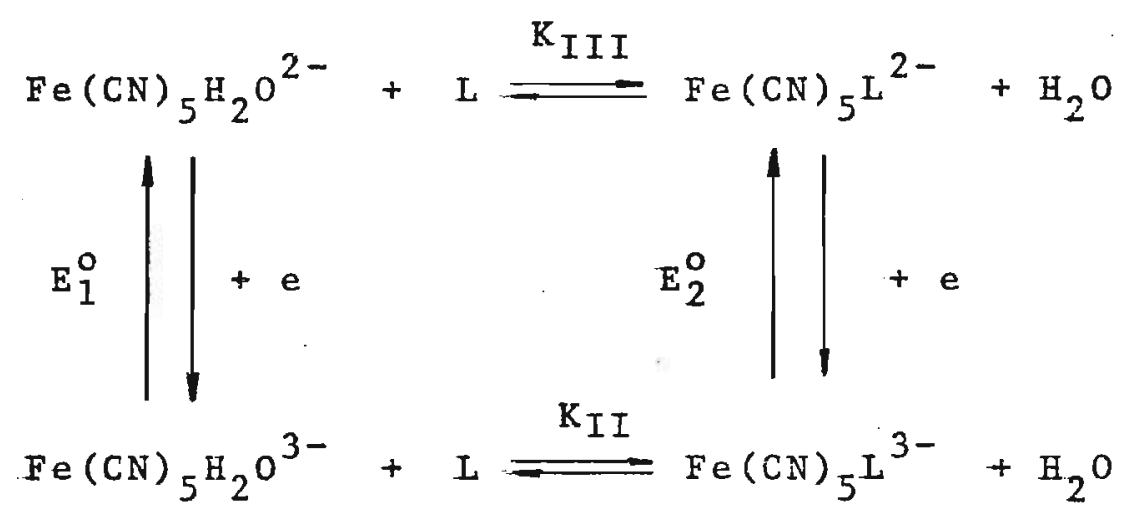

Com o aux $\hat{i} 1$ io da relação $\Delta \mathrm{G}=-\mathrm{RT} \ln \mathrm{K}=-\mathrm{nFE}$ o equacionamento desse ciclo fica descrito por:

$$
\mathrm{RT} \ln \mathrm{K}_{\mathrm{II}}+\mathrm{n} \mathrm{FE}_{1}^{\circ}=\mathrm{RT} \ln \mathrm{K}_{\mathrm{III}}+\mathrm{nFE}_{2}^{0^{\prime}}
$$

onde

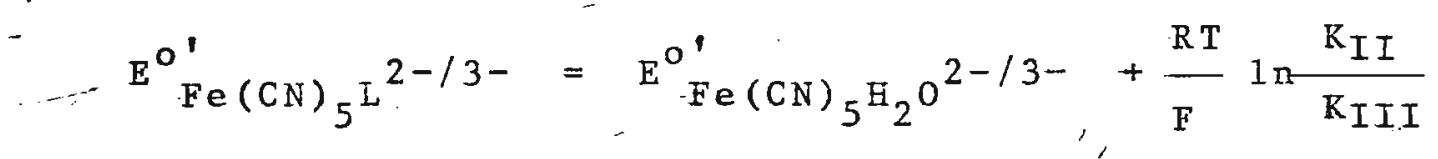

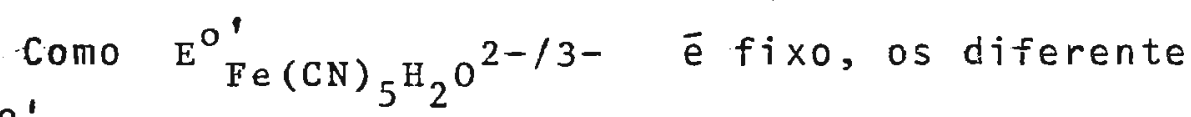
valores de $E^{0^{\prime}} \mathrm{Fe}(\mathrm{CN})_{5} \mathrm{~L}^{2-/ 3-}$ refletem na realidade as varia ŗões relativas nas constantes de estabilidade dos complexos na forma oxidada e reduzida.

Com base nos valores de $E^{O^{\prime}}$ e nos valores de $K_{I I}$ conhecidos (TAB.7.6.), pode-se então avaliar os valores correspondentes de KIII mostrados na tabela 7.7 .

A estabilidade dos complexos de pentacianoferrato(III) cresce rapidamente com a basicidade dos ligantes, em consequéncia da menor influéncia da retrodoação neste es tado de oxidação. 


\section{VIII - REAÇÕES FOTOINDUZIDAS}

8.1. Sistema $\mathrm{Fe}(\mathrm{CN}) 5$ py(CO)CHNOH${ }^{3}-$ Fotosubstituição de $\underline{C N}^{-}$

Figard e Petersen (214) verificaram que os com plexos de pentacianoferrato(II) com ligantes $\mathrm{N}$-heterociclicos apresentam a fotosubstituição do ligante L conforme a $\underline{e}$ quação

$$
\text { (NC) }{ }_{5} \mathrm{Fe}^{\mathrm{II} \mathrm{L}^{\mathrm{n}-}} \frac{\mathrm{h} \nu}{\mathrm{H}_{2} \mathrm{O}}(\mathrm{NC})_{5} \mathrm{Fe}^{\mathrm{II} \mathrm{OH}_{2}}{ }^{3-}+\mathrm{L}^{3-\mathrm{n}}
$$

0 rendimento quāntico do processo depende da posição do máximo de comprimento de onda da banda de transferēncia de carga. Observaram ainda que quando a tranșição de campo ligante (LF) ocorre em energia menor do que a tran sição de transferēncia de carga (CT), o rendimento quāntico para (NC) ${ }_{5} \mathrm{Fe}^{I I L^{n-}}$ é maior do que no complexo corresponden te de $\left(\mathrm{NH}_{3}\right)_{5} \mathrm{Ru}^{\mathrm{II}} \mathrm{L}^{\mathrm{n}+}$.

Segundo os autores, uma das explicações para justificar este rendimento maior, è o fato da fotoquimica do pentacianoferrato(II) ocorrer por um único processo; ape nas com a perda do ligante $L$, ao contrārio dos complexos anālogos de Ru(II) que apresentam também a fotosubstituição do $\mathrm{NH}_{3}$. A não observação da fotosubstituição do ligante cianeto $\left(\mathrm{CN}^{-}\right)$foi atribuỉda (214) à diferença relativamente grande entre os ligantes $\mathrm{L}$ e $\mathrm{CN}^{-}$( loco citato). 
No nosso trabalho preliminar (298), verifica mos a fotosubstituição do $\mathrm{CN}^{-}$também nos pentacianoferratos e, o fato pode ser observado através do uso de ligantes adequados que estabilizam os tetracianoferratos. Isto só é possivel utilizando-se os ligantes quelantes.

$$
\text { Os complexos (NC) } 5 \text { Fe.py(CO) } \mathrm{CHNOH}^{3-} \text { apresentam }
$$
comportamento fotoquímico típico, com deslocamento batocrômico das bandas de transferēncia de carga, no decorrer da ir radiação com luz visível e ultravioleta. O produto formado, e bastante inerte, diferenciando neste sentido com relação aos complexos de pentacianoferrato(II). O fato deste deslocamento espectral ocorrer mesmo para os complexos com os $1 \underline{\mathbf{i}}$ gantes substituĩdos em posição para e meta e, sempre com o $\lambda_{\max }$ em torno de $600 \mathrm{~nm}$, foi interpretado como indicativo da coordenaçăo bidentada através do oxigēnio da carbonila e o nitrogênio da oxima, formando um novo grupo cromóforo.

Para isso, teria que ocorrer inicialmente a fo tosubstituição do ligante $L$ coordenado pela piridina. Este, quando coordenado pela oxima, apresenta a possibilidade de formar o anel quelato com o uso do grupo $C=0$, logo após a saîda do cianeto, formando o tetracianoferrato(II) com - ligante py(CO)CHNOH coordenado por dois pontos. A forma ção deste composto pode envolver um outro mecanismo, como por exempio, a formação de tetracianoferrato(II) com tempo de vida suficiente para ocorrer a coordenação pelo py $(\mathrm{CO}) \mathrm{CH}$. NOH. 
maneira simples por

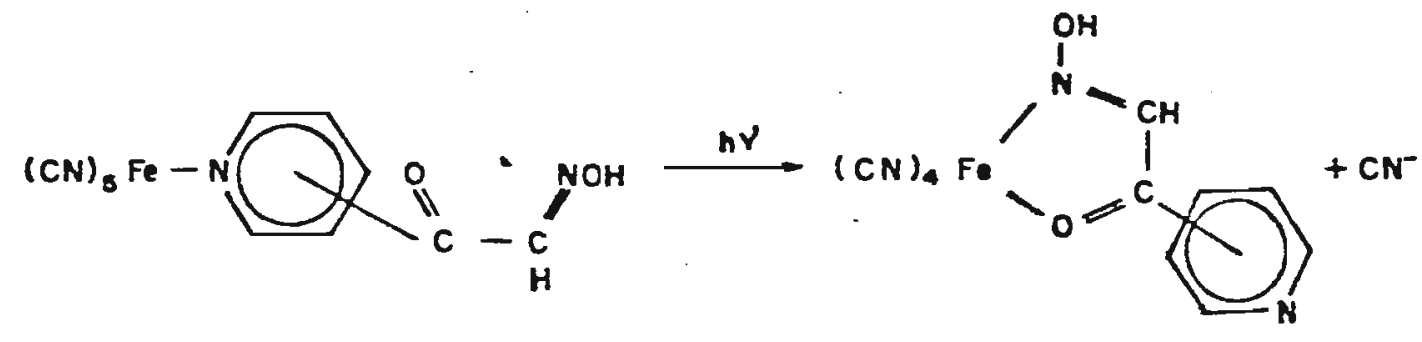

A figura 8.1. apresenta as variações observa das na solução de $\mathrm{Fe}(\mathrm{CN})_{5} \mathrm{p}-\mathrm{py}(\mathrm{CO}) \mathrm{CHNOH}^{3-}$ com o tempo de irradiação.

o comportamento do $\mathrm{Fe}(\mathrm{CN})_{5} \mathrm{~m}-\mathrm{Py}(\mathrm{CO}) \mathrm{CHNOH}^{3-} \mathrm{ir}-$ radiado a $366 \mathrm{~nm}$ (filtro 12.225) e a $405 / 408 \mathrm{~nm}$ e $436 \mathrm{~nm}$ (filtro 12.223) é aprésentado nas figuras 8.2. e 8.3.

A variação observada nos espectros destes complexos com o tempo de fotólise apresenta um ponto isosbēsti co, indicativo de que não há complicaçōes térmicas ou reações fotoquímicas secundārias.

Para se determinar a absortividade molar do produto fotoquímico adiciona-se o ligante p-py(CO) $\mathrm{CH}_{3}$ em ex cesso no final do perīodo de fotōlise e guarda-se a amostra no escuro o tempo suficiente para completar a reação representada a seguir

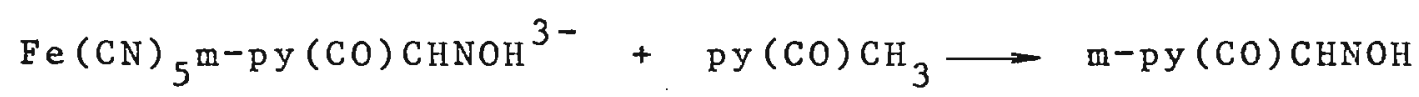

$$
\begin{aligned}
& +\mathrm{Fe}(\mathrm{CN}){ }_{5} \mathrm{P}-\mathrm{py}(\mathrm{CO}) \mathrm{CH}_{3}^{3-}
\end{aligned}
$$


302

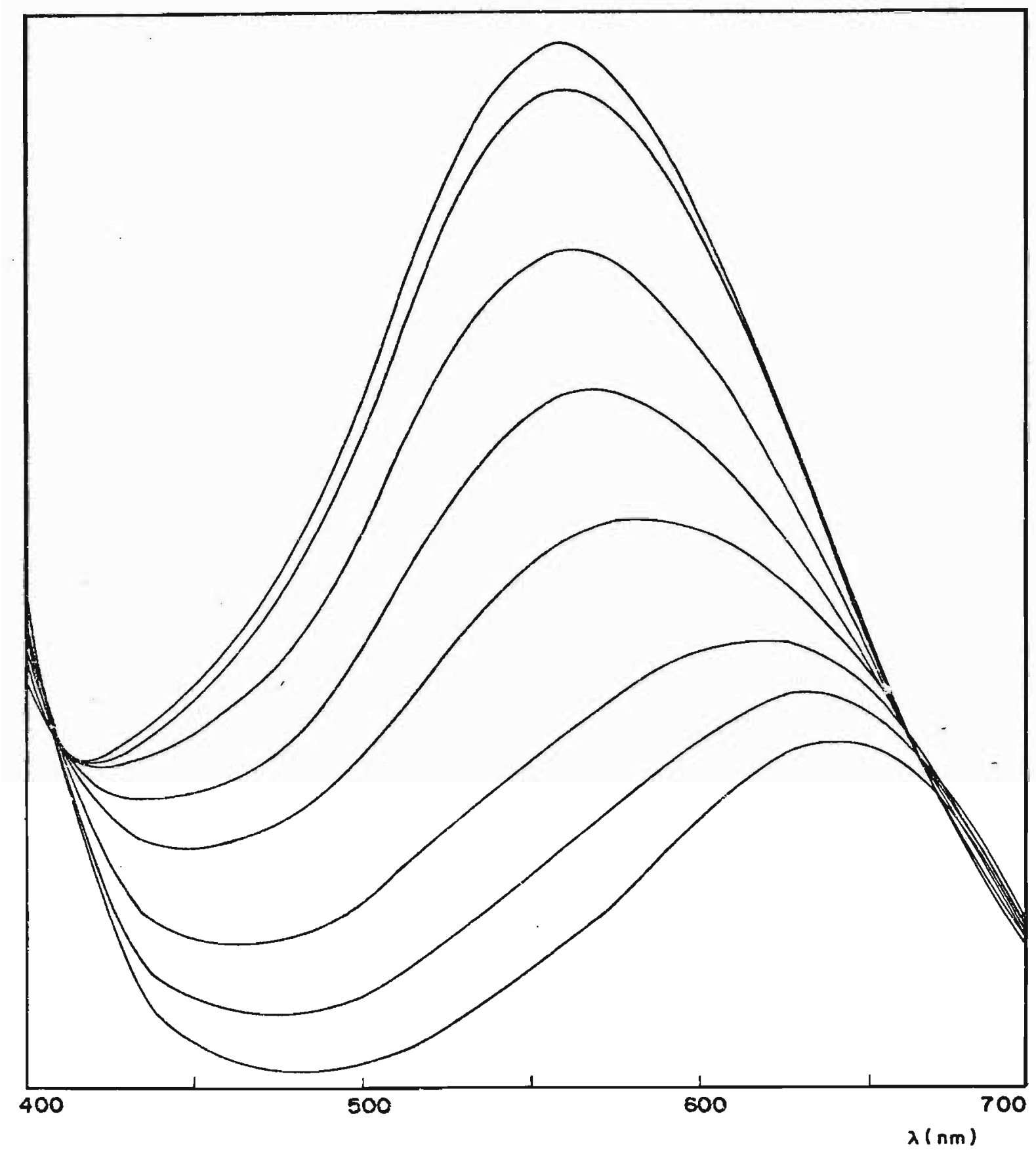

FIG.8.1. Espectro Eletrônico do $\mathrm{Fe}(\mathrm{CN}){ }_{5} \mathrm{P}^{-\mathrm{py}}(\mathrm{CO}) \mathrm{CHNOH}^{3-} \mathrm{com}^{-}$ o tempo de irradiação 


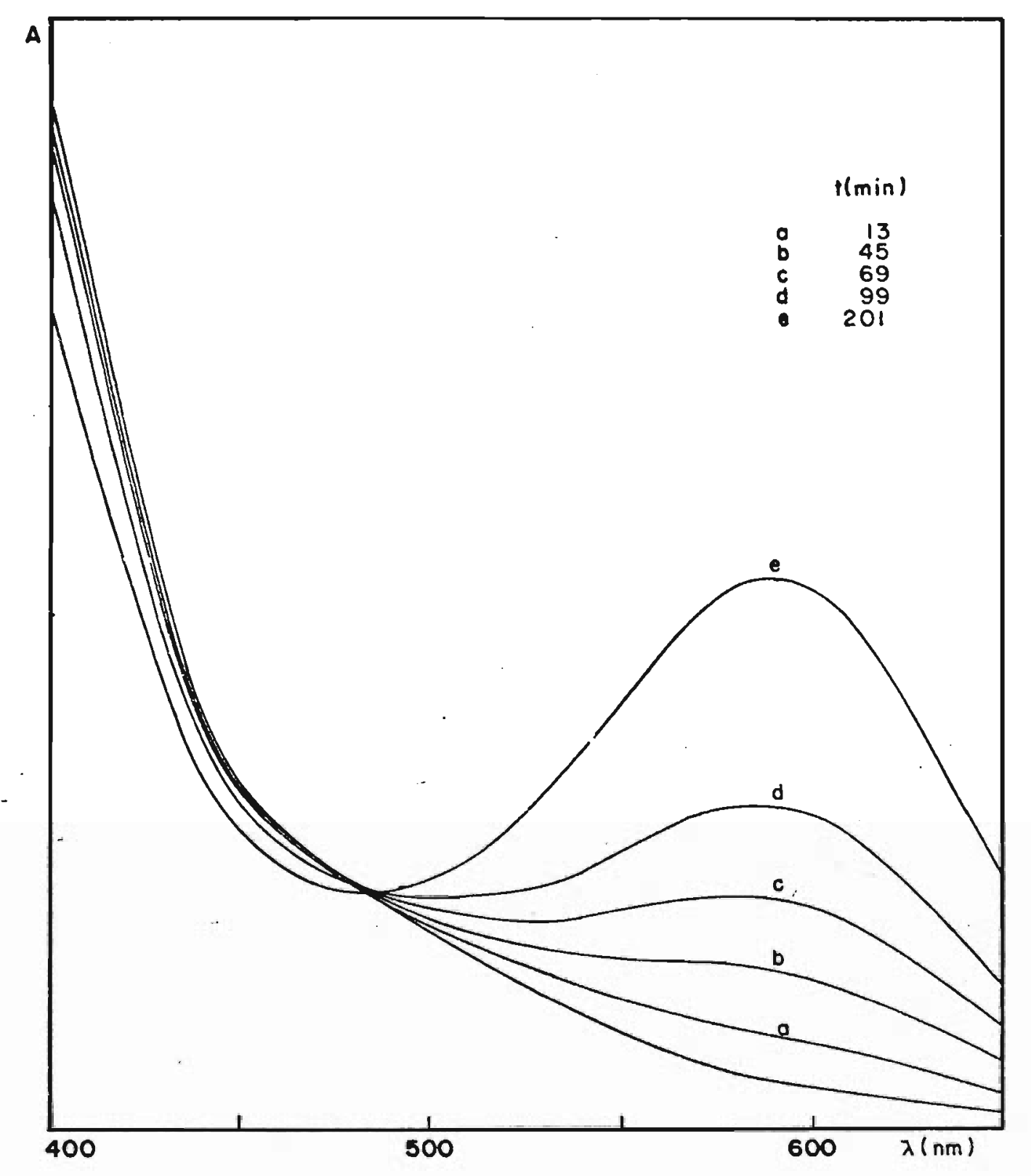

FIG.8.2. Espectro Eletrônico do Fe(CN) $5^{m-p y(C O) \mathrm{CHNOH}^{3-}}$ com o tempo de irradiação ( $\lambda_{\text {irr }}=366 \mathrm{~nm}$ ) utilizando o filtro 12225. 


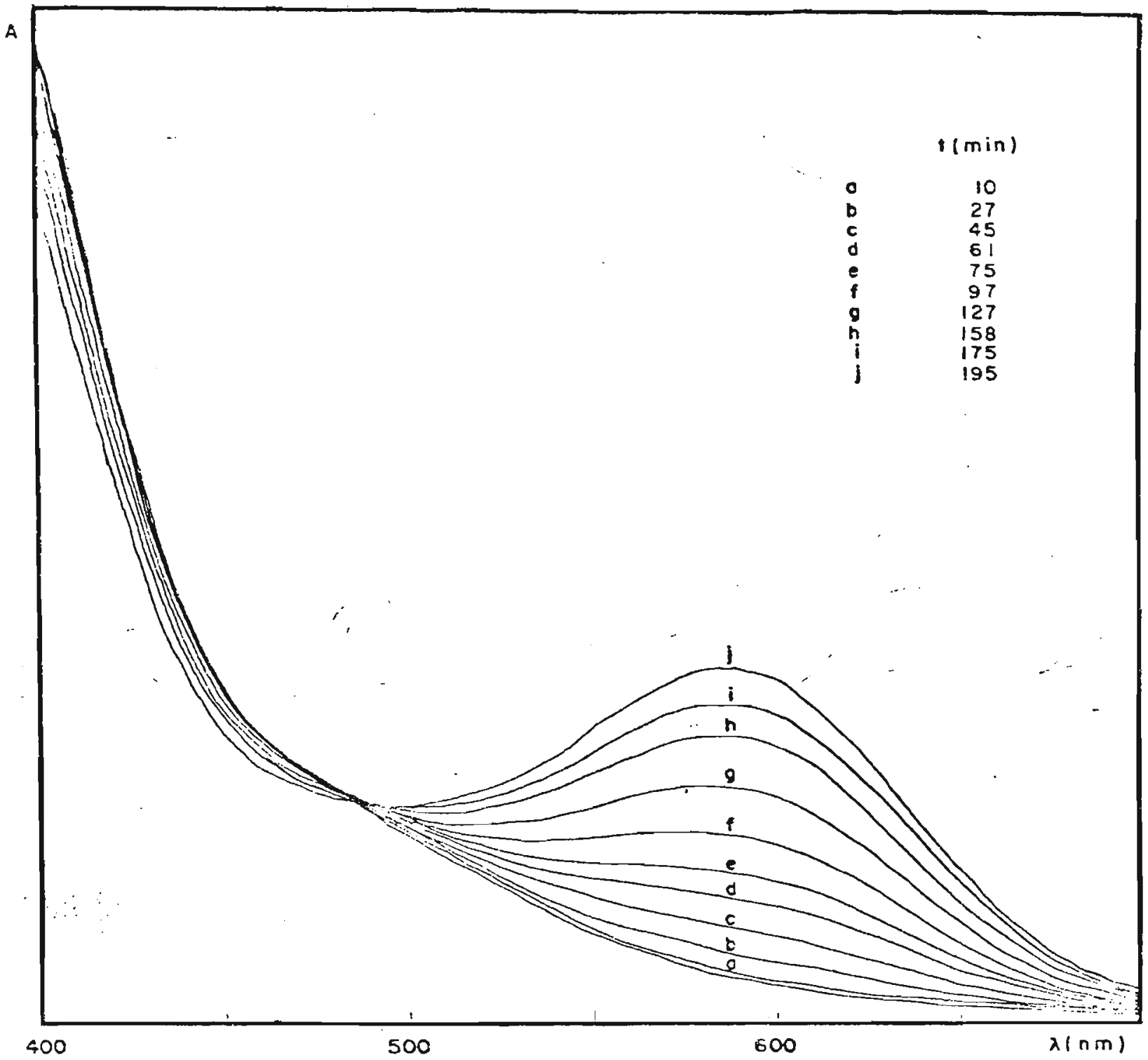

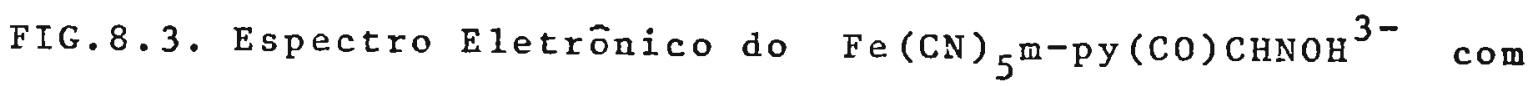
- tempo de irradiação, utilizando ofiltro 12223 da Coleman. 
o tetracianoferrato(II) (azu1) e termicamente inerte, e não sofre substituição com a acetilpiridina no tempo de traba 1 ho.

Apōs esse perīodo, a concentração da espēcie fotolisada é determinada pela diferença de concentração in cial e no tempo $t$ do pentacianoferrato(II) remanescente, 0 btida espectroscopicamente. A partir deste dado, determinase o rendimento quāntico a cada perîodo de irradiação e, os seus valores estão relacionados na tabela 8.1 .

Pelas etapas possíveis envolvidas na formação do produto fotoquímico, bem como pela variação do rendimento quāntico com o tempo de irradiação, pode-se afirmar que - produto não deve ser formado no processo primário da etapa- detarminante.

o próduto estável da reação fotoquĩmica deve ser formado de uma ou mais reações térmicas envolvendo os produtos primārios, dificultando a elaboração do mecanismo para a reação fotoinduzida.

E interessante notar que o rendimento quāntico aumenta com o tempo de irradiação ao contrário do que seria de se esperar para o processo simples, onde a concentração inicial da espécie que absorve a luz diminui com o tempo. E possîvel que esse perîodo inicial corresponda ao período de indução, determinada pela saĩda do ligante $L$ coordenado pela piridina.

De qualquer forma, a relação entre o rendimen- 


\section{6}

TABELA - 8.1 .

Variação do Rendimento Quântico com o Tempo de Exposição

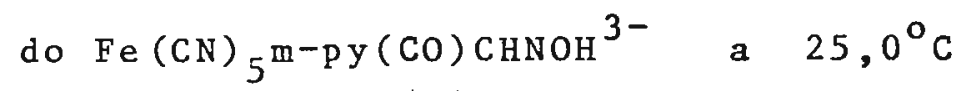

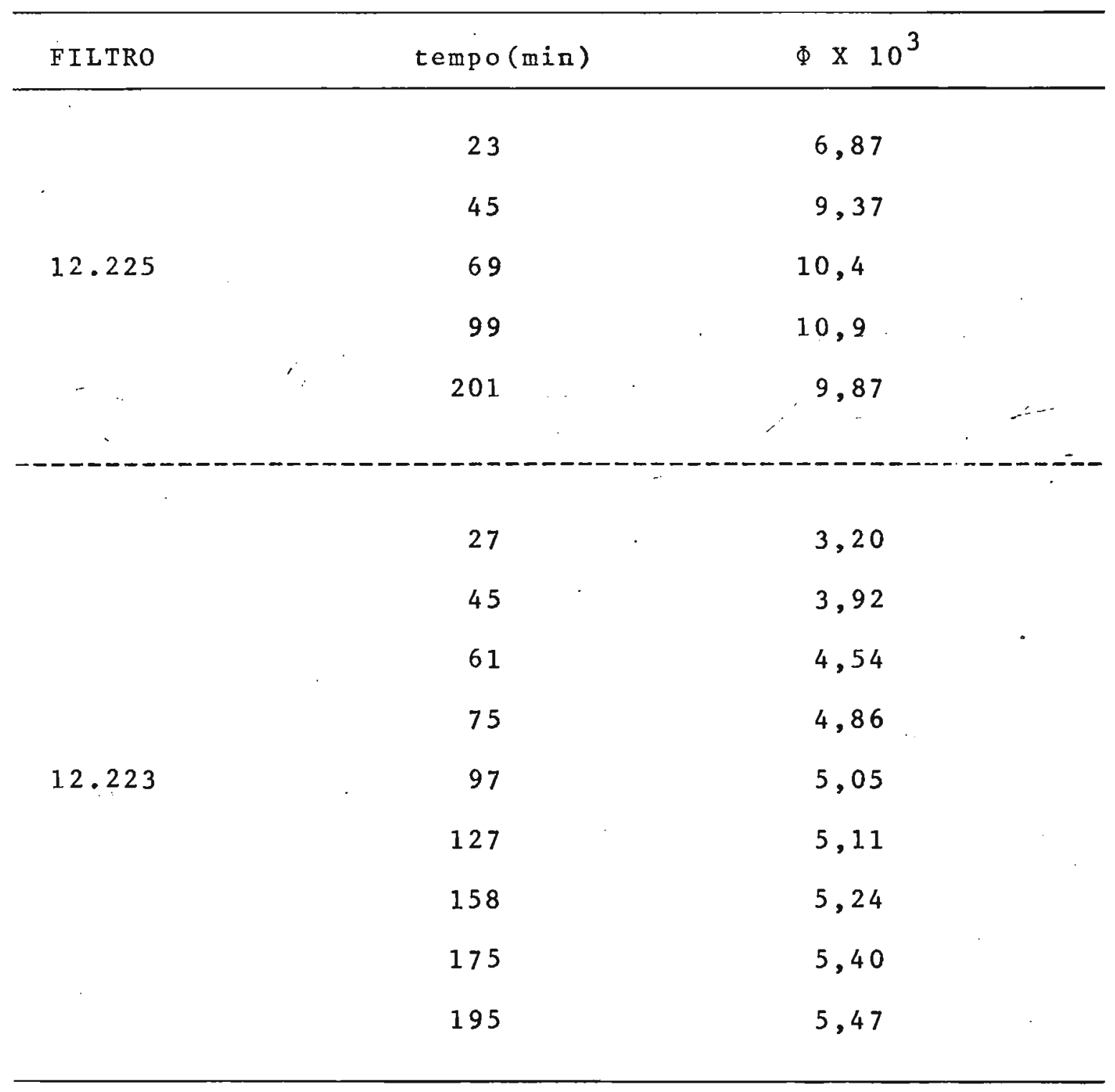


to quāntico e a reatividade torna-se mais complexa se o estado reativo não ē um daqueles diretamente alcançado pela a bsorção. Considere-se uma reação $A$ que se origina de um estado reativo $i$, o qual é alcançado através de uma sucessão de estados excītados secundārios $j$ com o tempo de vida $\tau_{j}$ e com velociades especificas de etapas de conversão $k_{j}$. Neste caso obtēm-se a seguinte expressão

$$
\Phi_{a}=k_{i, a} \tau_{i} \pi_{i} k_{j} \tau_{j}
$$

onde $\Phi_{a} \bar{e}$ o rendimento quāntico da reação A $k_{i, a}$ é a reatividade do estado i com respeito a reação A

$\tau_{i} \bar{e}$ o tempo de vida do estado i

$\pi_{i}{ }{ }_{j}{ }^{\tau}{ }_{j}$. representa fração de moléculas excitãadas que alcança o estado reativo

Se a reação ocorrer inteiramente do estado alcançado pela absorção, ou se a conversão desse estado ao $\underline{\text { s }}$ tado reativo ocorrer com a eficiência unitāria, o termo $\pi_{i}$ $k_{j} \tau_{j}$ iglaía-se $\bar{a}$ unidade e a equação fica reduzida a $\Phi_{a}=$ $k_{a} \tau$. Portanto a determinação da reatividade envolve uma de terminação do tempo de vida de pelo menos um estado excitado.

Para se elaborar o mecanismo da reação fotoinduzida do sistema $\mathrm{Fe}(\mathrm{CN})_{5} \mathrm{Py}(\mathrm{CO}) \mathrm{CHNOH}^{3-}$, deve-se investigar as reações fotoquĩmicas onde o fechamento de anel envolva menos etapas. 


\subsection{Sistema $\underline{F e(C N)} 5 e^{3-}$ - Fotosubstituição de CN $^{-}$}

Um ligante como a etilenodiamina (en) coordena - se ao pentacianoferrato(II) através de um grupo amina e apresenta o segundo grupo livre que permite o fechamento do anel subsequentemente à saida do cianeto, estabilizando o complexo tetracianoferrato(II). Este efeito de vizinhança deve melhorar a eficiência da deteção de fotosubstituição do cianeto ao mesmo tempo que elimina a inconveniência da $\underline{e}$ tapa de fotoisomerização ou fotosubstituição do ligante que acompanha o sistema pentacianoferrato-carbonil-oxima.

Além disso, a reação que se observa no processo apresenta um interesse particular, com possibilidade de aplicação na sintese de complexos tetracianoferrato(II) cọm ligantes a diiminas formando quelato, em analogia à reação quỉmica estudada (299) conforme o esquema apresentado a se guir
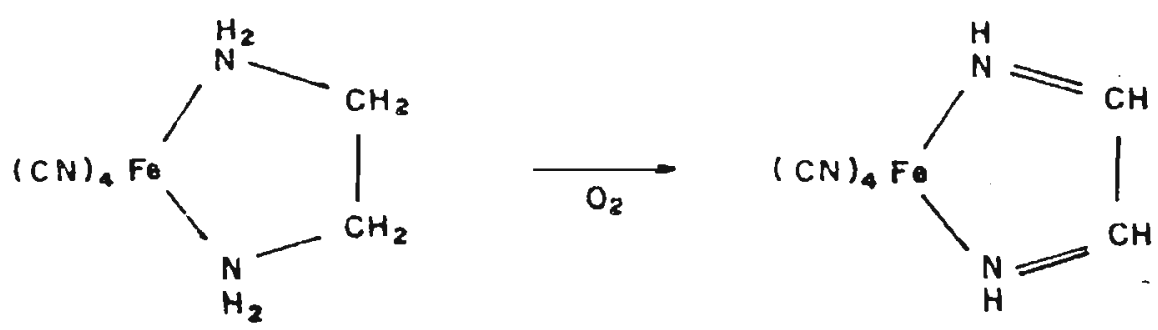

A experiencia foi conduzida no sistema descrito na seção 4.2.8. com irradiação quase monocromātica a $366 \mathrm{~nm}$.

Uma vez que o produto formado absorve na mesma 
região do reagente, a concentração da espécie formada só pode ser detetada no final de um determinado periodo de fotōlise, após o deslocamento do pentacianoferrato(II) remanescente com ligante pirazinaamida.

$$
\mathrm{Fe}(\mathrm{CN})_{5} \mathrm{en}^{3-}+\mathrm{pzamida} \longrightarrow \mathrm{Fe}(\mathrm{CN})_{5} \mathrm{pzamida}^{3-}+\text { en }
$$

Os rendimentos quānticos relacionados ra tabe1a 8.2. são, portanto, obtidos em experiēncias independentes e com amostras distintas.

$$
\text { TABELA - 8.2. }
$$

Rendimento Quântico do Processo Representado pela Reação (2) com o Tempo de Irradiação (Eq. p. 310)

\begin{tabular}{rc}
\hline $\begin{array}{r}\text { tempo de } \\
\text { irradiação (min) }\end{array}$ & $\Phi$ \\
$67: 05$ & 0,0859 \\
$118: 30$ & 0,0893 \\
$150: 00$ & 0,0899 \\
$195: 00$ & 0,0836 \\
\hline
\end{tabular}

0 rendimento quãntico permanece inalterado, den tro do erro experimental, com o tempo de fotolise. Isto in- 
dica que durante o período da medida estão se formando sempre os mesmos produtos nas mesmas proporções e estes, por sua vez não se fotolisam. A fim de comprovar que o produto da reação fotoinduzida e o $\mathrm{Fe}(\mathrm{CN})_{4} e^{2-}$, com etilenodiamina coordenada por dois pontos, de acordo com a reação:

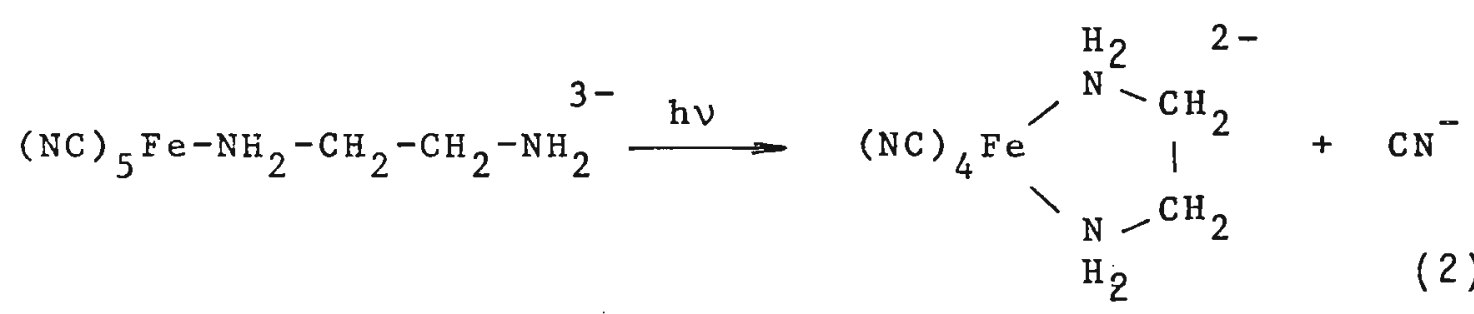

A espēcie formada fotoquimicamente foi isolada e sua identi dade confirmada de duas formas:

a. espectrofotometricamente

b. através da oxidação com formação do tetra cianoferrato(II) com diimina

Isolamento e Caracterização do Produto Fotoquímico

Apōs a fotōlise por trēs horas da solução de $\mathrm{Fe}(\mathrm{CN})_{5} \mathrm{en}^{3-}$ com excesso de etilenodiamina, interrompeu-se a irradiação e adicionou-se a solução de isoni cotinato de sōdio. Esta solução é mantida no escuro, pelo menos por 40 minutos, para que a reação térmica esquematiza da a seguir se complete

$\mathrm{Fe}(\mathrm{CN})_{5} \mathrm{en}^{3-}+$ isonicotinato $-\mathrm{Fe}(\mathrm{CN})_{5}{ }^{-} \operatorname{sonicotinat}^{4-}$ +en 
Este procedimento melhora a eficiēncia da sepa ração, onde se utiliza a técnica de troca iōnica, aumentando a diferença de carga entre o produto fotoquímico formado no processo, $\mathrm{Fe}(\mathrm{CN})_{4}$ en $^{2-}$, e o pentacianoferrato de partida. A resina utilizada foi Ag $1-X_{2}$ de 200 a 400 mesh na forma $\mathrm{Cl}^{-}$(Bio Rad Laboratories) com capacidade de $0,8 \mathrm{meq} / \mathrm{ml}$.

As condições para eluir cada uma das espécies anionicas quantitativamente foram previamente testadas com misturas simuladas destas espēcies na proporção de $1: 10$, $2: 10$ e $3: 10$ de complexos tetracianoferrato e penta cianoferrato, respectivamente.

o espectro do produto fotoquímico eluĩdo, apre sentado ra figura 8.4. é concordante com o obtido utilizando $\mathrm{Fe}(\mathrm{CN})_{4} \mathrm{en}^{2-}$ preparado quīmicamente (FIG.11.4) A carácie rização do produto foi ainda confirmada atravēs da oxidação deste para a etilenodiiminatetracianoferrato(II) correspondente (299).

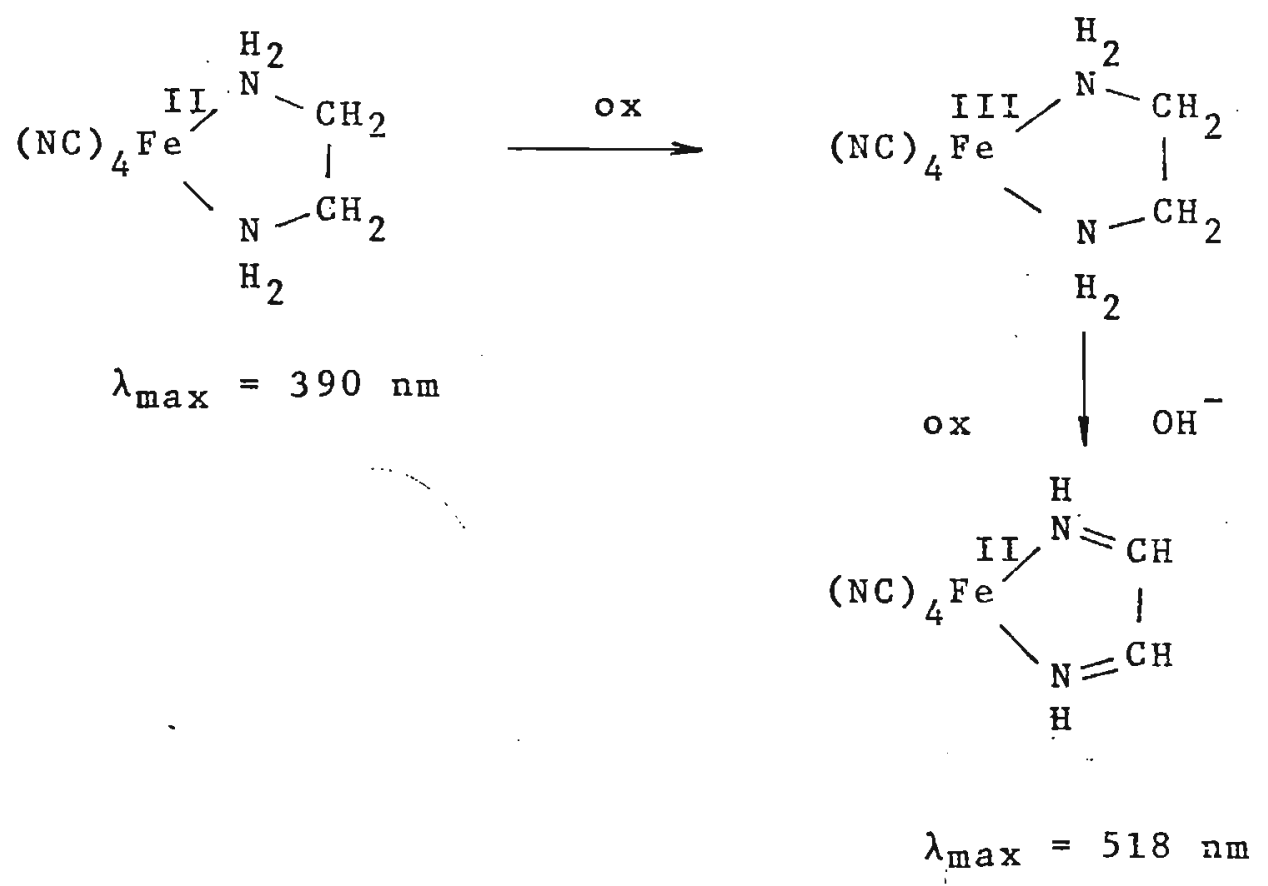




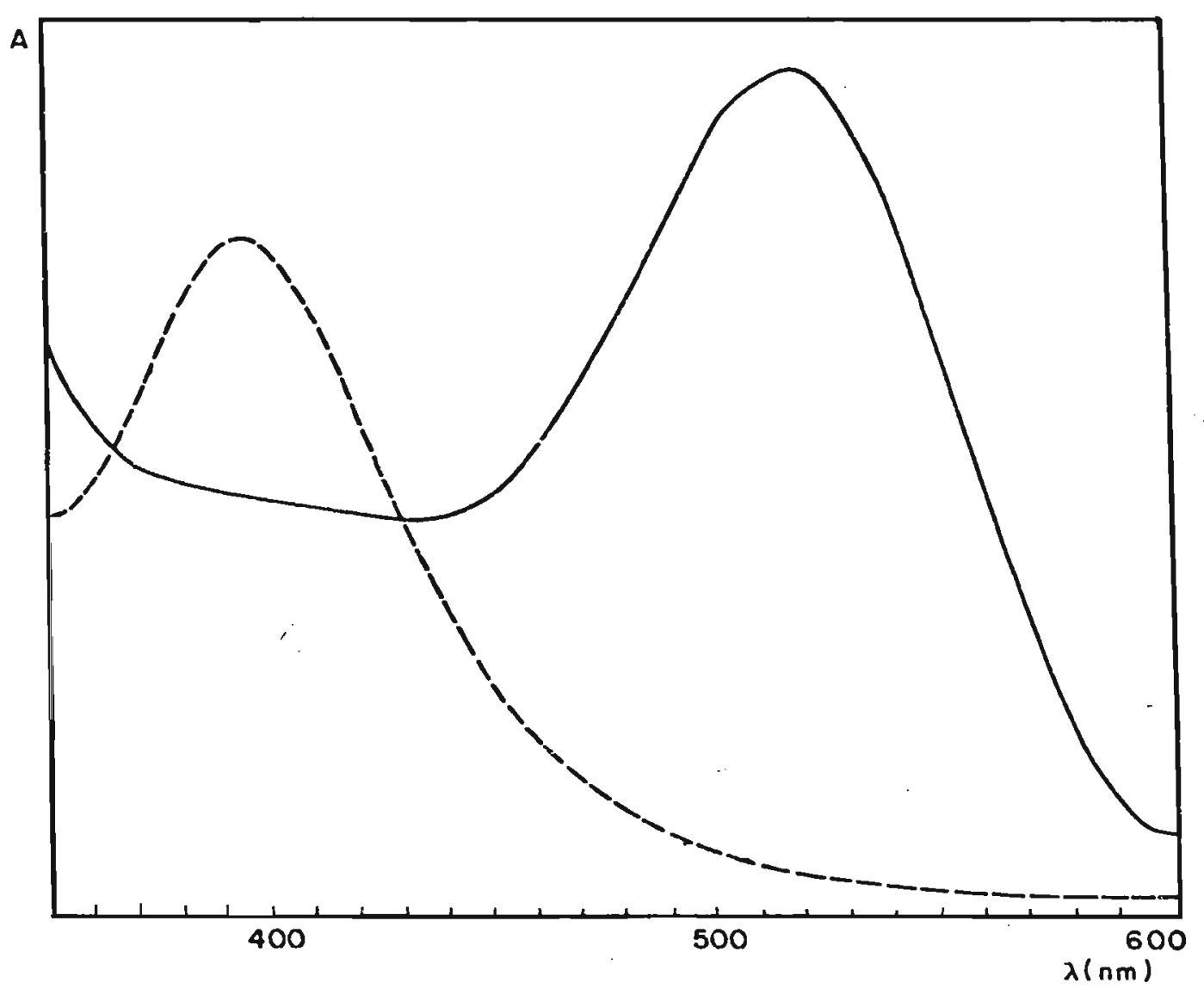

FIG.8.4. Espectro Eletrốnico de $\mathrm{Fe}(\mathrm{CN}) 4^{\mathrm{en}^{2-}}$ eluído da co luna de resina (--) e após a oxidação deste(-) 
Esta reação foi conduzida na presença de ferrị cianeto como oxidante na proporção estequiométrica num meio alcalino $\left(\left[\mathrm{OH}^{-}\right]-0,08 \mathrm{M}\right)$.

A figura 8.4. apresenta o espectro eletrōnico de $\mathrm{Fe}(\mathrm{CN})_{4} \mathrm{en}^{2-}$ e da sua forma oxidada.

A reaçăo representada pela equação (2) è o ūnị co processo fotoquímico efetivo que ocorre durante o perīodo de irradiação. Isto pode ser constatado fazendo-se a anā iise do pentacianoetilenodiaminaferrato(II) consumido e a quantidade do complexo tetraciano correspondente formada. 0 decaimento da banda em $490 \mathrm{~nm}$ de $\mathrm{Fe}(\mathrm{CN})_{5}(\mathrm{pzamida})^{3}$ indica que o consumo de $\mathrm{Fe}(\mathrm{CN})_{5} \mathrm{en}^{3-} \overline{\mathrm{e}}$ de $8,41 \times 10^{-6}$ moles. Este valor é exatamente igual ao nümero de moles de $\mathrm{Fe}(\mathrm{CN})_{4} \mathrm{en}^{2-}$ formado durante a irradiação.

0 mecanismo pelo qual poderia ocorrer o fechamento do anel está relacionado com a natureza associativa ou dissociativa do estado excitado. Com a população de orbi tais d antiligantes, a distorção de configuração no estado excitado reativo pode ser suficiente para possibilitar o ataque do grupo $\mathrm{NH}_{2}$, concomitante com a saída do cianeto.

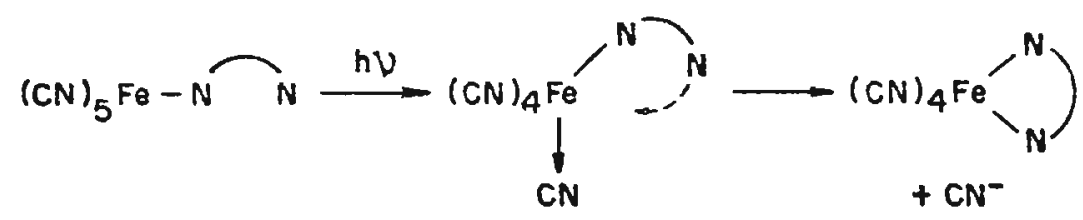

Caso isso não ocorra, a outra possibilidade se ria a da fotolabilização do cianeto, formando um intermediā 
rio pentacoordenado, que poderia sofrer ataque tanto do grupo $\mathrm{NH}_{2}$ como do solvente.

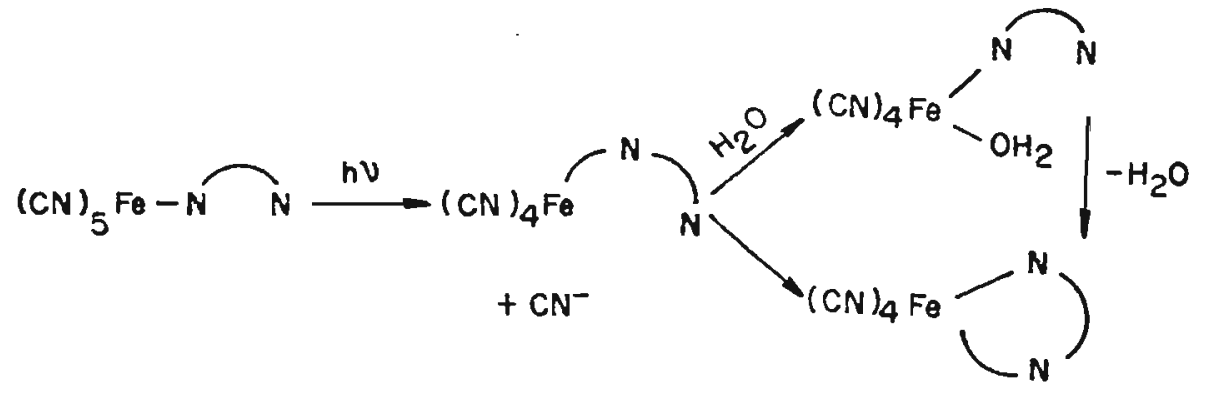

Em analogia com os pentacianoferratos, a āgua coordenada ao complexo (NC) ${ }_{4} \mathrm{Fe}\left(\mathrm{H}_{2} \mathrm{O}\right)(\mathrm{en})^{2-}$ seria läbil, e sofreria substituição com fechamento de anel. Existe ainda a possibilidade da entrada temporāria de outro etilenodiamina

$$
(\mathrm{CN})_{4} \mathrm{Fe}_{\mathrm{H}_{2} \mathrm{O}}^{\mathrm{NN}} \text { ten } \rightleftharpoons(\mathrm{CN})_{4} \mathrm{Fe}^{\mathrm{N}-\mathrm{N}}
$$

contudo esta etapa deveria ser deslocada para o produto mais inerte, $\mathrm{Fe}(\mathrm{CN})_{4} \mathrm{en}^{2-}$, que é favorecido pelo efeito quelato.

Para que este mecanismo seja formulado com confiabilidade maior, foram realizados estudos fotoquímicos especulativos, com vārias condições de mistura de reagentes que possam detetar os possĩveis produtos fotoquímicos primārios. A fotólise do etilenodiaminapentacianoferrato(II) na presença de etilenodiamina e fenantrolina foi efetuada com o intui 
to de confirmar se a formulação do intermediário tetracianoferrato(II) é viāvel.

Um ligante mais rigido, como 1,10 fenantrolina, não se coordena ao pentacianoferrato(II). A formação da espee cie $\mathrm{Fe}(\mathrm{CN})_{4}$ phen $^{2-}$, nestas condições, mostra que o interme diārio envolvendo a forma tetracianoferrato(II) tem o tempo de vida suficiente para que o fechamento do anel com fenar.trolina se concretize.

A anāilise dos produtos formados na reação fotoquỉmica do sistema, evidencia a formação do $\mathrm{Fe}(\mathrm{CN})_{4} \mathrm{phen}^{2-}$, embora em proporções menores $(\Phi-0,012)$ do que a espécie $\mathrm{Fe}(\mathrm{CN})_{4}$ en $^{2-}$ formada $(\bar{\Phi}-0,063)$.

Estes dados mostram que, o mecanismo de fecha mento de anel, quando se tem ligante que se coordena ao cumplexó e, apresenta caracteristicas quelantes, como a etileno diamina, pode ocorrer via caminhos mencionados, com contri buição maior do processo onde o fechamento do anel se dá com o nitrogēnio livre de etilenodiamina,já coordenada ao comple xo.

8.3. Sistema $\mathrm{Fe}(\mathrm{CN}) \mathrm{CO}^{3-}-$ Fotosubstituição do CO

A fotosubstituição do ligante L nos complexos $\mathrm{Fe}(\mathrm{CN})_{5} \mathrm{~L}^{3-}$, com excitação na banda de campo 1igante, foi pou co estudada até o momento. Devido à inércia da substituição tērmica do ligante CO, o complexo $\mathrm{Fe}(\mathrm{CN})_{5} \mathrm{CO}^{3-} \bar{e}$ um dos que são adequados para tal estudo em condição de irradiação a 
baixa intensidade. Coma uma inovação, o acompanhamento .. do processo fotoquimico foi feito com técnica de voltametria cî clica. Os resultados foram confirmados espectroscopicamente (215)

Embora o estudo tenha sido realizado com irradiação a $366 \mathrm{~nm}$, a alta concentração do complexo $\left(2,0 \times 10^{-2} \mathrm{M}\right)$, assegurou uma absorbāncia maior do que dois nessa região, pa ra que a fração da luz incidente absorvida pela amostra seja prōxima da unidade.

A deteção e anālise do produto fotoquímicamente produzido no processo primário, esquematizado a seguir

$$
\mathrm{Fe}(\mathrm{CN})_{5} \mathrm{CO}^{3-}(\mathrm{aq}) \stackrel{\mathrm{h \nu}}{\longrightarrow} \mathrm{Fe}(\mathrm{CN})_{5}^{3-}(\mathrm{aq})+\mathrm{CO}
$$

É feita com a utilização do imidazol em excesso, como ligan te auxiliar, para estabilizar o complexo pentacianoferratol II) formado

$$
\begin{aligned}
& \mathrm{Fe}(\mathrm{CN})_{5}{ }^{3-}(\mathrm{aq})+\mathrm{H}_{2} \mathrm{O} \rightleftharpoons \mathrm{Fe}(\mathrm{CN})_{5} \mathrm{H}_{2} \mathrm{O}^{3-} \\
& \mathrm{Fe}(\mathrm{CN})_{5} \mathrm{H}_{2} \mathrm{O}^{3-}+\mathrm{im}(\mathrm{aq}) \longrightarrow \mathrm{Fe}(\mathrm{CN})_{5} \mathrm{im}^{3-}(\mathrm{aq})
\end{aligned}
$$

A escolha desse ligante auxiliar foi feita em função do potencial de meia onda do complexo por ele formado $\left(E_{1 / 2}=0,120\right.$ v vs Ag/AgCl) de tal forma que não interfira, e que seja suficientemente deslocado em relação ao $\mathrm{E}_{1 / 2}$ correspondente ao sistema $\mathrm{Fe}(\mathrm{CN})_{5} \mathrm{CO}^{3-}(0,950 \mathrm{~V}$ vs. 


\section{7}

$\mathrm{Ag} / \mathrm{AgCl}$ ). Os dados de voltamentria cíclica deste último com plexo estão no apêndice (11.3).

A variação do voltamograma em função do tempo de fotōlise estā representada na figura 8.5. e a concentra ção do $\mathrm{Fe}(\mathrm{CN})_{5} \mathrm{im}^{3-}$ produzido, bem como o rendimento quānti co em função do tempo de irradiação está na tabela 8.3.

TABELA 8.3. - Rendimento quântico do processo representado pela equação (3) com o tempo de fotólise

\begin{tabular}{crc}
$t_{\text {irrad }}(\mathrm{min})$ & {$\left[\mathrm{Fe}(\mathrm{CN}){ }_{5} \mathrm{im}^{3-}\right] \times 10^{4} \mathrm{M}$} & $\Phi$ \\
\hline 21 & 1,47 & 0,21 \\
40 & 3,00 & 0,22 \\
67 & 4,98 & 0,22 \\
98 & 7,15 & 0,21 \\
120 & 8,42 & 0,21 \\
145 & 9,89 & 0,20 \\
170 & $11,33^{*}$ & 0,20
\end{tabular}

A concentração do $\mathrm{Fe}(\mathrm{CN})_{5} \mathrm{im}^{3-}$ produzido no final da irradiação é confirmada através da determinação espec trofotométrica do mesmo, com resultados excelentes que vem a

* concentrą̧ão determinada espectrofotometricamente $=11,4 \times 10^{-4}$, 


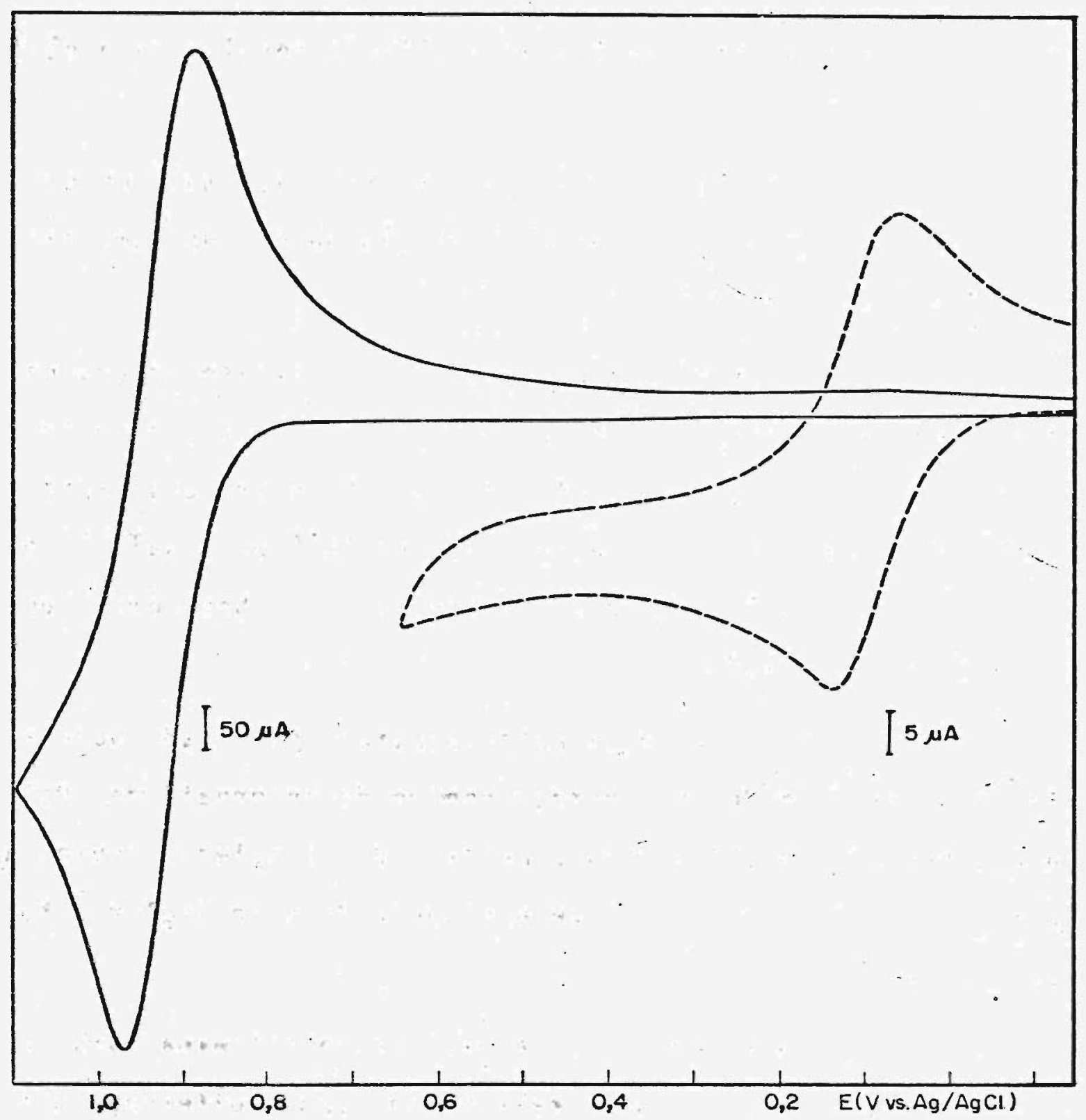

FIG.3.5. Voltamograma cíclico do complexo $\mathrm{Fe}(\mathrm{CN}){ }_{5} \mathrm{CO}^{3-} 2,00$ $\mathrm{x} 10^{-2} \mathrm{M}$ em $\mathrm{KCl} 0,5 \mathrm{M}$ a $25,0^{\circ} \mathrm{C}, \mathrm{v}=0,020 \mathrm{~V} . \mathrm{s}^{-1}$ antes da fotólise ( - )

Voitamograma cíclico do $\mathrm{Fe}(\mathrm{CN})_{5}(\mathrm{im})^{3-}$ obtido após a irradiação a $366 \mathrm{~nm}$ da solução anterior na presen f̧a de imidazol. 
mostrar um método alternativo de anālise sucessiva da espécie fotolisada.

0 resultado de vārias experiēncias mostrou que - rendimento quântico da fotodissociação de co do complexo $\mathrm{Fe}(\mathrm{CN})_{5} \mathrm{CO}^{3-} \overline{\mathrm{e}} 0,23 \pm 0,03$.

Após fotólise prolongada, observa-se traços de tetracianoferrato(II) que é estabilizado pela adição de fenantrolina na solução a ser fotolisada. Este processo apresenta rendimento quântico aproximado de $10^{-2} \mathrm{e}$, a saîda do cianeto pode resultar do complexo de partida, bem como do $\mathrm{Fe}(\mathrm{C} . \mathrm{N})_{5} \mathrm{im}^{3-}$ formado.

Embora o rendimento quântico encontrado para a fotosubstituição do co esteja dentro do intervalo de 0,2 a-0,4 encontrado (214) para a maioria dos complexos pentacia noferrato(II), é menor do que o encontrado pelo Vogler e Kun kely (212).

Não se tem ainda a explicação definida para a diferença, mas, pode estar relacionada com a diferença das condições empregadas $(0,50 \mathrm{M} \mathrm{KCl}$, atmosfera inerte, método de anālise), bem como, com excitação policromātica ( 300 a $370 \mathrm{~nm}$ ) empregada no trabalho anterior.

\subsection{Discussão}

o comportamento fotoquímico observado para os $\mathrm{Fe}(\mathrm{CN})_{5} \mathrm{~L}^{3-} \quad$ leva-nos a formular duas etapas primārias apresentadas a seguir 


\section{0}

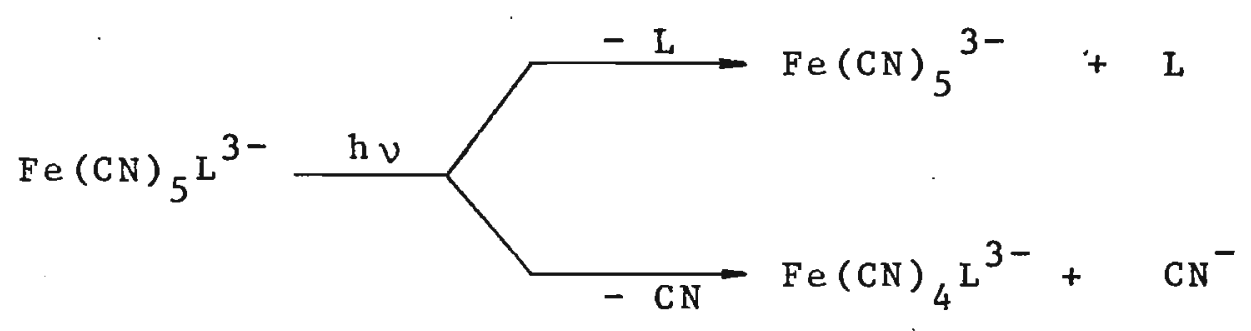

A natureza do estado excitado responsāvel pela reação de fotosubstituição è atribuĩda ao estado excitado triplet de campo ligante(LF).

O diagrama proposto por Figard e Petersen(214), representado no esquema a seguir (ESQ. 8.1.) para os siste mas reativos $(\Phi>0,1)$ e não reativos. $(\Phi<0,05)$, não con duz a uma explićação geral, uma vez que para $\Phi>0,1 ; 0$ es
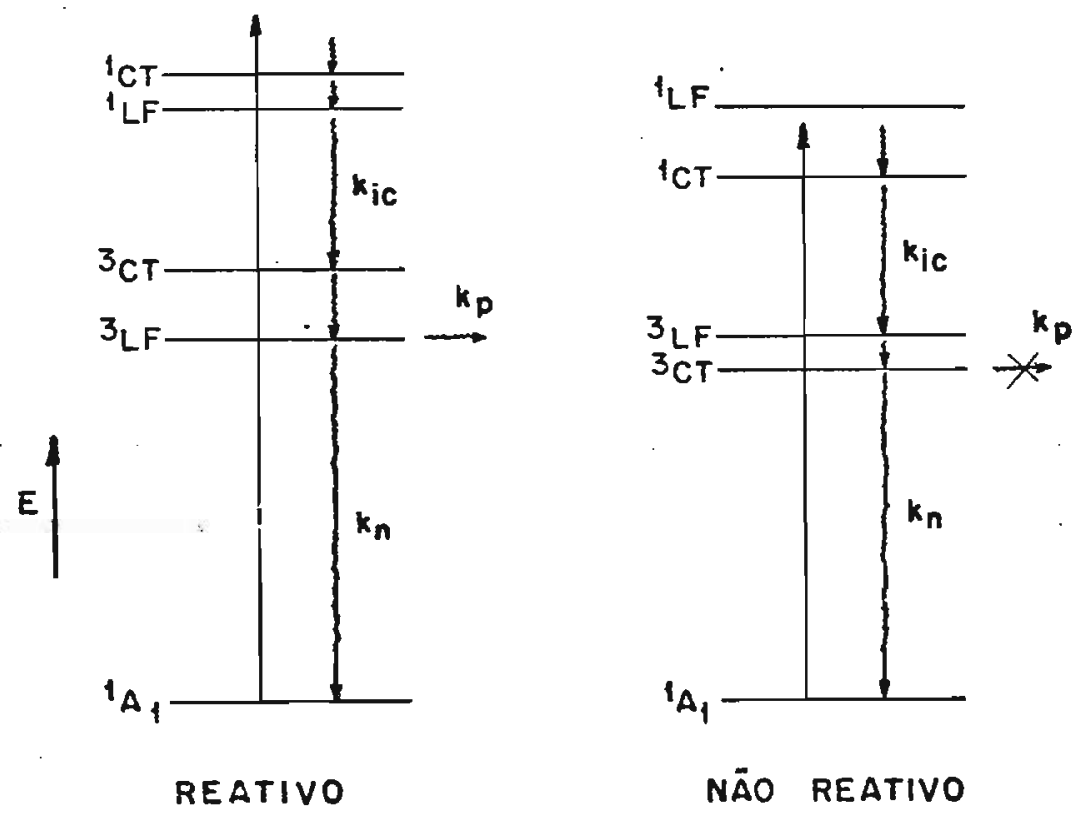

quema representado não è real, nem mesmo para a maioria dos sistemas discutidos pelos autores. Partindo-se da mesma con- 
sideração de que os grupos substituintes no anel piridinico não alteram substancialmente a energia do estado excitado de campo ligante (3), a transição de campo lịgante permitida por spin $\left({ }^{1} A_{1} \rightarrow{ }^{1} E(1)\right.$, CAP. V) deve ocorrer em torno de $26 \mathrm{kK}$. As bandas de transferéncia de carga $\nu_{T C}(\mathrm{Fe}-\mathrm{L})$ para a maioria dos 1 igantes $\mathrm{N}$-heterocīclicos apresentam energias menores do que esta (vide capitulo V). Dos $\mathrm{Fe}(\mathrm{CN})_{5} \mathrm{~L}^{3-}$ con siderados reativos, apenas a piridina poderia ser ainda re presentada pelo diagrama 8.1.A. onde o nível ${ }^{1} C_{I}$ está aci ma do ${ }^{1}$ LF. Este mesmo diagrama não é muito eficiente para explicar por que uma irradiação ria região do campo ligante a presentaria um rendimento menor do que a irradiação na re gião da banda de transferēncia de carga para o complexo $\mathrm{Fe}(\mathrm{CN})_{5} \mathrm{pz}^{3-}\left(\lambda_{\mathrm{irrad}}=365 \mathrm{~nm}, \bar{\Phi}=0,15 ; \lambda_{\mathrm{irrad}}=436 \mathrm{~nm}\right.$, $\left.\Phi^{-}=0,39\right)$.

Ao mesmo tempo, trabalho mais recente de espec tro, tempo de vida e supressão de estados excitados dos com plexos de polipiridinaferro(II) realizado por creutz et al (300), confirmam os trabalhos anteriores $(301,302)$, atribuin do os estados excitados triplets à natureza campo ligante, diferentes daqueles encontrados para os complexos de Ru e Os.

0 diagrama representado na figura 8.6 . parece ser mais provávei e coerente para explicar o comportamento fotoquímico dos complexos. Fe(CN) $5^{3-}$. Para que uma espécie no estado excitado seja transformada num produto quimicamente distinto do estado fundamental, deve ocorrer aigum tipo de reação química. Esta requer um período finito de tempo e 
322

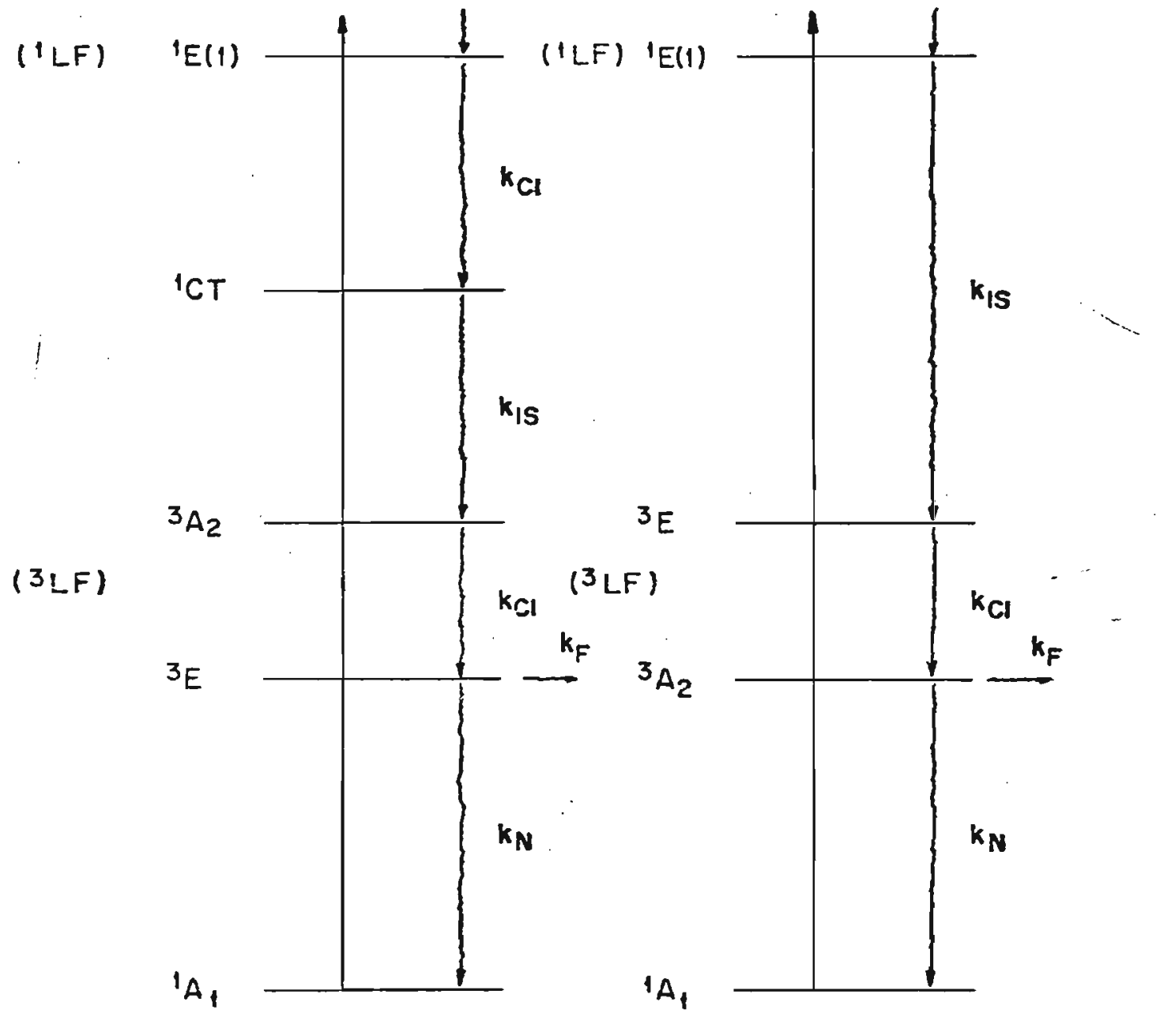

(A)

(B)

FIG.8.6. Diagrama proposto para $F e(C N){ }_{5} L^{3-}$ (A) para L de campo mais fraco do que $C N$ (B) para $L$ de campo mais forte do que $\mathrm{CN}$ 
ocorrerá com probabilidade maior nos estados excitados de tempo de vida mais longa do que nos estados excitados de vi da mais curta. Estados excitados em que a multiplicidade do spin difere daquele do estado fundamental, deve ter uma vida mais longa do que aqueles com a mesma multiplicidade de spin.

A maioria das reações fotoinduzidas nos comple xos $\mathrm{Fe}(\mathrm{CN})_{5} \mathrm{~L}^{3-}$ estudados, pode ser explicada pelo diagrama representado na figura 8.6. A., onde a excitação na banda $d-d$ conduz ao estado reativo triplet, campo ligante, atravēs da conversão interna inicial ${ }^{1}{ }_{L F} \rightarrow{ }^{1} C T$ seguida de cruzamento intersistema ${ }^{1} \mathrm{CT} \rightarrow{ }^{3} \mathrm{LF}$. A excitação direta ao ${ }^{1} \mathrm{CT}$ eliminaria a primeira etapa de conversão interna, au mentando a eficiência do processo.

$$
\text { Para o } \mathrm{Fe}(\mathrm{CN})_{5} \mathrm{CO}^{3-} \text { que se enquadra no caso }
$$
representado pelo diagrama 8.6 . B., a evidencia direta do es tado excitado triplet de natureza campo ligante $\left({ }^{3} \mathrm{~A}_{2}\right)$ foi diretamente detetada pelos Vera e Zuloaga (303), baseada na banda de emissão a 529 nm medida para um sói ido a $77 \mathrm{~K}$.

Os sistemas $\mathrm{Fe}(\mathrm{CN})_{5} \mathrm{~L}^{3-}$. que apresentam banda de transferēncia de carga a energia menor do que $20,8 \mathrm{kK}$, clas sificados como não reativos pelos Figard e Petersen (214) po deriam ser explicados num esquema, onde o abaixamento de energia da banda de transferēncia de carga é grande, desloca da neste caso a nīvel de energia bem pröxima ou menor do que ${ }^{3} L F$, conforme apresentado no diagrama 8.2. da página a seguir. 


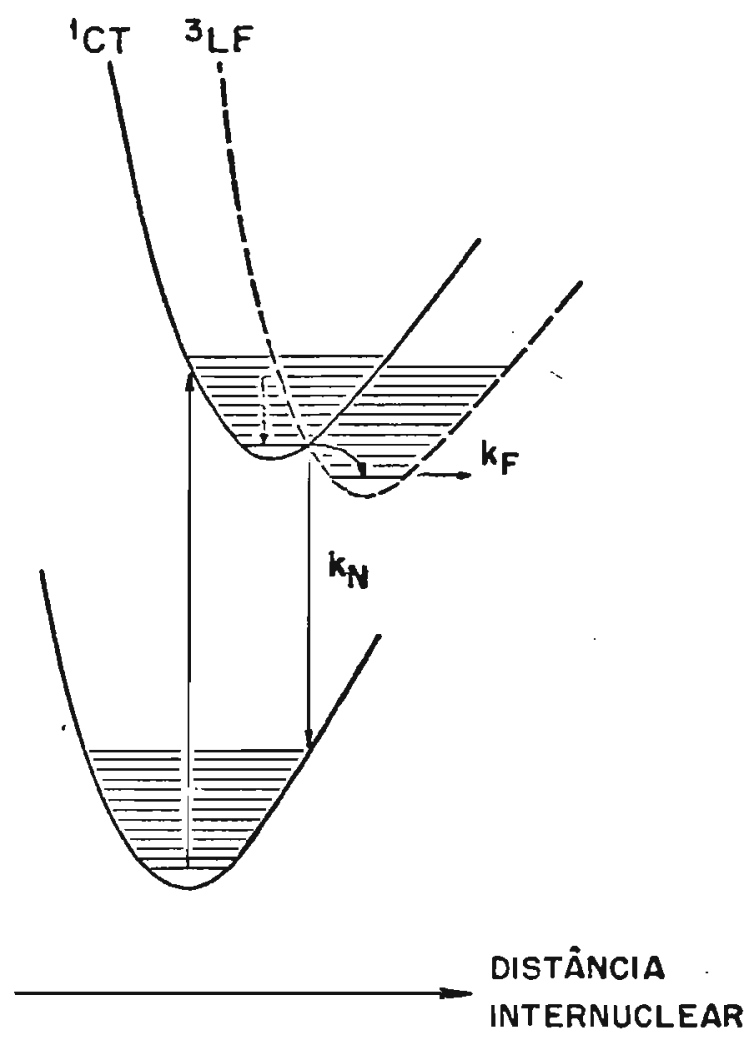

Estas informações posicionam o nível triplet reativo em torno de $20,9 \mathrm{kK}$ ( $480 \mathrm{~nm}$ ) em relação ao ${ }^{1} \mathrm{~A}_{1}$, sendo que para os ligantes com o campo mais fraco do que o cianeto, provaveimente deve corresponder ao nivel ${ }^{3} E$ de energia mais baixa. 


\section{iX - plano de pesquisa e alguns RESULTADOS PARCIAIS}

os planos de trabalho apresentados a seguir são propostos a fim de complementar os estudos realizados e ou, de dar prosseguimento às atividades de pesquisa envolvendo:

1. Catālise e Reações de Ligantes Coordenados

2. Reações Fotoinduzidas

3. Correlação entre as Propriedades Espectrais e Termodinâmicas

\subsection{Catälise e Reação de Ligantes Coordenados}

A reação quĩmica e a catālise através do ligante coordenado ē um campo de enorme potencial, com grandes im plicações tecnolögicas (vide introdução).

Dentro dessa linha, nretende-se investigar a in fluēncia do metal e o seu estado de oxidação na estabilizaçã ou ativação frente a determinadas reações e a sua utiliza ção para preparação de novos compostos de coordenação.

0 estudo foi iniciado com a investigação do sis tema pentacianoferrato(II)-4-formilpiridina que será descrito na seção 9.4 .

Ainda dentro desse campo, pretende-se estudar a reatividade das acetilpiridinas e carbonil-oximas obtidos, coordenados e não coordenados, com as aminas primārias, na 
obtenção de base de Schiff, conforme o esquema apresentado a seguir.
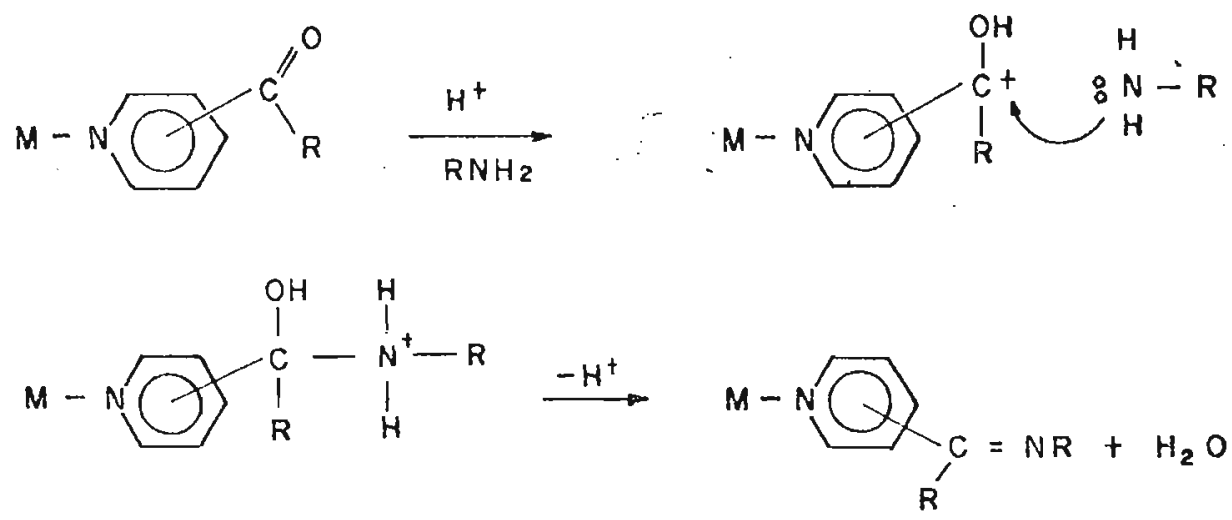

$M=\operatorname{meta} 1$

Atravēs destas reações, espera-se obter as piri dina-imina (dimina) da orto-acetilpiridina e oxima-imina, ou dioximas das carbonil-oximas atravēs da reação com hִidro xilamina. Esta ültima, realizada na presença de Fe(II) con- d’’z a um composto com intensa coloração vermelha.

A sỉntese bem como a reação desses ligantes bidentados que constituem uma classe importante, com grupos cromōforos característicos, apresenta importāncia na obten ção de ligantes multidentados e na formação de macrocĩclicos.

A reação entre as carbonil-oximas com etilenod $\underline{i}$ amina ou propilenodiamina na presença de Fe(II) leva à forma ção de composto com intensa coloração azu1, cuja provāvel es trutura é $A$ e $B$, respectivamente, representados na pāgina a seguir.

A sintese de macrocĩclico atravēs da reação de ligante coordenado, mostra outro aspecto da importância do 
tema devido à sua relevância a sistemas naturais.

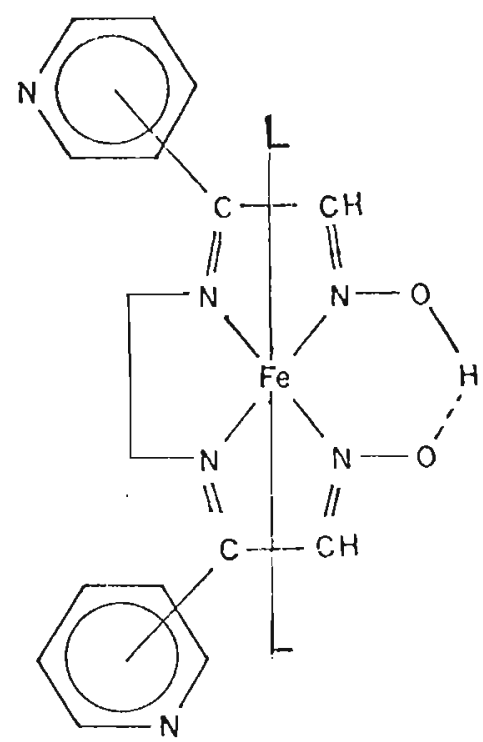

A

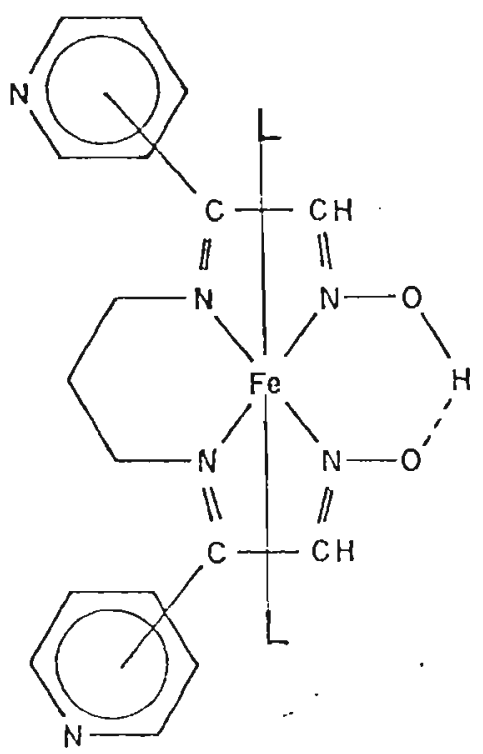

B

Os ligantes macrocíclicos podem proporcionar es tabilidade cinética mesmo para o íon metālico central que co mumente forma complexo 1ábil. Isto torna-se particularmente interessante no estudo das reações onde se pretende evitar a dissociação metal-1igante.

Nesses sistemas, pretende-se estudar as reações envolvidas, através de técnicas de cinētica convencional e räpida, bem como os processos redox, químico e eletroquímico dos produtos formados, e a influência do ligante $L$ nestas propriedades. 


\subsection{Reações Fotoinduzidas}

O comportamento fotoquímico do sistema pentacia noferrato(II)-carbonil-oxima apresentado na presente tese, mostrou que a formação do tetracianoferrato(II), com ligante coordenado por dois pontos, pode ser representada de uma maneira simples por

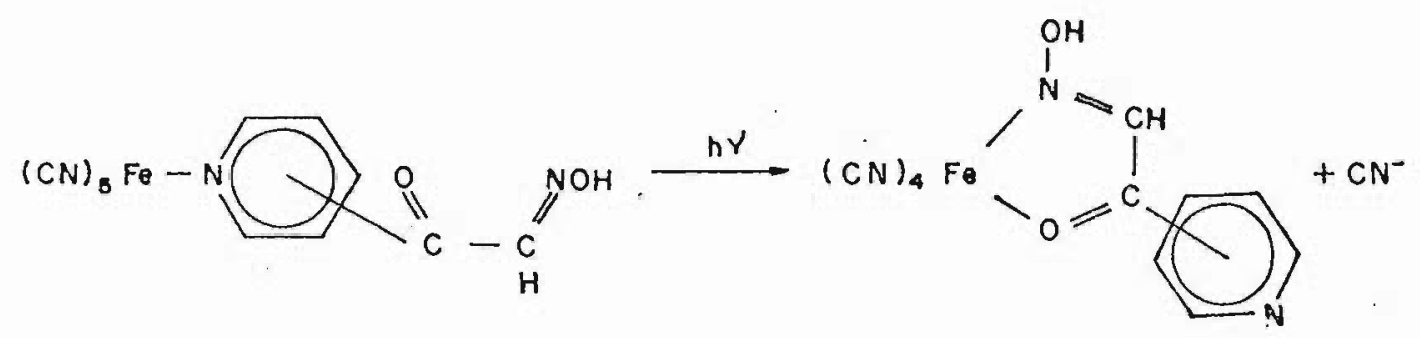

0 produto detetado na reação fotoquỉmica deve ser formado de uma ou mais reações térmicas, envolvendo maís de um produto fotoquímico primārio. o mecanismo da sua forma ção deve envolver vārias etapas como

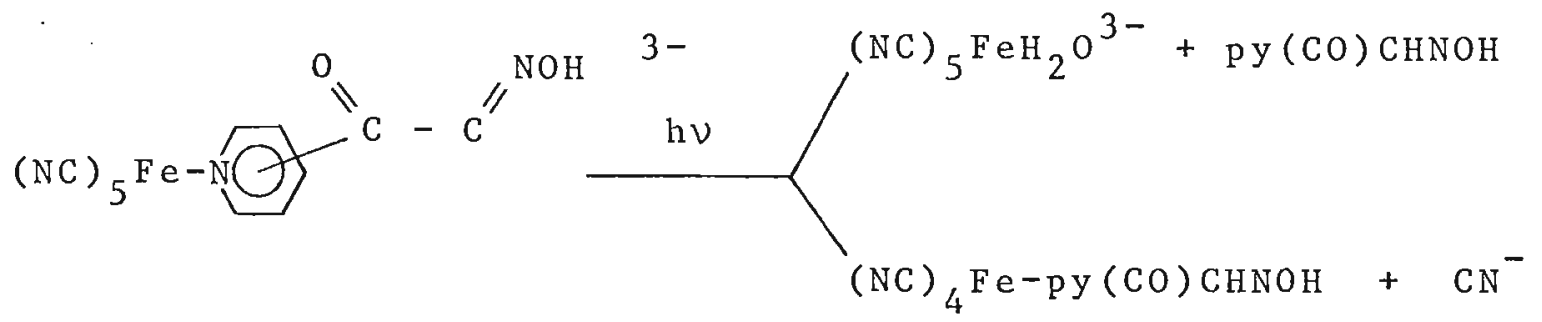

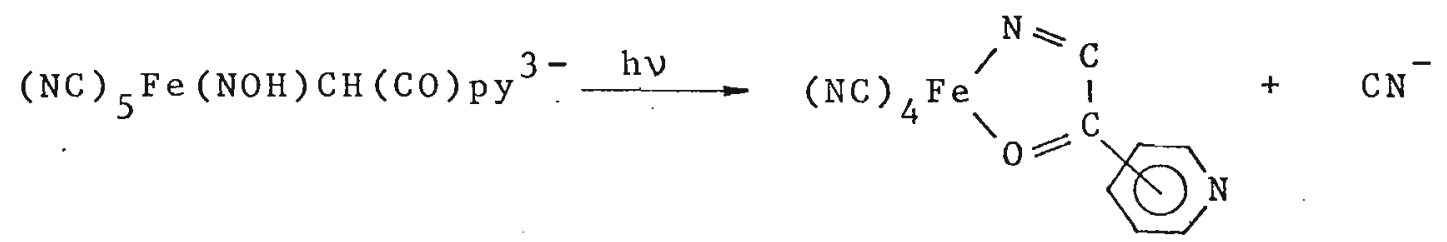


além daquelas normalmente presentes (vide seção 8.2. para o sistema $\left.\mathrm{Fe}(\mathrm{CN})_{5} \mathrm{en}^{3-}\right)$.

0 rendimento quāntico de sistemas mais simples

foi determinado com o objetivo de verificar o estado excitado reativo e compreender o mecanismo da reação de fotosubsti tuição, e a contribuição de cada uma das etapas associadas à formação de $\mathrm{Fe}(\mathrm{CN})_{4} \mathrm{py}(\mathrm{CO}) \mathrm{CHNOH}^{2-}$.

Este estudo deve ser estendido a todos os ligan tes que permitem o fechamento de anel, tal como dipiridina, o-acetilpiridina, e num sistema similar ao carbonil-oximas que. é a pirazinaamida.
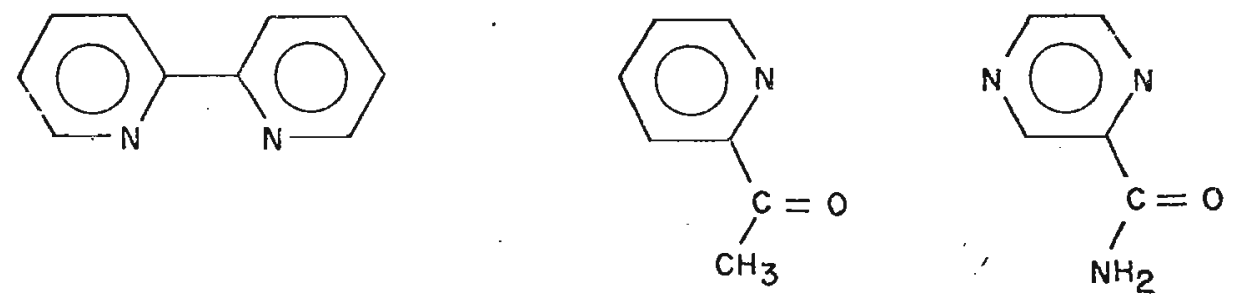

- Pretende-se irivestigar também as reações de fotossubstituição do ligante $L$ nos complexos de pentaciano ferrato(II) com $P \phi_{3}, P\left(\phi \mathrm{CH}_{3}\right)_{3}, \mathrm{As}\left(\phi \mathrm{CH}_{3}\right)_{3}$ e $\mathrm{Sb}\left(\phi \mathrm{CH}_{3}\right)_{3}$, que constituem uma classe de compostos inertes e apresentam apenas transições d-d. 0 sistema permitirā confirmar, o carāter campo ligante da natureza da reação de fotosubstituição, o estado excitado reativo e a validade do diagrama proposto. 


\subsection{Correlação entre as Propriedades Espectrais e Termodinâ micas nos compostos de coordenação}

A fim de correlacionar a estrutura, a velocidade e o mecanismo do processo redox mais precisamente, necessitam-se de informações sobre as propriedades do orbital redox e de outros fatores, principalmente relacionados à diferença das energias de formação da forma oxidada e reduzida.

Considerando-se a natureza do processo redox, pode-se correlacioná-lo com outro processo no qual a mudança no nūmero de elétrons seja causada por outro tipo de interação. Por exemplo, interação do sistema atômico com a radia ção causando, oú a ionização do sistema (correlação com as propriedades termodinâmicas do par redox), ou uma redistri buição interna da densidade eletrōnica ou configuração atōmica (correlação com os parāmetros cinéticos da pröpria rea ção redox ), ou uma excitação seguida por uma reação quị̂mica (processos redox fotoquímicos) para correlação com os fato res que determinam a diferença das energias de formação de formas oxidada e reduzida).

Dentro dessa linha, pretende-se investigar as propriedades espectrais e termodinämicas dos complexos men cionados nos temas anteriores, procurando correlacionar os dados de reatividade-estrutura.

O estudo deverá abordar a influência dos subst $\underline{i}$ tuintes nos ligantes $N$-heterociclico nas propriedades espectrais e nos potenciais redox dos pentacianoferrato(II). 
Pretende-se verificar as variações observadas, originadas $1 \mathrm{a}$

(i) influência da basicidade e habilidade de ligação $\pi$ do gante.

(ii) variação de entropia e a entalpia de hidratação do : complexo.

(iii) pelo efeito estērico proveniente do ligante ao adqu: rir uma orientação mais favorāvel em torno do ĩon me tālico central.

Destes estudos procurar-se-ā obter as correli ções entre os potenciais redox que poderão ser obtidos qu: ca e eletroquimicamente e frequências de transição de tri ferēncia de carga com pKa dos $N$-heterocíclico substituído: assim como como os parāmetros de substituintes - Taft Hámmett $(304,305)$. Posteriormente, a investigação poderá eı volver o sistema fotoquímico oxi-redutivo.

Para o desenvolvimento destes trabalhos, pre. de-se utilizar diversas técnicas, convencionais ou não, pi elucidação dos sistemas em questão, a fim de obter uma vi! ampla sobre as implicações dos fatores estruturais e elet। nicos na sistemática do comportamento químico.

\subsection{Resultados Parciais}

Dentro da linha envolvendo reação do ligante 
ordenado associada à correlação entre as propriedades espectrais e termodinâmicas, foi iniciada a investigação do siste ma pentacianoferrato(II)-4-formilpiridina.

0 ligante 4-formil piridina em solução aquosa, encontra-se em equilibrio com a sua forma hidratada, de acor do com a equação

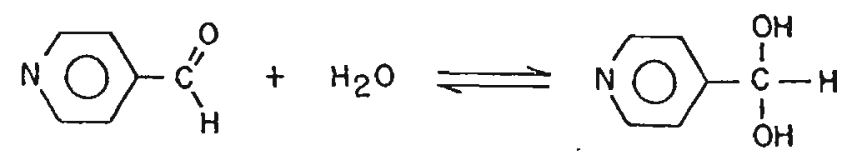

A coordenação do ligañte 4-formil piridina, num dado íon metálico ou complexo, pode afetar o equilíbrio da hidratação da seguinte forma:

a. favorecendo o processo de hidratação, atuando como prō ton

b. estabilizando a forma aldeído, atuando como doador de densidade eletrônica para o ligante

Um estudo anterior com o ligante em questão, en volvendo pentacianoferrato(II) (3) mostra que, quando este se apresenta com o estado de oxidação II, o efeito b é mar cante, estabilizando a forma aldeĩdo sobre a forma hidrato; jā com o estado de oxidação III, o efeito a é predominante, com o equilíbrio sendo totalmente deslocado para a forma hi- 
drato.

Tendo em mente o equilíbrio

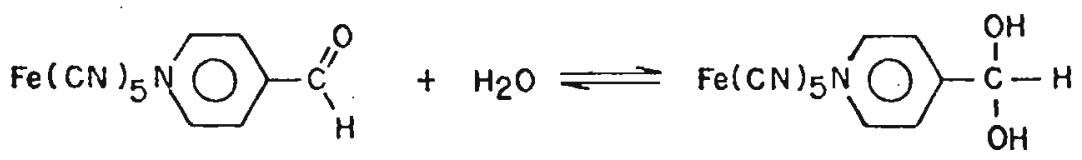

A

B

propos-se a estudar

a. influência desse equilíbrio na forma do voltamograma cîclico

b. o efeito produzido no $E^{0^{\prime}}$ pelo ligante nas duas formas

c. utilização da técnica de vol,tametria cîclica na elucidação de um sistema quĩmico.

9.4.1. Apresenção e Discussão de Dados

0 voltamograma ciclico a $25,0^{\circ} \mathrm{C}$ do sistema representado pelo equilíbrio (1) apresenta um único pico de o xidação e redução com aspecto de um voltamograma cíclico nor ma1, sem complicações (FIG.9.1.).

Uma anālise mais cuidadosa dos seus dados, apre sentados na tabela 9.1. mostra que $\Delta E_{p}$ diminui anormalmen. te com a diminuição da velocidade de varredura de potenciais 


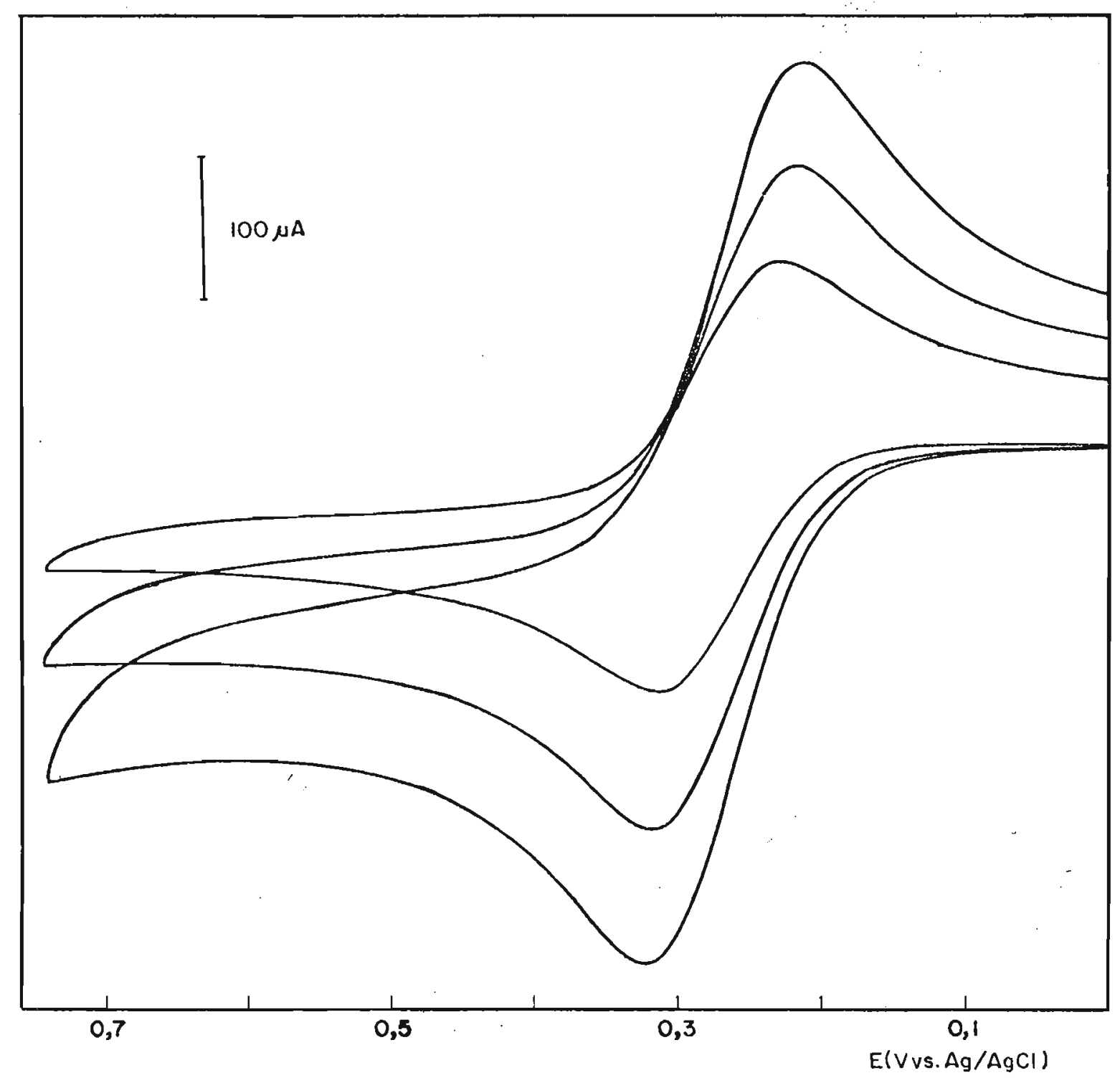

FIG.9.1. Voltamogramas cíclicos de solução $3,50 \times 10^{-3} \mathrm{M}$ de $\mathrm{Fe}(\mathrm{CN})_{5} \mathrm{p}-\mathrm{py}(\mathrm{CO}) \mathrm{H}^{3-}$ em $\mathrm{KCI} \quad 0,50 \mathrm{M}$ a $25,0^{\circ} \mathrm{C}$ $\mathrm{v}=0,100 ; 0,050 ; 0,020 \mathrm{~V} \cdot \mathrm{s}^{-1}$ 


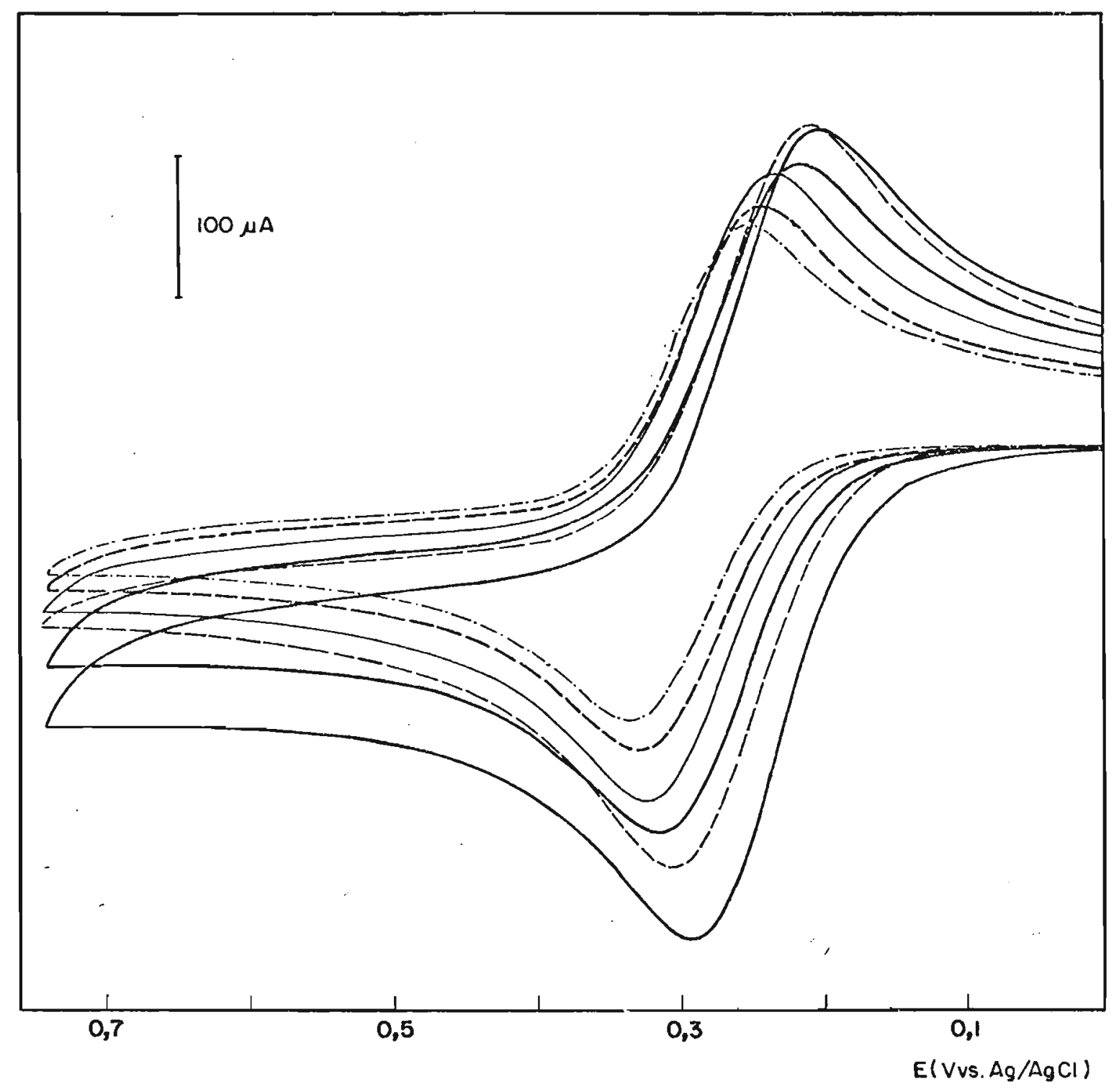

$-3$

FIG.9.2. Voltamogramacíclico do sistema $\mathrm{Fe}(\mathrm{CN}){ }_{5} \mathrm{p}-\mathrm{pyC}(\mathrm{OH}){ }_{2} \mathrm{H} /$ $\mathrm{Fe}(\mathrm{CN}){ }_{5} \mathrm{p}-\mathrm{py}(\mathrm{CO}) \mathrm{H}^{3-} \quad$ a diferentes temperaturas $\left(42,0 ; 35,0 ; 25,0 ; 17,0 ; 7,5 ; \mathrm{e} 0,5{ }^{\circ} \mathrm{C}\right.$, respecti vamente com o deslocamento do potencial no sentido 'anódico ) 
assim como a relação $i_{p a} / i_{p c}$ cresce rapidamente com a dimi nuição da velociade de varredura de potenciais.

Uma perturbação no sistema, como por exemplo, $\underline{u}$ ma variação na temperatura, poderia permitir a avaliação da constante de hidratação, alēm da informação de como cada uma das formas presentes no equilibrio contribuem para voltamo grama cíclico. Para tal, verificou-se o efeito da temperatura no comportamento eletroquímico do sistema (FIG.9.2).

0 mesmo efeito foi verificado no espectro de a $\underline{b}$ sorção no visível (3), representado na figura 9.3., cuja ban da a $504 \mathrm{~nm}$ é atribuîda ao pentacianoferrato(II) coordenado ao p-formilpiridina e a banda a $385 \mathrm{~nm}$ corresponde $\bar{a}$ forma hidratada. A variação observada indica que o abaixamento da temperatura favorece o equilibrio no sentido de maior formação do hidrato.

FIG. 9.3. - Influência da temperatura no equilíbrio

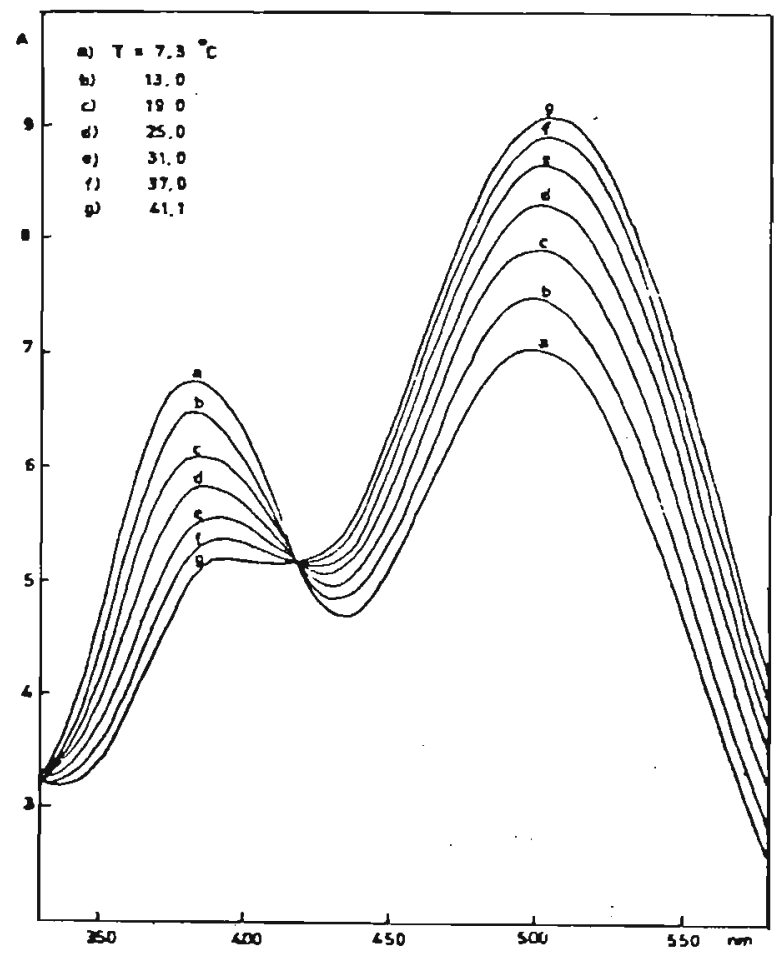


TABELA -9.1 .

Parâmetros eletroquímicos do complexo pentaciano(p-formil piridina)ferrato(II) obtidos dos voltamogramas ciclicos a diferentes velocidade de varredura de potenciais e temperatura em KC1 $0,50 \mathrm{M}$

$\mathrm{p}-\mathrm{pyC}(\mathrm{OH})_{2} \mathrm{H} / \mathrm{p}-\mathrm{py}(\mathrm{CO}) \mathrm{H}=3,50 \times 10^{-2} \mathrm{M}$

$\mathrm{Fe}(\mathrm{CN}){ }_{5} \mathrm{p}-\mathrm{pyC}(\mathrm{OH}){ }_{2} \mathrm{H}^{3-} / \mathrm{Fe}(\mathrm{CN}){ }_{5} \mathrm{p}-\mathrm{py}(\mathrm{CO}) \mathrm{H}^{3-},=4,00 \times 10^{-3} \mathrm{M}$

Potencial $( \pm 0,005) \mathrm{V}$ vs $\mathrm{Ag} / \mathrm{AgCl}(\mathrm{AgCl} \mathrm{sat} / \mathrm{KCl} 1,0 \mathrm{M})$ 


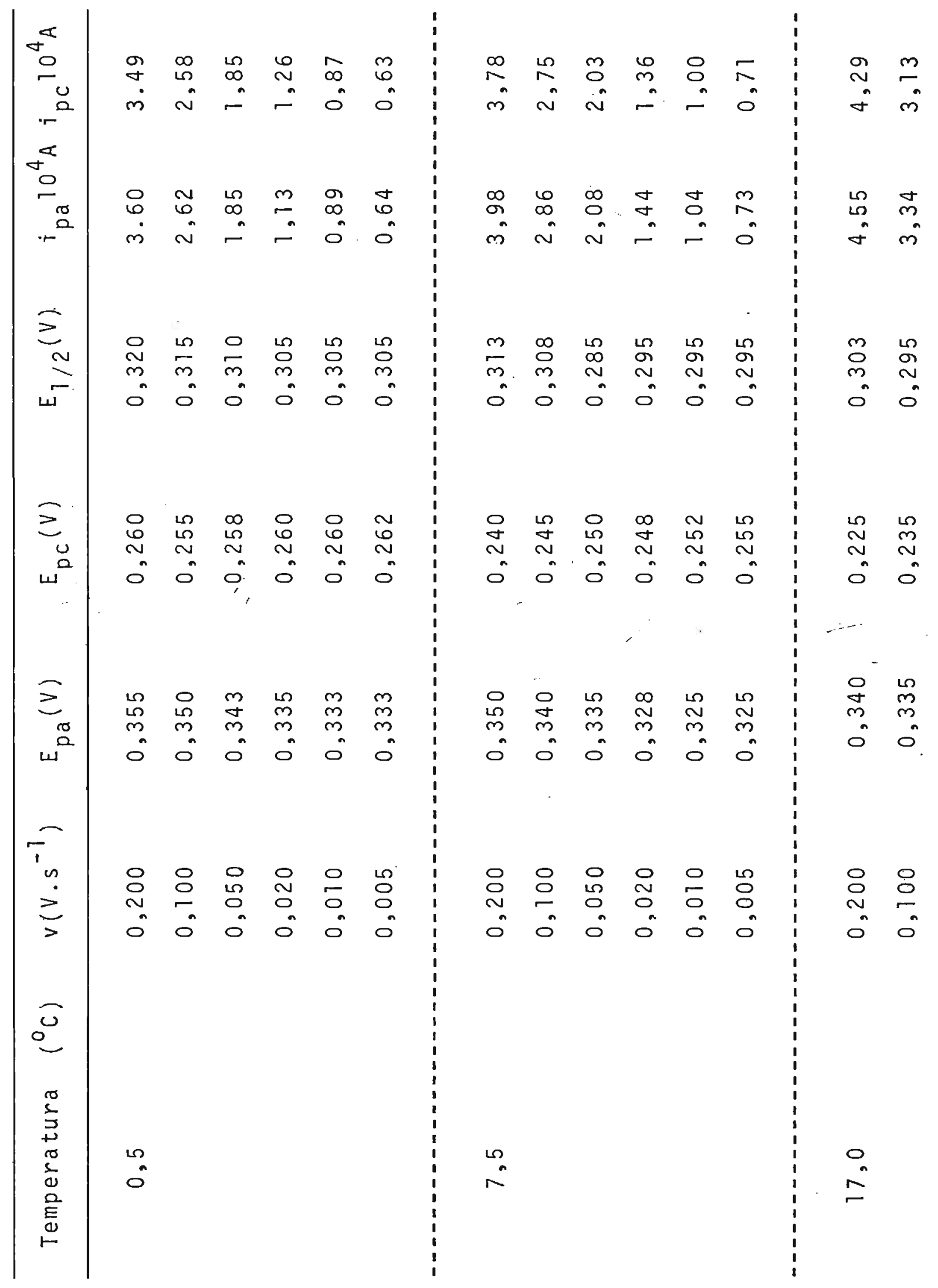




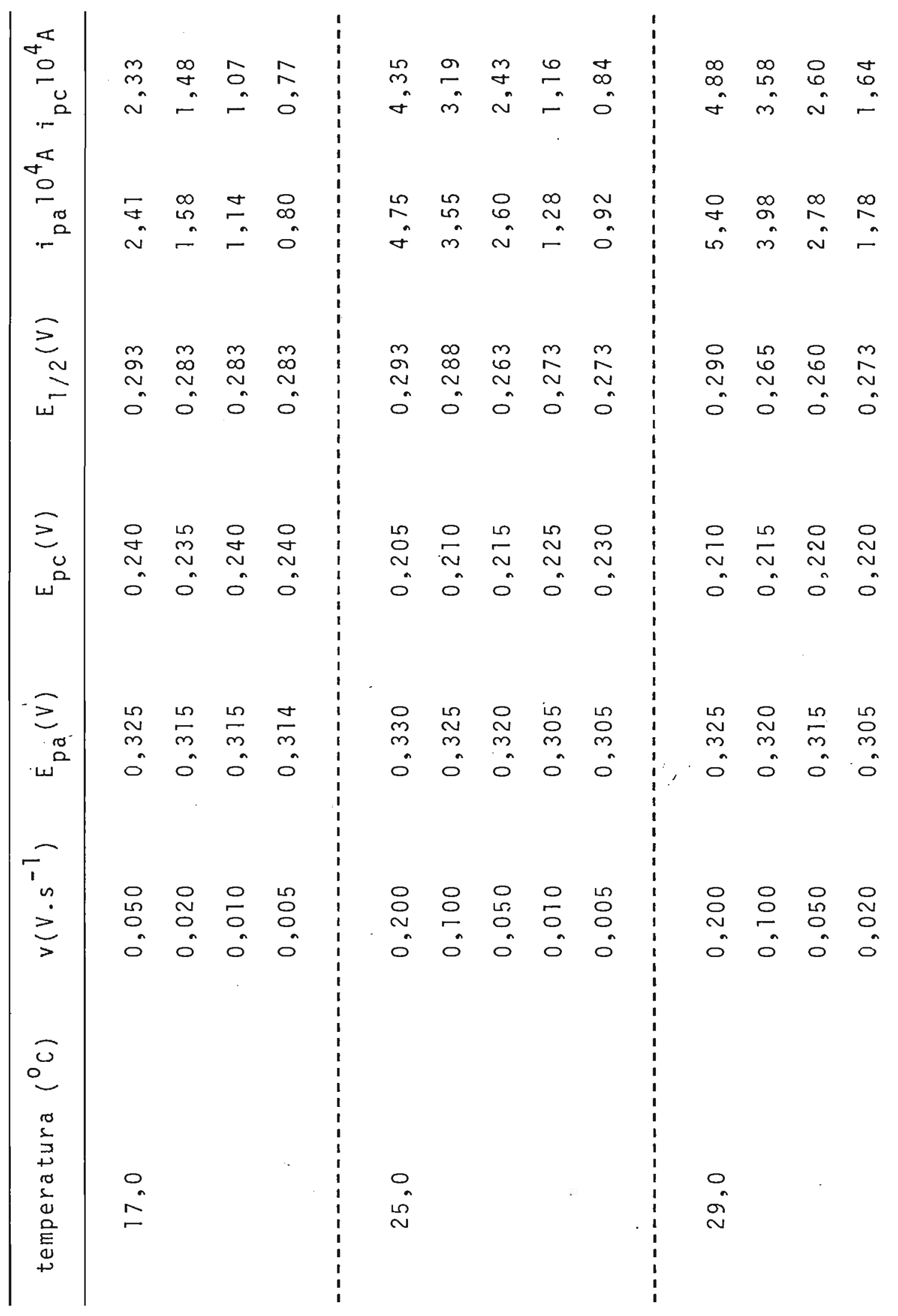




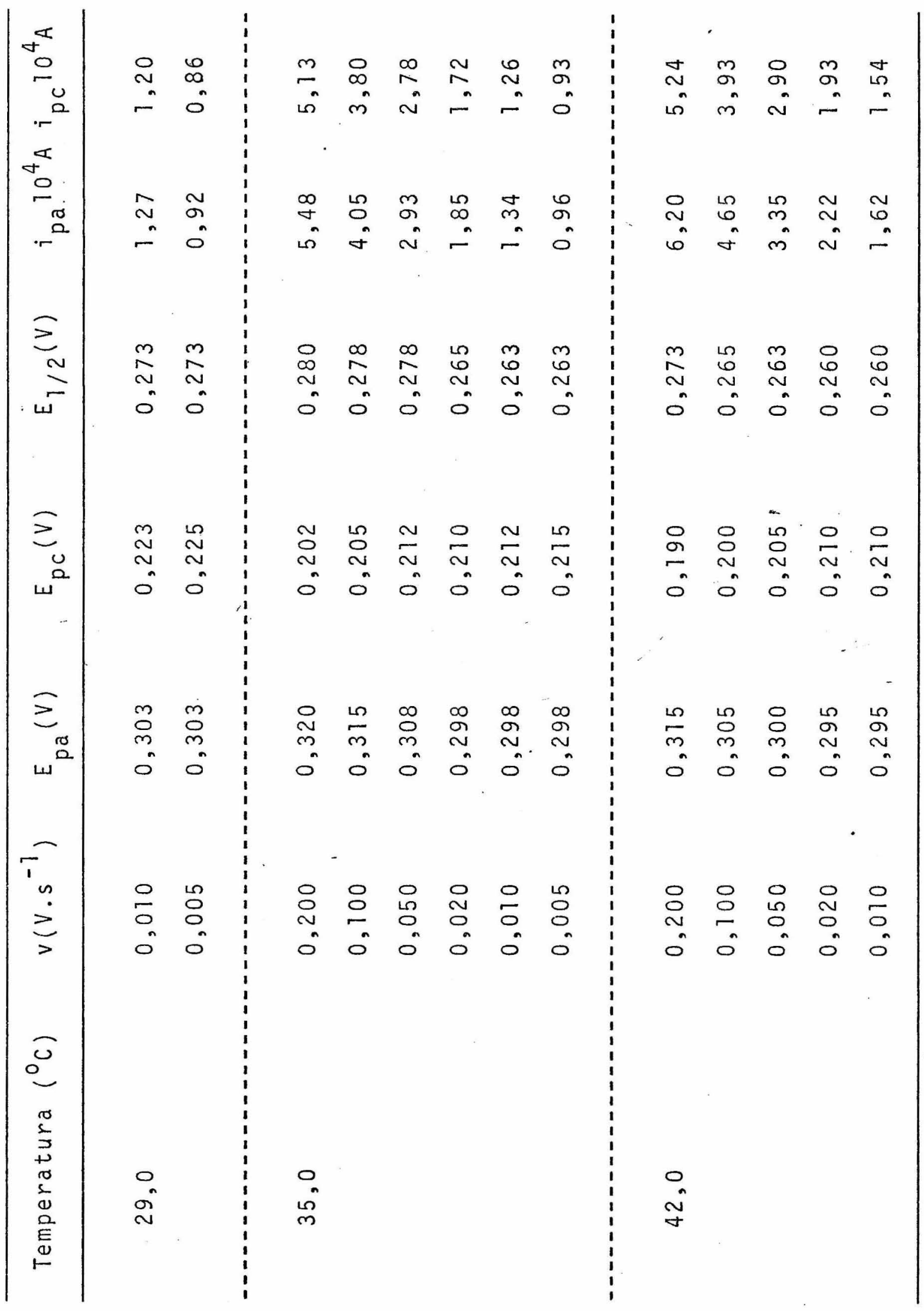


o comportamento do voltamograma cíclico em di rentes situações pode ser explicado da seguinte forma:

Na temperatura de $25,0^{\circ} \mathrm{C}$, onde se tem a prese ça das duas formas ( $A$ e $B$ ) em equilíbrio, o consumo da e pécie que é oxidada mais facilmente pode ser regenerada a certa extensão, atravēs do restabelecimento de equilíbrio a velocidade de varredura de potenciais for suficientement, 1enta. Mas, se esta for alta, não se tem tempo de restabe cer o equilibrio e, como as duas espécies presentes na sol ção não apresentam os $E_{1 / 2}$ suficientemente separados par resultar num voltamograma de dois picos, tem-se uma compos ção destes, como representado a seguir

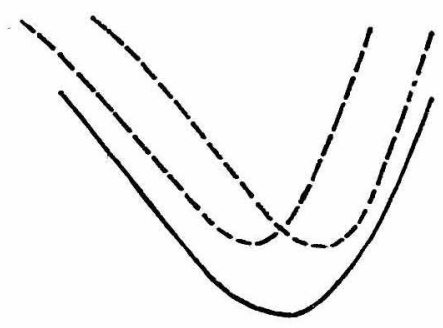

Essa composição tem como consequēncia um voltamograma com pico arredondado e menos definido, com um deslocamento do no sentido anōdico. Esse efeito também se reflete na corr te de pico anódico, apresentando uma corrente aparente men em relação à corrente que seria medida se houvesse uma ūni espécie eletroativa presente àquela concentração ( a soma não se efetua nos dois picos). 
Isto significa que voltamogramas à baixa veloci dade de varredura mostram uma contribuição mais acentuada da forma que se oxida mais facilmente e, se o equilibrio for deslocado nesse sentido com o auxîlio da variação adequada de temperatura, tem-se uma condição em que quase toda a espē cie a ser oxidada está convertida nesta forma.

Uma vez que a forma hidratada estabiliza melhor o estado de oxidação III em relação ao aldeĩdo, esta deverá se oxidar a potencial menor (menos anódico). Partindo-se dessa hipótese, que será confirmada mais tarde, sabe-se que tanto o abaixamento da temperatura como da velocidäde de var redura de potenciais favorecem no mesmo sentido, de tal forma que à baixa v́locidade de varredura de potenciais e tempe ratura, o voltamograma cíclico passa a se comportar como se estivesse presente uma ūnica espécie.

Is to significa que o $E_{1 / 2}$ determinado nessas condições, corresponde ao complexo na forma hidrato, $\mathrm{Fe}(\mathrm{CN})_{5}$ p-py $\left((\mathrm{OH})_{2} \mathrm{H}^{3-}\right.$. ou seja, uma vez que à baixa temperatura temse quase toda espécie na forma hidrato e, se a velocidade de varredura de potenciais for suficientemente baixa, o equilibrio se restabelece nesse sentido, o que faz com que nessas condições tenha melhor definição dos picos e, o sistema praticamente se comporta como se estivesse presente uma única espécie eletroativa, no caso o ion $\mathrm{Fe}(\mathrm{CN})_{5} \mathrm{p}-\mathrm{pyC}(\mathrm{OH})_{2} \mathrm{H}^{3-}$.

Analisando agora os gräficos de $i_{\mathrm{pa}} / \mathrm{v}^{1 / 2}$ em função de $v^{1 / 2}$ a diferentes temperaturas (Fig. 9.4. 9.5.), observa-se que à baixa temperatura (FIG.9.4.) apare 
343

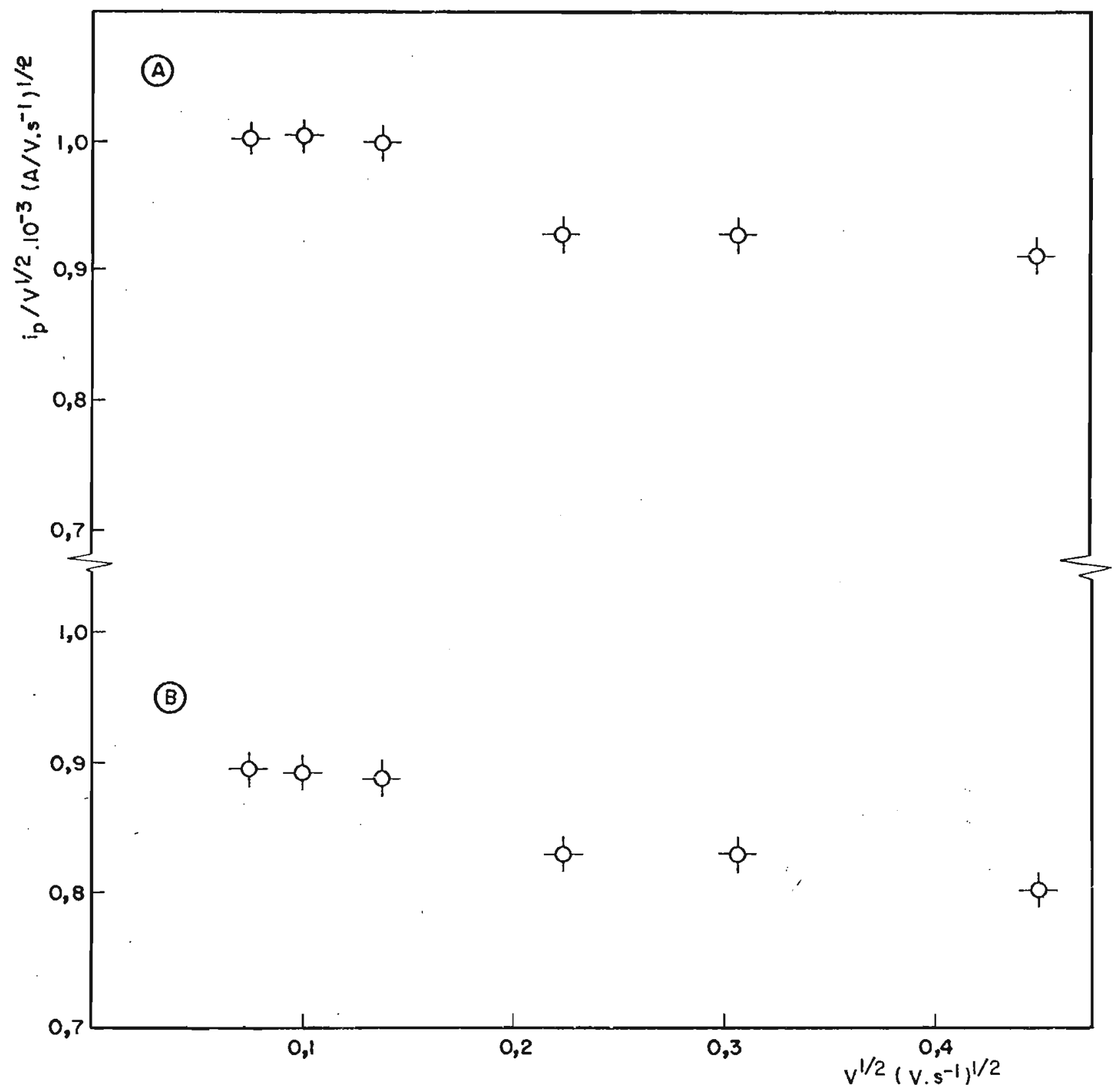

FIG.9.4. Variação do $i_{p} / v^{1 / 2}$ em função da velocidade da varredura de potenciais para o sistema $\mathrm{Fe}(\mathrm{CN})_{5}{ }^{3-}$ com p-py $(\mathrm{CO}) \mathrm{H} / \mathrm{p}-\mathrm{pyC}(\mathrm{OH}){ }_{2} \mathrm{H}$

(A) $\quad t=7,5^{\circ}$

C

(B) $\quad t=0,5^{\circ} \mathrm{C}$ 
344

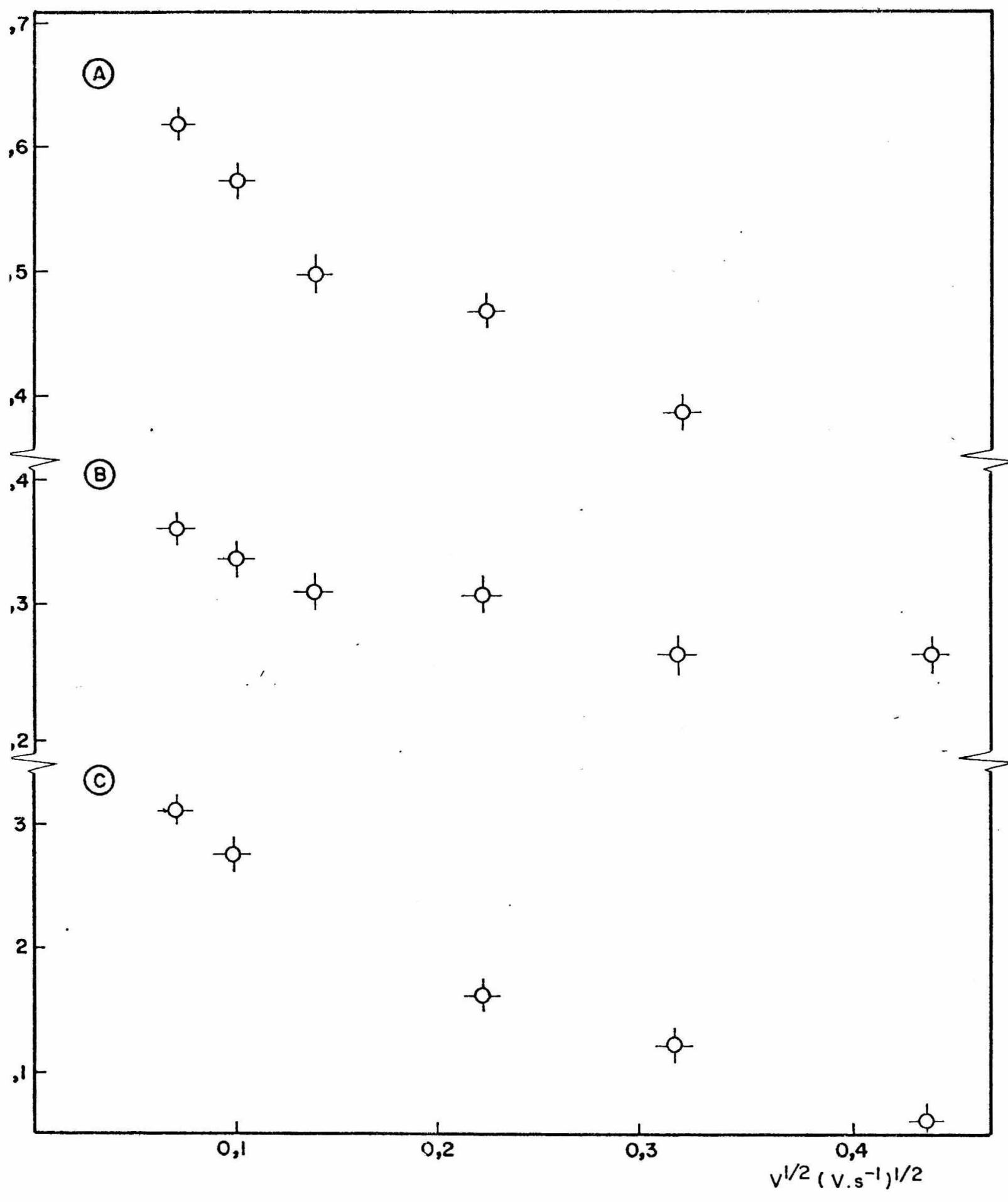

FIG.9.5.Variação do $i_{p} / v^{1 / 2}$ em função da velocidade de var redura de potenciais para o sistema $\mathrm{Fe}(\mathrm{CN})_{5}{ }^{3-}$ com $\mathrm{p}-\mathrm{py}(\mathrm{CO}) \mathrm{H} / \mathrm{p}-\mathrm{pyC}(\mathrm{OH}){ }_{2} \mathrm{H} \quad$ (A) 42,$0 ;$ (B) 35,0 e (C) $25,0^{\circ} \mathrm{C}$ 
ce uma queda brusca. Essa Inflexão pode ser atribuĩda à tran sição de uma situação em que ocorre oxidação preferencial de uma ūnica espécie para a situação em que as duas formas estão participando do processo de oxidação. Esta ūitima situação ocorre quando se aumenta a velociade de varredura de pó tenciais.

A presença do patamar representa portanto, uma condição em que o voltamograma obtido corresponde à espécie $\mathrm{Fe}(\mathrm{CN})_{5} \mathrm{p}-\mathrm{pyC}(\mathrm{OH})_{2} \mathrm{H}^{3-}$, o que só se verifica a baixa temperatu ra. A temperaturas superiores a $7,5^{\circ} \mathrm{C}$, as duas contribuições aparecem mesmo à baixa velocidade de varredura e que à medida que se aumenta a velocidade de varredura e a temperatura, a presença do complexo com o ligante na forma aldeỉdo acentua-se marcadamente.

Isto significa que, com o abaixamento da veloci dade de varredura de potenciais, os potenciáis de pico e de meia onda devem-se deslocar no sentido catódico, uma vez que está promovendo a oxidação da espécie com $E^{0}$ menor. Essa diminuição no $E_{p}$ e $E_{1 / 2}$ pode ser constatada na tabela 9.1.

Se tudo isso é verdade, à medida que o equilì brio é favorecido para a espécie que se oxida mais facilmente, tanto o $E_{p}$ como $E_{1 / 2}$ da oxidação deveriam ocorrer a potenciais menores. Sabendo-se que o abaixamento da temperatura favorece o equilíbrio no sentido de maior concentraçã da forma hidrato e, partindo-se do principio de que esta se oxida mais facilmente; os potenciais de pico e de meia onda a baixa temperatura devem ocorrer na região mais catódica. 
A primeira vista, observando-se os dados da tae1a 9.1., pode-se ter uma idéia errada de que o potencial e desloca no sentido contrário. Nos estudos de variação de emperatura, não se pode esquecer de computar tanto o efeito a temperatura nos potenciais de pico e meia onda ( vide taela 7.5.) como o próprio efeito no equilî́brio quỉmico.

0 efeito de temperatura no sistema similar, rea izado com $\mathrm{Fe}(\mathrm{CN})_{5} \mathrm{p}-\mathrm{py}(\mathrm{CO}) \mathrm{CH}_{3}{ }^{3-}$ mostra que à medida que se iminui a temperatura o potencial de pico desloca-se no sen ido mais anódico, numa proporção ditada pela equação

$$
\Delta G=-n F E=\Delta H-T \Delta S
$$

Atravēs da equação da variação do potencial em unção da temperatura, encontrada para o sistema $\mathrm{Fe}(\mathrm{CN})_{5}^{3-} \mathrm{com}$ igante $\mathrm{p}$-py $(\mathrm{CO}) \mathrm{CH}_{3} \quad\left(\mathrm{E}=0,72-1,32 \times 10^{-3} \mathrm{~T}\right)$, chega-se os dados relacionados na tabela 9.2.

Para o ligante p-formilpiridina poderia se espe ar um $\Delta \mathrm{H}$ e $\Delta \mathrm{S}$ semelhante ao sistema similar p-py(CO) $\mathrm{CH}_{3}$ sto causaria um deslocamento semelhante nos potenciais de ico se estivéssemos avaliando apenas o efeito da temperatua no potencial. Uma vez que o equilibrio químico presente - sistema causa um deslocamento de potencial no sentido con rário (catódico) ao da temperatura, os potenciais a baixa emperatura são bem menos deslocados em relação ao sistema imilar. 


$$
\text { TABELA - } 9.2 \text {. }
$$

Deslocamento do potencial de pico anódico em função da temperatura para:
(A) $\mathrm{Fe}(\mathrm{CN}){ }_{5} \mathrm{p}-\mathrm{py}(\mathrm{CO}) \mathrm{CH}_{3}{ }^{3-}$
(B) $\quad \mathrm{Fe}(\mathrm{CN})_{5} \mathrm{p}-\mathrm{py}(\mathrm{CO}) \mathrm{H}^{3-}$

Temperatura (K)

$$
\mathrm{E}_{\mathrm{pa}}(\mathrm{mV}) \text { vs } \mathrm{Ag} / \mathrm{AgCl}
$$

A

B

273,5

280,5

290,0

298,0

302,0

308,0

315,0
358

349

336

325,5

320

313

303
303

298

332,5

325

314

305

295 
$315,0 \mathrm{~K}$, contra $37 \mathrm{mV}$ encontrados para o mesmo intervalo de temperatura no. sistema em estudo, encontra-se um desvio de $18 \mathrm{mV}$ no sentido catódico para este $\bar{u} 1$ timo. Isto pode ser atribuído ao efeito da temperatura na posição de equilî̉rio (1) para a direita.

Se tomarmos o potencial de meia onda do sistema a $0,5^{\circ} \mathrm{C}$ como sendo correpondente à espēcie $\mathrm{Fe}(\mathrm{CN})_{5}^{3-} \mathrm{C}$ ordenada com o ligante na forma hidrato e, corrigindo-se o efeito de temperatura, o $E^{0^{\prime}}$ aproximado para a espécie, é de $0,50 \mathrm{~V}$. Este valor $\overline{\mathrm{e}}$ bastante coerente dentro da correla ção $E^{O^{\prime}}$ com a banda de transferēncia de carga.

Estudo recente realizado pelos Brisset e Biquard (306) não leva ém consideração esses efeitos e, muitos dos dados de potenciais bem como de informações sobre o sistema investigado diferem dos comumente encontrados.

Um tratamento mais detalhado poderia fornecer - $E_{1 / 2}$ do sistema $\mathrm{Fe}(\mathrm{CN})_{5} \mathrm{p}-\mathrm{py}(\mathrm{CO}) \mathrm{H}^{3-}$ e fornecer informaçöes acerca do equitîbrio (1). 


\section{$X$ - SUMMARY}

The reactions between the pentacyano(nitrosyl) ferrate(II) ion and the $0-, m-, p$-isomers of acetylpyridine ( $\mathrm{py}(\mathrm{CO}) \mathrm{CH}_{3}$ ) were investigated by stopped flow technique, in order to evaluate the mechanisms of nucleophilic attack on the coordinated nitric oxide ligand. The kinetics of these addition reactions were followed spectrophotometrically, under pseudo first order conditions, at a temperature of $25^{\circ} \mathrm{C}$, and $\mu=0,100$ ( 1 ithium perchlorate and lithium hydroxide). A deep blue compound can be observed with a half-life of a few seconds. The formation of such an intermediate was described in terms of the attack of the carbanion of acetylpyridine to the coordinate nitric oxide ligand, in competition with the addition of the hydroxide ion. The experimental rate law for the reaction can be expressed by a pseudo first order equation, consistent with our proposed mechanism; where

$$
\mathrm{k}_{\mathrm{obsl}}=\mathrm{K}_{\mathrm{k}} \mathrm{k}_{\mathrm{L}}\left[\mathrm{py}(\mathrm{CO}) \mathrm{CH}_{3}\right]\left[\mathrm{OH}^{-}\right]+\mathrm{k}_{\mathrm{OH}}\left[\mathrm{OH}^{-}\right]+\mathrm{k}_{-\mathrm{L}}
$$

The rate constants $k_{L}$ and $k_{-L}$ refer to the nucleophilic attack step and the reversal reaction, respectively. The equilibrium constant $K$ represents the formation of the carbanion, while $\mathrm{k}_{\mathrm{OH}}$ is associated with the parallel addition of the hydroxide ion to $\mathrm{NO}^{+}$. The values determined for $\mathrm{KK}_{\mathrm{L}}$ and $k_{-L}$ were, respectively, $196 \mathrm{M}^{-2} \mathrm{~s}^{-1}$, and $0.090 \mathrm{~s}^{-1}$ for $\mathrm{p}-\mathrm{py}(\mathrm{CO}) \mathrm{CH}_{3} ; 3.70 \mathrm{M}^{-2} \mathrm{~s}^{-1}$ and $0.080 \mathrm{~s}^{-1}$ for $\mathrm{m}-\mathrm{py}(\mathrm{CO}) \mathrm{CH}_{3} ;$ and 
$14.2 \mathrm{M}^{-2} \cdot \mathrm{s}^{-1}$ and $0.046 \mathrm{~s}^{-1}$ for $\mathrm{O}-\mathrm{py}(\mathrm{CO}) \mathrm{CH}_{3}$. The $\mathrm{k}_{\mathrm{OH}}$ value obtained under the experimental conditions is $0,302 \mathrm{M}^{-1} \mathrm{~s}^{-1}$

The decay of the intermediate yields the free carbonyloximes in solution. It may be associated with an intrinsic lability of the nitroso species, or even by an internal isomerization leading to a sterically hindered configuration of the ligand. The observed rate law was found to depend on the acetylpyridine and the hydroxide ion concentrations in the following way

$$
\mathrm{k}_{\mathrm{obs} 2}=\frac{\mathrm{k}_{\mathrm{d} \mathrm{K}_{\mathrm{T}}}\left[\mathrm{py}(\mathrm{CO}) \mathrm{CH}_{3}\right]\left[\mathrm{OH}^{-}\right]+\mathrm{k}_{\mathrm{OH}}\left[\mathrm{OH}^{-}\right]}{1+\mathrm{K}_{\mathrm{T}}\left[\mathrm{py}(\mathrm{CO}) \mathrm{CH}_{3}\right]\left[\mathrm{OH}^{-}\right]} .
$$

where $K_{T}=K \cdot k_{L} / k_{-L}$, and $k_{d}$ is the rate constant of dis= sociation of coordinated ligand. The experimental values of $K_{T}$ and $k_{d}$ were,respectively, $2.1 \times 10^{3} \mathrm{M}^{-2}$ and $0.082 \mathrm{~s}^{-1}$ for $\mathrm{p}-\mathrm{py}(\mathrm{CO}) \mathrm{CH}_{3} ; 390 \mathrm{M}^{-2}$ and $0.050 \mathrm{~s}^{-1}$ for m-py(CO)C.H $\mathrm{C}_{3}$; and $295 \mathrm{M}^{-2}$ and $0.032 \mathrm{~s}^{-1}$ for $\mathrm{O}-\mathrm{py}(\mathrm{CO}) \mathrm{CH}_{3}$.

Independent experiments using the intermediate species isolated as solids, allowed to confirm the consistency of our two step mechanism. From the pure carbonyl-oxime ligands obtained in this work we have synthesized the substituted complexes of pentacyanoferrate(II) coordinated by pyridine group.

An extensive characterization of the ligands and of the complexes was carried out in this work, including the analysis of the electronic spectra in terms of Gaussians 
and log-normal functions, and the assignments of the vibrational spectra. Also examined were the pH effects on the charge transfer spectra, as well as the evaluation of the basicity constants of the coordinated cyanide and the heterocyclic ligands. We have also characterized the intermediates in terms of their electronic and vibrational spectra.

Based on an electrochemical study, using mostly cyclic voltammetry, we have obtained the thermodynamic parameters of the several complexes. A linear correlation between the formal potentials and the energies of the charge transfer transitions was found in this work.

The $\mathrm{Fe}(\mathrm{CN})_{5} \dot{p y}(\mathrm{CO}) \mathrm{CHIOH}^{3-}$ complexes were found to be photosensitive, turning slowly to a deep blue color under sun or ordinary 1 ight. The photolysis under controlled conditions, with a mercury lamp, in the visible - near uv region, produced neat spectral changes, with isosbestic points indicating a well behaved photochemical process. The product, in contrast to pentacyanoferrate(II) species, was found to be inert toward dimethyl sulfoxide. The same behavior has been observed for tetracyanoferrate(II) complexes with bidentate ligands. In analogy, the blue product was formulated as

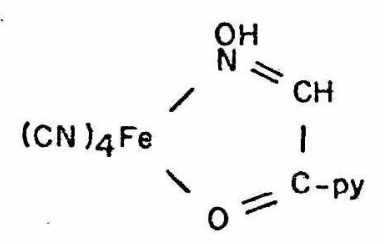


Quantum yields were determined at several wavelengths however, it was not possible to distinguish, between the following photochemical processes, leading to the tetracyano species:

(1) $\quad(\mathrm{NC})_{5} \mathrm{Fepy}(\mathrm{CO}) \mathrm{CH}(\mathrm{NOH}) \stackrel{\mathrm{hV}}{\longrightarrow} \mathrm{Fe}(\mathrm{CN})_{4} \mathrm{py}(\mathrm{CO}) \mathrm{CH}\left(\mathrm{NOH}+\mathrm{CN}^{-}\right.$

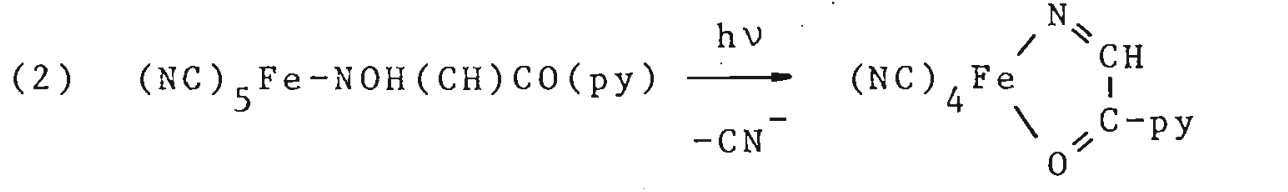

The, second process taking place on the oxime isomer, which may be eventually present in very small amount, is expected to be highly effective because of the neighbor = ing effect enhancing the formation of the 5 member ring. To clarify this point, we have investigated the photochemistry of the $\mathrm{Fe}(\mathrm{CN})_{5}(\mathrm{en})^{3-}$ complex.

The results indicated that the formation of the $\mathrm{Fe}(\mathrm{CN})_{4} \mathrm{en}^{2-}$ complex takes place with a quantum yield of $0,087 \pm 0,005$ at $366 \mathrm{~nm}$, which is nearly 10 times the values obtained for carbonyl-oxime complexes. In this case, the photochemical process can be analysed quantitatively by determining the amount of the starting complex, or by isola ting the tetracyanospecies by ionic exchange chromatography. Both ways gave comparable numbers, indicating that the measured quantum yields refer to the process 
(NC) ${ }_{5} \mathrm{Fe}-\mathrm{NH}_{2}-\mathrm{CH}_{2}-\mathrm{CH}_{2}-\mathrm{NH}_{2}^{3-} \longrightarrow$ hV $(\mathrm{NC})_{4} \mathrm{Fe}_{\substack{\mathrm{N}_{2} \\ \mathrm{H}_{2}}}^{\stackrel{\mathrm{C}_{2}^{2}}{\mathrm{C}_{2}} \mathrm{H}_{2}}+\mathrm{CN}^{-}$

We therefore concluded that the labilization of the $\mathrm{CN}$ ligands in the carbonyl-oxime complexes should take place mostly according to the first route. 
11.1. Decomposição das Bandas de Absorção

Um espectro de absorção de uma substância regị tra a variação do coeficiente de extinção molar $(\varepsilon)$ como fur ção do comprimento de onda $(\lambda)$ ou do número de onda $(\nu)$. Uma grande classe dos espctros de absorção eletrônica é com posta de uma ou mais bandas simétricas em relação ao máximo. Várias expressões $(237,309)$ tem sido propostas para descre ver a forma exata destas bandas.

Kuhn e Braun (296) citaram a curva Gaussiana si ples cono melhor aproximação onde pode-se tirar a expressão

$$
\varepsilon=\varepsilon_{0} 2-\left(\frac{\nu-\nu_{0}}{\delta}\right)^{2}
$$

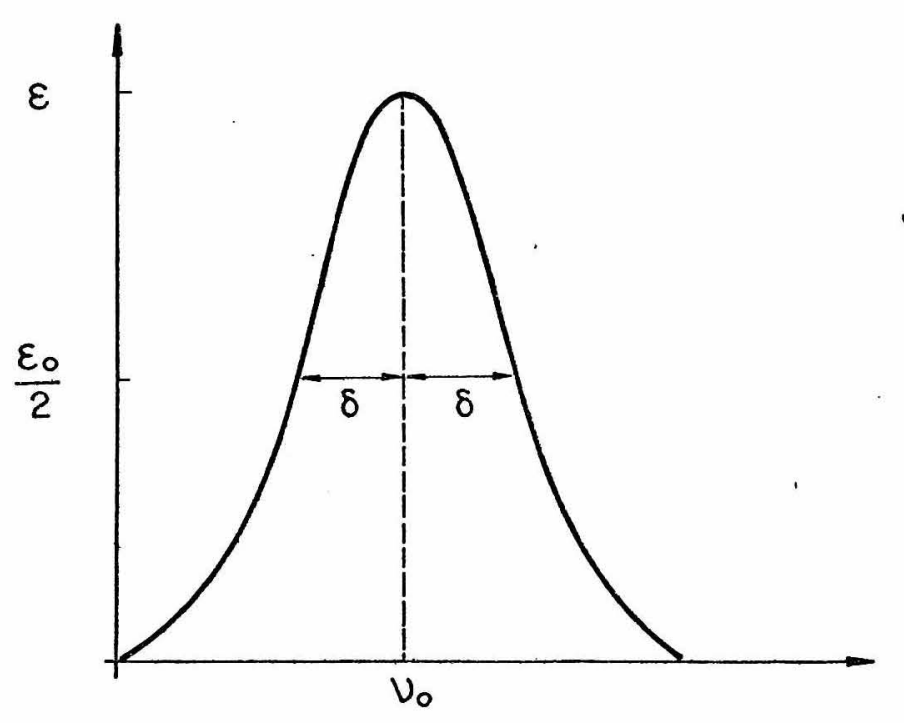

$\varepsilon_{0}=$ coeficiente de extinção no máximo de absor ção 
$\delta$ = metade da largura da meia banda (desde que $\varepsilon=\varepsilon_{0} / 2$ para $\sigma=\sigma_{0} \pm \delta$

$\nu_{0}=$ nūmero de onda no māximo de absorção

A ārea da banda nessa representação é proporcio nal ao produto de $\delta$ e $\nu_{0}$ para $\nu_{0} \gg \delta$

$$
\begin{aligned}
A & =\int_{0}^{\infty} \varepsilon \mathrm{d} \nu=2 \varepsilon_{0} \int_{0}^{\infty} \mathrm{e}^{-\left(\nu-\nu_{0}\right)^{2} \delta^{-2}} \ln 2 \mathrm{~d}\left(\nu-\nu_{0}\right) \\
& =\frac{\sqrt{\pi}}{\sqrt{\ln 2}}=\varepsilon_{0} \delta=2,1289 \varepsilon_{0} \delta
\end{aligned}
$$

Esta ārea é proporcional à força do oscilador. (310)da transição ( probabilidade da transição (P) )

$f=P=\frac{1000}{N} \cdot \frac{m c^{2}}{\pi e^{2}} 2,30 \int \varepsilon d \nu=4,32 \times 10^{-9} \int \varepsilon d \nu$

$$
=9,2 \times 10^{-9} \varepsilon_{0} \delta
$$

sendo $N=$ número de Avogadro, e e m a carga e a massa do elétron, e c a velocidade da luz no vácuo (311)

Lowry e Hudson (312) propuseram o uso da förmula Gaussiana com $\lambda$ como variavel independente, tendo conzido em muitos casos a uma melhor representação (318). 


$$
\varepsilon=\varepsilon_{0} \mathrm{e}^{-\left(\frac{\lambda-\lambda_{0}}{\delta}\right)^{2}}
$$

Jørgensen (236) ao analisar as bandas do espectro eletrōnico de diversos complexos definiu como curvas ligeiramente distorcidas com metade de meia banda ligeiramente diferentes $(\delta(-)$ e $\delta(+))$. Estas, quando usadas na expressão (1) para $\nu<\nu_{0}$ e $\nu>\nu_{0}$, respectivamente, descrevem o espectro dentro da precisão experimental de cerca de $1 \%(314)$.

o coeficiente diferencial descontínuo no māximo quando $\delta(-)$ e $\delta(+)$ são diferentes, não é significative comparado com as variações pequailas de $\varepsilon$ com $v$ próximo do māximo.

Tem-se assim um método comum para caracterizar as bandas através de $\tilde{\nu}_{0}\left(\mathrm{~cm}^{-1}\right), \quad \varepsilon_{0}\left(1\right.$ itro.mol $\left.{ }^{-1} \mathrm{~cm}^{-1}\right)$ e da àrea $A\left(1 . \mathrm{mol} . \mathrm{cm}^{-2}\right)$.

Para melhor representar a deformação, a ārea $A$ pode ser calculada através de uma expressão geral

$$
A=\delta_{\text {banda }}(\tilde{\nu}) d \tilde{\nu}=a_{s} \varepsilon_{0} H
$$

onde $H$ é a largura da meia banda $(\delta(+)$ e $\delta(-))$, a $s \bar{\epsilon}$ constante de Smakula (315) que depende da forma da banda, variando de 1,06 para a Gaussiana e a Gaussiana dupla ( 225) a 1,57 para a Lorenziana (316). 
Uma vez que as bandas quase nunca são totalmente simētricas, deve-se informar além destes trēs parāmetros, aquele correspondente à deformação. Um dado empîrico conve niente para tal fim é a razão das distāncias da banda a $\varepsilon_{0} / 2$ representada por $\rho$.

$$
\rho=\left(\frac{z_{2}-z_{0}}{z_{0}-z_{1}}\right)
$$

Uma reconstrução da forma das bandas de absorção, em todos os seus detalhes, pode ser feita pela fórmula de Edgewood $(237,316)$. Entretanto devido aos erros experimentais, especialmente nas extremidades das bandas onde ocorrem super posições das bandas adjacentes, um procedimento mais comum é utilizar o método de Pearson (317), ajustando funções frequên cia em estatistica.

Em 1969, Siano e Metzler (237) estudaram deta Thadamente a forma das bandas dos espectros eletrônicos. Os resultados levaram a uma expressão analîtica que se situa na distribuição de Pearson tipo VI. Os autores observaram que a distribuição conhecida como log normal $(319,320)$, descreve bem a forma destas bandas.

A curva log normal tem a seguinte expressão:

$g(z) d z=\left\{\frac{1}{\sqrt{2 \pi}} \cdot \frac{1}{c(z-a)}\right\} \exp -\left\{\frac{1}{2 c^{2}}\left[\ln \left(\frac{z-a}{b}\right)\right]^{2}\right\} d z$ 
$z>a$

$g(z) d z=0, \quad z<a$

Onde $g(z) d z$ é a probabilidade de observar ao acaso um valor da variāvel z entre $z$ e $z+d z$.

A $10 \mathrm{~g}$ normal descrita nessa forma tem a ārea to tal unitāria. Para uma função não normalizada, o coeficiente entre as chaves antes do termo exponencial é trocado pelo

$$
\left[y_{0} b /(z-a)\right] \exp \left(-c^{2} / 2\right)
$$

onde $y_{o} \quad \bar{e}$ māximo de $g(z)$ e os significados geomētrí cos dos parāmetros $a, b$ e c podem ser obtidos na figura abaixo que mostra uma curva log normal típica.

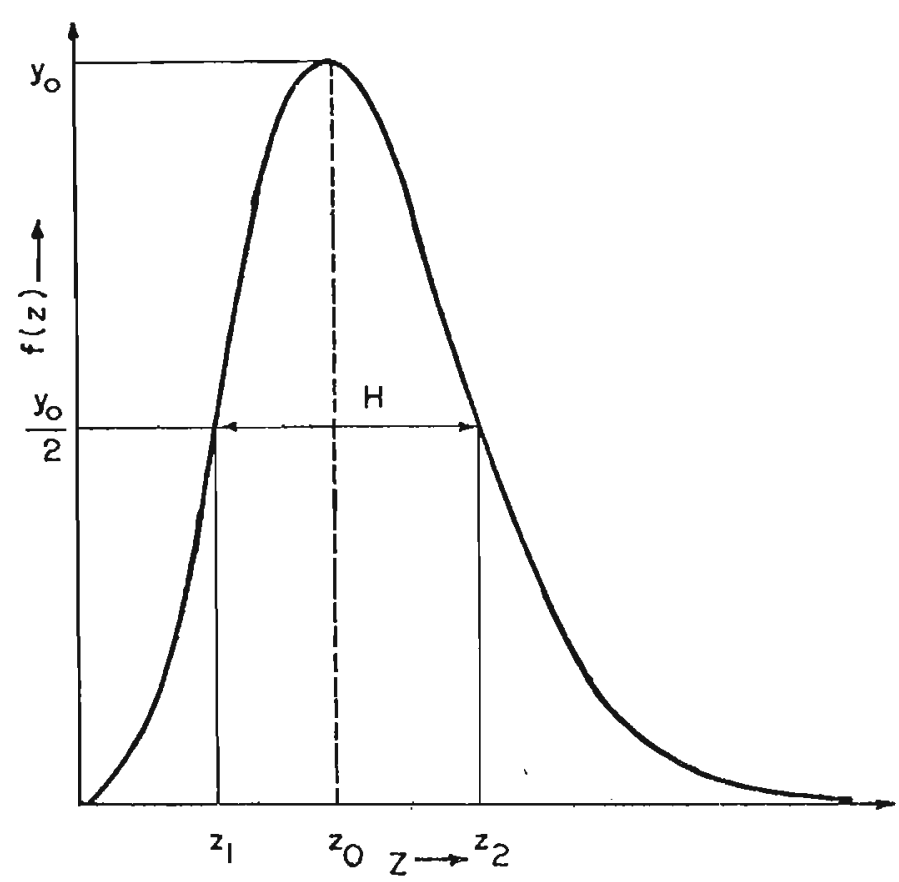


Condicionando a expressão (8) para passar atra vēs dos pontos $\left(\mathrm{y}_{0} / 2 ; z_{1}\right),\left(y_{0}, z_{0}\right)$ e $\left(y_{0} / 2, z_{2}\right)$ os parâmetros a, $b$ e c podem ser relacionados a $z_{0}$, H e $\rho$ pela expressão

$$
\begin{aligned}
& \mathrm{c}=(\ln \rho) \sqrt{2 \ln 2} \\
& \mathrm{~b}=\mathrm{H}\left[\rho /\left(\rho^{2}-1\right)\right] \text { exp }\left(c^{2}\right) \\
& \mathrm{a}=\mathrm{z}_{\mathrm{o}}-\mathrm{H} \rho /\left(\rho^{2}-1\right)
\end{aligned}
$$

Substituindo equações (9), (10) e (11) em (8) dá

$$
\begin{aligned}
& g(z)=y_{o} \exp -\left\{\frac{\ln 2}{(\ln \rho)^{2}}\left[\ln \left(\frac{z-z_{0}}{H} \frac{\rho^{2}-1}{\rho}+1\right)\right]^{2}\right\} \\
& z>z_{0}-\frac{\mathrm{H} \rho}{\rho^{2}-1}
\end{aligned}
$$

Sendo esta, uma forma conveniente para a log nor mal em termos de parāmetros empíricos facilmente obtidos como $\mathrm{y}_{\mathrm{o}}, \mathrm{z}_{\mathrm{o}}, \mathrm{H}$ e $\rho$. Através do uso sucessivo da regra de L'Hospital verifica-se que a medida que $\rho$ se aproxima de i,0; a distribuição log normal se aproxima assintoticamente a da Gaussiana (318).

A distribuição $\log$ normal tem algumas vanta gens sobre as outras funções possiveis que tem sido usadas para descrever distribuições assimētricas. Sua conecção ĩnti ma com a Gaussiana permite que muitas das suas propriedades 
sejam obtidas das propriedades da Gaussiana (319). Esta rela ção permite utilizar tabelas das Gaussianas nos cálculos. Mas, o mais importante é o fato que a log normal parece ajus tar os dados muito bem

11.2. Derivação das Leis de Velocidade

11.2.1. Derivação da lei de velocidade para o mecanismo

$$
\begin{gathered}
\mathrm{Fe}(\mathrm{CN})_{5} \mathrm{H}_{2} \mathrm{O}^{3-}(\mathrm{aq}) \stackrel{\mathrm{k}_{-\mathrm{a}}}{\mathrm{k}_{\mathrm{a}}} \mathrm{Fe}(\mathrm{CN})_{5}^{3-}(\mathrm{aq})+\mathrm{H}_{2} \mathrm{O} \\
\mathrm{Fe}(\mathrm{CN})_{5}{ }^{3-}(\mathrm{aq})+\mathrm{L}(\mathrm{aq}) \stackrel{\mathrm{k}_{1}}{\longrightarrow} \mathrm{Fe}(\mathrm{CN})_{5} \mathrm{~L}^{3-}(\mathrm{aq})
\end{gathered}
$$

Chamando: $\mathrm{Fe}(\mathrm{CN})_{5} \mathrm{H}_{2} \mathrm{O}^{3-}=\mathrm{R}$

$\mathrm{Fe}(\mathrm{CN})_{5} \mathrm{~L}^{3-}=\mathrm{P}$

$\mathrm{Fe}(\mathrm{CN})_{5}^{3-}=\mathrm{I}$

$\frac{d P}{d t}=k_{1}[I][L]$

$\frac{d[I]}{d t}=k_{-a}[R]-k_{a}[I]-k_{1}[L][I]$

Assumindo a hipótese do estado estacionārio para I, tem-se

$\frac{d[I]}{d t}=0 \quad[I]=\frac{k_{-a}[R]}{k_{a}+k_{1}[L]}$ 
$\frac{d[P]}{d t}=\frac{k_{1} k_{-a}[R][L]}{k_{a}+k_{1}[L]}$

sendo $[\mathrm{P}]_{\infty}=[\mathrm{P}]+[\mathrm{R}]$ e $[\mathrm{R}]=[\mathrm{P}]_{\infty}-[\mathrm{P}]$

segue que $\frac{d[P]}{[P]-[P]}=\frac{k_{1} k_{-a}[L]}{k_{a}+k_{1}[L]} d t$

integrando

$$
\mathrm{k}_{\mathrm{obs}}=\frac{\mathrm{k}_{1} \mathrm{k}_{-\mathrm{a}}[\mathrm{L}]}{\mathrm{k}_{\mathrm{a}}+\mathrm{k}_{1}[\mathrm{~L}]}
$$

11.2.2. Derivação da lei de velocidade paŕa o mecanismo

$$
\begin{aligned}
& \mathrm{Fe}(\mathrm{CN})_{5} \mathrm{~L}^{3-}(\mathrm{aq}) \stackrel{\mathrm{k}-1}{\mathrm{k} 1} \mathrm{Fe}(\mathrm{CN})_{5}{ }^{3-}(\mathrm{aq})+\mathrm{L}(\mathrm{aq}) \\
& \mathrm{Fe}(\mathrm{CN})_{5}{ }^{3-}(\mathrm{aq})+\mathrm{H}_{2} \mathrm{O} \stackrel{\mathrm{K}_{\mathrm{a}}}{\rightleftharpoons} \mathrm{Fe}(\mathrm{CN})_{5} \mathrm{H}_{2} \mathrm{O}^{3-}(\mathrm{aq}) \\
& \mathrm{Fe}(\mathrm{CN})_{5}{ }^{3-}(\mathrm{aq})+\mathrm{dmso}=\frac{\mathrm{k}_{2}}{\mathrm{k}-2} \mathrm{Fe}(\mathrm{CN})_{5} \mathrm{dmso}^{3-}(\mathrm{aq})
\end{aligned}
$$

$\begin{aligned} \text { Chamando } \quad & {\left[\mathrm{Fe}(\mathrm{CN})_{5} \mathrm{dmso}^{3-}\right]=\mathrm{P} } \\ & {\left[\mathrm{Fe}(\mathrm{CN})_{5}{ }^{3-}\right]=\mathrm{I} } \\ & {\left[\mathrm{Fe}(\mathrm{CN})_{5} \mathrm{~L}^{3-}\right]=\mathrm{R} } \\ & {[\text { dimeti1sulföxido }]=\text { dmso } }\end{aligned}$ 


$$
\begin{aligned}
& \frac{d P}{d t}=k_{2} \cdot I \cdot d m s o-k_{-2} \cdot P \\
& \frac{d I}{d t}=k_{-1} \cdot R+k_{-2} \cdot P-k_{1} \cdot I \cdot L-k_{2} \cdot I \cdot d m s o
\end{aligned}
$$

Assumindo-se a hipōtese do estado estacionārio em I, temse

$\frac{d I}{d t}=0$ e $I \cdot\left(k_{1} \cdot L+k_{2} \cdot d m s o\right)=k_{-1} \cdot R+k_{-2} \cdot P$

substituindo (2) em (1)

$\frac{d P}{d t}=k_{2} \frac{k_{-1} \cdot R+k_{-2} \cdot P}{k_{1} L+k_{2} \text { dmso }} d \mathrm{dmso}-k_{-2} \cdot P$

$\frac{\mathrm{d} P}{\mathrm{~d} t}=\frac{\mathrm{k}_{2} \mathrm{k}_{-1} \cdot \mathrm{R} \cdot \mathrm{dmso}-\mathrm{k}_{-2} \mathrm{k}_{1} \cdot \mathrm{P} \cdot \mathrm{L}}{\mathrm{k}_{1} \mathrm{~L}+\mathrm{k}_{2} \cdot \mathrm{dmso}}$

Chamando de $R_{0}$ a concentração total do complexo,

$$
\mathrm{R}_{\mathrm{O}}=\mathrm{R}+\mathrm{P}=\mathrm{R}_{\infty}-\mathrm{P}_{\infty}
$$

no equilībrio

$$
\frac{P_{\infty}}{R_{\infty}}=\frac{k_{2} k_{-1} \cdot d m s o}{k_{-2} k_{1} L}
$$


substituindo $R$ por $R_{0}-P$ na equação (3) tem -se

$\frac{d P}{d t}=\frac{k_{2} k_{-1} d m s o \cdot R_{0}-k_{2} k_{-1} d m s o \cdot P-k_{-2} k_{1} P \cdot L}{k_{1} L+k_{2} d m s o}$

introduzindo a equação (5) em (6), tem-se

$\frac{d P}{d t}=\frac{k_{2} k_{-1} d m s o\left(k_{0}-R-P+k_{-2} k_{1} L\right) P_{\infty}-P}{k_{1} L}$

considerando - se que $R_{0}-R=P_{\infty}$

$\frac{d P}{d t}=\frac{\left(k_{2} k_{-1} d m s o+k_{-2} k_{1} L\right)\left(P_{\infty}-P\right)}{k_{1}^{\prime} L+k_{2} \text { dmso }}$

$\frac{d P}{P_{\infty}-P}=\frac{k_{2} k_{-1} \text { dmso }+k_{-2} k_{1} L}{k_{1} L+k_{2} \text { dmso }} d t$

integrando

$$
k_{\text {obs }}=\frac{k_{2} k_{-1} d m s o+k_{-2} k_{1} L}{k_{1} L+k_{2} \text { dmso }}
$$

11.2.3. Derivação da Lei de velocidade para o mecanismo

$$
\begin{gathered}
\mathrm{A} \stackrel{\mathrm{K}}{\longrightarrow} \mathrm{B} \\
\mathrm{Fe}(\mathrm{CN})_{5} \mathrm{H}_{2} \mathrm{O}^{3-} \frac{\mathrm{k}_{-\mathrm{H}_{2} \mathrm{O}}}{\mathrm{k}_{\mathrm{H}_{2} \mathrm{O}}} \mathrm{Fe}(\mathrm{CN})_{5} 3-+\mathrm{H}_{2} \mathrm{O}
\end{gathered}
$$




\section{4}

$$
\mathrm{Fe}(\mathrm{CN})_{5}{ }^{3-}(\mathrm{aq})+\mathrm{B} \frac{\mathrm{k}_{\mathrm{B}}}{\mathrm{k}_{-\mathrm{B}}}(\mathrm{NC})_{5} \mathrm{Fe} \cdot \mathrm{B}^{3-}(\mathrm{aq})
$$

Chamando concentração do ligante na

$\begin{array}{ll}\text { forma não coordenante } & =A \\ \text { Concentração do ligante na } & =B \\ \text { forma coordenante } & =B\end{array}$

$\left[\mathrm{Fe}(\mathrm{CN}){ }_{5} \mathrm{H}_{2} \mathrm{O}^{3-}\right]=\mathrm{R}$

$\left[\mathrm{Fe}(\mathrm{CN})_{5}^{3-}\right]=\mathrm{I}$

$\left[\mathrm{Fe}(\mathrm{CN})_{5} \mathrm{~B}^{3-}\right] \quad=\mathrm{P}$

concentração total do

ligante $=L=A+B$

$\frac{d P}{d t}=k_{B} \cdot I \cdot B-k_{-B} \cdot P$

$\frac{d I}{d t}=k_{H_{2} O} R-k_{H_{2} O} I-k_{B} I B+k_{-B} P$

assumindo a hipótese do estado estacionário para o interme diārio I, onde $K=B / A$, com concentração predominate de

$\frac{d I}{d t}=0 \quad I=\frac{k_{-H_{2} \mathrm{O}}{ }^{R}}{k_{\mathrm{H}_{2} \mathrm{O}}}+\frac{{ }^{k}-\mathrm{B}}{k_{\mathrm{H}_{2} \mathrm{O}}}$ p se $k_{\mathrm{H}_{2} \mathrm{O}}>k_{B}$

substituindo na equação

$\frac{d P}{d t}=\frac{k_{1} k-H_{2} \mathrm{O}}{k_{\mathrm{H}_{2} \mathrm{O}}} K \cdot L \cdot R+\frac{k_{B}{ }^{k}-B}{k_{\mathrm{H}_{2} \mathrm{O}}} K \quad$ L $P-k_{-B} P$ 


$$
\begin{gathered}
\text { sendo } \frac{k_{B} k_{-H_{2} O}}{k_{H_{2} O}}=k_{f B} \text { a expressão (2) fica } \\
=k_{f B} \text { K.L.R. }+\left(\left(k_{B} k_{-B} / k_{H_{2} O}\right) K \cdot L-k_{-B}\right) \cdot P
\end{gathered}
$$

Fazendo o balanço de material

$$
\begin{aligned}
& \mathrm{R}_{\mathrm{eq}}+\mathrm{P}_{\mathrm{eq}}=\mathrm{R}+\mathrm{P} \rightarrow \mathrm{R}-\mathrm{R}_{\mathrm{eq}}=\mathrm{P}_{\mathrm{eq}}-\mathrm{P} \\
& \text { no equilíbrio } \frac{d P}{d t}=0 \text { e da equação } \\
& \mathrm{k}_{\mathrm{B}} \mathrm{I} \cdot \mathrm{B}=\mathrm{k}_{-\mathrm{B}} \cdot \mathrm{P}_{\mathrm{eq}} \\
& k_{f B} K \cdot L \cdot R_{e q}+\frac{k_{B} k_{-B}}{k_{H_{2} O}} K \cdot L \cdot P_{e q}=k_{-B} P_{e q} \\
& k_{f B} K \cdot L \cdot R_{e q}=\left(k_{-B}-\frac{{ }^{k}{ }_{B} k_{-B}}{k_{H_{2} O}} K \cdot L\right) P_{e q}
\end{aligned}
$$

somando e subtraindo na expressão

$$
\begin{aligned}
\frac{d P}{d t}= & k_{f B} K \cdot L \cdot\left(R-R_{e q}\right)+\left(\left(k_{B} k_{-B} / k_{H_{2} O}\right) \cdot K \cdot L\right)\left(P-P_{e q}\right) \\
& +k_{-B}\left(P_{e q}-P\right)
\end{aligned}
$$

$$
\begin{gathered}
\text { como } R-R_{e q}=P_{e q}-P \\
\frac{d P}{d t}=k_{f B} K \cdot L\left(P_{e q}-P\right)-\left(k_{B} k_{-B} / k_{H_{2} O}\right) K \cdot L \cdot\left(P_{e q}-P\right)+ \\
k_{-B}\left(P_{e q}-P\right)
\end{gathered}
$$


$\frac{d P}{d t}=\left\{k_{f B} K \cdot L+k_{-B}-\frac{k_{B} k_{-B}}{k_{H_{2} O}} K L\right\} \quad\left(P_{e q}-P\right)$ $\frac{d P}{P_{\text {eq }}-P}=k_{f B} K \cdot L+k_{-B}-\frac{k_{B} k_{-B}}{k_{H_{2} O}} K \cdot L$ $\mathrm{k}_{\mathrm{obs}}=\left(\mathrm{k}_{\mathrm{fB}}-\frac{\mathrm{k}_{\mathrm{B}} \mathrm{k}_{-\mathrm{B}}}{\mathrm{k}_{\mathrm{H}_{2} \mathrm{O}}}\right) \mathrm{K} \mathrm{L} ; \mathrm{k}_{-\mathrm{B}}$

como

$$
\begin{aligned}
& \mathrm{k}_{\mathrm{H}_{2} \mathrm{O}} \gg \mathrm{k}_{\mathrm{B}} \mathrm{k}_{-\mathrm{B}} \\
& \mathrm{k}_{\text {obs }}=\mathrm{k}_{f B} \mathrm{~K} L+k_{-B}
\end{aligned}
$$

11.2.4. Derivação da lei de velocidade para o mecanismo

(1) (NC) ${ }_{5} \mathrm{FeNO}^{2-}+\mathrm{OH}^{-}-{ }^{\mathrm{K}} \mathrm{OH}=(\mathrm{NC})_{5} \mathrm{FeNO}_{2} \mathrm{H}^{3-}$

(1a) (NC) ${ }_{5} \mathrm{FeNO}_{2} \mathrm{H}^{3-}+\mathrm{OH}^{-} \longrightarrow(\mathrm{NC})_{5} \mathrm{FeNO}_{2}{ }^{4-}+\mathrm{H}_{2} \mathrm{O}$

(2) $\mathrm{py}(\mathrm{CO}) \mathrm{CH}_{3}+\mathrm{OH}^{-} \rightleftharpoons \mathrm{K} \rightleftharpoons \mathrm{py}(\mathrm{CO}) \mathrm{CH}_{2}^{-}+\mathrm{H}_{2} \mathrm{O}$

(3) $(\mathrm{NC})_{5} \mathrm{FeNO}^{2-}+\mathrm{py}(\mathrm{CO}) \mathrm{CH}_{2}{ }^{-} \frac{\mathrm{kL}}{\mathrm{k}_{-\mathrm{L}}}(\mathrm{NC})_{5} \mathrm{Fe}^{\mathrm{I}}(\mathrm{NO}) \mathrm{CH}_{2}(\mathrm{CO}) \mathrm{py}^{3-}$

Chamando $\quad\left[(N C)_{5} \mathrm{Fe}(\mathrm{NO})^{2-}\right]=R$

$$
\begin{aligned}
& {\left[\mathrm{py}(\mathrm{CO}) \mathrm{CH}_{3}\right]=\mathrm{L}} \\
& {\left[\mathrm{py}(\mathrm{CO}) \mathrm{CH}_{2}^{-}\right]=\mathrm{L}^{-}} \\
& {\left[(\mathrm{NC})_{5} \mathrm{Fe}(\mathrm{NO}) \mathrm{CH}_{2}(\mathrm{CO}) \mathrm{py}^{3-}\right]=\mathrm{I}}
\end{aligned}
$$


Sendo a etapa (1a), uma reação rāpida, as etapas determinan tes da reação são (1), (2) e (3)

$-\frac{d R}{d t}=k_{L} R^{-}-k_{-L} I+k_{O H} R\left[\mathrm{OH}^{-}\right]$

sendo $\mathrm{L}^{-}=\mathrm{K} \quad \mathrm{L}\left[\mathrm{OH}^{-}\right]$

$-\frac{d R}{d t}=\mathrm{Kk}_{\mathrm{L}} \mathrm{R} \cdot \mathrm{L} \cdot\left[\mathrm{OH}^{-}\right]+\mathrm{k}_{\mathrm{OH}} \mathrm{R} \cdot\left[\mathrm{OH}^{-}\right]-\mathrm{k}_{-\mathrm{L}} \mathrm{I}$

no equilíbrio $\quad-\frac{\mathrm{d} R}{\mathrm{~d} t}=0 \quad$ da equação

$\mathrm{K} \mathrm{k}_{\mathrm{L}} \mathrm{I}\left[\mathrm{OH}^{-}\right] \mathrm{R}_{\mathrm{eq}}+\mathrm{k}_{\mathrm{OH}}\left[\mathrm{OH}^{-}\right] \mathrm{R}_{\mathrm{eq}}-\mathrm{k}_{-1} \mathrm{I}_{\mathrm{eq}}=0$ portanto

$\left(\mathrm{K} \cdot \mathrm{k}_{\mathrm{L}} \mathrm{L}\left[\mathrm{OH}^{-}\right]+\mathrm{k}_{\mathrm{OH}}\left[\mathrm{OH}^{-}\right]\right) \mathrm{R}_{\mathrm{eq}}=\mathrm{k}_{-\mathrm{L}} \mathrm{I}_{\mathrm{eq}}$

somando e subtraindo a equação (2) em (1)

$$
\begin{aligned}
-\frac{d R}{d t}= & \left(\mathrm{Kk}_{\mathrm{L}} \cdot \mathrm{L}\left[\mathrm{OH}^{-}\right]+\mathrm{k}_{\mathrm{OH}}\left[\mathrm{OH}^{-}\right]\right) \mathrm{R}-\mathrm{k}_{-\mathrm{L}} \mathrm{I}- \\
& \left(\mathrm{K} \cdot \mathrm{k}_{\mathrm{L}} \cdot \mathrm{L}\left[\mathrm{OH}^{-}\right]+\mathrm{k}_{\mathrm{OH}}\left[\mathrm{OH}^{-}\right]\right) \mathrm{R}_{\mathrm{eq}}+\mathrm{k}_{-\mathrm{L}} \mathrm{I}_{\mathrm{eq}}
\end{aligned}
$$

somando e substraindo a equação (2) em

$$
\begin{aligned}
-\frac{d R}{d t}= & \left(\mathrm{K}_{\mathrm{L}_{\mathrm{L}}} \cdot \mathrm{L} \cdot\left[\mathrm{OH}^{-}\right]+\mathrm{k}_{\mathrm{OH}}\left[\mathrm{OH}^{-}\right]\right)\left(\mathrm{R}-\mathrm{R}_{\mathrm{eq}}\right)+ \\
& \left(\mathrm{k}_{-\mathrm{L}}\left(\mathrm{I}_{\mathrm{eq}}-\mathrm{I}\right)\right.
\end{aligned}
$$

Fazendo o balanço de massa 
$\mathrm{R}_{\mathrm{eq}}+\mathrm{I}_{\mathrm{eq}}=\mathrm{R}+\mathrm{I}=\mathrm{R}_{\mathrm{T}}$

$$
R-R_{e q}=I_{e q}-I
$$

Da igualdade da expressão (4), a equação(3) pode ser escr ta da seguinte forma

$-\frac{d R}{d t}=\left(K_{0} k_{L} L \cdot\left[\mathrm{OH}^{-}\right]+k_{O H}\left[\mathrm{OH}^{-}\right]+k_{-L}\right) R-R_{e q}$
$-\frac{d R}{R-R_{e q}}=\left(K_{L_{L}} L\left[\mathrm{OH}^{-}\right]+k_{O H}\left[\mathrm{OH}^{-}\right]+k_{-L}\right) d t$

Integrando

$$
\mathrm{k}_{\mathrm{obs}}=\mathrm{K} \cdot \mathrm{k}_{\mathrm{L}} \mathrm{L}\left[\mathrm{OH}^{-}\right]+\mathrm{k}_{\mathrm{OH}}\left[\mathrm{OH}^{-}\right]+\mathrm{k}_{-\mathrm{L}}
$$

11.2.5. Derivação da lei de velocidade para o mecanismo

(1) $\mathrm{py}(\mathrm{CO}) \mathrm{CH}_{3}+\mathrm{OH}^{-} \stackrel{\mathrm{K}}{\rightleftharpoons} \mathrm{py}(\mathrm{CO}) \mathrm{CH}_{2}^{-}+\mathrm{H}_{2} \mathrm{O}$

(2) $(\mathrm{NC})_{5} \mathrm{FeNO}^{2-}+\mathrm{OH}^{-} \stackrel{\mathrm{K}_{\mathrm{OH}}}{\longrightarrow}(\mathrm{NC})_{5} \mathrm{FeNO}_{2} \mathrm{H}^{3-}$ (aq)

(2a) (NC) ${ }_{5} \mathrm{FeNO}_{2} \mathrm{H}^{3-}+\mathrm{OH}^{-} \stackrel{\text { rāpida }}{\longrightarrow}(\mathrm{NC})_{5} \mathrm{FeNO}_{2}{ }^{4-}(\mathrm{aq})+\mathrm{H}_{2} \mathrm{O}$

(3) $(\mathrm{NC})_{5} \mathrm{FeNO}^{2-}+\mathrm{py}(\mathrm{CO}) \mathrm{CH}_{2}-\frac{\mathrm{k}_{\mathrm{L}}}{\underset{\mathrm{k}_{-\mathrm{L}}}{\rightleftharpoons}}(\mathrm{NC})_{5} \mathrm{Fe}(\mathrm{NO}) \mathrm{CH}_{2}(\mathrm{CO}) \mathrm{py}^{3-}$

$$
\left(K_{I}\right)
$$

(4) $(\mathrm{NC})_{5} \mathrm{Fe}(\mathrm{NO}) \mathrm{CH}_{2}(\mathrm{CO}) \mathrm{py}^{3-} \stackrel{\mathrm{k}_{\mathrm{d}}}{-} \mathrm{Fe}(\mathrm{CN})_{5}^{3-}+\mathrm{py}(\mathrm{CO}) \mathrm{CH}_{2} \mathrm{NO}^{3-}$

(5) $\mathrm{py}(\mathrm{CO}) \mathrm{CH}_{2} \mathrm{NO}(\mathrm{aq})+\mathrm{OH}^{-} \stackrel{\text { räpida }}{-} \mathrm{py}(\mathrm{CO}) \mathrm{CHNO}^{-}+\mathrm{H}_{2} \mathrm{O}$ 
(6) $\mathrm{Fe}(\mathrm{CN})_{5}^{3-}+\mathrm{H}_{2} \mathrm{O} \stackrel{\mathrm{K}}{=} \mathrm{Fe}(\mathrm{CN})_{5} \mathrm{H}_{2} \mathrm{O}^{3-}$

(7) $\mathrm{Fe}(\mathrm{CN})_{5}^{3-}+\mathrm{py}(\mathrm{CO}) \mathrm{CH}_{3} \stackrel{\text { rápida }}{\longrightarrow} \mathrm{Fe}(\mathrm{CN})_{5} \mathrm{py}(\mathrm{CO}) \mathrm{CH}_{3}{ }^{3-}$

$$
\begin{aligned}
& \left.\begin{array}{ll}
\text { Chamando } & {\left[(N C)_{5} \mathrm{FeNO}_{2}^{4-}\right]} \\
& {\left[(N C)_{5} \mathrm{FeL}^{3-}\right]} \\
& {\left[(N C)_{5} \mathrm{FeH}_{2} \mathrm{O}^{3-}\right] *}
\end{array}\right\}= \\
& {\left[(N C)_{5} \mathrm{Fe}(\mathrm{NO}) \mathrm{CH}_{2}(\mathrm{CO}) \mathrm{py}^{3-}\right]=\mathrm{I}} \\
& {\left[\mathrm{Py}(\mathrm{CO}) \mathrm{CH}_{3}\right]=\mathrm{L}} \\
& {\left[\operatorname{py}(\mathrm{CO}) \mathrm{CH}_{2}^{-}\right]=\mathrm{L}^{-}} \\
& {\left[(N C)_{5} \mathrm{Fe}(\mathrm{NO})^{2-}\right]=R}
\end{aligned}
$$

$\frac{d P}{d t}=k_{d} I+k_{O H} R\left[\mathrm{OH}^{-}\right]$

$$
\mathrm{K}_{\mathrm{I}}=\frac{\mathrm{I}}{\mathrm{L}^{-} \cdot \mathrm{R}} \quad(\mathrm{a}) \quad \mathrm{K}=\frac{\mathrm{L}^{-}}{\mathrm{L} \cdot\left[\mathrm{OH}^{-}\right]}
$$

substituindo (b) enl (a)

$$
\mathrm{K}_{\mathrm{I}}=\frac{\mathrm{I}}{\mathrm{K} \cdot \mathrm{L} \cdot\left[\mathrm{OH}^{-}\right] \cdot \mathrm{R}}
$$

substituindo (c) na expressão (1) e rearranjando chamando de $K_{T}$ o produto. $K_{I} \cdot K$

apenas quando $L=0-p y\left(\mathrm{CO}^{\mathrm{C}} \mathrm{CH}_{3}\right.$ 
$\frac{d P}{d t}=\left(k_{d} K_{T} L\left[\mathrm{OH}^{-}\right]+k_{O H}\left[\mathrm{OH}^{-}\right]\right) \quad R$

Fazendo o balanço de massa

$\mathrm{P}_{\infty}=\mathrm{R}_{\mathrm{T}}=\mathrm{R}+\mathrm{I}+\mathrm{P} \quad \therefore \mathrm{P}_{\infty}-\mathrm{P}=\mathrm{R}+\mathrm{I}$

substituindo (c) em (3) e rearranjando

$P_{\infty}-P=\left(1+K_{T} L\left[\mathrm{OH}^{-}\right]\right) R$

$$
R=\frac{P_{\infty}-P}{1+K_{T} L\left[\mathrm{OH}^{-}\right]}
$$

substituindo (4) na expressão (2) e rearranjando

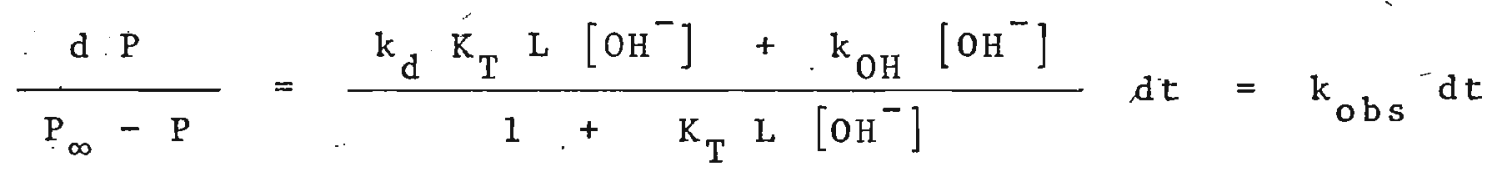

In tegrando

$$
k_{\mathrm{obs}}=\frac{\mathrm{k}_{\mathrm{d}} \mathrm{k}_{\mathrm{T}} \mathrm{L}\left[\mathrm{OH}^{-}\right]+\mathrm{k}_{\mathrm{OH}}\left[\mathrm{OH}^{-}\right]}{1+\mathrm{K}_{\mathrm{T}} \mathrm{L}\left[\mathrm{OH}^{-}\right]}
$$




\subsection{Resultados Experimentais Complementares}

11.3.1. Determinação de Teor de Ferro

A determinação analîtica do teor de ferro (II) nos complexos de pentacianoferrato foi feita através de titulação potenciométrica.

Empregou-se o Ce(IV) como agente oxidante, num meio tamponado com àcido acético e acetato de sódio 0,5M/ $0,5 \mathrm{M}$, para evitar a protonação dos complexos.

O potencial formal do Ce(IV) nas condições de trabalho foi avaliado como sendo da ordem de $0,8 \mathrm{~V}$, a par tir das curvas de titulação.

As curvas de titulação potenciométrica são bem comportadas, semelhantes àquela apresentada na figura 11.1. para $\mathrm{Fe}(\mathrm{CN})_{5} \mathrm{~m}-\mathrm{Py}(\mathrm{CO}) \mathrm{CHNOH}^{3-}$.

A partir destes dados, pode-se determinar a dosagem de ferro(II) presente em cada complexo. Os valores obtidos estão relacionados juntos com os dados de microanālise no capitulo IV.

A determinação do ponto de equivalência foi fei ta pelo método de Gran $(320,321)$ e o gráfico estā ilustrado na figura 11.2. para o mesmo complexo.

11.3.2. Determinação das Absortividades Molares

A determinação das absortividades dos complexos 


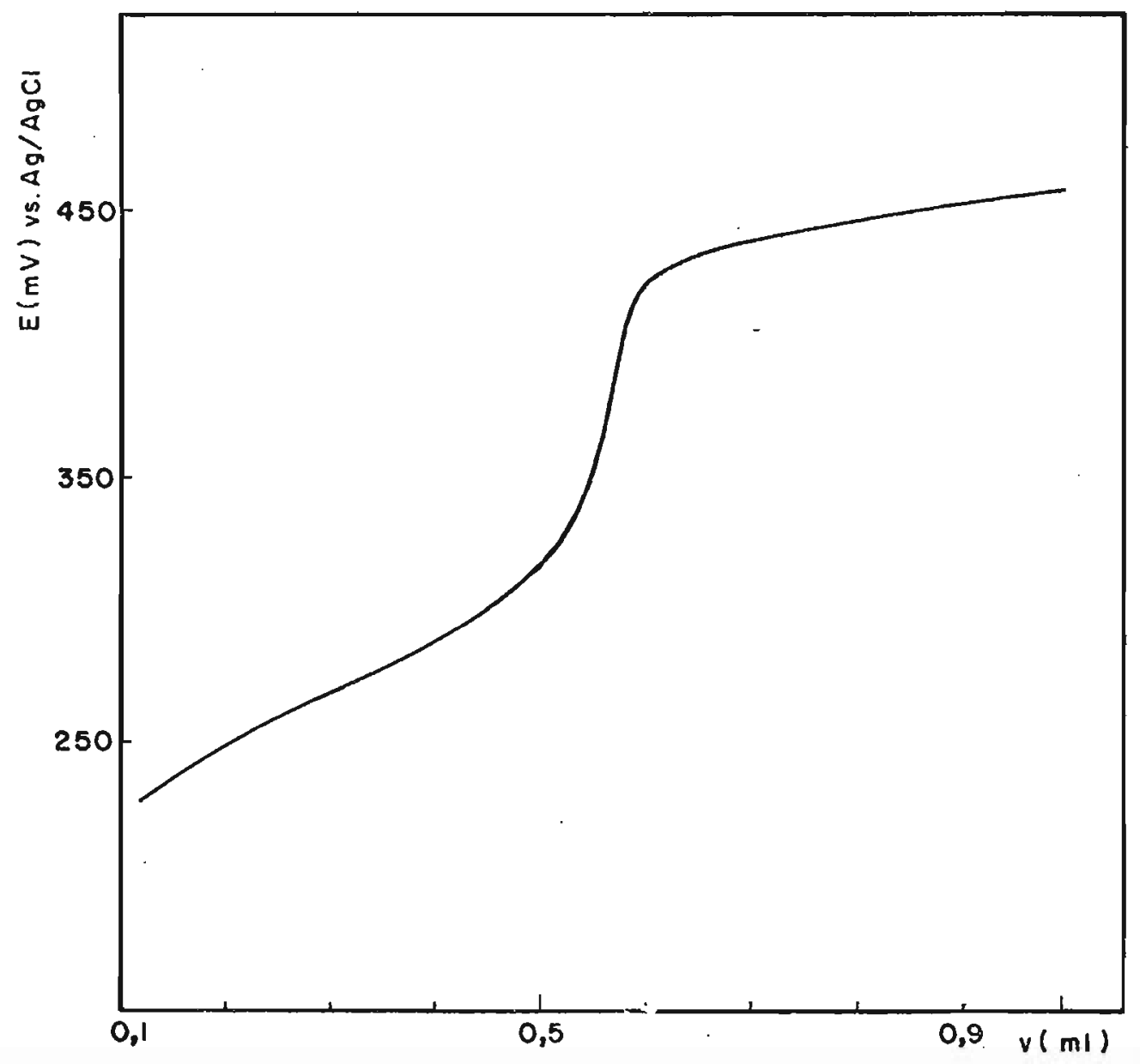

FIG.11.1. Curva de titulação potenciométrica do complexo $\mathrm{Fe}(\mathrm{CN}) 5^{\mathrm{m}-\mathrm{py}(\mathrm{CO}) \mathrm{CHNOH}^{3-}}$ com Ce(IV) em meio tamponado com $\mathrm{HAC} / \mathrm{NaAC}(0,5 \mathrm{M} / 0,5 \mathrm{M})$ 


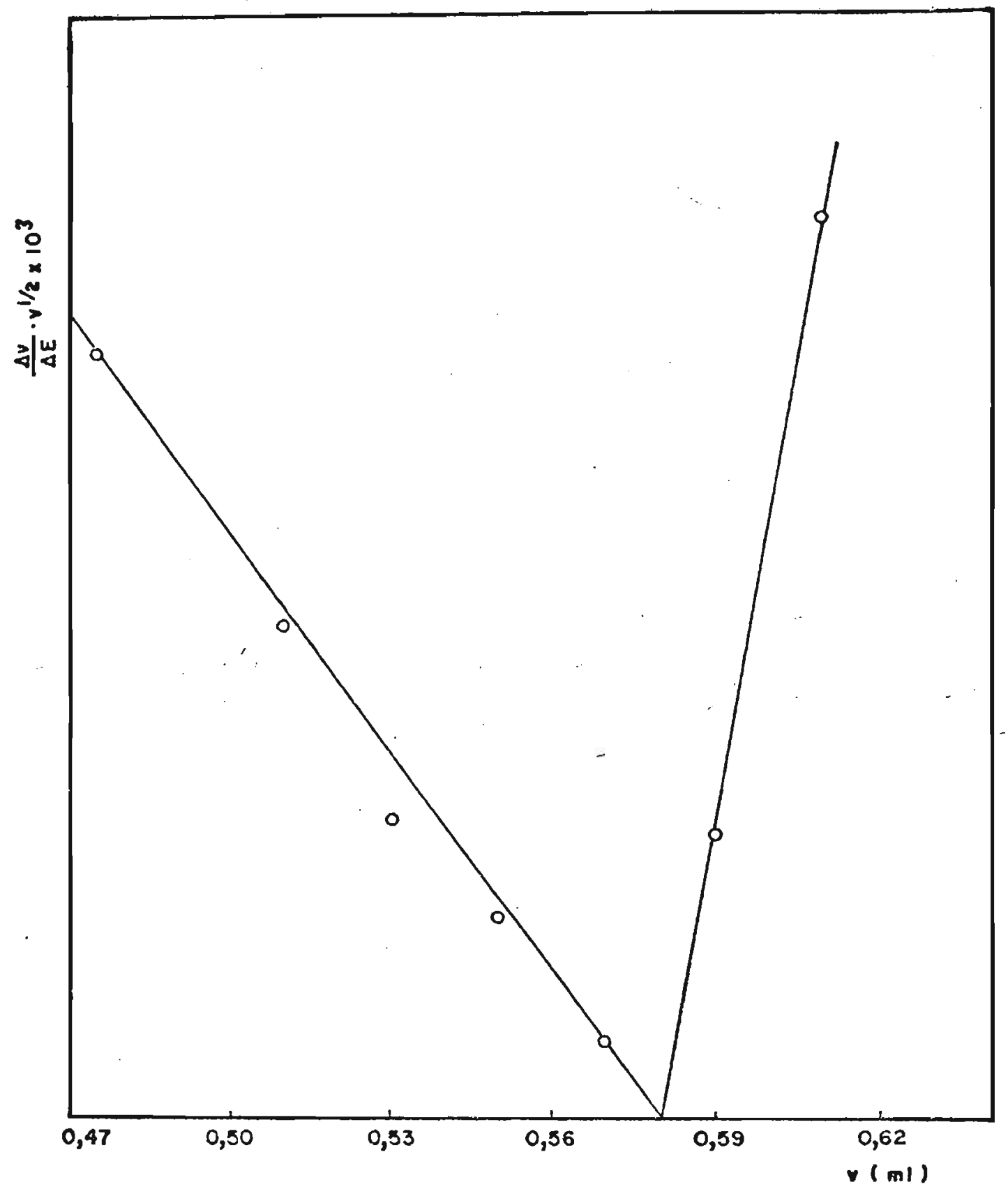

FIG.11.2. Avaliação do ponto de equivalência da titulação de $\mathrm{Fe}(\mathrm{CN})_{5}$ m-py $(\mathrm{CO}) \mathrm{CHNOH}^{3-} \operatorname{com} \mathrm{Ce}(\mathrm{IV})$ pelo mé todo de Gran 


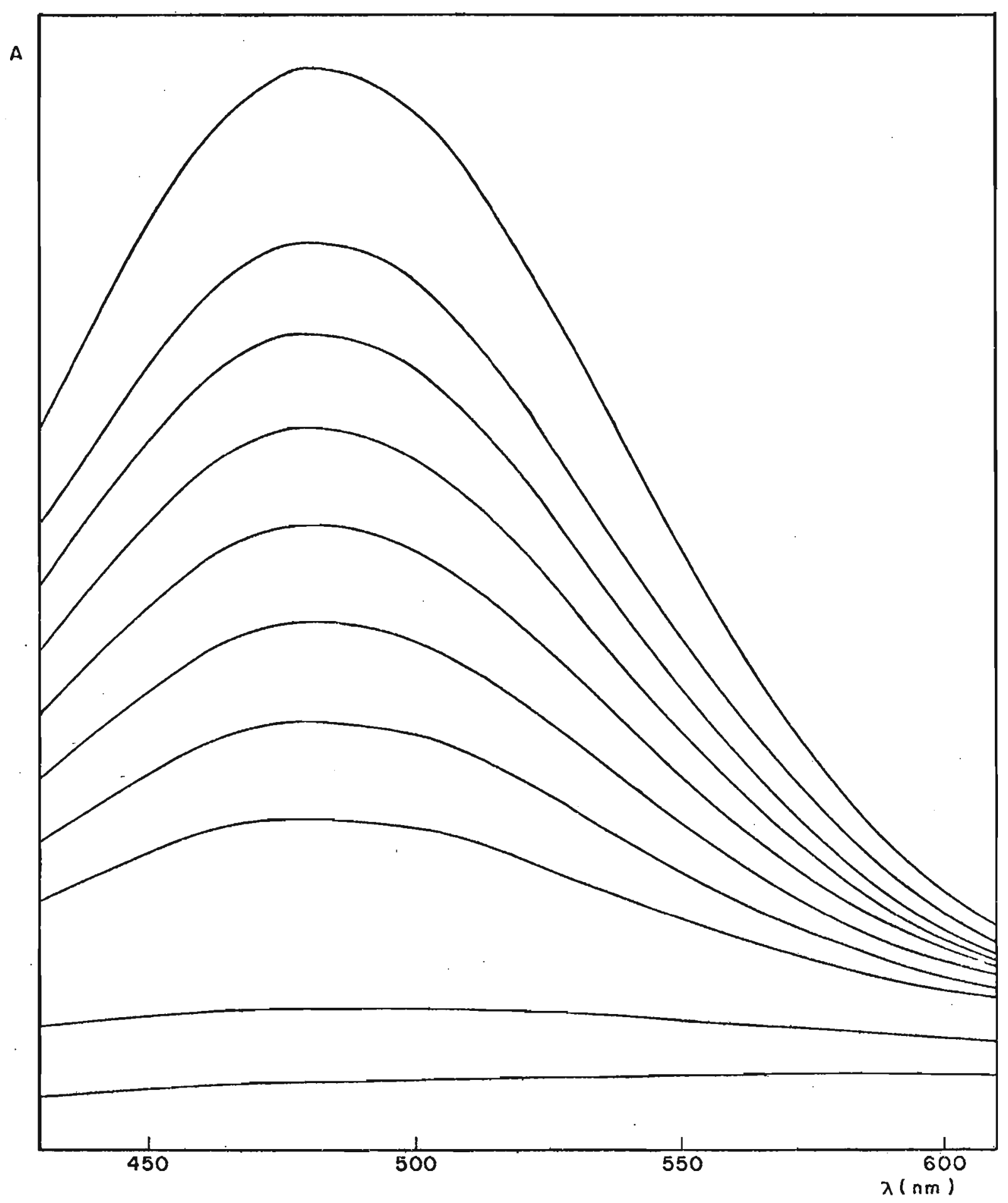

FIG.11.3. Espectro eletrônico de Absorção no visível para o complexo $\mathrm{Fe}(\mathrm{CN}){ }_{5} \mathrm{p}-\mathrm{py}(\mathrm{CO}) \mathrm{CH}_{3}{ }^{3-}$ em função da concen tração do complexo 


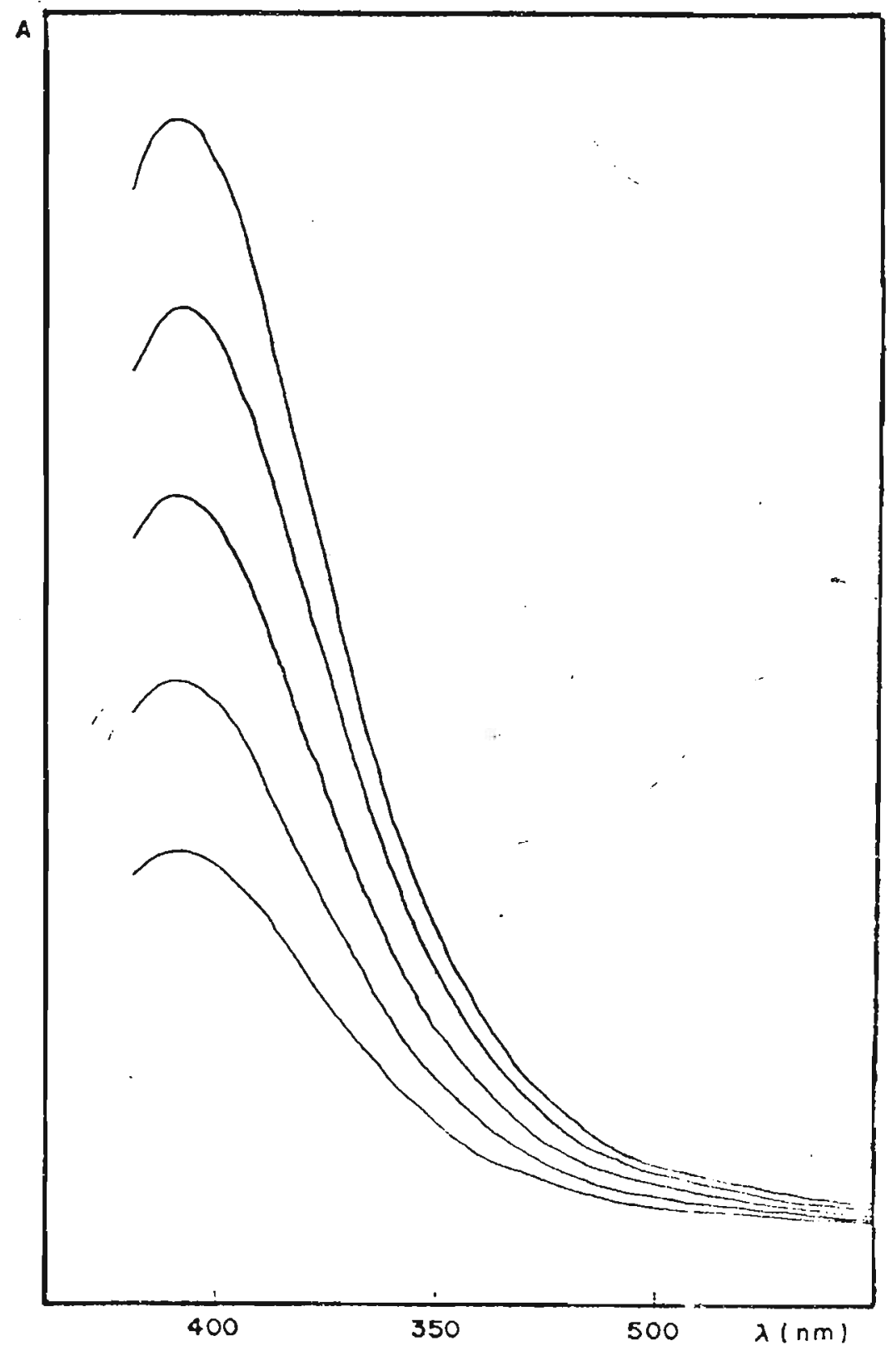

FIG.11.4. Espectro Eletrônico de Absorção no Visível para o Complexo $\mathrm{Fe}(\mathrm{CN})_{4} \mathrm{en}^{2-}$ a concentrações : 0,$80 ; 1,59$; 2,00 e $2,42 \times 10^{-3} \mathrm{M}$. 


\section{6}

utilizados para fins analiticos é feita a partir da medida de absorbāncia a várias concentrações (FIG.11.3. e 11.4.)

0 gräfico das figuras 11.5. e 11.6. permite ava liar um $E$ igual a $4,22 \times 10^{3} \mathrm{M}^{-1} \mathrm{~cm}^{-1}$ para o complexo

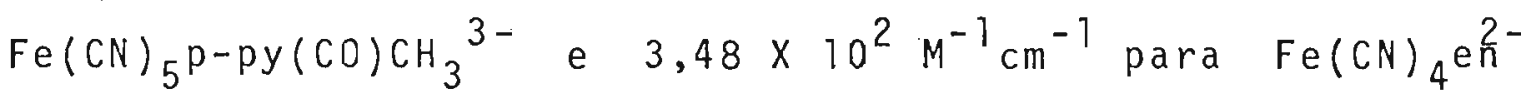
11.3.3. Parāmetros Eletroquímicos

Os voltamogramas ciclicos dos sistemas auxiliares como $\mathrm{Fe}(\mathrm{CN})_{5} \mathrm{p}-\mathrm{py}(\mathrm{CO}) \mathrm{NH}_{2}{ }^{3-}$ e $\mathrm{Fe}(\mathrm{CN})_{5} \mathrm{p}-\mathrm{py}(\mathrm{CO}) \mathrm{OCH}_{3}{ }^{3-}$ bem como do $\mathrm{Fe}(\mathrm{CN})_{5} \mathrm{CO}^{3-}$ estudado na fotosubstituição de co, estão nas figuras 11.7. a 11.9. e os parâmetros eletroquĩmicos obtidos estão relacionados nas tabelas 11.1. e 11.2.

Os coeficientes de difusão avaliados do gräfico de $i_{p a}$ versus concentração do complexo (FIG. 11.10 a 11. 12.). são, respectivamente, $0,51 \times 10^{-5} \mathrm{~cm}^{2} \mathrm{~s}^{-1} ; 0,41 \times 10^{-5}$ $\mathrm{cm}^{2} \mathrm{~s}^{-1}$ e $0,64 \times 10^{-5} \mathrm{~cm}^{2} \mathrm{~s}^{-1}$. 


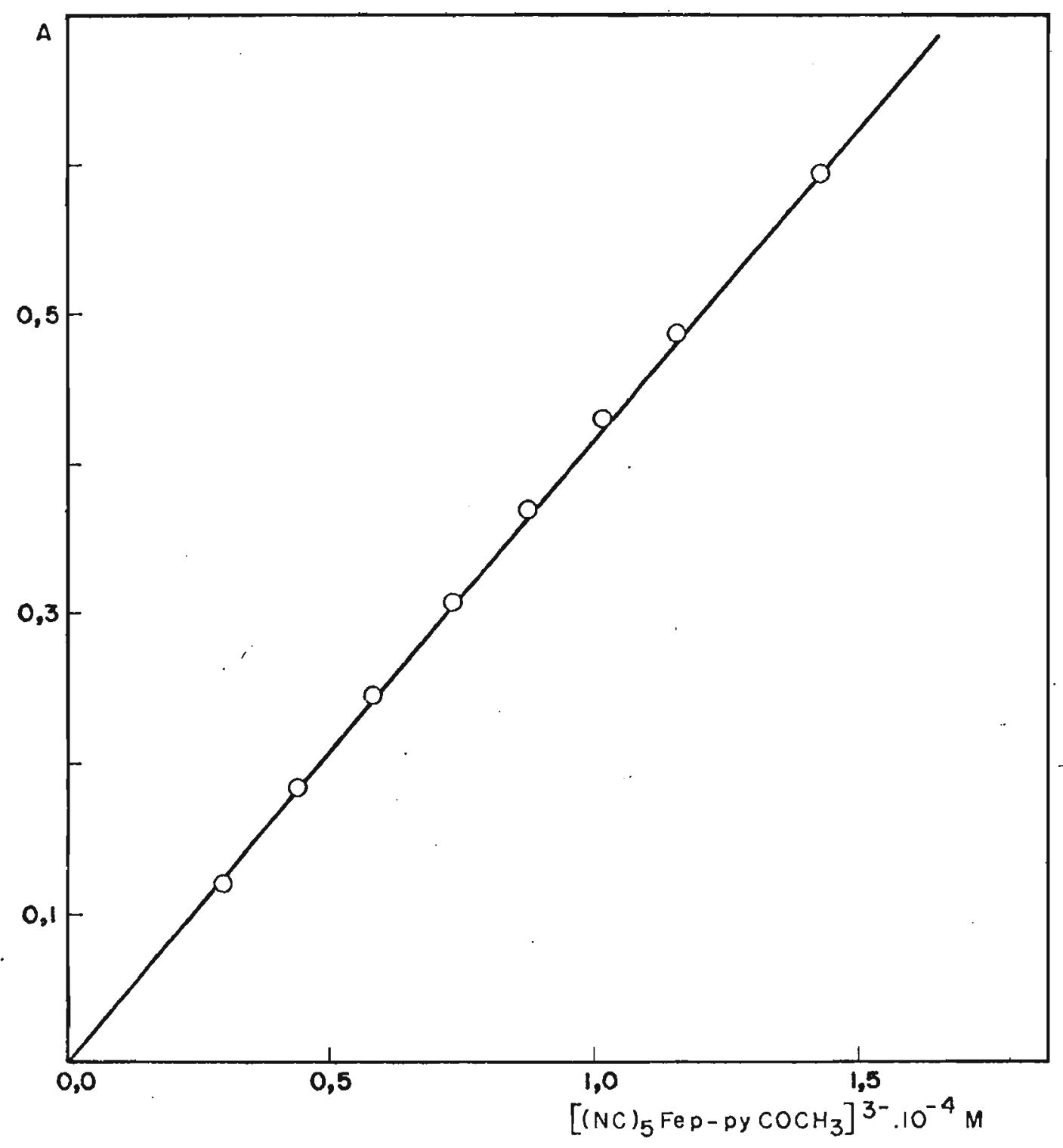

FIG.11.5. Absorbância em função da concentração do complexo $\mathrm{Fe}(\mathrm{CN}){ }_{5} \mathrm{p}-\mathrm{py}(\mathrm{CO}) \mathrm{CH}_{3}{ }^{3-}$ 


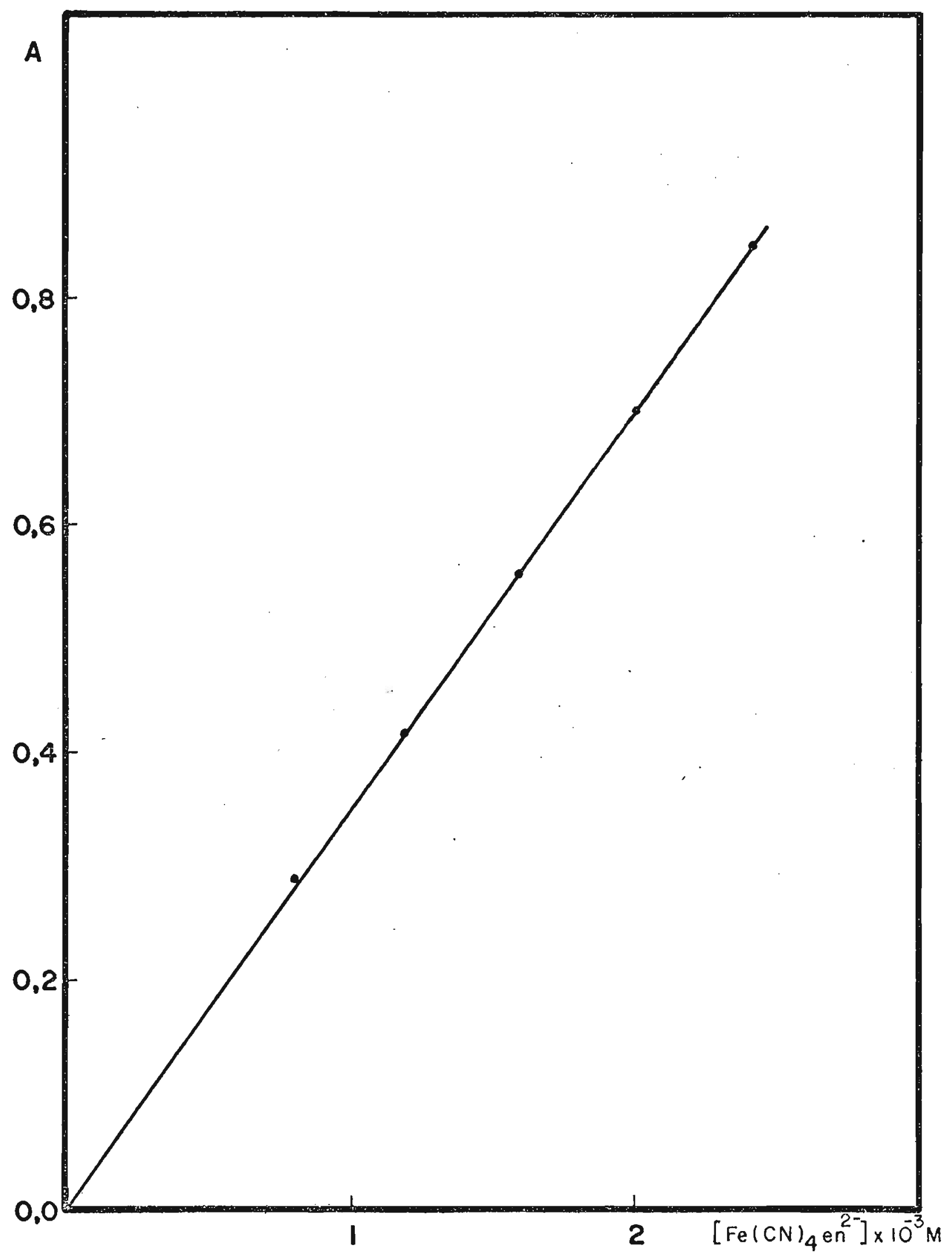

FIG. 11.6.Absorbância em função da concentração de Fe(CN) ${ }_{4}^{\text {en }}$ 


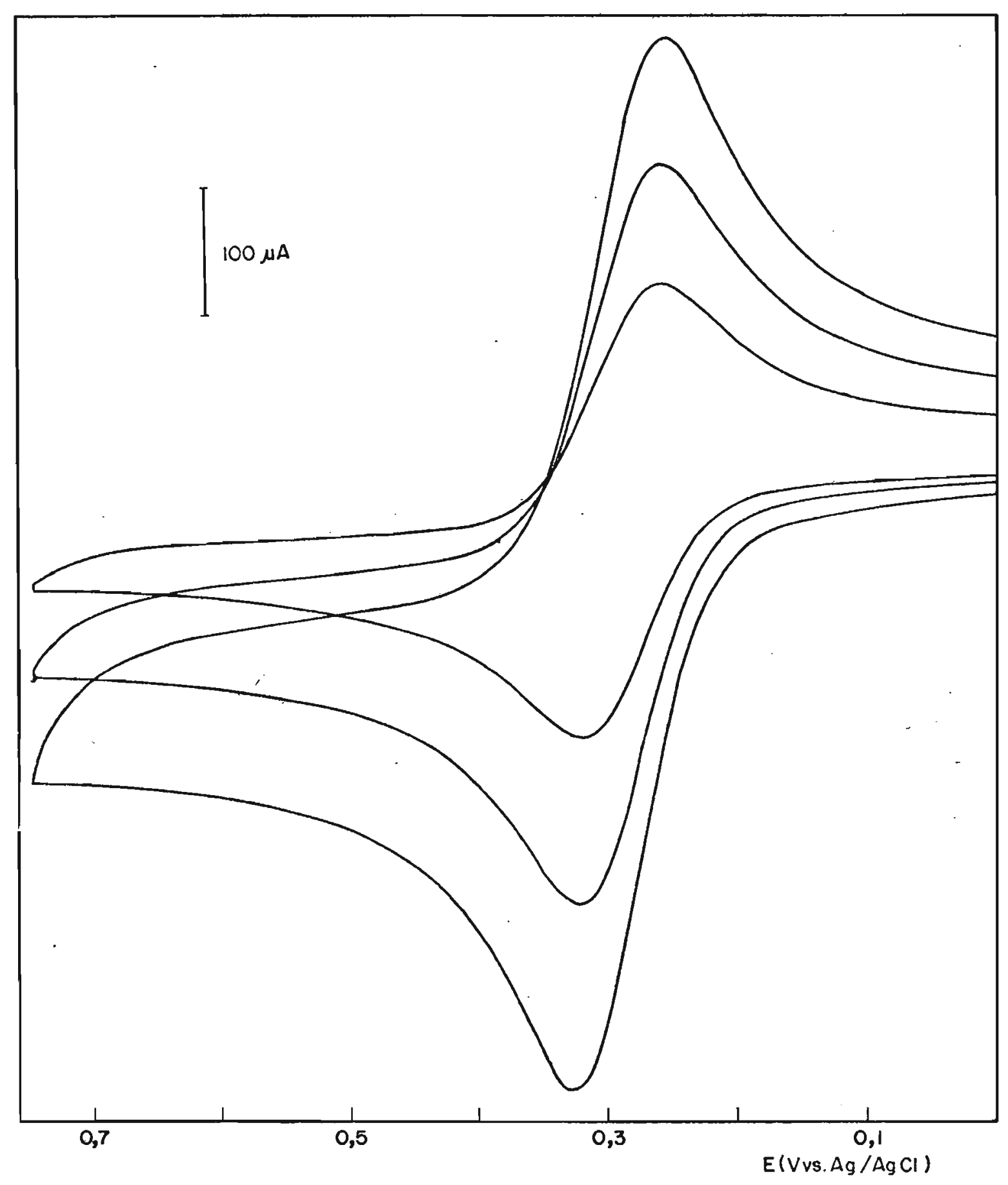

FIG.11.7. Voltamogramas cíclicos de solução $4,00 \times 10^{-3} \mathrm{M}$ de $\mathrm{Fe}(\mathrm{CN}){ }_{5} \mathrm{p}-\mathrm{py}(\mathrm{CO}) \mathrm{NH}_{2}{ }^{3-}$ em $\mathrm{KCl} 0,5 \mathrm{M}$ a $25,0^{\circ} \mathrm{C}$. $\mathrm{v}=0,100 ; 0,050 ; 0,020 \mathrm{v} \cdot \mathrm{s}^{-1}$. 


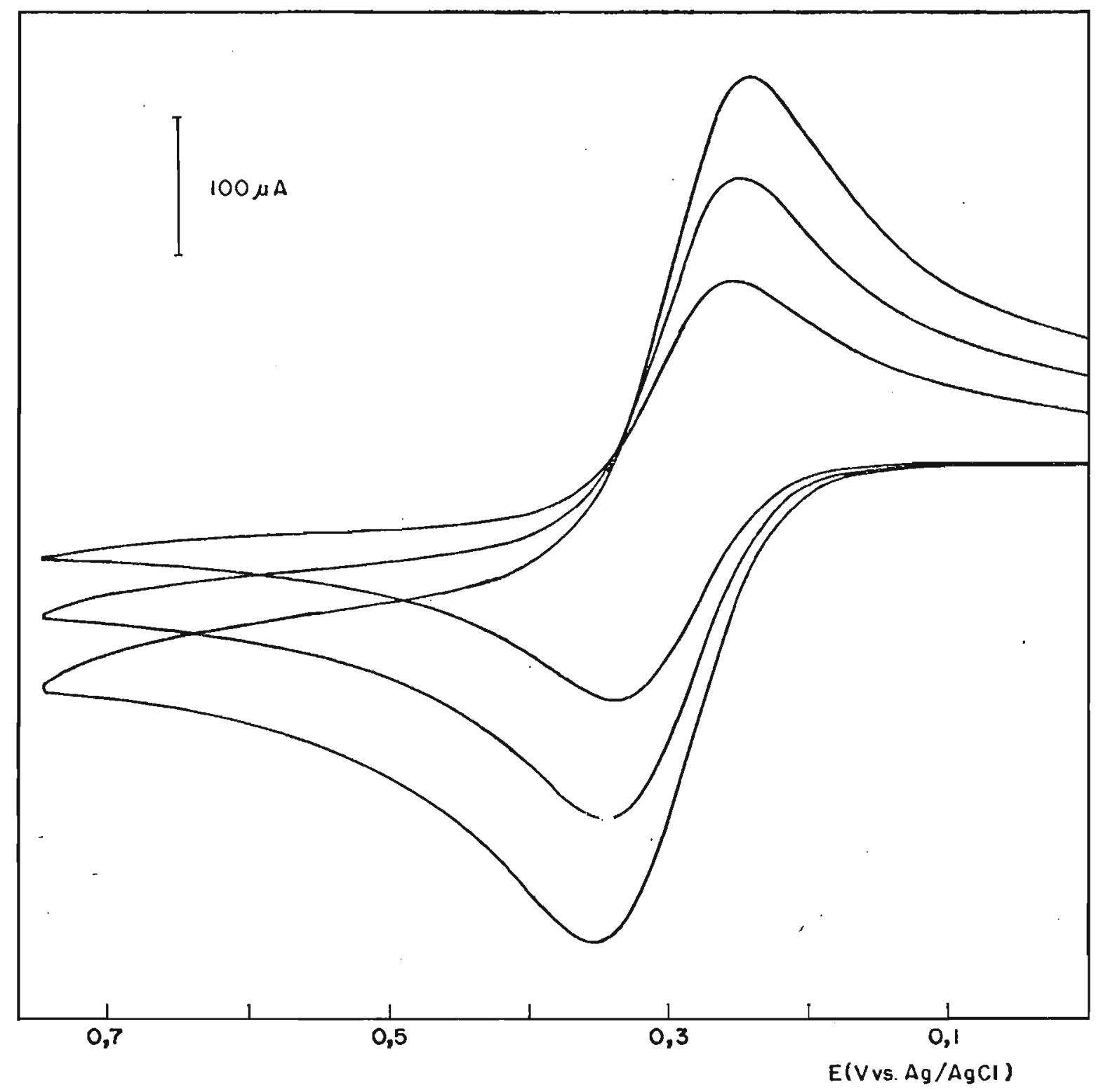

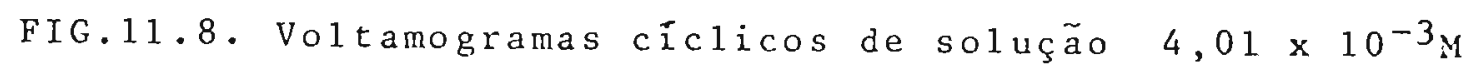

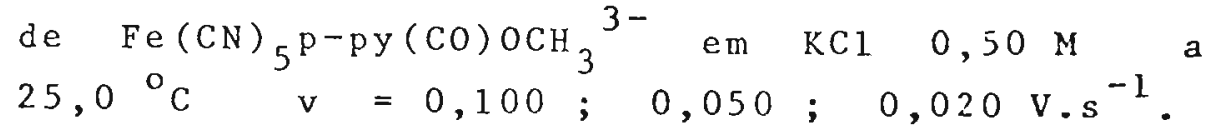




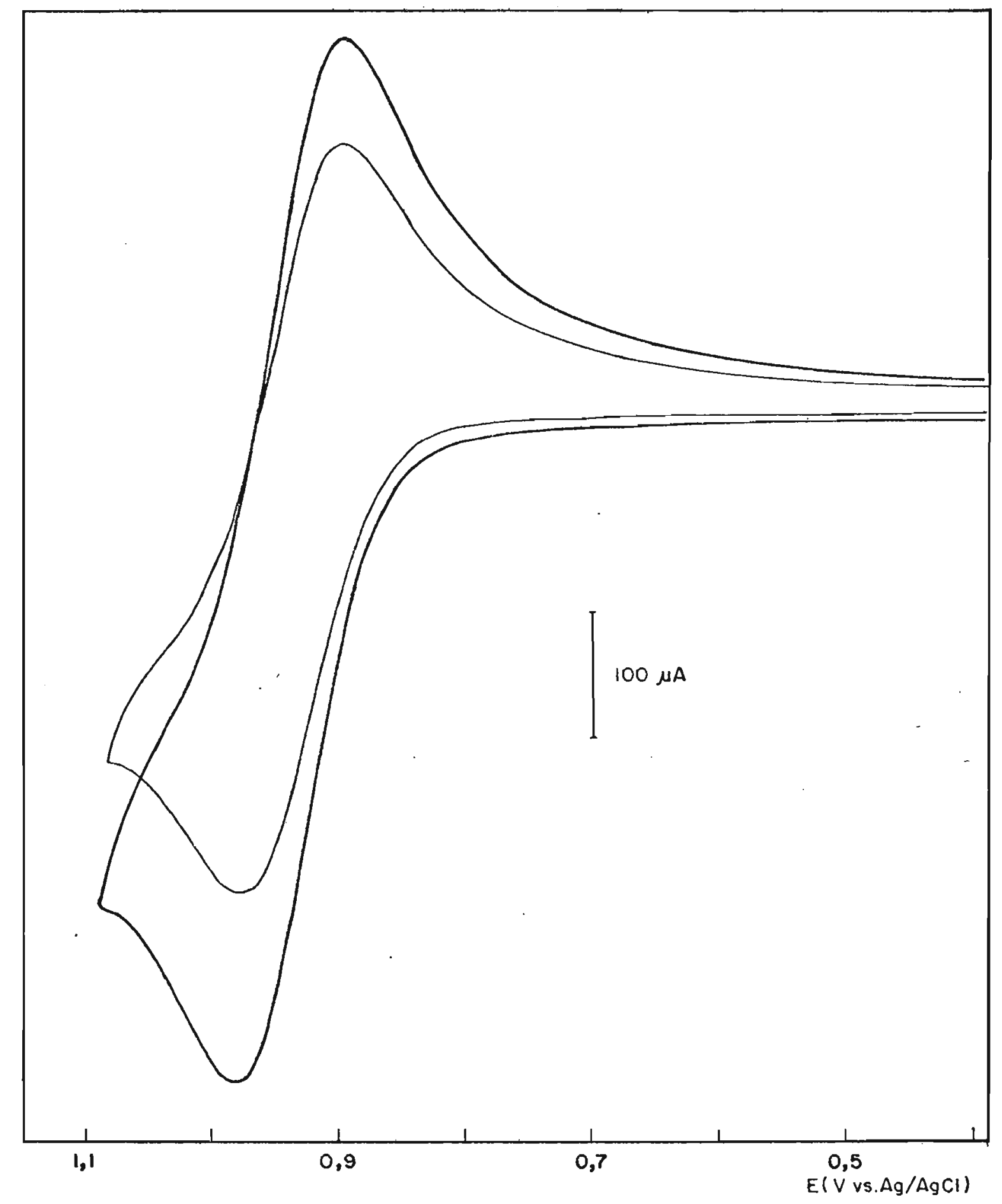

FIG.11.9. Voltamogramas Cíclicos de solução $1,00 \times 10^{-2} \mathrm{M}$ de $\mathrm{Fe}(\mathrm{CN})_{5} \mathrm{CO}^{3-}$ em $\mathrm{KCl} 0,50 \mathrm{M}$ a $25,0^{\circ} \mathrm{C}$ $\mathrm{v}=0,020 \mathrm{~V} \cdot \mathrm{s}^{-1}$ e $0,010 \mathrm{v} \cdot \mathrm{s}^{-1}$ 


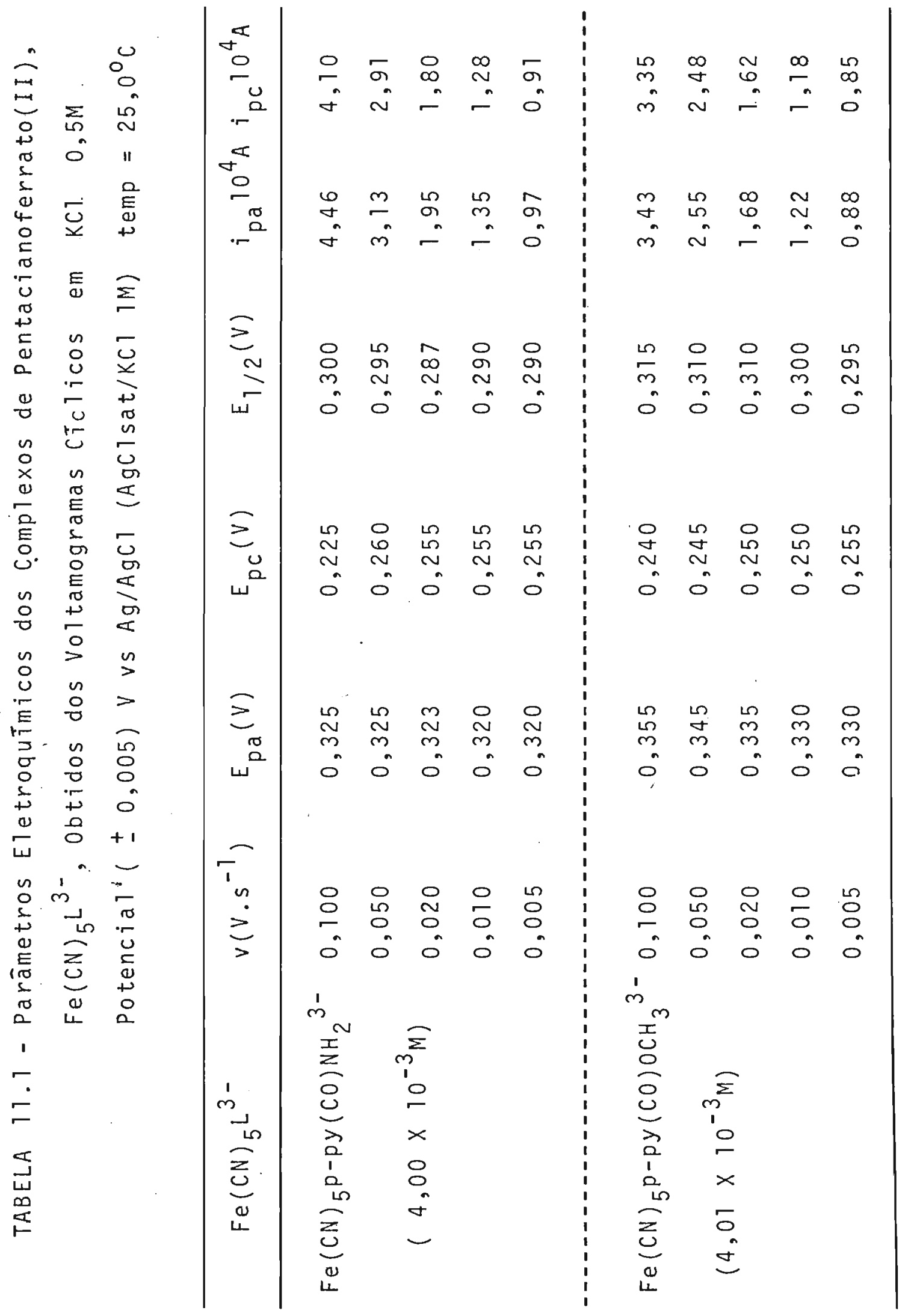




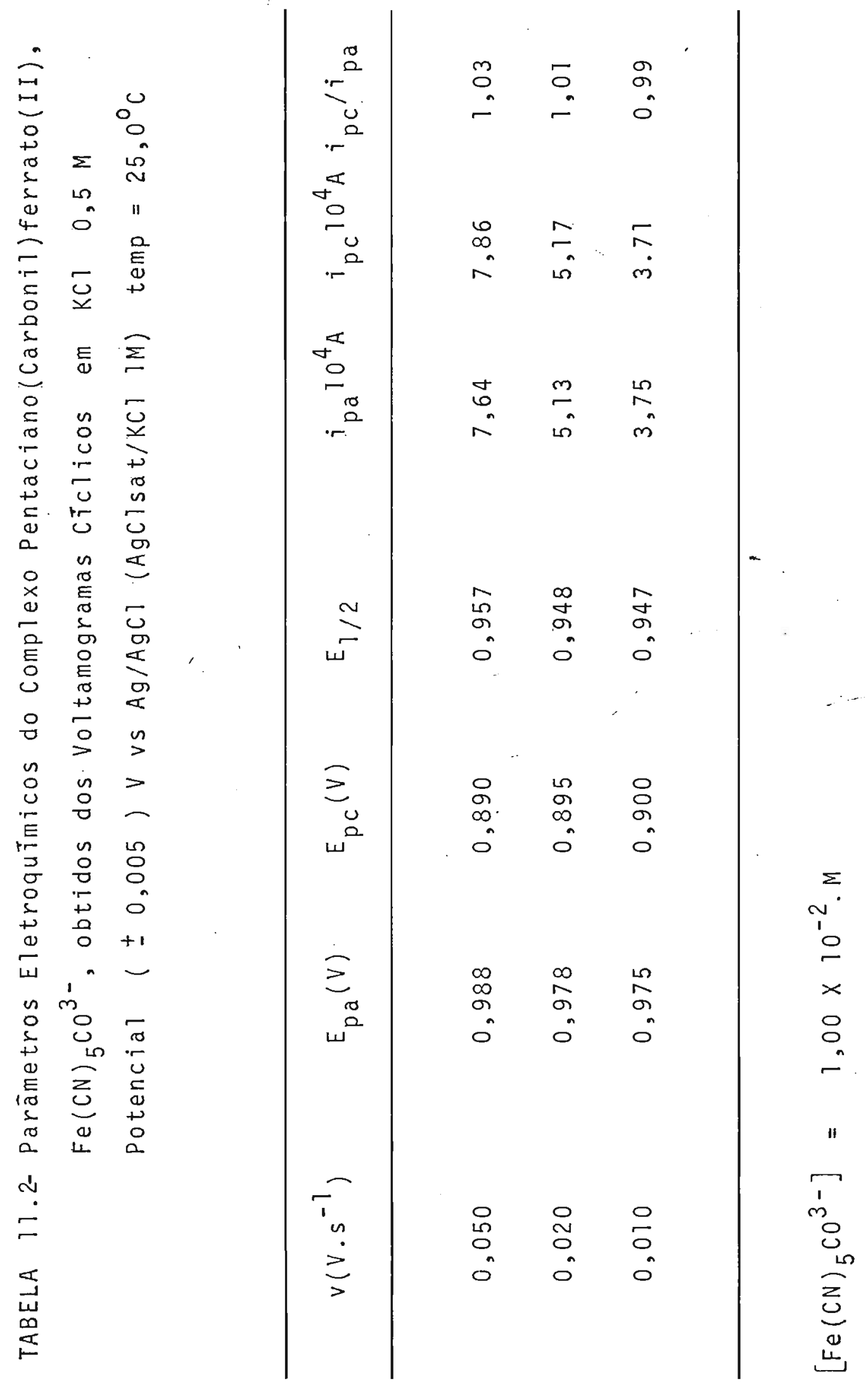




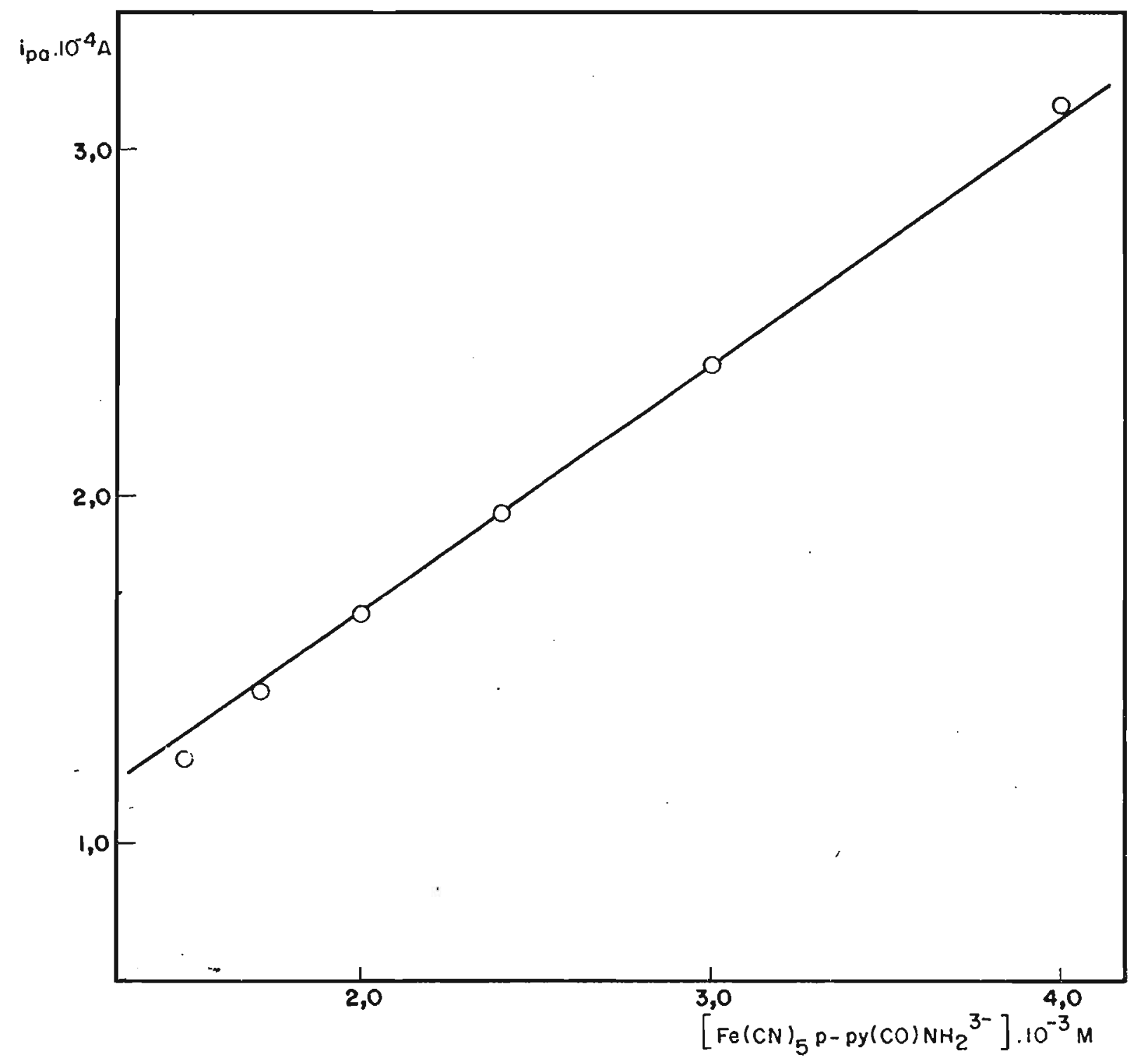

FIG.11.10. Corrente de pico anódico em função da concentração de $\mathrm{Fe}(\mathrm{CN})_{5} \mathrm{p}-\mathrm{py}(\mathrm{CO}) \mathrm{NH}_{2}{ }^{3-}$ 


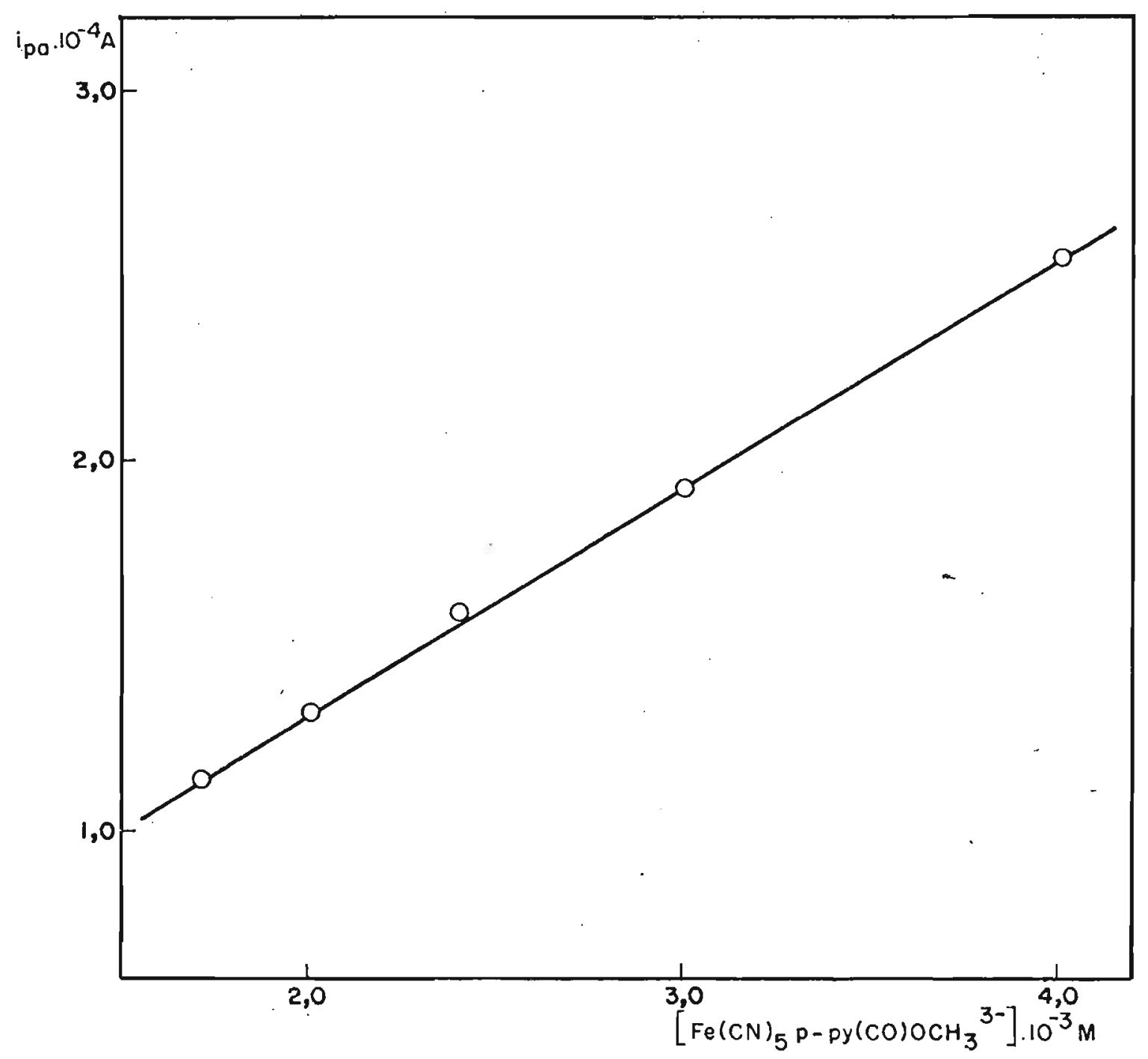

FIG.11.11. Corrente de pico anódico em função da concentração do complexo $\mathrm{Fe}(\mathrm{CN})_{5} \mathrm{p}-\mathrm{py}(\mathrm{CO}) \mathrm{OCH}_{3}{ }^{3-}$ 
386

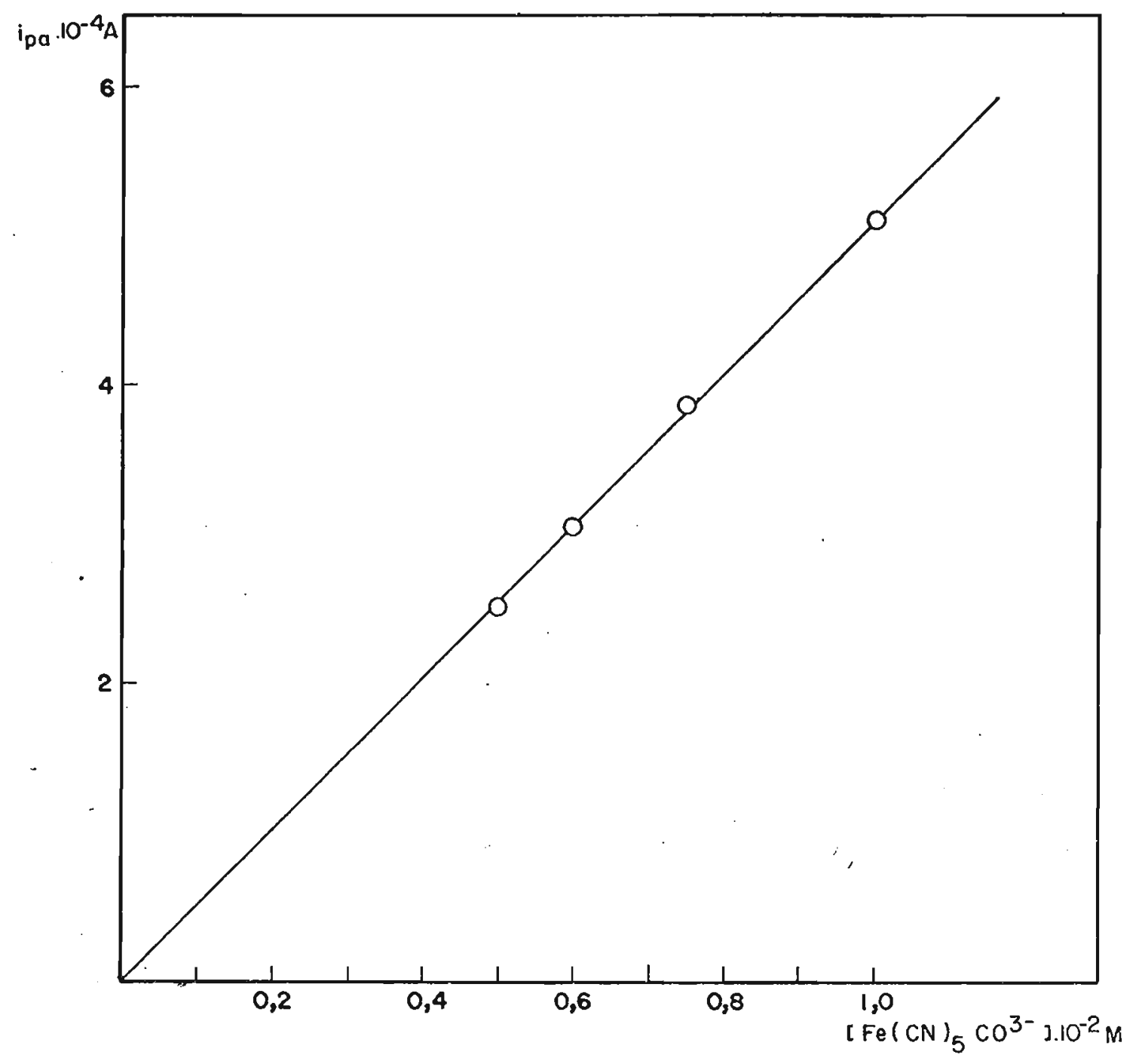

FIG.11.12. Corrente de pico anódico em função da concentração do complexo $\mathrm{Fe}(\mathrm{CN}){ }_{5} \mathrm{CO}^{3-}$ 


\section{XII- REFERÊNCIAS BIBLIOGRÁFICAS}

1. H.L.Conley Jr., R.B. Martin, J. Phys. Chem., 69, 2914 (1965)

2. P. Ford, De F. P. Rudd, R. Gaunder e H. Taube, J. Amer. Chem. Soc., 90, $1187(1968)$

3. H. E. Toma, "As Influências das Interąões de Transferên. cia de Elétrons no Comportamento dos Complexos de Pentaaminrutênio(II) e de Pentacianoferrato(II) com Ligantes insaturados", Tese de Doutoramento, Instituto de Quỉmica -USP, 1974

4. A. Zanella e H. Taube, ․ Amer. Chem. Soc., 93, 7166 (1971)

5. R.Breslow e D.Chipman, ‥Amer.Chem.Soc., 87, 4195 (1965)

6. M. C. Thompson e D.H. Busch, ․․ Amer. Chem. Soc., 84, 1762 (1962)

7. M. C. Thompson e D. H. Busch, J. Amer. Chem. Soc., $\underline{86}$, $213,(1964)$

8. E.L. Blinn e D.H. Busch, Inorg. Chem., I, 820 (1968)

9. N.F. Curtis e R.W. Hay, Chem. Commun., 524 (1966)

10. N.F. Curtis, Coord. Chem. Rev., 3, 3 (1968)

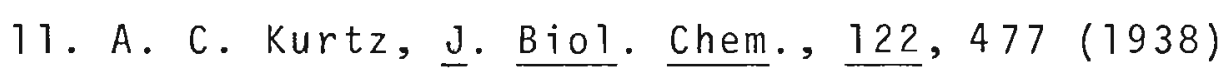

12. R. Breslow, R. Fairweather e J. Keana, J. Amer. Chem. Soc. $, \underline{89}, 2135$ (1967) 
13.R.F. Gould (ED.), Advan. Chem. Ser., 37, 1963 ;"Reactions of Coordinated Ligands"

14. R.W. Hay, Rev. Pure Appl. Chem., 13, 157 (1963)

15. M.M. Jones e W.A. Connor, Ind. Eng. Chem., 55, 15 (1963)

16. M. M. Jones, "EZementary Coordination Chemistry", Prenti ce-Ha11, 1964

17. Q. Fernando, Adv. Inorg. Chem. Radiochem., $\underline{7}, 185$ (1965)

18. M. M. Jones, Advan. Chem. Ser., $\underline{49}, 153$ (1965)

19. J. M. Collman, Trans. Metal Chem., 2, 1 (1966)

20. K. Ziegler, E. Holzkamp, H. Breiland, H. Martiñ, Angew. $\underline{\text { Chem. }}, \underline{67}, 541$ (1955)

21. G. Natta e I. Pasquon, Advan. Catalysis, 11, 1 (1959).

22. R. F. Gould (Ed.), Advan. Chem. Ser., 70, 1968; "Homogeneous Catalysis, Industrial Appizications and Implications"

23. 0. Roe1en, Angew. Chem., 60, 62 (1948)

24. J. Smidt, W. Hafner, R. Jira, R. Sieker, Angew. Chem. Internat $\cdot \underline{\text { Edit. }}, \underline{1}, 80$ (1962)

25. J. F. Roth, J. H. Craddock, A. Hershman e F. E. Paulik, Chem. Technol., 600 (1971)

26. F. E. Paulik e J.F. Roth, Chem. Commun., 1573 (1968); J. F. Roth, Plat. Metals Rev., 19, 12 (1975); D. Foster, J. Amer. $\underline{\text { Chem. Soc. }}$. 98, 8461 (1976)

27. A.W. Addison, W.R. Cullen, D. Dolphin e B.R. James, "Bio logical Aspects of Inorganic Chemistry", John Wiley \& Sons, 1977 
27.a. Ibidem, p. 141

28. G. L. Ejchhorn (Ed.), "Inorganic Biochemistry", V.I e II, Elsevier Scientific Pub. Co., 1973

28.a. Ibjdem, V.I, parte IV

28.b. Ibidem, V.II

29. R. F. Gould (Ed.), Advan. Chem. Ser., 100, 1971; "Bio inorganic Chemistry"

29. a. Ibidem, p.21

30. M. N. Hughes, "The Inorganic Chemistry of Biological Processes", John Wiley \& Sons, 1974

31. C. A. McAuliffe (Ed.), "Techniques and Topics in Bioinorganic Chemistry", William Clowes \& Sons, London,1975

31. I. Ibjdem p.61

32. Ei-ichiro Ochiai, "Bioinorganic Chemistry: An Introduction", Al1yn e Bacon Inc., 1978

33. P. D. Boyer, "The Enzimes", V.I a XIII.

33.a. Isidem, ‥, 587 (1971)

34. M. F. Dunn, Struct. Bond., 22, 61,1975

35. A.S. Mi1dVan e C. M. Grisham, Struct. Bond., 20, 1, 1974

36. R. D. Jones, D. A. Summerville e F. Basolo, Chem. Rev., 79, $139(1979)$

37. A. W. Adamson e P. D. Fleischauer, "Concepts of Inorganic Photochemistry", John Wiley \& Sons, Inc., 1975

38. M. S. Wrighton, Topics in Current Chemistry, 65, 378 $(1976)$ 
39. M. S. Wrighton, Acc. Chem. Res., 12, 303 (1979)

40. F. Basolo e R. G. Pearson, "Mechanism of Inorganic Reactions - A Study of Metal Complexes in Solution", 2nd. Ed., John Wiley \& Sons, Inc., 1967; CAP. 7 e 8.

41. A. E. Marte11, Pure Appl. Chem., 17, 129 (1968)

42. R. F. Gould (Ed.), Advan. Chem. Ser., 62, 1967, "Wener Centenniar"

43. N. F. Curtis, Coord. Chem. Rev., 3, 3 (1968)

44. Ei-ichiro Ochiai, Coord. Chem. Rev., 3, 49 (1968)

45. J.P. Collman, Acc. Chem. Res., 1, 137 (1968)

46. L. Vaska, Acc. Chem. Res., 1,335 (1968)

47. D. H. Busch, Science, 171,241 (1971)

48. M. A. Taqui Khan e A. E. Martell, "Homogeneous Catalysis by Metal Complexes ", V.1, Academic Press, N.Y. 1974

49. L. F. Lindoy, Chem. Soc. Rev., 4, 421 (1975)

50. G. Henrici 01 ive e S. 01 ivē, "Coordination and Catalysis" - Monographs in Modern Chemistry, V. 9, 1977

51. M. S. Healy e A. J. Rest, Adv. Inorg. Chem. Radiochem., $21,1,1978$

52. C. J. Hipp e D. H. Busch, "Coordination Chemistry ", Vol. $\underline{3}, 221,1978$

53. K. F. Purcel1 e J. C. Kotz, "Inorganic Chemistry", p.773 Saunders Co. Philadelphia, 1979 
54. J. E. Huheey, "Inorganic Chemistry. Principles of Structure and Reactivity!" 2nd. Ed., Cap. 13, Harper \& Row, 1978

55. D. F. Martin, "Preparative Inorganic Reactions ", I, 1964

56. P. Krumholz, Cienc. Cult., 24, 327 (1972)

57. B. F. G. Johnson e J. A. Mcleverty, Prog. Inorg. Chem., $\underline{7}, 277(1966)$

58. W. P. Griffith, Adv. Organometal. Chem., 7, 211 (1968)

59. J. Masek, Inorg. Chim. Acta Rev., 3, 99 (1969)

60.W. G. Connely, Inorg. Chim. Acta Rev., 6, 48, (1972)

61. J. H. Enemark e R. D. Feltham, Coord. Chem. Rev., 13.

- $339(1974)$

62. K. G. Caulton, Coord. Chem. Rev., 14, 317. (1974)

63. R. Eisenberg e C. D. Meyer, Acc. Chem. Res., 11, 158 (1978)

64. F. Bottomley, Acc. Chem. Res., 11, 158 (1978)

65. J. A. Mccleverty, Chem. Rev., 79, 53. (1979)

66. R. Davis, Coord. Chem. Rev., 1, 1 (1981)

67. H. Swinehart, Coord. Chem. Rev., 2, 385 (1967)

68. F. Feigl, "Qualitative fnalysis by Spot Tests ", p.289, 2nd. Ed., Elsevier, Amsterdam, 1939

69. W. Moser, R. A. Chalmers e A. G. Foggs, Anal. Chim. Acta, $\underline{36}, 248(1966)$ 
70. K. W. Loach e M. Carvalho, Anal. Lett., 6, 25, (1973)

71. G. S. Johar, Mikcrochim. Acta, 243 (1975 - I)

72. H. E. Toma, M. A. Brito e E. Giesbrecht, Cien. Cult., 30, $215(1978)$

73. M. T. Beck, A. Katho, L. Dozca, Magy. Kem. Foly, $\underline{86}$, 337, (1980); Chem. Abstr., 94, 31053q, 1981

74. G. Brauer, "Handbook of Preparative Inorganic Chemistry", 2nd. Ed., Vo1. II, Academic Press., N.Y., 1511 , 1965

75. A. G. Ramage, J. Pharmacol., 70, 63 (1980); Chem. Abstr. $249334, \underline{94}, 1981$

76. L. F. Hirsh', Stroke, 11, 60 (1980); Chem. Abstr., 94; $76792 w, 1981$

77. D. A. Lowe e B. P. Richardson, Prog. Respir. Res., 14, 134 (1980); Chem. Abstr., 94, 150060, 1981

J. W. Flacke, W. E. Flack e J. W. Cant, Anesth. Analg., 59, 909 (1980); Chem. Abstr., 94, 150183s, 1981

E. B. Douple, J. C. Green, M. G. Simic, Int. J. Radiat. Oncol. Biol. Phys., 6, 1545 (1980); Chem. Abstr., 94, 1981

78. B. Landauer, Anaesthescol. Intersivmed., 130, 430 (1980), Chem. Abstr., 94, $24574 \mathrm{~g}, 1981$

79. F. Bottomley, W. V. F. Brooks, S. G. Clarkson e S. B. Tong, $\underline{J} \cdot \underline{C} \cdot \underline{S}$. Chem. Comm., (1.973) 
35, 2193 (1979); Chem. Abstr., 91, 166804u (1979)

81. K. B. Yatsimirskii, Yu. P. Nazarenko, U. V. Zhilinskaya, Tezisy. Dobl. Vkr. Resp. Konf. Fiz. Khim., 12th, 98 (1977); Chem. Abstr., 92, 172116h (1979)

82. J. C. Long, J. L. Thomas, J. C. Lombardi, J. Inorg. Nucl. Chem.

83. T. W. Harkins, M. B. Ha11, Inorg. Chem., 19, 1735 (1980)

84. J. R. Grigera, G. Reederman, Rev. Chim. Miner., 17, 209, (1980); Chem. Abstr., 93, 247838 b, 1980

85. A. Golekiewski, E. Wasielewska, J. Mol. Struct., 67, 183 $(1980)$

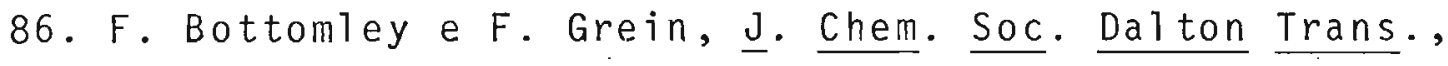
$1356(1980)$

87. M. C. Zerner e J. E. Ridley, Theor. Chim. Acta, 32, 111 (1973); R. S. Drago, "Physical Methods in Chemistry",p. 72 , Saunders, 1977

88. P. Lanza e A. Corbellini, Atti. Accad. Nazl. Lincei, 13, 406 (1952), 14, 65 (1965); Chem. Abstr., $\underline{47}, 9179,1953$

89. I. M. Kolthoff e P. E. Toren, ‥ Amer. Chem. Soc., 75, $1197(1953)$

90. P. Zuman e M. Kobat, Collect. Czech. Chem. Commun., 19: $875(1954)$

91. J. Masek, M. G. Bapat, B. Cosovic e J. Dempir, Collect. Czech. Chem. Commun., 34, 485 (1969)

92. J. Masek e J. Dempir, Collect. Czech. Chem. Commun., 34, 
$727(1969)$

93. J. Masek e E. Maslova, Collec. Czech. Chem. Commun., 39 $2141(1974)$

94. R. Nast e J. Schmidt, Angew. Chem. Int. Ed. Engl., $\underline{8}$, $383(1969)$

95. B. Jerowska - Trzebiatowska e A. Keller, Inorg. Chim. Acta, $13,201(1975)$

96. H. P. Griffith, J. Lewis e G. Wilkinson, J. Chem. Soc., $3993(1958)$

97. D. Mulvey e W. A. Waters, J. Chem.Soc. Dalton Trans., $951(1975)$

98. R. Nast e.'J. Schmidt, Z. Anorg. Al1gem. Chem., $421, \cdot 15$ $(1976)$

99. P.R. Alderman, P. G. Owston e J. M. Rowe, J. Chem. Soc., $668(1962)$

100. I. Bernal e E. F. Hockings, Proc. Chem. Soc. London, 361 (1962)

101. D. A. C. MCNei1, J.B. Raynor e M. C. R. Symons, J.Chem. Soc., $410(1965)$

102. J. B. Raynor, Nature (London) 201, 121 b (1964)

103. E. F. Hockings e I. Bernal, J. Chem. Soc., 5029 (1964)

104. H. Beinert, D. V. Dervartaniam, P. Hemmerich, C. Veegar e J. D. W. Van Voorst, Biochem. Biophys. Acta, 96, 530 (1965)

105. J. D. W. Van Voorst e P. Hemmerich, $\underline{\text { J }}$ Chem. Phys., $\underline{45}$, 
$3914(1966)$

106. R. G. Hayes, J. Chem. Phys., $\underline{48}, 4806$ (1968)

107. J. B. Raynor e M. C. R. Sumons, J. Chem. SoC. A., 339, (1970)

108. M. C. R. Symons, D. X. West e J. G. Wilkinson, Inorg. Nuc1. Chem. Lett., 11, 55 (1975)

109. R. L. Brennan, M. C. R. Symons e D. X. West, Inorg.Nucl. Chem. Lett., 11, $61(1975)$

110. D. Mulvey e W. A. Water, ․ Chem. Soc. Dalton, $951(1975)$

111. J. Schmidt e W. Dorn, Inorg. Chim. Acta, 16, 223 (1976)

112. M. C. R. Symons, D. X. West e J.G. Wilkinson, Inorg. $\underline{\text { Chem }}, \underline{15}, 1022(1976)$

113. W. L. OosterLuis e G. Lang, ․ㅡ. Chem. Phys., 50, 4381 (1569)

114. J. Schmidt. H. Kuhr, W. L. Doen e J. Kopf, Inorg. Nucl. Chem. Lett., 10, 55 (1974)

115. W. L. Bowden, P. Bonnar, D. B. Brown e W. Geiger, Jr., Inorg. Chem. 16,41 (1977)

116. R. P. Cheney, M. G. Simic, M. Z. Hoffman, I. A. Taub e K. D. Asmus, Inorg. Chem., 16, 2187 (1977)

117. Gmelin's Handbuch der Anorganischen, Chimie, Iron 59B, Verlag Chemie, GmbH, Berlin, p. 903 (1938)

118. 0. Baudisch, Science, 108, 443 (1948)

119. W. P. Griffith, Quart. Revs., 16, 188 (1962) 
120. R. P. Mitra, D. V. S. Jain, A. K. Banergee e K. V. R. Chari, $\mathrm{J}$. Inorg. Nucl. Chem., 25, 1263 (1963)

121. J. Danon, P. A. Muniz e H. Panapucci, J. Chem. Phys., $41,3651(1964)$

122. D. A. C. MacNeil, J. B. Raynor e M. C. R. Symons, Proc. Chem. Soc., 364 (1964)

123. B. Jezowska-Trzebiatowska, E. Kalecinska e J. Kalecinski, Bull. Acad. Pol. Sci. Ser. Sci. Chim., 15, 77 (1967); Chem. Abstr. $, \underline{66}, 120779 \mathrm{v}, 1967$

124. R. P. Mitra, B. K. Sharma e S. P. Mittal, J. Inorg. Nucl. Chem. 34,3919 (1972)

125. J.H. Espenson e S.G. Wolwnuk, Inorg. Chem., 11, 2034 (1972)

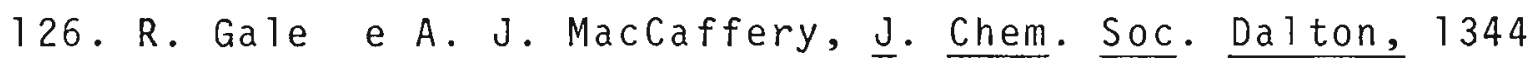
$(1973)$

127. S. K. Wolfe e J. H. Swinehart, Inorg. Chem., 14, 1049 (1975)

128. T. Jarzynowski, T. Senkowski e Z. Stasicka, Rocz. Chem. 51,2299 (1977); Chem. Abstr. $88,1442524,1978$

129. G.Y. Buxton, F.S. Dainton e J. Kalecinski, Int. J. Radiat. Phys. Chem., 1, 87 (1969); Chem. Abstr., 71, 34986g,1969

130. C. Andrade e J.H. Swinehart, Inorg. Chim. Acta., 5, 207 (1971)

131. N. Tarugi, Ann, Chem. Applic., 16, 407 (1926); 17, 519 (1927); Chem. Abstr., 21, 865 (1927) 
132. J. Dempir e J. Masek, Inorg. Chim. Acta, 2, 402 (1968)

133. A. Casolari, Rend. Soc. Chim. Ital., 5, 294 (1914); Chem. Abstr., $\underline{9}, 1435$ (1915)

134. V. G. Belikov e V.N. Bernshtein, Sb. Nauchn. Dokl., 38 (1960); Chem. Abstr., 59, 12182 (1963)

135. P. A. Storie e D. X. West, ‥ Inorg. Nucl. Chem., 36, $2347(1974)$

136. P. A. Stoeri e D.X. West, $\underline{J}$ Inorg. Nucl. Chem., $\underline{36}$, $3885(1974)$

137. L. Cambi, Atti. Accad. Nazl. Lincei, 22, 376 (1912); Chem. Zent., I, 1756,1913; Chem. Abstr., 7, 2551 (1913)

138. L. Cambi, Atti. Accad. Nazl. Lincei, 23, 812 (1914); Chem. Zent., II, 1099, 1914; Chem. Abstr., $\underline{9}, 452$ (1915)

139..L. Cambi, Atti. Accad. Naz1. Lincei, 24, 434 (1915); Chem. Abstr., 10, 1351 (1916)

140. L. Cambi, Am. Chim. Applic., 17, 55 (1927); Chem. Abstr. $21,1941(1927)$

141. L. Cambi e L. Szego, Atti. Accad. Nazl. Lincei, $\underline{5}$, 737 (1927); Gazz. Chim. Ita1., 58, 64 e 71 (1928); Chem. Abstr., $\underline{22}, 2722(1928)$

142. L. Cambi, A. Cagnasso e T. Ricci, Gazz. Chim. Ital., 61 3 (1931); Chem. Abstr., 25, 2383 (1931)

143. J. H. Swinehart e P.A. Rock, Inorg. Chem., $\underline{5}, 573$ (1966)

144. P. Zuman e M. Kabat, Chem. Listy, 48, 358 (1954)

145. D. X. West, ‥ Inorg. Nucl. Chem., 29, 1163 (1967) 
146. D. X. West, Dissertation Abstr., 25, 5552 (1965); Chem. Abstr., 63, 3680c, 1965

147. D. J. Kenney, T.P. Flynn e J.B. Gallini, J. Inorg. Nucl. Chem. 20,751 (1961)

148. M.T. Beck, L. Dozsa e I. Szilassy, ‥ Ind. Chem. Soc., $\underline{51,} 6(1974)$

149. N. E. Katz, M. A. Blesa, J.A. 01 abe e P.J. Aymonino, J. Inorg. Nucl. Chem., 42, 581 (1980)

150. S.K. Wolfe, C. Andrade e S.H. Swinehart, Inorg. Chem., $\underline{13}, 2567$ (1974)

151. B.N. Figgis e C.M. Harris, J. Chem. Soc., 855 (1955)

152. B.N. Figgis'e J. Lewis, Prog. Inorg. Chem., 6, 112 (1964)

153. P.A. Rock e J.H. Swinehart, Inorg. Chem., 5 , 1078 (1966)

154. E. J. Baran e A. Muller, Angew. Chem. Int. Ed. Engl., $8,890(1969)$

155. C. Scagliarini, Atti. V. Congr. Nazl: Chim. Pure Appl. Rome, 1935, Pt. I, 546 (1936); Chem. Abstr., 31, 3407 (1937)

156. P.J. Morando, E.B. Borghi, L.M. Schteingart e M.A. Ble sa, J. Chem. Soc. Dalion, 435 (1981)

157. G. Scagliarini e G. Avoni, Atti. Accad. Nazl. Lincei, 24, 215 (1936); Chem. Abstr., 31, 4276 (1937)

158. V. Vochek, Pharmazie, 15, 707; Chem. Abstr., 57, 15244 (1962) 
160. V.F. Toropova, A.A. Rybkina, Izv. Uyssh. Uchib. Zaved. Khin. Tkhnol., 16, 800 (1973) ; Chem. Abstr., 80,103546p

161. M. Jaksevac-Miksa, V. Hankonyi e V. Karas-Gasparec, Z. Phys. Chemie Leipzig, 261, 1041 (1980)

162. C. Boedeker, Liebig Ann. Chem., 117, 193 (1861); S. H. Swinehart, Coord. Chem. Rev., 2, 392 (1967)

163. J. Fages e Virgili, Compt. Rend., 134, 1143 (1903)

164. G. Scagliarini, Atti. IV. Congr. Nazl. Chim. Pura Appl, (1932), 597 (1933); Chem. Abstr., 29, 2872 (1932)

165. W. Moser, R.A. Chalmers e A.G. Fogg, J. Inorg. Nucl. Chem. 27,831 (1965)

166. A.G. Fogg, A.D. Jones e W. Moser, J. Inorg. Nucl. Chem. 28: $2428(1966)$

167.-A.G. Fogg, A.H. Norbury e W. Moser, J. Inorg. Nucl. Chem., 28, $2753(1966)$

168. A.G. Fogg, W. Moser e R. A. Chalmers, Anal. Chim.Acta, $36,248(1966)$

169. E. J. Baran e A. Muller, Z. Anorg. Allg. Chem., 368, $144 \cdot(1969)$

170. G.S. Johan, J.P. Singh e G. Majumdan, Curr. Sci., (India), $40,547(1971)$

171. C. Andrade e J. H. Swinehart, Inorg. Chem., 11, 648 $(1972)$

172. K.W. Loach e T.A. Turney, J. Inorg. Nucl. Chem., 18, $179(1961)$ 


\section{0}

173. M.Z. Yampol'skii e B. E. Geller, Trkomis po Analit. Khim., 13, 78 (1963); Chem. Abstr., 59, 6993d (1963)

174. J. H. Swinehart e W. G. Schmidt, Inorg. Chem., 6, 232 (1967)

175. S.K. Wolfe e J.H. Swinehart, Inorg. Chim., I, 1855 (1968)

176. K.W. Loach e M. Carvalho, Anal. Lett., 6, 25 (1973)

177. L. Pavalini, Bool. Chim. Farm., 69, 713,(1930)

178. 0. Baudisch, Science, 108,443 (1948)

179. D.Z. West e D.I. Hassemer, J. Inorg. Nucl. Čhem., 32, $2717(1970)$

180. J. R. Bellinger, K.R. Lindfors e D.X. West, J. Inorg. Nucl. Chem., 32, 3837 (1970)

181. J. Dempir e J. Masek, Inorg. Chim. Acta, 2, 402 (1968)

182. A.N. Sergeeva, D.I. Semenishin, A.U. Masepa, Zh. Neorg. Khim. , 20, 396 (1975)

183. M.T. Beck, A. Katho, L. Dozsa, Inorg. Chim. Acta; 55, L55 (1981)

184. V.F. Toropova, A.A. Rybkina, Zh. Anal. Khim., 28, 1355 (1973); J. Anal. Chem. USSR, 28, 1202 (1974)

185. V.N. Bernshtein e V.G. Belikov, Uspekh. Khim., $\underline{30}$, $582(1961)$

186. P. Capieri, R. Scott e E. Simpson, Anal. Chim. Acta, $547(1969)$

187. J.G. Calvert e J.N. Pitt Jr., "Photochemistry", John 
Wiley, N.Y., 1966

188. J. P. Simons, "Photochemistry and spectroscopy", Wiley (Interscience), London (1971)

189. J. M. Fitzgerald (Ed), "Analytical Photochemistry and Photochemical Analysis, Solids, Solutions and Polymers" Marcel Dekker, Inc., N.Y., 1971

189.a. Ibidem, H.A. Taylor, "Analytical Methods and Techniques for Actinometry", p.91

190. C.A. Parker, "Photoluminescence of Solutions", American E1sevier, N.Y., 1968

191. V. Balzani e V. Carassiti, "Photochemistry of Coordi nation Compounds", Academic Press, London, 1970

192. L.G. Geoffroy e M.S. Wrighton, "Organometalzic Photo Chemistry", Academic Press, N.Y., 1979

193. "Photochemistry", A Specialist Periodical Report, The Chemical Society, London

194. E.A.K. Von Gustorf, L.H.G. Leenders, I. Fischler e R. N. Perutz, Adv. Inorg. Chem. Radiochem., 19, 65 (1976)

195. J.F. Endicott, Survey of Progress in Chemistry, 7, 41 (1976)

196. J.M. Kel1y, Photochem., 9, 193 (1978); Chem. Abstr.,90 $178056 u, 1979$

197. B. Hajek, F. Benda, Chem. Listy, 73, 249 (1979)

198. P.C. Ford, Rev. Chem. Intermed., 2, 267 (1979), Chem. Abstr., 91, $45087 \mathrm{~d}, 1979$ 
198a. M.S. Wrighton, Adv. Chem. Ser., 168, 1978; "Inorganic and Organometallic Photochemistry"; Chem. Abstr., 89, $120787 w, 1978$

199. F. Scandola, org. Chem., 42, 549 (1980); Chem. Abstr., $\underline{94}, 22810 \mathrm{~g}(1981)$

200. M.S. Wrighton, O.S. Ginley, M.A. Schroeder, D.L. Morse, Pure App 1. Chem., 41,671 (1975)

201. A.W. Adamson, A.H. Sporer, J. Amer. Chem. Soc., 80, 3865 (1958)

202. A.W. Adamson e A.H. Sporer, $\underline{J}$. Inorg. Nucl. Chem., 8 , 209 (1958)

203. L. Moggi, F. Bolletta, V. Balzani, F. Scandola, J. Inorg. Nucl. Chem., 28, 2589 (1966)

204. A.W. Adamson, A. Chiang, E. Zinato, J. Amer. Chem. Soc., 91, 5468 (1969)

205. H.A. Davis Wohlers, K.D. Van Tassel, B.A. Bowerman e J. D. Petersen, Inorg. Chem., 19, 2837 (1980)

206. M.S. Wrighton, D. Bredesen, G.S. Hammond e H.B. Gray, Chem. Comm. $1018(1972)$

207. M.S. Wrighton, D. Bredesen, Inorg. Chem., 12, 1707 (1973)

208. A.W. Adamson, W.L. Waltz, E. Zinato, D.W. Watts, P.D.

Fleischauer e R.D. Lindholm, Chem. Rev., 68, $541(1968)$

209. G. Emschwiller e J. Legros, Compt. Rend., 261, 1535 $(1965)$

210. D.J. Kenney, T.P. Flynn e J.B. Gallini,Jr., Inorg. Nucl. 
$\underline{\text { Chem. }}, \underline{20}, 75(1961)$

211. W. Manchot, E. Meney e P. Woringer, Chem. Ber., 45, $2869(1912)$

212. A. Vogler e H. Kunkely, Z. Naturforsch, $\underline{30 b}, 355$ (1975)

213. J. Legros, J. Chem. Phys., 61, 923 (1964)

214. J.E. Figard e J. D. Petersen, Inorg. Chem., 17, 1059 (1978)

215. H.E. Toma, N.M. Moroi e N.Y.M. Iha, An. Acad. brasil. Ciênc., no prelo

216. M. Goto, M. Takashita, T. Sakai, Inorg. Chem., 17, 314 (1978)

217. C.G. Hatchard e C.A. Parker, Proc. Royal Soc. Sec. A, $-\underline{235}, 518(1958)$

218. E.F. Caldin, "Fast Reaction in Solution", John Wiley, 1964

219. S.L. Friess, E.S. Lewis e Weissberger (Eds), "Investigation of Rates and Mechanism of Reactions", Technique of Organic Chemistry, $\underline{8}$, Wiley Interscience, N.Y., 2nd. Ed., 1961

220. E.S. Swinbourne, "Analysis of Kinetic Data", Thomas Nel son and Sons, London, 1971

221. D.N. Hague, "Fast Reactions", Wiley (Interscience), Lon don, 1971

222. D.E. Nicodem, M.L.P.F. Cabral e J.C.N. Ferreira, Mol. 
Photochem., $\underline{8}, 213(1977)$

223. J. Drabek, I. Copciansky, J. Poskocil, Chem. Listy, 73, 139. (1979)

224. A.I. Voge1," A Textbook of Qauntitative Inorganic Analysis", Longmans, Green and Co., London, 2nd. Ed.

225. C. K. Jorgensen, "Absorption Spectra and Chemical Bonding in Complexes", Addison-Wesley, 1962

226. M.D. Seymour e Q. Fernando, ․ Chem. Ed., 54, 225 (1977)

227. A.A. Frost e K.G. Pearson, "Kinetics and Mechanism", John Wiley, N.Y., 1961

228. R.S. Nicholson, Anal. Chem., 38, 1406 (1966)

229. H.E. Toma;" Cianoferratos : Correlasões de Estrutura; Reatividade e Intervalência", Tese de Livre-Docência, Ins tituto de Química-USP, 1979; e as referēncias nela conti das

230. L.A.A. 01 iveira, "Cinética e Hecanismo de Transferência de Elëtrons no Ion Pentaamin(aimetilsulfóxido)Co(III), Tese de Doutoramento, Inst. de Quimica-USP, 1977

231. H.E. Toma. A.A. Batista, Anais V. Cong. Anual da Soc. Bras. Biofis., p.71, 1980; H.E. Toma, A.A. Batista e H. B. Gray, submetido à pub1icação

232. J.M. Martins, "Estudo Espectroscópico e Cinético da Interaça do Imidazol, Glicina e L-Histidina com Ion Pentacianoferrato(II), Dissertação de Mestrado, Inst. de Quimica-USP, 1978 
233. A.A. Batista, "Cinética da Interąão da Hetionina-Sulfóxido e Metionina-Sulfona com o ion Pentacianoferrato (II), Tese de Mestrado, Inst. de Química-USP, 1978

234. M.S. Takasugi e H.E. Toma, Cienc. Cult.(supl.), $\underline{32}$, $360(1980)$

235. T.M. Lowry e H. Hudson, Phi1. Trans., A232, 117 (1933)

236. C.K. Jorgensen, Acta. Chem. Scand., 8, 1495 (1954)

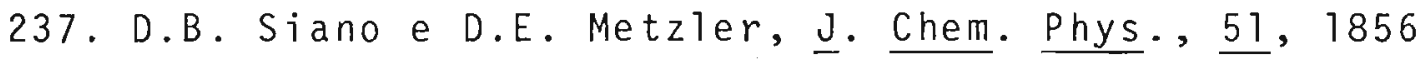
(1969)

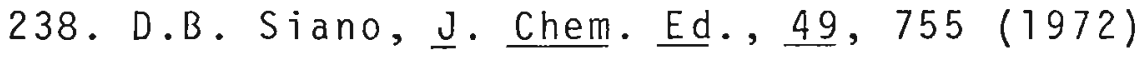

239. H.B. Gray e C.J. Bal1hausen, J. Chem. Phys., 36, 1151 (1962)

240. S.F. Mason, $\underline{\mathrm{J}}$. Chem. Soc., 2071 (1954)

241. S.F. Mason, J. Chem. Soc., 124 (1959); ibidem, 1247 (1959)

242. H.H. Jaffé e M. Orchin, "Theory and Applications of UZtraviolet Spectroscopy", John Wiley, N.Y., 1962

243. J.N. Murrel1, "The Theory of the Electronics Spectra of organic Molecules", Chapman and Hall Ltd., London, 1971

244. J.R. Dyer, "Aplicąão de Espectroscopia de Absorgão aos Compostos Orgânicos", Ed. Edgard Blucher Ltda. e Ed. da USP, 1969

245. P. Day e N. Sanders, J. Chem. Soc., 1536 (1967)

246. E. Rabnowitch, Rev. Mod. Phys., 32, 289 (1960)

247. C.C.J. Roothaan, Rev.Mod. Phys., 32, 289 (1960) 
248. M. Kauzmann, "Quantun Chemistry", Acad. Press, 6a. Ed., $1967^{-}$

249. R.S. Mul1iken, J. Amer. Chem. Soc., 74, 811 (1952)

250. R.A.D. Wentworth e T.S. Piper, Inorg. Chem., 4, 709 (1965)

251. R. Gale e A.J. MacCaffery, J. Chem. Soc. Dalton, 1344 $(1973)$

252. J.H. Espenson e S.G. Wolenuk Jr., Inorg. Chem., 11,2034 $(1972)$

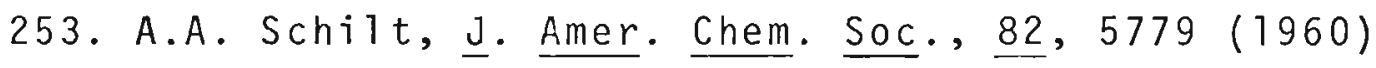

254. E.0. Fisher, Pure Appl. Chem., 30, 353 (1972)

255. A. Chakravorty, Coord. Chem. Rev., 13, 1 (1974)

256. N.Y. Murakami e H.E. ̈oma, Cien. Cu1t., (sup1.), 32, 4444 (1980)

257. M.S. Takasugi e H.E. Toma, Cien. Cu1t., (sup1.), 31, 333 (1979); 10 Encontro Regional de Química, p.74 (1979)

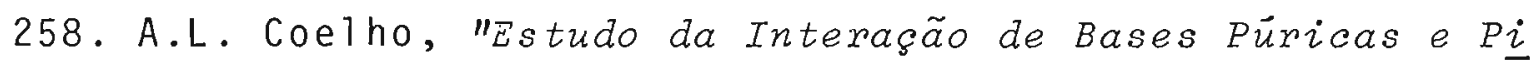
rimidicas com o Ion Pentacianoferrato(II), Tese de Dou toramento, Instituto de Quỉmica-USP, 1979

259. N.E. Katz, M.A. B1eza, J.A. 01 abe e P.J. Aymonino, Inorg. Chim. Acta, 27, L65 (1978)

260. D.H. Macartney e A. McAuley, Inorg. Chem., 18, 2891(1979)

261. G.C. Pedrosa, N.L. Hernāndez, N.E. Katz e M. Katz, ‥ Chem. Soc. Dalton, 2297 (1980) 
262. A.A. Batista e H.E. Toma, An. Acad. brasil. Ciēnc., $\underline{52}, 703(1980)$

263. N.Y. Murakami e H.E. Toma, Ciēnc. Cult., (supl.), 28, 8 $149(1978)$

264. H.E. Toma, J.M. Martins e E. Giesbrecht, J. Chem. Soc. Dalton, $1610(1978)$

265. R. Pionte11i, Gazz. Chim. Ita1., 89, 357 (1953)

266. N.B. Colthup, L.H. Daly e S.E. Wiberley, "Introduction to Infrared and Raman Spectroscopy", Academic Press, 1964

267. L.J. Bellamy, "The Infrared Spectra of Complex Molecules" Chapman and Ha11, London, 1975

268. A.R. Katritzky, "Physical Methods in Herocyclic Chemistry", Academic Press, 1963

269. K. Nakamoto, "Infrared Spectra of Inorganic and Coordination Compounds", Wiley Interscience, 20.Ed., 1970

270. C.N.R. Rao, "Chemical Applications of IR Spectroscopy", Academic Press, N.Y., 1963

271. D. Heinert e A.E. Marte11, ‥ Amer. Chem. Soc., 81 , $3933(1959)$

272. R.N. Jones, W.F. Forbes, W.A. Muller, Can. U. Chem., 35, $504(1957)$

273. R. N. Jones e E. Spinner, Can. J. Chem., 36, 1020

274. A.R. Katritzky, Quart. Rev., 13, 353 (1959)

275. A.R. Katritzky e A.R. Hands, J. Chem. Soc., 2202 (1958) 
276. A.R. Katritzky, A.R. Hands e R.A. Jones, J. Chem. Soc., $3165(1958)$

277. A.R. Katritzky e J.N. Gardner, J. Chem. Soc., 2198 (1958)

278. H.B. Colthup, ․․ㅁ․ Soc. Amer., 40, 397 (1950)

279. R.A. Krause, N.B. Colthup e D.H.Busch, J. Phys. Chem., $65,2216(1961)$

280. W.P. Griffith e G.T. Turner, ‥ Chem. Soc., A, 858 (1970)

281. D.R. Moura, "Voltametria Cíclica do Európio em Solução Aquosa e em Solucão de Agua e Formamida", Dissertação de Mestrado, Dept. Química - ICE - UFMG, 1974

282. A.V. Benedetti, "Oxidações EZetroquimicas de Derivados Organocobalto(III) com Estrutura Eletrônica Deslocalizada-Modelo do Coenzima B 12 ", Dissertação de Mestrado, Inst. de Química - USP, 1977

283. M. Rock, "Voltametria Ciclica, Propriedades Termodināmicas e Espectrais de Complexos Diiminicos de Ferro em Acetonitriza", Tese de Mestrado, Inst. de Química-USP, 1977

284. N. Y. Murakami, "Reducões Eletroquimicas dos Complexos Diiminicos de Ferro(II) em Acetonitriza", Tese de Mestra do, Inst. de Química - USP, 1977

285. L. 0. S. Bulhões, "Estudos de Reagões Eletroquimicas em Carbonato de Propizeno I-Lantanidios, II-Complexos Diiminicos de Ferro!" Tese de Doutoramento, Inst. de Química - USP, 1980 
286. A.V. Benedetti, "Estudo Eletroquímico de Derivados de organo-Cobalto(III) com Estrutura Eletrônica Deslocalizada", Tese de Doutoramento, Inst. de Química - USP, 1980

287. R.Adams, "Electrochemistry at Solid Electrodes", Marcel Dekker, Inc., N.Y., 1969

288. E.R. Brown e R.F. Large, "Cyclic Voltametry, AC Polarography and Related Techniques of Chemistry" no Physical Methods of Chemistry - Electrochemical Methods". V. I, II-A, p. 423, Wiley Interscience, N.Y., 1971

289. Z. Galus, "Fundamentals of Electrochemical Analysis", John Wiley \& Sons Inc., N.Y., 1976

290. R.S. Nicholson e I. Shain, Anal. Chem., 36, 706 (1964) ibidem, $37,178(1965)$

291. K.D. Schleintz e G. Von Loewis, Z. Chém., 15, 493 (1975); Chem. Abstr., 84, 79865b (1976)

292. A.A. Vlecek, Electrochim. Acta, 13, 1063 (1968)

293. M.J. Barker-Hawkes, E. Biliig e H.B. Gray, J. Amer. Chem Soc., 8 8, $4870(1966)$

294. I. Shupak, E. Billig, R.J.H. Clark, R. Williams e H.B. Gray, J. Amer. Chem. Soc., 86, 4594 (1964)

295. H. B. Gray, "Transition Metal Chemistry", R.L. Carlin (Ed.), Marcel Dekker, Inc., N.Y., vol. 1, p.239, 1965 296. W. Kuhn e E.Z. Braun, Z. Physik. Chem., 8B, 281 (1930) 297. N.Y. Murakami e H.E. Toma, 10 Encontro Regional de Quï- 
mica, p.72(1979)

298. N.Y. Murakami e H.E. Toma, Ciênc. Cult., (supl.), 32 $443(1980)$

299. A.M.C. Ferreira e H.E. Toma, Ciênc. Cu1t., (sup1.), 32, 361 (1980)

300.'C. Creutz, M. Chou, T.L. Netze1, M. Okumura e N. Sutin, J. Amer. Chem. Soc., 102, 1309 (1980)

301. A.D. Kirk, P.E. Hoggard, G.B. Porter, M.G. Rockeley e M. W. Windsor, Chem. Phys. Lett., 37, 199 (1976)

302. A.J. Street, D.M. Goodall e R.C. Greenhow, Chem. Phys. Lett., $\underline{56}, 326$ (1978)

303. L. Vera e'F. Zu1oaga, Inorg. Chem., 17, 765 (1978)

304. N.B. Chapman e J. Shorter Eds., "Advances in Free Eneirgy Relationships", Plenum Press, N.Y., 1972

305. J. Shorter, "Correzation Anazysis in Organic Chemistry: An Introduction to Linear Free-Energy Relationships", Clarindon Press, 0xford, 1973

306. J.L. Brisset e M. Biquard, Inorg. Chim. Acta, 53, L125, (1981)

307. R.P. Be11 e Lidwe11, Roy. Soc. A., 154, 414 (1936), apud. Trans. Faraday Soc., 39, 253 (1943)

308. R.P. Be11, Trans. Faraday Soc., 39, 253 (1943)

309. B.E. Barker, Chem. Soc. Rev., 9, 143 (1980)

310. A. Rubinowicz, Rept. Prog. Phys., 7, 14 (1939) 
311. L.J.F. Broer, C.J. Gorter e Hoogschagen, J. Physica. 11 $231(1945)$

312. T.M. Lowry e H. Hudson, Phi1. Trans., A232, 117 (1933)

313. A. Mead, Trans. Faraday Soc., 30, 1055 (1934)

314. C.K. Jorgensen, Acta Chem. Scand., 8, 175 (1954)

315. J.3. Markham, Rev. Mod. Phys., 31, 956 (1959)

316. H. Cramer, "Mathematical Methods of Statistics", Princeton Universty Press, N.J., 1954

317. K. Pearson, Phi1. Trans., 216, 456 (1912)

318, P. Yuan, Ann. Math. Stat., 4, 30 (1933)

319. J. Aitcheson, "The Log Normal Distribution", Cambridge Universty Press, Cambridge, 1953

320. G. Gran, Acta Chem. Scand., $\underline{4}, 559$ (1950)

321. F.J.C. Rossotti e H. Rossotti, ‥ Chem! Ed., 42,375 $(1965)$

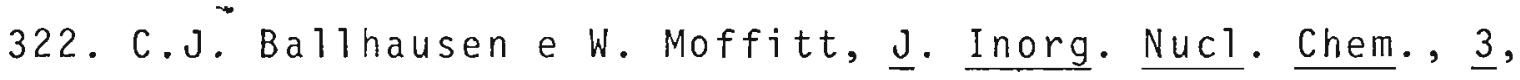
$178(1956)$ 